
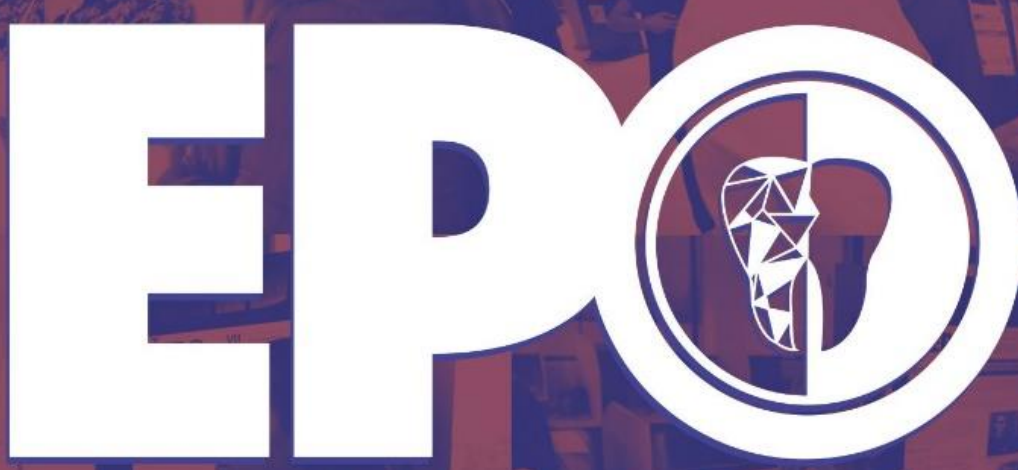

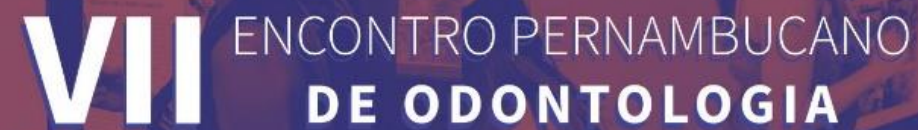

"A ODONTOLOGIA ALÉM DA ESTÉTICA: INTEGRALIDADE COM EFICIÊNCIA PARA SAÚDE DE EXCELÊNCIA."

\title{
ANAIS DO VII ENCONTRO PERNAMBUCANO DE ODONTOLOGIA
}

ACERVO Etals bevistias

As publicações mais rápidas do país!

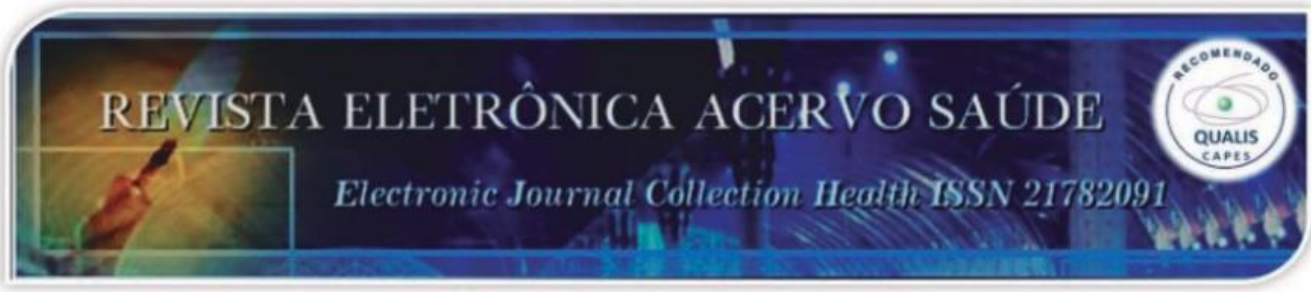

Indexada $\Theta$ Espenodicos latindex Sumários.org Google
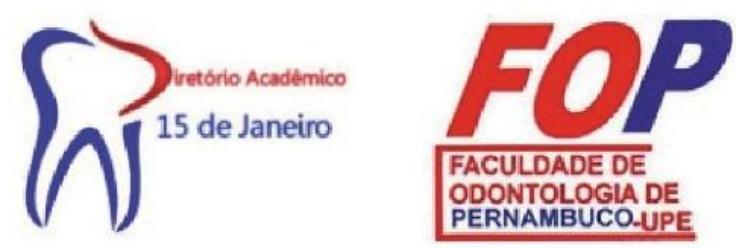

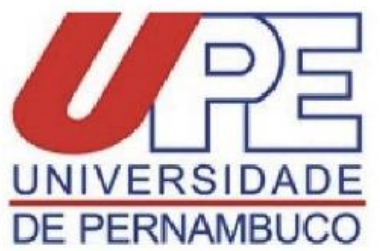


Organização destes Resumos (Anais) do VII Encontro Pernambucano de Odontologia - IIV EPO (2019):

\section{SINVAL VINÍCIUS BARBOSA DO NASCIMENTO}

Presidente do VII Encontro Pernambucano de Odontologia - VII EPO (2019)

Cirurgião-Dentista pela Faculdade de Odontologia de Pernambuco da Universidade de Pernambuco - FOP/UPE

\section{EDUARDO VINÍCIUS DE SOUSA SILVA}

Coordenador da Comissão Científica do VII Encontro Pernambucano de Odontologia - VII EPO (2019)

Cirurgião-Dentista pela Faculdade de Odontologia de Pernambuco da Universidade de Pernambuco - FOP/UPE

\section{KÁSSIA REGINA DE SANTANA}

Membro da Comissão Científica do VII Encontro Pernambucano de Odontologia - VII EPO (2019)

Acadêmica de Odontologia da Faculdade de Odontologia de Pernambuco da Universidade de Pernambuco - FOP/UPE

C2020 A reprodução desses Anais na íntegra ou em parte é permitida, desde que citados os créditos. Proibida a venda.

(C2020 Todos os direitos reservados conforme a Lei de Direitos Autorais $n^{\circ} 9.610$ de 19/02/1998. 


\section{REALIZAÇÃo}
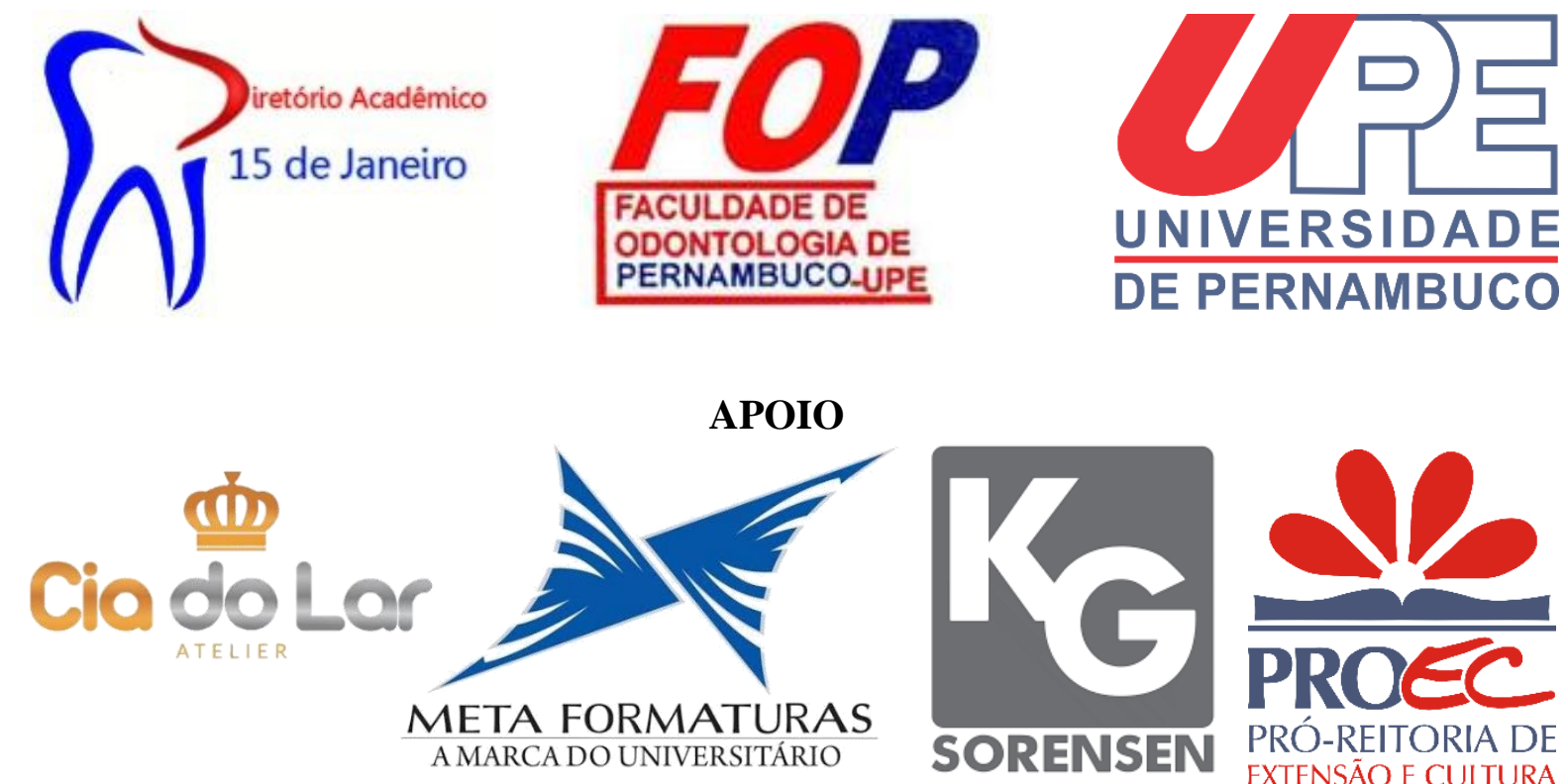

META FORMATURAS
AMARCA DO UNIVERSITÁRIO

DENTAL SORRISO

PRÓ-REITORIA DE EXTENSÃO E CULTURA

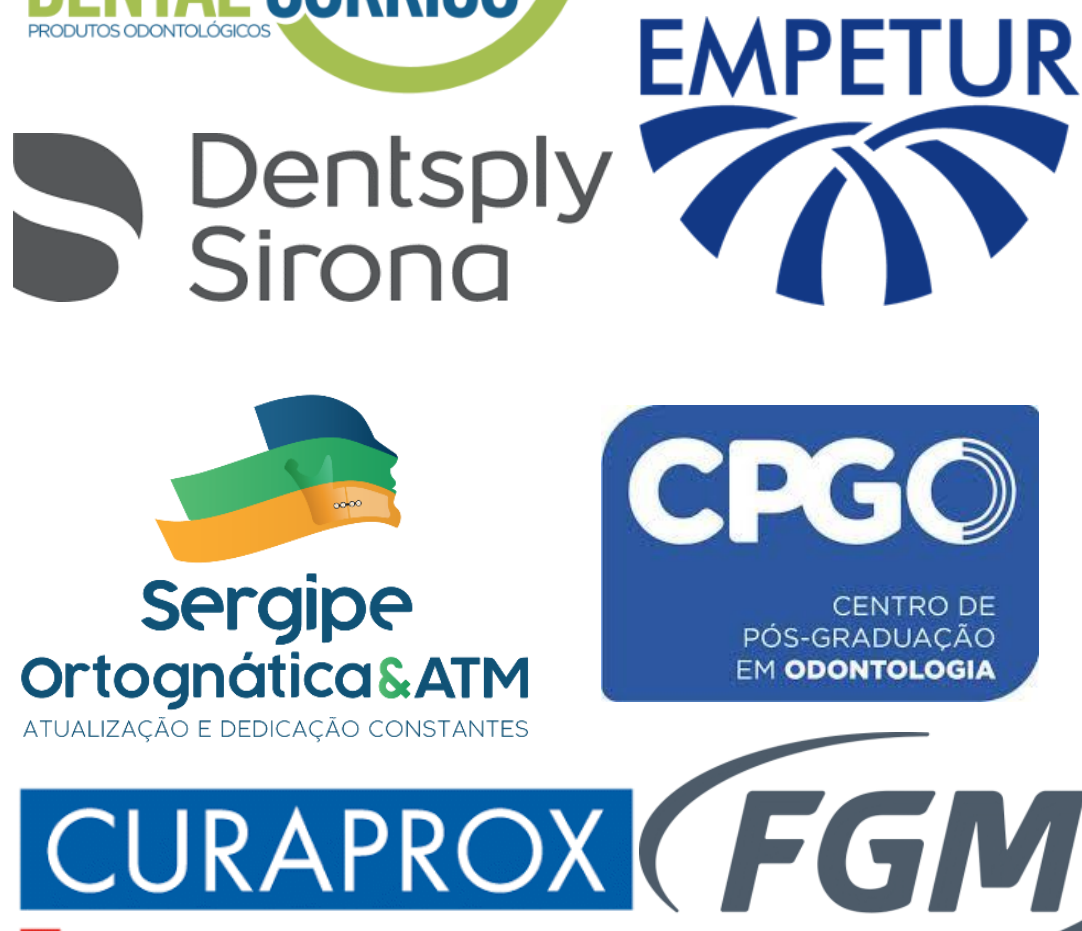

F SWISS PREMIUM ORAL CARE
SUPER

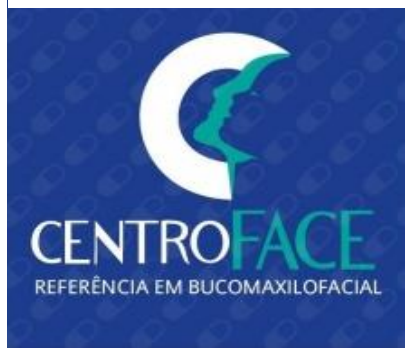

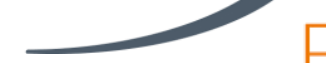

PerioGroup

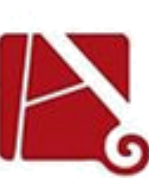

$\mathrm{G}$

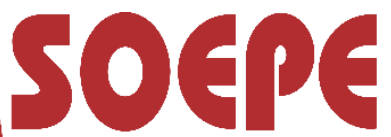

Sindicato dos Odontologistas no Estado de Pernambuco
Excelência em Periodontio

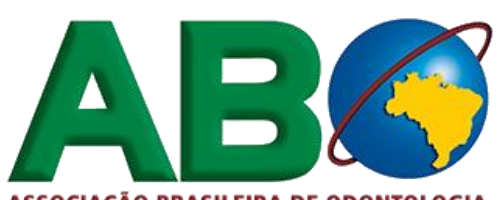

ASSOCIAÇÃO BRASILEIRA DE ODONTOLOGIA

THIAGO SANTANA

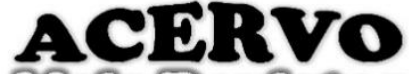

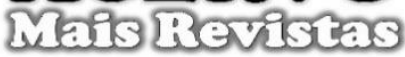

As publicações mais rápidas do país!

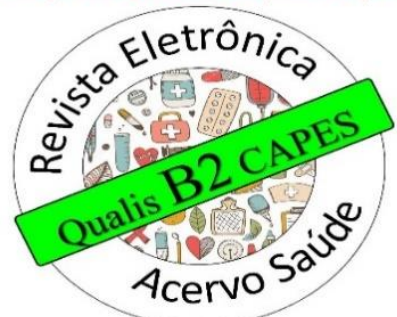




\section{APRESENTAÇÃO}

O Encontro Pernambucano de Odontologia (EPO) surgiu da ideia de uma aluna da Faculdade de Odontologia da Universidade de Pernambuco - FOP/UPE, de criar um congresso acadêmico. No seu primeiro ano, após um golpe financeiro sofrido por uma turma de concluintes da FOP/UPE, o que foi arrecadado no evento foi destinado para a formatura dessa turma. Dois anos após, o evento tornou uma atividade do Diretório Acadêmico (DA) 15 de janeiro, representação estudantil da referida faculdade.

Em 2019, o EPO, foi um evento de extensão do DA, em parceria com a Direção e Coordenação Setorial de Extensão e Cultura da FOP/UPE. Sendo um congresso científico organizado por alunos de graduação da FOP/UPE, em parceria com estudantes de outras faculdades do estado de Pernambuco, sem fins lucrativos, tendo como sua principal renda as inscrições e ajuda de apoiadores, sendo o seu lucro, caso tenha, para as atividades do Diretório para os estudantes da FOP.

Em sua sétima edição, realizada nos dias 26, 27 e 28 de setembro de 2019, com o tema central "A odontologia além da estética: integralidade com eficiência para saúde de excelência", o EPO teve como público alunos de graduação, pós-graduação, profissionais da odontologia e áreas afins.

Com mais de 350 participantes, além das apresentações de trabalhos científicos, o VII EPO teve em sua programação oito minicursos e 26 palestras, tendo como novidade o espaço direcionado para profissionais auxiliares e técnicos da odontologia, a arena EPO Experience e a mini feira EPO Exposure.

Todo o sucesso do evento deve-se a comissão organizadora, composta por 38 alunos de graduação de seis universidades diferentes, que, por um ano, construíram o evento e o fizeram de forma impecável. Logo, tenho que agradecer a cada um, desde os seis coordenadores, até os demais membros.

Também vale ressaltar o apoio que nos foi dado pela FOP/UPE e por todos os parceiros que contribuíram e confiaram no evento. Assim como de todos os congressistas que participaram das atividades propostas pela comissão.

Que estes anais, com os resumos dos trabalhos apresentados no evento, sejam a culminância, em forma de produto científico, do maior congresso acadêmico da região nordeste e melhor EPO, até esta edição, já realizado.

Atenciosamente, 


\section{MENSAGEM DO COORDENADOR DA COMISSÃO CIENTÍFICA}

A Comissão Científica, subdivisão da Comissão Organizadora do VII EPO, responsável pela submissão e apresentação de trabalhos científicos e grade cientifica tem o prazer de organizar esses anais, documento que culmina todo trabalho realizado por esta comissão e todas as outras que formam o evento.

Foram submetidos ao VII EPO 368 trabalhos, destes, 225 trabalhos foram aprovados, por estarem nas normas descritas no Edital de Submissão de Trabalho do VII EPO, assim podendo ser apresentados. Todos os 225 trabalhos foram apresentados, sendo 18 na Categoria Fórum Científico e 207 na Categoria Painel Científico.

Em nome de toda comissão científica e organizadora do EPO, agradeço a cada um dos participantes que submeteu trabalho ao VII EPO. O evento é pensado e executado para cada um de vocês.

Somos gratos também à Revista Eletrônica Acervo Saúde, pela parceria e disponibilidade em publicar os nossos anais.

Em especial, agradecemos aos participantes da comissão científica. Cada membro dessa comissão foi essencial para o bom funcionamento do evento. Obrigado Amanda, Cleiton, Gabriel, Isadora, Jonatas, Kássia e Rebeca.

Sou grato pelo convite do presidente do VII EPO, Sinval Vinícius, para assumir a coordenação da comissão científica. Obrigado pela confiança e credibilidade.

Sem mais, os presentes anais trazem todos os trabalhos apresentados na sétima edição do Encontro Pernambucano de Odontologia assim como os três melhores trabalhos na categoria Fórum Científico e os três melhores trabalhos em cada modalidade (Revisão de Literatura, Pesquisa Científica, Relato de Caso e Relato de Experiência) da categoria Painel Científico, além do melhor trabalho, dentre os melhores, apresentado no VII EPO. Os trabalhos que obtiveram a mesma pontuação no cálculo da média dos dois avaliadores, ficando empatados, ganharam a colocação pertinente.

Cordialmente, 

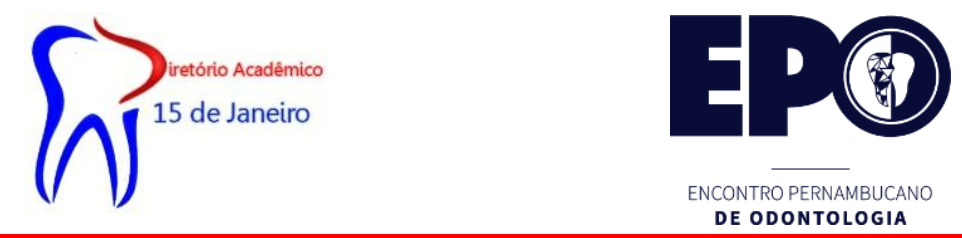

\section{COMISSÃO ORGANIZADORA DO VII ENCONTRO PERNAMBUCANO DE ODONTOLOGIA - VII EPO}

\section{PRESIDENTE}

Sinval Vinícius Barbosa do Nascimento

\section{PROFESSORA HOMENAGEADA}

Mônica Maria de Albuquerque Pontes

\section{CONSULTORES}

Hébert de Santana Arruda Juliana Raposo Souto Maior Costa Lara Marques Magalhães Moreno

COMISSÃO CIENTÍFICA

Eduardo Vinícius de Souza Silva Coordenador

Amanda Pereira Melo

Cleiton Rone dos Santos Lima Isadora Malaquias Mendes Barbosa Jonatas Silva de Oliveira

Kássia Regina de Santana

Rebeca Gomes da Silva Ronaldo Gabriel Martiniano da Silva

\section{COMISSÃO DE PATROCÍNIO}

Beatriz Borba Barros Bernardo Coordenadora

Fernanda Gomes Barros Greiciane Miguel de Azevedo Santos Matheus Vinicius Anunciação Neves

Raisa Rebeca da Silva Batista

\section{COMISSÃO SOCIAL}

Pedro Henrique Barbosa de Melo Coordenador

Ana Beatriz Albuquerque Meira

Francisco Henrique Lima Milhomens

Luíza Flôres da Costa Fagundes

Malú Virginia Santana Campos

Marcela Lins Braga
Saulo Valença de Farias Barbosa

Vinicius Cardoso Pyrrho Cirne de Azevedo

COMISSÃO DE SECRETARIA

Pamella Robertha Rosselinne Paixão

Celerino - Coordenadora

Ellen Rayssa Lopes do Nascimento

Emerllyn Shayane Martins de Araújo

Gabriela Máximo Pereira da Silva Isabela Araújo de Lima Robson de Lima Gomes

Taynara Franciele da Silva Souza

\section{COMISSÃO DE COMUNICAÇÃO} João Artur Peixoto Granja - Coordenador Amanda dos Santos Vasconcellos Hian Carvalho Souza Jose Paulo Amaral Guimarães Maria Sabrina Alves da Silva Mirela Carolaine Cunha da Cruz Taís Soares Ramos

\section{COMISSÃO FINANCEIRA}

Fernanda Teles Pereira - Coordenadora

Pedro Paulo Aguiar Santos Cavalcanti 


\section{SUMÁRIO}

TRABALHOS PREMIADOS

MELHOR TRABALHO APRESENTADO NO VII EPO

FC-01-2019 - A IMPORTÂNCIA DO TRATAMENTO PRECOCE DE MESIODENS: UM RELATO DE CASO

FC-02-2019 - ASSOCIAÇÃO ENTRE PROJEÇÕES CERVICAIS DE ESMALTE E DEFEITOS DE FURCA: REVISÃO DE LITERATURA.....

FC-03-2019 - AVALIAÇÃO DAS CONCENTRAÇÕES QUÍMICAS NOS DIFERENTES TECIDOS DENTAIS, SADIOS E CARIADOS, ATRAVÉS DA ESPECTROSCOPIA ATÔMICA. FC-04-2019 - CINE CLUB +: O PROJETO DE EXTENSÃO QUE INTEGRA A SAÚDE ATRAVÉS DA SÉTIMA ARTE - RELATO DE EXPERIÊNCIA......

FC-05-2019 - DIFERENCIAÇÃO OSTEOGÊNICA DE CÉLULAS-TRONCO IRRADIADAS COM LASER DE BAIXA POTÊNCIA

FC-06-2019 - EFICÁCIA CLÍNICA DE SISTEMAS ADESIVOS AUTOCONDICIONANTES DE UM PASSO E DOIS PASSOS EM LCNC: UMA REVISÃO SISTEMÁTICA E META-ANÁLISE 33 FC-07-2019 - EPIDEMIOLOGIA, DIAGNÓSTICO E TRATAMENTO DO TUMOR ODONTOGÊNICO PRIMORDIAL: REVISÃO SISTEMÁTICA

FC-08-2019 - EXOSTOSE ÓSSEA BILATERAL EM REGIÃO DE MAXILA: RELATO DE CASO

FC-09-2019 - EXPOSIÇÃO DO PACIENTE EM MÍDIAS SOCIAIS ENTRE ESTUDANTES DE ODONTOLOGIA

FC-10-2019 - MOLDAGEM DE DUPLA IMPRESSÃO MODIFICADA - SIMPLIFICANDO A TÉCNICA

FC-11-2019 - PROGRAMA DE EXTENSÃO UNIVERSITÁRIA RESGATANDO SORRISOS 9 .. 38 FC-12-2019 - RASTREAMENTO DE PATOLOGIAS DO COMPLEXO BUCOMAXILOFACIAL: ATENDIMENTO E PROMOÇÃO DE SAÚDE NO PROGRAMA DE EXTENSÃO RESGATANDO SORRISOS

FC-13-2019 - RELATO DE CUIDADORES SOBRE O ACESSO ODONTOLÓGICO DE CRIANÇAS E ADOLESCENTES COM PARALISIA CEREBRAL

FC-14-2019 - TRANSPLANTE TRANSALVEOLAR DE CANINO MAXILAR IMPACTADO:

RELATO DE CASO

FC-15-2019 - TRATAMENTO CIRÚRGICO DE CARCINOMA BASOCELULAR EM REGIÃO

INFRA-ORBITAL COM AUTO-ENXERTIA CUTÂNEA.

FC-16-2019 - TRATAMENTO CIRÚRGICO DE CISTO ODONTOGÊNICO QUERATOCISTO LOCALIZADO EM REGIÃO POSTERIOR DE MAXILA: RELATO DE CASO

FC-17-2019 - USO DA TOMOGRAFIA DE FEIXE CÔNICO COMO FERRAMENTA NO

DIAGNÓSTICO DE LESÕES PERRIRADICULARES: RELATO DE CASO.

FC-18-2019 - USO DO LASER COMO COADJUVANTE NA REPARAÇÃO ÓSSEA E NA IMPLANTODONTIA

PC-01-2019 - A AÇÃO DAS PROTEÍNAS SALIVARES NO DESENVOLVIMENTO DO BIOFILME DE CANDIDA ALBICANS

PC-02-2019 - A FLUORETAÇÃO DA ÁGUA COMO MEDIDA DE VIGILÂNCIA EM SAÚDE BUCAL 
PC-03-2019 - A IMPORTÂNCIA DA HUMANIZAÇÃO NO ATENDIMENTO ODONTOLÓGICO: REVISÃO DE LITERATURA

PC-04-2019 - A IMPORTÂNCIA DO ATENDIMENTO ODONTOLÓGICO ÀS GESTANTES:

REVISÃO DE LITERATURA

PC-05-2019 - A IMPORTÂNCIA DO PREENCHIMENTO E ARMAZENAMENTO CORRETO DO PRONTUÁRIO ODONTOLÓGICO: UMA REVISÃO DE LITERATURA ………………………...... 51

PC-06-2019 - A INTUBAÇÃO SUBMENTONIANA COMO MEDIDA ALTERNATIVA ................ 52 PC-07-2019 - A QUEILOSCOPIA COMO MÉTODO DE IDENTIFICAÇÃO HUMANA: REVISÃO DE LITERATURA

PC-08-2019 - A RELAÇÃO DO USO DOS BISFOSFONATOS COM A OSTEONECROSE DOS MAXILARES: REVISÃ̃O DE LITERATURA.

PC-09-2019 - A SÍFILIS E SUAS MANIFESTAÇÕES BUCAIS: RELATO DE CASO CLÍNICO .. 55 PC-10-2019 - ABORDAGEM CIRÚGICA DE ODONTOMA COMPOSTO EM MANDÍBULA: RELATO DE CASO

PC-11-2019 - ABORDAGEM CIRURGICA À PACIENTES COM COAGULOPATIAS HEREDITÁRIAS: UMA REVISÃO DE LITERATURA

PC-12-2019 - ABORDAGEM CIRÚRGICA EM GESTANTE NO TERCEIRO TRIMESTRE DA GESTAÇÃO: RELATO DE CASO

PC-13-2019 - ABORDAGEM CIRÚRGICA PARA ELEMENTOS SUPRANUMERÁRIOS INCLUSOS POR INDICAÇÃO ORTODÔNTICA

PC-14-2019 - ABORDAGEM CIRÚRGICA PARA TRATAMENTO DE LESÃO CENTRAL DE CÉLULAS GIGANTES: RELATO DE CASO

PC-15-2019 - ACESSO ÀS VIAS AÉREAS NA EMERGÊNCIA ODONTOLÓGICA: REVISÃO DE LITERATURA.

PC-16-2019 - ACIDENTES E COMPLICAÇÕES NA UTILIZAÇÃO DE MINI-PARAFUSOS COMO DISPOSITIVOS DE ANCORAGEM ORTODÔNTICA

PC-17-2019 - ADENOMA PLEOMÓRFICO: REVISÃO DE LITERATURA

PC-18-2019 - ALTERAÇÃO DE COR DOS CIMENTOS RESINOSOS UTILIZADOS EM PRÓTESE FIXA

PC-19-2019 - ALTERAÇÕES PATOLÓGICAS RELEVANTES PARA A CLÍNICA ODONTOPEDIÁTRICA: UMA REVISÃO DE LITERATURA

PC-20-2019 - AMELOBLASTOMA EXTENSO EM MAXILA: RELATO DE CASO

PC-21-2019 - AMELOGÊNESE IMPERFEITA: ABORDAGEM CONSERVADORA COM RESINAS COMPOSTAS

PC-22-2019 - ANEMIA DE FANCONI E SUAS REPERCUSSÕES EM CAVIDADE ORAL: UMA REVISÃO DE LITERATURA

PC-23-2019 - ANESTESIA LOCAL EM ODONTOLOGIA: POR QUE UTILIZAR TUBETE DE VIDRO?

PC-24-2019 - ANGINA BOLHOSA HEMORRÁGICA- RELATO DE CASO CLÍNICO.

PC-25-2019 - APLICAÇÃO DA TOXINA BOTULÍNICA COMO ALTERNATIVA PARA O

TRATAMENTO DA DISFUNÇÃO TEMPOROMANDIBULAR: REVISÃO DE LITERATURA .. 71 PC-26-2019 - APLICAÇÃO DE MODELAGEM MATEMÁTICA PARA AVALIAÇÃO DOS EFEITOS TÉRMICOS DO FS LASER NOS TECIDOS DENTÁRIOS

PC-27-2019 - APRESENTAÇÕES CLÍNICAS DA DISPLASIA CLEIDOCRANIANA: REVISÃO

DE LITERATURA

PC-28-2019 - APROVEITAMENTO DE DENTE INCLUSO ASSOCIADO A ODONTOMA COMPOSTO EM MAXILA - RELATO DE CASO 
PC-29-2019 - ARTROPLASTIA EM GAP NO TRATAMENTO DA ANQUILOSE DA ARTICULAÇÃO TEMPOROMANDIBULAR: RELATO DE CASO

PC-30-2019 - ASPECTOS ATUAIS DAS LESÕES NERVOSAS DECORRENTES DA CIRURGIA

DE TERCEIROS MOLARES INFERIORES INCLUSOS: REVISÃO DE LITERATURA

PC-31-2019 - ASPECTOS GERAIS E CONDUTAS TERAPÊUTICAS PARA O TRATAMENTO DOS AMELOBLASTOMAS: REVISÃO DE LITERATURA.

PC-32-2019 - ASPECTOS IMAGINOLÓGICOS DE MÚLTIPLOS QUERATOCISTOS

ODONTOGÊNICOS: RELATO DE CASO.

PC-33-2019 - ASPECTOS MICROBIOLÓGICOS DA CÁRIE DENTÁRIA

PC-34-2019 - ASPECTOS TOMOGRÁFICOS DAS DISPLASIAS CEMENTO-ÓSSEAS. 80

PC-35-2019 - ASSOCIAÇÃO DE TÉCNICAS PARA CLAREAMENTO DENTAL: RELATO DE CASO

PC-36-2019 - ATENDIMENTO ODONTOLÓGICO EM PACIENTE COM SÍNDROME

BARAITSER WINTER: RELATO DE CASO

PC-37-2019 - ATENDIMENTO PRIMÁRIO À VÍTIMA DE TRAUMABUCO MAXILO FACIAL:

UMA REVISÃO DE LITERATURA

PC-38-2019 - ATUAÇÃO DO PSICOONCOLOGISTA NA EQUIPE MULTIPROFISSIONAL DE PACIENTES COM CÂNCER DE CABEÇA E PESCOÇO: REVISÃO DE LITERATURA

PC-39-2019 - ATUAÇÃO E IMPORTÂNCIA DO CIRURGIÃO DENTISTA EM AMBIENTE HOSPITALAR: REVISÃO DE LITERATURA

PC-40-2019 - AUMENTODE COROA CLÍNICA ESTÉTICO PELA TÉCNICA FLAPLESS:

RELATO DE CASO CLÍNICO.

PC-41-2019 - AVULSÃO DE MARGEM E ASSOALHO DE ÓRBITA EM PACIENTE PEDIÁTRICO: RELATO DE CASO

PC-42-2019 - BENEFÍCIOS DA ARTROCENTESE EM PACIENTES PORTADORES DE

DISFUNÇÃO TEMPOROMANDIBULAR (DTM)

PC-43-2019 - CARACTERÍSTICAS BUCAIS DO PACIENTE INFANTOJUVENIL COM PARALISIA CEREBRAL: REVISÃO DE LITERATURA

PC-44-2019 - CIRURGIA PLÁSTICA PERIODONTAL PARA CORREÇÃO DE SORRISO

GENGIVAL: UM RELATO DE CASO

PC-45-2019 - CIRURGIA PLÁSTICA PERIODONTAL PARA TRATAMENTO DA ERUPÇÃO PASSIVA ALTERADA: RELATO DE CASO

PC-46-2019 - COMO SIMPLIFICAR A TÉCNICA DE RESTAURAÇÕES INDIRETAS EM DENTES POSTERIORES?

PC-47-2019 - COMPLICAÇÕES BUCAIS CAUSADAS PELA RADIOTERAPIA: REVISÃO DA LITERATURA.

PC-48-2019 - COMPLICAÇÕES CAUSADAS PELA ANQUILOGLOSSIA NO LACTENTE E A

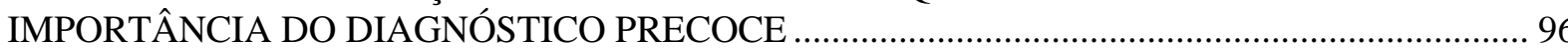

PC-49-2019 - CONDICIONANDO A ZIRCÔNIA COM ÁCIDO FLUORÍDRICO A 50\%

PC-50-2019 - CONDUTA DE CIRURGIÕES-DENTISTAS FRENTE À PARESTESIA PÓS CIRURGIA BUCAL

PC-51-2019 - CONDUTAS DO ODONTOPEDIATRA FRENTE À CASOS DE VIOLÊNCIA

INFANTIL: REVISÃO DE LITERATURA.

PC-52-2019 - CONTRIBUIÇÃO DO ÁCIDO SIÁLICO E DA FUCOSE NO PROCESSO DE METÁSTASE TUMORAL

PC-53-2019 - CONTROLE DA APNEIA OBSTRUTIVA DO SONO ATRAVÉS DO APARELHO

INTRA ORAL EM PACIENTE NÃO ADERENTE AO CPAP: RELATO DE CASO .... 101 
PC-54-2019 - CREPITAÇÃO E DISFUNÇÃO TEMPOROMANDIBULAR NA DOENÇA DE PARKINSON

PC-55-2019 - CRISTAIS DE COLESTEROL EM CISTO ÓSSEO SIMPLES DE MANDÍBULA: UM

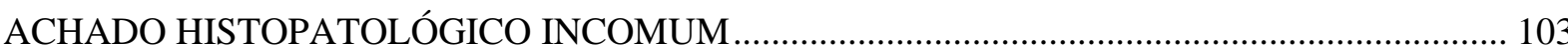

PC-56-2019 - DESCONTAMINAÇÃO GENGIVAL ATRAVÉS DO LASER ER-YAG ................. 104 PC-57-2019 - DESFECHOS REPORTADOS PELOS PACIENTES EM RELAÇÃO À TERAPIA PERIODONTAL

PC-58-2019 - DIAGNÓSTICO DE ANQUILOGLOSSIA E PROCEDIMENTO DE FRENECTOMIA LINGUAL REALIZADO NO PROJETO DE EXTENSÃO LÍNGUA SOLTA - RELATO DE CASO CLÍNICO.

PC-59-2019 - DIAGNÓSTICO DE DESORDENS SISTÊMICAS E ORAIS PELA SALIVA.......... 107 PC-60-2019 - DISPLASIA ODONTOMAXILAR SEGMENTAR: RELATO DE CASO ................. 108 PC-61-2019 - DISTÚRBIOS ALIMENTARES E A ODONTOLOGIA: REVISÃO DE LITERATURA.

PC-62-2019 - DOENÇA DO ENXERTO CONTRA O HOSPEDEIRO: RELATO DE CASO

PC-63-2019 - É POSSÍVEL REMOVER MANCHAS HIPERPLÁSICAS DE FORMA CONSERVADORA? RELATO DE CASO

PC-64-2019 - EDUCAÇÃO EM SAÚDE DO ESCOLAR: UM AGIR PARTICIPATIVO

PC-65-2019 - EFEITO CLAREADOR DE DENTIFRÍCIOS À BASE DE CARVÃO ATIVADO: REVISÃO DE LITERATURA

PC-66-2019 - EFEITO DA TERAPIA FOTODINÂMICA COMO ADJUVANTE À TERAPIA PERIODONTAL DE SUPORTE SOBRE BOLSAS RESIDUAIS

PC-67-2019 - EFEITO DA TERAPIA FOTODINÂMICA COMO ADJUVANTE A TERAPIA PERIODONTAL NÃO CIRÚRGICAS EM LESÕES DE FURCA

PC-68-2019 - EFEITO DA TERAPIA FOTODINÂMICA COMO ADJUVANTE À TERAPIA

PERIODONTAL NÃO CIRÚRGICA SOBRE O FLUIDO CREVICULAR GENGIVAL.

PC-69-2019 - EFEITOS DA ABRASIVIDADE DE CREMES DENTAIS CLAREADORES NO ESMALTE DENTÁRIO HUMANO

PC-70-2019 - EFEITOS DA TERAPIA PERIODONTAL NÃO CIRÚRGICA NA DOENÇA RENAL CRÔNICA.

PC-71-2019 - EFEITOS DO ÓXIDO NITROSO X REALIDADE VIRTUAL NOS

PROCEDIMENTOS ODONTOLÓGICOS

PC-72-2019 - EFEITOS TERAPÊUTICOS DA CIRURGIA ORTOGNÁTICA, CPAP E DAMs NO TRATAMENTO DA APNEIA OBSTRUTIVA DO SONO: REVISÃO DE LITERATURA .......... 122 PC-73-2019 - EFICÁCIA DA EMINECTOMIA NO TRATAMENTO DE LUXAÇÃO RECIDIVANTE DA ATM: RELATO DE CASO CLÍNICO

PC-74-2019 - ENDOCROWN PARA REABILITAÇÃO DE DENTES POSTERIORES TRATADOS ENDODONTICAMENTE: REVISÃO DA LITERATURA

PC-75-2019 - ENDODONTIA REGENERATIVA: PROTOCOLOS ATUAIS EM PACIENTES ADULTOS

PC-76-2019 - ENFISEMA SUBCUTÂNEO EXTENSO APÓS EXTRAÇÃO DE TERCEIRO MOLAR: RELATO DE CASO.

PC-77-2019 - ENXERTIA AUTÓGENA NA RECONSTRUÇÃO DE REBORDO MAXILAR ATRÓFICO: RELATO DE CASO.

PC-78-2019 - ENXERTO DE TECIDO CONJUNTIVO: RELATO DE CASO

PC-79-2019 - ENXERTO LIVRE DE CRISTA ILÍACA NA RECONSTRUÇÃO MANDIBULAR: 
PC-80-2019 - ENXERTO MICROVASCULARIZADO DE FÍBULA EM RECONSTRUÇÃO MANDIBULAR EXTENSA: CASO CLÍNICO.

PC-81-2019 - ESCANEAMENTO DIGITAL E PROTOTIPAGEM DE MODELO 3D PARA LENTES DE CONTATO DENTAIS - RELATO DE CASO

PC-82-2019 - ESCLEROTERAPIA DE HEMANGIOMA EM LÁBIO INFERIOR: RELATO DE CASO

PC-83-2019 - ESTUDO DA RESISTÊNCIA DE UNIÃO DOS SISTEMAS ADESIVOS

UNIVERSAIS EM DENTINA HÍGIDA

PC-84-2019 - ESTUDO DAS DISFUNÇÕES TEMPOROMANDIBULARES EM PACIENTES SINDRÔMICOS PORTADORES DE DOENÇAS DO TECIDO CONJUNTIVO COM HIPERMOBILIDADE ARTICULAR ...

PC-85-2019 - EXCISÃO CIRÚRGICA DE ADENOMA PLEOMÓRFICO EM GLÂNDULA

SALIVAR MENOR: RELATO DE CASO

PC-86-2019 - EXÉRESE DE EXTENSO GRANULOMA PIOGÊNICO EM NÍVEL HOSPITALAR: RELATO DE CASO

PC-87-2019 - FASCIÍTE NECROSANTE DE ORIGEM ODONTOGÊNICA: RELATO DE CASO

PC-88-2019 - FATORES DE RISCO, COMPLICAÇÕES E PREVENÇÃO DA GENGIVITE

ULCERATIVA NECROSANTE: UMA REVISÃO DE LITERATURA

PC-89-2019 - FAZENDO ART COM AS CRIANÇAS: UMA PROPOSTA DE PROMOÇÃO DA SAÚDE BUCAL

PC-90-2019 - FECHAMENTO DE DIASTEMA COM RESINA COMPOSTA: RELATO DE CASO

PC-91-2019 - FECHAMENTO DE DIASTEMA EM RESINA COMPOSTA: RELATO DE CASO

PC-92-2019 - FIBRO-ODONTOMA AMELOBLÁSTICO: UM RELATO DE CASO CLÍNICO ... 142 PC-93-2019 - FLUOROSE DENTÁRIA: EPIDEMIOLOGIA, DIAGNÓSTICO E TRATAMENTO

PC-94-2019 - FOLLOW-UP DE 3 ANOS DE ENXERTIA AUTÓGENA NA RECONSTRUÇÃO MANDIBULAR: RELATO DE CASO.

PC-95-2019 - FRATURA COMINUTIVA DE MANDÍBULA DEVIDO A AGRESSÃO POR

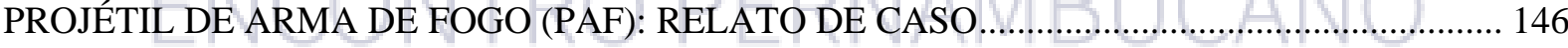
PC-96-2019 - FRATURA NASAL: REVISÃO DE LITERATURA

PC-97-2019 - FRENECTOMIA LABIAL SUPERIOR ATRAVÉS DE LASER DE ALTA POTÊNCIA Er:YAG

PC-98-2019 - FRENECTOMIA LINGUAL COMO FERRAMENTA PARA REABILITAÇÃO DA COMUNICAÇÃO E FUNCIONALIDADE EM PACIENTE ADULTO: RELATO DE CASO ...... 149 PC-99-2019 - FRENECTOMIA LINGUAL EM PACIENTE PRÉ-ADOLESCENTE NO PROJETO LÍNGUA SOLTA/UFPE: DO DIAGNÓSTICO À CIRURGIA

PC-100-2019 - FRENECTOMIA LINGUAL EM PRÉ-ADOLESCENTE NO PROJETO LÍNGUA SOLTA/UFPE - RELATO DE CASO

PC-101-2019 - FRENOTOMIA LINGUAL E SUA CORRELAÇÃO COM AMAMENTAÇÃO:

RELATO DE CASO CLÍNICO.

PC-102-2019 - GANCHO DE BARROS NO TRATAMENTO DA FRATURA DE ARCO

ZIGOMÁTICO: RELATO DE CASO.

PC-103-2019 - GRANULOMA PIOGÊNICO ULCERADO EM PACIENTE COM PARALISIA CEREBRAL - RELATO DE CASO 
PC-104-2019 - GRANULOMA PIOGÊNICO: UMA REVISÃO DE LITERATURA.

PC-105-2019 - HALITOSE: ASPECTOS DE IMPORTÂNCIA CLÍNICA PARA O CIRURGIÃODENTISTA

PC-106-2019 - HEMATOMA SUBLINGUAL ESPONTÂNEO SECUNDÁRIO AO USO

CONTÍNUO DE VARFARINA: RELATO DE CASO.

PC-107-2019 - HIPERPLASIA ENDOTELIAL PAPILAR INTRAVASCULAR ORAL: REVISÃO DE LITERATURA

PC-108-2019 - HIPERPLASIA FIBROSA INFLAMATÓRIA ASSOCIADA À SÍNDROME DA COMBINAÇÃO: RELATO DE CASO.

PC-109-2019 - IMPACTO DA FRENOTOMIA LINGUAL NA MELHORIA DOS SINTOMAS DA AMAMENTAÇÃO EM NEONATOS: RELATO DE CASO.

PC-110-2019 - IMPACTO DA SAÚDE BUCAL NA QUALIDADE DE VIDA DE CRIANÇAS E ADOLESCENTES COM CÂNCER

PC-111-2019 - IMPACTOS DA CIRURGIA ORTOGNÁTICA NA QUALIDADE DE VIDA DOS PACIENTES: REVISÃO DE LITERATURA

PC-112-2019 - IMPORTÂNCIA DA PROMOÇÃO À SAÚDE E EDUCAÇÃO ODONTOLÓGICA EM PACIENTES PORTADORES DE SÍNDROME DE DOWN

PC-113-2019 - IMPORTÂNCIA ODONTO-LEGAL DAS ANOMALIAS DENTAIS .

PC-114-2019 - INATIVAÇÃO FOTODINÂMICA DE PATÓGENOS CARIOGÊNICOS

UTILIZANDO A CURCUMINA COMO FOTOSSENSIBILIZADOR

PC-115-2019 - INDICAÇÕES DA FITOTERAPIA NA ODONTOLOGIA

PC-116-2019 - INFLUÊNCIA DO TIPO DE ÁGUA DE MANIPULAÇÃO NA ESTABILIDADE

DIMENSIONAL LINEAR DO GESSO TIPO IV

PC-117-2019 - INTERVENÇÃO CIRÚRGICA PARA TRANSMIGRAÇÃO DE CANINO:

REVISÃO DE LITERATURA

PC-118-2019 - ISOLAMENTO DE LEVEDURAS DO GÊNERO CANDIDA NO CONSULTÓRIO

ODONTOLÓGICO.

PC-119-2019 - LESÃO CENTRAL DE CÉLULAS GIGANTES TRATADA POR MEIO DE RESSECÇÃO PARCIAL E RECONSTRUÇÃO MANDIBULAR COM CRISTA ILÍACA: UM RELATO DE CASO

PC-120-2019 - LESÃO EM TECIDO MOLE NA REGIÃO BUCOMAXILOFACIAL DEVIDO A ACIDENTE DE TRABALHO: RELATO DE CASO

PC-121-2019 - LESÃO EXTENSA EM FACE DECORRENTE DE TRAUMA: RELATO DE CASO

PC-122-2019 - LESÕES BUCAIS DA PARACOCCIDIOIDOMICOSE: REVISÃO DE

LITERATURA.

PC-123-2019 - MANEJO CIRÚRGICO PARA REMOÇÃO DE ODONTOMA COMPOSTO EM

REGIÃO ANTERIOR DE MANDÍBULA: RELATO DE CASO.

PC-124-2019 - MANEJO DE HEMATOMA APÓS PROCEDIMENTO DE BICHECTOMIA:

RELATO DE CASO

PC-125-2019 - MANIFESTAÇÕES BUCAIS EM PACIENTES INTERNADOS EM UTI E A ATUAÇÃO DO CIRURGIÃO-DENTISTA: REVISÃO DE LITERATURA

PC-126-2019 - MANIFESTAÇÕES BUCAIS EM PACIENTES ONCOLÓGICOS PEDIÁTRICOS

PC-127-2019 - MANIFESTAÇÕES OROFACIAIS DA SÍNDROME DE NOONAN.

PC-128-2019 - MECANISMOS BIOLÓGICOS ENVOLVIDOS NO ESTADO INFLAMATÓRIO DE PACIENTES OBESOS E SUAS POSSÍVEIS IMPLICAÇÕES CLÍNICAS NA ODONTOLOGIA 179 
PC-129-2019 - MELANOMA MUCOSO DE CABEÇA E PESCOÇO: UMA REVISÃO DE LITERATURA.

PC-130-2019 - NÍVEL DE SATISFAÇÃO E QUALIDADE DE VIDA EM IDOSOS USUÁRIOS DE PRÓTESES TOTAIS

PC-131-2019 - O ACOLHIMENTO NA ATENÇÃO PRIMÁRIA A SAÚDE

182

PC-132-2019 - O BRUXISMO NA INFÂNCIA: UMA REVISÃO DE LITERATURA 183

PC-133-2019 - O DESAFIO DAS FACETAS UNITÁRIAS EM DENTES COM SUBSTRATO ESCURECIDO.

PC-134-2019 - O EMPREGO DA FOTOBIOMODULAÇÃO NO CONTROLE DA MUCOSITE ORAL DE PACIENTE SUBMETIDO À QUIMIOTERAPIA E RADIOTERAPIA DA REGIÃO DE CABEÇA E PESCOÇO: RELATO DE CASO

PC-135-2019 - O USO DO ENXERTO ÓSSEO DE MENTO NA REABILITAÇÃO ORAL COM IMPLANTES: UM RELATO DE CASO

PC-137-2019 - ORIENTAÇÃO DE HIGIENE BUCAL PARA ADOLESCENTES: REVISÃO DE LITERATURA.

PC-138-2019 - OSTEOMA OSTEÓIDE EM CORPO MANDIBULAR-RELATO DE CASO ...... 189 PC-139-2019 - OSTEONECROSE ASSOCIADA AO USO DE BISFOSFONATOS EM TÓRUS PALATINO.

PC-140-2019 - OSTEONECROSE DOS MAXILARES POR USO DE BIFOSFONATOS: REVISÃO DE LITERATURA

PC-141-2019 - OSTEONECROSE POR MEDICAMENTO EM MAXILA - RELATO DE CASO 192 PC-142-2019 - OSTEOSSÍNTESE EM FRATURA DE PAREDE ANTERIOR DE SEIO FRONTAL: RELATO DE CASO

PC-143-2019 - PALATO OGIVAL E SEUS POSSÍVEIS TRATAMENTOS: REVISÃO DE

LITERATURA.

PC-144-2019 - PAPEL DO CIRURGIÃO-DENTISTA FRENTE A PACIENTES ONCOLÓGICOS: REVISÃO DE LITERATURA

PC-145-2019 - PAPILOMA ESCAMOSO ORAL EM REBORDO ALVEOLAR INFERIOR:

RELATO DE CASO CLÍNICO.

PC-146-2019 - PARESTESIA TRANSITÓRIA UNILATERAL PÓS EXODONTIA DE TERCEIRO

MOLAR INFERIOR: RELATO DE CASO.

PC-147-2019 - PLANEJAMENTO VIRTUAL PARA CORREÇÃO CIRÚRGICA DE

DEFORMIDADE DENTOFACIAL: RELATO DE CASO.

PC-148-2019 - PROGRAMA DE EXTENSÃO UNIVERSITÁRIA RESGATANDO SORRISOS:

ESTUDO CLÍNICO E SOCIODEMOGRÁFICO DE USUÁRIOS DE PRÓTESE DENTÁRIA DA

REGIÃO NORDESTE BRASILEIRA

PC-149-2019 - PROJETO SAÚDE COLORIDA: RELATO DE EXPERIÊNCIA............................. 200

PC-150-2019 - PROMOÇÃO DE SAÚDE BUCAL NA PRAIA: RELATO DE EXPERIÊNCIA ... 201 PC-151-2019 - PRÓTESE ADESIVA DIRETA: ALTERNATIVA REABILITADORA PARA O SERVIÇO PÚBLICO DE SAÚDE.

PC-152-2019 - PROTOCOLO CIRÚRGICO DE FERIMENTO EXTENSO EM FACE POR ARMA BRANCA: RELATO DE CASO

PC-153-2019 - QUERATOCISTO MIMETIZANDO UMA LESÃO PERIAPICAL

INFLAMATÓRIA

PC-154-2019 - QUERUBISMO: REVISÃO DE LITERATURA 
PC-155-2019 - REABILITAÇÃO ESTÉTICA E FUNCIONAL EM PACIENTE COM CÁRIE SEVERA DA INFÂNCIA: RELATO DE CASO.

PC-156-2019 - REABILITAÇÃO ORAL ESTÉTICA EM DENTES ANTERIORES COM LAMINADOS CERÂMICOS DE DISSILICATO DE LÍTIO: UM RELATO DE CASO...

PC-157-2019 - REAÇÃO DE CORPO ESTRANHO EM LÁBIO INFERIOR 208

PC-158-2019 - REARMONIZAÇÃO ESTÉTICA DO SORRISO UTILIZANDO TÉCNICA SEMIDIRETA: RELATO DE CASO

PC-159-2019 - RECONSTRUÇÃO ANTERIOR DE MAXILA COM ENXERTO EM BLOCO AUTÓGENO: RELATO DE CASO CLÍNICO.

PC-160-2019 - RECONSTRUÇÃO DE DENTES TRATADOS ENDODONTICAMENTE: RELATO DE CASO

PC-161-2019 - RECONSTRUÇÃO MANDIBULAR POR MEIO DA TÉCNICA “TENT POLE”:

RELATO DE CASO.....

PC-162-2019 - REDUÇÃO E FIXAÇÃO DE FRATURA DENTOALVEOLAR EM MAXILA:

RELATO DE CASO

PC-163-2019 - REDUÇÃO INCRUENTA DE FRATURA DOS OSSOS PRÓPRIOS DO NARIZ -

RELATO DE CASO

PC-164-2019 - REFLEXO TRIGÊMINO-CARDÍACO DURANTE EXTRAÇÃO DENTÁRIA:

REVISÃO DE LITERATURA

PC-165-2019 - RELATO DE VIVÊNCIA DISCENTE EM UM TERRITÓRIO DA ATENÇÃO PRIMÁRIA À SAÚDE DO RECIFE

PC-166-2019 - REMOÇÃO DE CEMENTOBLASTOMA EM MAXILA: RELATO DE CASO .... 218 PC-167-2019 - REMOÇÃO DE CORPO ESTRANHO EM CAVIDADE ORBITÁRIA: RELATO DE CASO

PC-168-2019 - REMOÇÃO DE CORPO ESTRANHO EM FACE: RELATO DE CASO 220

PC-169-2019 - REMOÇÃO DE PROJÉTIL EM CÔNDILO MANDIBULAR ASSOCIADO À CORONOIDECTOMIA: RELATO DE CASO.

PC-170-2019 - REPARAÇÃO DE DEFORMIDADE FACIAL COM AUXÍLIO DE BIOMODELO: RELATO DE CASO

PC-171-2019 - RESOLUÇÃO DE APINHAMENTO SEVERO SEM EXTRAÇÃO COM APARELHO ORTODÔNTICO AUTOLIGADO

PC-172-2019 - RESSECÇÃO DE AMELOBLASTOMA EM MANDÍBULA: RELATO DE CASO

PC-173-2019 - SEQUELA DE FRATURA DO COMPLEXO NASO-ÓRBITO-ETMOIDAL:

RELATO DE CASO

PC-174-2019 - SEQUÊNCIA CIRÚRGICA PARA REDUÇÃO E FIXAÇÃO DE FRATURA DE

MANDÍBULA: RELATO DE CASO..

PC-175-2019 - SESSÃO ÚNICA EM CASOS COMPLEXOS: UMA REALIDADE

CONTEMPORÂNEA - RELATO DE CASO

PC-176-2019 - SIALOMETAPLASIA NECROSANTE: ASPECTOS ETIOLÓGICOS,

DIAGNÓSTICO E TRATAMENTO

PC-177-2019 - SUBSTITUIÇÃO DE RESTAURAÇÕES EM AMÁLGAMA DE PRATA POR RESINA COMPOSTA PELAS TÉCNICAS DIRETA E INDIRETA: RELATO DE CASO

PC-178-2019 - TÉCNICA DE CHAMPY NA FRATURA DE ÂNGULO MANDIBULAR: RELATO

DE CASO

PC-179-2019 - TÉCNICA DE ENXERTO GENGIVAL LIVRE PARA AUMENTO DE GENGIVA

QUERATINIZADA: RELATO DE CASO CLÍNICO 
PC-180-2019 - TÉCNICA MINIMAMENTE INVASIVA DE ARTROCENTESE PARA

PACIENTES COM DTM - RELATO DE CASO

PC-181-2019 - TERAPIAS REGENERATIVAS EM IMPLATODONTIA: O USO DO L-PRF ... 234 PC-182-2019 - TRATAMENTO CIRÚRGICO DE CISTO INFLAMATÓRIO ASSOCIADO A PROJÉTIL DE ARMA DE FOGO: RELATO DE CASO..

PC-183-2019 - TRATAMENTO CIRÚRGICO DE DISPLASIA FIBROSA: RELATO DE CASO 236 PC-184-2019 - TRATAMENTO CIRÚRGICO DE FRATURAS DO TERÇO MÉDIO E SUPERIOR DA FACE: RELATO DE CASO

PC-185-2019 - TRATAMENTO CIRÚRGICO DE GRANULOMA PIOGÊNICO: RELATO DE CASO

PC-186-2019 - TRATAMENTO CIRÚRGICO DE MÚLTIPLOS CERATOCISTOS

ODONTOGÊNICOS: RELATO DE CASO.

PC-187-2019 - TRATAMENTO DE DENTES ESCURECIDOS ATRAVÉS DE FACETAS DIRETAS EM RESINA COMPOSTA..

PC-188-2019 - TRATAMENTO DE REABSORÇÃO RADICULAR EXTERNA COM O USO DO MTA REPAIR HP: RELATO DE CASO

PC-189-2019 - TRATAMENTO ENDODÔNTICO DE PACIENTE EM USO DE BIFOSFONATOS: RELATO DE CASO

PC-190-2019 - TRATAMENTO FECHADO DE FIBROADERÊNCIAS EM ATICULAÇÃO TEMPOROMANDIBULAR: RELATO DE CASO

PC-191-2019 - TRATAMENTO PRÉ OPERATÓRIO EM UM QUADRO DE PERICORONARITE

AGUDA: RELATO DE CASO

PC-192-2019 - TRATAMENTO RESTAURADOR ATRAUMÁTICO INSERIDO NO PROGRAMA DE SAÚDE BUCAL DA ESTRATÉGIA DE SAÚDE DA FAMÍLIA

PC-193-2019 - TRATAMENTO/CONTROLE DA DOR DENTOALVEOLAR PERSISTENTE ... 246 PC-194-2019 - TRAUMA E INTRUSÃO DENTÁRIA: EFEITOS NA RAIZ E NO OSSO

ALVEOLAR - REVISÃO DE LITERATURA

PC-195-2019 - TUMOR ODONTOGÊNICO ADENOMATÓIDE: UMA REVISÃO DE

LITERATURA.

PC-196-2019 - TUMOR ODONTOGÊNICO CÍSTICO CALCIFICANTE COM PROLIFERAÇÃO AMELOBLASTOMOSA: REVISÃO DE LITERATURA

PC-197/2019 - USO DA LUZ VIOLETA NO TRATAMENTO DE CLAREAMENTO DENTAL:

REVISÃO DE LITERATURA

PC-198-2019 - USO DA TERAPIA FOTODINÂMICA COMO COADJUVANTE NA

DESCONTAMINAÇÃO EM CIRURGIA PARENDODÔNTICA: RELATO DE CASO

PC-199-2019 - USO DE ANTI-INFLAMATÓRIOS NÃO ESTERÓIRES (AINEs) EM PACIENTES

HIPERTENSOS: UMA REVISÃO DE LITERATURA

PC-200-2019 - USO DE BENZODIAZEPÍNICOS NO PRÉ-ATENDIMENTO ODONTOLÓGICO

PC-201-2019 - USO DE IMPLANTES IMEDIATOS: VANTAGENS E LIMITAÇÕES DA

TÉCNICA - REVISÃO DE LITERATURA

PC-202-2019 - USO DE MAGNETOS EM REABILITAÇÃO ORAL COM PRÓTESE TOTAL: RELATO DE CASO CLÍNICO

PC-203-2019 - USO DA TOXINA BOTULÍNICA TIPO A NA CORREÇÃO DO SORRISO

GENGIVAL: UMA REVISÃO DE LITERATURA

PC-204-2019 - USO DO INFILTRANTE RESINOSO NA ODONTOLOGIA: REVISÃO DE LITERATURA. 
PC-205-2019 - VANTAGENS DA UTILIZAÇÃO DE CIMENTOS DE IONÔMEROS DE VIDRO NA COLAGEM DE BRAQUETES ORTODÔNNTICOS: REVISÃO DE LITERATURA 259 PC-206-2019 - VANTAGENS DO USO DO SISTEMA CAD/CAM EM RESTAURAÇÃO ONLAY: RELATO DE CASO

PC-207-2019 - VISÃO DO PACIENTE EM RELAÇÃO AO GÊNERO E APARÊNCIA DO CIRURGIÃO DENTISTA
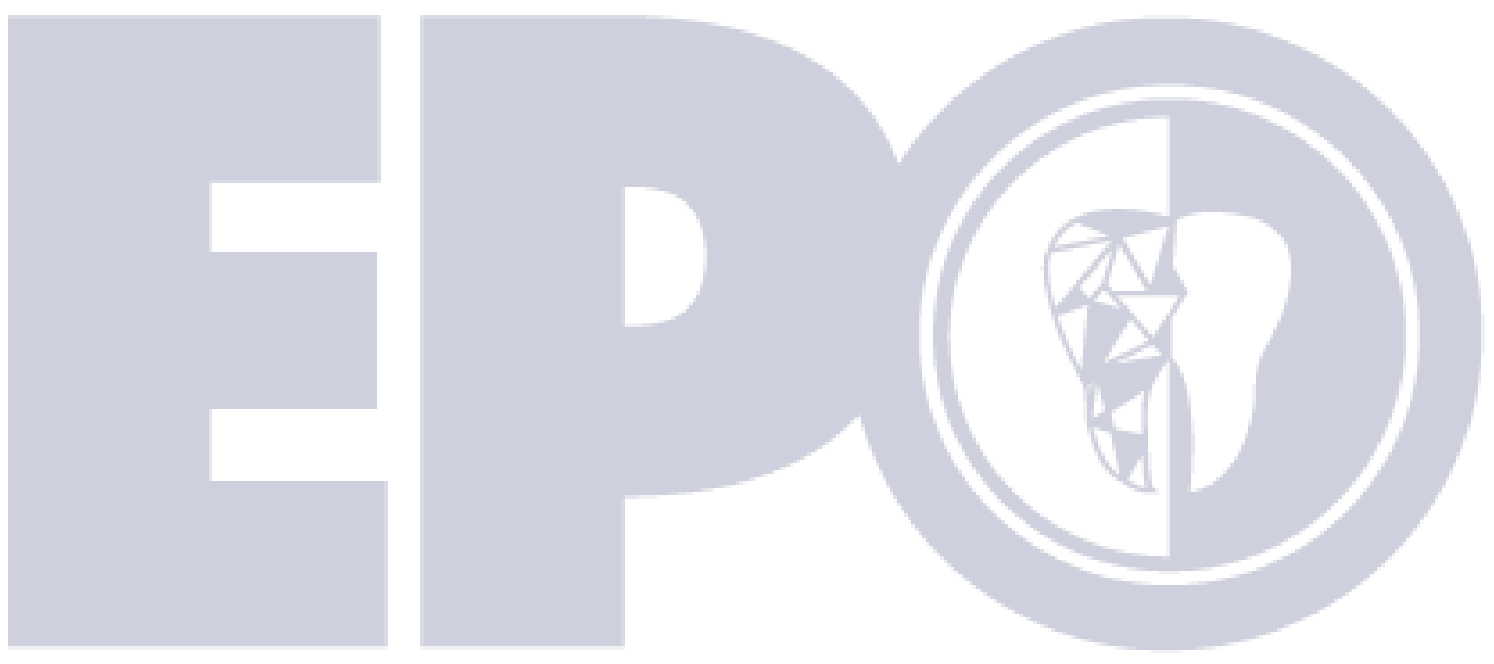

\section{ENCONTRO PERNAMBUCANO}




\section{CATEGORIA FÓRUM CIENTÍFICO}

\section{$1^{\circ}$ LUGAR}

\section{TP-CFC-1L-01-2019 - DIFERENCIAÇÃO OSTEOGÊNICA DE CÉLULAS-TRONCO IRRADIADAS COM LASER DE BAIXA POTÊNCIA}

Eduardo Vinícius de Souza Silva ${ }^{1}$; Sinval Vinícius Barbosa do Nascimento; ${ }^{1}$ Márcia Bezerra da Silva²; Cláudio Gabriel Rodrigues²; Jéssica Meirinhos Miranda ${ }^{1}$; Wyndly Daniel Cardoso

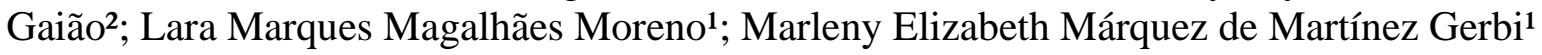

${ }^{1}$ Faculdade de Odontologia de Pernambuco - Camaragibe - PE - Brasil

${ }^{2}$ Universidade Federal de Pernambuco - Recife - PE - Brasil

Autor correspondente:

Eduardo Vinícius de Souza Silva

eviniciussz11@gmail.com

$2^{\circ}$ LUGAR

\section{TP-CFC-2L-01-2019 - EXPOSIÇÃO DO PACIENTE EM MÍDIAS SOCIAIS ENTRE ESTUDANTES DE ODONTOLOGIA}

Fábio Victor Dias Silva ${ }^{1}$; Marcos Aurélio Vasconcelos Lima Júnior ${ }^{1}$; Victória Mendonça Dias ${ }^{1}$

${ }^{1}$ Centro Universitário de João Pessoa - UNIPÊ - João Pessoa - PB - Brasil

Autor correspondente:

Fábio Victor Dias Silva

fabio_vct@hotmail.com

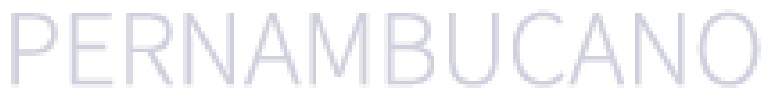

$3^{\circ}$ LUGAR

TP-CFC-3L-01-2019 - CINE CLUB +: O PROJETO DE EXTENSÃO QUE INTEGRA A SAÚDE ATRAVÉS DA SÉTIMA ARTE - RELATO DE EXPERIÊNCIA

Mirela Carolaine Cunha da Cruz ${ }^{1}$; Cláudia Cazal Lira ${ }^{1}$; Gutembergmann Batista Coutinho; Haryssa Guimarães de Lima ${ }^{1}$; Leniée Campos Maia ${ }^{1}$; Raiana Lacerda Coelho Matias ${ }^{1}$; Arthur Duviver Ortenblat ${ }^{1}$

${ }^{1}$ Universidade Federal de Pernambuco - Recife - PE - Brasil

Autor correspondente:

Mirela Carolaine Cunha da Cruz

mirela.carolaine@hotmail.com 

RESGATANDO SORRISOS 9

Rayanna Thayse Florêncio Costa ${ }^{1}$; Rafaella de Souza Leão ${ }^{1}$; Bruno Gustavo da Silva Casado ${ }^{1}$; Sandra Conceição Maria Vieira ${ }^{1}$; Mônica Vilela Heimer ${ }^{1}$; Marianne de Vasconcelos Carvalho ${ }^{1}$; Jose Luiz Magalhães de Carvalho ${ }^{1}$; Sandra Lúcia Dantas de Moraes ${ }^{1}$

${ }^{1}$ Faculdade de Odontologia de Pernambuco (FOP/UPE) - Camaragibe - PE - Brasil

Autor correspondente:

Rayanna Thayse Florêncio Costa

rayannatfcosta@gmail.com

\section{CATEGORIA PAINEL CIENTÍFICA}

\section{MODALIDADE PESQUISA CIENTÍFICA}

\section{$1^{\circ}$ LUGAR}

TP-CPC-MPC-1L-01-2019 - APLICAÇÃO DE MODELAGEM MATEMÁTICA PARA AVALIAÇÃO DOS EFEITOS TÉRMICOS DO FS LASER NOS TECIDOS DENTÁRIOS

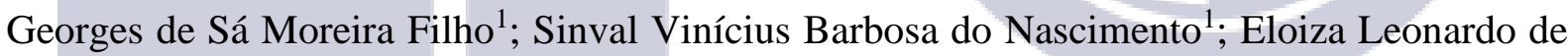
Melo ${ }^{1}$; Vânia Cavalcanti Ribeiro da Silva ${ }^{1}$; Maria Regina Almeida de Menezes ${ }^{1}$; Rebeca Ferraz de Menezes ${ }^{1}$; Lara Marques Magalhães Moreno; Marleny Elizabeth Márquez de Martínez Gerbi $^{1}$

${ }^{1}$ Faculdade de Odontologia de Pernambuco (FOP/UPE) - Camaragibe - PE - Brasil

Autor Correspondente:

Georges de Sá Moreira Filho

georges_moreira@hotmail.com

\section{TP-CPC-MPC-1L-02-2019 - VISÃO DO PACIENTE EM RELAÇÃO AO GÊNERO E APARÊNCIA DO CIRURGIÃO DENTISTA}

Fábio Victor Dias Silva ${ }^{1}$; Danielly Bruna Marques Neves ${ }^{1}$; Marcos Aurélio Vasconcelos Lima Júnior ${ }^{1}$

${ }^{1}$ Centro Universitário de João Pessoa - UNIPÊ - João Pessoa - PB - Brasil

Autor correspondente:

Fábio Victor Dias Silva

fabio_vct@hotmail.com 


\section{$2^{\circ}$ LUGAR}

\section{TP-CPC-MPC-2L-01-2019 - CONDUTA DE CIRURGIÕES-DENTISTAS FRENTE À PARESTESIA PÓS CIRURGIA BUCAL}

Sinval Vinícius Barbosa do Nascimento ${ }^{1}$; Eduardo Vinícius de Souza Silva ${ }^{1}$; Pedro Henrique Barbosa de Melo; Alleson Jamesson da Silva ${ }^{2}$; Manuela França Andrade Passos ${ }^{1}$; Cleiton Rone dos Santos Lima'; Emerson Filipe de Carvalho Nogueira'; Ricardo José de Holanda Vasconcellos ${ }^{1}$

${ }^{1}$ Faculdade de Odontologia de Pernambuco - Camaragibe - PE - Brasil

${ }^{2}$ Universidade Federal de Pernambuco - Recife - PE - Brasil

Autor correspondente:

Sinval Vinícius Barbosa do Nascimento

sinvalvinicius@outlook.com

\section{$3^{\circ}$ LUGAR}

\section{TP-CPC-MPC-3L-01-2019 - ESTUDO DA RESISTÊNCIA DE UNIÃO DOS SISTEMAS ADESIVOS UNIVERSAIS EM DENTINA HÍGIDA}

Micaela Maria de Sousa ${ }^{1}$; Aylanne Xavier de Lacerda Cavalcante Timoteo ${ }^{1}$; Cláudia Geisa Souza e Silva ${ }^{1}$; Cláudio Paulo Pereira de Assis ${ }^{1}$; Kássia Regina de Santana ${ }^{1}$; Maria Hermínia Anníbal Cavalcanti ${ }^{1}$; Pauliane Albuquerque da Silva ${ }^{1}$; Rodivan Braz da Silva ${ }^{1}$

${ }^{1}$ Faculdade de Odontologia de Pernambuco - Camaragibe - PE - Brasil

Autor correspondente:

Micaela Maria de Sousa

micamds@hotmail.com

MODALIDADE REVISÃO DE LITERATURA
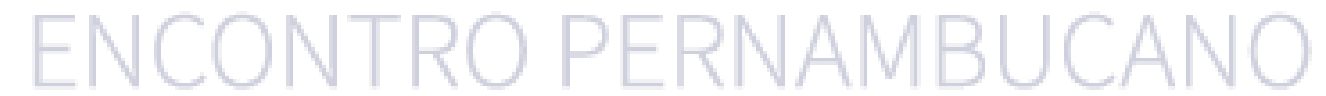

$1^{\circ}$ LUGAR

\section{TP-CPC-MRL-1L-01-2019 - A AÇÃO DAS PROTEÍNAS SALIVARES NO DESENVOLVIMENTO DO BIOFILME DE CANDIDA ALBICANS}

Aylanne Xavier de Lacerda Cavalcante Timoteo ${ }^{1}$; Ada Caroline Soares Ferreira ${ }^{1}$; Carolaine Rayane Xavier da Silva ${ }^{1}$; Emerllyn Shayane Martins de Araújo; ; Ingrid Patrícia de Moraes Lima $^{1}$; Kássia Regina de Santana ${ }^{1}$; Ycaro Lopes Briano²; Eliana Santos Lyra da Paz ${ }^{1}$.

${ }^{1}$ Faculdade de Odontologia de Pernambuco - Camaragibe - PE - Brasil.

2 Universidade Federal de Pernambuco - Caruaru - PE - Brasil.

Autor correspondente:

Aylanne Xavier de Lacerda Cavalcante Timoteo

aylannel@gmail.com 
TP-CPC-MRL-1L-02-2019 - DESFECHOS REPORTADOS PELOS PACIENTES EM RELAÇÃO À TERAPIA PERIODONTAL

Kewry Nunes do Nascimento ${ }^{1}$; Rayssa Maria da Silva Lima ${ }^{1}$; Carlos Frederico de Moraes Sarmento $^{1}$; Davi da Silva Barbirato ${ }^{2}$; Daniela da Silva Feitosa ${ }^{1}$; Mariana Fampa Fogacci ${ }^{1}$

${ }^{1}$ Universidade Federal de Pernambuco - Recife - PE - Brasil

${ }^{2}$ Faculdade de Odontologia de Pernambuco - Camaragibe - PE - Brasil

Autor correspondente:

Kewry Nunes do Nascimento

kewrykew@ hotmail.com

\section{TP-CPC-MRL-1L-03-2019 - ISOLAMENTO DE LEVEDURAS DO GÊNERO CANDIDA NO CONSULTÓRIO ODONTOLÓGICO}

Micaela Maria de Sousa ${ }^{1}$; Aylanne Xavier de Lacerda Cavalcante Timoteo ${ }^{1}$; Carolina Pereira da Silva ${ }^{1}$; Emerllyn Shayane Martins de Araújo ${ }^{1}$; Ingrid Patrícia de Moraes Lima ${ }^{1}$; Kássia Regina de Santana ${ }^{1}$; Laura do Nascimento Arruda ${ }^{1}$; Eliana Santos Lyra da Paz ${ }^{1}$.

${ }^{1}$ Faculdade de Odontologia de Pernambuco - Camaragibe - PE - Brasil

Autor correspondente:

Micaela Maria de Sousa

micamds@hotmail.com

TP-CPC-MRL-1L-04-2019 - MECANISMOS BIOLÓGICOS ENVOLVIDOS NO

ESTADO INFLAMATÓRIO DE PACIENTES OBESOS E SUAS POSSÍVEIS

IMPLICAÇÕES CLÍNICAS NA ODONTOLOGIA

Pedro Paulo Aguiar Santos Cavalcanti ${ }^{1}$; Maria Eduarda Arruda de Lucena' ${ }^{1}$, Gerciane Ramos Bezerra $^{1}$; Vanessa Bastos de Souza Rolim Lima ${ }^{1}$; Vinicius Balan Santos Pereira ${ }^{1}$; Belmiro Cavalcanti do Egito Vasconcelos ${ }^{1}$; Davi da Silva Barbirato ${ }^{1}$.

${ }^{1}$ Faculdade de Odontologia de Pernambuco - Camaragibe - PE - Brasil

Autor correspondente:

Pedro Paulo Aguiar Santos Cavalcanti

pedropauloaguiar@icloud.com 


\section{$2^{\circ}$ LUGAR}

\section{TP-CPC-MRL-2L-01-2019 - IMPACTOS DA CIRURGIA ORTOGNÁTICA NA QUALIDADE DE VIDA DOS PACIENTES: REVISÃO DE LITERATURA}

Emanuelly Soares de Melo Silva ${ }^{1}$; Ana Caroline Chalegre de Oliveira ${ }^{1}$; Jeferson Batista Santiago ${ }^{1}$; Olívia Augusta Araújo Dias ${ }^{1}$; Joana de Ângelis Alves Silva ${ }^{1}$; Mayara Monique Silva de Oliveira ${ }^{1}$; Ismael Sebastião da Silva Sousa ${ }^{1}$.

${ }^{1}$ Faculdade de Odontologia de Pernambuco - Camaragibe - PE - Brasil

Autor correspondente:

Emanuelly Soares de Melo Silva

nelly-soares@outlook.com

\section{$3^{\circ}$ LUGAR}

\section{TP-CPC-MRL-3L-01-2019 - FLUOROSE DENTÁRIA: EPIDEMIOLOGIA, DIAGNÓSTICO E TRATAMENTO}

Ingrid Sayonara Silva ${ }^{1}$; Pedro Henrique Lopes Cavalcanti ${ }^{1}$; Monalisa Suellen da Silva ${ }^{1}$; Aylanne Xavier de Lacerda Cavalcante Timoteo ${ }^{2}$; Emerllyn Shayane Martins de Araújo²; Kássia Regina de Santana²; Lucas Rafael Borges Santos²; Sally de Souza Brito ${ }^{3}$.

${ }^{1}$ Universidade Federal de Pernambuco - Recife - PE - Brasil

${ }^{2}$ Faculdade de Odontologia de Pernambuco - Camaragibe - PE - Brasil

${ }^{3}$ Centro de Pós-graduação em Odontologia - Recife - PE - Brasil

Autor correspondente:

Ingrid Sayonara Silva

ingridxs711@gmail.com

MODALIDADE RELATO DE CASO

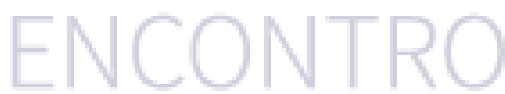

$1^{\circ}$ LUGAR

\section{TP-CPC-MRC-1L-01-2019 - A SÍFILIS E SUAS MANIFESTAÇÕES BUCAIS: RELATO DE CASO CLÍNICO}

Liana Carla Souza de Andrade Batista ${ }^{1}$; Letícia de Oliveira Santos ${ }^{1}$; Maria de Fátima Texeira Lemos de Souza ${ }^{1}$; Mariana Cecília de Oliveira Terêncio ${ }^{1}$; Nycole Valois Rocha Viera da Silva ${ }^{1}$; Ronaldo de Carvalho Raimundo ${ }^{1}$; Márcia Maria Fonseca da Silveira ${ }^{1}$; Vânia Cavalcanti Ribeiro da Silva ${ }^{1}$

${ }^{1}$ Faculdade de Odontologia de Pernambuco - Camaragibe - PE - Brasil

Autor correspondente:

Liana Carla Souza de Andrade Batista

lianabatist20@gmail.com 


\section{TP-CPC-MRC-1L-02-2019 - CIRURGIA PLÁSTICA PERIODONTAL PARA TRATAMENTO DA ERUPÇÃO PASSIVA ALTERADA: RELATO DE CASO}

Letícia de Oliveira Santos ${ }^{1}$; Gabriela Brito Vasconcelos ${ }^{2}$; Iasmin Cirino da Silva ${ }^{1}$; Ismael Sebastião da Silva Souza ${ }^{1}$; Liana Carla Souza de Andrade Batista ${ }^{1}$; Marilya Roberta Ferreira de Melo $^{1}$; Marcos Antônio Veloso Coutinho' ${ }^{1}$ Eduardo de Farias Barbosa ${ }^{2}$

${ }^{1}$ Faculdade de Odontologia de Pernambuco - Camaragibe - PE - Brasil

2 Universidade Federal de Pernambuco - Recife - PE - Brasil

Autor correspondente:

Letícia de Oliveira Santos

Oliveiraleticia_14@live.com

\section{TP-CPC-MRC-1L-03-2019 - CONTROLE DA APNEIA OBSTRUTIVA DO SONO ATRAVÉS DO APARELHO INTRA ORAL EM PACIENTE NÃO ADERENTE AO CPAP: RELATO DE CASO}

Ana Caroline Chalegre de Oliveira $^{1}$; Jeferson Batista Santiago ${ }^{1}$; Olívia Augusta Araújo Dias ${ }^{1}$; Joana de Ângelis Alves Silva ${ }^{1}$; Mayara Monique Silva de Oliveira ${ }^{1}$; Ismael Sebastião da Silva Sousa ${ }^{1}$; Josué Alves ${ }^{1}$.

${ }^{1}$ Faculdade de Odontologia de Pernambuco - Camaragibe - PE - Brasil

Autor correspondente:

Ana Caroline Chalegre de Oliveira carolinechalegreoliveira@gmail.com

\section{TP-CPC-MRC-1L-04-2019 - ENXERTO DE TECIDO CONJUNTIVO: RELATO DE CASO}

Camila Marques Zimmerle1; Fernanda Raquel Cabral Campos Carvalhoㅜㅜ Katharine Débora de Brito e Silva ${ }^{1}$; Marina Maria Ferreira Falcão ${ }^{1}$; Maria Catarina Almeida Lago ${ }^{1}$

${ }^{1}$ Faculdade de Odontologia de Pernambuco - Camaragibe - PE - Brasil

Autor correspondente:

Camila Marques Zimmerle

camilazimmerle@uol.com.br 


\section{TP-CPC-MRC-1L-05-2019 - QUERATOCISTO MIMETIZANDO UMA LESÃO PERIAPICAL INFLAMATÓRIA}

Victor Alexandre Felício Trancoso ${ }^{1}$; Hélen Kaline Farias Bezerra ${ }^{1}$; Flávia Maria de Moraes Ramos-Perez ${ }^{1}$; Danyel Elias da Cruz Perez ${ }^{1}$; Maria Luiza dos Anjos Pontual ${ }^{1}$; Andrea dos Anjos Pontual $^{1}$; Eduarda Helena Leandro Nascimento ${ }^{1}$

${ }^{1}$ Universidade Federal de Pernambuco - Recife - PE - Brasil

Autor correspondente:

Victor Alexandre Felício Trancoso

victortrancoso11@gmail.com

\section{$2^{\circ}$ LUGAR}

\section{TP-CPC-MRC-2L-01-2019 - LESÃO EXTENSA EM FACE DECORRENTE DE TRAUMA: RELATO DE CASO}

Eduarda Lapenda Gomes da Fonseca ${ }^{1}$; Belmiro Cavalcanti do Egito Vasconcelos ${ }^{2}$; Caio César Gonçalves Silva ${ }^{2}$; Priscila Sarmento Pinto ${ }^{2}$; Demóstenes Alves Diniz ${ }^{2}$; Jéssica da Silva Cunha ${ }^{2}$; Livia Mirelle Barbosa ${ }^{2}$

${ }^{1}$ UNIFACOL - Centro Universitário FACOL - Vitória de Santo Antão - PE - Brasil

${ }^{2}$ Faculdade de Odontologia de Pernambuco (FOP/UPE) - Camaragibe - PE - Brasil

Autor correspondente:

Eduarda Lapenda Gomes da Fonseca duda.-.lapenda@hotmail.com

\section{$3^{\circ}$ LUGAR}

\section{TP-CPC-MRC-3L-01-2019 - ESCANEAMENTO DIGITAL E PROTOTIPAGEM DE MODELO 3D PARA LENTES DE CONTATO DENTAIS - RELATO DE CASO}

Beatriz de Araújo Gusmão; Arthur Luna Santos ${ }^{1}$; Gabriela Queiroz de Melo Monteiro1; Millena Leal de Brito Rêgo ${ }^{1}$; Taísa Cabral de Lima Arruda ${ }^{1}$; Thayane Cavalcante Mendes da Silva $^{1}$; Vanessa Rodrigues Monteiro ${ }^{1}$; Luís Felipe Espíndola-Castro ${ }^{1}$

${ }^{1}$ Faculdade de Odontologia de Pernambuco - Camaragibe - PE - Brasil

Autor correspondente:

Beatriz de Araújo Gusmão

bia.gusmao09@gmail.com 


\section{MODALIDADE RELATO DE EXPERIÊNCIA}

\section{$1^{\circ}$ LUGAR}

\section{TP-CPC-MRE-1L-01-2019 - EDUCAÇÃO EM SAÚDE DO ESCOLAR: UM AGIR PARTICIPATIVO}

Andreza Cibelle Amaral da Silva ${ }^{1}$; Fabíola de Melo Linss ${ }^{1}$; João Alves Gonçalves Neto ${ }^{1}$; Júlya Karolina Gomes ${ }^{1}$; Maria Rafaela dos Santos ${ }^{1}$; Vanessa Lopes do Nascimento ${ }^{1}$; Jailma Santos Monteiro ${ }^{1}$; Márcia Maria Dantas Cabral de Melo ${ }^{1}$

${ }^{1}$ Universidade Federal de Pernambuco - Recife - PE - Brasil

Autor correspondente:

Andreza Cibelle Amaral da Silva

andreza.odonto@gmail.com

\section{TP-CPC-MRE-1L-02-2019 - PROMOÇÃO DE SAÚDE BUCAL NA PRAIA: RELATO} DE EXPERIÊNCIA

Lukas Mendes de Abreu ${ }^{1}$; Jacianny Laurindo Pereira ${ }^{1}$; Thalia Franciele Barreto Cordeiro ${ }^{1}$; Bergson Carvalho de Moraes²; Renata Patrícia Freitas Soares de Jesus ${ }^{2}$

${ }^{1}$ Centro Universitário Tiradentes - Recife - PE - Brasil

2 Universidade Federal de Pernambuco - Recife - PE - Brasil

Autor correspondente:

Lukas Mendes de Abreu

lukasmendes.abr@gmail.com

\section{$2^{\circ}$ LUGAR}

\section{TP-CPC-MRE-2L-01-2019 - RELATO DE VIVÊNCIA DISCENTE EM UM TERRITÓRIO DA ATENÇÃO PRIMÁRIA À SAÚDE DO RECIFE}

Marvison Henrique Ferreira da Silva ${ }^{1}$; Márcia Maria Dantas Cabral de Meloㅜㄹ Nylke Mirelle Ferraz de Menezes ${ }^{1}$; Palloma Bernardino Albuquerque ${ }^{1}$

${ }^{1}$ Universidade Federal de Pernambuco - Recife - PE - Brasil

Autor correspondente:

Marvison Henrique Ferreira da Silva

mavinho_mm@hotmail.com 


\section{$3^{\circ}$ LUGAR}

\section{TP-CPC-MRE-3L-01-2019 - PROJETO SAÚDE COLORIDA: RELATO DE EXPERIÊNCIA}

Letícia Fernanda Serafim Cabral ${ }^{1}$; Fabiana de Godoy Bené Bezerra Laureano ${ }^{1}$; Raíssa Soares dos Anjos ${ }^{1}$; Laís Lavínia Cruz Soares ${ }^{1}$; Maria Beatriz Arruda Albuquerque ${ }^{1}$; Fernanda Ariel da Silva Vasconcelos ${ }^{1}$; Maria Clara Ribeiro de Amorim Tabosa ${ }^{1}$; Pedro Paulo Aguiar Santos Cavalcanti ${ }^{1}$

${ }^{1}$ Faculdade de Odontologia de Pernambuco - Camaragibe - PE - Brasil

Autor correspondente:

Letícia Fernanda Serafim Cabral leticiafscabral@hotmail.com

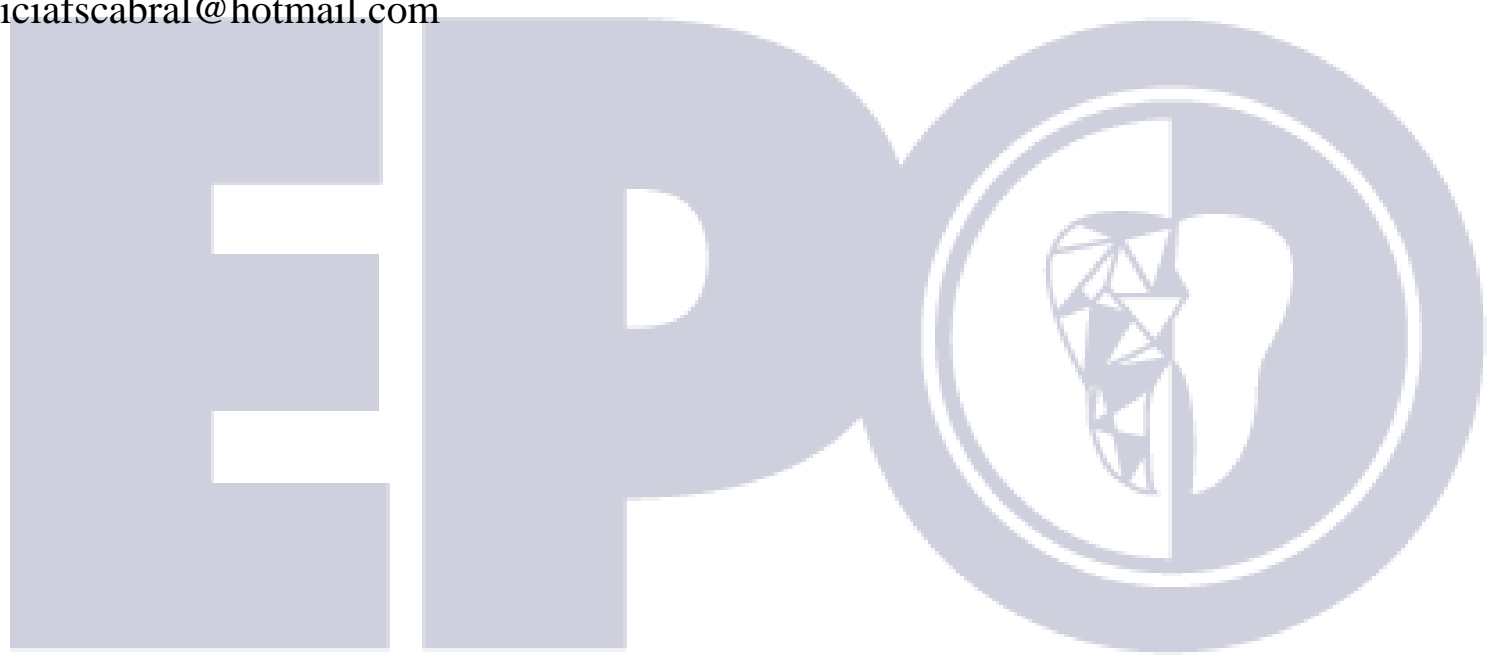




\section{MELHOR TRABALHO APRESENTADO NO VII EPO}

\section{LG-2019 - A SÍFILIS E SUAS MANIFESTAÇÕES BUCAIS: RELATO DE CASO CLÍNICO}

Liana Carla Souza de Andrade Batista ${ }^{1}$; Letícia de Oliveira Santos ${ }^{1}$; Maria de Fátima Texeira Lemos de Souza ${ }^{1}$; Mariana Cecília de Oliveira Terêncio ${ }^{1}$; Nycole Valois Rocha Viera da Silva ${ }^{1}$; Ronaldo de Carvalho Raimundo ${ }^{1}$; Márcia Maria Fonseca da Silveira ${ }^{1}$; Vânia Cavalcanti Ribeiro da Silva ${ }^{1}$

${ }^{1}$ Faculdade de Odontologia de Pernambuco - Camaragibe - PE - Brasil

Autor correspondente:

Liana Carla Souza de Andrade Batista lianabatist20@gmail.com

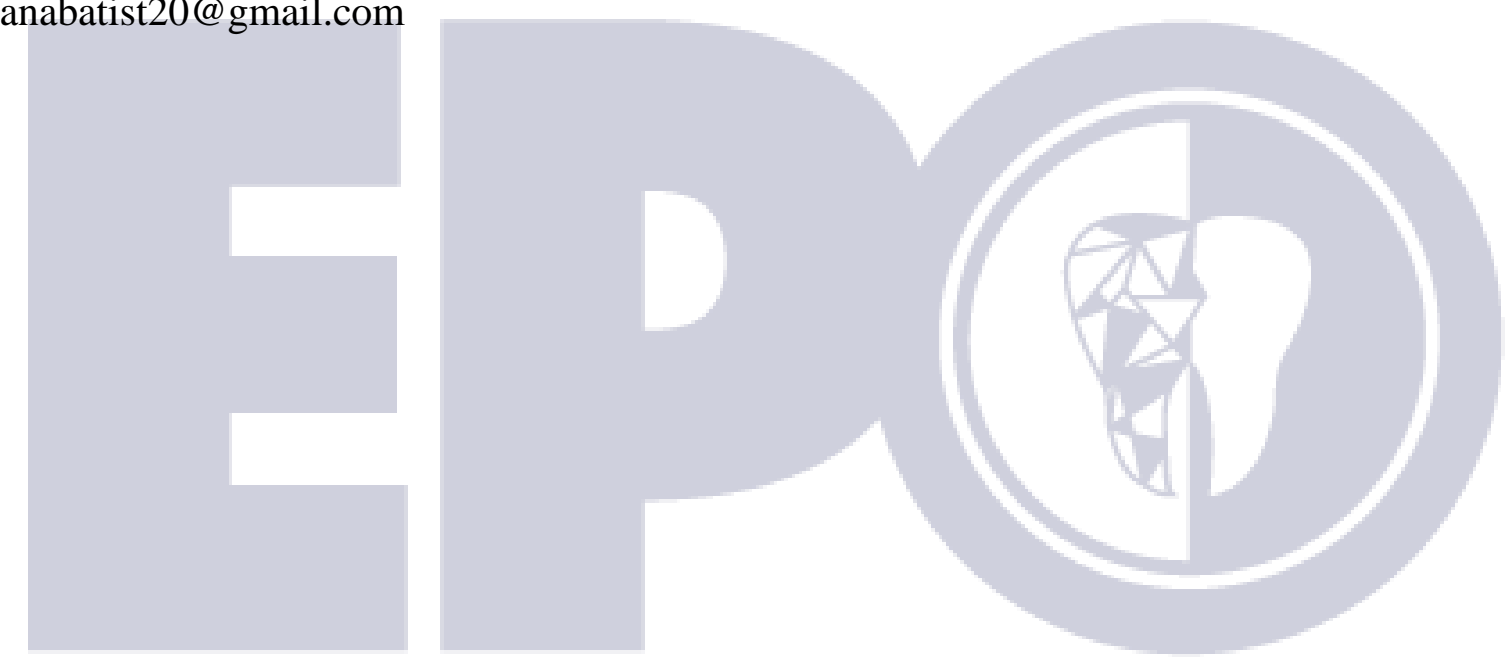



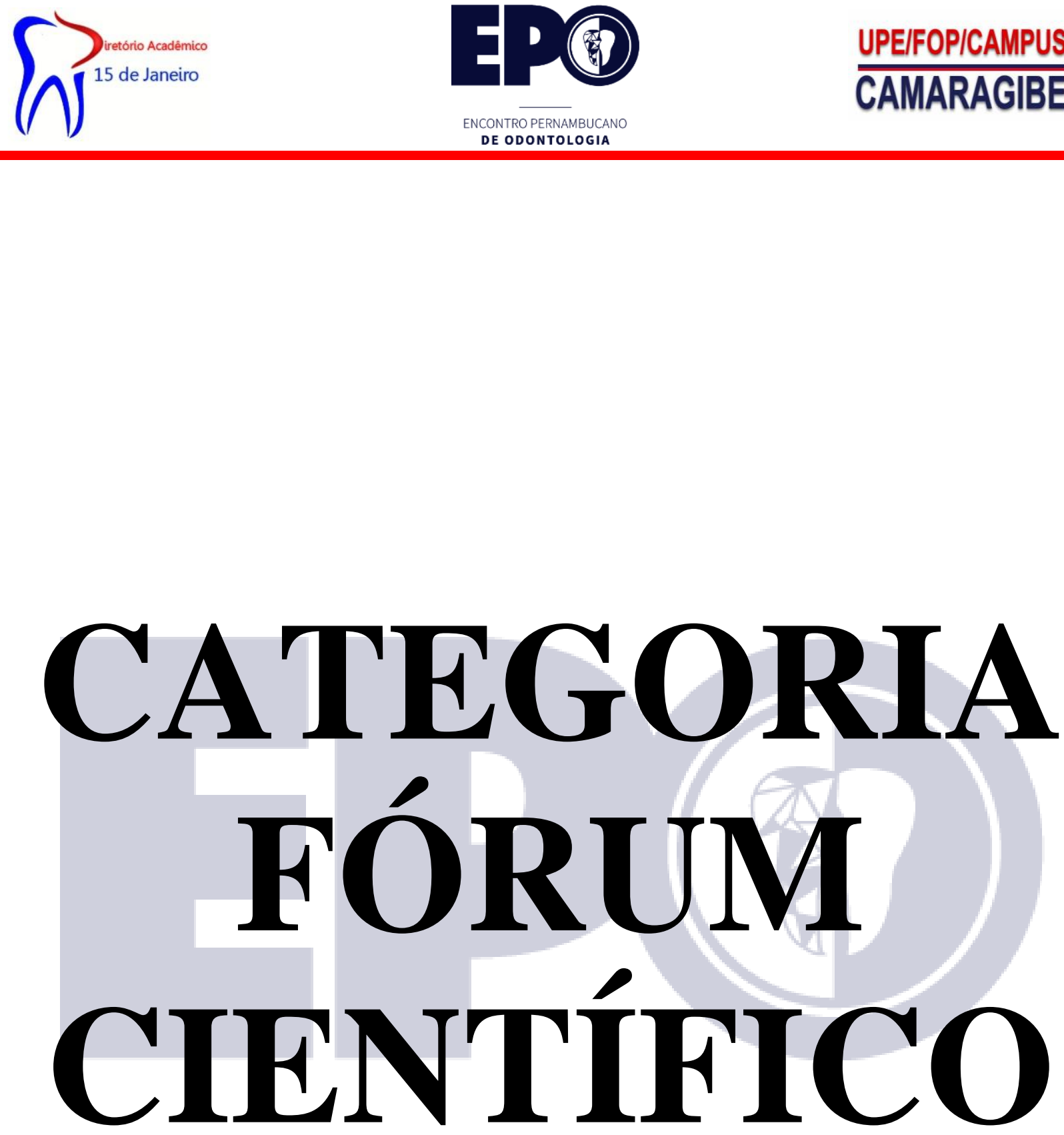

ENCONTRO PERNAMBUCANO

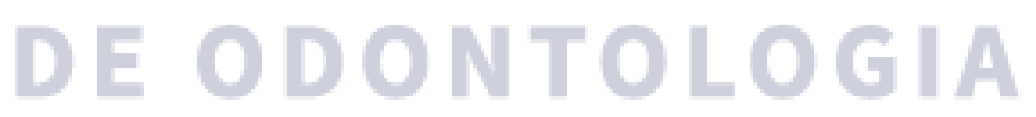




\section{FC-01-2019 - A IMPORTÂNCIA DO TRATAMENTO PRECOCE DE MESIODENS:} UM RELATO DE CASO

Kássia Regina de Santana ${ }^{1}$; Iasminy de Almeida Torres ${ }^{1}$; Cleiton Rone dos Santos Lima ${ }^{1}$; Emerllyn Shayane Martins de Araújo ${ }^{1}$; Aylanne Xavier de Lacerda Cavalcante Timoteo ${ }^{1}$; Raisa Rebeca da Silva Batista ${ }^{2}$; Ronaldo Gabriel Martiniano da Silva ${ }^{3}$; Maria Carlla Aroucha Lyra ${ }^{1}$

${ }^{1}$ Faculdade de Odontologia de Pernambuco - Camaragibe - PE - Brasil

${ }^{2}$ Universidade Federal de Pernambuco - Recife - PE - Brasil

${ }^{3}$ Centro Universitário Tiradentes de Pernambuco - Recife - PE - Brasil

Autor correspondente:

Kássia Regina de Santana

kassiaupe2016.1@gmail.com

Introdução: O mesiodens é o dente supranumerário mais frequente na cavidade bucal, está localizado entre os incisivos centrais superiores. A constatação do mesiodens, quando irrompido, é feita por meio de exame clínico de rotina, sendo sua identificação facilitada por sua forma e tamanho atípicos, com localização característica ${ }^{1}$. A presença de supranumerários pode ocasionar problemas e desordens funcionais e estéticas ${ }^{2}$, principalmente quando localizados na região anterior da maxila, contando, ainda, com complicações na erupção do elemento dental permanente da área afetada ${ }^{3}$. Caso não seja removido, esse dente pode trazer alguns efeitos deletérios para o paciente como a reabsorção radicular do dente adjacente, má oclusão, formação de cistos, retenção prolongada do dente permanente, diastema, dentre outros, deixando clara a importância de um diagnóstico precoce e do tratamento adequado. Objetivo: Este trabalho tem como objetivo relatar a sequência clínica de uma cirurgia de remoção de mesiodens irrompido em paciente pediátrico, desde sua detecção e remoção até o pósoperatório. Relato do caso: Paciente E.M.S., 5 anos de idade, sexo feminino, pesando $20 \mathrm{~kg}$, compareceu à clínica de Odontopediatria I, da Faculdade de Odontologia de Pernambuco, apresentando mesiodens irrompido em dentição mista, com a relação dos caninos em classe I bilateral. Discussão: Para auxílio do planejamento cirúrgico foi realizada uma radiografia oclusal de maxila. O cálculo anestésico utilizado foi a fórmula de Clark. O anestésico de escolha foi Lidocaína 2\%, com epinefrina 1:100000, sendo necessária a utilização de 1 tubete durante o procedimento. Dado que o diagnóstico foi estabelecido precocemente e $\mathrm{o}$ tratamento imediatamente realizado, não foi imperioso o encaminhamento da paciente para intervenção ortodôntica. Conclusões: Conclui-se, portanto, a imprescindível necessidade do diagnóstico precoce como forma de prevenção do desenvolvimento de problemas estéticos e funcionais em pacientes portadores de mesiodens.

Descritores: Dente Supranumerário; Odontopatias; Má Oclusão.

\section{Referências:}

1. ARITA VA, et al. Mesiodens: importância do diagnóstico e tratamento - relato de caso. Revista de Odontologia da UNESP, 2005; 34(Especial): 1-4

2. DIAS FA, et al. Supranumerário: a Importância do Tratamento Ortodôntico Precoce. Journal of Health Sciences, 2019; 21(2): 112-114

3. NUNES KM, et al. Dente supranumerário: revisão bibliográfica e relato de caso clínico. Rev. Odontol. Univ. Cid. São Paulo, 2015; 27(1): 72-81 


\section{FC-02-2019 - ASSOCIAÇÃO ENTRE PROJEÇÕES CERVICAIS DE ESMALTE E DEFEITOS DE FURCA: REVISÃO DE LITERATURA}

Robson de Lima Gomes ${ }^{1}$; Andressa Cristina da Silva Queiroz ${ }^{1}$; Carlos Frederico de Moraes Sarmento $^{1}$; Dara Karen Freire de Oliveira ${ }^{1}$; Daniela da Silva Feitosa ${ }^{1}$; Davi da Silva Barbirato ${ }^{2}$; Taynara Franciele da Silva Souza ${ }^{1}$; Mariana Fampa Fogacci ${ }^{1}$

${ }^{1}$ Universidade Federal de Pernambuco - Recife - PE - Brasil

${ }^{2}$ Universidade de Pernambuco - Camaragibe - PE - Brasil

Autor correspondente:

Robson de Lima Gomes

robsonlimalive@outlook.com

Introdução: A projeção cervical de esmalte (PCE) é uma anomalia dentária que atua como fator modificador local para a doença periodontal, e foi evidenciada sua possível associação com a presença de defeitos de furca. ${ }^{1,2,3,4,5}$. Objetivo: Realizar uma revisão da literatura a partir de evidências científicas acerca da associação das projeções cervicais de esmalte e defeitos de furca. Metodologia: Busca por artigos científicos no período de 2013 a 2018, nas bases de dados: Periódicos Capes, PubMed, SciELO e Google Acadêmico. Revisão de literatura: A PCE é uma projeção do esmalte a partir da junção cemento esmalte em direção à área de furca devido a uma atividade contínua dos ameloblastos após a formação do esmalte na coroa ${ }^{4}$. Em sua presença os tecidos conjuntivos não são capazes de se unir a PCE, possibilitando a adesão de biofilme dental. Isso, junto com um acesso reduzido para medidas de higiene bucal pode acelerar a perda dos tecidos periodontais na área de furca ${ }^{1,2,3,4}$. Alguns estudos avaliaram a correlação entre a prevalência de PCEs e defeitos de furca como positiva. A porcentagem de dentes com PCE na superfície vestibular ou lingual foi de $76 \%(746 / 982)^{3}$. Foi verificado que a presença de PCE e defeito de furca estavam presentes em 10,3\% (98/944) dos molares examinados, e, ainda, que dentes com PCE grau 3 apresentaram maior número de defeitos de furca ${ }^{1}$. Conclusão: Apesar do número reduzido de estudo sobre o tema, a presença da PCE pode atuar como um possível modificador local para a presença de defeitos de furca na periodontite. A PCE pode atuar como causa provável para formação rápida de bolsas, uma vez que a sua morfologia possibilita a adesão de placa dentária aumentando a perda de tecidos periodontais na área de furca.

Descritores: Periodontite; Esmalte dentário; Defeitos da furca.

\section{Referências:}

1. BHUSARI $P$, et al. Prevalence of enamel projections and its corelation with furcation involvement in maxillary and mandibular molars: A study on dry. Journal of Indian Society of Periodontology, 2013; 17(5):601-604

2. GOH EXJ, ONG MMA. Anatomical, microbiological, and genetic considerations in treatment of Chinese periodontal patients. Journal Invest Clin Dent, 2018;10: 1-9

3. KO MJ, et al. Characteristics of the molar surfasse after removal of cervical enamel projections: comparison of three different rotating instruments. J Periodontal Implant Sci, 2016; 46(2):107-115

4. LIM HC, et al. Prevalence of Cervical Enamel Projection and Its Impact on Furcation Involvement in Mandibular Molars: A Cone-Beam Computed Tomography Study in Koreans. The anatomical record, 2016; 299: 379-384

5. RODRÍGUEZ YC, et al. Características morfométricas de los dientes multirradiculares a nivel de la zona de furcación. Odontoestomatología, 2018; 20(31): 27-33 


\title{
FC-03-2019 - AVALIAÇÃO DAS CONCENTRAÇÕES QUÍMICAS NOS DIFERENTES TECIDOS DENTAIS, SADIOS E CARIADOS, ATRAVÉS DA ESPECTROSCOPIA ATÔMICA
}

\begin{abstract}
Maria Eduarda Ferrer Siqueira Carneiro ${ }^{1}$; Sinval Vinícius Barbosa do Nascimento ${ }^{1}$; Eloiza

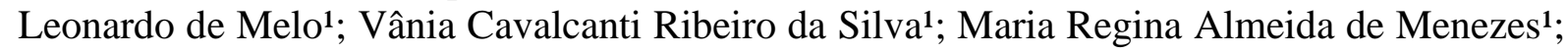
Rebeca Ferraz de Menezes ${ }^{1}$; Lara Marques Magalhães Morenoㅜㄹ Marleny Elizabeth Márquez de Martínez Gerbi ${ }^{1}$
\end{abstract}

${ }^{1}$ Faculdade de Odontologia de Pernambuco - Camaragibe - PE - Brasil

Autor Correspondente:

Maria Eduarda Ferrer Siqueira Carneiro

dudaferrer97@gmail.com

Introdução: Os Lasers de alta potência de Femtossegundos (fs-laser) têm se tornado uma ferramenta valiosa para o diagnóstico do tecido cariado e remoção desse tecido de forma minimamente invasiva. Além disso, a espectroscopia de ruptura induzida por laser (LIBS) pode fornecer a composição histoquímica dos dentes. O LIBS tem sido utilizado em várias aplicações biomédicas $^{2,3}$, como a análise clínica em humanos para identificar dentes cariados e tecidos cancerígenos. Objetivo: Avaliar as concentrações químicas nos diferentes tecidos dentais, sadios e cariados, através da espectroscopia atômica. Metodologia: Esse experimento incluiu o tecido alvo que foi o dente, um laser de femtosegundos de 1030nm (Amplitude Systems Tangerine, $320 \mathrm{fs}, 50 \mu \mathrm{J} /$ pulso) com uma taxa de repetição variável $(5 \mathrm{KHz}, 10 \mathrm{KHz}, 50 \mathrm{KHZ}$ e $200 \mathrm{KHz}$ ), um espectrômetro, um chip CCD (Princeton Instruments SpectraPro 2500i e Pixis 100B, respectivamente) e um computador para análise de dados. Como a intensidade do sinal fsLIBS é correlacionada com a energia do pulso, com microjoules por pulso sendo necessários para adquirir um sinal ${ }^{1}$, todas as experiências foram realizadas em triplicata com uma fluência de $40 \mathrm{~J} / \mathrm{cm} 2$. A amostra foi separada em subgrupos, para coletar os espectros LIBS em todos os tecidos dentais tanto saudáveis quanto cariados. Todos os dados foram analisados utilizando o programa MATLAB R2015. Resultados e Discussão: Os gráficos mostraram que os picos de Ca são sempre mais robustos nos dentes saudáveis do que nos cariados, provando que é possível distinguir locais de tecidos cariados através da espectroscopia atômica. Conclusão: Devido às tomâdas de espectro, somente a taxas de repetição ábaixo do limiar de carbonização dos tecidos dentários evitou-se ambiguidades espectrais que se desenvolvem à medida que a taxa aumentar acima do limiar, porém apenas diferenças modestas no espectro de comprimento de onda visível fsLIBS entre dentes saudáveis e cariados foram evidentes.

Descritores: Análise Espectral; Cárie Dental; Lasers.

\section{Referências:}

1. GILL RK, et al. Characterization os femtosecond laser-induced breakdown spectroscopy (fsLIBS) and applications for biological samples. Applied Spectroscopy, 2015; 68(9): 949-954 2. JEONG DC, et al. Prospect for feedback guided surgery with ultra-short pulsed laser light. Curr Opin Neurobiol, 2012; 22(1): 24-33

3. LO DD, et al. Femtosecond plasma mediated laser ablation has advantage over mechanical osteotomy of cranial bone. Lasers Surg. Med, 2012; 44: 805-81 


\section{FC-04-2019 - CINE CLUB +: O PROJETO DE EXTENSÃO QUE INTEGRA A SAÚDE ATRAVÉS DA SÉTIMA ARTE - RELATO DE EXPERIÊNCIA}

Mirela Carolaine Cunha da Cruz ${ }^{\text {; Cláudia Cazal Lira }}{ }^{\mathbf{1}}$; Gutembergmann Batista Coutinho'; Haryssa Guimarães de Lima ${ }^{1}$; Leniée Campos Maia ${ }^{1}$; Raiana Lacerda Coelho Matias ${ }^{1}$; Arthur Duviver Ortenblat ${ }^{1}$

${ }^{1}$ Universidade Federal de Pernambuco - Recife - PE - Brasil

Autor correspondente:

Mirela Carolaine Cunha da Cruz

mirela.carolaine@hotmail.com

Introdução: O cinema é capaz de proporcionar a expressão de ideias e sensações, sendo conhecido como a sétima arte ${ }^{1,2,3}$. Nesse ínterim, o cinema é um mecanismo de aproximação de diferentes espaços e tempos ${ }^{3}$, o que é capaz de trazer ao paciente uma fuga momentânea da sua realidade. Objetivo: Relatar a experiencia do projeto de extensão Cine club + , o qual envolve a participação de alunos e docentes responsáveis por usar a ferramenta áudiovisual na humanização e alívio de estresse no espaço hospitalar. Relato de experiência: Com auxílio de computador portátil e equipamento de projeção, foram exibidos, semanalmente, filmes de curtametragens pelos estudantes dos cursos de saúde, humanas e exatas de diversas instituições de Ensino Superior de Pernambuco. As sessões foram realizadas por um grupo de 4 a 5 graduandos, os quais selecionam, organizam e transportam o material e desenvolvem as sessões. As intervenções tiveram duração de, aproximadamente, duas horas e foram direcionadas a comunidade hospitalar e as diversas enfermarias do Hospital das Clínicas (HCUFPE). Discussão: Nesse sentido, observou-se que os pacientes saem de um estado de tensão para um estado de relaxamento, alegria e tranquilidade. A ociosidade concede lugar ao sorriso e a distração. Conclusão: Destarte, o cinema é capaz de transformar os sorrisos dos pacientes facilitando no processo de relaxamento perante o estresse causado pela internação. Além disso, o projeto integra os alunos de diversas áreas acadêmicas, tornando-os em profissionais mais humanizados.

Descritores: Humanização da Assistência; Sorriso; Filmes Cinematográficos.

\section{Referências:}

1. FONTES R. A escuta pedagógica à criança hospitalizada: discutindo o papel da educação no hospital. Revista Brasileira de Educação, 2005; (29): 119-138

2. LIMA JD, et al. Projeto educação e cinema: uma proposta educativa no hospital sobre o atuar dos profissionais da saúde na inclusão. Revista Inclusão Socia, 2011; 4(2): 82-90

3. OMELCZUK F, et al. Educação, cinema e infância: um olhar sobre práticas de cinema em hospital universitário. Interface - Comunicação, Saúde e Educação, 2015; 19(53): 387-394 


\section{FC-05-2019 - DIFERENCIAÇÃO OSTEOGÊNICA DE CÉLULAS-TRONCO IRRADIADAS COM LASER DE BAIXA POTÊNCIA}

Eduardo Vinícius de Souza Silva ${ }^{1}$; Sinval Vinícius Barbosa do Nascimento; ${ }^{\mathbf{1}}$ Márcia Bezerra da Silva²; Cláudio Gabriel Rodrigues²; Jéssica Meirinhos Miranda ${ }^{1}$; Wyndly Daniel Cardoso Gaião²; Lara Marques Magalhães Moreno ${ }^{1}$; Marleny Elizabeth Márquez de Martínez Gerbi ${ }^{1}$

${ }^{1}$ Faculdade de Odontologia de Pernambuco - Camaragibe - PE - Brasil

${ }^{2}$ Universidade Federal de Pernambuco - Recife - PE - Brasil

Autor correspondente:

Eduardo Vinícius de Souza Silva

eviniciussz11@gmail.com

Introdução: As células-tronco mesenquimais (CTMs) são células indiferenciadas caracterizadas pela sua capacidade de autorrenovação, proliferação e diferenciação em diversos tipos de células e tecidos (multipotência). Diversos estudos têm mostrado o potencial regenerativo das CTMs quando estimuladas por alguns fatores, como o Laser de Baixa Potência $(\mathrm{LBP})^{1-3}$. Objetivo: Avaliar a ação do LBP na diferenciação osteogênicas de CTMs originadas de cordão umbilical humano. Metodologia: Consiste em um estudo laboratorial in vitro de amostras independentes, 36018214.2.0000.5207. Após processamento do cordão e confluência das células, houve a tripnização, centrifugação e distribuição em novas garrafas, caracterizando uma passagem. $\mathrm{O}$ experimento se deu na terceira passagem, onde foi realizada a contagem do número celular e o plaqueamento. Após $24 \mathrm{~h}$, as células foram divididas em 4 grupos: G1 (CONTROLE); G2 (OSTEO); G3 (DMEM + LBP) e G4 (OSTEO + LBP). Os devidos grupos foram irradiados com o LBP $660 \mathrm{~nm}$ em emissão contínua, potência de $30 \mathrm{~mW}$, dose $1 \mathrm{~J} / \mathrm{cm}^{2}$ por 28s. Após 7, 14 e 21 dias foram feitas coloração com Alizarina Red e a análise morfológica realizada com microscópio óptico de fase invertida. Resultados e Discussão: $\mathrm{Na}$ análise histomorfométrica houve diferença estatística significativa entre todos os grupos experimentais em todos os tempos quando comparados ao G1, exceto no tempo de 7 dias para os grupos G2 e G3; porém, quando comparado ao G4, este apresentou os maiores valores de área de diferenciação osteogênica, sendo estatisticamente significante. Para o tempo de 14 e 21 dias entre os grupos experimentais houve diferença estatística significativa entre o grupo G2 e G3; porém o G4 apresentou mâiores valores de diferenciação, sendo estatisticamente significante. Conclusão: a maior diferenciação osteogênica foi no G4, seguido dos grupos G3, G2 e G1. Portanto, o LBP produziu efeito satisfatório na diferenciação osteogênica das CTMs no período analisado.

Descritores: Células-tronco; Irradiação a laser de baixa potência; Diferenciação celular.

\section{Referências:}

1. CASAGRANDE $\mathrm{L}$, et al. O emprego da engenharia tecidual na Odontologia. Rev Fac Odontol, 2009; 50(1): 20-23

2. KOUTNÁ M, et al. Effects of Low-power Laser on Cell Proliferation. ScriptaMedica (BRNO), 2003; 76(3):163-172

3. LEONIDA A, et al. Effects of low-level laser irradiation on proliferation and osteoblastic differentiation of human mesenchymal stem cells seeded on a three-dimensional biomatrix: in vitro pilot study. Lasers in Medical Science, 2013; 28:125-132 


\section{FC-06-2019 - EFICÁCIA CLÍNICA DE SISTEMAS ADESIVOS AUTOCONDICIONANTES DE UM PASSO E DOIS PASSOS EM LCNC: UMA REVISÃO SISTEMÁTICA E META-ANÁLISE}

Cláudia Geisa Souza e Silva ${ }^{1}$; Ademir Felix Arantes Junior ${ }^{1}$; Claudio Paulo Pereira de Assis ${ }^{\mathbf{1}}$; Emerllyn Shayane Martins de Araújo ${ }^{1}$; Kássia Regina de Santana ${ }^{1}$; Maria Hermínia Annibal ${ }^{1}$; Pauliane Albuquerque da Silva ${ }^{1}$; Rodivan Braz ${ }^{1}$

${ }^{1}$ Faculdade de Odontologia de Pernambuco - Camaragibe - PE - Brasil

Autor correspondente:

Cláudia Geisa Souza e Silva

claudiageisa@outlook.com

Introdução: Os sistemas adesivos sofreram importantes mudanças nos últimos anos, principalmente quanto à simplificação de sua aplicação ${ }^{1}{ }^{3}$. Os sistemas adesivos autocondicionantes tornaram-se populares para os clínicos devido ao fato de esses sistemas não necessitarem de um condicionamento ácido prévido da dentina ou um passo a mais de lavagem³ ${ }^{3}$ Geralmente, as lesões cervicais não cariosas (LCNC) são utilizadas como determinantes da efetividade clínica de adesivos, pois não requerem técnicas restauradoras complexas, apresentam baixo fator de contração de polimerização e comumente não fornecem retenção macromecânica². Objetivo: Avaliar se sistemas adesivos autocondicionantes de passo único são tão efetivos quanto os adesivos de dois passos em LCNC. Metodologia: Esta revisão sistemática foi conduzida de acordo com as diretrizes do Preferred Reporting Items for Systematic Reviews and Meta-analyses (PRISMA) e registrado no International Prospective Register of Systematic Reviews (PROSPERO) sob o número CRD42018096747. A pergunta PICO foi "Sistemas adesivos autocondicionantes de passo único são tão efetivos quanto os autocondicionantes de dois passos?". Uma busca eletrônica foi realizada até julho de 2018, nas seguintes bases de dados: PubMed/MEDLINE, Scopus e Cochrane Library. Utilizando a combinação dos termos: "Adhesive dental AND one-step AND two-step". Revisão de literatura: A busca nas bases de dados resultou em 476 estudos, após aplicados os critérios de elegibilidade sete estudos do tipo ensaio clínico controlado randomizado foram selecionados. Nos estudos incluídos foram avaliadas 1008 restaurações em LCNC's distribuídas em 300 pacientes com uma média de idade de 45 anos. Os resultádos môstraram que não houve diferença estatística entre One step (1SSE) e Two step (2SSE) quanto a retenção, sensibilidade pós-operatória, cárie secundária, color match, descoloração marginal, adaptação marginal e forma anatômica. Conclusão: Sistemas adesivos autocondicionantes de único passo são tão efetivos quanto os adesivos de dois passos, em um período de acompanhamento de 12 a 24 meses.

Descritores: Revisão Sistemática; Adesivos Dentinários; Dentística Operatória.

\section{Referências:}

1. LOGUERCIO AD, et al. A randomized clinical evaluation of a one- and two-step self-etch adhesive over 24 months. Operativy Dentstry, 2010; 35(3): 265-272

2. PEUMANS M, et al. Clinical effectiveness of contemporany adhesives for the restoration of non-carious cervical lesions: a systematic review. Dental Materials, 2014; 30(10): 1089-1103

3. VAN MEERBEEK B, et al. Relationship between bond-strength tests and clinical outcomes. Dental Materials, 2010; 26(2): 100-121 


\section{FC-07-2019 - EPIDEMIOLOGIA, DIAGNÓSTICO E TRATAMENTO DO TUMOR ODONTOGÊNICO PRIMORDIAL: REVISÃO SISTEMÁTICA}

Cleiton Rone dos Santos Lima ${ }^{1}$; Kássia Regina de Santana ${ }^{1}$; Carolina Pereira da Silva ${ }^{1}$; Luiz Ricardo Gomes de Caldas Nogueira Filho ${ }^{1}$; Sinval Vinícius Barbosa do Nascimento; Weslay Rodrigues da Silva ${ }^{2}$

${ }^{1}$ Faculdade de Odontologia de Pernambuco - Camaragibe - PE - Brasil

${ }^{2}$ Universidade Federal do Rio Grande do Norte - Natal - RN - Brasil

Autor correspondente:

Cleiton Rone dos Santos Lima

cleitonrone@live.com

Introdução: A mais recente classificação da Organização Mundial da Saúde (OMS) para tumores de cabeça e pescoço foi atualizada em 2017. Estas atualizações visam fornecer à comunidade de clínicos, patologistas e estomatologistas um protocolo para diagnóstico de patologias de cabeça e pescoço. Dentre elas, uma nova entidade foi inserida no grupo de tumores odontogênicos mistos: o Tumor Odontogênico Primordial, descrito pela primeira vez em 2014 ${ }^{1-3}$. Objetivo: Integrar os dados disponíveis na literatura sobre Tumor Odontogênico Primordial (TOP). Metodologia: Trata-se de uma revisão sistemática da literatura conforme a recomendação Preferred Reporting Items for Systematic Review and Meta-Analyses (PRISMA). A estratégia ("Odontogenic tumor primordial OR Primordial, odontogenic tumor") foi utilizada nas bases de dados: LILACS, PubMed, Scopus e Web of Science em busca de artigos publicados até julho de 2019. Dois revisores independentes realizaram a seleção dos estudos, avaliação da qualidade e coleta de dados. Foram elegíveis estudos de coorte, séries de casos e relatos de caso. Revisão de literatura: A estratégia de busca encontrou 149 artigos. Dentre estes, 17 foram considerados relevantes após análise do título e resumo. Finalmente, 7 artigos foram selecionados após análise de texto completo. Na literatura são descritos 13 casos de Tumor Odontogênico Primordial (TOP), o qual foi mais comum em homens $(n=8 ; 61,5 \%)$ do que em mulheres $(n=5 ; 38,5 \%)$, em uma média de idade de 10,7 anos, variando de 2-19 anos; os tratamentos empregados foram: enucleação do tumor, excisão e curetagem; quanto à localização, os tumores desenvolveram-se com prevalência na região de molares; o tempo médio de acompanhamento foi de 4,4 anos permanecendo sem recidiva. Conclusão: Apesar de tratar-se de uma entidade nova, as informações são limitadas, entretanto, conhecer as principais características apresentadas na literatura é importante para o diagnóstico e conduta terapêutica.

Descritores: Tumor bucal; Tumores odontogênicos; Patologia Bucal.

\section{Referências:}

1. TAYLOR AM, et al. Primordial odontogenic tumour: clinicopathological analysis of six cases of a previously undescribed entity. Histopathology, 2014; 65:606-612

2. TOLENTINO ES. Nova classificação da OMS para tumores odontogênicos: o que mudou?. Revista da Faculdade de Odontologia-UPF, 2018; 23(1): 119-123

3. WRIGHT JM, et al. Update from the 4th edition of the World Health Organization classification of head and neck tumours: odontogenic and maxillofacial bone tumors. Head Neck Pathology, 2017; 11(1):68-77 


\section{FC-08-2019 - EXOSTOSE ÓSSEA BILATERAL EM REGIÃO DE MAXILA: RELATO DE CASO}

Amanda Idalina de França Medeiros ${ }^{1}$; Amanda Cristina de Magalhães Souza ${ }^{1}$; Ildefonso Antônio Gouveia Cavalcanti ${ }^{2}$; Thalia Franciele Barreto Cordeiro ${ }^{1}$; Robson José dos Santos ${ }^{1}$

${ }^{1}$ Centro Universitário Tiradentes - Recife - PE - Brasil

${ }^{2}$ Faculdade de Odontologia de Pernambuco - Camaragibe - PE - Brasil

Autor correspondente:

Amanda Idalina de França Medeiros

amanda-idalina@hotmail.com

Introdução: A exostose é caracterizada como uma protuberância óssea de etiologia desconhecida, com tamanhos variáveis e aparência plana ou nodular. Geralmente desenvolvese entre a $2^{\mathrm{a}}$ e $3^{\mathrm{a}}$ década de vida, com maior incidência em região de maxila ${ }^{1,2}$. Objetivo: Discutir o caso a partir de evidências clínicas e histopatológicas. Relato de caso: Paciente J.C.A, gênero: feminino, 53 anos de idade, dependente de nicotina, edêntula superior. Procurou o serviço de atendimento do Centro Universitário Tiradentes, relatando má adaptação da prótese. Ao exame clínico notou-se aumento ósseo bilateral na região vestibular da maxila, assintomático. No exame radiográfico, não foi possível uma visualização adequada da área acometida. A paciente informou que já havia realizado o procedimento anteriormente para correção do defeito ósseo. Exame realizado há mais de uma década, com diagnóstico de displasia fibrosa. O tratamento de escolha foi a cirurgia pré-protética, realizada em duas sessões. Durante o ato cirúrgico, a despeito de todo cuidado empreendido houve discreta lesão do seio maxilar esquerdo. Procedeu-se à retirada do fragmento ósseo, o qual foi encaminhado para o exame histopatológico. Com a possível hipótese de diagnóstico de displasia fibrosa, ao término cirúrgico, foi prescrito (Amoxicilina de 500mg e Nimesulida 100mg). Deu-se continuidade ao procedimento cirúrgico e remoção da lesão do lado direito com sucesso. Discussão: O exame histopatológico contrariou a HD, sendo compatível com exostose óssea. A abordagem cirúrgica foi necessária, pois, em longo prazo, a lesão poderia acometer os tecidos periodontais e o aumento ósseo, impossibilitaria a adaptação da prótese. Conclusão: Após 15 dias da avaliação pós-cirúrgica, a paciente relatou presença de espícula óssea. Foi realizado retalho das áreas, não sendo encontrado nenhum fragmento em ambos os lados. No último átendimento, removeramse as suturas, constatou-se boa cicatrização. O tratamento foi finalizado e a mesma encaminhada para clínica de prótese da instituição.

Descritores: Exostose; Doenças Maxilares; Patologia Bucal.

\section{Referências:}

1. CELESTINO MLS, et al. Exostose óssea gigante em maxila: Relato de caso incomum. Revista da Universidade Vale do Rio Verde, 2014; 12 (3): 34

2. CEVALLOS CAR, et al. Exostose bucal em área estética da maxila: relato de um caso. Journal of Applied Oral Science, 2017; 25: 211

3. FRANCETTI L, et al. Caracterização Morfológica e Molecular do Tecido Gengival Humano Sobrejacente a Exostoses Múltiplas. Relatos de Casos em Odontologia. Journal Hindawi, 2019; 19: 10 


\section{FC-09-2019 - EXPOSIÇÃO DO PACIENTE EM MÍDIAS SOCIAIS ENTRE ESTUDANTES DE ODONTOLOGIA}

Fábio Victor Dias Silva ${ }^{1}$; Marcos Aurélio Vasconcelos Lima Júnior ${ }^{1}$; Victória Mendonça Dias ${ }^{1}$

${ }^{1}$ Centro Universitário de João Pessoa - UNIPÊ - João Pessoa - PB - Brasil

Autor correspondente:

Fábio Victor Dias Silva

fabio_vct@hotmail.com

Introdução: As mídias sociais têm tido grande utilidade na odontologia, ganhando destaque como ferramenta educativa ou como forma de impulsionar marcas pessoais ${ }^{2,4}$. Porém, alguns contextos contribuem para o desrespeito ao sigilo do paciente, tornando-se um problema moral que precisa ser discutido ${ }^{1,3}$. Objetivo: Verificar a utilização de mídias sociais com finalidade de divulgação de imagem e informações de pacientes, entre estudantes de Odontologia do Centro Universitário de João Pessoa - UNIPÊ. Metodologia: Foi realizada pesquisa exploratória, com abordagem quantitativa, utilizando a aplicação de questionário. $\mathrm{O}$ instrumento adotado foi adaptado do estudo de Nascimento (2016), desenvolvido na UnB-FS. Participaram alunos entre o $5^{\circ}$ e $10^{\circ}$ períodos que tivessem experiência com atendimento a pacientes na clínica escola. A amostra foi obtida por conveniência, totalizando 191 participantes. Foram atendidos os requisitos da Resolução $n^{\circ}$ 466/2012, tendo sido aprovado pelo Comitê de Ética em Pesquisa em Seres Humanos do UNIPÊ, sob Parecer Consubstanciado $\mathrm{n}^{\circ}$ 3.066.855. Após recolhidos, os questionários tiveram seus dados tabulados para elaboração das estatísticas descritivas, com auxílio de recurso de informática. Resultados e discussão: $89 \%$ dos participantes obtêm fotografias dos pacientes atendidos, $79 \%$ afirmaram sempre solicitar autorização para postagem das imagens, e esta autorização, na maioria das vezes, foi feita apenas de forma verbal (62\%); 68\% justificaram a utilização das imagens dos pacientes para ilustrar casos clínicos, enquanto $18 \%$ admitiram publicar em redes sociais. O Instagram e WhatsApp foram as mídias mais usadas para as postagens, e as principais motivações para exposição das fotografias foram a ilustração de casos clínicos e estratégia de marketing. Conclusão: A obtenção de fotografias é uma prática comum, e há um número significativo de alunos que postam essas imagens nas redes, motivados em divulgar seus casos e promover seu trabalho, mesmo que por aprendizado. Entretanto, não respeitam algumas regras e desconhecem o teor das legislações.

\section{Descritores: Mídias Sociais; Bioética; Deontologia}

\section{Referências:}

1. MARTORELL LB, et al. O uso de imagens em redes sociais e o respeito ao paciente odontológico. Journal of Health Sciences, 2016; 18(2): 104-110

2. MARTORELL LB, FINKLER M. Carta de natal - em busca da alforria para a utilização de imagem de pacientes em redes sociais.Revista Brasileira de Odontologia Legal, 2017; 4(3): $117-12$

3. ROBINSON JK, et al. Protection of patients' right to privacy in clinical photographs, video, and detailed case descriptions. JAMA Dermatology, 2014; 150(1): 14-16

4. SILVA A, et al. O uso das tecnologias de informação e comunicação no ensino e em odontologia. Revista da Academia Brasileira de Odontologia, 2019; 8(1): 33-39 


\title{
FC-10-2019 - MOLDAGEM DE DUPLA IMPRESSÃO MODIFICADA - SIMPLIFICANDO A TÉCNICA
}

\author{
Giovanna Siqueira Faustino da Silva ${ }^{1}$; Andreza Cibelle Amaral da Silva ${ }^{1}$; Paulo Fonseca \\ Menezes Filho ${ }^{1}$
}

${ }^{1}$ Universidade Federal de Pernambuco - Recife - PE - Brasil

Autor correspondente:

Giovanna Siqueira Faustino da Silva

giovsfs@gmail.com

Introdução: A moldagem na Odontologia é um passo importante nos procedimentos, tendo em vista a obtenção de informações que permitem reproduzir a cavidade bucal do paciente através da confecção de um modelo de gesso. O material mais preciso é a silicona de adição, pois possui estabilidade dimensional e riqueza de detalhes ${ }^{1}$. Objetivo: Relatar um caso clínico em que foi utilizada a moldagem em dupla impressão modificada para confecção de laminados cerâmicos. Relato de Caso: Após a obtenção do modelo de gesso, a partir da moldagem inicial, foi feito um enceramento nos dentes que receberiam os laminados cerâmicos. Nesta técnica de moldagem, o modelo encerado, foi moldado com uma silicona de adição de consistência pesada ( $1^{a}$ impressão). Em seguida, com esse molde, foi feita uma segunda impressão utilizando a silicona de consistência fluida para moldar a boca da paciente, que já estava com os dentes preparados. Previamente foram realizados recortes para facilitar a adaptação da moldeira. A partir desse molde ( $2^{\mathrm{a}}$ impressão), os laminados foram confeccionados em laboratório. Discussão: Existem na literatura diversas técnicas e materiais de moldagem e, uma das mais utilizadas, é a dupla impressão com silicona de adição ${ }^{3}$. O presente relato demostrou que a técnica proposta de dupla impressão modificada diminuiu o tempo de trabalho, não necessita do paciente para realizar a primeira impressão, nem de alívio em molde antes da segunda impressão, simplificando sobremaneira o procedimento. A moldagem é uma etapa fundamental nas reabilitações e, quando bem-feita, garante sucesso no tratamento e facilidade na obtenção dos laminados, satisfazendo o profissional e o paciente ${ }^{2}$. Conclusão: A simplicidade da técnica, redução do tempo de trabalho e obtenção de bons resultados justificam a utilização da dupla impressão modificada para um bom desempenho nos procedimentos clínicos, desde que dentro do planejamento o paciente possua um modelo com enceramento diagnóstico.

Descritores: Elastômeros de Silicone; Materiais para Moldagem Odontológica; Técnica de Moldagem Odontológica.

\section{Referências:}

1. DIAS DRCM, et al. Dimensão do alívio em técnica de dupla moldagem: uma revisão de literatura. Arquivo Brasileiro de Odontologia, 2016; 12(1): 17-23

2. LINS BR, et al. Moldagem de laminados cerâmicos com técnica modificada em três passos: relato de caso. Rev AcBO, 2017; 7(2): 139-144

3. SILVA FCFA, et al. Técnica de moldagem modificada usando silicona de adição. Rev Assoc Paul Cir Dent, 2016; 70(4): 364-368 


\section{FC-11-2019 - PROGRAMA DE EXTENSÃO UNIVERSITÁRIA RESGATANDO SORRISOS 9}

Rayanna Thayse Florêncio Costa ${ }^{1}$; Rafaella de Souza Leão ${ }^{1}$; Bruno Gustavo da Silva Casado ${ }^{1}$; Sandra Conceição Maria Vieira ${ }^{1}$; Mônica Vilela Heimer ${ }^{1}$; Marianne de Vasconcelos Carvalho ${ }^{1}$; Jose Luiz Magalhães de Carvalho ${ }^{1}$; Sandra Lúcia Dantas de Moraes ${ }^{1}$

${ }^{1}$ Faculdade de Odontologia de Pernambuco (FOP/UPE) - Camaragibe - PE - Brasil

Autor correspondente:

Rayanna Thayse Florêncio Costa

rayannatfcosta@gmail.com

Introdução: O "Resgatando Sorrisos" é um programa de extensão universitária que se propõe a levar à população conhecimentos que causem reflexão e melhora na sua qualidade de vida, proporcionar crescimento acadêmico e humanístico à equipe e soluções que resultem sempre em soma positiva para sociedade e universidade ${ }^{1,2}$. Objetivo: $O$ objetivo deste trabalho é relatar a experiência na $9^{a}$ edição do Resgatando Sorrisos. Relato de experiência: O programa ocorre durante todo o ano letivo da UPE e inclui atividades de administração, ações educativas, divulgação de informações em saúde através de mídias sociais e a realização de uma ação de intervenção na cidade de São José do Egito-PE. Neste ano de 2019 contou com as áreas de prótese dentária, dentística, pacientes com necessidades especiais, cirurgia oral, pesquisa científica, estomatopatologia e dermatologia. Discussão: A ação intervencionista realizada em São José do Egito resultou em 672 pessoas atendidas diretamente, 1640 procedimentos clínicos e laboratoriais e uma conferência voltada para prevenção do câncer de pele e boca. Até o presente momento, mais de 40 atividades educativas foram realizadas, 242 publicações em redes sociais e duas pesquisas em fase de finalização. No Brasil existe uma elevada desigualdade social e uma alta taxa de edentulismo (11\%). Programas governamentais e nãogovernamentais apresentam grande importância na melhoria das condições de saúde bucal no país, principalmente nas regiões norte e nordeste, as quais apresentam os maiores índices de desigualdades socioeconômicas em comparações com outras regiões ${ }^{3}$. Conclusões: É possível concluir que esta experiência extensionista foi capaz de contribuir de forma relevante a formação dos alunos de graduação, contribuindo para o crescimento e amadurecimento profissional dos pós-graduândos, professores e técnicos, gerando uma visão mais humanista por parte dos profissionais de Odontologia. Adicionalmente, o programa contribuiu com o município, gerando uma reflexão na gestão da sua Rede de Atenção à Saúde.

Descritores: Educação em saúde; Promoção da saúde; Odontologia Comunitária.

\section{Referências:}

1. MARTINS EF. Extensão como componente curricular: oportunidade de formação integral e de solidariedade. Ciências e Cognição, 2008; 13(2):201-209

2. PEREIRA SM, et al. Extensão universitária e trabalho voluntário na formação do acadêmico em Odontologia. Arq Odontol, 2011; 47(2):95-103

3. SOARES CL. Constructing public oral health policies in Brazil: issues for reflection. Braz

Oral Res, 2012; 26 Supp 11:94-102 


\section{FC-12-2019 - RASTREAMENTO DE PATOLOGIAS DO COMPLEXO BUCOMAXILOFACIAL: ATENDIMENTO E PROMOÇÃO DE SAÚDE NO PROGRAMA DE EXTENSÃO RESGATANDO SORRISOS}

Sinval Vinícius Barbosa do Nascimento ${ }^{1}$; Danielle Machado Farias ${ }^{1}$; Geovana Maria do Carmo Oliveira $^{1}$; Maria Alves Garcia Santos Silva ${ }^{2}$; Marianne de Vasconcelos Carvalho ${ }^{1}$; Sandra Lúcia Dantas de Moraes ${ }^{1}$

${ }^{1}$ Faculdade de Odontologia de Pernambuco - Camaragibe - PE - Brasil

${ }^{2}$ Universidade Federal de Goiás - Goiânia - GO - Brasil

Autor correspondente:

Sinval Vinícius Barbosa do Nascimento

sinvalvinicius@outlook.com

Introdução: A Extensão Universitária é um importante meio de atender a sociedade, visando à produção de conhecimentos e à interlocução das atividades acadêmicas de ensino e de pesquisa, através de processos ativos de formação ${ }^{2}$. Objetivo: Relatar a experiência e resultado da ação da equipe de estomatopatologia do programa de extensão universitária Resgatando Sorrisos (RS). Relato de experiência: O programa de extensão RS conta, desde sua segunda edição, com uma equipe voltada para estomatopatologia, que faz o rastreamento do câncer de boca e outras patologias que acometem o complexo maxilo facial. Em 2019, na sua nona edição, o programa esteve na cidade de São José do Egito, sertão de Pernambuco. A equipe composta de seis alunos de graduação e duas professoras especialistas na área atenderam em dois dias, por demanda espontânea, 261 moradores, destes 66 apresentaram alguma patologia. Dezesseis pessoas examinadas apresentaram diagnóstico clínico de desordens potencialmente malignas e câncer de boca. Todas foram encaminhadas para realização de biópsia. Discussão: $\mathrm{O}$ câncer de boca é o quinto câncer mais comum em homens e está entre os dez tipos que mais levam ao óbito $^{1}$. Acomete principalmente homens acima de 50 anos, que tem o hábito de fumar ${ }^{1,3}$. Além disso, o diagnóstico geralmente é tardio e está relacionado ao alto índice de morbimortalidade dessa neoplasia ${ }^{1}$. Ações de extensão universitária voltadas para o atendimento e promoção de saúde pode ajudar o diagnóstico precoce e ainda gerar um impacto positivo no aprendizado dos estudantes ${ }^{2}$. Conclusão: Ações de diagnóstico de patologias, além de permitir ao aluno de graduação uma vivência prática, permite o levântamento de dados épidemiológicos, diagnósticos de doenças e prevenção para a população visitada. Assim sendo uma prática extensionista totalmente positiva.

Descritores: Estomatologia; Educação em Saúde; Patologia Bucal.

\section{Referências:}

1. BORGES AKM, et al. Estimativa 2018: incidência de câncer no Brasil. Rio de Janeiro: Instituto Nacional de Câncer José Alencar Gomes da Silva, 2018; 130p

2. RIOS DRS, CAPUTO MC. Para além da formação tradicional em saúde: experiência de educação popular em saúde na formação médica. Revista Brasileira de Educação Médica, 2019; 43(3): 184-195

3. SIMÕES CA, et al. Prevalência das lesões diagnosticadas na região maxilofacial no laboratório de patologia oral da Universidade Federal de Pernambuco. International Journal of Dentistry, 2007; 6(2): 35-8 


\section{FC-13-2019 - RELATO DE CUIDADORES SOBRE O ACESSO ODONTOLÓGICO DE CRIANÇAS E ADOLESCENTES COM PARALISIA CEREBRAL}

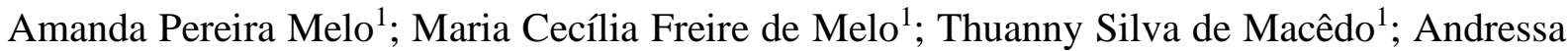
Kelly Alves Ferreira ${ }^{1}$; Marília de Carvalho Lima ${ }^{1}$; Gustavo Pina Godoy ${ }^{1}$; Arnaldo de França Caldas Júnior ${ }^{1}$; Elizabeth Louisy Marques Soares da Silva ${ }^{1}$

${ }^{1}$ Universidade Federal de Pernambuco - Recife - PE - Brasil

Autor correspondente:

Amanda Pereira Melo

amandamlo@outlook.com

Introdução: A Paralisia Cerebral (PC) é uma desordem não progressiva da postura e do movimento causada por um defeito ou insulto ao sistema nervoso central ${ }^{1}$. Representa a forma mais comum de deficiência neuromotora em crianças ${ }^{2}$ e gera dificuldades na prática de atividades de vida diária, tais como a realização da higiene bucal, como também na busca por cuidados odontológicos, necessitando muitas vezes do auxílio de cuidadores para a obtenção deste acesso e desses cuidados. Objetivo: Relatar as dificuldades, sob a visão dos cuidadores, acerca do acesso odontológico de crianças e adolescentes com PC. Metodologia: Realizou-se estudo observacional do tipo série de casos nos serviços de saúde que acompanham crianças e adolescentes com PC. Participaram da pesquisa 94 cuidadores de crianças e adolescentes com paralisia cerebral, de grau leve, moderado e severo, assistidas de janeiro a agosto de 2017, e que se enquadraram nos critérios de elegibilidade. Foi utilizado formulário próprio semiestruturado. O projeto foi aprovado pelo CEP da UFPE com $\mathrm{N}^{\circ} 1.979 .046$. Resultados e Discussão: Quanto ao acesso odontológico não foram observadas diferenças significativas entre os grupos em relação aos cuidados em saúde bucal. Verificou-se também uma proporção significantemente maior de crianças e adolescentes com PC mais grave com dificuldades relacionadas ao transporte e à acessibilidade aos serviços odontológicos. Neste estudo, foi evidenciado um baixo número de indivíduos que nunca foram ao dentista, podendo este dado estar relacionado a programas como o Brasil Sorridente e à Rede de Cuidados à Pessoa com Deficiência $^{3}$. As dificuldades relatadas quanto 0 acesso aos cuidados odontológicos se relacionou ao transporte e à acessibilidade aos serviços ${ }^{4}$. Conclusão: Há necessidade de iniciativas que promovam orientações aos cuidadores sobre a adoção de práticas cotidianas de higiene bucal juntamente a ações de maior acesso aos serviços odontológicos.

Descritores: Paralisia cerebral; Criança; Assistência Odontológica para Pessoas com Deficiências.

\section{Referências:}

1. FAIRHURST C. Cerebral palsy: the whys and hows. Archives of Disease in ChildhoodEducation and Practice, 2012; 4(97):122-31

2. JONES MW, et al. Cerebral palsy: introduction and diagnosis (part 1). Journal of Pediatric Health Care, 2007; 21(3):146-152

3. PUCCA JRG. Por um Brasil Sorridente. Revista da ABO, 2004; 12(2):73-9

4. SIMÕES CC, et al. A experiência dos pais no cuidado dos filhos com paralisia cerebral. Revista Eletrônica de Enfermagem, 2013; 15(1):138-45 


\section{FC-14-2019 - TRANSPLANTE TRANSALVEOLAR DE CANINO MAXILAR IMPACTADO: RELATO DE CASO}

Maria Fernanda Limeira Feitosa ${ }^{1}$; Fabio Tavares da Silva ${ }^{1}$; Ítalo Martins da Silva ${ }^{1}$; Luiz Ricardo Gomes de Caldas Nogueira²

${ }^{1}$ Faculdade Maurício de Nassau - Recife - PE - Brasil

${ }^{2}$ Faculdade de Odontologia de Pernambuco - Camaragibe - PE - Brasil

Autor correspondente:

Maria Fernanda Limeira Feitosa

Mariafernandalimeira3@gmail.com

Introdução: $O$ transplante dental autógeno é descrito como a manobra cirúrgica de remoção de um dente incluso ou erupcionado para um local diferente de sua origem, no mesmo indivíduo, em alvéolos de dentes recém-extraídos ou preparados cirurgicamente ${ }^{2}$. A principal vantagem dessa técnica é caracterizada pela preservação do dente natural do paciente, o que não ocorreria em um implante ${ }^{3}$. Objetivo: Demonstrar através do relato de caso a técnica de transplante dental autógeno como um procedimento viável e possível de ser realizado como alternativa conservadora para reabilitação do espaço edêntulo. Relato de caso: Paciente V.J.C.C., 27 anos, gênero masculino. Apresentava o canino superior esquerdo incluso, o qual foi submetido a tracionamento ortodôntico e constatado anquilose. Sugeriu-se realizar o autotransplante dental, confeccionando um alvéolo cirúrgico no qual recebeu o elemento 23 removido da região vestibular. Posteriormente ao enxerto ósseo autógeno nessa região, foi realizada sutura e contenção com fio de aço flexível. Após um ano avaliou-se estética, função mastigatória, mobilidade dentária, nível de crista óssea e espaço relativo ao ligamento periodontal, os quais estavam dentro da normalidade. Discussão: Perante a literatura citada, o autotransplante representa uma alternativa importante dentro da prática cirúrgica conservadora e com limitações socioeconômicas ${ }^{\mathbf{1}, 2}$. Conclusão: $\mathrm{O}$ transplante dentário autógeno mostrou-se uma opção eficiente, uma vez que se obteve sucesso no posicionamento correto do canino no arco, sem a ocorrência de complicações, apresentando um bom prognóstico e maior satisfação do paciente, devido a reabilitação ter sido feita com o próprio elemento dentário.

Descritores: Extração Dentária; Reabilitação Bucal; Trânsplante autólogo.

\section{Referências:}

1. CHUNG WC, et al. Outcomes of autotransplanted teeth with complete root formation: a systematic review and meta-analysis. J Clin Periodontol, 2014; 41: 412-423

2. GRISAR K, et al. Autogenous transalveolar transplantation of maxillary canines: a systematic review and meta-analysis.European Journal of Orthodontics, 2018; 40(6): 608-616 3. MIKAMI JR, et al. Transplante dental autógeno - relato de caso. Rev. Cir. Traumatol. BucoMaxilo-Fac., 2014; 14(4): 51-58 


\section{FC-15-2019 - TRATAMENTO CIRÚRGICO DE CARCINOMA BASOCELULAR EM REGIÃO INFRA-ORBITAL COM AUTO-ENXERTIA CUTÂNEA}

Camilla Siqueira de Aguiar ${ }^{1}$; Emerllyn Shayane Martins de Araújo ${ }^{2}$; Frederico Márcio Varela Ayres de Melo ${ }^{3}$; Bruna Heloísa Costa Varela Ayres de Melo ${ }^{3}$; Rodrigo Henrique Mello Varela Ayres de Melo ${ }^{4}$; Victor Leonardo Mello Varela Ayres de Melo ${ }^{1}$; Marcela Côrte real Fernandes ${ }^{1}$; Ricardo Eugenio Varela Ayres de Melo ${ }^{1}$

${ }^{1}$ Universidade Federal de Pernambuco - Recife - PE - Brasil

${ }^{2}$ Faculdade de Odontologia de Pernambuco - Camaragibe - PE - Brasil

${ }^{3}$ Universidade Maurício de Nassau - Natal - RN - Brasil

${ }^{4}$ Prefeitura Municipal de Arroio dos Ratos - Arroio dos Ratos - RS - Brasil

Autor correspondente:

Camilla Siqueira de Aguiar

camilla.aguiar@outlook.com.br

Introdução: Carcinoma basocelular (CBC), mais comum em caucasianos, representa $80 \%$ dos casos de câncer de pele ${ }^{1,2}$. Ele começa como pápulas sendo a coloração perolada ou eritematosa, crescem lentamente e a presença de ulcerações é comum ${ }^{1}$. A opção mais eficaz no tratamento do CBC é excisão cirúrgica ${ }^{1,3}$. Objetivo: Relatar o tratamento cirúrgico da ressecção de carcinoma basocelular seguido de auto enxertia. Relato de caso: Paciente sexo feminino, 82 anos, caucasiana, procurou o Ambulatório de CTBMF da UFPE, com queixa de lesão em região infraorbital direita. Ao exame físico apresentava nódulo perláceo de superfície ulcerada e sem sintomatologia dolorosa associada. Ela relatou que a lesão tinha longo tempo de evolução e que sofreu, ao longo dos anos, exposição solar repetitiva. A paciente foi submetida à cirurgia sob anestesia geral para remoção da lesão, seguida de autoenxerto. Ela segue em acompanhamento, sem sinais de complicações e apresentando melhora da estética facial. Discussão: A exposição à radiação ultravioleta é o principal fator de risco associado ao surgimento do $\mathrm{CBC}^{1,3}$. Isso corrobora o caso clínico, com dois importantes fatores de risco: a cor da pele e a intensa exposição à radiação solar. O CBC apresenta maior incidência na população acima de 40 anos 2 . Esse dado é consistente com o achado deste estudo, uma vez que a paciente tinha 82 anos. As queixas mais comuns relacionadas são mancha, coceira da pele, dor, sangramento, descamação, ferida que não cicatriza, alteração de cor, a elevação e aparência perolada, translúcida, avermelhada ou escura ${ }^{1}$. Neste estudo, a paciente queixou-se de uma lesão nodular, ulcerada, sem cicatrização. O tratamento do CBC depende do tamanho e localização da lesão ${ }^{3}$. A paciente do presente estudo teve como tratamento remoção cirúrgica. Conclusão: A auto enxertia cutânea em ressecções de lesões extensas é um tratamento bastante eficaz.

Descritores: Carcinoma Basocelular; Pele; Transplante Autólogo.

\section{Referências:}

1. CHINEM VP, MIOT HA. Epidemiologia do carcinoma basocelular. Anaisbrasileiro dermatologia, 2011; 86(2): 292-305

2. MARTIIN-GORGOJO A, PASTUSHENKO I. New Perspectives in the Management of Basal Cell Carcinoma. Actas Dermosifiliogr, 2014; 105(9): 874-875

3. TOTONCHY M, LEFFELL D. Emerging concepts and recent advances in basal cell carcinoma. F1000Research, 2017; 6(2085): 1-10 


\section{FC-16-2019 - TRATAMENTO CIRÚRGICO DE CISTO ODONTOGÊNICO QUERATOCISTO LOCALIZADO EM REGIÃO POSTERIOR DE MAXILA: RELATO DE CASO}

Emerllyn Shayane Martins de Araújoㅜ; Camilla Siqueira de Aguiar ${ }^{2}$; Rodrigo Henrique Mello Varela Ayres de Melo ${ }^{3}$; Deise Louise Bohn Rhoden ${ }^{4}$; Milena Mello Varela Ayres de Melo Pinheiro ; Victor Leonardo Mello Varela Ayres de Melo²; Marcela Côrte Real Fernandes²; Ricardo Eugenio Varela Ayres de Melo ${ }^{2}$

${ }^{1}$ Faculdade de Odontologia de Pernambuco - Camaragibe - PE - Brasil

${ }^{2}$ Universidade Federal de Pernambuco - Recife - PE - Brasil

${ }^{3}$ Prefeitura Municipal de Arroio dos Ratos - Arroio dos Ratos - RS - Brasil

${ }^{4}$ Laboratório Geyer - Porto Alegre - RS - Brasil

${ }^{5}$ Cooperativa de Fisioterapeutas - Recife - PE - Brasil

Autor correspondente:

Emerllyn Shayane Martins de Araújo

emerllyn_shayane@outlook.com

Introdução: Conhecido pela alta recidiva, o cistoodontogênicoqueratocisto surge dos restos celulares da lâmina dentária. É encontrado em pacientes com idade variável, desde jovens a adultos de 50 anos, com preferência pelo gênero masculino. Essa lesão geralmente afeta corpo e ramo da mandíbula ${ }^{1,3}$. Objetivo: Apresentar a técnica de Caldwell-Luc como alternativa terapêutica para um caso de cisto odontogênico queratocisto. Relato de caso: Paciente do gênero feminino, 52 anos, chegou ao serviço de Cirurgia e Traumatologia Bucomaxilofacial da UFPE, relatando aumento de volume próximo ao elemento 27 , com presença de secreção purulenta, hálito fétido e cefaleia constante durante 5 anos. Ao exame clínico, notou-se que a paciente não apresentava múltiplos elementos dentáriose verificou-se expansão das corticais na região referida. $\mathrm{O}$ exame radiográfico sugeria cisto odontogênico queratocisto, com imagem radiopacadelimitada, relacionada ao elemento 27 e ao seio maxilar esquerdo. Como forma de tratamento, optou-se pela enucleação cística, sinusectomia maxilar esquerda, em conjunto com remoção do elemento dentário. A paciente apresentou recuperação satisfatória após a cirurgia e segue sem recidiva e com boa cicatrização, após um ano de acompanhamento. Discussão: Esse caso foge dos padrões enquanto gênero, idade, localizaçãa e tumefação das corticais ósseas. Contudo, assemelha-se aos dados epidemiológicos pela sintomatologia dolorosa, edema e drenagem, e envolvimento de dentes como causa principal da patologia. A enucleação associada à técnica de Caldwell-Luc promove abordagem segura e acesso direto ao seio maxilar, facilitando a visualização e remoção completa da lesão reduzindo possibilidade de recidiva $^{2,3}$. Conclusão: A inserção da técnica de Caldwell-Luc nesse planejamento cirúrgico foi crucial para evitar o reaparecimento da lesão, vez que epitélio do seio maxilar também foi removido, sem ocorrência de fístulas. Apesar de antiga, essa abordagem continua gerando bons resultados.

Descritores: Cirurgia Bucal; Cistos Odontogênicos; Seio Maxilar.

\section{Referências:}

1. IDE F, et al. Infrequent clinicopathologic features of keratocystic odontogenic tumour: a 29-year multiinstitutional retrospective review. Oral Surgery, 2009; 2(1): 1-9

2. VENCIO EF, et al. Odontogenic keratocyst in maxillary sinus with invasive behaviour. Journal of oral pathology \& medicine, 2006; 35(4): 249-251

3. ZECHA JAEM, et al. Recurrence rate of keratocystic odontogenic tumor after conservative surgical treatment without adjunctive therapies-A 35-year single institution experience. Oral oncology, 2010; 46(10): $740-742$ 


\title{
FC-17-2019 - USO DA TOMOGRAFIA DE FEIXE CÔNICO COMO FERRAMENTA NO DIAGNÓSTICO DE LESÕES PERRIRADICULARES: RELATO DE CASO
}

\author{
Pereira Ferraz ${ }^{4}$; Nathalia Marília Pereira Ferraz ${ }^{4}$. \\ ${ }^{1}$ Centro Universitário Maurício de Nassau - Recife - PE - Brasil. \\ ${ }^{2}$ Centro Universitário Tiradentes - Recife - PE - Brasil. \\ ${ }^{3}$ Universidade Federal de Pernambuco - Recife - PE - Brasil. \\ ${ }^{4}$ Cursos de pós-graduação em odontologia CPGO - Recife - PE - Brasil.
}

Maria Izabel Silva Bezerra'; João Carlos Hazin de Godoy²; Sílvio Emanuel Acioly Conrado de Menezes $^{2}$; Tayse de Carvalho Cordeiro ${ }^{3}$; Elizabeth Louisy Marques Soares da Silva ${ }^{3}$; Anizabel

Autor correspondente e e-mail:

Maria Izabel Silva Bezerra

belbezerra54@gmail.com

Introdução: A Tomografia Computadorizada de Feixe Cônico (TCFC) introduzida na Odontologia, tem atraído o interesse de muitos Cirurgiões-Dentistas, principalmente por se tratar de imagens de alta resolução e de baixa dose de radiação comparada com a imagem tomográfica computadorizada helicoidal ${ }^{1,3}$. Objetivo: Relatar um caso de extensa lesão perirradicular em que a Tomografia Computadorizada de Feixe Cônico foi utilizada como meio diagnóstico e meio complementar de proservação. Relato do caso: Paciente P.A.D.C.F, 34 anos, foi encaminhado ao consultório particular para retratamento dos dentes 21 e 22, como preparo prévio para cirurgia parendodôntica. Ao exame clínico, foi verificada presença de fístula entre os referidos dentes e tumefação na região do palato. Ao exame radiográfico com rastreamento de fístula verificou-se a presença de lesão perirradicular e suspeita de trinca radicular do dente 22. Foi Solicitada a TCFC Prexiona, qual descartou a suspeita de trinca e mostrou a grande extensão da lesão, um adelgaçamento da cortical óssea vestibulare rompimento da palatina. Foi realizado o retratamento com o sistema Prodesign $\mathrm{S}$, determinação do diâmetro apical, limpeza e ampliação foraminal até a lima \#90; com o auxílio da solução clorexidina gel 2\%; foram realizadas sucessivas trocas de medicação à base de hidróxido de cálcio. Os sinais de regeneração óssea foram comprovados por meio da TCFC no decorrer do tratamento, a necessidade de intervenção cirúrgica foi descartada. Discussão: A TCFC permite a visualização de uma imagem tridimensional, possuindo como vantagens uma melhor visualização e delimitação das estruturas anatômicas ou patologias que acometam os tecidos duros dentais ou perirradiculares, sendo de grande importância seu uso no diagnóstico em Endodontia $^{1,2}$. Conclusão: Concluiu-se que o uso da TCFC na endodontia parece ser vantajoso permitindo maior detalhamento da imagem, gerando informações para o correto diagnóstico, planejamento e meio de proservação.

Descritores: Abscesso periapical; Endodontia; Tomografia Computadorizada de Feixe Cônico.

\section{Referências:}

1. COSTA FF, et al. Influence of cone-beam computed tomographic scan mode for detection of horizontal root fracture. Journal of Endodontics, 2014; 40(9): 1472-1476.

2. METSKA ME, et al. Detection of vertical root fractures in vivo in endodontically treated teeth by cone-beam computed tomography scans. Journal of Endodontics, 2012; 38: 13441347.

3. PAVELSKI M, et al. Paraendodontic surgery: case report. Revista Gaúcha de Odontologia, 2016; 64(4): 460-466. 


\section{FC-18-2019 - USO DO LASER COMO COADJUVANTE NA REPARAÇÃO ÓSSEA E NA IMPLANTODONTIA}

Pedro Henrique Barbosa de Melo ${ }^{1}$; Eduardo Vinícius de Souza Silva ${ }^{1}$; Fernanda Teles Pereira ${ }^{1}$; Lynn Morena Tavares Maciel $^{1}$; Marleny Elizabeth Márquez de Martínez Gerbi ${ }^{1}$; Sinval Vinícius Barbosa do Nascimento ${ }^{1}$; Lara Marques Magalhães Moreno ${ }^{1}$

${ }^{1}$ Faculdade de Odontologia de Pernambuco - Camaragibe - PE - Brasil

Autor correspondente:

Pedro Henrique Barbosa de Melo

peduhmelo@gmail.com

Introdução: $\mathrm{O}$ uso de implante é um grande aliado na reabilitação oral, porém alguns fatores precisam ser levados em conta para esse tipo de reabilitação, como a regeneração e saúde do periodonto. O Laser de Baixa Potência (LBP), quando utilizado nos parâmetros adequados tem sido um bioestimulador para aceleração tecidual ${ }^{1}$. Objetivo: Este trabalho objetiva, através de uma revisão de literatura, demonstrar a importância e efeitos clínicos satisfatórios do dos diversos tipos de Laseres nos tratamentos de implantes dentários. Metodologia: Foi realizado busca no banco de dados MEDLINE (via PubMed) de artigos entre os anos de 2009 a 2019 usando os descritores dental implantation, laser therapy e bone regeneration. Dos 23 artigos encontrados, 10 foram selecionados e usados para o estudo. Revisão de literatura: $\mathrm{O}$ uso da Fotobiomodulação Laser, através do LBP, além de ser uma alternativa para a redução da dor, inflamação e edema pós-implante, promove um pós-operatório mais confortável, favorecendo o imbricamento ósseo mecânico mais rápido e antecipando a colocação da supra-estrutura ${ }^{2}$. Também é encontrada na literatura a aplicação do Laser antes do uso de enxerto, assim a remodelação óssea ocorre quantitativa e qualitativamente melhor ${ }^{3}$. Conclusão: Tendo em vista a complexidade do processo de reparação tecidual, da adaptação de um implante dentário, da saúde dos tecidos periimplantares e da osseointegração, a Fotobiomodulação Laser, através de LBP, se mostrou uma importante aliada ao tratamento reabilitador do implante dentário.

Descritores: Implante Dentário; Terapia a Laser; Regeneração Óssea.

\section{Referências:}

1. MAYER L, et al. Peri-implant osseointegration after low-level laser therapy: microcomputed tomography and resonance frequency analysis in an animal model. Lasers Med Sci, 2016; 31(9):1789-1795

2. QUERIDO M. Implantes Osseointegrados: inovando soluções. São Paulo: Artes Médicas, 2004; 529p

3. SOARES LGP, et al. New bone formation around implants inserted on autologous and xenografts irradiated or not with IR laser light: a histomorphometric study in rabbits. Braz Dent J, 2013; 24(3):218-223 

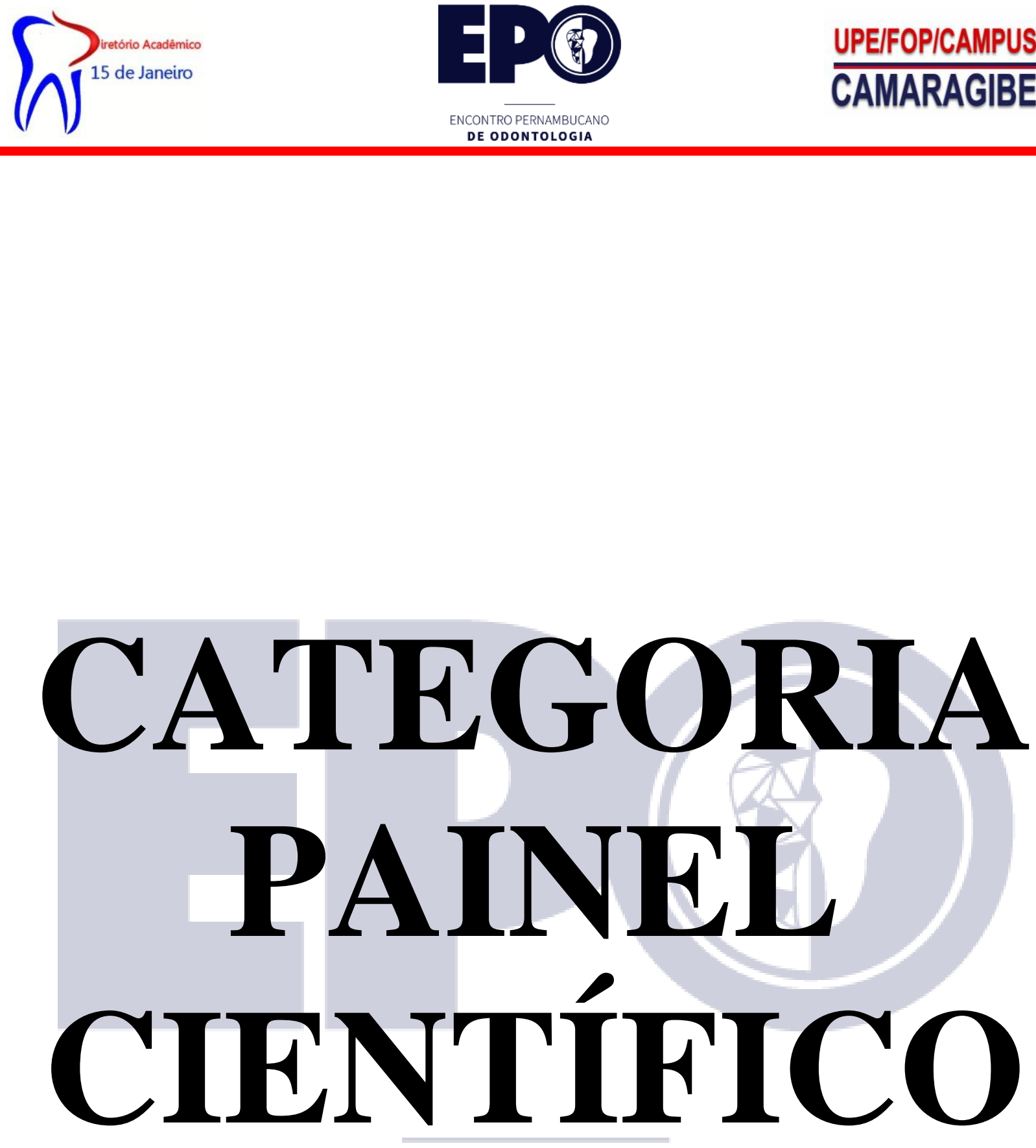

ENCONTRO PERNAMBUCANO 


\section{PC-01-2019 - A AÇÃO DAS PROTEÍNAS SALIVARES NO DESENVOLVIMENTO DO BIOFILME DE CANDIDA ALBICANS}

Aylanne Xavier de Lacerda Cavalcante Timoteo ${ }^{1}$; Ada Caroline Soares Ferreira ${ }^{1}$; Carolaine Rayane Xavier da Silva ${ }^{1}$; Emerllyn Shayane Martins de Araújo ${ }^{1}$; Ingrid Patrícia de Moraes Lima $^{1}$; Kássia Regina de Santana ${ }^{1}$; Ycaro Lopes Briano²; Eliana Santos Lyra da Paz ${ }^{1}$

${ }^{1}$ Faculdade de Odontologia de Pernambuco - Camaragibe - PE - Brasil

${ }^{2}$ Universidade Federal de Pernambuco - Caruaru - PE - Brasil

Autor correspondente:

Aylanne Xavier de Lacerda Cavalcante Timoteo

aylannel@gmail.com

Introdução: $O$ acúmulo de substâncias da saliva, restos celulares e bactérias da microbiota oral que se sobrepõem a algumas estruturas bucais é o que se caracteriza como biofilme. Entretanto, existem alguns micro-organismos fúngicos que têm a capacidade de produzir biofilme, um deles é a Candida albicans. Essa espécie apresenta elevada capacidade de formação de biofilmes, o que propicia sua adesão aos tecidos do hospedeiro. Alguns autores sugerem que a maioria das infecções causadas por C. albicans esteja associada a biofilmes ${ }^{2}$. Objetivo: Este trabalho tem por objetivo realizar uma revisão de literatura sobre a ação das proteínas salivares no desenvolvimento do biofilme de Candida albicans. Metodologia: Foi efetuada uma pesquisa nas bases de dados da SciELO, Medline e Google acadêmico. Revisão de literatura: Estudos prévios demonstraram que alterações na cavidade bucal como variações do conteúdo proteico nos fluídos orais, podem modular positivamente a virulência de biofilmes orais ${ }^{2}$. Sabe-se que a capacidade da C. albicans em formar biofilme é um importante fator de virulência. $\mathrm{O}$ desenvolvimento dos biofilmes está associado com um aumento na presença de matriz extracelular de polissacarídeos, a qual se sabe que interage com os produtos antimicrobianos e contribui para o aumento da resistência a drogas ${ }^{3}$. A histatina 5, estaterina, lactoferrina e mucina são proteínas salivares que apresentam propriedades antifúngicas. Logo, alterações que diminuam ou inibam a secreção dessas substâncias favorecem ao aparecimento de infecções fúngicas. Conclusão: Portanto, é possível perceber que uma cavidade bucal em equilíbrio, com a liberação fisiológica normal de suas proteínas possuem chances menores de sofrerem com infecções fúngicas.

Descritores: Placa dentária; Microbiologia; Candida albicans.

\section{Referências:}

1. CARDOSO B. Produção de biofilme e perfil de susceptibilidade a antifúngicos de isolados de Candida spp em episódios de candidemia no Hospital das Clínicas da FMRP-USP. Dissertação (Mestrado em biociência aplicada a farmácia) - Faculdade de Ciências Farmacêuticas de Ribeirão Preto. Universidade de São Paulo, Ribeirão Preto, 2017; 97 p

2. CUSTODIO W. Influência das proteínas salivares e plasmáticas no desenvolvimento de biofilmes de Candida albicans. Tese (Doutorado em clínica odontológica) - Faculdade de Odontologia de Piracicaba. Universidade Estadual de Campinas, Piracicaba, 2012; 127 p

3. MOFFA EB. Ação da histatina 5, uma proteína antimicrobiana, no desenvolvimento de biofilmes de Candida Albicans. Tese (Doutorado em Reabilitação oral) - Faculdade de Odontologia de Araraquara. Universidade Estadual Paulista, Araraquara, 2015; 78p 


\section{PC-02-2019 - A FLUORETAÇÃO DA ÁGUA COMO MEDIDA DE VIGILÂNCIA EM SAÚDE BUCAL}

Mariana Renata Camilo da Silva ${ }^{1}$; Carolina Pereira da Silva ${ }^{1}$; Heitor Tavares de Araújo ${ }^{1}$; Lucas Rafael Borges Santos ${ }^{1}$; Bruna Lucena Borges ${ }^{1}$; João Victor Neves Barbosa ${ }^{1}$; Normando Carlos da Silva Júnior ${ }^{1}$; Jéssica da Silva Cunha²

${ }^{1}$ Faculdade de Odontologia de Pernambuco - Camaragibe - PE - Brasil

${ }^{2}$ Hospital da Restauração Governador Paulo Guerra/SES - Recife - PE - Brasil

Autor correspondente:

Mariana Renata Camilo da Silva

Marianacamilo97@gmail.com

Introdução: A fluoretação da água de abastecimento público é uma tecnologia de saúde pública que consiste em ajustar a concentração do fluoreto na água com a finalidade de prevenir a cárie dentária em nível populacional. Por sua efetividade, segurança e baixo custo, a ação tem sido recomendada por importantes instituições científicas e sanitárias como a Federação Dentária Internacional (FDI), a International Association for Dental Research (IADR), a Organização Europeia de Pesquisas sobre a Cárie (ORCA) e a Organização Mundial da Saúde (OMS), devendo ser implementada e mantida onde for possível ${ }^{1}$. Objetivo: apresentar uma revisão da literatura sobre aspectos da fluoretação da água para ingestão como medida de vigilância em saúde. Metodologia: Realizou-se cruzamento dos descritores selecionados e escolheu-se 10 artigos publicados entre 2015 e 2019, encontrados nos periódicos das bases de dados LILACS, PubMed e SciELO. Revisão de Literatura: Representa umas das principais e mais importantes medidas de saúde pública, podendo ser considerada como uma medida de controle de cárie dentária efetiva e de ótima relação custo-benefício. Entretanto, para que a população se beneficie dos efeitos dessa importante medida, faz-se necessário que os teores de Flúor adicionados à água de abastecimento estejam dentro dos níveis recomendados ${ }^{2}$. O Brasil dispõe de um instrumento legal que ampara a fluoretação (uma tecnologia de saúde pública eficaz para prevenir a cárie dentária em nível populacional): a Lei Federal n. 6.050/1974. Como não há objeções científicas, o país deveria proteger tal instrumento ${ }^{3}$. Conclusão: No Brasil, desde 1977, a vigilância e o controle da qualidade da água são uma atribuição do setor saúde, a Lei n. 6.050/1974 tornou-se referencial jurídico importânte para a implantação dessa medida em milhares de municípios. Consequentemente, beneficia milhões de brasileiros, ultrapassando as limitações de acesso a ações de prevenção individuais e a assistência odontológica ${ }^{3}$.

Descritores: Fluoretação da água; Vigilância em saúde; Saúde Pública.

\section{Referências:}

1. ESPOSTI CDD, FRAZÃO P. O relevante papel da vigilância para assegurar a efetividade da fluoretação da água de abastecimento público. Revista Brasileira de Pesquisa em Saúde, 2016; 17(2): 4-6

2. UCHIDA TH, et al. Heterocontrole da fluoretação da água de abastecimento público da $15^{\mathrm{a}}$ Regional de Saúde do Paraná. Revista de Saúde Pública do Paraná, 2018; 1(1): 59-67

3. ZILBOVICIUS C, et al. Água e saúde: fluoretação e revogação da Lei Federal n. 6.050/1974.

Revista de Direito Sanitário, 2018; 18(3): 104-124 


\section{PC-03-2019 - A IMPORTÂNCIA DA HUMANIZAÇ̃̃O NO ATENDIMENTO ODONTOLÓGICO: REVISÃO DE LITERATURA}

Beatriz da Silva Lemos ${ }^{1}$; Kewry Nunes do Nascimento ${ }^{1}$; Thawan Lucas Rodrigues Mendonça ${ }^{1}$; Isabella Maria da Silva Lemos ${ }^{1}$; Yuri Victor Dias de Oliveira ${ }^{1}$; Brunna Stephanne Silvestre Sales$^{1}$; Iale Ferreira de Godoy ${ }^{1}$; Ivoneide Maria de Melo Zimmermann ${ }^{1}$

${ }^{1}$ Universidade Federal de Odontologia de Pernambuco - Recife - PE - Brasil

Autor correspondente:

Beatriz da Silva Lemos

singerbeatriz@gmail.com

Introdução: A humanização é definida como ato de humanizar, tornar afável e tratável e vem sendo preconizada como essencial no processo de formação do cirurgião-dentista ${ }^{1}$. A consulta é um momento de grande significado emocional para o paciente devido à intimidade do processo. Então, existe a necessidade da conscientização de que o trabalho do dentista deve ser revestido de um caráter mais humanizado e acolhedor ${ }^{3}$. Objetivo: Mensurar a importância da humanização no atendimento odontológico, como também na relação de confiança entre o cirurgião-dentista e paciente. Metodologia: Foram utilizadas as bases de dados: Google Acadêmico, LILACS, SciELO com os descritores: Serviços de saúde; Humanização; Odontologia. Revisão de Literatura: Nos serviços de saúde, a supervalorização do tecnicismo e da ciência implica uma negligência à atitude humanista. Todavia, o conhecimento da subjetividade dos pacientes quanto ao atendimento é de fundamental importância para uma boa evolução do tratamento a ser realizado ${ }^{2}$. A relação paciente/profissional abrange uma série de aspectos subjetivos que vão além do tratamento odontológico, pois humanizar o atendimento não é apenas chamar o paciente pelo nome ou recebê-lo com um sorriso, mas também compreender seus medos, angústias, incertezas, dando-lhes apoio e atenção permanentes ${ }^{1}$. Acredita-se que num futuro próximo esse sentimento seja minimizado em virtudes das novas políticas de humanização nos serviços de saúde ${ }^{3}$. Conclusão: As pessoas procuram profissionais capazes tecnicamente, mas almejam também o aspecto humano nas relações sociais ${ }^{1}$. Portanto, é necessário dar um significado humanístico à prática odontológica, pois, quanto mais o profissional é acolhedor, mais agradável é a visita ao dentista, possibilitando uma relação de confiança entre o paciente e o profissional como também a efétividade de um tratamento qualificado.

Descritores: Serviços de saúde; Humanização; Odontologia.

\section{Referências:}

1. CANALLI CSE, GONÇALVES SS.A humanização na Odontologia: uma reflexão sobre a prática educativa. Revista Brasileira de Odontologia, 2011; 68(1): 44-48

2. LIMA ENA, SOUZA ECF. Percepção sobre ética e humanização na formação odontológica. Revista Gaúcha de Odontologia, 2010; 58(2): 231-238

3. MOTA LQ, et al. Humanização no atendimento odontológico: acolhimento da subjetividade dos pacientes atendidos por alunos de graduação em Odontologia. Arquivos em Odontologia, 2012; 48(3): 151-158 


\section{PC-04-2019 - A IMPORTÂNCIA DO ATENDIMENTO ODONTOLÓGICO ÀS GESTANTES: REVISÃO DE LITERATURA}

Raiane Antônia de Andrade ${ }^{1}$; Lorena de Macêdo Silva ${ }^{2}$; Maria Cecília Freire de Melo ${ }^{3}$; Millena Mirella Silva de Araújo ${ }^{3}$; Jaciel Leandro de Melo Freitas; ${ }^{3}$ Paulo Cardoso Lins Filho ${ }^{3}$; Arnaldo de França Caldas Júnior ${ }^{2,3}$; Elizabeth Louisy Marques Soares da Silva ${ }^{3}$

${ }^{1}$ Centro Universitário Maurício de Nassau - Recife - PE - Brasil

${ }^{2}$ Faculdade de Odontologia de Pernambuco - Camaragibe - PE - Brasil

${ }^{3}$ Universidade Federal de Pernambuco - Recife - PE - Brasil

Autor correspondente:

Raiane Antônia de Andrade

raianeandrade.22@gmail.com

Introdução: As gestantes são consideradas pacientes especiais por se enquadrarem no grupo de risco de doenças bucais e pelo fato de apresentarem alterações físicas, biológicas e hormonais ${ }^{2}$. Objetivo: Realizar uma revisão de literatura acerca do atendimento odontológico às gestantes. Metodologia: Trata-se de uma revisão de literatura utilizando as bases de dados da Biblioteca Virtual de Saúde, SciELO e PubMed, com artigos publicados no período de 20142019, utilizando os descritores: gestantes, assistência odontológica, saúde bucal. Revisão de literatura: Ainda existem muitos mitos a respeito da assistência odontológica durante a gravidez, além de barreiras a serem enfrentadas, prejudicando a saúde bucal dessas pacientes ${ }^{2}$. É necessário que o Cirurgião-Dentista tenha domínio das principais alterações bucais que acometem este grupo específico ${ }^{3}$. Além disso, o profissional deve conhecer as peculiaridades de cada período da gestação, para que dessa forma possa conduzir o tratamento de forma adequada $^{2,4}$. Também é necessário o conhecimento sobre as medicações, sabendo os riscos e efeitos prejudiciais para o feto e a mãe $e^{3,4}$. Conclusão: Em síntese, a literatura estudada aponta para a necessidade de educação em saúde bucal, visando assim desmistificar diversas crenças do senso comum sobre o atendimento odontológico no período gestacional. No pré-natal odontológico é de extrema importância o profissional conhecer a paciente de forma abrangente, sendo assim ideal um atendimento multidisciplinar, promovendo saúde para a gestante e seu bebê.

Descritores: Gestantes; Assistência Odontológica; Saúde Bucal.

\section{Referências:}

1. BARBIERI W, et al. Fatores sociodemográficos associados ao grau de conhecimento em saúde bucal de gestantes. Einstein (São Paulo), 2018; 16(1): 1-8

2. LAMPERT L, BAVARESCO CS. Atendimento odontológico à gestante na atenção primária à saúde: revisão de literatura. Revista saúde \& ciência online, 2017; 6(2): 81-112

3. MATSUBARA AS, DEMETRIO ATW. Atendimento odontológico às gestantes: revisão da literatura. Revista UNINGÁ Review, 2018; 29(2): 42-47

4. RODRIGUES F, et al. Anestesia local em gestantes na odontologia contemporânea/Local anesthesia in pregnant women in contemporary dentistry/La anestesia local en mujeres embarazadas en la odontología contemporánea. Journal Health NPEPS, 2017; 2(1): 254-271 


\section{PC-05-2019 - A IMPORTÂNCIA DO PREENCHIMENTO E ARMAZENAMENTO CORRETO DO PRONTUÁRIO ODONTOLÓGICO: UMA REVISÃO DE LITERATURA}

Isabella Maria da Silva Lemos ${ }^{1}$; Beatriz da Silva Lemos ${ }^{1}$; Gabriela Miranda de Paula ${ }^{1}$; Kewry Nunes do Nascimento ${ }^{1}$; Sérgio Ricardo Silveira Leite ${ }^{1}$; Yuri Victor Dias de Oliveira ${ }^{1}$; Ivoneide Maria de Melo Zimmermann ${ }^{1}$, Rogério Dubosselard Zimmermann ${ }^{1}$

${ }^{1}$ Universidade Federal de Pernambuco - Recife - PE - Brasil

Autor correspondente:

Isabella Maria da Silva Lemos

isabellamlemos@gmail.com

Introdução: O prontuário odontológico é o conjunto de documentos ordenados, sistematizados e concisos que permitem em qualquer tempo comprovar o diagnóstico e tratamento empreendido ao paciente ${ }^{4}$. Objetivo: Analisar os aspectos éticos e legais que envolvem a confecção e guarda do prontuário odontológico. Metodologia: Trata-se de uma revisão sistemática de livros disponíveis nas bibliotecas de uma universidade de Pernambuco e dos artigos publicados em português entre os anos de 2010 e 2016 nas bases SciELO, LILACS, Google Acadêmico, utilizando-se como descritores: Odontologia Legal; Registros odontológicos; Ética. Revisão de literatura: Ainda que os procedimentos odontológicos sejam realizados de forma correta, ele pode não ocorrer com o preenchimento e armazenamento dos prontuários odontológicos ${ }^{2}$. Esse prontuário deve ser elaborado de forma adequada e criteriosa pelo cirurgião dentista podendo ser modificado ou adaptado à sua maneira seguindo as bases legais. Ele é composto por ficha de anamnese, exame clínico extra e intra-oral, radiografias, moldagens, plano de tratamento e atestados ${ }^{1}$. Além da importância clínica esses documentos têm importância legal, pois podem fornecer informações precisas às perícias odontológicas para identificação de cadáver, bem como respaldar o cirurgião dentista frente a um processo de responsabilidade profissional ${ }^{3}$. É importante não apenas o preenchimento cauteloso desse prontuário, mas também o armazenamento cuidadoso, visto que de acordo com o Código de ética Odontológica art. 18 inciso I constitui infração ética negar ao paciente ou periciado o acesso ao seu prontuário quando solicitado ${ }^{1}$. Conclusão: $O$ prontuário odontológico é o melhor instrumento de defesa do profissional em casos de reclamação quanto aos tratamentos executados, tanto em processos éticos como outras esferas judiciais. Portanto os profissionais devem manter esses registros completos, atualizados e armazenados cuidadosamente.

Descritores: Odontologia Legal; Registros odontológicos; Ética.

\section{Referências:}

1. BENEDICTO EM, et al. A importância da correta elaboração do prontuário odontológico. Odonto, 2010; 18(36): 41-50

2. BUENO AC, et al. Elaboração do prontuário odontológico. Revista Gestão \& Saúde, 2017; 19(2): $35-42$

3. SILVA CHF, et al. Papel da odontologia legal na identificação de corpos post mortem e a sua contribuição no âmbito jurídico: uma revisão de literatura. Revista Expressão Católica (Saúde), 2016; 1(1): 113-119

4. SILVA M, et al. Deontologia ética e legislação odontológica. São Paulo: Santos Editora, 2011; 592p 


\section{PC-06-2019 - A INTUBAÇÃO SUBMENTONIANA COMO MEDIDA ALTERNATIVA}

José Matheus Lima Ramos ${ }^{1}$; Carolina Pereira da Silva ${ }^{1}$; Heitor Tavares de Araújo ${ }^{1}$; Francisco Henrique Lima Milhomens ${ }^{1}$; Marcela Lins Braga ${ }^{1}$; Silas Cardoso Bezerra ${ }^{1}$; Wallacy Bruno Morais de Oliveira Silva ${ }^{1}$; Eugênia Leal de Figueiredo ${ }^{1}$

${ }^{1}$ Faculdade de Odontologia de Pernambuco - Camaragibe - PE - Brasil

Autor correspondente:

José Matheus Lima Ramos

matheuslima.lima046@gmail.com

Introdução: No tratamento das fraturas faciais, vários diferentes métodos de intubação são utilizados para o manejo das vias aéreas. Em casos de múltiplas fraturas faciais, nos quais a intubação oral e a nasal são contraindicadas e quando há necessidade de bloqueio maxilomandibular no transoperatório pelas injúrias presentes nessa região, a intubação submentoniana mostra-se segura e eficaz ${ }^{3,4}$. Objetivo: Apresentar uma técnica alternativa de intubação em operações que envolvem injúrias que contraindicam a intubação oral e nasal. Metodologia: Foi realizado um cruzamento dos descritores selecionados e escolheu-se alguns artigos encontrados nos periódicos das bases de dados LILACS, PubMed e SciELO. Revisão de literatura: $O$ procedimento consiste em após a intubação orotraqueal convencional, realizase uma incisão de aproximadamente 2 centímetros de extensão em pele, na região mediana submental diretamente posterior e paralela à borda inferior da mandíbula, seguida de divulsão romba dos tecidos e a passagem do tubo através do acesso. Além de ser uma técnica de fácil execução, possui uma menor morbidade quando comparada à traqueostomia e as complicações são $\operatorname{raras}^{1,3}$. Conclusão: A técnica mostra-se segura e eficaz para manter as vias aéreas no manejo de pacientes com múltiplas fraturas na face; possui mínimas complicações e riscos, e é de fácil execução quando comparada à traqueostomia ${ }^{2,4}$.

Descritores: Intubação; Respiração; Traqueostomia.

\section{Referências:}

1. NETO ADA, et al. Intubação submentoniana nas fraturas complexas do terço médio facial - relato de caso. Full Dentistry In Science, 2016; 7(26): 53-57

2. NUNES RR, et al. Intubação por via submentoniana em pacientes com fraturas múltiplas da face. Revista Brasileira de Anestesiologia, 1998; 48(1): 37-42

3. ROCHA NS, et al. Intubação submentoniana para o manejo das vias aéreas em paciente politraumatizado de face: relato de caso e revisão de literatura. Revista de Cirurgia e Traumatologia Buco-maxilo-facial, 2006; 6(3): 47-52

4. VALE DS, et al. Intubación submentoniana en cirugía buco-maxilofacial. Revista de Cirurgia e Traumatologia Buco-maxilo-facial, 2012;12(2): 13-18 


\section{PC-07-2019 - A QUEILOSCOPIA COMO MÉTODO DE IDENTIFICAÇÃO HUMANA: REVISÃO DE LITERATURA}

Hugo Igor Rodrigues de Barros ${ }^{1}$; Arthur Alves Thomaz de Aquino ${ }^{1}$; Caio Henrique Ribeiro de Lima $^{1}$; Carolina Pereira da Silva ${ }^{1}$; Cleiton Rone dos Santos Lima ${ }^{1}$; Fernanda Gomes Barros ${ }^{1}$; Heitor Tavares de Araújo ${ }^{1}$; Rosa Rayanne Lins de Souza ${ }^{2}$

${ }^{1}$ Faculdade de Odontologia de Pernambuco - Camaragibe - PE - Brasil

${ }^{2}$ Hospital da Restauração Governador Paulo Guerra - Recife - PE - Brasil

Autor correspondente:

Hugo Igor Rodrigues de Barros

Hu_hugo_@hotmail.com.br

Introdução: A Queiloscopia tem por definição o estudo dos lábios, suas características (como grossura, posição do sulco e estrias) e o registro das impressões deixadas por eles ${ }^{2}$. Objetivo: Este trabalho visa avaliar a efetividade da queiloscopia na identificação humana. Metodologia: Foi realizada uma busca bibliográfica com artigos disponíveis no LILACS, PubMed e Bireme, publicados entre 2009 e 2019, com os termos "Identificação Humana", "Lábio" e "Odontologia Legal". Revisão de Literatura: Em investigações criminais, a relação de pessoas com a cena do crime pode ser constatada através de impressões labiais visíveis no ambiente ${ }^{2}$. E para a odontologia forense, a cavidade bucal tem um importante papel devido a sua anatomia única. Nos lábios, por exemplo, existem variações na disposição das linhas e fissuras, sendo específicas e permanentes para cada indivíduo e que raramente se modificam, pois resistem a pequenos traumas, como inflamações e lesões herpéticas ${ }^{3,2}$. Porém, a queiloscopia é uma técnica que exige atenção no quesito da classificabilidade, pois, a minuciosidade dos sulcos e subjetividade de predominância requerem calibração efetiva para que a confiabilidade da pesquisa seja mantida ${ }^{1}$. Impressões latentes também podem ser reveladas empregando-se substâncias químicas específicas, como pó de nitrato de prata e de alumínioº ${ }^{2}$ Conclusão: Constatou-se que a literatura é um pouco escassa em trabalhos nesta área, mas que a aplicação da Queiloscopia, mesmo exigindo uma atenção considerável durante a sua realização, mostrase eficaz para a identificação de pessoas ${ }^{2}$.

Descritores: Identificação Humana; Lábio; Odontologia Legãl.

\section{Referências:}

1. FERNANDES LCC, et al. A queiloscopia na identificação humana: o papel da calibração. Revista Brasileira de Odontologia Legal, 2017; 4(1): 25-33

2. HERRERA LM, et al. Identificação humana por meio da queiloscopia convencional e digital: um estudo da literatura. Revista Gaúcha de Odontologia, 2013; 61(1): 113-120

3. LIMA MVFN, et al. Verificação da praticabilidade e da unicidade na queiloscopia e palatoscopia como métodos de identificação humana. Revista Brasileira de Odontolologia Legal, 2016; 3(1): 5-14 


\title{
PC-08-2019 - A RELAÇÃO DO USO DOS BISFOSFONATOS COM A OSTEONECROSE DOS MAXILARES: REVISÃO DE LITERATURA
}

\begin{abstract}
Iasmin Cirino da Silva ${ }^{1}$; Ademir Félix Arantes Júnior ${ }^{1}$; Carolaine Rayane Xavier da Silva ${ }^{1}$; Girlane Iris da Silva ${ }^{1}$; Iasminy de Almeida Torres ${ }^{1}$; Maíra Letícia Ferreira de Santana ${ }^{1}$; Joyce Feitosa Pinho Gomes ${ }^{1}$; Bruno da Silva Mesquita ${ }^{1}$
\end{abstract}

${ }^{1}$ Faculdade de Odontologia de Pernambuco - Camaragibe - PE - Brasil

Autor correspondente:

Iasmin Cirino da Silva

iasmincirino@gmail.com

Introdução: Os bisfosfonatos têm sido amplamente indicados aos tratamentos de lesões ósseas como a osteoporose e metástases tumorais. O uso crônico deste medicamento pode causar a osteonecrose dos maxilares, principalmente, em pacientes submetidos à exodontias ${ }^{2}$. Objetivo: O objetivo deste estudo visa associar o uso dos bisfosfonatos com a osteonecrose dos maxilares por meio de uma breve revisão de literatura. Metodologia: Foi efetuada uma pesquisa nas bases de dados SciELO e Scholar Google, com estudos publicados entre os anos 2006 e 2017 e utilizando os seguintes descritores: Osteonecrose; bisfosfonatos; doenças maxilares. Revisão de literatura: Os bisfosfonatos diminuem a reabsorção óssea ao inibirem o recrutamento dos osteoclastos e promoverem a sua apoptose. Com o decréscimo da atividade osteoclástica, ocorre o bloqueio da liberação de fatores de crescimento $^{2}$. A remodelação óssea fica comprometida tornando-se frágil e quebradiça ${ }^{1}$. A osteonecrose dos maxilares associada ao uso de bisfosfonatos tem sido relatada principalmente em pacientes submetidos a intervenções odontológicas invasivas, como as exodontias ${ }^{2}$. Conclusão: Por se tratar de uma condição nova, ainda não existe um protocolo de tratamento definido. Os pacientes que necessitam o uso dos bisfofonatos devem ser submetidos a um exame odontológico criterioso, no qual todos os procedimentos necessários sejam realizados previamente ao seu uso. Além disso, é importante considerar a possibilidade de substituição do medicamento, observando o estado geral do paciente e a relação risco-benefício.

Descritores: Osteonecrose; Bisfosfonatos; Doenças Maxilares.

\section{Referências:}

1. BROZOSKI MA, et al. Osteonecrose maxilar associada ao uso de bisfosfonatos. Revista Brasileira de Reumatologia, 2012; 52(2): 260-270

2. GEGLE A, et al. Bisfosfonatos e osteonecrose maxilar: revisão da literatura e relato de dois casos. Revista Brasileira de Cancerologia, 2006; 52(1): 25-31.

3. MENEGHINI LS, et al. Avaliação de fatores de risco para osteonecrose em pacientes usuários de bifosfonatos no HUCAM/UFES. Revista Periodontia, 2017; 27(2): 07-16 


\section{PC-09-2019 - A SÍFILIS E SUAS MANIFESTAÇÕES BUCAIS: RELATO DE CASO CLÍNICO}

Liana Carla Souza de Andrade Batista ${ }^{1}$; Letícia de Oliveira Santos ${ }^{1}$; Maria de Fátima Texeira Lemos de Souza ${ }^{1}$; Mariana Cecília de Oliveira Terêncio ${ }^{1}$; Nycole Valois Rocha Viera da Silva ${ }^{1}$; Ronaldo de Carvalho Raimundo ${ }^{1}$; Márcia Maria Fonseca da Silveira ${ }^{1}$; Vânia Cavalcanti Ribeiro da Silva ${ }^{1}$

${ }^{1}$ Faculdade de Odontologia de Pernambuco - Camaragibe - PE - Brasil

Autor correspondente:

Liana Carla Souza de Andrade Batista

lianabatist20@gmail.com

Introdução: A sífilis é uma doença sistêmica, exclusiva do ser humano, causada pela bactéria Treponema pallidum. Pode acometer qualquer órgão do corpo e se não tratada adequadamente pode resultar em problemas neurológicos, cardiovasculares e ósseos ${ }^{2}$. Suas principais vias de transmissão são a vertical e a sexual, embora também possa acontecer através de objetos contaminados $^{2}$. Apresenta manifestações clínicas diversas, sendo incomum a existência de lesões em cavidade bucal ${ }^{2,3}$. Objetivo: Apresentar o caso clínico de um paciente portador de sífilis cujo diagnóstico foi estabelecido a partir das lesões bucais. Relato de caso: Paciente do sexo masculino, 26 anos de idade, procurou a clínica de estomatologia da FOP/UPE por apresentar lesões múltiplas, irregulares, esbranquiçadas, localizadas em palato, lábios, mucosa jugal e língua. Exibia também linfonodo palpável em região submentoniana. Com hipótese clínica de doença sexualmente transmissível, foram solicitados exames complementares. $\mathrm{O}$ paciente apresentou positividade ao VDRL e ao teste de Mantoux. Encaminhado à clínica médica, foi submetido a testes específicos que confirmaram o diagnóstico de sífilis. O paciente foi tratado com a Penicilina G Benzatina, 2,4 milhões UI, via intramuscular, com aplicações semanais, por três semanas. Logo após as primeiras doses, apresentou regressão total das lesões bucais. Discussão: A sífilis é uma doença milenar, mas ainda hoje considerada um problema de saúde pública. Dados da Organização Mundial de Saúde revelam que mais de 12 milhões de pessoas são acometidas pela infecção em todo o mundo ${ }^{1}$. O desafio reside na multiplicidade de manifestações clínicas que podem dificultar o reconhecimento da doença ${ }^{4}$. Conclusão: Embora a cavidade bucal não seja frequentemente acometida por lesões de sífilis, ela se constitui numa das localizações extragenitais mais frequentes da doença. $\mathrm{O}$ exame clínico detalhado associado à solicitação de exames sorológicos são fundamentais para o estabelecimento do diagnóstico, e o cirurgião-dentista deve estar preparado para o reconhecimento das lesões bucais.

Descritores: Súfilis; Manifestações Bucais; Medicina Bucal.

\section{Referências:}

1. BRASIL. Ministério da Saúde. Secretária de Vigilância em Saúde. Departamento de Vigilância, Prevenção e Controle das Infecções Sexualmente Transmissíveis do HIV/Aids e das Hepatites Virais (DIAHV). Boletim Epidemiológico de Sífilis. Brasil: Ministério, 2018

2. KENT ME, Romanelli F. Reexamining syphilis: an update on epidemiology, clinical manifestations, and management. Ann Pharmacother, 2008;42:22-36

3. LITTLE JW. Syphilis: an update. Oral Surg Oral Med Oral Pathol Oral Radiol Endodontol, 2005;100:3-9

4. SOUZA BC. Manifestações clínicas orais da sífilis. Revista Da Faculdade De Odontologia UPF, 2017;22(1):82-85 


\section{PC-10-2019 - ABORDAGEM CIRÚGICA DE ODONTOMA COMPOSTO EM MANDÍBULA: RELATO DE CASO}

Thayane Cavalcante Mendes da Silva ${ }^{1}$; Beatriz Borba Barros Bernardo ${ }^{1}$; Kalyne Kelly Negromonte Gonçalves ${ }^{2}$; Demóstenes Alves Diniz ${ }^{2}$; Arthur Camillo de Souza ${ }^{1}$; Vinicius Balan Santos Pereira ${ }^{1}$; Virgílio Bernardino Ferraz Jardim ${ }^{3}$; Caio César Gonçalves Silva ${ }^{1}$

${ }^{1}$ Faculdade de Odontologia de Pernambuco - Camaragibe - PE - Brasil

${ }^{2}$ Hospital da Restauração - Recife - PE - Brasil

${ }^{3}$ Hospital Universitário Oswaldo Cruz - Recife - PE - Brasil

Autor correspondente:

Thayane Cavalcante Mendes da Silva

thayanecmss@gmail.com

Introdução: O odontoma é um tumor odontogênico benigno de origem epitelial e mesenquimal, sendo o de maior prevalência entre os tumores odontogênicos. São considerados mais como distúrbios de desenvolvimento (hamartomas) do que como neoplasias verdadeiras 1,2. A etiologia dos odontomas ainda é desconhecida, mas acredita-se estar relacionada a traumas, infecção ou pressão no local da formação, causando perturbação no mecanismo genético e controlador do desenvolvimento dentário ${ }^{3}$. Objetivo: Relatar o diagnóstico e tratamento de um odontoma composto. Relato de Caso: Paciente A.V.M., 14 anos, sexo feminino, encaminhada ao Hospital da Face (Recife-PE) com radiografia panorâmica evidenciando massa radiopaca contendo pequenas estruturas calcificadas com radiopacidade semelhante à de estruturas dentárias localizada na região dos dentes 43 e 44 . Ao exame físico apresentava discreto aumento de volume na região lingual do 43 , apinhamento do elemento 43, sem queixa álgica associada. Com base na história clínica e nos achados radiográficos, estabeleceu-se o diagnóstico clínico de odontoma composto. $\mathrm{O}$ tratamento proposto foi remoção cirúrgica sob anestesia local. Cirurgia para enucleação e curetagem ocorreu conforme planejado. A paciente segue em acompanhamento ambulatorial com radiografia panorâmica sugerindo neoformação óssea na área antes ocupada pelo odontoma, sugerindo sucesso da conduta cirúrgica. Discussão: Muitos autores relatam que a idade média no momento do diagnóstico é em torno dos 14 anos, embora possam ser observados ocasionalmente em qualquer idade. Pode-se ainda encontrar na literatura que ambos os tipos de odontoma atingem mais o sexo feminino ${ }^{3}$. Dados que vão de encontro aos apresentados no relato de caso. Conclusões: Odontomas são tumores de fácil diagnóstico clínico, que geralmente são encontrados em exames de rotina e podem causar retenção de dentes permanentes. Seu tratamento de escolha consiste na excisão cirúrgica com curetagem.

Descritores: Odontoma; Tumores Odontogênicos; Anormalidades Dentárias.

\section{Referências:}

1. FREITAS DA, et al. Elemento dental impactado por odontoma composto. Rev. Bras. Cir. Cabeça Pescoço, 2009; 38(3): 198 - 199

2. PIRES LS, et al. Odontoma: estado da arte e relato de caso clínico. Stomatos, 2007; 13(24): 21-29

3. SANTOS MESM, et al. Odontoma como fator de retenção dentária: relato de casos clínicos. Rev. Cir. Traumatol. Buco-Maxilo-Fac., 2010; 10(2): 25-30 


\section{PC-11-2019 - ABORDAGEM CIRURGICA À PACIENTES COM COAGULOPATIAS HEREDITÁRIAS: UMA REVISÃO DE LITERATURA}

Rebeca Gomes da Silva ${ }^{1}$; Miquéias Pereira Lima do Amaral ${ }^{2}$; Gilberto Cunha de Sousa Filho ${ }^{1}$

${ }^{1}$ Universidade Federal de Pernambuco - Recife - PE - Brasil

${ }^{2}$ Centro universitário São Miguel - Recife - PE - Brasil

Autor correspondente:

Rebeca Gomes da Silva

Becaaaag@gmail.com

Introdução: Pacientes com deficiência na coagulação sanguínea hereditária, modificação das proteínas plasmática, isto é, fatores, responsável pela coagulação, apresentam um desafio na clínica odontológica com diversas patologias hemorrágicas existentes, manifestações cirúrgicas e possíveis complicações ${ }^{4}$. Objetivo: Apresentar uma revisão da literatura sobre a abordagem cirúrgica de pacientes que apresentam coagulopatias hereditárias e o manejo na clínica odontológica. Metodologia: Foi realizado um levantamento adotando-se artigos publicados entre 2012 e 2018, na base dos dados Scholar Google com os descritores: transtornos herdados da coagulação sanguínea, procedimentos maxilofaciais e hemostasia cirúrgica. Revisão de literatura: Pacientes portadores de coagulopatias hereditárias representam um desafio para a prática clínica odontológica ${ }^{1}$. Diagnosticada através de uma anamnese detalhada do histórico médico $^{1}$, pacientes acometidos podem apresentar sangramentos ${ }^{2}$. O profissional deve estar atento para um correto protocolo de atendimento, podendo utilizar, nesses casos, vários recursos hemostáticos ${ }^{2}$. Os tratamentos cirúrgicos oferecem riscos para esse tipo de paciente devendo sempre ser discutidos e autorizados pelo hematologista ${ }^{3}$. Evitando ao máximo que haja complicações na conduta clínico-cirúrgica ${ }^{3}$. Extração de terceiros molares devem ser consideradas como procedimento de alto risco de sangramento, com indicação de reposição prévia de concentrados de fatores de coagulação ${ }^{4}$. O controle da dor de origem odontológica deve ser feito com derivados de paracetamol ou dipirona, porém a aspirina e seus derivados são contra-indicados ${ }^{4}$. A anestesia troncular deve ser evitada, dando-se preferência às anestesias infiltrativas, intrapulpar e intraligamentar ${ }^{4}$ A boca é uma região altamente vascularizada, permitindo ao profissional de odontologia ser um dos primeiros a verificar distúrbios da homeostasia ${ }^{5}$. Conclusão: A Conduta do cirurgião-dentista frente aôs problemàs sistêmicos dos pacientes durante cirurgias deve proporcionar segurança ao paciente, sendo necessário conhecimento adequado do cirurgião-dentista sobre o processo de hemostasia bem como atuação integrada com o hematologista a fim proporcionar êxito nas abordagens cirúrgicas.

Descritores: Transtornos Herdados da Coagulação Sanguínea; Procedimentos Maxilofaciais; Hemostasia Cirúrgica.

\section{Referências:}

1. FON BL, et al. Atendimento odontológico em paciente portador de coagulopatia congênita: relato de caso. Revista da Academia Brasileira de Odontologia, 2018; 27(1): 1-8

2. LEITE RB, et al. Conhecimento dos cirurgiões-dentistas em atendimento de pacientes com coagulopatias hereditárias. Revista da Faculdade de Odontologia, 2018; 23(2): 150-155

3. MAGRO AKD, et al. Manejo odontológico de pacientes com coagulopatias - revisão de literatura e relato de caso: síndrome de Bernard Soulier. Revista da Faculdade de Odontologia, 2011; 16(2): 193 199

4. MARQUES RVCF, et al. Atendimento odontológico em pacientes com Hemofilia e Doença de von Willebrand.Arquivos em Odontologia, 2010; 46(3): 176-180

5. SILVA SC, et al. Tratamento Periodontal de Paciente Hemofílico. Revista Brasileira de Ciências da Saúde, 2012; 16(2): 243-248 


\section{PC-12-2019 - ABORDAGEM CIRÚRGICA EM GESTANTE NO TERCEIRO TRIMESTRE DA GESTAÇÃO: RELATO DE CASO}

Pedro Henrique Barbosa de Melo ${ }^{1}$; Lidiane Jacinto do Nascimento ${ }^{2}$; Jéssica Silva Peixoto Bem $^{2}$; Bruna Yasmin de Brito Silva ${ }^{2}$; Fernanda Teles Pereira' ${ }^{1}$; Samuel Rodrigo De Andrade Veras²; Ana Catarina Gaioso Lucas Leite²

${ }^{1}$ Faculdade de Odontologia de Pernambuco - Camaragibe - PE - Brasil

${ }^{2}$ Instituto Instituto de Medicina Integral Professor Fernando Figueira - Recife - PE - Brasil

Autor correspondente:

Pedro Henrique Barbosa de Melo

peduhmelo@gmail.com

Introdução: O granuloma piogênico está classificado, segundo levantamentos epidemiológicos em diversos centros de referência do Brasil, como uma das lesões bucais benignas mais frequentes ${ }^{1}$. Objetivo: Relatar o caso clínico da paciente M.J.A.S, de 28 anos de idade, no oitavo mês de gestação, que procurou o serviço de saúde da Atenção Secundária (UPA) para tratamento de lesão proliferativa em lábio inferior. Relato de caso: A paciente chegou ao serviço com queixa principal de "um sinal que tinha crescido no lábio" durante a gestação. Referiu que procurou outros serviços, mas não teve êxito no tratamento. Preocupada com o crescimento relativamente rápido e o comprometimento estético que lhe causava desconforto para relações interpessoais, procurou o serviço para resolução do caso. Durante a anamnese, foram questionados toda a história pregressa da saúde geral, bem como sobre o prénatal. Ao exame clínico, observou-se uma lesão nodular com crescimento exofítico com aspecto escurecido e ressecado. Foram solicitados exames pré-operatórios e marcado data para retorno. Todos os exames mostraram taxas normais, optou-se por fazer a biópsia excisional da lesão do lábio com envio da peça para histopatológico. A conclusão do histopatológico foi: quadro histológico compatível com granuloma piogênico ulcerado, exibindo hiperplasia digitiforme do epitélio escamoso, com alterações reparativas, reacionais. Discussão: Embora este tumor tenha sido conhecido por regredir espontaneamente dentro de meses após o fim da gravidez, a lesão pode exigir excisão cirúrgica se interferir na mastigação ou ulcerar. Em mais de $5 \%$ das gestantes pode ocorrer durante o segundo trimestre de gestação ${ }^{2,3}$. Conclusões: Este relato de caso, mostra o sucesso de um tratamento cirúrgico de lesão labial em paciente no oitavo mês de gestação mostrando a efetividade do atendimento na UPA, bem como o restabelecimento emocional da gestante após remoção de lesão com interferência estética.

Descritores: Granuloma Piogênico; Gestantes; Terceiro Trimestre da Gravidez.

\section{Referências:}

1. GOMES SR, et al. Pyogenic granuloma of the gingiva: A misnomer? - A case report and review literature. J. Indian Soc. Periodontol, 2013; 17(4):514-519

2. TARSITANO BF, ROLLINGS RE. The pregnant dental patient evaluation and management. GenDent, 1993; 41:226-34

3. VANESSA CP, et al. Atendimento odontológico em gestantes: uma revisão da literatura. Stomatos, 2008; 14(26):64-75 


\section{PC-13-2019 - ABORDAGEM CIRÚRGICA PARA ELEMENTOS SUPRANUMERÁRIOS INCLUSOS POR INDICAÇÃO ORTODÔNTICA}

Thawan Lucas Rodrigues Mendonça ${ }^{\mathbf{1}}$; Isabella Maria da Silva Lemos ${ }^{\mathbf{1}}$; Marcela Nogueira dos Santos²; Kalyne Kelly Negromonte Gonçalves³; Jéssica da Silva Cunha3 ${ }^{3}$ Caio César Gonçalves Silva $^{3}$; Priscilla Sarmento Pinto ${ }^{3}$; Demóstenes Alves Diniz ${ }^{3}$;

${ }^{1}$ Universidade Federal de Pernambuco - Recife - PE - Brasil

${ }^{2}$ Faculdade de Odontologia do Recife - Recife - PE - Brasil

${ }^{3}$ Universidade de Pernambuco - Recife - PE - Brasil

Autor correspondente:

Thawan Lucas Rodrigues Mendonça

thawanlucasr@gmail.com

Introdução: Os dentes seguem uma sequência de erupção favorável no desenvolvimento da oclusão normal, mas algum distúrbio desse mecanismo, nesse período de transição da dentição mista para a permanente, pode levar a alterações na sequência ou mesmo no trajeto de erupção, levando a impactação de dentes, uma dessas alterações é a presença de dentes supranumerários inclusos, havendo, dessa forma, a necessidade de exodontia desses elementos dentários ${ }^{1}$. Objetivo: O presente estudo tem como objetivo relatar um caso clínico de uma paciente, 10 anos, gênero feminino, leucoderma, que procurou o serviço de Cirurgia e Traumatologia BucoMaxilo-Facial do Hospital da Face, Recife-PE. Relato de Caso: Clinicamente apresentava ausência do elemento dentário 21 , foi encaminhada do ortodontista para remoção de elementos dentários impactados em região de pré-maxila. Ao exame de imagem (Tomografia cone bean) evidenciou a presença de 2 dentes supranumerários em palato duro, que causavam impactação do elemento 21. Dessa forma, foi realizado exodontia sob anestesia local dos elementos supranumerários, acesso intrasulcular pela região palatina, para deslocamento de retalho. Discussão: $O$ paciente e/ou responsáveis devem estar cientes das vantagens e riscos do tratamento escolhido, principalmente pois nem sempre é possível realizar o correto tracionamento do dente permanente que está incluso, após a remoção dos supranumerários subjacentes, podendo o mesmo sofrer anquilose, perda da vitalidade, entre outros ${ }^{2}$. Da mesma forma da não opção pelo tratamento e consequente risco de desenvolvimento de lesões patológicas de origens dentárias e movimentações dentárias não previstâs ${ }^{3}$. Conclusão: Paciente segue em acompanhamento ambulatorial BMF e seguimento por tratamento ortodôntico para reabilitação. Dessa forma, fica claro, a importância do diagnóstico prévio de hiperdontias, seu estudo e tratamento para não provocar danos futuros ao paciente sejam eles estéticos ou funcionais.

Descritores: Dente não erupcionado; Cirurgia Bucal; Ortodontia.

\section{Referências:}

1. ALMEIDA RR, et al. Abordagem da impactação e/ou irrupção ectópica dos caninos permanentes: considerações gerais, diagnóstico e terapêutica. Revista Dental Press de Ortodontia e Ortopedia Facial, 2001; 6(1): 93-116

2. CAPPELLETTE $M$, et al. Caninos permanentes retidos por palatino: diagnóstico e terapêutica- uma sugestão técnica de tratamento. Revista Dental Press de Ortodontia e Ortopedia Facial, 2008; 13(1): 60-73

3. JARJOURA K, et al. Maxillary canine impactacions: orthodontic and surgical management. Compendium of Continuing Education in Dentistry, 2002; 23(1): 23-31 


\section{PC-14-2019 - ABORDAGEM CIRÚRGICA PARA TRATAMENTO DE LESÃO CENTRAL DE CÉLULAS GIGANTES: RELATO DE CASO}

Fernanda Gomes Barros ${ }^{1}$; Francisco Henrique Lima Milhomens ${ }^{1}$; Carolina Pereira da Silva ${ }^{1}$; Maria Eduarda Arruda de Lucena ${ }^{1}$; Manuela França Andrade Passos ${ }^{1}$; Maria Beatriz Arruda Albuquerque $^{1}$; Bruna Lucena Borges ${ }^{1}$; Fabricio Souza Landim ${ }^{1}$

${ }^{1}$ Faculdade de Odontologia de Pernambuco - Camaragibe - PE - Brasil

Autor correspondente:

Fernanda Gomes Barros

fernandagomesbarros@hotmail.com

Introdução: A lesão central de células gigantes é um processo patológico incomum, correspondendo a menos de $7 \%$ das lesões benignas que acometem o complexo maxilomandibular ${ }^{3}$. Comumente trata-se de uma lesão assintomática que acomete principalmente crianças e adultos jovens com menos de 30 anos de idade com maior predileção pela mandíbula, acometendo duas vezes mais o sexo feminino ${ }^{1,3}$. Objetivo: O objetivo desse trabalho é relatar através de um caso clínico a abordagem terapêutica de uma lesão central de células gigantes na maxila. Relato de caso: Paciente I.S.R., leucoderma, 74 anos, gênero feminino, apresentou-se no bloco cirúrgico da Faculdade de Odontologia de Pernambuco relatando a presença de uma lesão localizada no palato. A paciente relatou que o crescimento ocorreu de forma assintomática ao longo de seis meses e que apresentava dificuldade para se alimentar. Ao exame clínico, foi possível observar a presença de uma lesão em região do forame nasopalatino, com coloração parda com áreas eritematosas, formato irregular, consistência mole, pediculada e com aspecto de benignidade. Discussão: Devido as características clínicas da lesão, a paciente foi submetida a procedimento cirúrgico sob anestesia local para excisão cirúrgica da lesão através de uma biópsia excisional, que foi levada a análise histopatológica e obteve-se o diagnóstico de lesão central de células gigantes. Conclusões: A lesão central de células gigantes é uma patologia pouco frequente que, apesar de benigna, pode ser altamente destrutiva e o diagnóstico precoce possibilita tratamentos mais eficazes e com menor morbidade ${ }^{1-3}$.

\section{Descritores: Células Gigantes; Patologia; Cirurgia Bủcāl.}

\section{Referências:}

1. NEVILLE BW, et al. Patologia Oral e Maxilofacial. $2^{\mathrm{a}}$ ed. Rio de Janeiro: Guanabara Koogan, 2004; 798p

2. RODRIGUES AC, et al. Lesão central de células gigantes: relato de um caso clínico. Revista da Associação Paulista de Cirurgiões Dentistas, 2012; 66: 167-171

3. SARMENTO DJS, et al. Tratamento cirúrgico de lesão central de células gigantes na maxila: relato de caso. Brazilian Journal of Otorhinolaryngology, 2011; 77: 255- 260 


\section{PC-15-2019 - ACESSO ÀS VIAS AÉREAS NA EMERGÊNCIA ODONTOLÓGICA: REVISÃO DE LITERATURA}

Emerllyn Shayane Martins de Araújo ${ }^{1}$; Camilla Siqueira de Aguiar ${ }^{2}$; Rodrigo Henrique Mello Varela Ayres de $\mathrm{Melo}^{3}$; Bruna Heloísa Costa Varela Ayres de Melo ${ }^{4}$; Frederico Márcio Varela Ayres de Melo Júnior ${ }^{4}$; Victor Leonardo Mello Varela Ayres de Melo²; Marcela Côrte Real Fernandes $^{2}$; Ricardo Eugenio Varela Ayres de Melo ${ }^{2}$

${ }^{1}$ Faculdade de Odontologia de Pernambuco - Camaragibe - PE - Brasil

${ }^{2}$ Universidade Federal de Pernambuco - Recife - PE - Brasil

${ }^{3}$ Prefeitura Municipal de Arroio dos Ratos - Arroio dos Ratos - RS - Brasil

${ }^{4}$ Universidade Maurício de Nassau - Natal - RN - Brasil

Autor correspondente:

Emerllyn Shayane Martins de Araújo

emerllyn_shayane@outlook.com

Introdução: A obstrução aguda das vias aéreas superiores é uma complicação grave e de caráter emergencial no ambulatório, devendo o cirurgião-dentista estar preparado para reverter esse quadro rapidamente, garantindo o suporte básico à vida ${ }^{1}$. Objetivo: Apresentar as manobras de desobstrução e acesso às vias aéreas em ocasiões de emergência, detalhando os procedimentos em ordem de prioridade, indicações e contra-indicações: manobra de Heimlich, jaw thrust, chin lift, cricotireoidostomia, intubação endotraqueal e traqueostomia. Metodologia: Realizou-se a revisão de literatura constando de 90 artigos científicos entre os anos de 1985 e 2014, abordando os aspectos práticos das manobras e procedimentos. Revisão de literatura: A manobra de Heimlich consiste na compressão infradiafragmática em " $L$ " e sua aplicação reduz a incidência de acidentes fatais ${ }^{3}$. A manobra de jaw thrust é caracterizada pela protrusão da mandíbula, enquanto na chin lift realiza-se a hiperextensão cervical e elevação do mento. A cricotireoidostomia é um procedimento invasivo que consiste na criação de uma abertura através da membrana cricotireoidea, entre as cartilagens tireoidea e cricoide ${ }^{2}$. A intubação endotraqueal garante o fluxo do ar nas vias aéreas por meio da aposição de uma cânula por via oral ou nasal. A traqueostomia consiste em um procedimento cirúrgico para a criação de uma abertura na traqueia, realizada entre o $2^{0}$ e o $3^{0}$ anel traqueal ${ }^{3}$. Conclusão: A manobra de Heimlich é eleita como primeira alternativa nas situâções de sufocamento e obstrução aguda. As manobras de Jaw Thrust, Chin Lift e o posicionamento da cânula de Guedel são eleitos para a abertura das vias aéreas. A intubação endotraqueal representa a medida profilática em caso de anafilaxia. A cricotireoidostomia é o procedimento invasivo de primeira escolha para o reestabelecimento da ventilação em ocasiões de emergência, seguida da traqueostomia, de caráter eletivo, demandando maior tempo de procedimento, infraestrutura e experiência profissional.

Descritores: Emergências; Obstrução das Vias Respiratórias; Primeiros Socorros.

\section{Referências:}

1. MARSICO PS, MARSICO GA. Traqueostomia. Pulmão RJ, 2010; 19(1-2): 24-32.

2. RODRIGUES MS, et al. Utilização do ABCDE no atendimento do traumatizado. Revista de Medicina, 2017; 96(4): 278-280

3. SANT'ANNA F, et al. Cricotireotomia no manejo de obstrução aguda das vias aéreas. Revista de Cirurgia e Traumatologia Buco-maxilo-facial, 2010; 10(2): 35-41 


\title{
PC-16-2019 - ACIDENTES E COMPLICAÇÕES NA UTILIZAÇÃO DE MINI- PARAFUSOS COMO DISPOSITIVOS DE ANCORAGEM ORTODÔNTICA
}

\author{
João Vítor Queiroz Mendes dos Santos ${ }^{1}$; Paulo Roberto Kohno de Oliveira ${ }^{1}$ \\ ${ }^{1}$ Faculdade de Odontologia de Pernambuco - Camaragibe - PE - Brasil \\ Autor correspondente: \\ João Vítor Queiroz Mendes dos Santos \\ jvitorqueiroz@hotmail.com
}

Introdução: Os mini parafusos são utilizados em várias áreas da maxila e mandíbula e em diversas situações clínicas, como em casos que necessitam de retração anterior (superior, inferior ou ambos), intrusão de dentes anteriores ou posteriores, fechamento de espaços de dentes ausentes, pacientes não colaboradores com outros métodos de ancoragem, verticalização de molares e outras alterações encontradas nos diversos tipos de más oclusões ${ }^{2,3}$. Objetivo: Este trabalho se propõe a fazer uma revisão da literatura em relação aos acidentes, complicações, dificuldades e fatores de insucesso quando da utilização de mini parafusos como dispositivos temporários de ancoragem ortodôntica. Metodologia: Foi efetuada uma revisão de literatura nas bases de dados BBO, SciELO e Medline, entre anos de 2015 e 2019. Revisão de literatura: Outros fatores que podem ser considerados importantes no sucesso ou insucesso dos mini parafusos, como dispositivo temporário de ancoragem, estão relacionados com o paciente (idade, gênero, higienização, espessura do osso cortical), ao operador (conhecimento das técnicas e de seus limites), ao local de inserção e ao tipo de mini parafuso utilizado ${ }^{1,4}$. Conclusão: A maioria dos autores concorda que a ocorrência de insucesso está relacionada a motivos multivariáveis, entretanto divergem sobre os fatores mais relevantes que podem afetar a taxa de sucesso na utilização de mini parafusos como dispositivos temporários de ancoragem ortodôntica.

Descritores: Técnicas de Movimentação Dentária; Procedimentos de Ancoragem Ortodôntica; Ortodontia.

\section{Referências:}

1. ENKLING N, et al. A prospective cohort study on survival and success of one-piece mini implants with associated changes in oral function: Five-year outcomes. Clinical Oral Implants Research, 2019; 30(6):570-577

2. GRETA G, et al. Dental roots' and surrounding structures' response after contact with orthodontic mini implants: A systematic literature review. Stomatologija, Baltic Dental and Maxillofacial Journal, 2018; 20:73-81

3. GUILHERME FCS. Riscos e complicações na utilização de mini-parafusos como dispositivos de ancoragem. Trabalho de Conclusão de Curso (Odontologia) - Universidade Estadual de Londrina, Londrina, 2015; 48

4. LISSANDRO SDB. Iatrogenias resultantes da inserção de mini-implantes. Dissertação (Mestrado em Medicina Dentária) - Faculdade de Ciências da Saúde. Universidade Fernando Pessoa, Porto, 2017; 23 


\section{PC-17-2019 - ADENOMA PLEOMÓRFICO: REVISÃO DE LITERATURA}

Giovana Lordsleem de Mendonça ${ }^{1}$; Carolina Pereira da Silva ${ }^{1}$; Heitor Tavares de Araújo ${ }^{1}$; Rebecca Siqueira da Cunha Machado'; Luiza de Carvalho Paranhos Agra ${ }^{1}$; Tatianny Carneiro Fonseca $^{1}$; Pedro Xavier Moura da Silva ${ }^{1}$; Rosa Rayanne Lins de Souza ${ }^{2}$

${ }^{1}$ Faculdade de Odontologia de Pernambuco - Camaragibe - PE - Brasil

${ }^{2}$ Hospital da Restauração Governador Paulo Guerra/SES - Recife - PE - Brasil

Autor correspondente:

Giovana Lordsleem de Mendonça

giovanalord@gmail.com

Introdução: O adenoma Pleomórfico é uma neoplasia benigna que pode acometer tanto as glândulas menores como as maiores, sendo a parótida a mais afetada; apresenta peculiaridades como ocorrência de recidivas e potencial de malignização ${ }^{1,3}$. Objetivo: $O$ estudo visa descrever as características do Adenoma Pleomórfico, a fim de se obter uma melhor explanação sobre tal patologia. Metodologia: Foi realizada uma busca bibliográfica com artigos disponíveis no LILACS, PubMed e Bireme, publicados entre 2006 e 2019, com os termos "Glândulas salivares", "Adenoma pleomorfo" e "Neoplasia". Revisão de Literatura: Tumor de glândula salivar mais comum caracterizado pela diversidade morfológica, não apenas entre diferentes tumores, mas também em diferentes partes de um mesmo tumor. Normalmente é uma lesão nodular única, com margens bem delimitadas, superfície lobulada, consistência endurecida, móvel e indolor à palpação. $\mathrm{O}$ tratamento de eleição consiste na excisão cirúrgica com pequena margem de segurança, em virtude da possibilidade de recidiva, caso permaneçam células tumorais ${ }^{3}$. Para lesões localizadas no lobo superficial da glândula parótida é recomendada a parotidectomia superficial, com a identificação e preservação do nervo facial. Uma complicação potencial é a transformação maligna, que origina o carcinoma ex-adenoma pleomorfo $(\mathrm{CAP})^{2}$. Conclusão: De diagnóstico nem sempre fácil e tratamento cirúrgico, o adenoma pleomórfico merece atenção do cirurgião-dentista, sendo seu diagnóstico precoce e pronto tratamento, fatores determinantes para o sucesso terapêutico ${ }^{1}$.

Descritores: Glândulas Salivares; Adenoma Pleomorfo; Neoplasia.

\section{Referências:}

1. CASTRO AL, et al. Adenoma pleomórfico em palato: relato de caso clínico. Revista da Associação Paulista de Cirurgiões-Dentistas, 2008; 62(1): 59-61

2. PRADO RF, TAVEIRA LAA. Adenoma pleomorfo e carcinoma ex-adenoma pleomorfo: uma revisão clínica e morfológica. Ciência odontológica Brasileira, 2006; 9(4): 18-26

3. SILVA DN, et al. Enucleação de Adenoma Plemórfico: considerações terapêuticas e relato de caso. Revista de Cirurgia e Traumatologia Buco-maxilo-facial, 2007; 7(4): 25-30 


\section{PC-18-2019 - ALTERAÇÃO DE COR DOS CIMENTOS RESINOSOS UTILIZADOS EM PRÓTESE FIXA}

Douglas Felipe de Lima e Silva ${ }^{1}$; Maria Fernanda Limeira Feitosa ${ }^{1}$; Alice Mendes Siqueira ${ }^{1}$; Alyson José de Sá Quirino Santos ${ }^{1}$; Amanda Cristina de Paula Bento ${ }^{1}$; Marília de Lima Soares ${ }^{1}$

${ }^{1}$ Centro Universitário Maurício de Nassau - Recife - PE - Brasil

Autor correspondente:

Douglas Felipe de Lima e Silva

douglasfls@hotmail.com

Introdução: Os cimentos resinosos têm grande aplicabilidade hoje em dia na odontologia, seu uso vai desde a cimentação de pinos intra-radiculares a coroas e facetas ${ }^{1}$. Possuem polimerizações variadas, sendo divididos em fotopolimerizáveis, dupla polimerização e químicos ${ }^{2}$. Objetivo: $\mathrm{O}$ estudo avaliou a alteração de cor dos cimentos resinosos de diferentes mecanismos de polimerização frente ao café e o vinho. Metodologia: Foram confeccionados 18 corpos de provas de cada cimento de acordo com o tipo de polimerização. Os mesmos foram divididos entre os que foram imersos em café com 30 minutos $(n=3)$, em café por 150 minutos $(n=3)$, em vinho por 30 minutos $(n=3)$, em vinho por 150 minutos $(n=3)$ e o grupo controle $(n=3)$ que permaneceram imersos em soro por todo o experimento. Perfazendo um total de 39 espécimes. O ciclo de duração do experimento foi de 15 dias. Ao final os corpos de prova foram avaliados subjetivamente em comparação com a escala Vita da possível alteração de cor decorrente do manchamento por pigmentos. Resultados e Discussão: $O$ vinho manchou mais que o café em todos os cimentos exceto no grupo do cimento fotopolimerizável em 150 minutos, os cimentos de polimerização química tiveram a maior alteração seguindo pelo dual e fotopolimerizável independentemente do tempo de imersão aos corantes. Estes achados concordam com os encontrados ${ }^{3}$, por que encontrou que vinho foi a solução que promoveu maior mudança de cor. No estudo in vitro, a maioria dos corpos apresentaram maior alteração de cor imersos no vinho (exceto o fotopolimerizável de 150 minutos), concordando $\operatorname{com}^{1,3}$ que justifica o teor alcoólico como responsável pela maior alteração de cor. Conclusão: Nessa perspectiva, a escolha do cimento resinoso de acordo com sua polimerização na prática clínica é de suma importância para a longevidade estética frente aos corantes rotineiramente utilizados na atualidade.

Descritores: Prótese Dentária; Corantes; Polimerização.

\section{Referências:}

1. BEHESHTEH MA, et al. Effect of Ingested Liquids on Color Change of Composite Resins. J Dent, 2015; 12(8): 577-84

2. SHIOZAWA M, et al. Color stability of adhesive resin cements after immersion in coffee. Clin Oral Investig, 2015; 19(2): 309-17

3. TOPCU FT, et al. Influence of different drinks on the colour stability of dental resin composites. Euro J Dent, 2009; 3(1): 50-56 


\section{PC-19-2019 - ALTERAÇÕES PATOLÓGICAS RELEVANTES PARA A CLÍNICA ODONTOPEDIÁTRICA: UMA REVISÃO DE LITERATURA}

Fernanda Teles Pereira ${ }^{1}$; Roberta Neto Gomes ${ }^{2}$; Weslay Rodrigues da Silva ${ }^{2}$; Rômulo César de Alencar ${ }^{2}$; Larissa Hellen de Paiva Felix²; Marina Lins Maymone de Melo²; Thyago Morais Vicente da Silva ${ }^{2}$

${ }^{1}$ Faculdade de Odontologia de Pernambuco - Camaragibe - PE - Brasil

${ }^{2}$ Universidade Federal de Pernambuco - Recife - PE - Brasil

Autor correspondente:

Fernanda Teles Pereira

fernandatelespereira@gmail.com

Introdução: O conhecimento das lesões mais prevalentes na cavidade bucal da população infantil pode ajudar a assentar as bases teóricas de sua formação ${ }^{3}$, como também melhor direcionar a sua prática clínica ${ }^{1}$. Objetivo: Realizar uma revisão de literatura narrativa sobre as principais alterações estomatológicas na infância, com ênfase na etiologia, epidemiologia, características clínicas, diagnóstico e tratamento das lesões. Buscando encargar o cirurgiãodentista clínico geral sobre essas alterações, já que muitas vezes essas lesões não recebem a devida atenção, em decorrência da formação odontocentrada da profissão. Metodologia: Caracteriza-se como uma revisão de literatura narrativa, considerando as bases de dados PubMed, Google acadêmico e Biblioteca Virtual em Saúde. O principal termo de pesquisa foi: lesões estomatológicas pediátricas. Os trabalhos foram selecionados de acordo com o título e resumo, onde, a partir de então foram aplicados os critérios de inclusão, estando dentre eles: os trabalhos de relato de caso, pesquisa e revisão de literatura, publicações feitas entre os anos de 1999 a 2017, em inglês ou português e que fossem relevantes para o nosso estudo. A partir de então os achados foram entregues a 2 avaliadores para averiguação dos critérios de inclusão.

Revisão de literatura: Após aplicação da metodologia proposta, foram encontrados 73 trabalhos, mas apenas os 29 trabalhos mais importantes para a temática foram utilizados, estes foram lidos integralmente e condensados na revisão de literatura correspondente às doenças: mucocele, rânula, ulceração aftosa recorrente, candidíase, herpangina, doença dos pés mãos e boca, gengivoestomatite herpética primária e herpes recorrente., as mais pertinentes ao estudo. Conclusão: Espera-se, portanto, que esse trabalho ajude o clínico geral a reconhecer e tratar essas patológias, que são comuns na infância, já que quando não diagnosticadas e tratadas de maneira precoce diminuem a qualidade de vida dos pacientes ${ }^{2}$.

Descritores: Medicina bucal; Doenças da boca; Odontopediatria.

\section{Referências:}

1.ALVES F, et al. Lesões estomatológicas em crianças HIV positivas e suas implicações clínicas. Arquivos em odontologia, 2009; 45:191-198

2. CAVALCANTE ASR, et al. Lesões bucais de tecido mole e ósseo em crianças e adolescentes. Brazilian Dental Science, 1999; 2:67-75

3. MOREIRA MR. Lesões bucais em pacientes pediátricos: estudo retrospectivo de 620 biópsias registradas no Laboratório de Patologia Bucal da Universidade Federal de UberlândiaMG-Brasil. Dissertação (Mestrado em Ciências da Saúde) - Universidade Federal de Uberlândia. Uberlândia, 2006; 64 p 
Maria Sabrina Alves da Silva ${ }^{1}$; Emerllyn Shayane Martins de Araújo²; Caio César Gonçalves Silva $^{2}$; Marcelo Soares dos Santos ${ }^{2}$; Demóstenes Alves Diniz ${ }^{3}$; Jéssica da Silva Cunha ${ }^{3}$; Kalyne Kelly Negromonte Gonçalves ${ }^{3}$; Belmiro Cavalcanti do Egito Vasconcelos ${ }^{3}$

${ }^{1}$ Centro Universitário Faculdade Osman Lins - Vitória de Santo Antão - PE - Brasil

${ }^{2}$ Faculdade de Odontologia de Pernambuco - Camaragibe - PE - Brasil

${ }^{3}$ Hospital da Restauração - Recife - PE - Brasil

Autor correspondente:

Maria Sabrina Alves da Silva

alvesmariasabrina@gmail.com

Introdução: O ameloblastoma é um tumor odontogênico de maior significado clínico. Sua frequência relativa se iguala à de todos os outros tumores odontogênicos, excluindo os odontomas $^{2}$. Objetivo: Relatar o caso clínico de uma paciente com diagnóstico de ameloblastoma em maxila. Relato de caso: Paciente do sexo feminino, 18 anos de idade, procurou o serviço de Cirurgia e Traumatologia Buco-Maxilo-Facial do Hospital da Restauração, Recife-PE, com queixa de aumento de volume em face há 02 anos. Ela havia sido submetida há 01 ano a biópsia incisional e instalação de dispositivo, porém sem sucesso. Apresentava laudo histopatológico prévio compatível a ameloblastoma. Ao exame físico apresentava aumento de volume em hemiface direita, causando assimetria facial e sem sintomatologia dolorosa associada. Ao exame intra-oral apresentava expansão de cortical vestibular de maxila direita, bem como presença de dispositivo em região. O exame de imagem sugeria presença de lesão radiolúcida associado a coroa de dente 13 incluso. Esta foi submetida à cirurgia sob anestesia geral para ressecção de tumor, bem como de dente incluso associado, através de acesso vestibular maxilar direito. Ela segue em acompanhamento ambulatorial, sem sinais de complicações. Discussão: Apesar de várias formas de tratamento já terem sido largamente debatidas na literatura, ainda não há um consenso sobre qual seria a mais indicada ${ }^{1}$. Conclusão: Visto que o diagnóstico é de extrema importância para fechamento do tratamento e seu prognóstico. $\mathrm{O}$ tratamento varia desde o conservador até abordagens mais agressivas. $\mathrm{O}$ exame histopatólogico é conclusivo para o fechamento do diagnóstico ${ }^{3}$.

Descritores: Ameloblastoma; Maxila; Tumores Odontogênicos.

\section{Referências:}

1. MELO RB, et al. Tratamento cirúrgico de ameloblastoma sólido convencional: relato de caso clínico. Revista da Faculdade de Odontologia, 2016; 21: 246-250

2. NEVILLE BW, et al. Patologia Oral e Maxilofacial. $2^{\mathrm{a}}$ ed. Rio de Janeiro: Guanabara, 2004; $798 \mathrm{p}$

3. SANTANA KM, et al. Ameloblastoma e suas características clínicas e radiográficas: relato de caso clínico. Revista Odontológica de Araçatuba, 2019; 40: 48-53 


\section{PC-21-2019 - AMELOGÊNESE IMPERFEITA: ABORDAGEM CONSERVADORA COM RESINAS COMPOSTAS}

José Matheus Lima Ramos ${ }^{1}$; Carolina Pereira da Silva ${ }^{1}$; João Victor Neves Barbosa ${ }^{1}$; Luís Felipe Espíndola Castro²; Paulo Fonseca Menezes Filho²; Cláudio Heliomar Vicente da Silva²; Gabriela Queiroz de Melo Monteiro²; Juliana Raposo Souto Maior ${ }^{2}$

${ }^{1}$ Faculdade de Odontologia de Pernambuco - Camaragibe - PE - Brasil

${ }^{2}$ Centro de Pós-Graduação em Odontologia - Recife - PE - Brasil

Autor correspondente:

José Matheus Lima Ramos

matheuslima.lima046@gmail.com

Introdução: A amelogênese imperfeita é uma alteração do desenvolvimento dentário onde há uma deficiência na deposição dos sais de hidroxiapatita ${ }^{1}$, tornando-o mais rugoso e amarelado, uma vez que há o adelgaçamento desta camada. Ambas dentições podem ser afetadas e a estética também é comprometida em vários casos, esses que podem ser solucionados com procedimentos restauradores diretos como a resina composta. Objetivo: Analisar uma das alternativas de tratamento estético da amelogênese imperfeita que é a confecção de restaurações diretas em resina composta. Relato de caso: Paciente do sexo masculino, 13 anos, foi levado pelo responsável à procura de atendimento odontológico no Centro de Pós-Graduação em Odontologia queixando ser alvo de bullying na escola por conta dos dentes que eram rugosos e amarelados. Nem todos os dentes permanentes estavam irrompidos, então foram restaurados os elementos 11, 12, 21 e 22, com objetivo de deixá-los mais estéticos, promovendo uma maior naturalidade e consequentemente melhor aceitação da sociedade. Foi realizada uma asperização da superfície dentária com ponta diamantada $\mathrm{n}^{\circ} 4138$, profilaxia com pedra pomes e água, condicionamento com ácido fosfórico a 37\%, aplicação do sistema adesivo e restauração. Foram utilizadas resinas compostas Filltek Z350XT (3M) nas cores A1B e A1 Esmalte. Após o procedimento restaurador foi realizado o acabamento e polimento. Discussão: Um exame clínico minucioso e diagnóstico correto são importantes para determinar a melhor forma de tratamento para cada paciente. A queixa do paciente era o aspecto estético dos seus dentes, portanto, as restaurações solucionaram o problema, devolvendo a autoestima e socialização dele. Conclusões: Com a melhoria das resinas compostas e das técnicas restaurãdoras é possível tratar alterações com um alto comprometimento estético com procedimentos minimamente invasivos, preservando assim uma maior quantidade de tecido sadio.

Descritores: Amelogênese Imperfeita; Estética Dentária; Restauração Dentária Permanente.

\section{Referências:}

1. BERALDO S, et al. Amelogênese imperfeita: relato de caso clínico. Revista da Faculdade de Odontologia da Universidade de Passo Fundo, 2015; 20(1):101-104

2. GADHIA K, et al. Amelogenesis imperfecta: an introduction. British Dental Journal, 2012; 212(8):377-379

3. REZENDE AA, TAKAHASHI K. Amelogênese imperfeita e o padrão hereditário. Revista Dens, 2008; 16(2):37 


\section{PC-22-2019 - ANEMIA DE FANCONI E SUAS REPERCUSSÕES EM CAVIDADE ORAL: UMA REVISÃO DE LITERATURA}

Larissa de Araújo Braga ${ }^{1}$; Nataly Salete Nunes Silva Mendonça ${ }^{1}$; Taynara Franciele da Silva Souza $^{1}$; Augusto César Leal da Silva Leonel ${ }^{1}$

${ }^{1}$ Universidade Federal de Pernambuco - Recife - PE - Brasil

Autor correspondente:

Larissa de Araújo Braga

Laricaa.lb@gmail.com

Introdução: A Anemia de Fanconi (AF) é uma rara desordem genética recessiva, com incidência mundial de 3:1 milhão, caracterizada por uma instabilidade cromossômica que induz a alterações congênitas nos indivíduos. Algumas das possíveis evoluções da doença se manifestam na cavidade oral ${ }^{1,2}$. Objetivo: Relatar, através de uma revisão da literatura, as principais manifestações orais da AF. Metodologia: Foram selecionados, nas bases de dados SciELO e PubMed, artigos científicos em inglês e português publicados no período de 2014 a 2018, utilizando as palavras-chave "Anemia de Fanconi" e "repercussões orais". Revisão de Literatura: Os achados clínicos bucais descritos na literatura incluem alterações periodontais, anomalias dentárias, ulceração aftosa recorrente, atrofia das papilas linguais, macroglossia e maior predisposição para desenvolver carcinoma espinocelular. ${ }^{1,2}$ Esses sinais clínicos estão ligados a variações no metabolismo do cálcio durante a odontogênese, alterações endócrinas e hematológicas - como a trombocitopenia e neutropenia, além da grande exposição, desses indivíduos, a drogas imunossupressora, pois o único tratamento terapêutico com possibilidade de cura é o transplante de medula óssea ${ }^{1,3}$. O alto risco de malignidade é resultado de instabilidade cromossômica associada a defeitos no reparo de danos no DNA ${ }^{2}$. Conclusão: Devido à susceptibilidade aumentada para desenvolver alterações em cavidade oral, é imprescindível que os indivíduos portadores de AF sejam acompanhados rotineiramente por Cirurgiões-dentistas.

Descritores: Anemia de Fanconi; Boca; Anormalidades da Boca.

\section{Referências:}

1. D'AGULHAM, et al. Fanconi Anemia: main oral manifestations. Rev Gaúch Odontol, 2014; 62(3): 281-288.

2. FURQUIM, et al. Oral cancer in Fanconi anemia: Review of 121 cases. Crit Rev Oncol Hematol, 2018; 125:35-40

3. FURQUIM, et al. Moutch self-examination as a screening tool for oral cancer in a high-risk group of patients with Fanconi anemia. Oral Surg Oral Med Oral Pathol Oral Radiol, 2014; 118(4): 440-446 


\section{PC-23-2019 - ANESTESIA LOCAL EM ODONTOLOGIA: POR QUE UTILIZAR TUBETE DE VIDRO?}

Sérgio Salomão de Oliveira Moura ${ }^{1}$; Micaela Maria de Sousa ${ }^{1}$; Aylanne Xavier de Lacerda Cavalcante Timoteo ${ }^{1}$; Emerllyn Shayane Martins de Araújo ${ }^{1}$; Kássia Regina de Santana ${ }^{1}$; Lucas Rafael Borges Santos ${ }^{1}$; João Victor Neves Barbosa ${ }^{1}$; Sally de Souza Brito ${ }^{2}$

${ }^{1}$ Faculdade de Odontologia de Pernambuco - Camaragibe - PE - Brasil

${ }^{2}$ Centro de Pós-graduação em Odontologia - Recife - PE - Brasil

Autor correspondente:

Sérgio Salomão de Oliveira Moura

sergiosalomao15@gmail.com

Introdução: A segurança e eficácia da anestesia local em odontologia dependem de vários fatores, entre eles: dosagem recomendada, utilização da técnica corretamente, da anamnese prévia, além da habilidade e rapidez do profissional assim como precauções adequadas a serem tomadas. Incluso no armamentário a ser utilizado pelo dentista a fim de realizar anestesia, está o tubete anestésico, um cilindro que pode ser de plástico ou vidro e que contém a droga anestésica local ${ }^{1}$. Objetivo: Apresentar uma revisão da literatura sobre os motivos do tubete anestésico de vidro ser superior ao de plástico, garantindo uma anestesia mais segura. Metodologia: Foi realizado cruzamento dos descritores selecionados e foram escolhidos 10 artigos publicados entre os anos de 2000 e 2019, encontrados nos periódicos das bases de dados LILACS, PubMed e SciELO. Revisão de Literatura: Os tubetes de plástico representam a maioria no mercado nacional brasileiro. Entretanto, o uso deste foi abandonado em países como Estados Unidos, Canadá e Inglaterra devido às altas porcentagens de falha (ruptura/vazamento) que proporciona, a pressão necessária para o vazamento em tubetes plásticos era muito menor que a pressão para provocar quebra dos tubetes de vidro, além disso, tubetes de plástico possuem metilparabeno, um bacteriostático que pode causar reações alérgicas ${ }^{1,3}$, também ocorre do êmbolo não deslizar suavemente nas paredes do tubete de plástico, isso faz com que haja oscilação de intensidade na injeção, o deslizamento "áspero" do êmbolo leva à esguinchos repentinos de anestésico administrado. As informações impressas sobre o anestésico no tubete de plástico não são totalmente visíveis, podendo suscitar dúvidas ao dentista. A validade do anestésico no tubete de vidro geralmente é maior ${ }^{2,3}$. Conclusão: $O$ tubete de vidro é superior ao de plástico porque é mais seguro, apresenta menor risco de falha, o de plástico por sua vez ainda é o mais encontrado nos serviços públicos.

Descritores: Anestesia Local; Anestésicos; Dosagem.

\section{Referências:}

1. CARVALHO B, et al. O emprego dos anestésicos locais em Odontologia: Revisão de Literatura. Revista Brasileira de Odontologia, 2013; 70(2): 178-181

2. CARVALHO RWF, etal. Anestésicos Locais: Como Escolher e Prevenir Complicações Sistêmicas. Revista Portuguesa de Estomatologia, Medicina Dentária e Cirurgia Maxilofacial, 2010; 51(2): 113-120

3. RAMACCIATO JC. Avaliação da estabilidade química das soluções anestésicas locais comerciais e das propriedades físicas dos tubetes sob diferentes condições de armazenamento. Tese (Doutorado em Odontologia) - Faculdade de Odontologia de Piracicaba. Universidade Estadual de Campinas, Piracicaba, 2003; 147p 


\title{
PC-24-2019 - ANGINA BOLHOSA HEMORRÁGICA- RELATO DE CASO CLÍNICO
}

\author{
Aline Roberta Oliveira da Silva ${ }^{1}$; José Ricardo Dias Pereira ${ }^{1}$ \\ 1Universidade Federal de Pernambuco - Recife - PE - Brasil \\ Autor correspondente: \\ Aline Roberta Oliveira da Silva \\ aliinerobertaa@gmail.com
}

Introdução: A angina bolhosa hemorrágica $(\mathrm{ABH})$ é um distúrbio raro e benigno, geralmente localizado na camada subepitelial da mucosa oral, faríngea e esofágica. As lesões são caracterizadas por seu início repentino, são indolores, assintomáticas e ocorrem mais comumente no palato mole. Elas aparecem como uma bolha indolor, tensa, vermelha escura e cheia de sangue na boca, que se expandem rapidamente e se rompem espontaneamente em 24 a 48 horas, de etiologia desconhecida, embora possa ser um fenômeno multifatorial, incluindo diabetes e inaladores de esteróides. A condição não é atribuível a discrasias sanguíneas, nem a outros distúrbios vesiculos-bolhosos ${ }^{1,2,3,4}$. Objetivo: Relatar caso de lesão avermelhada com presença de bolhas sem necessidade de tratamento, foi instituído bochechos com clorexidina 0,12\% e acompanhamento. Relato de caso: Paciente JAF, sexo masculino, foi encaminhado para a clínica de Estomatologia da Universidade Federal de Pernambuco com queixa de uma lesão vesículo-bolhosa de coloração avermelhada, indolor, com aproximadamente $3 \mathrm{~cm}$ de diâmetro, no palato mole. Não foi realizado nenhum procedimento no paciente, foi prescrito bochechos de clorexidina a $0,12 \%$ duas vezes ao dia, por um minuto, e a lesão evoluiu satisfatoriamente, sem intercorrências, cicatrizou nos próximos 21 dias. Paciente foi recomendado a retornar em 7 dias para uma reavaliação, repetindo-se por mais duas semanas e foi observada remissão total da lesão. Discussão: A ABH apresenta-se clinicamente com bolhas cheias de sangue que ocorrem predominantemente no palato mole. Elas geralmente atingem um diâmetro de $2 \pm 3 \mathrm{~cm}$ e tendem a explodir espontaneamente, deixando uma úlcera irregular que cura sem cicatrizes ${ }^{3}$. O prognóstico da angina bolhosa hemorrágica é bom e somente tratamento paliativo é necessário ${ }^{1}$. Conclusões: É possível o estabelecimento de um diagnóstico essencialmente clínico. Exames hematológicos são recomendados para a exclusão de outras patologias. A prescrição de bochechos com clorexidina mostrou-se eficaz como auxiliar do processo de cicatrização ${ }^{4}$.

Descritores: Medicina Bucal; Mucosa Bucal; Palato mole.

\section{Referências:}

1. BEGUERIE JR, GONZALES S. Angina Bullosa Hemorrhagica: Report of 11 Cases. Dermatology Reports, 2014; 6(1): 5-7

2.RAI S, et al. Angina bullosa hemorrhagica: Report of two cases. Indian journal of dermatology, 2012; 57(6): 503

3. SHASHIKUMAR BM, et al. Oral Hemorrhagic Blister: An Enigma. Indian journal of dermatology, 2013; 58(5): 407

4.VOLKWEIS R, GALEAZZI S. Angina bolhosa hemorrágica - uma revisão de 14

casos. Revista Da Faculdade De Odontologia - UPF, 2011; 15(3): 300-303 


\section{PC-25-2019 - APLICAÇÃO DA TOXINA BOTULÍNICA COMO ALTERNATIVA PARA O TRATAMENTO DA DISFUNÇÃO TEMPOROMANDIBULAR: REVISÃO DE LITERATURA}

Carolina Viana Vasco Lyra ${ }^{1}$; Ademir Félix Arantes Júnior ${ }^{1}$; Carolaine Rayane Xavier da Silva ${ }^{1}$; Emilly Araújo Pereira ${ }^{1}$; Laura do Nascimento Arruda ${ }^{1}$; Maria Cecília Andrade de Arribas ${ }^{1}$; Maíra Letícia Ferreira de Santana ${ }^{1}$; Bruno da Silva Mesquita ${ }^{1}$

${ }^{1}$ Faculdade de Odontologia de Pernambuco - Camaragibe - PE - Brasil

Autor correspondente:

Carolina Viana Vasco Lyra

carol-lyra98@hotmail.com

Introdução: A disfunção temporomandibular (DTM) engloba um conjunto de alterações que podem envolver estruturas musculoesqueléticas associadas à cabeça e pescoço e, apresenta a dor como o seu principal sintoma ${ }^{1}$. Objetivo: O propósito desta revisão de literatura é avaliar o uso da toxina botulínica como uma escolha no tratamento da disfunção temporomandibular.

Metodologia: Foi realizado um estudo nas bases de dado SciELO e LILACS, com estudos publicados entre os anos de 2009 a 2018 e utilizando os seguintes descritores: Toxina botulínica tipo A; Dor e Reabilitação. Revisão de literatura: A DTM é causada por uma dor miofascial crônica que resulta comumente de hiperatividade da musculatura mastigatória por apertamento ou bruxismo e hipermobilidade do côndilo. Essa disfunção tem como uma opção de tratamento o uso da toxina botulínica tipo A (TxB-A), com o intuito de aliviar a sintomatologia dolorosa. A TxB-A é proveniente de uma bactéria anaeróbica gram-positiva, o clostridium botulinum, que age basicamente inibindo a liberação exocitótica da acetilcolina nos terminais nervosos motores levando a uma diminuição da contração muscular. Esta característica a torna útil, clínica e terapeuticamente, em uma série de condições onde existe excesso de contração muscular, como é o caso da DTM ${ }^{2,3,4}$. Conclusão: Em conclusão, pode-se dizer que a TxB-A está indicada como uma alternativa no tratamento de disfunções de origem muscular, porém, mais estudos são necessários para estabelecer sua eficácia ${ }^{1,2}$.

Descritores: Dor; Reabilitação; Toxinas botulínicas tipo A.

\section{Referências:}

1. ANTONIA MD, et al. Jaw muscles myofascial pain and botulinum toxin. Revista Dor, 2013; 14(1): 52-57

2. COLHADO OCG, et al. Toxina Botulínica no Tratamento da Dor. Revista Brasileira Anestesiologia, 2009; 59(3): 366-381

3. PETROLLI GOP, et al. Tratamento de disfunções temporomandibulares com toxina botulínica tipo A. Revista da Faculdade de Odontologia UPF, 2018; 23(2): 236-241

4. SPOSITO MMM, TEIXEIRA SAF. Toxina Botulínica Tipo A para bruxismo: analise sistemática. Revista Acta Fisiátrica, 2014;21(4):201-204 


\section{PC-26-2019 - APLICAÇÃO DE MODELAGEM MATEMÁTICA PARA AVALIAÇÃO DOS EFEITOS TÉRMICOS DO FS LASER NOS TECIDOS DENTÁRIOS}

Georges de Sá Moreira Filho ${ }^{1}$; Sinval Vinícius Barbosa do Nascimento ${ }^{1}$; Eloiza Leonardo de Melo $^{1}$; Vânia Cavalcanti Ribeiro da Silva ${ }^{1}$; Maria Regina Almeida de Menezes ${ }^{1}$; Rebeca Ferraz de Menezes ${ }^{1}$; Lara Marques Magalhães Moreno ${ }^{1}$; Marleny Elizabeth Márquez de Martínez Gerbi $^{1}$

${ }^{1}$ Faculdade de Odontologia de Pernambuco (FOP/UPE) - Camaragibe - PE - Brasil

Autor Correspondente:

Georges de Sá Moreira Filho

georges_moreira@hotmail.com

Introdução: Os Lasers de alta potência de Femtossegundos tem como sua grande vantagem um potencial mínimo de gerar calor. Sendo assim, foi construído um modelo térmico no programa SolidWorks ${ }^{\mathrm{TM}}$ que forneceu fidelidade e flexibilidade adequadas para ser parametrizado com $2^{\circ}$ pré-molares ${ }^{3}$. Objetivo: Reproduzir os experimentos in vitro em um modelo matemático e comparar os resultados de ambos. Metodologia: O modelo sólido compreendeu uma coroa de rotação simétrica e a geometria de raiz bissimétrica. O modelo é parametrizado e pode, portanto, ser convenientemente dimensionado para aproximar os $2^{\circ}$ prémolares utilizados nas experiências. As propriedades térmicas para o esmalte e para a dentina foram encontradas em Brown et al. ${ }^{1} \mathrm{e}$ as propriedades para a polpa foram encontradas em Lin et al. ${ }^{2}$. Um coeficiente de convecção de $15 \mathrm{~W} / \mathrm{m}^{\wedge} 2 \mathrm{~K}$ foi utilizado como um ponto de partida prático e rendeu concordância razoável com as experiências. A potência incidente foi dimensionada para $35 \%$ da potência medida na saída da óptica de origem. Este fator de escala foi encontrado para produzir concordância razoável com as experiências. Resultados e Discussão: Temperaturas semelhantes aos resultados do trabalho in vitro foram estimadas pelos resultados do modelo matemático. Conclusão: Levando-se em conta os resultados obtidos, ficou assim demonstrado que um modelo paramétrico linear pode ser utilizado para avaliar os aumentos de temperaturas esperados durante a ablação por laser de femtossegundos.

Descritores: Laser; In vitro; Simulação.

\section{Referências:}

1. BROWN WS, et al. Thermal Properties of Teeth. Journal of dental research, 1970; 49: 752755

2. LIN M, et al. Thermal Pain in Teeth: Electrophysiology Governed by Termomechanics. Applied mechanics reviews, 2014; 66(3): 4-14

3. NELSON SJ, ASH MM. Wheeler's dental anatomy, physiology, and occlusion. 9nded. St. Louis: Saunders Elsevier, 2010; 368p 


\section{PC-27-2019 - APRESENTAÇÕES CLÍNICAS DA DISPLASIA CLEIDOCRANIANA: REVISÃO DE LITERATURA}

Hugo Igor Rodrigues de Barros ${ }^{1}$; Arthur Alves Thomaz de Aquino ${ }^{1}$; Carolina Pereira da Silva ${ }^{1}$; Cleiton Rone dos Santos Lima ${ }^{1}$; Fernanda Gomes Barros ${ }^{1}$; Heitor Tavares de Araújo ${ }^{1}$; Pedro Xavier Moura da Silva ${ }^{1}$; Rosa Rayanne Lins de Souza ${ }^{2}$

${ }^{1}$ Faculdade de Odontologia de Pernambuco - Camaragibe - PE - Brasil

${ }^{2}$ Hospital da Restauração Governador Paulo Guerra/SES - Recife - PE - Brasil

Autor correspondente:

Hugo Igor Rodrigues de Barros

Hu_hugo_@hotmail.com.br

Introdução: A displasia cleidocraniana (DC) é uma síndrome genética rara, relacionada com a perda de um dos alelos do gene CBFA1 e que apresenta comportamento autossômico dominante. A DC é representada por anormalidades esqueléticas e manifestações bucais ${ }^{3,1}$. Objetivo: O trabalho tem como objetivo apresentar os aspectos clínicos da síndrome referida. Metodologia: Foi realizada uma busca bibliográfica com artigos disponíveis no LILACS, PubMed e Bireme, publicados entre 2000 e 2019, com os termos "Displasia Cleidocraniana", "Disostose Cleidocraniana" e "Clavícula". Revisão de Literatura: A presença de ossos wormianos na calota craniana, abaulamento frontal e parietal, maxila subdesenvolvida, clavículas ausentes ou rudimentares, alterações oculares e nos ossos longos podem ser sinais clínicos da DC. Já as manifestações bucais podem se apresentar como palato arqueado, impactação, atraso na erupção de dentes permanentes, múltiplos dentes supranumerários ${ }^{4}$. Esses sinais podem causar consequências à oclusão, o desenvolvimento de hábitos bucais e até um efeito negativo na aparência facial ${ }^{2}$. Tornando necessário um tratamento adequado para cada caso. Conclusão: Para um melhor planejamento e intervenção multidisciplinar, é importante um diagnóstico precoce nos pacientes portadores da Displasia Cleidocraniana.

Descritores: Displasia Cleidocraniana; Disostose Cleidocraniana; Clavícula.

\section{Referências:}

1. GASSEN HT, et al. Relato de dois casos familiares de disôstose cleidocraniana. Revista da Faculdade de Odontologia Universidade de Passo Fundo, 2006; 11(1): 31-35

2. GIUBLIN LGS, et al. Incisivos centrais superiores permanentes retidos: considerações cirúrgico-ortodônticas. Jornal Brasileiro de Ortodontia e Ortopedia Facial, 2002; 6(36): 472479

3. QUEIROZ RM, et al. Displasia cleidocraniana: descrição com ênfase nos aspectos radiográficos de três casos em uma família. Revista Medicina (Ribeirão Preto), 2017; 50(6): 371-376

4. TRINDADE AKF, et al. Displasia Cleidocraniana. Revista Brasileira de Ciências da Saúde, 2010; 14(2): 73-76 


\section{PC-28-2019 - APROVEITAMENTO DE DENTE INCLUSO ASSOCIADO A ODONTOMA COMPOSTO EM MAXILA - RELATO DE CASO}

Alleson Jamesson da Silva ${ }^{1}$; Jessyca Maria Alencar e Sá1; Lucas Viana Silva Ramos ${ }^{1}$; Maria Heloisa Martins ${ }^{\mathbf{1}}$; Sinval Vinícius Barbosa do Nascimento ${ }^{2}$; Aída Juliane Ferreira dos Santos²; Caio César Gonçalves Silva²; Carolina Chaves Gama Aires²

${ }^{1}$ Universidade Federal de Pernambuco - Recife - PE - Brasil

${ }^{2}$ Faculdade de Odontologia de Pernambuco - Camaragibe - PE - Brasil

Autor correspondente:

Alleson Jamesson da Silva

allesonjamesson@gmail.com

Introdução: Os odontomas são tumores odontogênicos mais comuns ${ }^{2}$. O tipo composto é formado por múltiplas estruturas pequenas semelhantes a dentes e ocorre frequentemente na região ântero-superior ${ }^{2,3}$. Geralmente diagnosticados em exames radiográficos de rotina.1 Objetivo: Discutir um relato de caso de odontoma composto em região anterior de maxila associado a dente incluso. Relato de Caso: Paciente do sexo masculino, 12 anos, feoderma, compareceu ao serviço de CTBMF do Hospital da Face, Recife-PE, para avaliação de lesão radiopaca localizada na região anterior da maxila retendo o elemento 21 . A lesão foi percebida durante planejamento ortodôntico e teve a hipótese diagnóstica de odontoma composto. Foi proposta a remoção cirúrgica da lesão e o tracionamento do dente associado. Durante anamnese constatou-se ausência de histórico de trauma e/ou infecções na região. Em bloco cirúrgico, após anestesia local com vasoconstrictor, realizou-se uma incisão em envelope do elemento 12 ao 23 com uma relaxante em seu ponto mais distal e descolamento do retalho mucoperiosteal, remoção do odontoma composto por 43 estruturas com formatos e tamanhos distintos, exposição da coroa do dente incluso e instalação do botão ortodôntico para tracionamento, lavagem copiosa e sutura. Após uma semana a sutura foi removida e o paciente foi encaminhado ao ortodontista para finalização do caso. Discussão: Clinicamente, o odontoma apresenta-se assintomático, de crescimento lento e tamanho variável. O tratamento é cirúrgico conservador, simples, pela fácil clivagem, e a recidiva é remota ${ }^{1}$. Devido à natureza benigna do tumor, a manutenção do dente 21 associado com o tracionamento ortodôntico foi possível, aproveitando o elemento e minimizando o impacto de uma ausência dentária. Conclusão: O odontoma ocorre frequentemente no complexo maxilomandibular, a melhor forma de tratamento é a excisão local com favorável prognóstico. Suas características permitiram um tratamento mais conservador com relação ao dente incluso e seu possível aproveitamento após conclusão de tratamento ortodôntico.

Descritores: Tumores Odontogênicos; Odontoma; Hamartoma.

\section{Referências:}

1. JAEGER F, et al. Odontoma composto - relato de caso clínico. Revista Portuguesa de Estomatologia, Medicina Dentária e Cirurgia Maxilofacial, 2012; 4:252-257

2. NEVILLE BW et al. Patologia Oral e Maxilofacial. $3^{\text {a }}$ ed. Rio de Janeiro: Elsevier, 2009; $972 \mathrm{p}$

3. WHITE SC, PHAROAH MJ. Radiologia Oral - Fundamentos e Interpretação. $5^{\text {a }}$ ed. Rio de Janeiro: Elsevier, 2007; 882p 


\section{PC-29-2019 - ARTROPLASTIA EM GAP NO TRATAMENTO DA ANQUILOSE DA ARTICULAÇÃO TEMPOROMANDIBULAR: RELATO DE CASO}

Carla Regina Lima de Barros ${ }^{1}$; Caio César Gonçalves Silva ${ }^{2}$; Kalyne Kelly Negromonte Gonçalves ${ }^{3}$; Demóstenes Alves Diniz ${ }^{3}$; Virgílio Bernardino Ferraz Jardim²; Niviane Marielly da Costa Oliveira ${ }^{2}$; Luan Carlos Barbosa Lourenço ${ }^{1}$; Belmiro Cavalcanti do Egito Vaconcelos ${ }^{3}$

${ }^{1}$ Centro Universitário Mauricio de Nassau- Recife-PE- Brasil

${ }^{2}$ Faculdade de Odontologia de Pernambuco- Camaragibe-PE- Brasil

${ }^{3}$ Hospital da Restauração Governador Paulo Guerra- Recife-PE- Brasil

Autor correspondente:

Carla Regina Lima de Barros

regina_lb@hotmail.com

Introdução: A anquilose é uma condição patológica da articulação temporomandibular (ATM) caracterizada pela união do complexo disco-côndilo, componentes da superfície da articulação temporomandibular do osso temporal, restringindo, de tal forma, os movimentos articulares ${ }^{2,4}$. Os fatores etiológicos da anquilose podem estar relacionados a processos infecciosos locais ou sistêmicos, traumatologia local, radioterapia e tumores na ATM. Dentre as consequências da patologia estão a limitação da abertura bucal, capacidade de mastigação limitada, dificuldade da fonação e higiene bucal ${ }^{3}$. Objetivo: Relatar um caso clínico de anquilose bilateral da ATM e levantar questões a respeito no tratamento de escolha. Relato de caso: Paciente do gênero masculino, 48 anos, procurou o serviço de Cirurgia e Traumatologia Buco-Maxilo-Facial do Hospital da Restauração, Recife-PE com histórico de agressão por projétil de arma de fogo (PAF) há, aproximadamente, 1 ano. Ao exame clínico, apresentava $3 \mathrm{~mm}$ de distância interincisal. Exame de imagem evidenciando massa anquilótica em região de ATM direita. Sendo diagnosticado com anquilose da articulação temporomandibular, o tratamento de escolha foi a artroplastia em gap do lado direito juntamente com a coronoidectomia bilateral. Paciente segue em acompanhamento ambulatorial, sem sinais de complicações e com abertura interincisal de $33 \mathrm{~mm}$. Discussão: Essa artroplastia apresenta uma boa alternativa para o tratamento de paciente adulto com anquilose de $\mathrm{ATM}^{3}$. Ela consiste na ressecção da massa óssea entre a cavidade articular e o ramo da mandíbula sem material interposicional e a ressecção do processo coronóide' ${ }^{1}$ É uma técnica bastante utilizada, porém devido à falta de material interposicional, pode apresentar chance de recidiva ${ }^{3}$. Conclusão: $O$ resultado satisfatório foi alcançado pela remoção óssea do processo coronóide esquerdo e do bloco anquilótico de forma adequada, com excelente movimento articular intraoperatória, bem como pelo acompanhamento fisioterápico precoce e de longo prazo.

Descritores: Artroplastia; Anquilose; Articulação Temporomandibular.

\section{Referências:}

1. FIGUEIREDO, et al. Artroplastia interposicional para tratamento de anquilose da articulação temporomandibular. Revista Bahiana de Odontologia, 2013; 4(2):129-137

2. PORTO GG, VASCONCELOS BCE. Tratamento de anquilose na articulação temporomandibular. Revista de Ciências Médicas, 2007; 16(1):43-50

3. SANTOS MBP, et al. Tratamento de anquilose da articulacão temporomandibular. Relato de um caso. Revista Portuguesa de Estomatología, Medicina Dentária e Cirugia Maxilofacial, 2011; 52(4): 205-211

4. VASCONCELOS BCE, et al. Treatment of temporomandibular joint ankylosis by gap arthroplasty. Med Oral Patol Oral Cir Bucal, 2006; 11: 66-69 


\section{PC-30-2019 - ASPECTOS ATUAIS DAS LESÕES NERVOSAS DECORRENTES DA CIRURGIA DE TERCEIROS MOLARES INFERIORES INCLUSOS: REVISÃO DE LITERATURA}

Paulo Roberto Kohno de Oliveira ${ }^{1}$; Ana Beatriz Leme de Andrade ${ }^{1}$ João Vítor Queiroz Mendes dos Santos ${ }^{1}$

${ }^{1}$ Faculdade de Odontologia de Pernambuco - Camaragibe - PE - Brasil

Autor Correspondente:

Paulo Roberto Kohno de Oliveira

paulo_kohno@hotmail.com

Introdução: A cirurgia dentoalveolar é um procedimento comum em cirurgia bucomaxilofacial, com resultados previsíveis ${ }^{1}$. Porém é bem reconhecido que há possíveis complicações associadas com esse tipo de cirurgia. Essas complicações incluem o risco de lesão ao nervo alveolar inferior e ao nervo lingual ${ }^{2}$. Objetivo: Apresentar uma revisão de literatura acerca das lesões nervosas após a cirurgia de terceiros molares inclusos. Metodologia: Foi realizado uma pesquisa na base de dados SciELO e MEDLINE entre os anos de 2014 a 2018 com os descritores: terceiro molar, nervo alveolar inferior e parestesia. Revisão de Literatura: A etiologia das lesões nervosas é variada, porém a principal causa está relacionada com a exérese de terceiros molares inferiores inclusos ${ }^{1}$. Vários fatores de risco têm sido apontados como possíveis responsáveis pelo aparecimento dos sintomas, como a idade, o grau de inclusão dentária, a experiência do cirurgião e a técnica cirúrgica ${ }^{3}$. Quando ocorrem, a literatura tem mostrado que uma parte dos casos têm resolução espontânea, porém alguns casos necessitam de tratamento ${ }^{3}$. Conclusão: Conhecendo as causas das lesões nervosas e seus fatores de risco, pode ser realizado um bom planejamento do caso para que esta complicação seja evitada sempre que possível.

Descritores: Dente não Erupcionado; Parestesia; Terceiro Molar.

\section{Referências:}

1. ISHII S, et al. The horizontal inclination angle is associated with the risk of inferior alveolar nerve injury during the extraction of mandibular third molârs. International journal of oral and maxillofacial surgery, 2017; 46(12): 1626-1634

2. NGUYEN E, et al. Risk factors for permanent injury of inferior alveolar and lingual nerves during third molar surgery. Journal of Oral and Maxillofacial Surgery, 2014; 72(12): 2394-2401 3. SARIKOV R, JUODZBALYS G. Inferior alveolar nerve injury after mandibular third molar extraction: a literature review. Journal of oral \& maxillofacial research, 2014; 5(4) 


\section{PC-31-2019 - ASPECTOS GERAIS E CONDUTAS TERAPÊUTICAS PARA O TRATAMENTO DOS AMELOBLASTOMAS: REVISÃO DE LITERATURA}

Carla Cecília Lira Pereira de Castro ${ }^{1}$; Jeferson Batista Santiago ${ }^{1}$; Olívia Augusta Araújo Dias ${ }^{1}$; Mayara Monique Silva de Oliveira ${ }^{1}$; Joana de Ângelis Alves Silva ${ }^{1}$; Ismael Sebastião da Silva Sousa $^{1}$; Fernanda Cardoso Gurgel ${ }^{1}$; Laura Buarque Caminha Lins ${ }^{1}$

${ }^{1}$ Faculdade de Odontologia de Pernambuco - Camaragibe - PE - Brasil

Autor correspondente:

Carla Cecília Lira Pereira de Castro

carlalpc@hotmail.com

Introdução: Segundo a Organização Mundial de Saúde (OMS), o Ameloblastoma é um tumor odontogênico de origem epitelial, caracterizado por alto índice de recidiva e por predileção pela região posterior da mandíbula. É o tumor mais comum da cavidade oral, exceto pelos odontomas. Localmente invasivo e de difícil diagnóstico precoce, o tratamento varia de acordo com a extensão da lesão ${ }^{1,2,3}$. Objetivo: Apresentar uma revisão de literatura a respeito dos tumores odontogênicos Ameloblastomas. Metodologia: Foi realizada uma pesquisa na base de dados SciELO com os descritores: Ameloblastoma, tumores odontogênicos, neoplasias mandibulares. Revisão de literatura: Os Ameloblastomas originam-se dos resquícios celulares do epitélio do órgão do esmalte, assemelhando-se aos cistos odontogênicos. Sua etiologia é desconhecida e caracteriza-se pelo crescimento expansivo, lento e inicialmente indolor, com alta taxa de reicidiva ${ }^{1}$. Contudo, essa neoplasia pode apresentar crescimento tardio e acelerado, acarretando parestesia, deformidade facial, limitações na mastigação e abertura da mandíbula ${ }^{2}$. Apresenta um maior acometimento em pacientes com 30 anos de idade, sem prevalência entre os sexos. Classifica-se em: unicístico, multicistico e periférico, sendo histologicamente iguais, radiolúcidos, mas se diferenciando no tratamento. O ameloblastoma unicístico é a variante menos agressiva e está associado a terceiros molares não irrompidos. Desta forma, adota-se uma abordagem mais conservadora como enucleação e curetagem, removendo-se apenas a lesão sem margem de segurança. Entretanto, lesões multicísticas são tratadas através de uma ressecção do tumor com margem de segurança ${ }^{3}$. A variante periférica é incomum e é encontrada em 1 a $10 \%$ dos casos $^{4}$. Há ainda os ameloblastomas malignos, esses apresentam metástases à distância, difundindo-se nas vias hematogênica e linfática, acometendo principalmente os pulmões e os linfonodos cervicais ${ }^{2}$. Conclusão: Os tumores odontogênicos ameloblastomas têm origem indefinida e podem ser benignos ou metastáticos. Apresentam alta taxa de recidiva e as formam de tratamento variam de acordo com a expansão da lesão.

Descritores: Ameloblastoma; Tumores odontogênicos; Neoplasias mandibulares.

\section{Referências:}

1. BALDASSERINI G, et al. Perfil epidemiológico de los pacientes portadores de ameloblastoma sometidos a cirugía en un hospital terciario del estado de São Paulo. Rev. Odont. Mex, 2018; 22(2): 82-87

2. MOGOLLÓN-REYES G. Malignant ameloblastoma: multiple local recurrence and metastasis in the scalp. Case report. Case reports, 2019; 5(1): 36-45

3. MOREIRA TG, et al. Ameloblastoma unicístico mural com componente intraluminal revisão e relato de caso. Rev. cir. traumatol. buco-maxilo-fac, 2010; 10(1): 67-72

4. SILVA LNA, et al. Peripheral Ameloblastoma with Dystrophic Calcification: An Unusual Feature in Non-Calcifying Odontogenic Tumors. Braz. Dente. J, 2014; 25 (3): 253-256 


\section{PC-32-2019 - ASPECTOS IMAGINOLÓGICOS DE MÚLTIPLOS QUERATOCISTOS ODONTOGÊNICOS: RELATO DE CASO}

Andressa Cristina da Silva Queiroz ${ }^{1}$; Robson de Lima Gomes ${ }^{1}$; Maria Eduarda Ferreira Santiago ${ }^{1}$; Andrea dos Anjos Pontual de Andrade Lima ${ }^{1}$; Eduarda Helena Leandro do Nascimento ${ }^{1}$; Maria Luiza dos Anjos Pontual ${ }^{1}$; Luiz Alcino Monteiro Gueiros ${ }^{1}$; Flávia Maria de Moraes Ramos Perez ${ }^{1}$

${ }^{1}$ Universidade Federal de Pernambuco - Recife - PE - Brasil

Autor correspondente:

Andressa Cristina da Silva Queiroz

d.d.essa@hotmail.com

Introdução: Os queratocistos odontogênicos são cistos do desenvolvimento e apresentam uma frequência que varia de $4 \%$ a $12 \%$ de todos os cistos odontogênicos. Mais prevalentes em homens e a região posterior da mandíbula é o local geralmente mais acometido ${ }^{3}$. Radiograficamente, varia de uma lesão hipodensa unilocular ou multilocular, de limites bem definidos, podendo causar expansão vestíbulo lingual. Quando múltiplos, podem estar associados a Síndrome de Gorlin-Goltz (SGG) ${ }^{2}$. A SGG é uma desordem autossômica dominante hereditária. Suas manifestações clínicas mais comuns são: Carcinomas basocelulares múltiplos queratocistos odontogênicos, depressões palmares e/ou plantares, calcificações ectópicas da foice cerebral e malformações esqueléticas ${ }^{1}$. Objetivo: Descrever os aspectos imaginológicos de múltiplos queratocistos odontogênicos, utilizando imagens de tomografia computadorizada de feixe cônico (TCFC). Relato de caso: Paciente MBS, sexo feminino, 19 anos, apresenta múltiplas lesões hipodensas em maxila e mandíbula. Na maxila evidencia-se lesão hipodensa, multilocular, limites bem definidos, na região dos dentes 17 e 18, que causa o deslocamento do dente 17 para o seio maxilar, enquanto que na região posterior do lado esquerdo (região do dente 28), a lesão tem forma unilocular, desloca superiormente o assoalho do seio, além de causar o deslocamento dentário. As lesões mandibulares também se apresentam com limites bem definidos, têm forma unilocular e estão localizadas na região periapical dos dentes $31,32,33,41$ e 42, no corpo mandibular do lado esquerdo (região dos dentes 37 e 38) e no ramo mandibular esquerdo. Diante disto, a principal hipótese de diagnóstico foi de múltiplos queratocistos odontogênicos. Discussão: Múltiplos queratocistos odontogênicos são algumas das características presentes na SGG, entretanto há a necessidade de pesquisa de demais alterações e/ou avaliação genética para confirmação do diagnóstico ${ }^{1,2,3}$. Conclusão: ATCFC é uma importante ferramenta que auxilia o Cirurgião-Dentista na visualização dos diversos aspectos radiográficos da lesão, permitindo um melhor planejamento e tratamento cirúrgico do paciente.

Descritores: Síndrome do Nevo Basocelular; Tomografia computadorizada de Feixe Cônico; Cistos Odontogênicos.

\section{Referências:}

1. MAGRO AKD, et al. Síndrome de gorlin-goltz- relato de casos. Revista da Faculdade de Odontologia, 2014; 19(2): 239-244

2. MANJIMA S, et al. Multiple jaw cysts-unveiling the Gorlin-Goltz syndrome. Contemp Clin Dent, 2015; 6(1): 102-105

3. WITTEVEEN ME, et al. Odontogenic keratocysts located in the buccal mucosa: A description of two cases and review of the literature. SAGE Open Med Case Rep, 2019; 7: 1-4 


\section{PC-33-2019 - ASPECTOS MICROBIOLÓGICOS DA CÁRIE DENTÁRIA}

Kássia Regina de Santana ${ }^{1}$; Cleiton Rone dos Santos Lima ${ }^{1}$; Cláudia Geisa Souza e Silva ${ }^{1}$; Emerllyn Shayane Martins de Araújo ${ }^{1}$; Aylanne Xavier de Lacerda Cavalcante Timoteo ${ }^{1}$; Ingrid Patrícia de Moraes Lima ${ }^{1}$; Ramisse Moreira de Albuquerque ${ }^{1}$; Eliana Santos Lyra da Paz ${ }^{1}$

${ }^{1}$ Faculdade de Odontologia de Pernambuco - Camaragibe - PE - Brasil

Autor correspondente:

Kássia Regina de Santana

kassiaupe2016.1@gmail.com

Introdução: A cavidade oral apresenta uma grande diversidade de microrganismos. A microbiota bucal encontra-se normalmente em harmonia com o hospedeiro, porém, em condições anormais tem o potencial de gerar infecções bucais e sistêmicas graves ${ }^{1}$. A cárie é uma doença infectocontagiosa, de caráter crônico e multifatorial. Sabe-se da indispensabilidade de microrganismos na superfície dental para que tenhamos o desenvolvimento da doença cárie, porém só a presença deles não é o bastante ${ }^{3}$. Objetivo: $O$ presente estudo teve como objetivo verificar a importância da microbiota oral no processo saúde-doença da cárie dentária. Metodologia: Foi realizada uma revisão de literatura, por meio de pesquisa nas bases de dados: SciELO, BIREME e Google Acadêmico, com os descritores: Cárie Dentária; Suscetibilidade à Cárie Dentária; Microbiologia. Tendo como critérios de inclusão: artigos científicos que tratassem sobre a temática, publicados entre 2000 e 2019. Revisão de Literatura: Os resultados demonstraram que a microbiota oral sofre influência da temperatura, $\mathrm{pH}$, presença de oxigênio, disponibilidade de nutrientes e os mecanismos de defesa do hospedeiro ${ }^{3}$. Os trabalhos indicam a diversidade de microrganismos que habitam a superfície dentária e que a cárie dentária é um dos problemas de saúde bucal mais comum na humanidade, está relacionada à desmineralização do esmalte, dentina e cemento dentário, iniciada por uma atividade microbiana que causa alterações no $\mathrm{pH}$ bucal $^{2}$, assim como à atividade imunológica contra as bactérias que é diversificada em imunidade inata e imunidade adquirida, que conseguem atuar isoladamente ou simultaneamente. Conclusão: Desse modo, é indispensável discutir acerca dos fatores microbiológicos e imunológicos que conferem proteção ao hospedeiro, visto que as respostas imunológicas contra bactérias podem ser distintas, ressaltando a importância das relações sobre o sistema imunológico com relação à cárie dentária e saúde bucal.

Descritores: Cárie Dentária; Suscetibilidade à Cárie Dentária; Microbiologia.

\section{Referências:}

1. JÚNIOR JCCS, et al. Microbiota oral e sua implicação no binômio saúde-doença. Revista Contexto \& Saúde, 2019; 19(36): 91-99

2. JÚNIOR VHSD, et al. Imunologia da cárie dentária: revisão de literatura. Unicatólica Quixadá, 2019; 4(1): 1-5

3. LEITES ACBR, et at. Aspectos microbiológicos da cárie dental. Salusvita, 2005; 25(2): 239252 


\section{PC-34-2019 - ASPECTOS TOMOGRÁFICOS DAS DISPLASIAS CEMENTO-ÓSSEAS}

Marvison Henrique Ferreira da Silva ${ }^{1}$; Andréa dos Anjos Pontual ${ }^{1}$; Danyel Elias da Cruz Perez ${ }^{1}$; Dara Karen Freire de Oliveira ${ }^{1}$; Eduarda Helena Leandro Nascimento ${ }^{1}$; Flávia Maria de Moraes Ramos Perez ${ }^{1}$; Maria Luiza dos Anjos Pontual ${ }^{1}$; Rebeca de Almeida Buriti da Silva ${ }^{1}$

${ }^{1}$ Universidade Federal de Pernambuco - Recife - PE - Brasil

Autor correspondente:

Marvison Henrique Ferreira da Silva

mavinho_mm@hotmail.com

Introdução: Displasias cemento-ósseas são lesões fibro-ósseas benignas, mais comuns na mandíbula ${ }^{4}$, e se caracterizam pela substituição do osso normal por tecido fibroso contendo áreas de substância mineralizada ${ }^{1}$. São subdividas de acordo com sua localização em displasias ósseas periapical, focal e florida ${ }^{4}$. Objetivo: Apresentar aspectos imaginológicos de displasias cemento-ósseas através de dois relatos de caso. Relatos de caso: No primeiro caso, paciente do sexo feminino, 22 anos, realizou uma tomografia computadorizada de feixe cênico (TCFC) para avaliação pré-cirúrgica dos terceiros molares. Como achado incidental, observou-se uma imagem hiperdensa circunscrita por área hipodensa na região periapical do dente 23, sugestiva de displasia cemento-óssea periapical. No segundo caso, o exame de TCFC de uma paciente do sexo feminino, 56 anos, revelou áreas hipodensas com hiperdensidades no seu interior, bem delimitadas na região periapical dos dentes 31, 41, 42 e 43. Observou-se também adelgaçamento e discreta expansão da cortical vestibular, na região dos dentes 41,42 e 43 . A principal hipótese de diagnóstico foi de displasia cemento-óssea periapical. Discussão: As displasias cemento-ósseas são assintomáticas ${ }^{4}$, ocorrem preferencialmente em mulheres, pacientes negros, com maior incidência na quarta e quinta década de vida ${ }^{2}$. Estão localizadas na região periapical dos dentes e geralmente são identificadas em exames radiográficos de rotina $^{1}$. Dependendo do estágio de desenvolvimento da lesão, podem ocorrer erroneamente diferentes diagnósticos diferenciais ${ }^{3}$ e a realização de procedimentos inadequados ${ }^{4}$. Dessa forma, é imprescindível o conhecimento do cirurgião-dentista sobre os estágios evolutivos da lesão para evitar equívocos em seu diagnóstico e realização de procedimento inadequados ${ }^{4}$. Conclusão: As displasias cemento-ósseas são lesões detectadas por exames imaginológicos de rotina que necessitam do cirurgião-dentista um determinado conhecimento clínico e radiológico a fim de evitar erros em seu diagnóstico.

\section{Descritores: Tomografia; Cementoma; Doenças Periodontais.}

\section{Referências:}

1. CAVALCANTI PHP, et al. Cemento-osseous dysplasias: Imaging features based on cone beam computed tomography scans. Braz. Dent. J., 2018; 29(1): 99-104

2. MACDONALD-JANKOWSKI DS. Focal cemento-osseous dysplasia: a systematic review. Dentomaxillofac Radiol., 2008; 37(6): 350-360

3. SIROTHEAU CPF, et al. Nonendodontic lesions misdiagnosed as apical periodontitis lesions: serie of case reports and review of literature. J. Endod., 2014; 40(1): 16-27

4. WALDRON CA. Fibro-osseous lesions of the jaws. J Oral Maxillofac Surg, 1993; 51(8): $828-835$ 


\section{PC-35-2019 - ASSOCIAÇÃO DE TÉCNICAS PARA CLAREAMENTO DENTAL: RELATO DE CASO}

Maria Beatriz Arruda Albuquerque ${ }^{1}$; Francisco Henrique Lima Milhomens ${ }^{1}$; Héberte de Santana Arruda ${ }^{1}$; Eduardo Borges da Costa Leite ${ }^{2}$; Amanda Maciel do Prado ${ }^{1}$; Fernanda Gomes Barros $^{1}$; Carolina Pereira da Silva ${ }^{1}$; Marcos Antônio Japiassú Resende Montes ${ }^{1}$

${ }^{1}$ Faculdade de Odontologia de Pernambuco - Camaragibe - PE - Brasil

${ }^{2}$ Universidade Federal de Pernambuco- Recife- PE - Brasil

Autor correspondente:

Maria Beatriz Arruda Albuquerque

mariaarruda12@gmail.com

Introdução: Atualmente o conceito de estética está relacionado principalmente a dentes brancos e bem alinhados. Assim, a busca por dentes mais claros tem sido uma constante, tornando o clareamento dental um dos tratamentos mais procurados nos consultórios odontológicos $^{3,5}$. Ele pode ser planejado tanto para dentes vitais como não vitais, sendo diferenciado quanto ao tipo de agente clareador, sua concentração e técnica de aplicação ${ }^{5}$. O clareamento dental externo oferece ao cirurgião-dentista uma forma simples e conservadora para melhorar a estética do sorriso. As técnicas disponíveis atualmente incluem o clareamento realizado em consultório, o caseiro e a associação de ambas ${ }^{4}$. Objetivo: $\mathrm{O}$ objetivo desse trabalho foi relatar um caso clínico em que dentes naturalmente amarelados foram clareados utilizando associação das técnicas de clareadoras. Relato de caso: Paciente de 25 anos procurou a Clínica do Curso de Especialização em Dentística, relatando que seus dentes estavam "amarelados", o que a deixava incomodada ao sorrir. Após realização de exame clínico e fotográfico elaborou-se um plano de tratamento que consistiu em fazer uma associação de técnicas, o clareamento caseiro ao clareamento de consultório, visando alcançar um resultado mais eficiente. Discussão: A terapia clareadora pode ser conduzida com uma terapia mais amena, empregando a técnica caseira com o peróxido de carbamida ou de forma mais intensa na chamada técnica in-office ou de consultório, que emprega substâncias mais concentradas ${ }^{1}$. Optou-se pela associação das técnicas uma vez que a eficácia e a segurança desse protocolo estão bem difundidas na literatura. Conclusão: A técnica de clareamento dental combinado mescla a rapidez da sessão em consultório com a versatilidade do clareamento domiciliar supervisionado, trazendo os benefícios de ambas as técnicas para o paciente ${ }^{2,4}$.

\section{Descritores: Clareamento Dental; Estética Dentária; Odontologia.}

\section{Referências:}

1. BERSEZIO C, et al. Quality of Life and Stability of Tooth Color Change at Three Months After Dental Bleaching. Quality of Life Research, 2018; 27(12): 199-207

2. KAEWPINTA A, et al. Tooth Whitening Efficacy of Pigmented Rice Gels Containing Carbamide Peroxide. Drug Discoveries \& Therapeutics,2018; 12(3):126-132

3. MONTENEGRO AK, et al. Alterações das Propriedades Óticas do Esmalte e da Dentina Após o Clareamento Dental - Uma Revisão da Literatura. Revista da Faculdade de Odontologia de Lins/Unimep, 2016; 26(2):75-82

4. PASQUALI EL, et al. Estudo dos Efeitos do Clareamento Dental sobre o Esmalte: Uma Revisão das Evidências para a Indicação Clínica. Perspectiva, 2014; 38(141):99-108. SOSSAI N, et al. Clareamento Dental. Revista Saúde e Pesquisa, 2011; 4(3):425-436 


\title{
PC-36-2019 - ATENDIMENTO ODONTOLÓGICO EM PACIENTE COM SÍNDROME BARAITSER WINTER: RELATO DE CASO
}

\author{
Amanda Cristina de Magalhães Souza ${ }^{1}$; Amanda Idalina de França Medeiros ${ }^{1}$; Robson José dos \\ Santos $^{1}$; Valéria Fernandes Maranhão ${ }^{2}$ \\ ${ }^{1}$ Centro Universitário Tiradentes - Recife - PE - Brasil \\ ${ }^{2}$ Universidade de Pernambuco - Recife - PE - Brasil
}

Autor correspondente:

Amanda Idalina de França Medeiros

amanda-idalina@hotmail.com

Introdução: Está síndrome tem como características marcantes hipertelorismo, nariz largo com ponta grande, ptose congênita e sobrancelhas arqueadas, também são observados Fendas labiais e palatinas em alguns casos ${ }^{1,3}$. Objetivo: Expor 0 atendimento prestado baseado em evidências clínicas. Relato de caso: Paciente G.C.D., 08 anos de idade, gênero: feminino, diagnóstico de síndrome Baraitser Winter, uma condição rara, sendo a única criança da América Latina. Recebemos a menor em nossa Clínica Escola Centro Universitária Tiradentes para atendimento odontológico, acompanhada de sua genitora, está relatando durante anamnese que a paciente possui histórico de Epilepsia Refratário devido sua síndrome, e fazendo uso dos medicamentos Canabidiol, Vimpat, Sonebon e Lamitor. Ao exame clínico constatou-se grande quantidade dentes cariados, fratura de dentes devido trauma durante episódio crise convulsiva. Necessitando de tratamento restaurador nos dentes 41, 11, 55, 64, 65, 75, 85 e 46. Discussão: O ambiente de escolha foi o atendimento ambulatorial. Porém, após duas sessões de condicionamento e sedação medicamentosa, não foi possível realizar o procedimento proposto, devido comportamento da menor, sendo constatada necessidade de atendimento odontológico sob anestesia geral. Foram realizados protocolos para a realização do atendimento a nível hospitalar: exames laboratoriais e parecer cardiológico. $\mathrm{O}$ atendimento se deu no Hospital Infantil Manoel da Silva Almeida na cidade do Recife, sob supervisão do profissional e equipamentos necessários. Foram realizados os seguintes procedimentos raspagem e polimento dental como adequação do meio e restaurações: dente 11 classe III em resina composta, dente 41 classe III em resina composta, dente 55 classe I em resina composta, dente 64 classe II em resina composta, dente 65 classe I em resina composta, dente 75 classe I em resina composta, dente 85 classe I em resina composta e dente 46 classe I em resina composta. Conclusão: Resultando em melhora na condição de saúde bucal e psicossocial do paciente ${ }^{2}$.

Descritores: Odontopediatria; Mutação; Síndrome.

\section{Referências:}

1. BARAITSER M, WINTER RM. Íris coloboma, ptose, hipertelorismo e retardo mental: uma nova síndrome. Revista de genética médica, 1988; 25(01): 41

2. DI DONATO N, et al. Severe forms of Baraitser-Winter syndrome are caused by ACTB mutations rather than ACTG1 mutations. European Journal of Human Genetics, 2014; 22(2): 179

3. VERLOES A, et al. Baraitser-Winter cerebrofrontofacial syndrome: delineamento do espectro em 42 casos. Revista Europeia de Genética Humana, 2015; 23(3): 292 


\section{PC-37-2019 - ATENDIMENTO PRIMÁRIO À VÍTIMA DE TRAUMABUCO MAXILO FACIAL: UMA REVISÃO DE LITERATURA}

Camilla Siqueira de Aguiar ${ }^{1}$; Emerllyn Shayane Martins de Araújo ${ }^{2}$; Frederico Márcio Varela Ayres de $\mathrm{Melo}^{3}$; Bruna Heloísa Costa Varela Ayres de Melo ${ }^{3}$; Rodrigo Henrique Mello Varela Ayres de Melo ${ }^{4}$; Victor Leonardo Mello Varela Ayres de Melo ${ }^{1}$; Marcela Côrte real Fernandes ${ }^{1}$; Ricardo Eugenio Varela Ayres de Melo ${ }^{1}$

${ }^{1}$ Universidade Federal de Pernambuco - Recife - PE - Brasil

${ }^{2}$ Faculdade de Odontologia de Pernambuco - Camaragibe - PE - Brasil

${ }^{3}$ Universidade Maurício de Nassau - Natal - RN - Brasil

${ }^{4}$ Prefeitura Municipal de Arroio dos Ratos - Arroio dos Ratos - RS - Brasil

Autor correspondente:

Camilla Siqueira de Aguiar

Camilla.aguiar@outlook.com.br

Introdução: O Trauma Buco Maxilo Facial é uma modalidade de trauma que apresenta diversos tipos de agravantes no que diz respeito à apresentação clínica, manejo e tratamento. Este tipo de trauma afeta tanto tecidos moles quanto estruturas ósseas, sendo sua reabilitação um processo demorado e custoso ${ }^{1}$. Objetivo: O estudo visa, a partir de uma revisão da literatura, identificar principais agravos do trauma facial que se caracterizam como fatores de empecilho à instituição de procedimentos de atendimento primário e suporte básico à vida. Metodologia: Foi realizada uma pesquisa na base de dados Scholar Google com os descritores: Traumatologia, Face, Cuidados de Suporte Avançado de Vida no Trauma. Revisão de literatura: Pode ser identificado que a vítima de trauma facial apresenta agravos na avaliação inicial, que dificultam ou impossibilitam alguns dos consagrados métodos da Advanced Trauma Life Suport (ATLS), conhecido por ser o padrão ouro no tratamento de vítimas de traumatismo ${ }^{2,4}$. Na avaliação primária da vítima é preconizado o uso do padrão ABCDE. Sendo o acesso e manutenção das vias aéreas com proteção da coluna cervical, ou "A", o maior obstáculo, até mesmo porque manobras como Chin Lift e Jaw Thrust são difíceis em certos tipos de trauma. Há obstáculos ainda na instituição dos procedimentos das etapas de respiração e ventilação, ou "B"; em "C" é prioritário o controle hemorrágico; "D" avalia o nível de consciência do paciente e "E" representa expor o paciente, ou seja, despi-lo e controlar o ambiente prevenindo a hipotermia. Além disso, encontra-se dificuldade na criação de uma via aérea temporária ${ }^{3,5}$. Conclusão: A vítima de trauma facial apresenta vários fatores agravantes que devem ser conhecidos pelo socorrista e profissional responsável pelo tratamento, a fim de otimizar o quadro e evolução do paciente além de evitar danos secundários.

Descritores: Traumatologia; Face; Cuidados de Suporte Avançado de Vida no Trauma.

\section{Referências:}

1. DOUCET JC. Helping Anesthesiologists Understand Facial Fractures. Maxillofacial Surgery Clinics of North America, 2013; 25(2): 561-572

2. PERRY M. Advanced Trauma Life Support (ATLS) and facial trauma: can one size fitall? Part 1: Dilemmas in the management of the multiply injured patient with coexistingfacial injuries. International Journal of Oral and Maxillofacial Surgery, 2008; 37(1): 209-214

3. PERRY M, et al. Advanced Trauma Life Support (ATLS) and facial trauma: can one size fit all? Part 3: Hypovolaemia and facial injuries in the multiply injured patient. International Journal of Oral and Maxillofacial Surgery, 2008; 37(1): 405-414

4. PERRY M, MORRIS C. Advanced Trauma Life Support (ATLS) and facial trauma: can one size fit all? Part 2: ATLS, maxillofacial injuries and airway management dilemmas. 
International Journal of Oral and Maxillofacial Surgery, 2008; 37(1): 309-320

5. RAY BR, et al. Anaesthetic management of maxillofacial trauma. Trends in Anaesthesia and Critical Care, 2013; 3(1): 231-237.
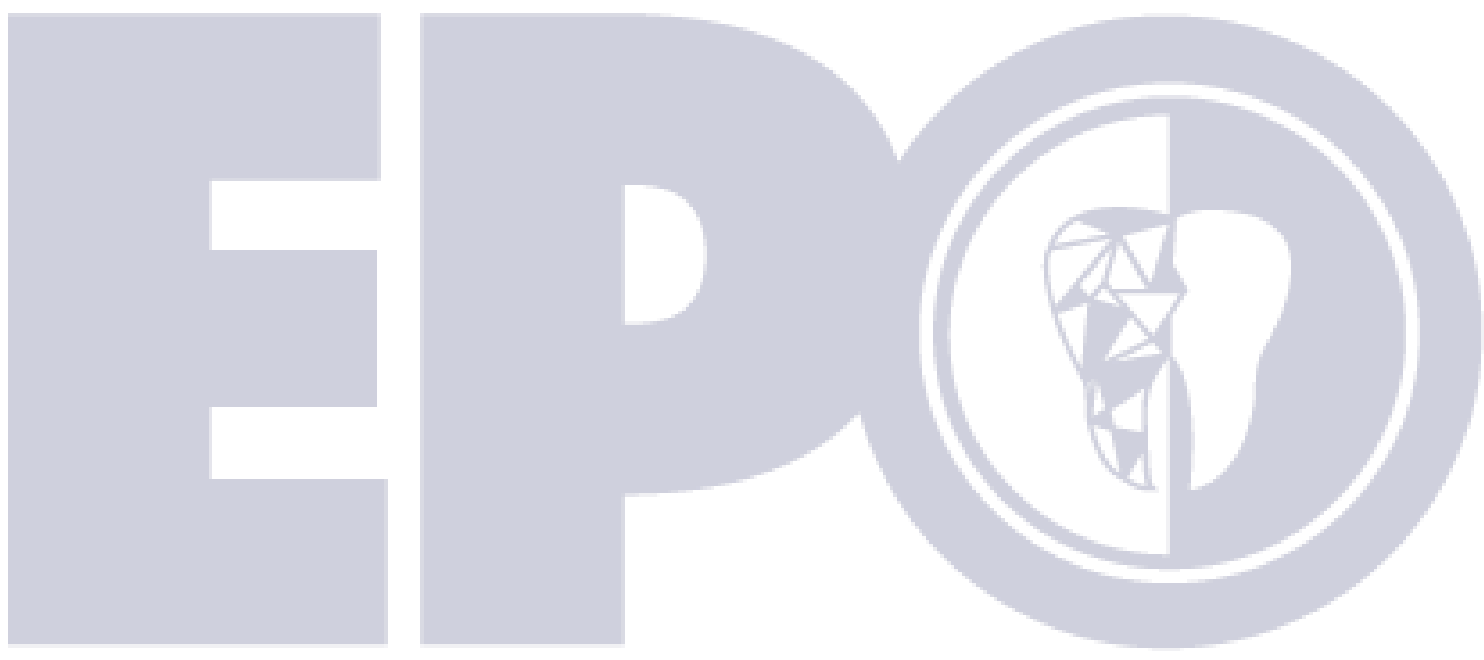


\section{PC-38-2019 - ATUAÇÃO DO PSICOONCOLOGISTA NA EQUIPE MULTIPROFISSIONAL DE PACIENTES COM CÂNCER DE CABEÇA E PESCOÇO: REVISÃO DE LITERATURA}

Mirela Carolaine Cunha da Cruz ${ }^{1}$; Silvana Orestes Cardoso ${ }^{1}$; Héberte de Santana Arruda ${ }^{1}$; Mariana Galindo Soares; Giovanna Tarquino Sales Munizi; Thomas Douglas de Araújo Figuerêdo ${ }^{1}$

${ }^{1}$ Universidade Federal de Pernambuco - Recife - PE - Brasil

Autor correspondente:

Mirela Carolaine Cunha da Cruz

mirela.carolaine@hotmail.com

Introdução: A Psicooncologia é uma área de conhecimento multidisciplinar que tem por objeto estudar os fatores biopsicossociais que influenciam o aparecimento, o desenvolvimento, a adesão a tratamentos e qualidade de sobrevida de pacientes diagnosticados com câncer ${ }^{1,2,3}$. Objetivo: O presente estudo consistiu em identificar as principais atuações do psicooncologista frente a pacientes com câncer de cabeça e pescoço. Metodologia: Foi realizada uma revisão de literatura a partir de busca nas bases de dados eletrônicas sobre o tema, a exemplo de PubMed, SciELO, LILACS. Foram selecionados 20 artigos, utilizando-se descritores tais como: oncologia, cabeça e pescoço, psicooncologia, aspectos emocionais e doenças crônicas. Revisão de literatura: Os resultados obtidos enfatizam a importância do profissional que atua nessa área, identificando o contexto em que os pacientes estão inseridos e auxiliando a instruir para que o processo de combate à doença seja mais eficaz. É de grande importância a função que esse profissional desempenha no tratamento dos fatores psicológicos relacionados ao diagnóstico de câncer, ajudando os pacientes no enfrentamento do estresse, na adaptação aos limites que a doença proporciona, além de prepará-lo, antecipadamente, para procedimentos invasivos e dolorosos relacionados ao tratamento ${ }^{4,5}$. Conclusão: Diante da complexidade e variabilidade dos problemas decorrentes do tratamento oncológico, amplamente comprovado na literatura, é de grande valia considerar não apenas os aspectos clínicos, mas também os sociais e psicológicos associados ao câncer, para isso, a interdisciplinaridade é fundamental. Diferentes profissionais estabelecem uma relação recíproca com os pacientes, levando a um favorecimento de intervenções técnicas e humanizadas no cuidado.

Descritores: Odontologia; Oncologia; Psicologia.

\section{Referências:}

1. ARAUJO TCF. Câncer Infantil: intervenção, formação e pesquisa em psico-oncologia pediátrica. Psicol. hosp., 2006; 4 (1): 1-12

2. JUNIOR ALC. O desenvolvimento da psico-oncologia: implicações para a pesquisa e intervenção profissional em saúde. Psicol. cienc. prof., 2001; 21 (2): 36-43

3. SCANNAVINO CSS, et al. Psico-Oncologia: atuação do psicólogo no Hospital de Câncer de Barretos. Psicologia USP, 2013; 24(1): 35-53

4. SOUZA JR, SEIDL EMF. Distress e enfrentamento: da teoria à prática em psico-oncologia. Brasília Med, 2014; 50 (3): 242-252 


\title{
PC-39-2019 - ATUAÇÃO E IMPORTÂNCIA DO CIRURGIÃO DENTISTA EM AMBIENTE HOSPITALAR: REVISÃO DE LITERATURA
}

\begin{abstract}
Kataryne Maria dos Santos ${ }^{1}$; Gabriela Laiza Candido da Silva ${ }^{1}$; Izaias Manoel da Silva ${ }^{1}$; Ismael Sebastião da Silva Sousa ${ }^{1}$; Jeferson Batista Santiago ${ }^{1}$; Joana de Ângelis Alves Silva ${ }^{1}$; Mayara Monique Silva de Oliveira ${ }^{1}$; Olívia Augusta Araújo Dias ${ }^{1}$
\end{abstract}

${ }^{1}$ Faculdade de Odontologia de Pernambuco - Camaragibe - PE - Brasil

Autor correspondente

Kataryne Maria dos Santos

kataryne.07@hotmail.com

Introdução: A odontologia hospitalar é a prática que visa os cuidados das alterações bucais que exigem procedimentos de equipes multidisciplinares de alta complexidade ${ }^{2}$. Tais cuidados são advindos das morbidades individuais, em um contexto que busca o atendimento de forma integral ao paciente ${ }^{3}$. Objetivo: Apresentar uma revisão de literatura sobre a atuação e importância da odontologia hospitalar. Metodologia: Revisão de literatura realizada através de pesquisas de artigos feitas na base de dados SciELO, a partir das seguintes palavras chave: Equipe hospitalar de odontologia, Unidade hospitalar de odontologia, Assistência odontológica. Revisão de literatura: O estado da saúde bucal possui influência na evolução e resposta das condições e alterações sistêmicas, assim como alterações sistêmicas e até mesmo interações medicamentosas podem comprometer a saúde bucal ${ }^{4}$. Por este motivo é dada a importância do controle químico e mecânico da colonização bucal em ambiente hospitalar, a fim de se prevenir os desfechos desfavoráveis de saúde, principalmente o aparecimento de infecções oportunistas, sobretudo as infecções do trato respiratório ${ }^{1,4}$. Desta forma, o atendimento odontológico não pode ser negligenciado na atenção terciária ${ }^{2}$. A atuação do cirurgião dentista nos hospitais se dá principalmente pela realização de técnicas corretas de higiene, já que a autonomia para o autocuidado encontra-se frequentemente comprometida em pacientes hospitalizados ${ }^{4}$. $\mathrm{O}$ cirurgião dentista pode atuar conjuntamente, desde o momento do diagnóstico até o processo de melhoria dos pacientes, realizando terapias de tratamento ou ainda sendo coadjuvante durante os procedimentos de rotina nos hospitais ${ }^{3}$. Conclusão: Dados epidemiológicos e de atuação profissional em saúde são necessários para o delineamento de políticas e estratégias em saúde voltadas para a atuação do cirurgião-dentista em ambiente hospitalar. Apesar da importância de a intervenção odontológica nos hospitais ser reconhecida, a presença desse profissional na equipe hospitalar ainda é restrita, o que reflete na precariedade desse serviço no país.

Descritores: Equipe hospitalar de odontologia; Assistência odontológica; Unidade hospitalar de Odontologia.

\section{Referências:}

1. BLUM DFC, et al. A atuação da Odontologia em unidades de terapia intensiva no Brasil. Rev Bras Ter Intensiva, 2018; 30(3): 327-332

2. GONDIM CG, et al. Saúde bucal de pacientes internados em hospital de emergência. Arq Odontol, 2012; 48(4): 270-279

3. MICLOS PV, et al. Prática da promoção e educação em saúde bucal nos hospitais de grande porte da região metropolitana de Belo Horizonte, Minas Gerais. Arq Odontol, 2013; 49(2): 8287

4. ROCHA AL, FERREIRA EF. Odontologia hospitalar: a atuação do cirurgião dentista em equipe multiprofissional na atenção terciária. Arq Odontol, 2014; 50(4): 154-160 


\section{PC-40-2019 - AUMENTO DE COROA CLÍNICA ESTÉTICO PELA TÉCNICA FLAPLESS: RELATO DE CASO CLÍNICO}

Iasmin Cirino da Silva ${ }^{1}$; Marilya Roberta Ferreira de Melo ${ }^{1}$; Letícia de Oliveira Santos ${ }^{1}$; Ismael Sebastião da Silva Sousa ${ }^{1}$; Eduardo de Farias Barbosa ${ }^{1}$; Gabriela Brito Vasconcelos ${ }^{2}$

${ }^{1}$ Faculdade de Odontologia de Pernambuco - Camaragibe - PE - Brasil

${ }^{2}$ Universidade Federal de Pernambuco - Recife- PE - Brasil

Autor correspondente:

Iasmin Cirino da Silva

iasmincirino@gmail.com

Introdução: Sorriso gengival é o termo utilizado quando há exposição exagerada de gengiva maxilar durante o sorriso, caracterizado pela exposição gengival maior que $3 \mathrm{~mm}$. A origem do sorriso gengival é multifatorial, fazendo-se necessário uma adequada análise para o correto diagnóstico e tratamento ${ }^{1,3}$. Objetivo: Relatar um caso clínico de correção de sorriso gengival através da cirurgia de aumento de coroa clínica pela técnica sem retalho "flapless". Relato de caso: Paciente leucoderma, sexo feminino, 25 anos, procurou o serviço odontológico com queixa estética relacionada ao tamanho da coroa clínica do elemento dentário 22 . Foi constatada coroa clínica curta conferindo sorriso gengival estético, com indicação para a técnica "flapless" nos dentes incisivos laterais superiores. Primeiramente, estabelecido o posicionamento da incisão pela JCE, realizada a incisão e remoção do tecido gengival e refinamento das margens gengivais. A osteotomia é feita via sulco gengival com utilização de microcinzéis. Discussão: Tradicionalmente, os procedimentos de osteotomia/osteoplastia dependem da elevação do retalho para a exposição da crista óssea. De acordo com a literatura ${ }^{1}$, isso é válido para casos com periodonto espesso, já que a osteoplastia se faz necessária para otimizar a arquitetura óssea e melhorar a adaptação do tecido mole na região cervical. Nesse contexto, sendo livre de retalho, a técnica "flapless" é indicada para biótipos finos e intermediários bem como é minimamente invasiva. Os benefícios da técnica incluem a finalização do procedimento sem a necessidade de suturas, a diminuição do desconforto pós-operatório e resultado satisfatório em menor espaço de tempo. Com estética favorável e aumento do nível de previsibilidade do resultado ${ }^{1,2}$. Conclusão: $\mathrm{O}$ uso da técnica "flapless" pode ser uma ótima alternativa cirúrgica para a correção do sorriso gengival pelas vantagens mencionadas. Os resultados são previsíveis e esteticamente favoráveis, desde que se respeitem as indicações adequadas e se obedeça criteriosamente ao protocolo de execução.

Descritores: Aumento da Coroa Clínica; Estética Dentária; Cirurgia Bucal.

\section{Referências:}

1. CARVALHO PFM, et al. Aumento de coroa clínica estético sem retalho: uma nova alternativa terapêutica. Revista da Associação Paulista de Cirurgiões Dentistas, 2010; ed esp (1): 26-33

2. LEMES LTO, et al. Aumento de coroa clínica com a técnica flapless: relato de caso. Revista Eletrônica SOBRAPE, 2018; 28(3): 73-78

3. MENDES APM. Sorriso Gengival: etiologia, diagnóstico e opções de tratamento.

Dissertação (Mestrado Integrado em Medicina Dentária) - Universidade de Lisboa, Lisboa, $2011 ; 38 p$ 


\section{PC-41-2019 - AVULSÃO DE MARGEM E ASSOALHO DE ÓRBITA EM PACIENTE PEDIÁTRICO: RELATO DE CASO}

Pedro Paulo Ribeiro de Farias ${ }^{1}$; Kalyne Kelly Negromonte Gonçalves ${ }^{2}$; Priscilla Sarmento Pinto $^{2}$; Jéssica da Silva Cunha²; Demóstenes Alves Diniz ${ }^{2}$; Caio César Gonçalves Silva ${ }^{3}$; Dirceu de Oliveira Filho ${ }^{2}$

${ }^{1}$ Faculdade de Odontologia de Pernambuco - Recife - PE - Brasil

${ }^{2}$ Hospital da Restauração - Recife - PE - Brasil

${ }^{3}$ Universidade de Pernambuco - Recife - PE - Brasil

Autor correspondente:

Pedro Paulo Ribeiro de Farias

prfarias97@gmail.com

Introdução: Por causa do crescimento, a criança que sofre traumatismo pode apresentar sequelas, principalmente se a fratura atingir centros de crescimento facial ${ }^{1}$. Traumas na região periorbital ou mesmo fraturas do complexo zigomático são comuns em casos de trauma de face e frequentemente se estendem ao assoalho da órbita ${ }^{2}$. Diferentes materiais têm sido utilizados para a recomposição dos assoalhos orbitários, como tela de titânio, osso autógeno e tela bioabsorvível, permitindo o reposicionamento do globo ocular à sua posição anatômica de origem ${ }^{3}$. Objetivo: Relatar um caso clínico de um paciente pediátrico apresentando avulsão de assoalho de órbita e margem infra-orbitária esquerda. Relato de caso: Paciente do gênero masculino, 10 anos de idade, compareceu ao serviço de Cirurgia e Traumatologia Buco-MaxiloFacial do Hospital da Restauração, Recife-PE, com história de queda de carroça. Ao exame físico apresentava edema e equimose periorbitário esquerdo, ferimento extenso em face, amaurose em olho esquerdo, desvio nasal e queixa respiratória. $\mathrm{O}$ paciente seguiu em acompanhamento na enfermaria aguardando regressão progressiva do edema. Após 07 dias, o paciente seguiu com ptose em pálpebra esquerda e distopia importante em olho esquerdo, bem como se mantinha a amaurose em olho esquerdo. A equipe de oftalmologia indicou acompanhamento ambulatorial. $\mathrm{O}$ paciente foi submetido à cirurgia sob anestesia geral, para redução de ossos próprios do nariz, com instalação de tampão nasal anterior, bem como reconstrução de assoalho orbitário esquerdo utilizando tela de titânio $1.5 \mathrm{~mm}$, através do acesso infraorbitário esquerdo. O paciente segue em acompanhamento ambulatorial, com melhora do desvio nasal, sem queixa respiratória e melhora da distopia ocular. Discussão: Em concordância com a literatura, o caso em questão traz complicações importantes associadas às fraturas de assoalho orbital, que necessitam de reparo precoce. Conclusão: Evidencia-se que fratura de assoalho orbitário traz complicações estéticas e funcionais importantes e são de difícil tratamento, principalmente se realizada tardiamente.

Descritores: Fraturas Orbitárias; Órbita; Titânio.

\section{Referências:}

1. DOURADO E, et al. Trauma facial em pacientes pediátricos. Revista de Cirurgia e Traumatologia Buco-Maxilo-Facial, 2004; 4(2): 105-114

2. GURGEL JDC, et al. Ricinus communis membrane for orbital reconstruction. Brazilian Journal of Otorhinolaryngology, 2011; 77(2): 268

3. OLIVEIRA RB, et al. Utilização de diferentes materiais de reconstrução em fraturas do assoalho de órbita: relato de seis casos. Revista de Cirurgia e Traumatologia Buco-MaxiloFacial, 2005; 5(3): 43-50 


\section{PC-42-2019 - BENEFÍCIOS DA ARTROCENTESE EM PACIENTES PORTADORES} DE DISFUNÇÃO TEMPOROMANDIBULAR (DTM)

Marcela Lins Braga ${ }^{1}$; Bruna Lucena Borges ${ }^{1}$; Carolina Pereira da Silva ${ }^{1}$; Déborah Abigail Morais Kirniew ${ }^{1}$; Lívia Mirelle Barbosa ${ }^{1}$; Luíza Flôres da Costa Fagundes ${ }^{1}$; Priscilla Sarmento Pinto $^{2}$; Belmiro Cavalcanti do Egito Vasconcelos ${ }^{1}$

${ }^{1}$ Faculdade de Odontologia de Pernambuco - Camaragibe - PE - Brasil

Universidade Federal da Paraíba - João Pessoa - PB - Brasil

Autor correspondente:

Marcela Lins Braga

marcelalinsbraga@hotmail.com

Introdução: A artrocentese é uma das primeiras opções de tratamento cirúrgico para pacientes portadores de DTM que não respondem à terapia conservadora ${ }^{1}$. Consiste na lavagem do espaço articular superior da articulação temporomandibular (ATM), sem uma visão direta deste, com a finalidade primária de eliminar tecidos necrosados, sangue e mediadores álgicos, objetivando a melhora da sintomatologia relatada pelo paciente ${ }^{2}$. Objetivo: Apresentar uma revisão de literatura a respeito dos benefícios da técnica de artrocentese em pacientes com DTM. Metodologia: Foi realizada uma pesquisa na base de dados PubMed com os descritores: articulação temporomandibular, artrocentese e transtornos da articulação temporomandibular. Revisão de Literatura: São indicações para a artrocentese situações em que há o aumento da viscosidade do líquido sinovial dentro da cápsula articular com a formação de aderências e retenções na superfície do disco, causando dores e comprometimento funcional. A técnica tradicional consiste em lavar e injetar medicações no espaço articular utilizando duas agulhas, uma para a entrada da solução e outra para a saída². A injeção do líquido, através da pressão hidráulica, proporciona o rompimento da união adesiva entre superfície do disco e fossa mandibular, além da melhora na abertura bucal, alívio de dores e estalidos ${ }^{3}$. Conclusão: Temse a técnica como uma opção terapêutica benéfica e satisfatória diante da falha no tratamento conservador prévio, com baixa morbidade, baixo custo, podendo ser realizada sob anestesia local e exigindo pouco equipamento cirúrgico, corrobora para o ganho na abertura bucal, movimentos de lateralidade, diminuição de queixas álgicas e principalmente, apresenta bom prognóstico quando indicâda corretamente, oferecendo conforto para o paciente de forma menos invasiva.

Descritores: Articulação Temporomandibular; Artrocentese; Transtornos da Articulação Temporomandibular.

\section{Referências:}

1. GROSSMANN E. Técnicas de artrocentese aplicadas às disfunções artrogênicas da articulação temporomandibular. Revista Dor, 2012; 13(4): 374-381

2. LOPES TS, et al. Artrocentese: Por que e quando indicar? - Relato de caso clínico. Revista de Cirurgia e Traumatologia Buco-maxilo-facial, 2017; 17(3): 11-15

3. VASCONCELOS BCE, et al. Artrocentese da articulação temporomandibular: avaliação de resultados e revisão da literatura. Revista Brasileira de Otorrinolaringologia, 2006; 72(4): 634638 


\section{PC-43-2019 - CARACTERÍSTICAS BUCAIS DO PACIENTE INFANTOJUVENIL COM PARALISIA CEREBRAL: REVISÃO DE LITERATURA}

Raiane Antônia de Andrade ${ }^{1}$; Lorena de Macêdo Silva ${ }^{2}$; Maria Cecília Freire de Melo $^{3}$; Rafaela Brito Vasconcelos'; Thuanny Silva de Macêdo ${ }^{3}$; Andressa Kelly Ferreira Alves ${ }^{3}$; Arnaldo de França Caldas Júnior ${ }^{2,3}$; Elizabeth Louisy Marques Soares da Silva ${ }^{3}$

${ }^{1}$ Centro Universitário Maurício de Nassau - Recife - PE - Brasil

${ }^{2}$ Faculdade de Odontologia de Pernambuco - Camaragibe - PE - Brasil

${ }^{3}$ Universidade Federal de Pernambuco - Recife - PE - Brasil

Autor correspondente:

Raiane Antônia de Andrade

raianeandrade.22@gmail.com

Introdução: Crianças e adolescentes com Paralisia Cerebral apresentam características bucais importantes $^{1}$ no que se referem ao atendimento odontológico e os cuidados realizados no domicílio. Esses indivíduos possuem alterações no movimento e na postura que repercutem no desempenho de atividades comuns no dia-a-dia, tais como fazer sua própria higiene bucal ${ }^{2}$, dependendo muitas vezes do auxílio de um cuidador. Objetivo: Realizar uma revisão de literatura acerca das características bucais do paciente infantojuvenil com Paralisia Cerebral. Metodologia: Trata-se de uma revisão de literatura utilizando o Google Scholar, SciELO e PubMed, com artigos publicados no período de 2009-2019. Revisão de literatura: Quanto às características bucais, nenhuma anomalia intraoral é exclusiva das pessoas com Paralisia Cerebral, porém indivíduos com essa condição são de alto risco para problemas dentários, incluindo: maloclusão, pobre higiene bucal, traumatismos dentários, bruxismo e sialorreia ${ }^{1,2}$. Além disso, estudos relatam que a prevalência de cárie, doença periodontal, maloclusão e quantidade de biofilme dentário é maior nos pacientes com deficiência neuromotora do que na população em geral. Isso está relacionado à inadequação da nutrição e da higiene bucal, consistência da dieta e retenção prolongada de resíduos alimentares na cavidade bucal em função de uma inabilidade da língua ${ }^{3,4}$. Outro fator agravante é o uso de anticonvulsivantes medicações frequentemente utilizadas por esses indivíduos, que associadas à presença de placa bacteriana podem propiciar o crescimento gengival e favorecer a ocorrência de problemas periodontais $^{1,4}$. Todos esses fatores, portanto, podem levar a ümá maior necessidade de tratamento odontológico, o que pode aumentar com a idade da criança e variar com a gravidade da Paralisia Cerebral ${ }^{4}$. Conclusão: É de suma importância o conhecimento do estado da saúde bucal e das necessidades de tratamento desta população com paralisia cerebral, levando em consideração os fatores relacionados ao paciente e sua família, como também àqueles relacionados à abordagem do Cirurgião-Dentista.

Descritores: Criança; Paralisia Cerebral; Assistência Odontológica para Pessoas com Deficiências.

\section{Referências:}

1. AGUIAR SMHCA, ALVES MCRR. Dental care for cerebral palsy patients using auxiliary resources to inhibit pathological tonic reflexes. Archives of Health Investigation, 2013; 2(4): 39-44

2. ALMEIDA ADG, et al. Influência da Dieta e da Higiene Oral na Prevalência da Cárie Dentária de Crianças com Paralisia Cerebral. Pesquisa Brasileira em Odontopediatria e Clínica Integrada, João Pessoa, 2011; 11(3): 433-38

3. CARVALHO RB, et al. Oral health and oral motor Function in children with cerebral palsy. Special Care in Dentistry, 2011; 31(2): 58-62 
4. DOUGHERTY NJ. A review of cerebral palsy for the oral health professional. Dental Clinics of North America, 2009; 53(2): 329-338
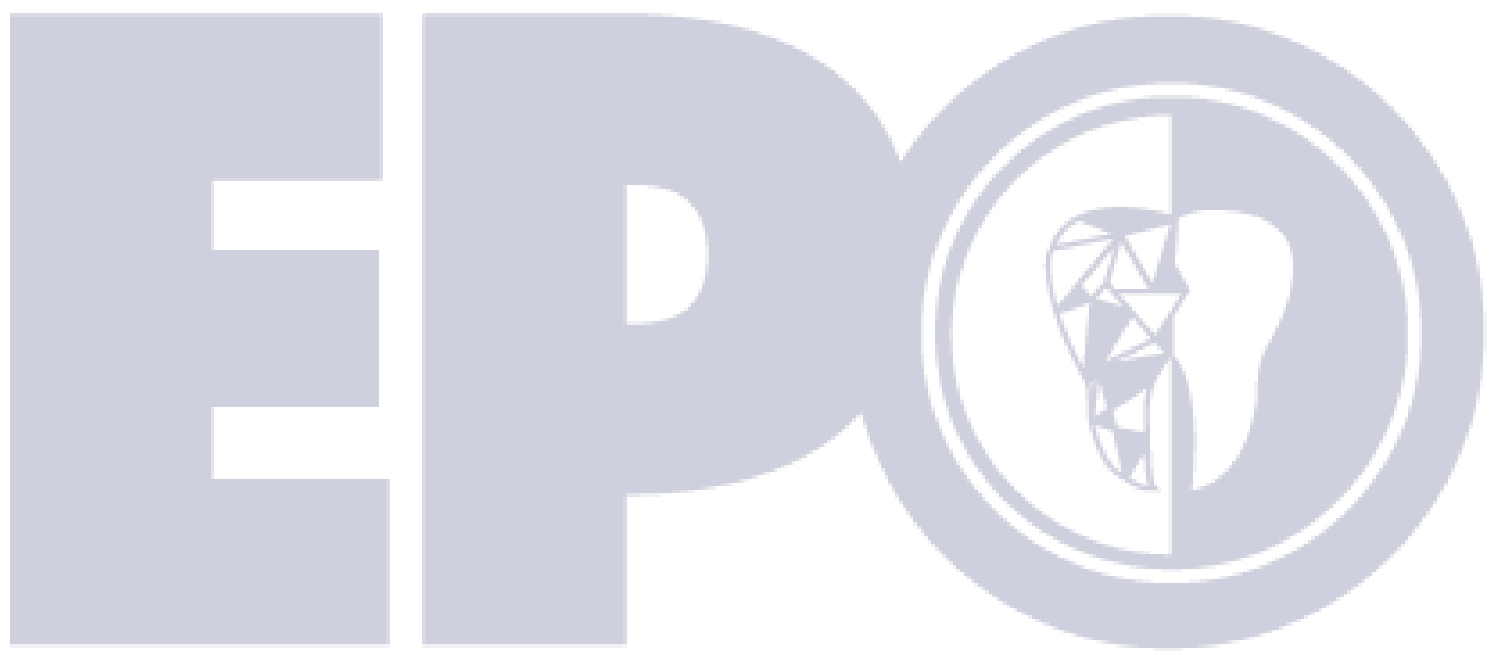

ENCONTRO PERNAMBUCANO DE ODONTOLOGIA 


\section{PC-44-2019 - CIRURGIA PLÁSTICA PERIODONTAL PARA CORREÇÃO DE SORRISO GENGIVAL: UM RELATO DE CASO}

Maria Luiza Feitosa Bandeira de Oliveira ${ }^{\mathbf{1}}$; Déborah Abigail Morais Kirniew ${ }^{\mathbf{1}}$; Luíza Flôres da Costa Fagundes ${ }^{1}$; Cláudia Geisa Souza e Silva ${ }^{1}$; Cácio Lopes Mendes ${ }^{1}$; Claudio Paulo Pereira de Assis ${ }^{1}$; Rodivan Braz ${ }^{1}$; Maria Hermínia Annibal ${ }^{1}$

${ }^{1}$ Faculdade de Odontologia de Pernambuco - Camaragibe - PE - Brasil

Autor correspondente:

Maria Luiza Feitosa Bandeira de Oliveira

m_luizafeitosa@hotmail.com

Introdução: Atualmente cada vez mais os padrões de beleza da sociedade têm norteado a estética odontológica ${ }^{2}$. O sorriso é um dos aspectos que causa impacto no relacionamento social $^{1}$. Logo, a exposição demasiada da gengiva durante o sorriso pode causar aspecto desfavorável ${ }^{1}$. Dentre as cirurgias plásticas periodontais, o aumento de coroa clínica tem sido um procedimento cada vez mais utilizado para melhorar a condição estética, especialmente na região ântero-superior em pacientes portadores de sorriso gengival. Os pacientes que apresentam esta condição, frequentemente, procuram o cirurgião-dentista, buscando reduzir esse desconforto estético. Objetivo: Relatar um caso clínico de aumento de coroa clínica em região estética. Relato de caso: $O$ procedimento foi realizado numa paciente do gênero feminino, 26 anos, leucoderma, que compareceu à Clínica de Periodontia da ABO/PE com queixas de dentes curtos. Após anamnese e exame clínico, verificou-se que a paciente não apresentava alterações patológicas e os exames complementares estavam dentro do nível de normalidade. Contudo, a paciente apresentava erupção passiva alterada, o que é uma das indicações para cirurgia de correção do sorriso gengival. Discussão: A cirurgia envolve procedimentos para remoção de tecidos moles e duros a fim de se obter uma coroa clínica com margens cervicais íntegras, preservando o espaço biológico ${ }^{3}$. A paciente relatou uma melhora da condição estética do seu sorriso após a realização da cirurgia, elevando sua autoestima. Conclusão: $O$ aumento de coroa clínica está indicado em muitas situações clínicas e podem resolver ou amenizar consideravelmente este efeito negativo do sorriso gengival. Além disso, é de fundamental importância a realização de um correto diagnóstico associado a um bom planejamento para obtenção de resultados satisfatórios.

Descritores: Gengiva; Gengivoplastia; Periodonto.

\section{Referências:}

1. BORDIN D, et al. Aumento de coroa clínica com objetivo estético. Revista PerioNews, 2010; 4(3):225-31

2. LIMA K, et al. Aumento de coroa clínica no sorriso gengival - Revisão De Literatura. Univap, 2016; 22(40):851-856

3. RISSATO M, TRENTIN M. Aumento de coroa clínica para restabelecimento das distâncias biológicas com finalidade restauradora - revisão da literatura. RFO, 2012; 17(2):234-239 


\section{PC-45-2019 - CIRURGIA PLÁSTICA PERIODONTAL PARA TRATAMENTO DA ERUPÇÃO PASSIVA ALTERADA: RELATO DE CASO}

Letícia de Oliveira Santos ${ }^{1}$; Gabriela Brito Vasconcelos ${ }^{2}$; Iasmin Cirino da Silva ${ }^{1}$; Ismael Sebastião da Silva Souza ${ }^{1}$; Liana Carla Souza de Andrade Batista ${ }^{1}$; Marilya Roberta Ferreira de Melo $^{1}$; Marcos Antônio Veloso Coutinho' ${ }^{1}$ Eduardo de Farias Barbosa ${ }^{2}$

${ }^{1}$ Faculdade de Odontologia de Pernambuco - Camaragibe - PE - Brasil

${ }^{2}$ Universidade Federal de Pernambuco - Recife - PE - Brasil

Autor correspondente:

Letícia de Oliveira Santos

Oliveiraleticia_14@live.com

Introdução: O sorriso gengival é uma entidade clínica complexa, definida como uma alteração estética relativamente frequente caracterizada pela exibição excessiva das gengivas durante o sorriso $^{3}$. Apresenta diversas etiologias, sendo a erupção passiva alterada a causa em que o periodontista está estritamente relacionado ${ }^{4}$. Objetivo: Relatar um caso clínico de correção de sorriso gengival a partir da utilização da técnica de gengivectomia associada a osteotomia e osteoplastia. Relato de caso: Paciente do sexo feminino, 22 anos, procurou o serviço odontológico, relatando insatisfação com a aparência do seu sorriso, que exibia muita gengiva. Foi realizado o exame clínico com sondagem periodontal e exames radiográficos, e após as mensurações foi diagnosticada a erupção passiva alterada e um fenótipo periodontal espesso. Como opção de tratamento foi proposta a cirurgia plástica periodontal para correção do sorriso gengival através da técnica da gengivectomia mais osteotomia e osteoplastia nos elementos superiores, com exceção dos molares. A osteotomia foi realizada com o auxílio de brocas e cinzeis. Ao término, os tecidos foram reposicionados com suturas simples. Discussão: No planejamento da cirurgia plástica periodontal, é importante perceber, que de acordo com o fenótipo periodontal, as abordagens e estratégias cirúrgicas, passam a ser individualizadas, e a determinação do fenótipo periodontal é essencial para o sucesso do tratamento ${ }^{1,2}$. No caso apresentado o fenótipo era espesso, desta forma, fez-se necessário uma abordagem com retalho de espessura total para expor a JCE e as cristas ósseas alveolares, e uma estratégia cirúrgica de restabelecimento do espaço biológico com $3 \mathrm{~mm}$. Conclusão: Conclui-se que a gengivectomia associada a osteotomia e osteoplastia é uma técnica efetiva na correção do sorriso gengival em casos de erupção passiva alterada com um bom prognóstico a longo prazo, desde que faça um correto diagnóstico e obedeça um criterioso protocolo de execução.

Descritores: Periodontia; Sorriso; Estética dentária.

\section{Referências:}

1. ARORA R, et al. Supracrestal gingival tissue: assessing relation with periodontal biotypes in a healthy periodontium. Int J Periodontics Restorative Dent, 2013; 33(6):763-71

2. DE ROUCK T, et al. The gingival biotype revisited: transparency of the periodontal probe through the gingival margin as a method to discrinate thin from thick gingiva. J Clin Periodontology, 2009; 36(5):428-33

3. MELE. M, et al. Esthetic treatment of altered passive eruption. Periodontol, 2000; 77(1):6583

4. SEIXAS MR, et al. Checklist dos aspectos estéticos a serem considerados no diagnóstico e tratamento do sorriso gengival. Dental Press J. Orthod, 2011; 16(2):131-57 


\section{PC-46-2019 - COMO SIMPLIFICAR A TÉCNICA DE RESTAURAÇÕES INDIRETAS EM DENTES POSTERIORES?}

Brenda Luhana Campos Silva ${ }^{1}$; Hilcia Mezzalira Teixeira ${ }^{1}$; Lívia Maria de Moraes ${ }^{\mathbf{1}}$; Renata Pedrosa Guimarães ${ }^{1}$

${ }^{1}$ Universidade Federal de Pernambuco - Recife - PE - Brasil

Autor correspondente:

Brenda Luhana Campos Silva

brendaluhana2@gmail.com

Introdução: Com o surgimento e constante aprimoramento dos sistemas adesivos, a resina composta atualmente propicia um tratamento restaurador que alia a exigência estética com as necessidades biológicas e funcionais tanto em dentes anteriores como em dentes posteriores ${ }^{1}$. Para dentes extensamente comprometidos, a técnica restauradora indireta é muitas vezes escolhida devido a sua facilidade de restabelecer contorno e contatos proximais durante a confecção da restauração no laboratório além da maior resistência e diminuição de contração de polimerização². Objetivo: Relatar um caso clínico de restauração indireta em dente posterior com utilização de recursos técnicos que facilitam a técnica como silicone para modelos e troquelização alternativa. Relato de Caso: Paciente procurou atendimento, queixando-se de necessidade restauradora do elemento 46 o qual apresentava extensa cavidade preenchida com ionômero de vidro. Optou-se pela técnica indireta em resina composta devido à extensão da cavidade. Foi realizado o preparo cavitário com características de expulsividade, com ponta tronco-cônica de extremidade arredondada. Posteriormente moldagem em alginato e vazamento do molde em silicone (Silicone dye/Voco). Para troquelização do modelo de silicone foi utilizada uma peça de Lego® ${ }^{\circledR}$ como auxiliar. A cimentação adesiva foi realizada após a termopolimerização em autoclave. Discussão: As técnicas direta e indireta podem ser utilizadas no plano de tratamento para restaurar e conservar dentes posteriores, além de que a técnica indireta minimiza as desvantagens das restaurações diretas fornecendo maior polimerização e a compensação da contração polimérica na cimentação ${ }^{1,2,3}$. Conclusões: A utilização do silicone para modelos e a troquelização alternativa com peça de Lego® facilitou a técnica de restauração indireta em resina composta, com possibilidade de conclusão em única sessão.

Descritores: Dente Molar; Dentística Operatória; Restauração Dentária Permanente.

\section{Referências:}

1. HIRATA R, et al. Simplificando o uso de resinas compostas em dentes posteriores. Revista Dental Press Estética, 2004; 1(1): 18-34

2. RIBEIRO CO, et al. Restauração indireta onlay: seleção do sistema cerâmico e cimentação com cimento auto-adesivo - relato de caso clínico. Revista Odontológica do Brasil Central, 2012; 21(58): 529-533

3. TONOLLI G, HIRATA R. Técnica de restauração semi-direta em dentes posteriores - uma opção de tratamento. Revista da Associação Paulista de Cirurgiões-Dentistas, 2010; ED $\operatorname{ESP}(1): 90-96$ 


\section{PC-47-2019 - COMPLICAÇÕES BUCAIS CAUSADAS PELA RADIOTERAPIA: REVISÃO DA LITERATURA}

Amanda Pereira Melo ${ }^{1}$; Andressa Kelly Alves Ferreira ${ }^{1}$; Thuanny Silva de Macêdo ${ }^{1}$; Elizabeth Louisy Marques Soares da Silva ${ }^{1}$; Mônica Moreira Dias da Cruz²; Maria Cecília Scheidegger Neves Gueiros ${ }^{1}$; Gustavo Pina Godoy ${ }^{1}$; Maria Cecília Freire de Melo ${ }^{1}$

${ }^{1}$ Universidade Federal de Pernambuco - Recife - PE - Brasil

${ }^{2}$ Hospital Universitário Oswaldo Cruz - Recife - PE - Brasil

Autor correspondente:

Amanda Pereira Melo

amandamlo@outlook.com

Introdução: A radioterapia é uma modalidade de terapia antineoplásica que pode ocasionar efeitos colaterais bucais incapacitantes levando o paciente a tolerar pequenas doses, adiar o tratamento ou interromper completamente. Dentre esses efeitos tem-se xerostomia, osteorradionecrose e mucosite oral $(\mathrm{MO})^{1,2,3}$. Objetivo: Apresentar uma breve revisão de literatura sobre as principais complicações bucais decorrentes da radioterapia. Metodologia: Foi realizado uma busca ao acervo bibliográfico nas bases de dados PubMed, LILACS e SciELO, utilizando os descritores Radioterapia, Mucosa Oral, Lesão. Revisão da literatura: A radioterapia age no DNA celular levando a perda da sua capacidade reprodutiva ou morte. Sabe-se que as células neoplásicas estão em constante atividade mitótica, tornando-as, assim, mais susceptíveis às radiações ${ }^{1}$. Essa terapia pode ocasionar complicações na cavidade bucal, dentre elas, a MO e a osteorradionecrose ${ }^{1,2}$. A MO é uma reação inflamatória de toxicidade na mucosa oral caracterizada por áreas eritematosas, ulceradas, dolorosas restringindo assim, sua nutrição, apresentando também, maior risco às infecções bucais e sistêmicas. A osteorradionecrose (ORN) pode ser definida como uma exposição óssea através de uma abertura na pele ou mucosa, persistindo como uma ferida que não se cura por três meses ou mais e que pode ocorrer espontaneamente ou provocada por traumas. Sua maior prevalência de acometimento é na mandíbula em relação ao osso maxilar. A sua incidência pode chegar a $22 \%{ }^{1,2,4}$. Conclusão: Diante do exposto na literatura, a radioterapia pode ocasionar efeitos colaterais bucais graves e dolorosos reduzindo a qualidade de vida do paciente em tratamento oncológico. $\mathrm{O}$ cirurgião-dentista inserido na equipe multiprofissional hospitalār é fundamental atuando com medidas preventivas, controlando e tratando as complicações bucais advindas desta terapia.

Descritores: Radioterapia; Mucosa Oral; Lesão.

\section{Referências:}

1. FREITAS DA, et al. Oral sequelae of head and neck radiotherapy. Revista CEFAC, 2011; 13(6): 1103-1108

2. JHAM BC, FREIRE ARS. Oral complications of radiotherapy in the head and neck. Revista Brasileira de Otorrinolaringologia, 2006; 72(5):704-8

3. KHAN S, et al. Effect of Fractionated Dose of Radiotherapy on Oral Mucosa in Head and Neck Cancer Patients: A Cytological Assessment. Gulf Journal of Oncology, 2016; 1(21):30-5 4. OMOLEHINWA TT, AKINTOYE SO. Chemical and Radiation-Associated Jaw Lesions. Dental Clinics of North America, 2016; 60(1):265-277 


\section{PC-48-2019 - COMPLICAÇÕES CAUSADAS PELA ANQUILOGLOSSIA NO LACTENTE E A IMPORTÂNCIA DO DIAGNÓSTICO PRECOCE}

Ericka Maria da Silva ${ }^{1}$; Ericka Gleyze da Silva Santos²; Cleiciane Bofim de Souza²; Ranielly de Souza Silva²; Thalita Vitória Silva da Cruz ${ }^{1}$

${ }^{1}$ Universidade Federal de Pernambuco - Recife - PE - Brasil

${ }^{2}$ Centro Universitário Tiradentes - Recife - PE - Brasil

Autor correspondente

Ericka Maria da Silva

erickasilvas689@gmail.com

Introdução: Durante o processo de formação da língua que acontece até o segundo mês de vida intrauterina, podem acontecer distúrbios no seu desenvolvimento. Dentre esses distúrbios pode acorrer a anquiloglossia, que é uma anomalia onde o freio lingual se apresenta mais curto ${ }^{2}$. Para a identificação precoce de alterações como esta, a realização do teste da linguinha é essencial em bebês a fim de eliminar antecipadamente as consequências dessa anomalia e promover melhor qualidade de vida ${ }^{1}$. Objetivo: Mostrar a importância do diagnóstico precoce da anquiloglossia, como forma de prevenção de complicações futuras. Metodologia: Trata-se de uma revisão integrativa da literatura com abordagem descritiva. Onde a pesquisa foi feita nas bases de dados LILACS e SciELO. Revisão de literatura: Na anquiloglossia em lactentes, podem ocorrer limitações do movimento da língua durante o choro, à lalação, e posteriormente, dificuldades de dicção. Os principais sintomas associados à anquiloglossia na amamentação são dor no mamilo da mãe, dificuldades na ordenha e sucção, que resultam em desmame precoce e perda de peso ${ }^{1,3}$. O protocolo de avaliação de frênulo da língua em bebês - Teste da Linguinha, deve ser aplicado durante a triagem neonatal, nas primeiras 48 horas de vida, observando-se o assoalho lingual e avaliando a inserção do frênulo que levará ao diagnostico, caso no ato da avaliação haja dúvida, o bebê passará por um novo teste quando estiver com 30 dias de vida, onde será realizado o protocolo completo, explicando aos pais todo o procedimento e possíveis riscos da anquiloglossia ${ }^{2}$. Conclusão: Os profissionais de saúde devem estar capacitados para incentivar a realização do teste da linguinha como principal forma de prevenção de alterações no frênulo lingual, beneficiando o desenvolvimento das funções de sucção, mastigação, deglutição e fala, que promoverá dessa forma uma melhôr qualidade de vida para os bebês.

Descritores: Anquiloglossia; Freio Lingual; Diagnóstico.

\section{Referências:}

1. BRAGA LAS, et al. Prevalência de alterações no frênulo lingual e suas implicações na fala de escolares. Revista CEFAC, 2009; 11(3): 378-390

2. MARTINELLI RLC, et al. Validade e confiabilidade na triagem: 'Teste da Linguinha'. Revista CEFAC, 2016; 18(6): 1323-1331

3. PROCOPIO IMS, et al. Frenotomia lingual em lactentes. Revista da Faculdade de Odontologia, 2017; 22(1): 114-119 


\section{PC-49-2019 - CONDICIONANDO A ZIRCÔNIA COM ÁCIDO FLUORÍDRICO A $\mathbf{5 0 \%}$}

Maíra Letícia Ferreira de Santana ${ }^{1}$; Carolaine Rayane Xavier da Silva ${ }^{1}$; Claudio Paulo Pereira de Assis ${ }^{1}$; Joyce Feitosa Pinho Gomes ${ }^{1}$; Leonardo José Rodrigues de Oliveira ${ }^{1}$; Lívia Xavier da Silva Teles²; Sarah Freitas Araújo'; Rodivan Braz ${ }^{1}$

${ }^{1}$ Faculdade de Odontologia de Pernambuco - Camaragibe - PE -Brasil

${ }^{2}$ Universidade Federal de Pernambuco - Recife - PE - Brasil

Autor correspondente:

Maíra Letícia Ferreira de Santana

maira_leticia12@hotmail.com

Introdução: Apesar da Y-TZP possuir propriedades superiores às demais cerâmicas, a sua adesão ainda não é bem estabelecida ${ }^{3}$. Objetivo: O objetivo deste trabalho foi avaliar a influência do condicionamento da zircônia, com ácido fluorídrico a 50\%, na resistência de união por cisalhamento. Metodologia: Cem cilindros de zircônia foram confeccionados pelo sistema CAD/CAM e divididos aleatoriamente em 10 grupos $(n=10)$, de acordo com o tratamento superficial: (Ctrl) - Controle - Nenhum tratamento; (CCP) - Clearfil Ceramic Primer; (SU) Scotchbond Universal; (CCP/SU) - Clearfil Ceramic Primer + Scotchbond Universal; (HF/SU) - Ácido Fluorídrico a 50\% + Scotchbond Universal; (AB) - Jateamento (50 $\mu \mathrm{m}-\mathrm{Al} 2 \mathrm{O} 3)$;

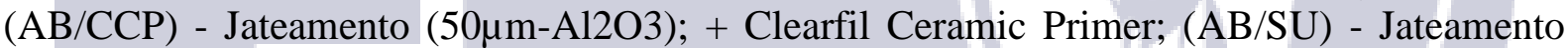
$(50 \mu \mathrm{m}-\mathrm{Al} 2 \mathrm{O} 3)+$ Scotchbond Universal; $(\mathrm{AB} / \mathrm{CCP} / \mathrm{SU})-$ Jateamento $(50 \mu \mathrm{m}-\mathrm{Al} 2 \mathrm{O} 3)+\mathrm{Clearfil}$ Ceramic Primer + Scotchbond Universal; $(\mathrm{AB} / \mathrm{HF} / \mathrm{SU})$ - Jateamento $(50 \mu \mathrm{m}-\mathrm{Al} 2 \mathrm{O} 3)+$ Ácido Fluorídrico a $50 \%+$ Scotchbond Universal. Todos os espécimes foram cimentados com o Panavia $\mathrm{F}$ 2.0. Todos foram armazenados em água destilada $\left(37^{\circ} \mathrm{C} / 30\right.$ dias $)$ e termociclados (5000 ciclos; $5^{\circ}$ a $55^{\circ} \mathrm{C}$ ). $O$ teste de resistência de união por cisalhamento foi realizado em uma máquina de ensaio universal ( $1 \mathrm{~mm} / \mathrm{min}$ ) e a análise da superfície da zircônia foi feita em $\mathrm{MEV}^{2}$.

Resultados e Discussão: Os maiores valores de resistência de união por cisalhamento (SBS) foram apresentados pelo grupo (AB/HF/SU) com 14.09 MPa, seguido dos grupos (HF/SU) com 12.65 Mpa, (AB/SU) com 11.02 Mpa, (AB/CCP/SU) com 9.72 Mpa, (JPC)1. Conclusão: O ácido fluorídrico a $50 \%$ associado ao adesivo Single Bond Universal promoveu uma união estável para a zircônia, com ou sem jateamento.

Descritores: Ácido Fluorídrico; Cerâmica; Resistência ao Cisalhamento.

\section{Referências:}

1. CHAI H, et al. On the interfacial fracture of porcelain/zirconia and graded zirconia dental structures. Acta Biomater, 2014; 10:3756-3761

2. DOGAN S, et al. Prospective cohort clinical study assessing the 5-year survival and success of anterior maxillary zirconia-based crowns with customized zirconia copings. J Prosthet Dent, 2017; 117:226-232

3. ZAHER AM, et al. Shear bond strength of zirconia-based ceramics veneered with 2 different techniques. J Prosthet Dent, 2017; 118:221-227 


\section{PC-50-2019 - CONDUTA DE CIRURGIÕES-DENTISTAS FRENTE À PARESTESIA PÓS CIRURGIA BUCAL}

Sinval Vinícius Barbosa do Nascimento ${ }^{1}$; Eduardo Vinícius de Souza Silva ${ }^{1}$; Pedro Henrique Barbosa de Melo; Alleson Jamesson da Silva²; Manuela França Andrade Passos ${ }^{1}$; Cleiton Rone dos Santos Lima ${ }^{1}$; Emerson Filipe de Carvalho Nogueira ${ }^{1}$; Ricardo José de Holanda Vasconcellos ${ }^{1}$

${ }^{1}$ Faculdade de Odontologia de Pernambuco - Camaragibe - PE - Brasil

${ }^{2}$ Universidade Federal de Pernambuco - Recife - PE - Brasil

Autor correspondente:

Sinval Vinícius Barbosa do Nascimento

sinvalvinicius@outlook.com

Introdução: A parestesia é a insensibilização de uma região após uma lesão do nervo do local. ${ }^{1}$ Os procedimentos cirúrgicos realizados pelos cirurgiões-dentistas (CDs) podem lesionar um nervo ${ }^{1}$. Objetivo: Avaliar a eficácia clínica das terapias mais utilizadas pelos CDs professores e pós-graduandos em Cirurgia e Traumatologia Bucomaxilofacial (CTBMF) da Faculdade de Odontologia de Pernambuco da Universidade de Pernambuco em casos de parestesia pós exodontias. Metodologia: O projeto é um estudo prospectivo com avaliação qualitativa baseado em questionários, sob CAAE: 17384619.2.0000.5207. Foram analisados dados de frequência, através de uma avaliação censitária onde foram entrevistados CDs, acerca dos principais manejos terapêuticos e suas eficácias no tratamento de parestesia pós exodontias. $\mathrm{O}$ questionário constou de perguntas relacionadas ao perfil do profissional, incidência de parestesia labial (PLa) ou lingual (PLi) após exodontias, forma de tratamento, sucesso e adesão do paciente. Resultados e discussão: $25 \%$ dos participantes tiveram 1 caso de PLa e 12,5\% tiveram mais de 5 casos. 62,5\% não tiveram casos de PLa. Sobre o acometimento de PLi, 50\% relataram ter, cada um, um paciente acometido e $50 \%$ não tiveram. O Laser foi a terapia mais indicada, seguida de medicação sem especificação, fisioterapia e Etna. Entre os tratamentos apontados como mais eficazes estão: Etna; fisioterapia; medicação; e associação entre laseterapia e medicação. Porém não chegou a um consenso, igual a literatura ${ }^{1}$. Assim como foi apontado que o resultado depende do tipo de parestesia e que a maioria delas tem regeneração espontânea, ou quando usado um neurorregenerador, como descrito na literatura ${ }^{2,3} .25 \%$ relataram não sentir resistência na adesão do tratamento, 62,5\% responderam que às vezes sentem resistência e 12,5\% não responderam. Conclusão: O Laser foi a terapia mais citada. Não teve um consenso em terapia mais eficaz. Às vezes há dificuldade na adesão ao tratamento. A continuação do estudo é necessária para resultados representativos.

Descritores: Parestesia; Nervo Lingual; Cirurgia Bucal.

\section{Referências:}

1. ALVES ALRF, et al. Parestesia, por que o endodontista deve se preocupar? Full Dent. Sci., 2016; 8(29):133-140

2. ARIKOV R, JUODZBALYS G. Inferior Alveolar Nerve Injury after Mandibular Third Molar Extraction: a Literature Review. Journal Of Oral And Maxillofacial Research, 2014; 5(4): $1-15$

3. HILLERUP S, STOLTZE K. Lingual nerve injury in third molar surgery. International Journal Of Oral And Maxillofacial Surgery, 2007; 36(10): 884-889 


\section{PC-51-2019 - CONDUTAS DO ODONTOPEDIATRA FRENTE À CASOS DE VIOLÊNCIA INFANTIL: REVISÃO DE LITERATURA}

Arthur Alves Thomaz de Aquino ${ }^{1}$; Carolina Pereira da Silva ${ }^{1}$; Heitor Tavares de Araújo ${ }^{\mathbf{1}}$; Hugo Igor Rodrigues de Barros ${ }^{1}$; Fernanda Gomes Barros ${ }^{1}$; Micaela Maria de Sousa ${ }^{1}$; Rosa Rayanne Lins de Souza ${ }^{2}$

${ }^{1}$ Faculdade de Odontologia de Pernambuco - Camaragibe - PE - Brasil

${ }^{2}$ Hospital da Restauração Governador Paulo Guerra/SES - Recife - PE - Brasil

Autor correspondente:

Arthur Alves Thomaz de Aquino

arthur.aquino29@gmail.com

Introdução: O Odontopediatra, como profissional em constante contato com crianças, encontra-se em posição extremamente favorável para detecção do abuso infantil ${ }^{3}$. Diante disso, cabe a ele saber quais medidas necessárias para tal situação. Objetivo: Relatar a contribuição do cirurgião-dentista na identificação de maus-tratos contra a criança ${ }^{2}$. Metodologia: Foi realizada uma busca bibliográfica com artigos disponíveis no LILACS, PubMed e Bireme, publicados entre 2000 e 2019, com os termos "Maus-tratos Infantis", "Violência Infantil" e "Odontopediatria". Revisão de Literatura: Nesses casos, o profissional encontra-se em um dilema, principalmente em entender que muitas vezes o agressor são aqueles a quem se poderia recorrer para cessar a agressão existente ou evitar agressão iminente ${ }^{4}$. O Estatuto da Criança e do Adolescente em 1990 tornou obrigatória a notificação de casos suspeitos ou confirmados de maus-tratos contra crianças e adolescentes, devendo todos os profissionais que lidam com estes, fazê-lo. O cirurgião-dentista deve estar capacitado para identificar casos de crianças ou adolescentes vítimas de maus-tratos, oferecer os cuidados dentários de emergência que sejam necessários e notificar as autoridades competentes ${ }^{1}$. Conclusão: Cabe ao odontopedíatra, durante o atendimento, o reconhecimento das manifestações de violência física e a denúncia destas, visando prevenir novos atos violentos ou até mesmo a morte da criança ${ }^{3,2}$.

Descritores: Maus-tratos Infantis; Violência Infantil; Odontopediatria.

\section{Referências:}

1. CAMPOS PCM. Odontopediatras e violência contra crianças e adolescentes: como eles atuam? Revista Fluminense de Odontologia, 2010; 16(34): 49-54

2. CAVALCANTI AL, et al. A importância do cirurgião-dentista no diagnóstico de maus tratos em crianças: relato de caso. Revista Odonto Ciência, 2009; 24(4): 432-434

3. CAVALCANTI AL. Manifestações físicas do abuso infantil: aspectos de interesse odontológico. Revista Paulista de Odontologia, 2003; 25(5): 16-19

4. PERES AS, et al. Odontologia e o desafio da identificação de maus-tratos. Odontologia Clínico-Científica, 2008; 7(3): 185-189 


\title{
PC-52-2019 - CONTRIBUIÇÃO DO ÁCIDO SIÁLICO E DA FUCOSE NO PROCESSO DE METÁSTASE TUMORAL
}

\begin{abstract}
Sinval Vinícius Barbosa do Nascimento ${ }^{1}$; Eduardo Vinícius de Souza Silva ${ }^{1}$; Pedro Henrique Barbosa de Melo ${ }^{1}$; Alleson Jamesson da Silva ${ }^{2}$; Manuela França Andrade Passos ${ }^{1}$; Cleiton Rone dos Santos Lima ${ }^{1}$; Ana Paula Veras Sobral ${ }^{1}$
\end{abstract}

${ }^{1}$ Faculdade de Odontologia de Pernambuco - Camaragibe - PE - Brasil

${ }^{2}$ Universidade Federal de Pernambuco - Recife - PE - Brasil

Autor correspondente:

Sinval Vinícius Barbosa do Nascimento

sinvalvinicius@outlook.com

Introdução: A metástase é um processo complexo de disseminação de uma neoplasia maligna que, na maioria das vezes, causa a morte do indivíduo ${ }^{3}$. A glicosilação é alterada durante a transformação maligna e progressão tumoral, sendo dois dos seus principais representantes o ácido siálico ${ }^{4}(\mathrm{AS})$ e a fucose ${ }^{1}$, que estão intimamente ligados no processo de metástase. Objetivo: Entender, através de uma revisão de literatura, as contribuições do AS e da fucose no processo de metástase. Metodologia: Foi realizada uma pesquisa na base de dados MEDLINE, no período de 2010 a julho de 2019, usando os descritores: metástase, ácido siálico e fucose, dos artigos encontrados, quatro foram usados para referenciar este trabalho. Revisão de literatura: A sialilação da superfície celular medeia à adesão celular, o reconhecimento imunológico e a transdução de sinal, os genes envolvidos nesse processo estão significativamente associados à diminuição da sobrevida de pacientes com câncer de mama, assim a sialilação aumentada ou aberrante da superfície celular tem sido relatada como uma característica da malignidade do câncer ${ }^{1,5}$. O AS também protege as células cancerosas da apoptose, podendo contribuir pra a resistência a drogas ${ }^{1}$. A fucosilação medeia a ligação das células tumorais à E-selectina vascular, iniciando o extravasamento das células tumorais que estão na corrente sanguínea ou linfática, para outras regiões ${ }^{2}$. Estudos feitos apontam que uma baixa expressão de fucose é associado a: alto grau de metástase; responsividade quimioterápica mais negativa; e faz com que o sistema imune, possivelmente, tenha um menor reconhecimento do tumor, assim diminuindo as vias imunológicas ${ }^{4}$. Conclusão: $\mathrm{O}$ aumento da sialilação e a diminuição na fucosilação em células tumorais, permite várias características málignas, como adesão, migração, proliferação celular e expressão de fatores de crescimento. Novos estudos são necessários, a fim de um melhor entendimento sobre a contribuição desses açucares, principalmente em neoplasias maxilofaciais.

Descritores: Metástase; Ácido Siálico; Fucose.

\section{Referências:}

1. BADR HA, et al. Harnessing cancer cell metabolism for theranostic applications using metabolic glycoengineering of sialic acid in breast cancer as a pioneering example. Biomaterials, 2017; 116: 158-173

2. CARRASCAL MA, et al. Inhibition of fucosylation in human invasive ductal carcinoma reduces E-selectin ligand expression, cell proliferation, and ERK1/2 and p38 MAPK activation. Molecular Oncology, 2018; 12: 579-593

3. KUMAR V, et al. Robbins Patologia Básica. $9^{a}$ ed. Rio de Janeiro: Elsevier, 2013; 928p.

4. LAU E, et al. The transcription factor ATF2 promotes melanoma metastasis by suppressing protein fucosylation. Science Signaling, 2015; 8:124-147

5. TEOH ST, et al. Sialic Acid Metabolism: A Key Player in Breast Cancer Metastasis Revealed by Metabolomics. Frontiers In Oncology, 2018; 8:1-15 


\section{PC-53-2019 - CONTROLE DA APNEIA OBSTRUTIVA DO SONO ATRAVÉS DO APARELHO INTRA ORAL EM PACIENTE NÃO ADERENTE AO CPAP: RELATO DE CASO}

Ana Caroline Chalegre de Oliveira ${ }^{1}$; Jeferson Batista Santiago ${ }^{1}$; Olívia Augusta Araújo Dias ${ }^{1}$; Joana de Ângelis Alves Silva ${ }^{1}$; Mayara Monique Silva de Oliveira ${ }^{1}$; Ismael Sebastião da Silva Sousa $^{1}$; Josué Alves ${ }^{1}$

${ }^{1}$ Faculdade de Odontologia de Pernambuco - Camaragibe - PE - Brasil

Autor correspondente:

Ana Caroline Chalegre de Oliveira

carolinechalegreoliveira@gmail.com

Introdução: A síndrome da apneia e hipopneia obstrutiva do sono (SAHOS) é um distúrbio do sono caracterizado pela presença de apneias (obstrução total das vias aéreas) e hipopneias (diminuição do fluxo respiratório) $^{5}$. Estão frequentemente presentes neste distúrbio: hipercapnia transitória, hipoxemia intermitente e despertares frequentes ${ }^{4}$. $\mathrm{O}$ uso do aparelho intra oral (AIO) é considerado um tratamento alternativo ao CPAP (Continuous Positive Airway Pressure), porém estudos mostram a eficácia do mesmo em todos os graus de apneia do sono ${ }^{1-2}$. Objetivo: Relatar um caso de uso do AIO por um paciente que não conseguiu se adaptar ao CPAP, analisando algumas das alterações do sono que ocorreram durante o período de uso, através de polissonografias e de um questionário com perguntas comparativas acerca do uso do AIO e/ou CPAP. Relato de caso: Paciente de 55 anos, gênero masculino, compareceu ao consultório odontológico para começar o tratamento da SAHOS com o AIO, relatando não conseguir continuar a terapia com o CPAP por achá-lo incômodo de usar. Durante o período de adaptação não houve queixas, e o paciente relatou melhoras dos sinais e sintomas que possuía, tais como: ronco, sonolência diurna e cefaleia. Após um ano e seis meses de tratamento, de acordo com os resultados das polissonografias e registro do questionário, o paciente havia normalizado os parâmetros polissonográficos analisados no estudo, saindo de um quadro de apneia leve $(\mathrm{IAH}=11,26 / \mathrm{h})$ para o controle da SAHOS $(\mathrm{IAH}=3,9 / \mathrm{H})$ pelo uso do AIO. Discussão: $O$ tratamento foi considerado um sucesso, pois reduziu o IAH para menos de cinco eventos por hora ${ }^{3}$. Conclusão: A cura para a SAHOS ainda não existe, porém em pacientes que conseguem aderir ao tratamento com o AIO, este é considerado um método eficàz no controle da síndrome, proporcionando conforto durante o sono, dessa forma consolidando o sucesso da terapia.

Descritores: Síndromes da Apneia do Sono; Transtornos do Sono-Vigília; Sono.

\section{Referências:}

1. BACHOUR P, et al. Oral appliance in sleep apnea treatment: respiratory and clinical effects and long-term adherence. Sleep Breath, 2016; 20(2): 805-12

2. BITTENCOURT LRA, et al. Abordagem geral do paciente com síndrome da apneia obstrutiva do sono. Rev Bras Hipertens, 2009;16(3): 158-163

3. CAMPOSTRINI DDA, et al. Síndrome da apneia obstrutiva do sono e doenças cardiovasculares. Revista Neurociências, 2014; 22(1): 102-112

4. GUIMARÃES MLR, et al. Severe obstructive sleep apnea treatment with mandibular advancement device: A case report. Sleep Science, 2018; 11(2): 118-122

5. SUTHERLAND K, et al. Oral Appliance Treatment for Obstructive Sleep Apnea: An Update. Journal of clinical sleep medicine, 2014; 10(2): 215-227 


\section{PC-54-2019 - CREPITAÇÃO E DISFUNÇÃO TEMPOROMANDIBULAR NA DOENÇA DE PARKINSON}

Jonatas Silva de Oliveira ${ }^{1}$; Cleiton Rone dos Santos Lima ${ }^{2}$; Taysa Vannoska de Almeida Silva ${ }^{1}$; Maria das Graças Wanderley de Sales Coriolano ${ }^{1}$; Carla Cabral dos Santos Accioly Lins ${ }^{1}$

${ }^{1}$ Universidade Federal de Pernambuco - Recife - PE - Brasil

${ }^{2}$ Universidade de Pernambuco - Recife - PE - Brasil

Autor correspondente:

Jonatas Silva de Oliveira

jonatassilva517@gmail.com

Introdução: A Doença de Parkinson (DP) é uma síndrome degenerativa que leva a morte progressiva dos neurônios dopaminérgicos, principalmente da substância negra ${ }^{1}$. É mais evidente em pessoas idosas e se manifesta com tremores e rigidez ${ }^{3}$. Alterações na cabeça podem levar a fenômenos como a crepitação, fazendo com que haja mais chances do desenvolvimento de disfunções ${ }^{2}$. Objetivo: Analisar a relação entre crepitação e disfunção temporomandibular (DTM) na Doença de Parkinson. Metodologia: Trata-se de um estudo analítico, quantitativo de coorte transversal, aprovado pelo comitê de ética sobre o número CAAE: 59421416.9.0000.5208, realizado no período de novembro/2016 a julho/2017, no qual os participantes foram pessoas com DP do Hospital das Clínicas de uma universidade do Pernambuco, avaliados pelo questionário padrão ouro para diagnóstico de DTM - Critério para Diagnóstico para Pesquisa em Disfunção Temporomandibular (RDC/TMD). Assim, foi usado como critérios de elegibilidade: estar entre os estágios 1 a 3 da doença, sob efeito do fármaco antiparkinsoniano, pessoas com dentes ou fazendo uso de próteses e terem o nível cognitivo satisfatório. Os dados foram analisados a partir de estatísticas descritivas e foi aplicado o Odds ratio (OR) do Qui-quadrado (X2) com intervalo de confiança (IC) de $95 \%$ e nível de significância de 0,05. Resultados e Discussão: A amostra foi composta por 110 pessoas. Sendo $65 \%$ do sexo masculino, com média de idade de 62 anos, 50,9\% encontravam-se no estágio 2 da doença e $35 \%$ apresentaram diagnóstico de DTM. Analisando a variável crepitação (OR= 4,$5 ; \mathrm{IC}=1,78-11,4 ;$ Especificidade $=86 \% ; \mathrm{p}=0,002$ ) percebe-se que a sua presença representa 4,5 vezes maior chance de predispor a DTM, tendo uma possível relação com a idade dos indivíduos devido à presença constante da crepitação nô envelhecimento ${ }^{4}$. Conclusão: Neste estudo, observou-se que a crepitação presente na DP favorece ao aparecimento da DTM, contribuindo para o desconforto no sistema estomatognático.

Descritores: Articulação Temporomandibular; Doença de Parkinson; Transtornos da Articulação Temporomandibular

\section{Referências:}

1. FRANÇA SA, et al. Severidade dos Sintomas da Doença de Parkinson. Saúde (Santa Maria), 2019; 45(1): 1-10

2. OLMOS SR, et al. The effect of condyle fossa relationships on head posture. Cranio, 2005; 23: 48-52

3. SILVA RM, et al. Prevalence of temporomandibular joint disorder in people with Parkinson's disease in a public university hospital. Revista CEFAC, 2019; 21(3): 1-10

4. SILVA TVA, et al. Pain, Click and Crepitation as factors associated with temporomandibular dysfunction in Parkinson's disease. Br J Pain, 2018; 1(3): 248-254 


\title{
PC-55-2019 - CRISTAIS DE COLESTEROL EM CISTO ÓSSEO SIMPLES DE MANDÍBULA: UM ACHADO HISTOPATOLÓGICO INCOMUM
}

\begin{abstract}
Hélen Kaline Farias Bezerra ${ }^{1}$; Iale Ferreira de Godoy ${ }^{1}$; Elaine Judite de Amorim Carvalho ${ }^{1}$; Jurema Freire Lisboa de Castro $^{1}$; Augusto César Leal da Silva Leonel ${ }^{1}$; Flávia Maria de Moraes Ramos-Perez ${ }^{1}$; Danyel Elias da Cruz Perez ${ }^{1}$
\end{abstract}

${ }^{1}$ Universidade Federal de Pernambuco - Recife - PE - Brasil

Autor correspondente:

Hélen Kaline Farias Bezerra

helenkalinefb@hotmail.com

Introdução: O cisto ósseo simples (COS) é uma lesão pseudocística intra-óssea, frequentemente assintomática e que tende a afetar adultos jovens ${ }^{3}$. Além disso, acomete mais comumente os ossos longos do que os ossos da região maxilomandibular ${ }^{4}$ e tem o trauma como o fator etiológico mais provável ${ }^{2}$. Objetivo: Relatar um caso de COS em mandíbula com uma apresentação histopatológica atípica de cristais de colesterol. Relato de caso: Paciente, do sexo masculino, 20 anos, apresentou uma lesão radiolúcida, unilocular e bem delimitada, na região adjacente à distal do dente 38 , como um achado em uma radiografia panorâmica de rotina. $\mathrm{O}$ paciente retornou após 3 meses para o diagnóstico da lesão e uma tomografia computadorizada de feixe cônico (TCFC) foi realizada para melhor avaliação. A TCFC revelou adelgaçamento das corticais vestibular e lingual da mandíbula, sem abaulamento de nenhuma delas. Então, o paciente foi submetido inicialmente a uma punção do conteúdo da lesão, a qual revelou um líquido castanho claro, seguida de curetagem da cavidade e remoção do elemento 38 , sob anestesia local. A análise microscópica do material removido revelou um tecido conjuntivo fibroso apresentando muitas imagens negativas de cristais de colesterol e alguns focos de hemossiderina, entremeado por trabéculas de osso normal. Portanto, o diagnóstico de COS foi estabelecido. Após 18 meses do procedimento cirúrgico, observou-se reparo ósseo completo na área afetada. Discussão: O caso chama atenção por apresentar um COS em mandíbula exibindo muitos cristais de colesterol, o que é uma característica incomum em COSs mandibulares, sendo, no entanto, mais observada quando essa lesão ocorre em ossos longos ${ }^{5}$. Tal característica pode estar relacionada a alterações degenerativas lentas do conteúdo hemorrágico da cavidade ${ }^{5}$ ou à necrose óssea ${ }^{1}$. Conclusão: Os cristais de colesterol são achadôs raros em COSs da maxila e mandíbula e, aparentemente, não representam fatores de mudança no comportamento clínico dessas lesões.

Descritores: Cistos Ósseos; Mandíbula; Diagnóstico.

\section{Referências:}

1. HARNET JC, et al. Solitary bone cyst of the jaws: a review of the etiopathogenic hypotheses. Journal of Oral and Maxillofacial Surgery, 2008; 66(11):2345-2348

2. PAIVA LCA, et al. Cisto ósseo simples - Relato de caso. Revista de Cirurgia e Traumatologia Buco Maxilo Facial, 2011; 11(2): 15-20

3. RIBEIRO EB, et al. Cisto ósseo simples: relato de casos clínicos. Revista da Faculdade de Odontologia-UPF, 2014; 19(3): 359-363

4. SABINO-BEZERRA JR, et al. Atypical presentations of simple bone cysts of the mandible: A case series and review of literature. Journal of Cranio-Maxillofacial Surgery, 2013; 41(5): 391-396

5. TAKADA J, et al. A comparative study of clinicopathological features between simple bone cysts of the calcaneus and the long bone. Foot \& Ankle International, 2014; 35(4): 374-382 


\section{PC-56-2019 - DESCONTAMINAÇÃO GENGIVAL ATRAVÉS DO LASER ER-YAG}

Luanna Gabriela Ferreira Leão Brasil ${ }^{1}$; Carolina Pereira da Silva ${ }^{1}$; Heitor Tavares de Araújo ${ }^{1}$; Ada Caroline Soares Ferreira ${ }^{1}$; Isabela Araújo de Lima ${ }^{1}$; Lucas Rafael Borges Santos ${ }^{1}$; Eloiza Leonardo de Melo ${ }^{1}$; Maria Regina Almeida de Menezes ${ }^{1}$

${ }^{1}$ Faculdade de Odontologia de Pernambuco - Camaragibe - PE - Brasil

Autor correspondente:

Luanna Gabriela Ferreira Leão Brasil

luanna_brasil@hotmail.com

Introdução: O principal objetivo da terapia periodontal é conseguir uma superfície radicular biocompatível através da remoção de biofilmes bacterianos e smear layer. Ultrassons e instrumentos manuais são os mais utilizados em procedimentos para desbridamento de raiz na terapia periodontal ${ }^{3}$. Nos últimos anos, o laser Er-YAG tem sido sugerido como alternativa de modalidade de instrumentação do tratamento de periodontite crônica. Objetivo: Relatar um caso clínico de descontaminação gengival através de laser Er:YAG. Relato de caso: Paciente leucoderma, C.V.D, sexo feminino, com 30 anos de idade, compareceu a Clínica da FOP/UPE, com queixa de incômodo na gengiva da região anterossuperior. $\mathrm{O}$ exame clínico não revelou necessidade da realização de exames complementares. Verificou-se que a gengiva dos dentes 11,21 e 22 se apresentava inflamada, edemaciada, caracterizando gengivite. Foram realizadas 6 sessões na clínica da FOP/UPE com laser Er-YAG. Discussão: O laser de Erbium, apresenta um bom efeito bactericida e desintoxicante contra as bactérias patogênicas ${ }^{3}$. Usado com comprimentos de onda de 2,940 nm no Er:YAG, apresenta absorção ideal pela hidroxiapatita e pela água, tornando-se eficiente para a ablação de esmalte e dentina. Mesmo com um aquecimento mínimo, usando spray de água, produz micro-explosões nos tecidos duros, provocando um dano térmico mínimo aos tecidos adjacentes. São ideais para remoção de cálculo ${ }^{2}$. No entanto deve-se ter cuidado porque os tecidos duros têm moderada concentração de água e pode, por arrasto, remover cemento. Penetra nos tecidos até $5 \mathrm{~mm}$, pode ser usado de modo contínuo ou pulsado, e com ou sem contacto com os tecidos. Conclusão: O laser ErYAG apresenta-se como uma boa alternativa para tratamento não cirúrgico periodontal, com resultados confiáveis de descontaminação e recuperação tecidual na gengivite1.

Descritores: Periodontia; Lasers de Er-YAG; Odontologia.

\section{Referências:}

1. CRESPI R, et al. Effects of Er: YAG laser compared to ultrasonic scaler in periodontal treatment: A 2-year follow-up split-mouth clinical study. Journal of Periodontology, 2007; 78(7): 1195-1200

2. DERDILOPOULOU FV, et al. Microbiological findings after periodontal therapy using curettes, Er: YAG laser, sonic, and ultrasonic scalers. Journal of Clinical Periodontology, 2007; 34(7): 588-598

3. ISHIKAWA I, et al. Clinical application of Erbium: YAG laser in periodontology. Journal of the International Academy of Periodontology, 2008; 10(1): 22-30 


\section{PC-57-2019 - DESFECHOS REPORTADOS PELOS PACIENTES EM RELAÇÃO À TERAPIA PERIODONTAL}

Kewry Nunes do Nascimento ${ }^{1}$; Rayssa Maria da Silva Lima ${ }^{1}$; Carlos Frederico de Moraes Sarmento $^{1}$; Davi da Silva Barbirato ${ }^{2}$; Daniela da Silva Feitosa ${ }^{1}$; Mariana Fampa Fogacci ${ }^{1}$

${ }^{1}$ Universidade Federal de Pernambuco - Recife - PE - Brasil

${ }^{2}$ Faculdade de Odontologia de Pernambuco - Camaragibe - PE - Brasil

Autor correspondente:

Kewry Nunes do Nascimento

kewrykew@hotmail.com

Introdução: As diversas terapias periodontais representam a possibilidade para o restabelecimento da saúde dos tecidos que compõem o periodonto. Diante disso, é primordial perceber quais parâmetros têm sido reportados pelos pacientes avaliados em amostras de pesquisas para uma visão e análise integrais de saúde. Objetivo: Realizar uma revisão da literatura existente sobre os principais desfechos reportados pelos pacientes em relação à terapia periodontal. Metodologia: O presente trabalho analisou uma amostra dos 40 ensaios clínicos randomizados publicados mais recentemente, entre os anos de 2018 e 2019, avaliando parâmetros relacionados à terapia periodontal. Utilizou-se como critérios de inclusão ensaios clínicos randomizados que relataram pelo menos um desfecho reportado pelo paciente. Revisão de literatura: Dos 40 artigos avaliados, apenas cinco apresentaram desfechos reportados pelos pacientes como parâmetro pós-terapia periodontal, além de parâmetros clínicos. Dos 40 ensaios clínicos randomizados, apenas quatro obtiveram o desfecho dor, que foi avaliado por meio de escala visual analógica ${ }^{1,2,3,4}$. Outros desfechos relatados pelos pacientes como qualidade de vida e percepção de saúde bucal foram observados em apenas um artigo, sendo avaliadas por meio do questionário validado OHIP-14 (Oral Health Impact Profile) ${ }^{5}$. Conclusão: Os desfechos subjetivos dos pacientes, tais como medo, ansiedade, estresse, dor, qualidade de vida são importantes e deveriam ser considerados ao se avaliar o resultado de terapias periodontais, uma vez que complementariam a análise de efetividade de diferentes terapias. Entretanto, não foram reportados na maioria dos mais recentes ensaios clínicos randomizados em Periodontia, uma vez que os parâmetros clínicos periodontais são os principalmente reportados.

Descritores: Periodontia; Doença periodontal; Ensaio clínico.

\section{Referências:}

1. CULHAOGLU R, et al. Evaluation of the effect of dose-dependent platelet-rich fibrin membrane on treatment of gingival recession: a randomized, controlled clinical trial. Journal of Applied Oral Science, 2018; 26:2017-0278

2. GHOLAM L, et al. Comparison of gingival depigmentation with Er,Cr:YSGG laser and surgical stripping, a 12-month follow-up. Lasers in Medical Science, 2018; 33(8):1647-1656

3. GIANNELLI M, et al. Treatment of severe periodontitis with a laser and lightemitting diode (LED) procedure adjunctive to scaling and root planing: a double-blind, randomized, singlecenter, splitmouth clinical trial investigating its efficacy and patientreported outcomes at 1 year. Lasers Surgical Medicine, 2018; 33:991-1002

4. HEIDARI M, et al. Evaluating the effect of photobiomodulation with a 940-nm diode laser on post-operative pain in periodontal flap surgery. Lasers in Medical Science, 2018; 33(8):1639-1645

5. TRIVEDI R, et al. Novel PAradigm to improve Inflammatory burden in end stage Renal disease (rePAIR): study protocol for a randomized controlled trial. Trials, 2018; 19(1):370 


\section{PC-58-2019 - DIAGNÓSTICO DE ANQUILOGLOSSIA E PROCEDIMENTO DE FRENECTOMIA LINGUAL REALIZADO NO PROJETO DE EXTENSÃO LÍNGUA SOLTA - RELATO DE CASO CLÍNICO}

Ingrid Melo Schüler Arreguy ${ }^{\mathbf{1}}$; Italo Ferreira Monteiro ${ }^{\mathbf{1}}$; Maria Luísa Alves Lins ${ }^{\mathbf{1}}$; Bianca Lais Gomes dos Santos²; Alfredo de Aquino Gaspar ${ }^{1}$; Manassés de Oliveira Pereira ${ }^{1}$; Malú Virginia Santana Campos ${ }^{1}$; Ana Cláudia da Silva Araújo ${ }^{1}$

${ }^{1}$ Universidade Federal de Pernambuco - Recife - PE - Brasil

${ }^{2}$ Faculdade Pernambucana de Saúde - Recife - PE - Brasil

Autor correspondente:

Ingrid Melo Schüler Arreguy

ingridarreguy@gmail.com

Introdução: $\mathrm{O}$ frênulo lingual é um ligamento membrano mucoso que une a parte inferior da língua ao assoalho da boca e faz com que a língua realize com êxito as suas importantes funções de sucção, deglutição, mastigação e a fala ${ }^{3,1}$. É válido destacar que o frênulo também possibilita a livre movimentação da língua e funciona como um calibrador desses movimentos, permitindo que ela se mova adequadamente ${ }^{1}$. Um frênulo lingual curto ou com inserção muito anterior, pode gerar anquiloglossia, o que dificulta os movimentos da língua e que pode prejudicar as diversas funções dessa estrutura ${ }^{2}$. A condição geralmente se resolve sozinha, mas, há casos que se faz necessário tratar cirurgicamente. Objetivo: Descrever um caso de anquiloglossia em criança do sexo feminino, 7 anos, atendida na clínica de Odontologia da UFPE. Através da anamnese (Teste de Marchesan), identificamos o diagnóstico de anquiloglossia de escore 8 ou mais (muito alterado), sendo necessária a cirurgia para liberação do frênulo lingual. Relato de caso: Foi utilizado o Protocolo de Avaliação do Frênulo da Língua em crianças, adolescentes e adultos (Teste de Marchesan) como instrumento de avaliação no diagnóstico de língua presa, o direcionamento para os exames solicitados ao paciente, seguindo o protocolo de atendimento do projeto e posteriormente a realização da cirurgia de frenectomia lingual. Discussão: Foi possível observar que a paciente teve sua língua completamente liberada com a frenectomia e que foram devolvidas suas funções anatômicas. Conclusão: $O$ exame rotineiro do freio lingual permite a identificação de anormalidades de sua inserção e possibilita o tratamento correto e bem-sucedido. A paciente reagiu bem a cirurgia e os resultados (positivoś) foram de grande relevância, visto que, as funções corretas da língua foram resgatadas, bem como a autoestima, posto que a anquiloglossia interfere no convívio social do indivíduo.

Descritores: Anquiloglossia; Cirurgia; Freio Lingual.

\section{Referências:}

1. MARCHESAN IQ. Frênulo de língua: classificação e interferência na fala. Rev Cefac, 2003; 5(4): 341-345

2. MARCHESAN IQ. Protocolo de avaliação do frênulo da língua. Rev Cefac, 2010; 12(6): 977-989

3. SUTER VGA. Ankyloglossia: facts and myths in diagnosis and treatment. Journal of Periodontology, 2009; 80(8): 1204-1219 


\section{PC-59-2019 - DIAGNÓSTICO DE DESORDENS SISTÊMICAS E ORAIS PELA SALIVA}

Aylanne Xavier de Lacerda Cavalcante Timoteo ${ }^{1}$; Carolaine Rayane Xavier da Silva ${ }^{1}$; Emerllyn Shayane Martins de Araújo ${ }^{1}$; Claúdia Geisa Souza e Silvaa ${ }^{1}$ Kássia Regina de Santana ${ }^{1}$; Micaela Maria de Sousa ${ }^{1}$; Ycaro Lopes Briano²; Sally de Souza Brito ${ }^{3}$

${ }^{1}$ Faculdade de Odontologia de Pernambuco - Camaragibe - PE - Brasil

${ }^{2}$ Universidade Federal de Pernambuco - Caruaru - PE - Brasil

${ }^{3}$ Centro de Pós-graduação em Odontologia - Recife - PE - Brasil

Autor correspondente:

Aylanne Xavier de Lacerda Cavalcante Timoteo

aylannel@gmail.com

Introdução: A saliva é uma secreção aquosa encontrada na boca, representada por uma complexa mistura de produtos secretórios (orgânicos e inorgânicos) de glândulas salivares e de outras substâncias provenientes da mucosa da orofaringe, vias aéreas superiores, refluxo gastrintestinal, fluido do sulco gengival, restos alimentares e componentes derivados do sangue $^{4}$. É uma um importante recurso para obtenção de diagnósticos, uma vez que a saliva é um fluido biológico complexo que contém uma variedade de hormônios, proteínas, enzimas, anticorpos, constituintes antimicrobianos e citoquinas ${ }^{3}$. Objetivo: Apresentar uma revisão de literatura sobre o diagnóstico de desordens sistêmicas e orais pela saliva. Metodologia: Foi efetuada uma pesquisa nas bases de dados da SciELO, MEDLINE e Google Acadêmico. Revisão de literatura: $O$ interesse pela saliva como ferramenta de diagnóstico advém do fato de que muitos biomarcadores que são encontrados nela também estão presentes na urina e no sangue. Os vários constituintes salivares que integram a saliva passam por diferentes processos bioquímicos: síntese local de proteínas pelas glândulas salivares, difusão passiva de moléculas provenientes do plasma ou soro, transporte ativo, ultrafiltração e através de locais de inflamação e dano tecidular. No entanto, a maior parte dos constituintes integra a saliva através da síntese local pelas glândulas salivares e difusão passiva para o meio extracelular' ${ }^{1}$. Logo, o potencial para que a saliva funcione como diagnóstico precoce de muitas doenças é possível, sejam elas doenças infecciosas, neoplasias malignas ou alterações hormonais. Conclusão: Com isso, o uso da saliva como método diagnóstico é bastante instigador por ser de fácil acesšo e coleta, e ser de baixo custo. Além de que muitas doenças sistêmicas e orais alteram a composição da saliva, sendo possível através de estudos a identificação dessas desordens.

Descritores: Saliva; Diagnóstico; Biomarcadores.

\section{Referências:}

1. AZEVEDO DFS. Saliva como fonte de biomarcadores para o diagnóstico de doenças neurodegenerativas. Dissertação (Mestrado integrado em medicina dentária) - Faculdade de medicina dentária da Universidade do Porto. Universidade do Porto, Porto, 2018; $35 \mathrm{p}$

2. CURVELO JAR, et al. Análise da saliva nas desordens sistêmicas. Revista de Odontologia da Universidade Cidade de São Paulo, 2010; 22(2):163-73

3. FARINHA FI. A saliva como meio de diagnóstico. Dissertação (Mestrado integrado em medicina dentária) - Instituto superior de ciências da saúde Egas Moniz, Almada, 2015; 87 p

4. LIMA DP, et al. O uso de saliva para diagnóstico de doenças orais e sistêmicas. Revista Odontológica de Araçatuba, 2014; 35:55-59 


\section{PC-60-2019 - DISPLASIA ODONTOMAXILAR SEGMENTAR: RELATO DE CASO}

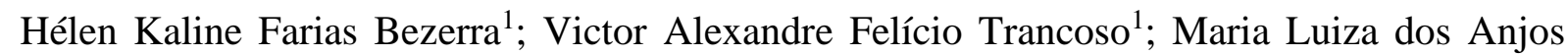
Pontual $^{1}$; Andrea dos Anjos Pontual ${ }^{1}$; Flávia Maria de Moraes Ramos-Perez ${ }^{1}$; Danyel Elias da Cruz Perez ${ }^{1}$; Eduarda Helena Leandro Nascimento ${ }^{1}$

${ }^{1}$ Universidade Federal de Pernambuco - Recife - PE - Brasil

Autor correspondente:

Hélen Kaline Farias Bezerra

helenkalinefb@hotmail.com

Introdução: A displasia odontomaxilar segmentar (DOS) é uma anormalidade rara do desenvolvimento, recentemente reconhecida e de etiologia desconhecida, caracterizada por um aumento unilateral da maxila e gengiva adjacente, acompanhado por assimetria facial e anormalidades dentárias ${ }^{3}$. Objetivo: Relatar um caso de DOS que apresentou, como primeiro sinal clínico, anormalidades na erupção dos dentes de uma hemi-maxila. Relato de caso: Paciente do sexo masculino, 12 anos, compareceu a uma clínica de Radiologia Odontológica para realizar uma radiografia panorâmica, cuja indicação era avaliar o processo de erupção dentária. Clinicamente, o paciente apresentava discreto aumento de volume no lado direito da face e o exame intrabucal revelou, além da permanência prolongada dos dentes 55 e 53 , a erupção ectópcia do dente 15 . Na radiografia panorâmica, observou-se o dente 13 incluso, em posição mesioangular; atraso no desenvolvimento do germe do dente 14 ; sobreposição dos dentes 15 e 16, com possível alteração de forma de suas raízes; dente 17 incluso, em posição distoangular; e dente 18 em formação, em posição mesiangular e deslocado superiormente, apresentando aumento do espaço pericoronário. Diante dessas características clínicas e radiográficas, foi estabelecido o diagnóstico da DOS. Discussão: A DOS pode provocar leve assimetria facial indolor por alterações no crescimento e maturação de uma hemi-maxila ${ }^{2}$, conferindo uma aparência radiográfica de trabéculas ósseas escleróticas verticais ${ }^{1}$. Dentre as anormalidades dentárias possivelmente associadas estão agenesias, hipoplasias, atraso na erupção, retenção de decíduos, morfologia anormal ${ }^{4}$, sendo essas três últimas encontradas no presente caso. É geralmente diagnosticada na infância, porém há casos de diagnóstico tardio por não reconhecimento dessa patologia ou diagnósticos prévios equivocados, pois outras patologias como a displasia fibrosa monostótica e a hiperplasia hemifacial podem fazer diagnóstico diferencial ${ }^{1}$. Conclusão: Como é uma entidade ainda pouco conhecida, relatar um caso de DOS pode contribuir para sua elucidação e, consequentemente, para evitar diagnósticos equivocados ou tardios.

Descritores: Diagnóstico; Diagnóstico por Imagem; Odontologia.

\section{Referências:}

1. FRIEDLANDER-BARENBOIM $\mathrm{S}$, et al. Clinical and radiological presentation of hemimaxillofacial dysplasia/segmental odontomaxillary dysplasia: critical analysis and report of a case. Oral and Maxillofacial Radiology, 2012; 113(2): 268-273

2. GONZÁLEZ-ARRIAGADA WA, et al. Segmental odontomaxillary dysplasia: report of 3 cases and literature review. Head and Neck Pathology, 2012; 6(2): 171-177

3. MINETT CP, DALEY TD. Hemimaxillofacial dysplasia (segmental odontomaxillary dysplasia): case study with 11 years of follow-up from primary to adult dentition. Journal of Oral and Maxillofacial Surgery, 2012; 70(5): 1183-1191

4. SMITH MH, et al. Segmental odontomaxillary dysplasia: an underrecognized entity. The Journal of the American Dental Association, 2018; 149(2): 153-162 


\section{PC-61-2019 - DISTÚRBIOS ALIMENTARES E A ODONTOLOGIA: REVISÃO DE LITERATURA}

Emilly Araújo Pereira ${ }^{1}$; Emilia Alves do Nascimento ${ }^{1}$; Ademir Félix Arantes Júnior ${ }^{1}$; Aylanne Xavier de Lacerda ${ }^{1}$; Carolaine Rayane Xavier da Silva ${ }^{1}$; Joyce Feitosa Pinho Gomes ${ }^{1}$; Maíra Leticia Ferreira de Santana ${ }^{1}$; Maria Carolina Tavares de Lyra Menezes ${ }^{1}$

${ }^{1}$ Faculdade de Odontologia de Pernambuco - Camaragibe - PE - Brasil

Autor correspondente:

Emilly Araújo Pereira

emillyaraujope@gmail.com

Introdução: Hábitos extremos de consumo alimentar podem caracterizar distúrbios alimentares como a anorexia e a bulimia nervosa. Tais distúrbios podem gerar complicações bucais, sendo assim, o cirurgião dentista pode ser o primeiro profissional a identificar essas doenças ${ }^{3}$. Objetivo: O propósito deste trabalho foi investigar a relação entre saúde bucal e os distúrbios alimentares através de uma breve revisão de literatura. Metodologia: Foi efetuada uma pesquisa científica nas bases de dados LILACS e SciELO, entre os anos de 2000 a 2013, com as palavras chaves Adolescência, Transtornos da alimentação e Saúde bucal. Revisão de literatura: Os principais distúrbios alimentares são a anorexia e a bulimia nervosa ${ }^{2}$. Esses distúrbios trazem consigo diversas manifestações bucais, como exemplo temos a erosão dental, cárie, xerostomia, hipersensibilidade dentinária, lesões nos tecidos moles, dentre outras ${ }^{2}$. A alteração bucal de maior prevalência é a erosão, em geral relacionada a episódios de regurgitação, sendo uma perda irreversível dos tecidos duros dentais por processo químico, ocorrendo perda de esmalte e em seguida de dentina ${ }^{2}$. Devido a essas manifestações bucais, principalmente a erosão, o cirurgião dentista pode investigar de forma precoce a presença de transtornos alimentares e dessa forma encaminhar o paciente para um atendimento multidisciplinar ${ }^{1}$. Conclusão: Conclui-se que, na equipe de saúde, o cirurgião dentista pode ser o primeiro profissional a realizar o diagnóstico, contribuindo de forma relevante para o tratamento dos transtornos alimentares ${ }^{1}$.

Descritores: Adolescência; Transtornos da alimentação; Saúde bucal.

\section{Referências:}

1. COLARES V, et al. A saúde oral e os transtornos alimentares entre adolescentes. Revista Brasileira de Odontologia, 2012; 69(2): 190-193

2. NAVARRO VP, et al. Desordens alimentares: aspectos de interesse na odontologia. Revista Gaúcha de Odontologia, 2011; 59: 15-18

3. TRAEBERT J, MOREIRA EAM. Transtornos alimentares de ordem comportamental e seus efeitos sobre a saúde bucal na adolescência. Pesquisa Odontológica Brasileira, 2001; 15(4): 359-363 


\section{PC-62-2019 - DOENÇA DO ENXERTO CONTRA O HOSPEDEIRO: RELATO DE CASO}

Nathalia Gomes Buarque Rodrigues ${ }^{1}$; Matheus Eduardo da Silva Paz ${ }^{1}$; Esther Monteiro Coutinho Cabral ${ }^{1}$; Vânia Cavalcanti Ribeiro da Silva ${ }^{2}$

${ }^{1}$ Faculdade de Odontologia de Pernambuco - Camaragibe - PE - Brasil

${ }^{2}$ Universidade Federal de Pernambuco - Recife - PE - Brasil

Autor correspondente:

Nathalia Gomes Buarque Rodrigues

buarquenath@gmail.com

Introdução: Dentre as complicações do transplante de medula óssea (TMO), a principal é a Doença do Enxerto Contra Hospedeiro (DECH), que é uma reação imunológica resultante do enxerto de células imunocompetentes de um doador para um hospedeiro imunocomprometido. A DECH ocorre entre $50 \%$ e $80 \%$ dos pacientes submetidos à TMO, e é a principal causa de morbimortalidade a longo prazo ${ }^{1}$. As manifestações clínicas do DECH afetam mais frequentemente a pele, fígado, trato gastrintestinal e mucosa oral ${ }^{3}$. Objetivo: Apresentar um relato de caso clínico acerca da doença do enxerto contra o hospedeiro. Relato de caso: Paciente do gênero masculino, 35 anos, deu entrada na clínica de estomatologia da FOP apresentando lesões assintomáticas de cor branca nos lábios, mucosa jugal, língua e palato. Foram analisadas biópsias de março de 2016 e abril de 2018 (quando se constatou hiperplasia epitelial, hiperparaqueratose e displasia epitelial leve). Além disso, o paciente apresentou ferritina elevada $(687,0 \mathrm{ng} / \mathrm{mL})$. Discussão: As lesões orais indicativas de DECH exibem aspecto eritematoso e liquenóide e estão localizadas principalmente na mucosa jugal e labial e na língua ${ }^{2}$. São constantemente acompanhadas de dor e podem ser confundidas com outras lesões auto-imunes, como eritema multiforme, pênfigo vulgar e líquen plano ${ }^{4}$. As lesões ulceradas exibem bordas eritematosas e difusas, com superfície serofibrinosa, e podem dificultar a ingestão de alimentos ${ }^{2}$. Conclusão: Como fatores relacionados a pacientes transplantados destaca-se a DECH, cujo cuidado e atenção aos sinais e sintomas em pacientes transplantados devem ser dobrados, pois muitas vezes a boca é o primeiro, e por muito tempo, pode ser o único local de manifestação da $\mathrm{DECH}$. O estomatologista tem papel importante na avaliação clínica, auxiliando no reconhecimento precoce, complicações e acompanhamento de pacientes transplantados.

Descritores: Doença Enxerto-Hospedeiro; Transplante Homólogo; Manifestações bucais.

\section{Referências:}

1. MICHALLET AS, et al. Outcome and long-term follow-up of alloreactive donor lymphocyte infusions given for relapse after myeloablative allogeneic hematopoietic stem cell transplantations (HSCT). Bone Marrow Transplant, 2005; 35(6): 601-8

2. PEREIRA CM, et al. Detection of human herpesvirus 6 in patients with oral chronic graftvs-host disease following allogeneic progenitor cell transplantation. Oral Diseases, 2007; 13(3): 329-34

3. RATANATHARATHORN V, et al. Chronic graft-versus-host disease: clinical manifestation and therapy. Mini review. Bone Marrow Transplant, 2001; 28: 121-9.

4. SCHUBERT MM, et al. Oral manifestations of chronic graft-v-host disease. Archives of Internal Medicine, 1984; 144(8): 1591-5 


\section{PC-63-2019 - É POSSÍVEL REMOVER MANCHAS HIPERPLÁSICAS DE FORMA CONSERVADORA? RELATO DE CASO}

Maria Eduarda Arruda de Lucena ${ }^{1}$; Ana Beatriz Albuquerque Meira ${ }^{1}$; Pedro Paulo Aguiar Santos Cavalcanti' ${ }^{1}$; Fernanda Gomes Barros ${ }^{1}$; Francisco Henrique Lima Milhomens ${ }^{1}$; Maria Regina Almeida de Menezes ${ }^{1}$; Mônica Maria de Albuquerque Pontes ${ }^{1}$; Juliana Raposo Souto Maior Costa ${ }^{1}$

${ }^{1}$ Faculdade de Odontologia de Pernambuco - Camaragibe - PE - Brasil

Autor correspondente:

Maria Eduarda Arruda de Lucena

marrudadelucena@gmail.com

Introdução: Os padrões da sociedade estão cada vez incitando a busca pelos dentes perfeitos, tornando-se uma meta comum entre muitos, e um sorriso harmônico seja em proporção, forma, alinhamento e cor se tornou sinônimo de bem-estar e saúde ${ }^{2}$. As alterações acometendo o esmalte durante o estágio de formação da matriz podem resultar na redução da espessura ou da quantidade de esmalte, promovendo a presença de hipoplasias, apresentando mudanças na cor do esmalte para bege, marrom ou amarelo-escuro, sendo que fóssulas, fissuras ou perda maior de algumas áreas de esmalte podem ser observadas ${ }^{3}$. Objetivo: Devido ao momento atual que a Odontologia vive, preconizando procedimentos minimamente invasivos, este trabalho relata um caso clínico que foi empregado a técnica da microabrasão no tratamento da hipoplasia do esmalte, sem que haja um desgaste em excesso do esmalte. Relato de caso: Paciente, sexo feminino, 21 anos, queixava-se de manchas hipoplásicas generalizadas presentes nos elementos dentários 13 a 23. Foi avaliada a profundidade das manchas para planejamento da técnica restauradora de microabrasão do esmalte com a utilização do produto opalescence. Iniciou-se o procedimento com isolamento absoluto nos dentes envolvidos, aplicando o opalescence 10 vezes em cada elemento durante 10 segundos. Foi feita uma nova reavaliação dos elementos dentários para avaliar a necessidade de uma nova aplicação do opalescence. Já no final da primeira sessão, a paciente se encontrava satisfeita com o resultado obtido. Discussão: Esse tratamento se tornou recorrente nos consultórios, devido a busca pelo sorriso padrão, repercutindo diretamente na autoestima do paciente, fazendo com que o CD fique diante a decisão de eleger o procedimento mais adequado, que sölucione tais alterações de coloração e conjuntamente mantenha a estrutura dentária da melhor maneira possível ${ }^{2}$. Conclusão: A técnica de microabrasão pode ser considerada alternativa interessante para as opções de tratamento cirúrgico convencional devolvendo estética para a paciente ${ }^{1}$.

Descritores: Hipoplasia do Esmalte Dentário; Esmalte Dentário; Microabrasão do Esmalte.

\section{Referências:}

1. GUPTA A, et al. A comparison of various minimally invasive techniques for the removal of dental fluorosis stains in children. J Indian Soc Pedod Prev Dent, 2017; 35(3): 260-268

2. HERMES SR. Microabrasão do esmalte dental para tratamento de fluorose. Rev. Gaúcha de Odontologia, 2013; 61(0): 427-433

3. SEOW WK. A study of the development of the permanent dentition in very low birthweight children. Pediatr Dent, 1996; 18(5): 84-379 


\section{PC-64-2019 - EDUCAÇÃO EM SAÚDE DO ESCOLAR: UM AGIR PARTICIPATIVO}

Andreza Cibelle Amaral da Silva ${ }^{1}$; Fabíola de Melo Linss ${ }^{1}$; João Alves Gonçalves Neto ${ }^{1}$; Júlya Karolina Gomes $^{1}$; Maria Rafaela dos Santos ${ }^{1}$; Vanessa Lopes do Nascimento ${ }^{1}$; Jailma Santos Monteiro'; Márcia Maria Dantas Cabral de Melo ${ }^{1}$

${ }^{1}$ Universidade Federal de Pernambuco - Recife - PE - Brasil

Autor correspondente:

Andreza Cibelle Amaral da Silva

andreza.odonto@gmail.com

Introdução: A educação em saúde e prevenção de agravos recorre aos referenciais teóricometodológicos da educação popular em saúde para qualificar as práticas profissionais da Atenção Primária à saúde (APS) voltadas aos diferentes grupos sociais alvo das intervenções, como os escolares adolescentes ${ }^{3}$. Objetivo: apresentar as estratégias pedagógicas participativas adotadas em uma ação extensionista de âmbito escolar em um território da APS. Relato de experiência: um diagnóstico situacional foi realizado com a comunidade da escola municipal de Engenho do Meio situada em um território de saúde do Recife, o distrito sanitário IV. Três temáticas de educação em saúde foram selecionadas para serem trabalhadas semanalmente com um grupo de adolescentes da escola. Temáticas: cultura de paz, musicalidade e alimentação saudável. Foram planejadas oficinas lúdico-participativas onde os escolares em rodas de conversa eram estimulados por uma situação-temática para levantarem hipóteses e encontrarem soluções. Metodologias ativas e participativas foram adotadas para a construção do diálogo ${ }^{1}$. Sendo o ponto fundamental a escuta ativa dos facilitadores das oficinas, promovendo o protagonismo dos adolescentes no relato de suas expectativas, emoções, opiniões e sentimentos vivenciados. Levando-os a identificar criticamente os principais problemas apontados e as possibilidades de intervenções na comunidade. Discussão: A proposta educativa em saúde pautada na educação popular em saúde potencializou as ações de Promoção à Saúde e foram condizentes com valores e atribuições requeridos ao agir na APS. A experiência traz consigo conceitos de "empoderamento", "maior participação" e "valorização do saber popular" em práxis, vivenciando também o "compartilhamento dos saberes" e "construção de parcerias". Conclusões: constatou-se que as estratégias educativas utilizadas promoveram vínculos, amorosidade, troca de saberes, autonomia, fortalecimento dâ autoconfiança entre os participantes, além da construção de cidadania na comunidade escolar².

Descritores: Educação em Saúde; Adolescente; Atenção Primária à Saúde

\section{Referências:}

1. CARVALHO FFB. A saúde vai à escola: a promoção da saúde em práticas pedagógicas. Physis Revista de Saúde Coletiva, 2015; 25(4): 1207-1227

2. GUIMARÃES G, et al. A escola promotora da saúde e o desenvolvimento de habilidades sociais. Diaphora, 2014; 12(2): 88-95

3. MACHADO MFAS, et al. Programa saúde na escola: estratégia promotora de saúde na atenção básica no Brasil. Journal of Human Growth and Development, 2015; 25(3): 307-312 


\section{PC-65-2019 - EFEITO CLAREADOR DE DENTIFRÍCIOS À BASE DE CARVÃO ATIVADO: REVISÃO DE LITERATURA}

Fábio Victor Dias Silva ${ }^{1}$; Abimael Mágbys Pessoa Flor ${ }^{1}$; Ana Beatriz Pires de Medeiros ${ }^{1}$; Gabrielly Lima da Silva ${ }^{1}$; Marcos Aurélio Vasconcelos Lima Júnior ${ }^{1}$

${ }^{1}$ Centro Universitário de João Pessoa - UNIPÊ - João Pessoa - PB - Brasil

Autor correspondente:

Fábio Victor Dias Silva

fabio_vct@hotmail.com

Introdução: Desde a Grécia Antiga, o carvão vegetal vem sendo utilizado pela população em sua higiene bucal, alcançando, posteriormente, outras partes do mundo ${ }^{1}$. Atualmente, dentifrícios de carvão ativado são produtos de higiene oral da moda, ganhando destaque em mídias sociais pelo seu marketing que promete clareamento dentário ${ }^{2}$. Objetivo: Verificar a eficácia dos dentifrícios à base de carvão ativado no clareamento das estruturas dentárias após a escovação. Metodologia: Foram realizadas buscas de artigos internacionais nas bases de dados PubMed e MEDLINE, publicados entre os anos de 2015 e 2019, utilizando os descritores Carvão Ativado, Dentifrícios e Dentes, onde foram selecionados 3 artigos que apresentavam relação direta com o tema. Revisão de literatura: Analisando os rótulos de dentifrícios à base de carvão ativado comercializados na Internet, 96\% alegavam promoção de clareamento dental $^{1}$. O efeito de branqueamento do carvão ocorre devido à sua alta capacidade de adsorver e reter cromóforos que estão presentes na boca ${ }^{3}$. Somado a isso, o carvão apresenta alta porosidade e abrasividade que resulta em uma limpeza eficiente dos dentes ${ }^{1}$, já que, quanto mais abrasiva a partícula de carvão, maior será a remoção de manchas extrínsecas e outros depósitos na superfície dentária². Em dentifrícios à base de carvão, não foram observados efeitos imediatos após a primeira escovação, sendo perceptíveis efeitos clareadores efetivos apenas após o uso contínuo ${ }^{3}$. Conclusão: Com o intuito de gerar clareamento dental, o uso constante de dentifrícios à base de carvão ativado será eficaz apenas no branqueamento superficial da estrutura dentária, sem alterar a coloração intrínseca. Além disso, torna-se imprescindível buscar orientação do cirurgião-dentista antes de fazer uso de dentifrícios à base de carvão, já que estes podem causar desgaste da superfície dental.

Descritores: Carvão Ativado; Dentifrícios; Dentes.

\section{Referências:}

1. BROOKS JK, et al. Charcoal and charcoal-based dentifrices: a literature review. The Journal of the American Dental Association, 2017; 148(9): 661-670

2. GREENWALL LH, et al. Charcoal-containing dentifrices. British Dental Journal, 2019; 226(9): 697-700

3. VAZ VTP, et al. Whitening toothpaste containing activated charcoal, blue covarine, hydrogen peroxide or microbeads: which one is the most effective. Journal of Applied Oral Science, 2019; 27: 1-8 


\title{
PC-66-2019 - EFEITO DA TERAPIA FOTODINÂMICA COMO ADJUVANTE À TERAPIA PERIODONTAL DE SUPORTE SOBRE BOLSAS RESIDUAIS
}

\begin{abstract}
Yuri Victor Dias de Oliveira' ${ }^{1}$; Beatriz da Silva Lemos ${ }^{1}$; Isabella Maria da Silva Lemos ${ }^{1}$; Victor Alexandre Felício Trancoso ${ }^{1}$; Carlos Frederico de Moraes Sarmento ${ }^{1}$; Davi da Silva Barbirato ${ }^{2}$; Daniela da Silva Feitosa ${ }^{1}$; Mariana Fampa Fogacci ${ }^{1}$
\end{abstract}

1Universidade Federal de Pernambuco - Recife - PE - Brasil

${ }^{2}$ Universidade de Pernambuco - Camaragibe - PE - Brasil

Autor correspondente:

Yuri Victor Dias de Oliveira

oliveiravd@outlook.com

Introdução: Decorrente da necessidade de novas alternativas de tratamento, a fim de aprimorar a eficácia do tratamento odontológico periodontal, tem sido possível observar o desempenho da terapia fotodinâmica (PDT) e seu caráter complementar na terapia periodontal de suporte. Objetivo: Avaliar o impacto da PDT, adjuvante à terapia periodontal não cirúrgica de raspagem e alisamento radicular (RAR), sobre os níveis de profundidade de bolsa à sondagem (PBS), sangramento à sondagem (SS) e nível clínico de inserção $(\mathrm{NCI})$ nas bolsas residuais de pacientes submetidos à terapia de suporte. Metodologia: Foi realizado um levantamento bibliográfico, selecionando artigos indexados nas bases eletrônicas SciELO e MEDLINE através dos descritores "fotoquimioterapia", "periodontite" e "bolsa periodontal". Revisão de Literatura: Quatro principais artigos foram encontrados e seus resultados apresentados. Após uma semana de tratamento, $73 \%$ dos sítios submetidos a RAR+PDT apresentaram SS negativo, além de demonstrarem uma redução significativa nos níveis de PBS em relação ao controle ${ }^{4}$. Os sítios testados expressaram uma redução significativa em relação a NCI e a PBS comparados com os sítios controle no período de três meses ${ }^{3}$. Após três meses, foi constatado, no grupo submetido a RAR + PDT, níveis de PBS reduzidos e ganho de NCI comparado ao grupo que realizou apenas a RAR, bem como uma redução no número de sítios com PBS $<5 \mathrm{~mm}$ sem $\mathrm{SS}^{2,1}$. Em seis meses essas diferenças não se apresentavam mais significativas ${ }^{4}$. Conclusão: Ao avaliar os parâmetros referentes a PBS, SS e NCI nas bolsas residuais de diferentes pacientes submetidos a RAR+PDT, pôde-se constatar uma melhora clínica considerável quando comparados à RAR isolada. Desse modo, a aplicação adjuvante da PDT póde levar a uma resolução significativa das bolsas residuais. Por outro lado, mais pesquisas se fazem necessárias para a confirmação desses achados, visto que ainda há pouca literatura sobre o tema.

Descritores: Fotoquimioterapia; Periodontite; Bolsa Periodontal.

\section{Referências:}

1. CAMPOS GN, et al. The adjunctive effect of photodynamic therapy for residual pockets in single-rooted teeth: a randomized controlled clinical trial. Lasers in medical science, 2013; 28(1): 317-324

2. CORREAA MG, et al. Short-term microbiological effects of photodynamic therapy in nonsurgical periodontal treatment of residual pockets: A split-mouth RCT. Lasers in surgery and medicine, 2016; 48(10): 944-950

3. GOH EX, et al. Effects of root debridement and adjunctive photodynamic therapy in residual pockets of patients on supportive periodontal therapy: a randomized split-mouth trial. Photodiagnosis and photodynamic therapy, 2017; 18:342-348

4. MONGARDINI C, et al. Light-activated disinfection using a light-emitting diode lamp in the red spectrum: clinical and microbiological short-term findings on periodontitis patients in maintenance. A randomized controlled split-mouth clinical trial. Lasers in medical science, 


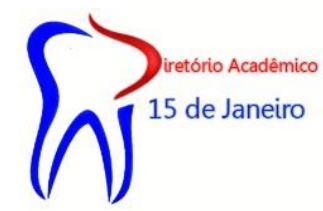

2014; 29(1): 1-8
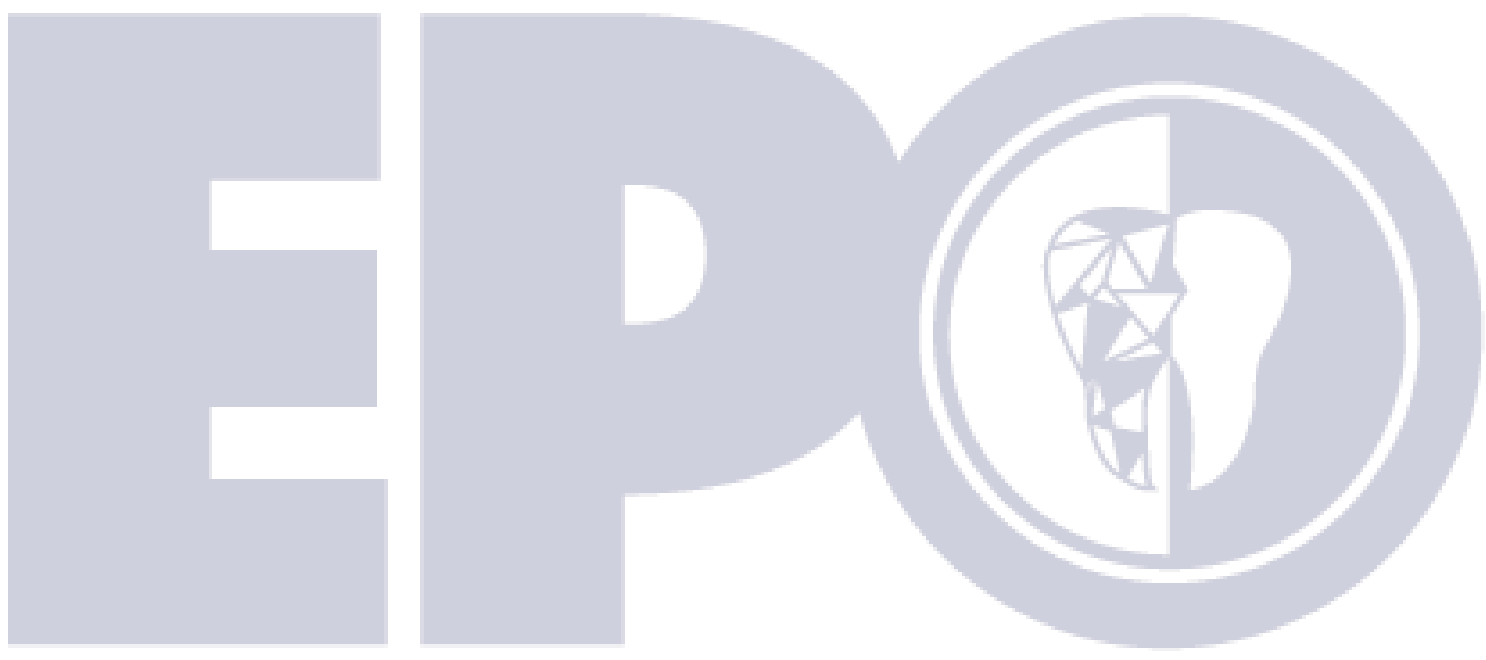

ENCONTRO PERNAMBUCANO

DE ODONTOLOGIA 


\section{PC-67-2019 - EFEITO DA TERAPIA FOTODINÂMICA COMO ADJUVANTE A TERAPIA PERIODONTAL NÃO CIRÚRGICAS EM LESÕES DE FURCA}

Aline Roberta Oliveira da Silva ${ }^{1}$; Andressa Cristina da Silva Queiroz ${ }^{1}$; Manassés de Oliveira Pereira $^{1}$; Victor Alexandre Felício Trancoso ${ }^{1}$; Carlos Frederico de Moraes Sarmento ${ }^{1}$; Davi da Silva Barbirato²; Daniela da Silva Feitosa ${ }^{1}$; Mariana Fampa Fogacci ${ }^{1}$

${ }^{1}$ Universidade Federal de Pernambuco - Recife - PE - Brasil

${ }^{2}$ Universidade de Pernambuco - Camaragibe - PE - Brasil

Autor correspondente:

Aline Roberta Oliveira da Silva

aliinerobertaa@gmail.com

Introdução: A implementação da terapia fotodinâmica (TF) tem sido proposta como uma terapia adjunta aos procedimentos convencionais de RAR, em casos de tratamento de lesões de furca ${ }^{1,3,4}$. Objetivo: Avaliar o efeito da terapia fotodinâmica como adjuvante à terapia periodontal não cirúrgica em lesões de furca. Metodologia: Baseado em uma revisão de literatura, foram escolhidos quatro artigos com enfoque no tema proposto, com lapso temporal de seis anos. Revisão de Literatura: Os envolvimentos de furca são frequentemente observados em indivíduos apresentando periodontite e aproximadamente $50 \%$ dos molares em pacientes acima de 40 anos de idade exibem essas condições ${ }^{3,2}$. A TF é considerada um método terapêutico não invasivo capaz de inativar seletivamente os patógenos periodontais, reduzindo os danos aos tecidos do hospedeiro. O princípio biológico é baseado na inativação de célulasalvo, microrganismos ou moléculas, pelo uso de um fotossensibilizador e uma fonte de luz laser de baixa potência. Em um estudo com molares inferiores apresentando lesão de furca classe III, sugeriu-se que a TF associada à terapia periodontal não cirúrgica e cirúrgica, pode modular a remodelação óssea e a matriz extracelular, regulando a relação mRNA de TIMP-2/MMP-2 e OPG/RANKL ${ }^{1}$. Outro estudo demonstrou que protocolo da TF em comparação com RAR apresentou efeito adicional para a concentração de TGF- $\beta$ no líquido crevicular 45 dias após a terapia não cirúrgica, e para o volume do líquido 21 dias após a terapia cirúrgica ${ }^{4}$. Ademais, a TF não promoveu benefícios clínicos para lesões de furca classe II; entretanto, foram demonstradas vantagens nos níveis locais de citocinas e redução dos periodontopatógenos ${ }^{3}$. Conclusão: No geral, foi demonstrado que a TF alcânçou melhorias em níveis locais de inflamação ${ }^{3,2}$. É importante, portanto, que mais ensaios clínicos randomizados sejam conduzidos para determinar qual o protocolo de TF mais eficaz na ação antimicrobiana no tratamento da periodontite'

Descritores: Fotoquimioterapia; Defeitos da Furca; Periodontite.

\section{Referências:}

1. ANDRADE PF, et al. Adjunct effect of the antimicrobial photodynamic therapy to an association of non-surgical and surgical periodontal treatment in modulation of gene expression: A human study. Journal of Photochemistry and Photobiology B: Biology, 2013; 126: $119-125$

2.BRINGEL AC, et al. Terapia fotodinâmica como coadjuvante ao tratamento periodontal. Revista de Pesquisa em Saúde, 2013; 14(3): 179-183

3. LUCHESI VH, et al. Photodynamic therapy in the treatment of class II furcation: a randomized controlled clinical trial. Journal of Clinical Periodontology, 2013; 40: 781-788

4.SOUZA SL, et al. Effects of Antimicrobial Photodynamic Therapy on Transforming Growth Factor-b1 Levels in the Gingival Crevicular Fluid. Photomedicine and Laser Surgery, 2013; 31(2): $65-71$ 


\title{
PC-68-2019 - EFEITO DA TERAPIA FOTODINÂMICA COMO ADJUVANTE À TERAPIA PERIODONTAL NÃO CIRÚRGICA SOBRE O FLUIDO CREVICULAR GENGIVAL
}

\begin{abstract}
Yuri Victor Dias de Oliveira ${ }^{1}$; Beatriz da Silva Lemos ${ }^{1}$; Isabella Maria da Silva Lemos ${ }^{1}$; Victor Alexandre Felício Trancoso ${ }^{1}$; Carlos Frederico de Moraes Sarmento ${ }^{1}$; Davi da Silva Barbirato²; Daniela da Silva Feitosa ${ }^{1}$; Mariana Fampa Fogacci ${ }^{1}$
\end{abstract}

${ }^{1}$ Universidade Federal de Pernambuco - Recife - PE - Brasil

${ }^{2}$ Universidade de Pernambuco - Camaragibe - PE - Brasil

Autor correspondente:

Yuri Victor Dias de Oliveira

oliveiravd@outlook.com

Introdução: A terapia periodontal não cirúrgica visa a erradicação dos agentes moduladores das doenças do periodonto, sendo uma fase crucial para a subsequência do tratamento e seu sucesso. Devido a sua importância, pesquisas a respeito de técnicas complementares vêm sendo realizadas, como a terapia fotodinâmica (PDT). Objetivo: Avaliar o impacto da PDT como adjuvante à terapia periodontal não cirúrgica de raspagem e alisamento radicular (RAR), sobre os parâmetros clínicos e bioquímicos do fluído crevicular gengival (FCG) em pacientes com periodontite em estágios avançados. Metodologia: Foi realizado um levantamento bibliográfico, selecionando artigos indexados nas bases eletrônicas SciELO e MEDLINE através dos descritores "fotoquimioterapia", "periodontite" e "líquido do sulco gengival". Revisão de Literatura: Quatro principais artigos foram encontrados e seus resultados apresentados. Os níveis de RANK-L foram significantemente diminuídos no grupo que fez utilização da RAR associada a PDT em comparação ao grupo que realizou apenas a RAR ${ }^{3}$. A PDT reduziu de modo considerável os níveis de IL-1 $\beta$ e IL-17, em relação ao cenário base ${ }^{4}$. Utilizando um laser de 638-nm e azul de toluidina como corante fotossensibilizador, apenas os níveis de TNF- $\alpha$ apresentaram melhora significativa nos grupos que utilizaram a RAR associada a $\mathrm{PDT}^{2}$. A taxa de fluxo do FCG, por sua vez, demonstrou um decréscimo em relação ao cenário base, apresentando maior queda tanto sete dias, quanto três meses após o tratamento ${ }^{1}$. Conclusão: Estudos realizados em diferentes grupos, que testaram a eficácia da PDT+RAR, apresentaram resultados significativos ao longo de treze semanas. Ao avaliar os marcadores inflamatórios presentes no FCG, bem como os marcadores bioquímicos do metabolismo ósseo, confirmou-se estatisticamente um decréscimo em relação ao cenário base, configurando uma melhoria no quadro clínico dos pacientes acometidos por periodontite em estágios avançados. Entretanto, mais pesquisas são necessárias para confirmar os achados, uma vez que há poucos estudos no tema.

Descritores: Fotoquimioterapia; Periodontite; Líquido do Sulco Gengival.

\section{Referências:}

1. BRAUN A, et al. Short-term clinical effects of adjunctive antimicrobial photodynamic therapy in periodontal treatment: a randomized clinical trial. Journal of clinical periodontology, 2008; 35(10): 877-884

2. POURABBAS R, et al. Effects of photodynamic therapy on clinical and gingival crevicular fluid inflammatory biomarkers in chronic periodontitis: A split-mouth randomized clinical trial. Journal of periodontology, 2014; 85(9): 1222-1229

3. SEGARRA-VIDAL M, et al. Effects of photodynamic therapy in periodontal treatment: A randomized, controlled clinical trial. Journal of clinical periodontology, 2017; 44(9): 915-925

4. TEYMOURI F, et al. The effect of photodynamic therapy and diode laser as adjunctive 

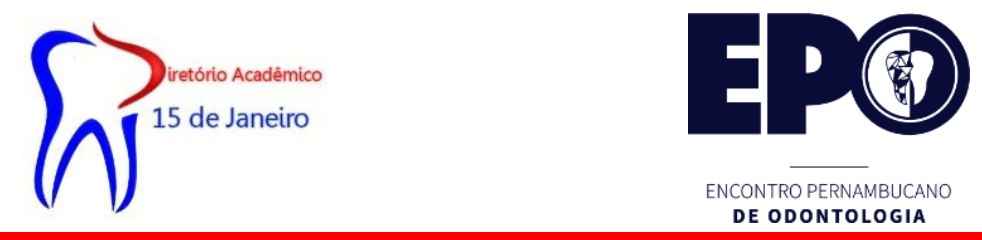

UPE/FOPICAMPUS CAMARAGIBE

periodontal therapy on the inflammatory mediators levels in gingival crevicular fluid and clinical periodontal status. Journal of Dentistry, 2016; 17(3): 226-232
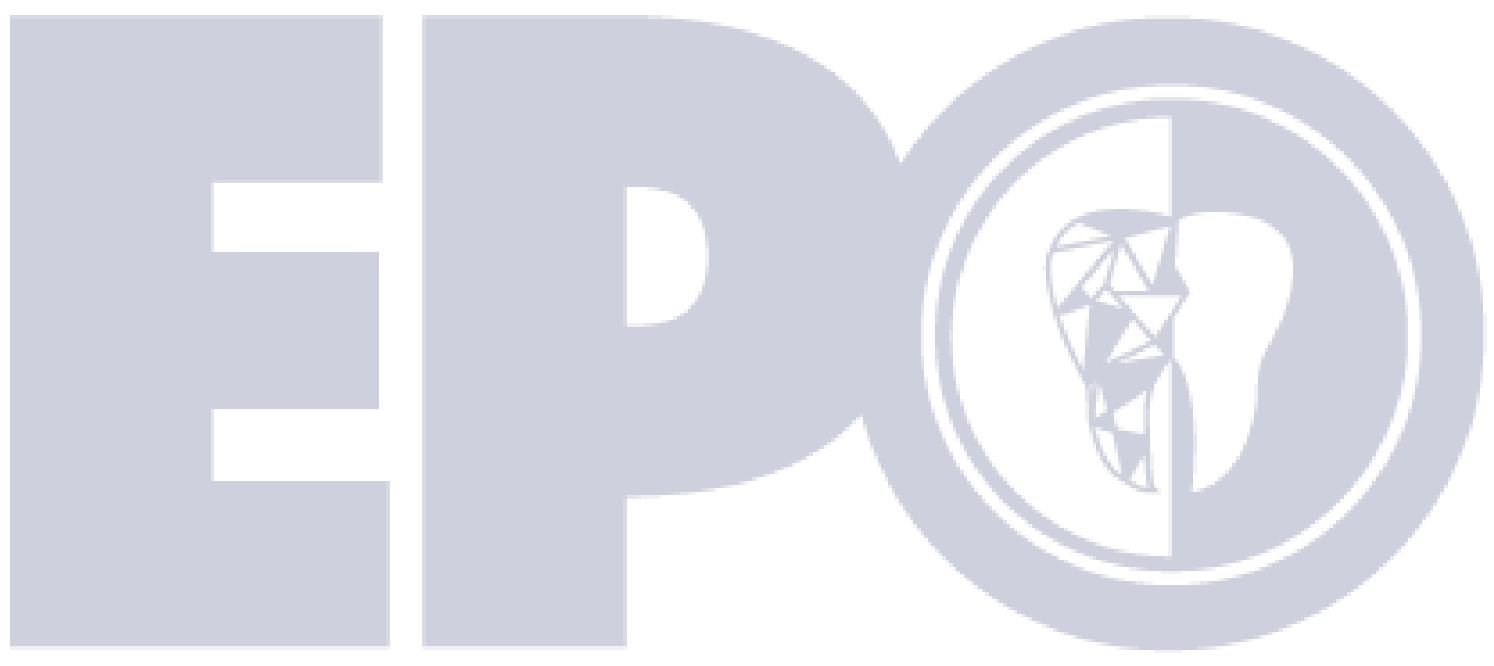

\section{ENCONTRO PERNAMBUCANO}

DE ODONTOLOGIA 


\section{PC-69-2019 - EFEITOS DA ABRASIVIDADE DE CREMES DENTAIS CLAREADORES NO ESMALTE DENTÁRIO HUMANO}

Maria Heloisa Martins ${ }^{1}$; Cecília Maria de Sá Barreto Cruz Falcão ${ }^{1}$; Alesson Jamesson da Silva ${ }^{1}$; Bruna Wanderley Braga'; Cibele Virgínia Morais de Melo ${ }^{1}$; Isabela Silva Ferreira ${ }^{1}$; Jessyca Maria Alencar e Sá1; Taís Soares Ramos ${ }^{2}$

${ }^{1}$ Universidade Federal de Pernambuco - Recife - PE - Brasil

${ }^{2}$ Faculdade de Odontologia de Pernambuco - Camaragibe - PE - Brasil

Autor correspondente:

Maria Heloisa Martins

Heloisa711@gmail.com

Introdução: A busca por um sorriso com dentes mais brancos tem impulsionado o consumo de produtos odontológicos que prometem esse resultado ${ }^{3}$. Diferentes marcas de dentifrícios disponíveis para o uso doméstico veiculam na mídia um efeito clareador nos dentes associado a determinado período de uso ${ }^{5}$. Objetivo: O presente estudo teve por objetivo realizar uma análise dos principais efeitos no esmalte dentário, relacionados à abrasividade de cremes dentais clareadores. Metodologia: Foi realizada uma revisão de literatura a partir de artigos obtidos na base de dados BIREME, utilizando os seguintes descritores: Dentifrícios, clareamento dental e abrasão dentária. Revisão de literatura: Nestes dentifrícios, os principais componentes ativos encontrados foram substâncias clareadoras e agentes abrasivos ${ }^{1}$. Percebeu-se que existe um grau de abrasividade que é bem tolerado para um resultado satisfatório da limpeza dos dentes e remoção de manchas da superfície dentária ${ }^{4}$. A propriedade abrasiva dos dentifrícios esteve relacionada à quantidade e tamanho das partículas dos agentes abrasivos, bem como da influência química de outros tipos de componentes no produto ${ }^{2}$. Conclusão: Constatou-se que o uso prolongado ou incorreto, pôde produzir desgaste ao esmalte. Sendo assim, a avaliação do teor da abrasividade nos dentifrícios clareadores, bem como sua correta utilização é relevante para evitar danos significativos ao esmalte dentário.

Descritores: Dentifrícios; Clareamento dental; Abrasão dentária.

\section{Referências:}

1. HILGENBERG SP, et al. Physical-chemical characteristics of whitening toothpaste and evaluation on its effects on enamel roughness. Brazilian Oral Research, 2011; 25(4): 288-294

2. JOHANNSEN G, et al. The importance of measuring toothpaste abrasivity in both a quantitative and qualitative way. Acta Odontologica Scandinavica, 2013; 71(3-4): 508-517.

3. JOINER A, et al. The measurement of enamel wear by four toothpastes. Internacional Dental Journal, 2008; 58(1): 23-28

4. JOINER A, et al. An in situ model to study the toothpaste abrasion of enamel. Journal of Clinical Periodontology, 2004; 31(6): 434-438

5. PICKLES M, et al. In vitro efficacy of a whitening toothpaste containing calcium carbonate and perlite. Internacional Dental Journal, 2005; 55(3): 197-202 


\title{
PC-70-2019 - EFEITOS DA TERAPIA PERIODONTAL NÃO CIRÚRGICA NA DOENÇA RENAL CRÔNICA
}

\author{
Manassés de Oliveira Pereira ${ }^{1}$; Aline Roberta Oliveira da Silva ${ }^{1}$; Carlos Frederico de Moraes \\ Sarmento $^{1}$; Davi da Silva Barbirato ${ }^{2}$; Daniela da Silva Feitosa ${ }^{1}$; Mariana Fampa Fogacci ${ }^{1}$ \\ ${ }^{1}$ Universidade Federal de Pernambuco - Recife - PE - Brasil \\ ${ }^{2}$ Universidade de Pernambuco - Camaragibe - PE - Brasil
}

Autor correspondente:

Manassés de Oliveira Pereira

manassesop@gmail.com

Introdução: A periodontite é uma doença inflamatória crônica bastante prevalente em adultos, causada pelo acúmulo de biofilme, desencadeando uma resposta imune-inflamatória que acarreta destruição dos tecidos periodontais de sustentação dos dentes ${ }^{1,5}$. Além disso, essa condição induz uma resposta inflamatória sistêmica, que poderá estar associada ao desenvolvimento e/ou agravamento da doença renal crônica (DRC) ${ }^{3}$. Dessa forma, a terapia periodontal não cirúrgica, raspagem e alisamento radicular (RAR) tem sido associada com a redução dos mediadores inflamatórios sistêmicos, podendo, portanto, melhorar o quadro da DRC $^{2,5}$. Objetivo: Avaliar o efeito da RAR na DRC. Metodologia: Através de uma busca bibliográfica na base de dados PubMed, foram selecionados cinco artigos relevantes para uma revisão de literatura. Revisão de literatura: Pacientes com DRC apresentam maior risco de progressão e mortalidade devido ao aumento da carga inflamatória sistêmica, que tem sido observado em pacientes com periodontite ${ }^{4}$. Isso porque as bactérias Gram-negativas e seus produtos tóxicos estimulam as células do hospedeiro a secretarem citocinas, como a proteína C-reativa (PCR) e a Interleucina-6, que se disseminam via circulação sanguínea, instituindo uma condição de inflamação sistêmica ${ }^{1,4,5}$. Entretanto, têm sido relatados em pacientes com DRC os efeitos da remoção de depósitos bacterianos por meio de RAR, administração local de antibióticos para sítios mais profundos, instrução de controle de placa e consultas de manutenção duas a quatro vezes por ano. Os estudos de base populacional indicam que pacientes com doença periodontal, submetidos à RAR, tiveram probabilidade $40 \%$ menor de progressão da DRC ${ }^{2}$. Observa-se uma redução dos níveis de PCR e Interleucina-6 no sangue após a RAR em pacientes com DRC, sugerindo sua eficácia ${ }^{2,5}$. Conclusão: Mais ensaios clínicos randomizados são necessários para confirmar os achados. Em princípio, os benefícios da RAR sobre a DRC são promissores e podem indicar uma abordagem terapêutica complementar à prevenção e ao tratamento da DRC.

Descritores: Insuficiência Renal Crônica; Periodontite; Proteína C-reativa.

\section{Referências:}

1. ALMEIDA $S$, et al. Periodontal treatment in patients with chronic kidney disease: a pilot study. Journal of periodontal research, 2017; 52(2):262-267

2. GRAZIANI F, et al. Effects of non-surgical periodontal therapy on the glomerular filtration rate of the kidney: an exploratory trial. Journal of clinical Periodontology, 2010; 37(7):638-643 3. KIM YJ, et al. Evaluation of periodontal condition and risk in patients with chronic kidney disease on hemodialysis. Einstein, 2017; 15(2):173-177

4. SHARMA P, et al. Influence of successful periodontal intervention in renal disease (inspired): study protocol for a randomised controlled pilot clinical trial. Trials, 2017; 18(1):535-545

5. VILELA EM, et al. Treatment of chronic periodontitis decreases serum prohepcidin levels in patients with chronic kidney disease. Clinics, 2011; 66(4):657-662 


\title{
PC-71-2019 - EFEITOS DO ÓXIDO NITROSO X REALIDADE VIRTUAL NOS PROCEDIMENTOS ODONTOLÓGICOS
}

\author{
Rebeca Gomes da Silva ${ }^{1}$; Brendda Juliane dos Santos ${ }^{1}$; Irani de Farias Cunha Júnior ${ }^{1}$ \\ ${ }^{1}$ Universidade Federal de Pernambuco - Recife - PE - Brasil
}

Autor correspondente:

Rebeca Gomes da Silva

Becaaaag@gmail.com

Introdução: As técnicas anestésicas visam reduzir o sentimento de desconforto do paciente no ambiente odontológico, diante disso é importante evidenciar tais técnicas e os efeitos colaterais a partir do uso de óxido nitroso e realidade virtual. Objetivo: Analisar os efeitos colaterais que os pacientes odontológicos podem sentir ao ser submetidos à utilização das técnicas anestésicas por óxido nitroso, e a distração por realidade virtual. Metodologia: Foi realizado um levantamento com base nos dados Scholar Google com os descritores: Terapia de exposição a realidade virtual, óxido Nitroso e anestesia dentária. Revisão de literatura: A dor é uma experiência individual e subjetiva ${ }^{1}$. O sucesso no manejo da dor envolve a avaliação contínua e rigorosa ${ }^{1}$. combinando métodos farmacológicos e não farmacológicos ${ }^{1}$. Sedação consciente é um estado de relaxamento, no qual o paciente permanece consciente e cooperativo durante o tratamento odontológico ${ }^{2}$. A técnica de Sedação Consciente com Óxido Nitroso é uma ótima opção para controlar a ansiedade, reduzir o medo ${ }^{2}$. evita a indicação de intervenções sob anestesia geral ${ }^{2}$. fenômeno conhecido como "hipóxia difusão"2. Produz cefaleia, náusea e letargia ${ }^{2}$. Ressalta-se que se deve evitar qualquer risco de toxicidade para o paciente ${ }^{2}$. Métodos não farmacológicos que vem sendo estudado é a Realidade Virtual ${ }^{3}$. Permite ao usuário ficar imerso em ambiente virtual ${ }^{3}$. Contribuindo na redução da dor ${ }^{3}$. $\mathrm{O}$ objetivo da RV foi complementar o tratamento farmacológico ${ }^{3}$. A confusão entre o físico estável e o psicológico em movimento pode ser tanta, que os efeitos colaterais como cansaço visual, náusea e dor de cabeça, podem aparecer ${ }^{4}$. Conclusão: $\mathrm{O}$ uso da realidade virtual e o óxido nitroso, proporciona conforto ao paciente, o cirurgião-dentista deve ter o conhecimento acerca dessas técnicas e das particularidades do paciente para que seja utilizada a técnica que traga a prevenção de complicações durante procedimentos odontológicos.

Descritores: Terapia de Exposição a Realidade Virtual; Óxido Nitroso; Anestesia Dentária.

\section{Referências:}

1. DIJKSTRA KT, et al. The soothing sea: A virtual coastal walk can reduce experienced and recollected pain. Environment and Behavior, 2018; 50(6): 599-625

2. DUARTE AM, et al. Conhecimento dos acadêmicos de odontologia sobre sedação consciente com a utilização do óxido nitroso. Revista Odontologia Clínico-Científica, 2011; 10(2): 137-141

3. SCAPIN SQ, et al. Utilização da realidade virtual no tratamento de crianças queimadas: relato de casos. Revista Brasileira de Enfermagem, 2017; 70(6): 1291-1295

4. WIEDERHOLD MD, et al. Clinical use of virtual reality distraction system to reduce anxiety and pain in dental procedures. Cyberpsychology, Behavior, and Social Networking, 2014; 17(6): 359-365 


\section{PC-72-2019 - EFEITOS TERAPÊUTICOS DA CIRURGIA ORTOGNÁTICA, CPAP E DAMS NO TRATAMENTO DA APNEIA OBSTRUTIVA DO SONO: REVISÃO DE LITERATURA}

Carla Cecília Lira Pereira de Castro ${ }^{1}$; Jeferson Batista Santiago ${ }^{1}$; Olívia Augusta Araújo Dias ${ }^{1}$; Mayara Monique Silva de Oliveira ${ }^{1}$; Joana de Ângelis Alves Silva ${ }^{1}$; Ismael Sebastião da Silva Sousa $^{1}$; Fernanda Cardoso Gurgel ${ }^{1}$; Laura Buarque Caminha Lins ${ }^{1}$

${ }^{1}$ Faculdade de Odontologia de Pernambuco - Camaragibe - PE - Brasil

Autor correspondente:

Carla Cecília Lira Pereira de Castro

carlalpc@ hotmail.com

Introdução: Relacionada a obstrução das vias aéreas faríngeas durante o sono, a síndrome da apneia obstrutiva do sono (SAOS) é influenciada por alterações anatômicas que causam uma redução do espaço faríngeo, além da obesidade e do tabagismo'. O tratamento se faz, à princípio, com o CPAP ou dispositivos de avanços mandibulares (DAMs), embora a cirurgia ortognática seja a melhor alternativa ${ }^{1-3}$. Objetivo: Apresentar uma revisão de literatura a respeito dos principais métodos terapêuticos para a SAOS. Metodologia: Foi realizada uma pesquisa na base de dados do PubMed e SciELO com os descritores: Cirurgia Ortognática, apneia e Síndromes da Apneia do Sono. Revisão de literatura: A SAOS é caracterizada pela obstrução total ou parcial das vias áreas, podendo ser causada por fatores anatômicos e associados a obesidade e tabagismo ${ }^{1}$. Faz-se necessário seu tratamento, uma vez que esta causa, principalmente, asfixia progressiva, acarretando hipoximia e fragmentação do sono, além de sonolência, fadiga e ronco ${ }^{3}$. O CPAP é um dispositivo de pressão contínua nas vias aéreas que possibilita sua expansão e enquadra-se no padrão ouro de tratamento dessa desordem. Entretanto, o uso de dispositivos de avanços mandibular (DAMs) também é uma opção, pois aumentam o espaço orofaríngeo e, consequentemente, diminuem os eventos obstrutivos. Acredita-se que o mais eficiente seja a realização da cirurgia ortognática - avanço combinado da maxila e mandíbula (AMM), através da formulação de placas que quando implementadas garantem o reposicionamento da maxila e/ou mandíbula ${ }^{2,3}$. Esta é a opção que oferece a maior probabilidade de cura $^{1-3}$. Conclusão: SAOS é uma doença que influencia de forma direta na qualidade de vida dos indivíduos afetados. CPAP e DAMs̄ são uma opção inicial para o tratamento, mas para os pacientes com apneia severa indica-se a cirurgia ortognática.

Descritores: Cirurgia ortognática; Apneia; Síndromes da Apneia do Sono.

\section{Referências:}

1. FABER J, et al. Obstructive sleep apnea in adults. Dental Press J. Orthod, 2019; 24(3): 99109

2. LAGANÁ F, et al. Maxillomandibular advancement in obstructive sleep apnea syndrome. European Journal of Internal Medicine, 2013; 24(8): 94-95

3. MEHRA P, WOLFORD LM. Surgical Management of Obstructive Sleep Apnea. Baylor University Medical Center Proceedings, 2000; 13(4): 338-342 


\section{PC-73-2019 - EFICÁCIA DA EMINECTOMIA NO TRATAMENTO DE LUXAÇÃO RECIDIVANTE DA ATM: RELATO DE CASO CLÍNICO}

Ana Beatriz Albuquerque Meira ${ }^{1}$; André Marquim Nogueira da Fonte Cornelio ${ }^{1}$; Belmiro Cavalcanti do Egito Vasconcelos ${ }^{1}$; Emanuel Dias de Oliveira e Silva ${ }^{1}$; João Roberto Trindade Costa Filho²; Marcelo Soares dos Santos²; Maria Cecilia Souza Pires Gurgel ${ }^{1}$; Natália Barbosa Siqueira ${ }^{2}$

${ }^{1}$ Faculdade de Odontologia de Pernambuco - Camaragibe - PE - Brasil

${ }^{2}$ Hospital Universitário Oswaldo Cruz - Recife - PE - Brasil

Autor correspondente:

Ana Beatriz Albuquerque Meira

anabeatrizameira@gmail.com

Introdução: Situações em que o côndilo mandibular se move para fora da cavidade glenóide e assume posição anterior e permanente, a eminência articular, são chamadas luxação da articulação temporomandibular (ATM). É chamada de recidivante nos casos em que o número de episódios se torna frequente ${ }^{2}$. A eminectomia é um dos tratamentos propostos e aceitos pela literatura para esta condição ${ }^{4}$. Consiste na remoção da eminência articular, por meio de osteotomias, com finalidade de promover movimentos mandibulares livres ${ }^{3}$. Objetivo: $\mathrm{O}$ objetivo deste trabalho é apresentar a técnica cirúrgica de eminectomia através de um relato de caso. Relato de caso: Paciente E.N.F., feoderma, gênero feminino, 29 anos, compareceu a um serviço de Cirurgia e Traumatologia Bucomaxilofacial de um hospital, em Recife - PE, relatando episódios de luxação mandibular. Paciente apresentava história clínica de episódios recorrentes de luxação mandibular com frequência de 3 a 5 episódios por semana. Havia sido previamente submetida ao tratamento de hemoterapia em ATM direita e esquerda, onde não se obteve resultados significativos. Ao exame clínico foi constatada luxação da ATM recidivante bilateral. Sob anestesia geral foi realizado tratamento cirúrgico através de eminectomia bilateral associada à capsulorrafia. No momento a paciente encontra-se em acompanhamento pósoperatório de aproximadamente 10 meses sem apresentar novos episódios de luxação. Discussão: A técnica da eminectomia vem sendo uma das mais estudadas e que apresenta os melhores resultados em casos de luxação recidivante. Mostra-se mais eficaz não só em permitir movimentação livre da manđíbula, mas também em relação à variável crepitação articular e dor articular ${ }^{1}$. Conclusão: O tratamento cirúrgico através da eminectomia em casos de luxação recidivante da ATM mostrou-se satisfatório, eficaz e sem recorrências.

Descritores: Articulação Temporomandibular; Luxações Articulares; Artropatias.

\section{Referências:}

1. CARDOSO AB, et al. Comparative study of eminectomy and use of bone miniplate in the articular eminence for the treatment of recurrent temporomandibular joint dislocation. Brazilian Journal of Otolaryngology, 2005; 71(1): 1-6

2. IWANAGA J, et al. Eminectomy for Habitual Luxation of the Temporomandibular Joint with Sedation and Local Anesthesia: A Case Series. Case Reports in Dentistry, 2016; 2016(3): $1-4$

3. MARQUÉS-MATEO M, et al. Temporomandibular chronic dislocation: The long-standing condition. Medicina Oral Patologia Oral y Cirurgia Bucal, 2016; 21(6): 776-783

4. OHTA R, et al. Treatment outcomes after articular eminectomy in patients with longstanding/habitual temporomandibular joint dislocation. Journal of Oral and Maxillofacial Surgery, Medicine and Pathology, 2018; 30(3): 238-241 


\section{PC-74-2019 - ENDOCROWN PARA REABILITAÇÃO DE DENTES POSTERIORES TRATADOS ENDODONTICAMENTE: REVISÃO DA LITERATURA}

Tuany Rodrigues da Silva ${ }^{1}$; Ana Luisa Cassiano Alves Bezerra ${ }^{1}$; Thaiany Barros Nascimento; Márcia de Almeida Durão ${ }^{2}$

${ }^{1}$ Centro Universitário Maurício de Nassau - Recife - PE - Brasil

${ }^{2}$ Faculdade de Odontologia da Universidade de Pernambuco - Camaragibe - PE - Brasil

Autor correspondente:

Tuany Rodrigues da Silva

Tuany_rodrigues@hotmail.com

Introdução: A reabilitação de dentes tratados endodonticamente com coroas amplamente destruídas constitui um desafio para o cotidiano clínico ${ }^{1}$. As Endocrowns, ou coroas adesivas endodônticas, surgem nesse contexto como uma alternativa promissora ao clássico caminho do uso de retentores intrarradiculares ${ }^{3}$. Objetivo: Apresentar um método alternativo para restauração de dentes posteriores desvitalizados, através da utilização de Coroas Endocrowns, destacando as suas indicações e principais vantagens na substituição de coroas individuais com retenção intrarradicular. Metodologia: Foram realizadas pesquisas por artigos científicos, nos idiomas português e inglês, através das bases de dados LILACS, PubMed e SciELO, tendo como palavras chave: coroa dentária, cimentação, dente não vital e reabilitação bucal, sendo selecionados 5 artigos. Revisão de literatura: As Endocrowns são coroas adaptadas na câmara pulpar como recurso mecânico de retenção através da integração com seu remanescente por meio de cimentação adesiva, evitando a necessidade de pinos e preparos mais extensos ${ }^{3,4}$. Indicada para dentes posteriores, principalmente molares, que apresentam coroa clínica curta e espaço interoclusal insuficiente, estando associadas às cerâmicas adesivas ${ }^{5,2}$. Trata-se de um procedimento que possui suas vantagens na preservação da estrutura dental e resultados estéticos harmoniosos, além de executado em menos sessões clínicas ${ }^{4}$. O desenvolvimento dos sistemas adesivos e dos cimentos resinosos aliados ao desenvolvimento dos sistemas cerâmicos aumentou a longevidade e a performance clínica para este tipo de restauração ${ }^{1}$. Conclusão: Restaurações do tipo Endocrown apresentam resultados clínicos favoráveis para tratamento de dentes posteriores não vitais do ponto de vista funcional e estético, sendo uma alternativa mais conservadora, rápida, segura e de menor custo.

Descritores: Coroa dentária; Dente não vital; Reabilitação bucal.

\section{Referências:}

1. CLAVIJO VGR, et al. Coroas Endocrown - uma Opção para Dentes Posteriores Desvitalizados. Clínica - International Journal of Brazilian Dentistry, 2007; 3(3): 246-252.

2. JUNIOR HFB, et al. Endocrown - Avaliação Da Resistência Dos Cimentos Dentários. Revista Odontológica de Araçatuba, 2013; 34(2): 23-26

3. POLUHA RL, et al. Reabilitação Estética em Elemento Posterior Endocrown. Revista Odontológica de Araçatuba, 2015; 36(1): 75-81

4. TZIMAS K, et al. Endocrown restorations for extensively damaged posterior teeth: clinical performance of three cases. Restorative Dentistry \& Endodontics, 2018; 43(4): e38

5. ZAVANELLI AC, et al. Coroas Endoncrown: uma revisão de literatura e relato de caso. Arch Health Invest, 2017; 6(8): 382-389 


\section{PC-75-2019 - ENDODONTIA REGENERATIVA: PROTOCOLOS ATUAIS EM PACIENTES ADULTOS}

Caio Henrique Ribeiro de Lima ${ }^{1}$; Carolina Pereira da Silva ${ }^{1}$; Heitor Tavares de Araújo ${ }^{1}$; Kalyne Kelly Negromonte Gonçalves ${ }^{2}$; Niviane Marielly da Costa Oliveira ${ }^{1}$; Caio César Gonçalves Silva $^{1}$; Arthur Camilo de Souza Laranjeira ${ }^{1}$; Diana Santana de Albuquerque ${ }^{1}$

${ }^{1}$ Faculdade de Odontologia de Pernambuco - Camaragibe - PE - Brasil

${ }^{2}$ Hospital da Restauração - Recife - PE - Brasil

Autor correspondente:

Caio Henrique Ribeiro de Lima

lmacahe@gmail.com

Introdução: A revascularização pulpar consiste em um tratamento conservador que visa restabelecer determinadas funções e características do tecido pulpar. É induzida a formação de um tecido por meio do estímulo dos fatores de crescimento para a diferenciação das células estaminais $^{3}$. Esta alternativa objetiva reestabelecer o espaço pulpar através de células-tronco no interior do canal radicular que vão se diferenciar e contribuir para a neoformação tecidual, permitindo o espessamento das paredes dentinárias radiculares e fechamento apical ${ }^{1,3}$. Alguns protocolos já vêm sendo descritos na literatura, mostrando resultados promissores ${ }^{1}$. Objetivo: Este trabalho objetiva apresentar os protocolos atuais acerca da endodontia regenerativa em pacientes adultos. Metodologia: Para a realização deste trabalho, foram realizadas pesquisas no PubMed e SciELO, incluindo artigos nas línguas portuguesa e inglesa, entre os anos de 2011 e 2019. Revisão da literatura: Uma das alternativas de tratamento endodôntico para pacientes que apresentam rizogênese incompleta é a apicificação. Entretanto, esta técnica requer diversas consultas a fim de renovar a medicação intra canal até a constrição apical ${ }^{4}$. Contudo, a endodontia regenerativa surgiu para estes casos com um diferencial que é o alargamento das paredes dentinárias e fechamento apical. Nos protocolos pioneiros, eram realizadas sobre instrumentações, visando estimular o sangramento para o interior do canal e permitir o crescimento tecidual a partir do coágulo ${ }^{2}$. Foi observado que os dentes tratados dessa maneira eram mais susceptíveis a estresse de fratura devido às finnas paredes da dentina ${ }^{1}$. Portanto, protocolos utilizando o plasma rico em plaquetas aparece como uma alternativa aplicável, pois contém fatores que promovem $\mathrm{o}$ início da vascularização, melhoram cicatrização tecidual, induzem diferenciação celular e promovem continuação do desenvolvimento radicular ${ }^{4}$. Conclusão: A revascularização pulpar fornece resultados benéficos, promovendo o término do desenvolvimento radicular, reforço da parede dentinária e fechamento apical, apresentando-se como um tratamento promissor.

Descritores: Polpa Dentária; Endodontia; Endodontia Regenerativa.

\section{Referências:}

1. ARAUJO PRS, et al. Pulp revascularization: a literature review. The open dentistry journal, 2017; $10: 48$

2. CONDE MCM, et al. A scoping review root canal revascularization: relevant aspects for clinical success and tissue formation. International endodontic journal, 2017; 50(9): 860-874

3. LOVELACE TW, et al. Evaluation of the delivery of mesenchymal stem cell into the root canal space of necrotic immature teeth after clinical regenerative endodontic procedure. Journal of endodontics, 2011; 37(2): 133-138

4. WINGLER R, et al. Revascularization: a treatment for permanent teeth with necrotic pulp and incomplete root development. Journal of endodontics, 2013; 39(3): 319-326 


\section{PC-76-2019 - ENFISEMA SUBCUTÂNEO EXTENSO APÓS EXTRAÇÃO DE TERCEIRO MOLAR: RELATO DE CASO}

Lisandre Letícia Gomes da Silva ${ }^{1}$; João Artur Peixoto Granja ${ }^{1}$; Amanda Regina Silva de Melo ${ }^{3}$; Priscilla Sarmento Pinto ${ }^{3}$; Cláudia Nely Mendonça ${ }^{1}$; Maria Victorya Ferreira de Arruda ${ }^{1}$; Giovanna Siqueira Faustino da Silva ${ }^{4}$; Aída Juliane Ferreira dos Santos ${ }^{3}$

${ }^{1}$ Centro Universitário Tiradentes - Recife - PE - Brasil

${ }^{2}$ Faculdade de Odontologia de Pernambuco - Recife - PE - Brasil

${ }^{3}$ Hospital da Restauração Governador Paulo Guerra - Recife - PE - Brasil

${ }^{4}$ Universidade Federal de Pernambuco - Recife - PE - Brasil

Autor correspondente:

Lisandre Letícia Gomes da Silva

lisandre_leticia2011@hotmail.com

Introdução: $\mathrm{O}$ enfisema subcutâneo é um acidente em que ocorre a passagem forçada de ar e/ou outros gases para o interior dos tecidos moles, abaixo da camada dérmica ou mucosas ${ }^{3}$. Em certas ocasiões, o ar pode migrar ao longo dos planos faciais para estruturas profundas, causando sérias complicações, como o enfisema do mediastino ${ }^{2}$. Objetivo: Relatar um caso clinicode um enfisema subcutâneo que ocorreu durante a extração de um terceiro molar inferior. Relato de caso: Paciente do sexo feminino, 20 anos de idade, compareceu ao serviço CTBMF do Hospital da Face com queixa de dor em região do terceiro molar inferior esquerdo. Ao radiográfico comprovou-se as indicações de extrações dos elementos dentários 28 e 38. Durante o procedimento cirúrgico foi realizado a assepsia e aposição de campo estéril, deixando exposto apenas a região buco nasal. A cirurgia foi realizada com uso da caneta de alta rotação para odontossecção, sem intercorrências. Foi observado um aumento de volume em região periorbital gerando oclusão palpebral e acometendo também a região temporal, geniana, retromandibular, cervical e clavicular apenas do lado esquerdo. As palpações foram sentidas crepitações subcutâneas que são características de enfisema subcutâneo, preservação das funções dos nervos faciais, oftálmicos e ocular, sem disfagia nem disfonia. A paciente foi mantida em observação, com administração de corticoide e analgésico intravenoso, antibioticoterapia via oral para casa, recebendo alta sem intercorrências. Discussão: As medidas tomadas pelo cirurgião-dentista no caso estão de acordo com os descritos na literatura, devido ao tratamento geralmente ser sintomático o uso de analgésicos ${ }^{1}$. No entanto, a literatura também faz menção de anti-inflamatórios e da antibioticoterapia para prevenir o desenvolvimento de infecções. Conclusão: É de suma importância que o enfisema seja corretamente diagnosticado, com exames clínicos e radiográficos, diferenciando-o da fasceíte necrotizante. Devendo-se tomar consciência das precauções medicamentosas que evitam infecções oriundas do enfisema.

Descritores: Terceiro molar; Enfisema subcutâneo; Cirurgia bucal.

\section{Referências:}

1. COSTA RR, et al. Enfisema subcutâneo abrangendo os espaços temporal, orbital, bucal, submandibular e cervical após cirurgia para extração de terceiro molar. Revista de Cirurgia e Traumatologia Buco-Maxilo-Facial, 2017; 17(3): 7-10

2. EDUARDO KP, et al. Enfisema em decorrência de procedimentos odontológicos - Revista de literatura. Revista Odonto Ciência, 2005; 20(50): 384-386

3. GUIMARÃES BR, et al. Enfisema subcutâneo durante a remoção de terceiros molares aspectos de interesse ao cirurgião-dentista. Revista da Faculdade de Odontologia Universidade de Passo Fundo, 2010; 15(2): 165-170 


\section{PC-77-2019 - ENXERTIA AUTÓGENA NA RECONSTRUÇÃO DE REBORDO MAXILAR ATRÓFICO: RELATO DE CASO}

João Artur Peixoto Granja ${ }^{1}$; Cláudia Nely Mendonça dos Santos ${ }^{1}$; Maria Victorya Ferreira de Arruda $^{1}$; Caio César Gonçalves Silva ${ }^{2}$; Kalyne Kelly Negromonte Gonçalves ${ }^{3}$; Demóstenes Alves Diniz ${ }^{3}$; Vinicius Balan Santos Pereira ${ }^{2}$; Carlos Augusto Pereira do Lago ${ }^{3}$

${ }^{1}$ Centro Universitário Tiradentes - Recife - PE - Brasil

${ }^{2}$ Faculdade de Odontologia de Pernambuco - Recife - PE - Brasil

${ }^{3}$ Hospital da Restauração Governador Paulo Guerra - Recife - PE - Brasil

Autor correspondente:

João Artur Peixoto Granja

artur.granja@hotmail.com

Introdução: A utilização de enxertos ósseos teve grande impulso no início da década de 80, quando os princípios biológicos foram delimitados ${ }^{3}$. O aumento ósseo horizontal do rebordo alveolar tem sido indicado para correção de rebordos com espessura insuficiente para instalação de implantes ${ }^{2}$. Objetivo: Relatar o caso de uma paciente, 36 anos, submetida à reconstrução de maxila atrófica com enxerto de mento. Relato de Caso: A paciente procurou o serviço de CTBMF do Hospital da Face, Recife-PE, com história de perda de dentes 11, 12, 21 e 22 há, aproximadamente, 6 anos. Foi submetida a instalação de 02 implantes em maxila, há mais ou menos 1 ano, evoluindo com falta de estabilidade dos implantes. Ao exame físico apresentava exposição intra-oral dos implantes vestibularizados. Foi submetida à cirurgia sob anestesia geral para remoção dos implantes, bem como reconstrução de pré-maxila através de enxerto de mento utilizando acesso vestibular mandibular. O enxerto autógeno foi fixado a maxila utilizando 01 parafuso $1.5 \mathrm{~mm}$. Complementar ao enxerto de mento, foi utilizado Bio-oss e membrana de colágeno Bio Gide para recobrimento, bem como realizada sutura dos acessos. A paciente segue em acompanhamento sem sinais de débito ou deiscência dos acessos, aguardando instalação de novos implantes. Discussão: Entre os materiais para enxertia óssea, o osso autógeno ainda é considerado o padrão-ouro. Além de atuar como um importante material osteogênico e osteoindutor o osso autógeno expressa propriedade osteocondutora devido à liberação dos fatores de crescimento durante a cicatrização ${ }^{1}$. No presente caso foram adotadas condutas semelhantes as encontradas na literatüra obtendo-se êxito nó prognostico da paciente. Conclusão: Se faz necessário que o cirurgião-dentista saiba realizar as técnicas de enxertos ósseos constituindo boas alternativas para a reabilitação estética e funcional nos pacientes com rebordos alveolares atróficos.

Descritores: Implantação dentária; Maxila; Transplante ósseo.

\section{Referências:}

1. MOLON RS, et al. Reconstrução de maxila atrófica utilizando enxerto ósseo homógeno. Revista de Cirurgia e Traumatologia Buco-Maxilo-Facial, 2009; 9(4): 25-30

2. PICHOTANO EC, et al. Reabilitação protética de maxila anterior atrófica enxertada com osso autógeno: relato de caso clínico com acompanhamento longitudinal de um ano. ImplantNewsPerio, 2015; 12(4): 462-8

3. SOBREIRA T, et al. Enxerto ósseo homógeno para reconstrução de maxila atrófica. Revista de Cirurgia e Traumatologia Buco-Maxilo-Facial, 2011; 11(1): 1808-5210 


\section{PC-78-2019 - ENXERTO DE TECIDO CONJUNTIVO: RELATO DE CASO}

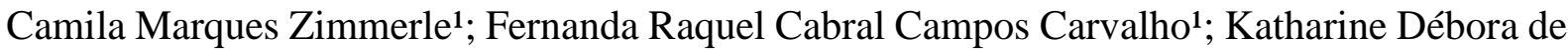
Brito e Silva ${ }^{1}$; Marina Maria Ferreira Falcãoํㅜㄹ Maria Catarina Almeida Lago ${ }^{1}$

${ }^{1}$ Faculdade de Odontologia de Pernambuco - Camaragibe - PE - Brasil

Autor correspondente:

Camila Marques Zimmerle

camilazimmerle@uol.com.br

Introdução: As retrações gengivais ocasionam a exposição da superfície radicular, comprometendo a estética do sorriso do paciente e contribuindo para o desenvolvimento de alterações funcionais diversas ${ }^{2}$. A técnica de enxerto de tecido conjuntivo proporciona a reabilitação anatômica do periodonto de proteção através da criação de um epitélio juncional longo e de mínima formação de cemento e osso alveolar ${ }^{1}$. Objetivo: Relatar a experiência da utilização de tecido conjuntivo no tratamento de recessões gengivais, a fim de solucionar problemas estéticos e funcionais do paciente. Relato de Caso: Paciente A.L.C.,48 anos, sexo masculino, compareceu ao curso de especialização em periodontia da FFO - FUNDECTO USP com a intenção de realizar procedimento de recobrimento radicular em retrações múltiplas nas regiões ântero-superior e inferior, classes I e II de Miller. Paciente não relatou hipersensibilidade. Após exames, optou-se pela realização da técnica de enxerto de tecido conjuntivo. Discussão: Paciente encaminhado após tratamento ortodôntico para a tratamento das retrações. Após resultado dos exames clínico e radiográfico, optou-se pela técnica de Zuchelli associada a enxerto de tecido conjuntivo coletado do palato. Conclusão: Pôde-se concluir que a técnica escolhida é a ideal para o ganho de gengiva inserida, possibilitando melhorias na condição a longo prazo, além de excelente resultado estético ${ }^{3}$.

Descritores: Retração gengival; Tecido Conjuntivo; Transplante.

\section{Referências:}

1. GAMBIN DJ, et al. Recobrimento radicular de recessões gengivais classe II de Miller: dois relatos de casos clínicos. Braz J Periodontol, 2019; 29(1):22-29

2. LANDIM FS, et al. Enxerto subepitelial de tecido conjuntivo para recobrimento radicular. Rev. Cir. Traumatol. Buco-Maxilo-fac, 2009; 9(4):31-3

3.VENTURIM RTZ, et al. Técnicas cirúrgicas de enxerto de tecido conjuntivo para o tratamento da recessão gengival. RGO, Rev. gaúch. odontol, 2011; 59(1):147-152 


\section{PC-79-2019 - ENXERTO LIVRE DE CRISTA ILÍACA NA RECONSTRUÇÃO MANDIBULAR: RELATO DE CASO}

Joyce Stephany Martins Gomes ${ }^{1}$; Caio César Gonçalves Silva ${ }^{2}$; Kallyne Kelly Negromonte Gonçalves ${ }^{3}$; Demóstenes Alves Diniz ${ }^{3}$; Arthur Camillo de Souza ${ }^{2}$; Allan Vinícius Martins de Barros $^{2}$; Luan Carlos Barbosa Lourenço ${ }^{1}$; Suzana Célia de Aguiar Soares Carneiro ${ }^{3}$

${ }^{1}$ Centro Universitário Mauricio de Nassau - Recife -PE - Brasil

${ }^{2}$ Faculdade de Odontologia de Pernambuco - Camaragibe -PE- Brasil

${ }^{3}$ Hospital da Restauração Governador Paulo Guerra - Recife- PE- Brasil

Autor correspondente:

Joyce Stephany Martins Gomes

joycestaphany@gmail.com

Introdução: Defeitos ósseos decorrentes de diversos tipos de traumas e patologias podem acometer a mandíbula, para tratamento desses defeitos o emprego de enxerto de crista ilíaca é uma opção viável, a utilização de enxerto para reconstrução óssea deve objetivar a restauração da estrutura esquelética, permitindo reestabelecimento de forma e função ${ }^{1,2}$. Objetivo: Relatar o caso clínico de paciente com defeito mandibular reabilitado através da utilização de enxerto livre de crista ilíaca. Relato de Caso: Paciente do sexo masculino, 48 anos, procurou o serviço de Cirurgia e Traumatologia Buco-maxilo-facial do Hospital da Restauração, queixando-se de deformidade em terço inferior de face após agressão por projétil de arma de fogo há aproximadamente 1 ano. Ao exame físico observou-se perda de substância óssea com perda de projeção mandibular do terço inferior da face direita, desvio mandibular em abertura bucal para esquerda, discreta maloclusão e limitação de abertura bucal, sem dor, com déficit e queixas estéticas e funcionais. Exames imaginológicos evidenciaram defeito ósseo medindo aproximadamente $3,5 \mathrm{~cm}$ de comprimento em região de ângulo mandibular direito. Foi proposta reconstrução do defeito mandibular com enxerto livre de crista ilíaca. Paciente segue em acompanhamento pós-operatório sem sinal de infecção, boa abertura bucal e oclusão estável. Discussão: Enxertos de crista ilíaca podem ser livres, quando constituídos exclusivamente por tecido ósseo, indicados para defeitos de até $7 \mathrm{~cm}$, ou vascularizados quando possuem vascularização adicional, indicados para defeitos mais amplos ${ }^{3}$. Ambos são bem indicados para reconstrução mandibular e possuem vantagens como, disponibilidade de quantidade óssea, cicatrizes menores e tempo de recuperação reduzido quando comparados a enxertos de fíbula que também são utilizados com essa finalidade ${ }^{2,3}$. Conclusão: Diante disso, um diagnóstico preciso, planejamento minucioso e boa execução da técnica de reconstrução mandibular com enxerto livre de crista ilíaca proporcionaram resultados estéticos satisfatórios, além de adequados contornos e volume ósseo.

Descritores: Ferimentos por Arma de Fogo; Transplante Ósseo; Reconstrução Mandibular.

\section{Referências}

1. COSTA SM, et al. Reconstrução da mandíbula. Revista Brasileira de Cirurgia Craniomaxilofacial, 2010; 13(3): 169-74

2. ROMULO JÚNIOR O, et al. Princípios da reconstrução mandibular com enxerto ósseo vascularizado. Revista de Cirurgia e Traumatologia Buco-maxilo- facial, 2008; 8(1): 15- 22 3. VASCONCELOS RJH, et al. Enxerto ósseo microvascularizado na reconstrução mandibular: relato de caso. Revista de Cirurgia e Traumatologia Buco-maxilo- facial, 2016; 16(2): 45-49 


\title{
PC-80-2019 - ENXERTO MICROVASCULARIZADO DE FÍBULA EM RECONSTRUÇÃO MANDIBULAR EXTENSA: CASO CLÍNICO
}

\author{
Sinval Vinícius Barbosa do Nascimento ${ }^{2}$; Belmiro Cavalcanti do Egito Vasconcelos ${ }^{3}$ \\ ${ }^{1}$ Centro Universitário Tiradentes - Recife - PE - Brasil \\ ${ }^{2}$ Faculdade de Odontologia de Pernambuco - Recife - PE - Brasil \\ ${ }^{3}$ Hospital da Restauração Governador Paulo Guerra - Recife - PE - Brasil
}

Cláudia Nely Mendonça dos Santos ${ }^{1}$; João Artur Peixoto Granja ${ }^{1}$; Caio César Gonçalves Silva ${ }^{2}$; Demóstenes Alves Diniz ${ }^{3}$; Jéssica da Silva Cunha ${ }^{3}$; Kalyne Kelly Negromonte Gonçalves ${ }^{3}$;

Autor correspondente:

Cláudia Nely Mendonça dos Santos

claudia_johari@msn.com

Introdução: Defeitos mandibulares podem ser causados por diversos fatores, tais como, traumas, osteomielite, osteonecrose e tumores malignos e benignos ${ }^{1}$. A não reparação óssea mandibular desses defeitos pode causar dificuldades na fala, diminuição da capacidade mastigatória e desfiguração facial ${ }^{2}$. O enxerto microvascularizado da fíbula é o mais utilizado em defeitos mandibulares maiores, pois a irrigação imediata minimiza os riscos de insucesso da reconstrução, por promover suprimento vascular adicional ${ }^{3,4}$. Objetivo: Acompanhamento do tratamento de fratura mandibular com o emprego de enxerto microvascularizado de fíbula em paciente com trauma decorrente de acidente motociclístico. Relato de caso: Paciente do sexo masculino, 31 anos de idade, compareceu ao serviço de cirurgia e traumatologia bucomaxilo-facial com histórico de acidente motociclístico há aproximadamente 04 anos, apresentando fratura complexa de mandíbula, sendo realizadas em um primeiro tempo cirúrgico, a redução e fixação da fratura com sistema de reconstrução $2.4 \mathrm{~mm}$ em corpo e ângulo mandibular esquerdos. Um segundo tempo cirúrgico sucedeu-se 03 anos após a primeira abordagem, em conjunto com a equipe de cirurgia plástica, sendo realizado o enxerto microvascularizado de fíbula e instalação de dreno. Atualmente, o paciente aguarda um terceiro tempo cirúrgico para instalação de expansor de tecido mole. Discussão: $O$ enxerto microvascularizado de fíbula em reconstrução mandibular extensa tem sido uma importante modalidade de tratamento em traumas, restaurando os papéis estéticos e funcionais da mandíbula ${ }^{2}$. Em casos de não reconstrução mandibular, provoca instabilidade longitudinal entre os segmentos, prejudica a oclusão e a função mastigatória, e provoca a perda do contorno facial $^{4}$. Além de restabelecer a função e a estética, os enxertos ósseos permitem uma melhora significativa da qualidade de vida dos pacientes submetidos a este procedimento cirúrgico. Conclusão: $O$ enxerto microvascularizado de fíbula vem demonstrando-se como uma alternativa viável para reconstruções mandibulares, proporcionando aspectos funcionais e estéticos adequados.

Descritores: Traumatologia; Reconstrução mandibular; Acidentes de trânsito.

\section{Referências:}

1. BRASILEIRO BF, et al. Avaliação de traumatismos faciais por acidentes motociclísticos em Aracaju/SE. Revista de Cirurgia e Traumatologia Buco-maxilo-facial, 2010;10(2): 97-104

2. FRANCA AJB, et al. Enxerto ósseo microvascularizado na reconstrução mandibular: relato de caso. Revista de Cirurgia e Traumatologia Buco-Maxilo-Facial, 2016; 16(1): 45-49

3. HE Y, et al. Double-barrel fibula vascularized free flap with dental rehabilitation for mandibular reconstruction. Journal of Oral and Maxillofacial Surgery, 2011; 69(10): 2663-2669

4. KOKOSIS G, et al. Mandibular reconstruction using the free vascularized fibula graft: an overview of different modifications. Archives of Plastic Surgery, 2016; 43(1): 3-9 


\section{PC-81-2019 - ESCANEAMENTO DIGITAL E PROTOTIPAGEM DE MODELO 3D PARA LENTES DE CONTATO DENTAIS - RELATO DE CASO}

Beatriz de Araújo Gusmão; ${ }^{1}$ Arthur Luna Santos ${ }^{1}$; Gabriela Queiroz de Melo Monteiro ${ }^{1}$; Millena Leal de Brito Rêgo ${ }^{1}$; Taísa Cabral de Lima Arruda'; Thayane Cavalcante Mendes da Silva $^{1}$; Vanessa Rodrigues Monteiro ${ }^{1}$; Luís Felipe Espíndola-Castro ${ }^{1}$

${ }^{1}$ Faculdade de Odontologia de Pernambuco - Camaragibe - PE - Brasil

Autor correspondente:

Beatriz de Araújo Gusmão

bia.gusmao09@gmail.com

Introdução: Reabilitações odontológicas com laminados cerâmicos requerem procedimentos minuciosos e extremamente precisos. Desde a concepção do planejamento até a etapa de cimentação, podem ocorrer distorções que comprometam o sucesso do tratamento. Nesta perspectiva, a utilização do escaneamento intra oral e prototipagem 3D do modelo de trabalho, permite minimizar as falhas, distorções e desadaptações das peças protéticas devido sua alta precisão de reprodução. Objetivos: Relatar um caso clínico de nove lentes de contato dentais em que foi empregado o escaneamento digital e confecção do modelo de trabalho por impressora 3D. Relato de caso: Paciente do gênero feminino, 59 anos, queixava-se de desproporcionalidade dentária ao sorrir. No exame clínico, observou-se que esta era ocasionada por inclinação maxilar provocando desarmonia dento facial. Após planejamento, enceramento, mock up e aprovação pela paciente, iniciou-se os preparos dentários. Sequencialmente, foi realizado o escaneamento, troquelização digital, e a prototipagem do modelo 3D, o qual foi encaminhado ao laboratório para confecção dos laminados. Por fim, procedeu-se com a cimentação. Discussão: Em um estudo comparativo, foi avaliado clinicamente coroas unitárias obtidas pelo método de moldagem digital e convencional em 30 dentes posteriores. As coroas obtidas com moldagem digital obtiveram resultados estatisticamente superiores. Por este método, houve maior adaptação marginal e melhores pontos de contato ${ }^{1}$. Resultados: Observou-se fácil reprodução das estruturas dentárias, sem gerar desconforto à paciente, alta precisão da troquelização digital e boa adaptação das peças protéticas. Conclusão: A tecnologia empregada mostrou-se eficiente no caso apresentado, podendo ser empregada em tratamentos reabilitadores complexos.

Descritores: Estética Dentária; Projeto Auxiliado por Computador; Facetas Dentárias.

\section{Referências:}

1. BERRENDERO $\mathrm{S}$, et al. Comparative study of all-ceramic crowns obtained from conventional and digital impressions: clinical findings. Clinical oral investigations, 2019; 23(4): 1745-1751

2. NASR E, et al. All-ceramic Computer-aided Design and Computer-aided Manufacturing Restorations: Evolution of Structures and Criteria for Clinical Application. J Contemp Dent Pract, 2019; 20(4): 516-523

3. PAPADIOCHOU S, PISSIOTIS AL. Marginal adaptation and CAD-CAM technology: A systematic review of restorative material and fabrication techniques. J Prosthet Dent, 2018; 119(4): 545-551

4. PEREIRA TM, et al. Reabilitação estética de dentes anteriores com laminados cerâmicos: relato de caso. J Dent Pub H, 2018; 9(3): 195-204 


\section{PC-82-2019 - ESCLEROTERAPIA DE HEMANGIOMA EM LÁBIO INFERIOR: RELATO DE CASO}

Andressa Cristina da Silva Queiroz ${ }^{1}$; Robson de Lima Gomes ${ }^{1}$; Aline Roberta Oliveira Santos ${ }^{1}$; Kelayne Ferreira Rodrigues da Silva ${ }^{1}$; Marvison Henrique Ferreira da Silva ${ }^{1}$; Luiz Alcino Gueiros $^{1}$; Jair Carneiro Leão ${ }^{1}$; Alessandra de Albuquerque Tavares Carvalho ${ }^{1}$

${ }^{1}$ Universidade Federal de Pernambuco - Recife - PE - Brasil

Autor correspondente:

Andressa Cristina da Silva Queiroz

d.d.essa@hotmail.com

Introdução: O hemangioma é uma neoplasia benigna comum na região de cabeça e pescoço. Pode causar prejuízo estético e funcional na região oral e perioral ${ }^{2}$. As regiões orais mais afetadas são os lábios, a língua, a mucosa bucal, as gengivas e o palato. Ademais, apresenta maior prevalência no sexo feminino $(65 \%)^{1}$. A escleroterapia é uma das opções de tratamento de grande sucesso em lesões pequenas e localizadas em áreas estéticas, nas quais o procedimento cirúrgico poderia gerar cicatrizes antiestética ${ }^{3}$. Objetivo: Relatar caso de lesão vascular tratada com esclerose terapêutica com o uso de oleato de monoetanolamina (Ethamolin) e soro fisiológico. Relato de caso: Paciente MGFC, 58 anos, sexo feminino, foi encaminha para a clínica de Estomatologia da Universidade Federal de Pernambuco com queixa de lesão de coloração arroxeada, indolor, com aproximadamente $5 \mathrm{~cm}$ de diâmetro, em mucosa labial inferior, lado direito, com duração de 2 anos. Foi observado que a paciente possuía hábito de segurar e pressionar uma perna do óculo na boca, na mesma região da lesão. Paciente relatou não fazer uso de medicamentos, tem antecedentes familiares de diabetes e hipertensão e hábito de fumar, este interrompido há 20 anos. Foi aplicada uma solução de soro fisiológico $(2 \mathrm{ml})+$ ethamolin $(1 \mathrm{ml})$ intralesional em apenas uma sessão até que a lesão fosse reduzida visualmente. Paciente foi recomendada a retornar em 7 dias para uma reavaliação e foi observada remissão total da lesão. Discussão: Os hemangiomas orais são mais frequentes na região de lábio ${ }^{1}$. O tratamento do hemangioma depende da localização, do tamanho e da natureza (venosa ou arterial) da lesão ${ }^{2}$. A escleroterapia é um método seguro, tornando possível a regressão total ou parcial da lesão ${ }^{3}$. Conclusão: A escleroterapia promoveu a involução da lesão de modo rápido e seguro, de mâneira minimamente invasiva, favorecendo â recuperação estética da paciente.

Descritores: Hemangioma; Escleroterapia; Estética.

\section{Referências:}

1. FERNANDES DT, et al. Benign oral vascular lesions treated by sclerotherapy with ethanolamine oleate: A retrospective study of 43 patients. Med Oral Patol Oral Cir Bucal, 2018; 23(2): 180-187

2. QUEIROZ SIML, et al. Tratamento de hemangioma oral com escleroterapia: relato de caso. Jornal Vascular Brasileiro, 2014; 13(3):249-253

3. SILVA WB, et al. Oral capillary hemangioma: a clinical protocol of diagnosis and treatment in adults. Oral Maxillofac Surg, 2014; 18(4):431-437 


\title{
PC-83-2019 - ESTUDO DA RESISTÊNCIA DE UNIÃO DOS SISTEMAS ADESIVOS UNIVERSAIS EM DENTINA HÍGIDA
}

\begin{abstract}
Micaela Maria de Sousa ${ }^{1}$; Aylanne Xavier de Lacerda Cavalcante Timoteo ${ }^{1}$; Cláudia Geisa Souza e Silva ${ }^{1}$; Cláudio Paulo Pereira de Assis ${ }^{1}$; Kássia Regina de Santana ${ }^{1}$; Maria Hermínia Anníbal Cavalcanti ${ }^{1}$; Pauliane Albuquerque da Silva ${ }^{1}$; Rodivan Braz da Silva ${ }^{1}$
\end{abstract}

${ }^{1}$ Faculdade de Odontologia de Pernambuco - Camaragibe - PE - Brasil

Autor correspondente:

Micaela Maria de Sousa

micamds@hotmail.com

Introdução: O Adesivo Universal contém monômeros que interagem quimicamente com a hidroxiapatita protegendo as fibrilas de colágeno ao longo do tempo ${ }^{1}$, considerando as diferenças estruturais entre esmalte e dentina que torna distinta a adesão a estes substratos ${ }^{2}$, ele possibilita confeccionar variados procedimentos restauradores com elevado índice de sucesso ${ }^{3}$. Objetivos: Este estudo buscou avaliar a resistência de união (RU) à dentina hígida dos adesivos universais. Metodologia: Utilizou-se 16 molares humanos hígidos (cujo uso foi aprovado pelo Comitê de Ética em Pesquisa, sob $\mathrm{n}^{\circ}$ de protocolo/CAAE: 89598618.4.0000.5207), com superfícies oclusais removidas expondo a dentina superficial. Após padronização da smear layer, os dentes foram divididos aleatoriamente em grupos de acordo com o sistema adesivo universal utilizado: ClearFil Universal [CFU], Scotch Bond Universal [SBU], Ambar Universal [AMU], YBOND Universal [YBU], All-Bond Universal [ABU], Tetric N-Bond Universal [TNU], Prime \& Bond Universal [PBU] e um autocondicionante ClearFil SE Bond [CSB] como grupo controle. Após o adesivo universal, os dentes foram restaurados com resina composta e seccionados para obtenção dos palitos. $\mathrm{O}$ teste de microtração foi realizado em uma máquina de ensaio universal a uma velocidade de $0,5 \mathrm{~mm} / \mathrm{min}$. A análise estatística foi realizada pelo teste de Kruskal-Wallis. Resultados e Discussão: As médias obtidas (Mpa) para RU foram as seguintes: 24h - SBU (33,98), CFU (31,59), PBU (29,73), TNU (29,63), AMU (26,07), ABU $(24,73)$, CSB (20,77). O grupo YBU apresentou falha pré-teste sendo excluído da análise de dados. Embora neste estudo o adesivo SBU apresente melhores resultados quanto à RU, são necessários mais estudos para se obter uma melhor resposta do seu comportamento para o sucesso das restaurações, enfatizando que todos os adesivos universais estudados obtiveram médias de RU superiores ao grupo controle CSB. Conclusão: $O$ adesivo SBU apresentou numericamente o maior valor em RU entre os adesivos universais, sendo todos superiores ao grupo controle CSB.

Descritores: Adesividade; Dentina; Materiais Dentários.

\section{Referências:}

1. BRESCHI L, et al. Dentin bonding systems: From dentin collagen structure to bond preservation and clinical applications. Dental Materials, 2018; 34(1): 78-96

2. COELHO A, et al. Perspetiva histórica e conceitos atuais dos sistemas adesivos amelodentinários - revisão da literatura. Revista Portuguesa de Estomatologia, Medicina Dentária e Cirurgia Maxilofacial, 2012; 53(1): 39-46

3. VAN MEERBEEK B, et al. Relationship between bond-strength testsand clinical outcomes. Dental Materials, 2010; 26(2): 100-21 


\title{
PC-84-2019 - ESTUDO DAS DISFUNÇÕES TEMPOROMANDIBULARES EM PACIENTES SINDRÔMICOS PORTADORES DE DOENÇAS DO TECIDO CONJUNTIVO COM HIPERMOBILIDADE ARTICULAR
}

\author{
Maria Eduarda Arruda de Lucena ${ }^{1}$; Gerciane Ramos Bezerra ${ }^{1}$; Pedro Paulo Aguiar Santos \\ Cavalcanti $^{1}$; Vinicius Balan Santos Pereira ${ }^{1}$; Belmiro Cavalcanti do Egito Vasconcelos ${ }^{1}$; Davi \\ da Silva Barbirato ${ }^{1}$
}

${ }^{1}$ Faculdade de Odontologia de Pernambuco - Camaragibe - PE - Brasil

Autor correspondente:

Maria Eduarda Arruda de Lucena

marrudadelucena@gmail.com

Introdução: A hipermobilidade articular generalizada caracteriza-se pelo aumento benigno e não patológico ${ }^{1-3}$ da flexibilidade das articulações, por alterações metabólicas do colágeno ${ }^{1}$. Apesar do primeiro relato ter ocorrido no período de Hipócrates e da importância clínica, o conhecimento acerca das doenças relacionadas com os sinais e sintomas clínicos ainda é limitado. Objetivo: Compilar de forma sistemática características das disfunções temporomandibulares (DTM) e resultados terapêuticos para essas condições em pacientes com Síndromes de Marfan, Ehlers-Danlos, Stickler e Osteogênese Imperfeita. Metodologia: Revisão integrativa de artigos científicos consultados nas bases de dados de indexação de periódicos científicos. As palavras-chave foram definidas utilizando as ferramentas do Mesh (PubMed) e DeCS (BVS) e pelos operadores booleanos "AND" e "OR" (estratégia de busca). Revisão de literatura: Variações significativas dos colágenos tipos I e III podem levar a condições patológicas importantes relacionadas à hipermobilidade, podendo ocorrer lesões, instabilidades, dores articulares e músculoesqueléticas. Defeitos estruturais do colágeno influenciam os ligamentos resultando em frouxidão e aumento da mobilidade articular ${ }^{3}$, pela regulação aferente dos receptores de estiramento múscular ser limitada, reduzindo a propriocepção e estabilidade articulares. A hipermobilidade articular, especialmente a generalizada, pode acometer a articulação temporomandibular (ATM), resultando em distúrbios dessa articulação. Frouxidão ligamentar (hiperlaxidão) somada a propriocepção comprometida podem resultar em condições degenerativas, desarranjos internos e inflamação da ATM. Distúrbios miofaciais orofaciais podem causar desequilíbrio funcional da ATM ou consequência da DTM, situações associadas às doenças do colágeno. Estímulos nociceptivos provenientes da oclusão e/ou da ATM podem resultar em alterações posturais compensatórias importantes, influenciar a forma e a função do sistema estomatognático. Conclusão: Hiperlaxidão da ATM parece a principal causa de DTM em pacientes com as condições sistêmicas estudadas. A abordagem cirúrgica da articulação parece estar indicada em casos mais avançados e tardios da doença. Estudos epidemiológicos acerca do diagnóstico precoce e da abordagem terapêutica destes pacientes devem ser realizados.

Descritores: Instabilidade Articular; Transtornos da Articulação Temporomandibular; Síndrome de Marfan.

\section{Referências:}

1. CAVENAGHI S, et al. Prevalência de hipermobilidade articular e sintomas álgicos em trabalhadores industriais. Arq Ciênc Saúde, 2006; 13(2): 8-64

2. EGRI D, YOSHINARI NH. Hipermobilidade articular generalizada. Rev Bras Reumatol, 1999; 39(4): 6-231

3. MARINO LHC, et al. Hipermobilidade articular nos joelhos da criança. Arq Ciênc Saúde, 2004; 11(2): 2-4 


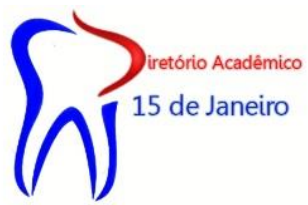

\section{PC-85-2019 - EXCISÃO CIRÚRGICA DE ADENOMA PLEOMÓRFICO EM GLÂNDULA SALIVAR MENOR: RELATO DE CASO}

Cleiton Rone dos Santos Lima ${ }^{1}$; Hugo Igor Rodrigues de Barros ${ }^{1}$; Kássia Regina de Santana ${ }^{1}$; Heitor Tavares de Araújo ${ }^{1}$; Carolina Pereira da Silva ${ }^{1}$; Luiz Ricardo Gomes de Caldas Nogueira Filho" ${ }^{1}$ Sinval Vinícius Barbosa do Nascimento ${ }^{1}$; Thyago Morais Vicente da Silva ${ }^{2}$

${ }^{1}$ Faculdade de Odontologia de Pernambuco - Camaragibe - PE - Brasil

${ }^{2}$ Universidade Federal de Pernambuco - Recife - PE - Brasil

Autor correspondente:

Cleiton Rone dos Santos Lima

cleitonrone@live.com

Introdução: Os tumores das glândulas salivares são raros, representando apenas de 3 a $6 \%$ de todos os tumores de cabeça e pescoço, e ocorrem com maior frequência na glândula parótida. Dentre eles, o adenoma pleomórfico é responsável por cerca de 40 a $70 \%$ de todos os tumores dessas glândulas ${ }^{1,3}$. Objetivo: relatar um caso de adenoma pleomórfico acometendo glândulas salivares menores. Relato de caso: Paciente do sexo feminino, 38 anos, natural de Recife, foi encaminhado ao serviço odontológico para avaliação de aumento de volume intra-oral de crescimento lento e com duração de 03 anos. Observou-se mucosa normocromada com a presença de uma tumoração de consistência amolecida na transição entre palato duro e mole. Foi realizada a biópsia incisional da lesão, que revelou tratar-se de um adenoma pleomórfico. Com todos os exames pré-operatórios normais, o tratamento proposto foi de remoção da lesão, com margens de segurança, sob anestesia geral. $O$ material excisado, medindo aproximadamente $2,5 \mathrm{~cm}$ em seu maior diâmetro, seguiu para análise histopatológica, cujo diagnóstico ratificou o anterior. Discussão: Essa neoplasia pode se apresentar em qualquer faixa etária, sendo mais comum em adultos jovens de idade entre 30 e 60 anos do sexo feminino. O tratamento do adenoma pleomórfico se dá pela excisão cirúrgica de toda a lesão com margens de segurança para evitar recidiva. A cirurgia deve ser baseada na exérese subperióstica através do afastamento da lesão de sua inserção, sendo removido também o periósteo junto com a mucosa bucal que a reveste ${ }^{2}$. Conclusão: Observar e investigar aumentos de volumes indolores na mucosa oral dos pacientes é essencial, pois podem indicar, dentre outras lesões, o adenoma pleomórfico, que muitas vezes pode estar presente por anos sêm que o paciènte perceba.

Descritores: Adenoma Pleomorfo; Cirurgia Bucal; Patologia Bucal.

\section{Referências:}

1. CURRY JL, et al. Synchronous benign and malignant salivary gland tumors in ipsilateral glands: A report of two cases and a review of literature. Head Neck, 2002; 24 (3): 301-306

2. NEVILLE BW, et al. Patologia Oral \& Maxilofaxial. 3 ed. Rio de Janeiro: Elsevier; 2016

3. ZENGEL P, et al. Does Virtual Touch IQ elastography help to improve the preoperative diagnosis of parotid tumors: A prospective trial. Clinical Hemorheology and Microcirculation, 2017; 67 (3-4): 425-434 


\section{PC-86-2019 - EXÉRESE DE EXTENSO GRANULOMA PIOGÊNICO EM NÍVEL HOSPITALAR: RELATO DE CASO}

Hian Carvalho Souza ${ }^{1}$; Emerllyn Shayane Martins de Araújo'; Sinval Vinícius Barbosa do Nascimento ${ }^{1}$; Caio César Gonçalves Silva ${ }^{1}$; Kalyne Kelly Negromonte Gonçalves ${ }^{2}$; Priscilla Sarmento Pinto ${ }^{2}$; Demóstenes Alves Diniz ${ }^{2}$; Dirceu de Oliveira Filho ${ }^{2}$

${ }^{1}$ Faculdade de Odontologia de Pernambuco - Camaragibe - PE - Brasil

${ }^{2}$ Hospital da Restauração - Recife - PE - Brasil

Autor correspondente:

Hian Carvalho Souza

hianvalho@gmail.com

Introdução: O Granuloma piogênico é uma neoplasia benigna e sua etiologia está associada a resposta a um trauma local, irritação crônica ou desequilíbrio hormonal ${ }^{1,2}$. Clinicamente é de cor similar à mucosa e crescimento indolor ${ }^{1}$. Objetivo: Relatar um caso clínico de uma paciente com extenso granuloma piogênico em mandíbula. Relato de caso: Paciente do sexo feminino, 35 anos de idade, procurou o serviço de Cirurgia e Traumatologia Buco-Maxilo-Facial do Hospital da Restauração, Recife-PE, relatando aumento de volume em região anterior de mucosa gengival de mandíbula há mais ou menos 02 anos, tendo iniciado quando estava grávida, sendo de aspecto sangrante. Ao exame físico apresentava dificuldade de selamento labial devido à extensão da lesão, má higiene oral com presença de múltiplos restos radiculares e gengivite associada, presença de lesão pediculada e ulcerada envolvendo os dentes 33,32 e 41. Ao exame de imagem apresentava imagem sugestiva de lesão que causava deslocamento dentário e reabsorção óssea. A paciente foi submetida a cirurgia sob anestesia geral para biópsia excisional de lesão, bem como remoção de dentes associados com a lesão e de restos radiculares. Como a lesão era de aspecto sangrante, foi necessária a realização de eletrocoagulação. Ela segue em acompanhamento ambulatorial, encaminhada a especialidade de periodontia para readequação do meio e sem sinais de complicações. Discussão: $O$ Granuloma piogênico acomete com mais frequência a maxila do que a mandíbula, sendo as mulheres mais afetadas que os homens. O tratamento é a excisão completa da lesão e a eliminação dos fatores irritantes locais ${ }^{1,2,3}$. Alguns autores defendem o tratamento periodontal associado ${ }^{3}$. Conclusão: $\mathrm{O}$ granuloma piogênico é uma lesão benignà, sendo necessário a sua excisão como forma tratamento, como também realizar o histopatológico após a biópsia para garantir o diagnóstico diferencial.

Descritores: Granuloma Piogênico; Patologia Bucal; Mandíbula.

\section{Referências:}

1. GONZÁLEZ MGR, et al. Granuloma piógeno de localización atípica: reporte de un caso. Revista ADM, 2017; 74(4): 198-201

2. LIMA VS. Granuloma piogênico: relato de caso clínico. Trabalho de Conclusão de Curso (Graduação em Odontologia) - Centro Universitário do Planalto Central Apparecido dos Santos, Brasília, 2018; 8 p

3. MORAES SH, et al. Granuloma piogênico: relato de caso clínico. Revista Gestão \& Saúde, 2013; 9(2): 12-19 


\section{PC-87-2019 - FASCIÍTE NECROSANTE DE ORIGEM ODONTOGÊNICA: RELATO DE CASO}

Marcela Lins Braga ${ }^{1}$; Caio César Gonçalves Silva ${ }^{1}$; Carolina Pereira da Silva ${ }^{1}$; Davi da Silva Barbirato ${ }^{1}$; Isabela Araújo de Lima1; Luíza Flôres da Costa Fagundes ${ }^{1}$; Maria Eduarda de Arruda Lucena ${ }^{1}$; Vinicius Balan Santos ${ }^{1}$

${ }^{1}$ Faculdade de Odontologia de Pernambuco - Camaragibe - PE - Brasil

Autor correspondente:

Marcela Lins Braga

marcelalinsbraga@hotmail

Introdução: Fasciíte necrosante é uma infecção bacteriana rara, rápida e progressiva da fáscia e do tecido adiposo subcutâneo. Está associada a altos índices de morbimortalidade, se não tiver tratamento precoce. Pode desenvolver-se a partir de uma infecção odontogênica que se dissemina para os planos faciais profundos do pescoço e acomete predominantemente pacientes com doenças que levam à imunossupressão sistêmica ${ }^{1,2,3}$. Objetivo: descrever um caso de fasciíte necrosante de origem odontogênica, seu diagnóstico, evolução clínica e tratamento. Relato de Caso: Paciente do sexo masculino, 56 anos, diabético tipo II, foi admitido na emergência do Hospital Getúlio Vargas com quadro de infecção severa de origem odontogênica, sem resolução com antibioticoterapia por via oral. Ao exame físico, apresentava múltiplos restos radiculares em mandíbula, trismo severo, dor à palpação de região submandibular bilateral, submentual e sublingual, dificuldade de mobilidade lingual e cervical, disfagia, disfonia e edema submandibular bilateral e submentual e descendente para região cervical, com pontos de tumefação, rubor e calor na área. Foi solicitada tomografia helicoidal da região para avaliação dos tecidos e espaços faciais, diagnosticando fasciíte necrosante. Foi indicado o desbridamento cirúrgico de urgência da região afetada. Discussão: Quando o diagnóstico é concluído, o paciente deve ser submetido à cirurgia imediatamente, visando minimizar o seu risco de vida. Por isso realizou-se o acesso aos espaços faciais necrosados e não aderidos, instalação de dreno, antibioticoterapia, remoção de focos infecciosos e desbridamento cirúrgico. A lavagem dos tecidos e administração empírica de antibiótico com amplo espectro, bem como a utilização de curativos e controle glicêmico auxiliaram a cicatrização. Após internação e melhora do quâdro, o paciente recebeu alta hospitalar. Conclusão: A fasciíte necrosante necessita ser diagnosticada e manejada imediatamente. A terapêutica adequada para a de origem dentária é composta de antibioticoterapia, remoção de focos infecciosos, desbridamento cirúrgico e monitoramento intensivo.

Descritores: Fasciíte Necrosante; Infecção Focal Dentária; Desbridamento.

\section{Referências:}

1. FREIRE FFP, et al. Fasceíte necrotizante facial causada por infecção odontogênica. Revista de Cirurgia e Traumatologia Buco-maxilo-facial, 2014; 14(1): 43-48

2. FERREIRA GM, et al. Fasceíte necrotizante em região maxilofacial: relato de caso. Revista de Cirurgia e Traumatologia Buco-maxilo-facial, 2009; 9(4): 45-49

3. NETO NT, et al. Infecções graves de partes moles: relato de caso de fasciíte necrotizante de face utilizando curativo a vácuo e revisão da literatura. Revista Brasileira de Cirurgia Plástica, 2011; 26(2): 353-359 


\section{PC-88-2019 - FATORES DE RISCO, COMPLICAÇÕES E PREVENÇÃO DA GENGIVITE ULCERATIVA NECROSANTE: UMA REVISÃO DE LITERATURA}

Mariana Cecília de Oliveira Terêncio ${ }^{1}$; Liana Carla Souza de Andrade Batista ${ }^{1}$; Hian Carvalho Souza $^{1}$; Jamesson de Oliveira Maciel Filho ${ }^{1}$; Évila Castro de Lima ${ }^{1}$; Letícia de Oliveira Santos ${ }^{1}$; Nycole Valois Rocha Vieira da Silva ${ }^{1}$; Lucas Vinícius Moreira de Araújo ${ }^{2}$

${ }^{1}$ Faculdade de Odontologia de Pernambuco - Camaragibe - PE - Brasil

${ }^{2}$ Universidade Federal de Pernambuco - Caruaru - PE - Brasil

Autor correspondente:

Mariana Cecília de Oliveira Terêncio

marianaccecília@gmail.com

Introdução: A gengivite ulcerativa necrosante (GUN) é uma patologia causada, principalmente, pelas bactérias Fusobacterium nucleatum e Prevotellaintermedia, porém, pesquisas atuais têm sugerido que os vírus Epstein-Barr e herpes simples contribuem com o início e progressão da doença ${ }^{1}$. Objetivo: O presente trabalho tem como finalidade abordar as principais complicações na qualidade de vida dos pacientes com GUN, bem como os fatores de risco associados, no intuito de entender os métodos de prevenção. Metodologia: Foi utilizado como base de dados o PubMed e LILACS, aplicando como descritores: "necrotizing ulcerative gingivitis", "prevention" e "risk factor". Ao filtrar os artigos que foram publicados a partir de 2010, foram escolhidos três trabalhos por possuírem maior relação com o tema pesquisado. Revisão de literatura: A GUN é caracterizada por rápida destruição tecidual e possui sintomatologia dolorosa com lesões gengivais ulcerativas e áreas de necrose que podem evoluir para perda de função. Na grande maioria dos casos, as papilas interdentais apresentam-se inflamadas e hemorrágicas. Além disso, o paciente pode manifestar halitose, salivação excessiva, gosto metálico, dor intensa, febre e linfadenopatia ${ }^{1,2}$. A infecção ocorre, geralmente, na presença de estresse psicológico, porém alguns fatores de risco estão relacionados, tais como: imunossupressão, tabagismo, sono inadequado e, principalmente, má higiene bucal ${ }^{1,3}$. A GUN, não tratada adequadamente, pode evoluir para periodontite e mucosite ulcerativa necrosante, e, mais gravemente, o cancrum oris ${ }^{1}$. Conclusão: A GUN, por ter alto potencial agressivo se não manejada corretamente, pode causar danos na qualidade de vida dos indivíduos afetados $^{2}$, como a perda dentária, consequência que mais oferece impactos, seja no âmbito funcional, nutricional e até mesmo psicossocial, sendo necessária a prevenção primária a fim de minimizar a incidência dessa patologia ${ }^{1}$. Assim, fazem-se necessárias medidas como a reeducação alimentar, cessação do tabagismo, controle do estresse e, principalmente, um maior cuidado com a saúde bucal ${ }^{1,2}$.

Descritores: Gengivite Ulcerativa Necrosante; Fatores de Risco; Prevenção.

\section{Referências:}

1. DUFTY J, et al. Necrotising Ulcerative Gingivitis: A Literature Review.Oral Health Prev Dent, 2017; 15(4): 321-327

2. DUFTY J, et al. Prevalence and treatment of necrotizing ulcerative gingivitis (NUG) in the British Armed Forces: a case-control study.Clin Oral Investig, 2017; 21(6): 1935-1944

3. KATO H, IMAMURA A. Unexpected Acute Necrotizing Ulcerative Gingivitis in a Wellcontrolled HIV-infected Case.Intern Med, 2017; 56(16): 2223-2227 


\section{PC-89-2019 - FAZENDO ART COM AS CRIANÇAS: UMA PROPOSTA DE PROMOÇÃO DA SAÚDE BUCAL}

Fabiola Feitosa Freitas ${ }^{1}$; Évila Castro Lima ${ }^{1}$; Hian Carvalho Souza ${ }^{1}$; Maíra Belo da Rocha Carvalho $^{1}$; Renata Laís Pontes de Carvalho ${ }^{1}$; Fernanda Ariel da Silva Vasconcelos ${ }^{1}$; Ana Carolina de Souza Leitão ${ }^{1}$; Viviane Colares ${ }^{1}$

${ }^{1}$ Faculdade de Odontologia de Pernambuco - Camaragibe - PE - Brasil

Autor correspondente:

Fabíola Feitosa Freitas

fabiolafeitosaf@hotmail.com

Introdução: Esse projeto de extensão é voltado para a aplicação da técnica ART (tratamento restaurador atraumático), a qual consiste no controle da cárie dentária com remoção da dentina infectada e uso de materiais efetivos e seguros, indicado para o serviço público ${ }^{2}$. Esta ação é realizada em crianças em atendimento em um centro de Oncohematologia Pediátrica, vinculado a um hospital universitário de Pernambuco. Objetivo: Visa a promoção da saúde bucal das crianças em tratamento oncológico, utilizando a técnica de ART. Relato de Experiência: O projeto se baseia em uma proposta de ação educativa, preventiva e curativa com uma oferta de atendimento odontológico atraumático, realizado por graduandos e pós-graduandos em odontologia, baseado na orientação de higiene bucal, aconselhamento dietético, selamento de fossas e fissuras e restaurações atraumáticas (ART). A população-alvo da ação consiste em pacientes na primeira infância, pré-escolares, escolares e adolescentes. A abordagem proposta, ART, tem apresentado boa aceitação pelos pacientes por ter uma abordagem minimamente invasiva que compreende medidas preventivas, terapêuticas e restauradoras em relação à cárie dental e no controle dessa doença ${ }^{3}$. Vários estudos realizados com o Tratamento Restaurador Atraumático citam porcentagens de sucesso próximas a de tratamentos odontológicos convencionais em curtos períodos de avaliação ${ }^{1}$. Discussão: $O$ projeto acompanha crianças que estão em tratamento oncológico, uma vez que estas necessitam de cuidados especiais pois encontram-se debilitadas, podendo levar ao descuido da higiene bucal. Conclusões: Quando ocorrendo em paralelo, atendimento odontológico e tratamento médico oncológico, há por objetivo promover e manter a saúde bucal do paciente que está em atendimento. O tratamento atraumático restaurador tem se mostrado um excelente mecanismo para intervir na cárie dentária, proporcionar uma abordagem mais tranquila e calma, além de agregar a criança ao tratamento e estimular sua cooperação ao mesmo.

Descritores: Higiene bucal; Odontopediatria; Oncologia.

\section{Referências:}

1. BRESCIANI E. Avaliação clínica de restaurações de cavidades realizadas pela técnica de tratamento restaurador atraumático (ART) em comunidade de alto risco à cárie. Dissertação (Mestrado em Dentística) - Faculdade de Odontologia de Bauru, da Universidade de São Paulo, Bauru, 2003; 99 p

2. KUHNEN M, et al. Uso do tratamento restaurador atraumático na Estratégia Saúde da Família. Revista de Odontologia da UNESP, 2013; 42 (4): 291-297

3. NAVARRO M, et al. Tratamento restaurador atraumático: realidade e perspectivas. Revista da Associação Paulista de Cirurgiões-Dentistas, 2015; 69 (2): 289-301 


\section{PC-90-2019 - FECHAMENTO DE DIASTEMA COM RESINA COMPOSTA: RELATO DE CASO}

Tuany Rodrigues da Silva ${ }^{1}$; Ana Luisa Cassiano Alves Bezerra ${ }^{1}$; Aiane Maria Ferreira Conrado $^{1}$; Márcia de Almeida Durão ${ }^{2}$

${ }^{1}$ Centro Universitário Maurício de Nassau - Recife - PE - Brasil

${ }^{2}$ Faculdade de Odontologia da Universidade de Pernambuco - Camaragibe - PE - Brasil

Autor correspondente:

Tuany Rodrigues da Silva

Tuany_rodrigues@hotmail.com

Introdução: Os diastemas são espaços interdentais que podem ser resolvidos com a ortodontia, no entanto, pode haver limitações, necessitando complementar com técnicas restauradoras ${ }^{1,5}$. Objetivo: Apresentar um relato sobre fechamento de diastema com resina composta direta, concluindo um tratamento ortodôntico. Relato de caso: Paciente do sexo feminino, 23 anos, procurou a Clínica Escola de Odontologia da Uninassau, insatisfeita com seu diastema inter incisivo (dentes 11 e 21). Foi proposto o fechamento do espaço e aumento da borda incisal com resina composta Opallis e Vittra APS (FGM, Brasil). Após condicionamento ácido do esmalte, dos incisivos centrais e laterais, foi aplicado adesivo universal Ambar (FGM, Brasil), fotopolimerizado 20 segundos. A resina composta Vittra Aps (FGM, Brasil), translúcida, cor $\mathrm{B} 1$ foi inserida na guia de silicone (previamente confeccionada), e esta foi adaptada à boca $\mathrm{e}$ fotopolimerizada por 20 segundos. Sobre a parede palatina foi feita estratificação com resina opaca, cor A1, para construção dos mamelos. Em seguida, foi utilizada uma resina de efeito TNeutral, entre os mamelos (região de opalescência), e uma fina camada de resina Opallis flow (FGM, Brasil), cor B0,5 na área do halo incisal, sendo cada incremento fotopolimerizado por 40 segundos. Por fim, foi aplicada, uma camada da resina Opallis opaca, cor B1, reproduzindo o esmalte dental. Após a fotopolimerização, foi seguido o protocolo de acabamento e polimento para resinas composta. Discussão: A utilização de resinas compostas para fechamento de diastemas anteriores tem se mostrado bastante interessante, já que é uma técnica de execução rápida, efetiva e de baixo custo ${ }^{2}$. $\mathrm{O}$ emprego de materiais com diferentes graus de translucidez e opacidade, aliado ao conhecimento e correta execução da técnica possibilitam a mimetização da estrutura dental ${ }^{3,4}$. Conclusão: A utilização de resina composta para o fechamento de diastema como finalização do tratamento ortodôntico mostrou-se como uma excelente alternativa, quando bem planejada e executada.

Descritores: Diastema; Estética dentária; Resinas compostas.

\section{Referências:}

1. BERWANGER C, et al. Fechamento de diastema com resina composta direta - relato de caso clínico. Rev Assoc Paul Cir Dent, 2016; 70(3): 317-22

2. BOAVENTURA JNC, et al. Associação de microabrasão e fechamento de diastemas com resina composta: relato de caso clínico. Rev Dental Press Estética, 2012; 9(2): 84-93

3. FONSECA RB, et al. Técnica de Estratificação e Texturização Superficial de Resinas Compostas em Dentes Anteriores - Seis Meses de Acompanhamento. Clinica International Journal of Brazilian Dentistry, 2013; 9(3): 324-332

4. SCHWARZ V, et al.Fechamento de Diastema com Resina Composta: Relato de Caso. J Oral Invest, 2013; 2(1): 26-31

5. VIEIRA PLS, LIMA-ARSATI YBO. Fechamento de diastema posterior como complemento de um tratamento ortodôntico: caso clínico. RGO, 2007; 55(4): 399-402 


\section{PC-91-2019 - FECHAMENTO DE DIASTEMA EM RESINA COMPOSTA: RELATO} DE CASO

Douglas Felipe de Lima e Silva ${ }^{1}$; Maria Fernanda Limeira Feitosa ${ }^{1}$; Amanda Cristina de Paula Bento $^{1}$; Stefanny Nataline de Oliveira Mota ${ }^{1}$; Alice Mendes Siqueira ${ }^{1}$; Marília de Lima Soares ${ }^{1}$

${ }^{1}$ Centro Universitário Maurício de Nassau - Recife - PE - Brasil

Autor correspondente:

Douglas Felipe de Lima e Silva

douglasfls@hotmail.com

Introdução: Com os avanços da odontologia novas possibilidades de tratamentos estéticos restauradores se ressaltam através da evolução dos procedimentos adesivos, proporcionando resultados convincentes no restabelecimento da forma, função e estética ${ }^{1}$. Objetivo: Este trabalho objetiva descrever a sequência clínica de uma reabilitação estética através de fechamento de diastemas por técnica semi-direta. Relato de Caso: Paciente M.W.F, sexo masculino, 26 anos de idade, compareceu na escola de Odontologia do Centro Universitário Maurício de Nassau, relatando seu descontentamento em relação aos espaços e restaurações apresentados entre os dentes superiores anteriores decorrente da presença de diastemas, que comprometiam a sua estética. Iniciou-se com a remoção das restaurações pré-existentes insatisfatórias nos elementos dentários $12,11,21$ e 22, seguido de moldagem para confecção de fragmentos resinosos em resina composta. Os laminados resinosos foram confeccionados sobre o modelo em sessão laboratorial utilizando as resinas de cor previamente selecionadas. Após a cimentação dos fragmentos, foi realizado acabamento e o polimento da restauração, conferindo a textura e o brilho final. Discussão: Os diastemas são considerados espaços entre dentes que em grande parte dos casos torna o sorriso não agradável esteticamente ${ }^{2}$. A presença de diastemas anterossuperiores é considerada um problema estético comum e frequente 3 . Para a resolução deste problema, têm-se lançado mão cada vez mais das técnicas com resinas compostas realizadas diretamente ou indiretamente ${ }^{2,3}$. Conclusão: Conclui-se que a técnica utilizada proporcionou resultados excelentes tanto na função quanto na estética.

Descritores: Diastema; Facetas Dentárias; Estética Dentária.

\section{Referências:}

1. ARAUJO E. Fragmento cerâmico, uma alternativa para a realização de tratamentos estéticos minimamente invasivos. Clínica, 2010; 6(1): 14-25

2. ROSA FM, et al. A importância do enfoque multidisciplinar no recontorno estético de diastemas e incisivos conóides. Clínica - Int. J. Braz. Dent, 2007; 3(1): 42-48

3. SILVA JMF, et al. Resinas compostas: estágio atual e perspectivas. Revista odonto, 2008; 16(32): 98-104 


\section{PC-92-2019 - FIBRO-ODONTOMA AMELOBLÁSTICO: UM RELATO DE CASO CLÍNICO}

Giovanna Barbosa Brito de Sousa Bione ${ }^{1}$; Carolina Chaves Gama Aires ${ }^{1}$; Eugênia Leal de Figueiredo²; Caio César Gonçalves da Silva²;

${ }^{1}$ Universidade Federal de Pernambuco - Recife - PE - Brasil

2Universidade de Pernambuco - Recife - PE - Brasil

Autor correspondente:

Giovanna Barbosa Brito de Sousa Bione

giovannabione.gb@gmail.com

Introdução: O fibro-odontoma ameloblástico é uma neoplasia odontogênica benigna, semelhante ao fibroma ameloblástico, porém caracterizado pela formação de esmalte e dentina $^{1,2}$. É mais frequente em crianças e adultos jovens, crescimento lento e assintomático e, geralmente, é acidentalmente descoberto através de exames radiográficos de rotina ${ }^{1,2}$. Objetivo: Apresentar um relato de caso de paciente portadora de fibro-odontoma ameloblástico. Relato de caso: Paciente L. G. S., do sexo feminino, 18 anos de idade, procurou o serviço de saúde apresentando aumento de volume assintomático em região posterior de maxila esquerda. Ao se realizar o exame físico, notou-se aumento de volume endurecido à palpação em região de rebordo alveolar maxilar esquerdo, além de ausência dos dentes 27 e 28 na cavidade oral. Sendo assim, foi solicitada radiografia panorâmica, para uma avaliação inicial. O resultado do exame sugeria a presença do elemento 27 incluso, associado a uma lesão cística envolvendo a região posterior esquerda de maxila e seio maxilar. Discussão: Após avaliação radiográfica inicial, solicitou-se uma tomografia da face, que evidenciou a presença de imagem oteolítica, expansiva, de margens bem definidas, circunscrevendo a coroa do dente 27 , além de uma imagem de maior densidade associada a imagens hiperdensas e centro hipodenso em seu interior $^{2}$ e deslocamento súpero-posterior desse elemento para o terço médio do seio maxilar. Após criteriosa análise das informações obtidas pelos exames complementares, optou-se pela excisão cirúrgica da lesão através de acesso intra-oral e osteotomia lateral para acesso do seio maxilar esquerdo, possibilitando a completa remoção da lesão e do dente associado através de cuidadosa curetagem local ${ }^{2}$. A análise anátomo-patológica evidenciou presença de tecido conjuntivo semelhante à papila dentária contendo cordões de epitélio odontogênico, concluindo-se que a lesão correspondia a um fibro-odontoma ameloblástico ${ }^{3}$. Conclusão: a intervenção cirúrgica para curetagem da lesão e remoção do elemento dentário associado foi eficaz como proposal terapêutica do caso.

Descritores: Neoplasias Maxilares; Odontoma; Tumores Odontogênicos.

\section{Referências:}

1. MUMMOLO S, et al. Ameloblastic fibro-odontoma: a case report. Annali di Stomatologia, 2010; 1(2): 11-13

2. RAO AJP, et al. Ameloblastic fibro-odontoma in a 14 year old girl: a case report. Journal of Cancer Research and Therapeutics, 2019; 15(3): 715-718

3. VOLKWEIS MR, et al. Fibro-odontoma ameloblástico em terço médio da face. Revista Gaúcha de Odontologia, 2006; 54(1): 77-80 


\section{PC-93-2019 - FLUOROSE DENTÁRIA: EPIDEMIOLOGIA, DIAGNÓSTICO E TRATAMENTO}

Ingrid Sayonara Silva ${ }^{1}$; Pedro Henrique Lopes Cavalcanti ${ }^{1}$; Monalisa Suellen da Silva ${ }^{1}$; Aylanne Xavier de Lacerda Cavalcante Timoteo ${ }^{2}$; Emerllyn Shayane Martins de Araújo ${ }^{2}$; Kássia Regina de Santana²; Lucas Rafael Borges Santos²; Sally de Souza Brito ${ }^{3}$

${ }^{1}$ Universidade Federal de Pernambuco - Recife - PE - Brasil

${ }^{2}$ Faculdade de Odontologia de Pernambuco - Camaragibe - PE - Brasil

${ }^{3}$ Centro de Pós-graduação em Odontologia - Recife - PE - Brasil

Autor correspondente:

Ingrid Sayonara Silva

ingridxs711@gmail.com

Introdução: O uso de fluoretos traz consideráveis benefícios no controle da cárie dentária, porém pode aumentar o risco de fluorose dentária, uma alteração provocada por exposição prolongada do germe dentário ao flúor durante sua formação. Os índices epidemiológicos de prevalência e severidade da fluorose são importantes para a avaliação das condições de saúde bucal e necessidades de tratamento, porém suas limitações devem ser consideradas, pois não mensuram a aceitabilidade estética das manchas fluoróticas ${ }^{2}$. Objetivo: Apresentar uma revisão da literatura sobre fluorose dentária, aspectos e índices epidemiológicos relacionados, diagnóstico e tratamento da patologia. Metodologia: Foi realizado cruzamento dos descritores selecionados e foram escolhidos 8 artigos publicados entre os anos de 2010 e 2019, encontrados nos periódicos das bases de dados LILACS, PubMed e SciELO. Revisão de literatura: O principal índice epidemiológico utilizado é o índice de DEAN, o qual considera os aspectos do esmalte dentário e o classifica em 5 categorias, de normal a fluorose severa. No levantamento epidemiológico nacional, o SB Brasil 2010, foram avaliadas 7.232 pessoas na faixa etária de 12 anos de idade, demonstrando que, no Brasil, 16,7\% dessa população apresentavam fluorose, sendo que $15,1 \%$ foram representados pelos níveis de severidade muito leve $(10,8 \%)$ e leve $(4,3 \%)$. O nível de fluorose moderada foi identificada em $1,5 \%$ da população avaliada. $\mathrm{O}$ percentual de examinados com fluorose grave foi considerado nulo. O principal diagnóstico diferencial é com hipoplasia do esmalte e cárie. Para tratamento podem ser utilizados clareamento dental, microabrasão e macroabrasão, ou a combinação das técnicas ${ }^{1,3}$. Conclusão: As evidências sugerem que a fluorose não é considerada um problema de saúde pública, o índice de DEAN é o mais aceito pela literatura por sua praticidade e eficácia, é indispensável realizar diagnóstico diferencial $\mathrm{e}$ as modalidades de tratamento disponíveis buscam de forma satisfatória controlar a condição.

Descritores: Fluorose Dentária; Diagnóstico; Epidemiologia.

\section{Referências:}

1. CARVALHO RWF, et al. Estudo da prevalência de fluorose dentária em Aracaju. Ciência \& Saúde Coletiva, 2010; 15(1): 1875-1880

2. FURTADO GES, et al. Percepção da fluorose dentária e avaliação da concordância entre pais e filhos: validação de um instrumento. Cadernos de Saúde Pública, 2012; 28(8): 14931505

3. RIGO L, et al. Estudo sobre a fluorose dentária num município do sul do Brasil. Ciências \&Saúde Coletiva, 2010; 15 Supl. 1: 1439-1448 


\section{PC-94-2019 - FOLLOW-UP DE 3 ANOS DE ENXERTIA AUTÓGENA NA RECONSTRUÇÃO MANDIBULAR: RELATO DE CASO}

Fabyano Palheta Costa ${ }^{1}$; Beatriz Borba Barros Bernardo ${ }^{1}$; Kalyne Kelly Negromonte Gonçalves $^{2}$; Demóstenes Alves Diniz²; Vinicius Balan Santos Pereira ${ }^{1}$; Virgílio Bernardino Ferraz Jardim³ ${ }^{3}$ Caio César Gonçalves Silva ${ }^{1}$; Suzana Célia de Aguiar Soares Carneiro ${ }^{4}$

${ }^{1}$ Faculdade de Odontologia de Pernambuco - Camaragibe - PE - Brasil

${ }^{2}$ Hospital da Restauração - Recife - PE - Brasil

${ }^{3}$ Hospital Universitário Oswaldo Cruz - Recife - PE - Brasil

${ }^{4}$ Universidade Tiradentes - Recife - PE - Brasil

Autor correspondente:

Fabyano Palheta Costa

palhetaf@hotmail.com

Introdução: A reconstrução anatômica mandibular é uma tarefa árdua para o cirurgião, tendo em vista a complexidade da função da mandíbula e as peculiaridades do tratamento das lesões que acometem o segmento cérvico-facial. Para essa reconstrução, atualmente, é preferível a utilização da reconstrução combinada de revestimento mucoso, estrutura óssea e revestimento cutâneo oferece resultados superiores comparada a tratamentos anteriores com retalhos locais pediculados. Os retalhos de crista ilíaca e fíbula proporcionam maior quantidade de osso e são escolhidos no tratamento de lesões que comprometem áreas extensas da mandíbula. O ilíaco apresenta uma forma que se adapta bem à curvatura lateral do arco mandibular, dispensando, muitas vezes, as osteotomias. Sua estrutura facilita o uso dos implantes ósseointegrados ${ }^{1}$. Objetivo: O presente trabalho tem como objetivo relatar o acompanhamento de 3 anos de um paciente após enxerto autógeno na reconstrução da mandíbula. Relato de Caso: Paciente do sexo masculino, 48 anos, com procedimento cirúrgico prévio, aproximadamente, 3 anos, para reconstrução mandibular com enxerto livre da crista ilíaca. Ao exame físico apresenta boa abertura bucal, oclusão estável, manutenção do contorno facial. Paciente segue em acompanhamento pós-operatório, aguardando instalação de implante dental. Discussão: Nas enxertias ósseas é necessário estímulo do organismo para não reabsorver esse enxerto. Esse estímulo se constitui em reabilitação com implante. O paciente, por não ter condições, está na fila de espera de um curso de aperfeiçoamento de implante. Apesar deste tipo de enxerto ter uma reabsorção mínima de $50 \%$, que requer cuidados operatórios imediatos de cinco a seis semanas $^{2}$, exames imaginológicos evidenciam discreta absorção do enxerto ilíaco. Conclusões: Os enxertos autógenos são mais vantajosos pois possuem relativa resistência à infecção, incorporação pelo hospedeiro, não ocorrendo reação de corpo estranho. Permitindo assim reabilitação funcional e estética para o paciente.

Descritores: Reconstrução Mandibular; Enxerto de Tecidos; Procedimentos Cirúrgicos Reconstrutivos.

\section{Referências:}

1. BRAGA-SILVA J, et al. Reconstrução do segmento ósseo mandibular: comportamento dos implantes ósseo-integrados nos retalhos vascularizados de crista ilíaca e fíbula. Rev. Soc. Bras. Cir. Plást., 2005; 20(3): 176-81

2. LUNARDI DV, et al. Tratamento cirúrgico do ameloblastoma com reconstrução de mandíbula com enxerto de crista ilíaca não vascularizado - estudo de sete casos. Revista do Colégio Brasileiro de Cirurgiões, 2000; 28(1): 9-12

3. PEREIRA CCS, et al. Enxertos ósseos autógenos mandibulares para reconstrução de processos alveolares atróficos: revisão e técnica cirúrgica. Innov Implant J, Biomater Esthet, 


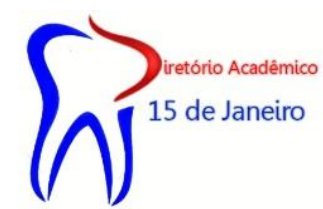

2009; 4 (3): 96-102
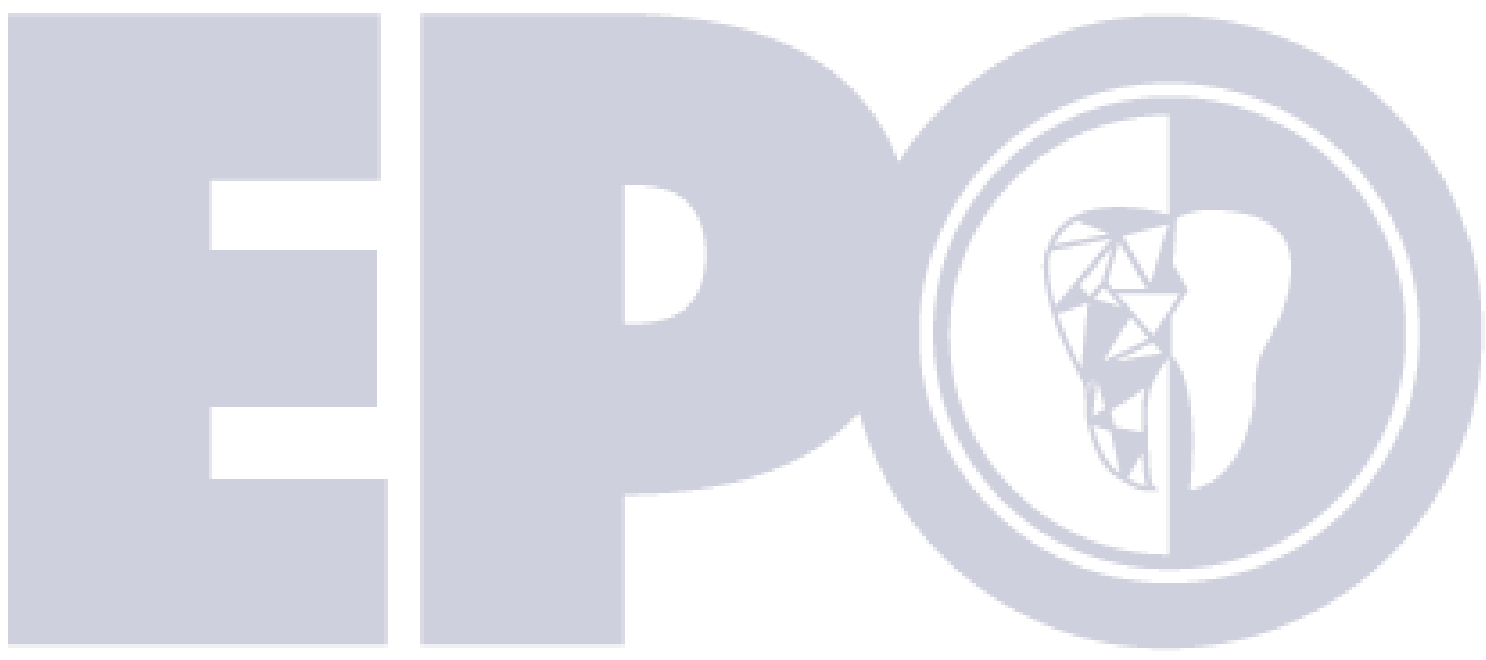

ENCONTRO PERNAMBUCANO DE ODONTOLOGIA 


\title{
PC-95-2019 - FRATURA COMINUTIVA DE MANDÍBULA DEVIDO A AGRESSÃO POR PROJÉTIL DE ARMA DE FOGO (PAF): RELATO DE CASO
}

\author{
Costa $^{1}$; Ruan de Souza Viana ${ }^{1}$; Walter Ferreira Marinho Neto ${ }^{5}$ \\ ${ }^{1}$ Hospital da Restauração Governador Paulo Guerra - Recife - PE - Brasil \\ ${ }^{2}$ Universidade Federal de Pernambuco - Recife - PE - Brasil \\ ${ }^{3}$ Faculdade de Odontologia do Recife - Recife - PE - Brasil \\ ${ }^{4}$ Centro Universitário Tiradentes de Pernambuco - Recife - PE - Brasil \\ ${ }^{5}$ Centro Universitário Brasileiro - Recife - PE - Brasil
}

Ronaldo Gabriel Martiniano da Silva ${ }^{4}$; Amanda Regina Silva de Melo; Amanda Silva Nascimento ${ }^{2}$; Leandro Pimentel Cabral2; Lilyann Dominike da Silva ${ }^{3}$; Rodolfo José Rangel

Autor correspondente:

Ronaldo Gabriel Martiniano da Silva

Ronaldo.rgms77@gmail.com

Introdução: A mandíbula é o único osso móvel da face e participa de funções básicas como mastigação, fonação e deglutição, fraturas deste osso podem levar a deformidades, sejam por deslocamentos ou perdas ósseas não-restauradas ${ }^{1}$. Os ferimentos por projétil de arma de fogo têm se tornado um problema de saúde pública mundial, cerca de $61 \%$ das vítimas, os ferimentos ocorreram na cabeça e/ou face, com maior incidência na região de mandíbula ${ }^{3}$. Objetivo: Relatar caso clínico do paciente vítima de PAF, com abordagem cirúrgica e sutura complexa da região mandibular. Relato de Caso: Paciente, J.P.F, sexo masculino, 19 anos, adentrou no serviço de urgência/emergência do Hospital da Restauração Governador Paulo GuerraSES/UPE, vítima de agressão por PAF, apresentando perda de substância em tecido mole, tecido ósseo em região mandibular e dificuldade respiratória. Com lesão totalmente exposta, presença de cotos mandibulares direito e esquerdo e porção cominutiva da mandíbula. No planejamento cirúrgico definiu-se que o paciente seria traqueostomizado, para melhor visualização e abordagem cirúrgica. Em seguida realizou-se a limpeza cirúrgica com soro fisiológico e clorexidina, fazendo a remoção de alguns fragmentos ósseos e reaproximação dos cotos mandibulares com fio de aço $\mathrm{n}^{\circ} 1$. Foi realizada uma odontossíntese na região inferior da mandíbula, deixando o bloco anterior presente em oclusão e fez-se sutura por planos de toda região. Discussão: Durante a admissão, vítimas de PAF devem ser atendidas dentro do protocolo ATLS. Lesões aparentemente inócuas podem trazer desagradáveis surpresas para a equipe assistente, havendo necessidade de uma avaliação multidisciplinar, para que haja a definição da indicação ou contraindicação de uma abordagem cirúrgica imediata ou tratamento conservador, visando mitigar maiores danos ${ }^{2}$. Conclusão: Foi discutido com a equipe de CTBMF do Hospital da Restauração, abordagem em segundo momento cirúrgico, com instalação da prótese em resina para devolução da função do sistema estomatognático.

Descritores: Mandíbula; Trauma; Armas de fogo.

\section{Referências:}

1. ANDRADE FILHO EF, et al. Fraturas de mandíbula: análise de 166 casos.Revista da Associação Médica Brasileira, 2000; 46(3): 272-276

2. MORAIS HHA, et al. Tratamento imediato de fratura de mandíbula por projétil de arma de fogo. Revista Gaúcha de Odontologia, 2010; 58(3): 399-403

3. RIBEIRO ILH, et al. Tratamento de fratura mandibular por projétil de arma de fogo com uso de fixador externo: relato de caso. Revista de Ciências Médicas e Biologia, 2012; 11(3): 341345 


\section{PC-96-2019 - FRATURA NASAL: REVISÃO DE LITERATURA}

Isabela Araújo de Lima ${ }^{1}$; Pedro Paulo Aguiar Santos Cavalcanti ${ }^{1}$; Marcela Lins Braga ${ }^{1}$; Carolina Pereira da Silva ${ }^{1}$; Heitor Tavares Araújo ${ }^{1}$; Bruna Lucena Borges ${ }^{1}$; Letícia Fernanda Serafim Cabral ${ }^{1}$; Maria Carolina da Silva Moura de Almeida ${ }^{1}$

${ }^{1}$ Faculdade de Odontologia de Pernambuco - Camaragibe - PE - Brasil

Autor correspondente:

Isabela Araújo de Lima

Belalima999@gmail.com

Introdução: $\mathrm{O}$ trauma em ossos nasais é a terceira maior incidência de todo esqueleto, e, no grupo de fraturas faciais, são os ossos mais acometidos, uma vez que o nariz se encontra em uma posição central e sua projeção na face proporciona uma maior facilidade ao trauma ${ }^{1}$. Objetivo: Demonstrar através de uma revisão de literatura a incidência e diagnóstico das fraturas nasais, além da etiologia e possíveis condutas de tratamento. Metodologia: A metodologia aplicada foi uma revisão e literatura, a partir de buscas nas bases de dados SciELO, PubMed e monitores de busca, como o Google Acadêmico, sendo considerados critérios de exclusão artigos publicados antes do ano de 2010. Revisão de literatura: O tipo e extensão das fraturas nasais possuem variáveis uma vez que dependem do agente traumático, da direção da intensidade da força de impacto, geralmente acometem mais o sexo masculino e os fatores etiológicos comuns são: acidentes motociclísticos, agressões físicas e acidentes desportivos. O diagnostico deve-se iniciar pela história detalhada do acidente e sobre a existência de lesões anteriores, seguida pelo exame clínico (inspeção e palpação) e complementando com exames de imagem². O tratamento para ser bem-sucedido deve ser feito nas primeiras 2 ou 3 horas após o trauma, antes que o estado da lesão fique mascarado por edema, hematoma ou obstrução das vias respiratórias, após a instalação desse quadro deve-se aguardar de quatro a cinco dias para fazer a manipulação ${ }^{2,3}$. Conclusão: Portanto, as fraturas nasais são lesões de ocorrência associada a indivíduos jovens e do gênero masculino, principalmente envolvidos em situações de agressão física, tendo como principal tratamento a redução com reposição dos fragmentos fraturados seja por meio de uma anestesia geral ou local.

Descritores: Osso nasal; Cirurgia; Traumatismos faciais.

\section{Referências:}

1. ANDRADE MG, et al. Tratamento cirúrgico de fratura nasal: Relato de caso. Rev. Cir. Traumatol. Buco-Maxilo-Fac., 2019; 19(1): 37-40

2. BORGHESE B, et al. Estudo retrospectivo da abordagem das fraturas nasais no Hospital de Clínicas da Unicamp. Ver. Bras. Cir. Plást.,2011; 26(4): 608-612

3. MARCOLINO PRB, et al. Fraturas nasais: uma opção de tratamento. Rev. Cir. Traumatol. Buco-Maxilo-Fac., 2011; 12(4): 57-60 


\section{PC-97-2019 - FRENECTOMIA LABIAL SUPERIOR ATRAVÉS DE LASER DE ALTA POTÊNCIA Er:YAG}

Geovana Maria do Carmo Oliveira' ${ }^{1}$ Carolina Pereira da Silva ${ }^{1}$; Eloiza Leonardo de Melo ${ }^{1}$; Isabela Araújo de Lima ${ }^{1}$; Lucas Rafael Borges Santos ${ }^{1}$; Ana Paula Bezerra ${ }^{1}$; Maria Regina Almeida de Menezes ${ }^{1}$

${ }^{1}$ Faculdade de Odontologia de Pernambuco - Camaragibe - PE - Brasil

Autor correspondente:

Geovana Maria do Carmo Oliveira

geovanadocarmooliveira@gmail.com

Introdução: O laser cirúrgico de alta potência pode ser empregado em diversas intervenções nos tecidos moles e duros, como em gengivectomias; gengivoplastias; incisão para drenagem de abscessos bucais; excisão de diversos tipos de tumores; hemangiomas e outras lesões ${ }^{3}$. Objetivo: Relatar um caso clínico de frenectomia labial superior através de laser Er:YAG. Relato de caso: Paciente leucoderma, M.A.S, sexo feminino, com 35 anos de idade, compareceu a Clínica da FOP/UPE, com queixa de diastema. Verificou-se que o freio lingual apresentava grande inserção na face interna da maxila. $O$ freio labial superior apresentava marcante inserção associada à presença de diastema entre os incisivos superiores. Optou-se pela frenectomia a laser. O aparelho utilizado foi o laser de Er:YAG II(KAVO). Para a realização da frenectomia, foi infiltrada solução anestésica ao redor do freio, realizou-se a remoção através de disparos do laser, foi feita a ablação dos tecidos do freio, percorrendo toda sua extensão, inclusive sobre a área fibrosa existente no diastema. Por fim, realizou- se a incisão periosteal. Após o término da cirurgia, empregou-se o laser de baixa potência, com 4 Joules em aplicação puntiforme com a quantidade de aplicações necessárias à cobrir toda a área da cirurgia. Discussão: O laser de alta potência ao ser absorvido pelos tecidos, gera a vaporização e sublimação, resultando em corte e exérese, além de auxiliar na cicatrização ${ }^{1}$. Devido ao maior controle da hemorragia transoperatória, é possível obter um procedimento cirúrgico limpo e que frequentemente dispensa suturas ${ }^{2}$. Conclusões: É lícito concluir que a utilização do laser cirúrgico, independentemente do tipo de aparelho empregado, é um recurso terapêutico promissor que pode ser instituído na cavidade bucal para as diversas necessidades.

Descritores: Freio Labial; Laser; Cirurgia.

\section{Referências:}

1. CARDOSO MV, et al. Vantagens da frenectomia labial por laser de diodo de alta intensidade. ImplantNewsPerio international journal, 2016; 1(3): 772-778

2. GONTIJO I, et al. The applications of diode and Er: YAG lasers in labial frenectomy in infant patients. Journal of dentistry for children, 2005; 72(1): 10-15

3. MACEDO MP, et al. Frenectomia labial superior em paciente portador de aparelho ortodôntico: relato de caso clínico. Revista da Faculdade de Odontologia-UPF, 2012; 17(3): 332-335 


\section{PC-98-2019 - FRENECTOMIA LINGUAL COMO FERRAMENTA PARA REABILITAÇÃO DA COMUNICAÇÃO E FUNCIONALIDADE EM PACIENTE ADULTO: RELATO DE CASO}

Ingrid Sayonara Silva ${ }^{1}$; Ellen Rayssa Lopes do Nascimento ${ }^{2}$; Italo Ferreira Monteiro ${ }^{1}$; Maria Luísa Alves Lins ${ }^{1}$; Alfredo de Aquino Gaspar Júnior ${ }^{1}$; Malú Virginia Santana Campos ${ }^{1}$; Jady Cristina Lázaro Sales ${ }^{1}$; Ana Claudia da Silva Araújo ${ }^{1}$

${ }^{1}$ Universidade Federal de Pernambuco - Recife - PE - Brasil

${ }^{2}$ Faculdade Maurício de Nassau - Recife - PE - Brasil

Autor correspondente:

Ingrid Sayonara Silva

ingridxs711@gmail.com

Introdução: O frênulo lingual é uma prega mediana de túnica mucosa que conecta a língua ao assoalho da boca ${ }^{1}$. Uma vez que a produção adequada da fala depende do equilíbrio entre as suas bases motoras e estruturas anatomofuncionais, a presença de alterações no frênulo lingual como, por exemplo, a anquiloglossia - popularmente conhecida como "língua presa" -, compromete movimentos e habilidades fonéticas ${ }^{1,2}$. Para solucionar esses problemas, é utilizado um procedimento cirúrgico, e a esse tipo de procedimento dá-se o nome de "frenectomia" -que consiste na excisão de todo o frênulo e tecido interdental ${ }^{3}$. Objetivo: Apresentar um relato clínico de frenectomia lingual em paciente adulto que apresentava dificuldades na comunicação. Relato de caso: Paciente de 19 anos, do gênero masculino, procurou o projeto de extensão "língua solta" da UFPE, requerendo a realização da frenectomia lingual, após ser encaminhado por uma cirurgiã-dentista da região. Durante o diagnóstico, foi detectado que o frênulo tinha inserção no ápice da língua, impedindo assim a movimentação correta do órgão, fazendo com que sua fala fosse comprometida. Ao término da intervenção cirúrgica, foram passadas todas as orientações pós-operatórias como, por exemplo, a utilização de analgésico em caso de dor e a terapia fonoaudiológica, com o intuito de auxiliar na reabilitação fonética. Discussão: A frenectomia foi realizada devido à dificuldade significativa de mobilidade da língua, fato constatado clinicamente após a verificação da fixação do freio lingual no ápice do órgão, impedindo os movimentos peculiares. Estudos revelam que tais alterações podem causar dificuldade fonéticas e sociais. Conclusão: De acordo com o relato de caso, fica claro que uma pequena alteração anatômica no frênulo lingual pode acarretar grandes prejuízos - tanto fisiológicos quanto sociais- para o indivíduo. Por isso, a associação entre a odontologia e a fonoaudiologia são indispensáveis para a melhoria do desenvolvimento fisiológico e emocional do paciente.

Descritores: Freio Lingual; Anquiloglossia; Intervenção Cirúrgica.

\section{Referências:}

1. BERCINI F, et al. Frenectomia: um caso clínico. Revista da Faculdade de Odontologia de Porto Alegre, 1996; 37(1): 15-17

2. CARRILHO ACA, REHDER MI. Frênulo lingual: classificação e conduta segundo ótica fonoaudiológica, odontológica e otorrinolaringológica. Revista CEFAC, 2008; 10(3): 343-351 3. CAVALHEIRO MG, et al. Interferência do frênulo lingual para a evolução do quadro fonológico: caso clínico. Distúrbios da Comunicação, 2018; 30(4): 785-790 


\title{
PC-99-2019 - FRENECTOMIA LINGUAL EM PACIENTE PRÉ-ADOLESCENTE NO PROJETO LÍNGUA SOLTA/UFPE: DO DIAGNÓSTICO À CIRURGIA
}

\begin{abstract}
Manassés de Oliveira Pereira ${ }^{1}$; Italo Ferreira Monteiro ${ }^{1}$; Maria Luísa Alves Lins ${ }^{1}$; Ingrid Melo Schüler Arreguy ${ }^{1}$; Alfredo de Aquino Gaspar ${ }^{1}$; Bianca Lais Gomes dos Santos ${ }^{2}$; Alexsandro Silva de Andrade ${ }^{3}$; Ana Cláudia da Silva Araújo ${ }^{1}$
\end{abstract}

${ }^{1}$ Universidade Federal de Pernambuco - Recife - PE - Brasil

${ }^{2}$ Faculdade Pernambucana de Saúde - Recife - PE - Brasil

${ }^{3}$ Faculdade Frassinetti do Recife - Recife - PE - Brasil

Autor correspondente:

Manassés de Oliveira Pereira

manassesop@gmail.com

Introdução: O frênulo lingual é uma estrutura anatômica em forma de prega que está localizado entre o ventre da língua e o assoalho da cavidade bucal ${ }^{1}$. Quando esse encontra-se fixado muito próximo à ponta da língua dificultando sua movimentação chama-se de anquiloglossia ou, popularmente conhecido, língua presa ${ }^{1,2}$. Objetivo: Relatar um caso de anquiloglossia em paciente pré-adolescente. Relato de caso: Paciente de 11 anos, gênero masculino, foi trazido ao Projeto Língua Solta por seus responsáveis requerendo a realização da frenectomia lingual. Durante o diagnóstico foi detectado que o frênulo tinha inserção na crista alveolar e localizado no ápice. O paciente tinha a movimentação lingual limitada, mas se comunicava sem alterações. Após análise dos exames pré-operatórios, o paciente foi encaminhado para cirurgia. Foi aplicado anestésico tópico no assoalho do frênulo e, em seguida, meio tubete de Lidocaína a 2\%, com epinefrina 1:100.000, totalizando um tubete anestésico. Após efeito anestésico local, foi utilizado a tenta cânula para imobilizar e elevar o frênulo, facilitando a incisão feita com uma tesoura Goldman- Fox reta até o romper as fibras inseridas. Posteriormente comprimiu-se com gaze estéril, para promoção da hemostasia e, na ferida cirúrgica, foram feitos pontos de sutura simples utilizando fiode nylon. Após o procedimento, as orientações pós-operatórias foram repassadas aos responsáveis, bem como a indicação de um analgésico em caso de dor. A reavaliação cirúrgica foi marcada para 7 dias após o procedimento para remoção da sutura e preservação. Discussão: Diante dessa alteração, a intervenção cirúrgica através da frenectomia tem sido a mais indicada, sendo eficaz e devolvendo a função parcial ou tótal da língua ${ }^{1,3}$. Conclusão: A frenectomia foi realizada devido à dificuldade significativa de mobilidade da língua, fato constatado clinicamente, impedindo os movimentos peculiares. Estudos revelam que tais alterações podem causar dificuldade fonéticas e dificuldades sociais, sendo necessária a intervenção cirúrgica.

Descritores: Anquiloglossia; Freio Lingual; Língua.

\section{Referências:}

1. MARCHESAN IQ. Protocolo de avaliação do frênulo da língua. Revista CEFAC, 2010; 12(6):977-989

2. MARTINELLI RLC, et al. Validade e confiabilidade da triagem: "teste da linguinha". Revista CEFAC, 2016; 18(6):1323-1331

3. SILVA HL, et al. Frenectomia: revisão de conceitos e técnicas cirúrgicas. SALUSVITA, 2018; 37(1):139-150 


\title{
PC-100-2019 - FRENECTOMIA LINGUAL EM PRÉ-ADOLESCENTE NO PROJETO LÍNGUA SOLTA/UFPE - RELATO DE CASO
}

\begin{abstract}
Wilson Mateus Chaves Félix ${ }^{1}$; Maria Luísa Alves Lins ${ }^{1}$; Ítalo Ferreira Monteiro; Gustavo Passos de Freitas Lima²; Alfredo Aquino Gaspar Júnior ${ }^{1}$; Manoel Nunes Da Silva Neto; Amanda Carolini Marques de Melo ${ }^{1}$
\end{abstract}

${ }^{1}$ Universidade Federal de Pernambuco - Recife - PE - Brasil

${ }^{2}$ Faculdade de Odontologia do Recife - Recife - PE - Brasil

Autor correspondente:

Wilson Mateus Chaves Félix

wilson11mateus@gmail.com

Introdução: A língua possui em sua face inferior uma pequena prega de membrana mucosa, denominada frênulo da língua, que a conecta ao assoalho da boca ${ }^{1}$. Essa membrana pode limitar os movimentos da língua em graus variados; podendo causar, nesse contexto, prejuízos no desenvolvimento das faculdades psíquicas e físicas do indivíduo ${ }^{3}$. Quando esse frênulo lingual é mínimo, ou inexistente, caracteriza a anquiloglossia, que seria a fusão completa ou parcial da língua ao assoalho da boca ${ }^{2,3}$. A anquiloglossia também é caracterizada como uma limitação dos movimentos da língua por um frênulo curto ou ausente ${ }^{2}$. Objetivos: O objetivo deste trabalho é relatar o caso clínico de frenectomia lingual em um pré-adolescente. Relato de caso: Paciente de 9 anos, gênero masculino, o qual compareceu à clínica do projeto de extensão língua solta da Universidade Federal de Pernambuco - UFPE, encaminhada pela psicóloga que observou no paciente uma retração na comunicação ocasionada pela anquiloglossia. Após aplicação do protocolo com escore 16 e relato da avó de dificuldade da criança na deglutição de alimentos sólidos e na articulação de palavras foi indicado a frenectomia lingual. O estudo foi aprovado pelo Comitê de Ética em pesquisa da UFPE sob o número CAAE 66361417.4.0000.5208 e parecer 2.094.353. Discussão: No retorno para avaliação clínica foi feita a anamnese e percebido que o frênulo se apresentava com cicatrização normal. A avó também relatou que a sua mastigação e deglutição apresentaram uma melhora significativa e quanto a dicção de palavras houve um desenvolvimento parcial, sendo indicado a continuação do tratamento com a fonoaudiologia. Conclusão: Como é demonstrado no relato é importante ressaltar não só a prática cirúrgica, como também a importância do trabalho multidisciplinar entre o cirurgião-dentista e o fonoaudiólogo para um diagnóstico clínico mais eficaz. Além de destacar a melhoria da qualidade de vida do paciente.

Descritores: Anquiloglossia; Língua; Freio Lingual.

\section{Referências:}

1. BRITO SF, et al. Frênulo Lingual: classificação e conduta segundo a ótica fonoaudiológica, odontológica e otorrinaringológica. Revista CEFAC, 2008; 10(3): 343-351

2. MARCHESAN IQ. Frênulo de Língua: classificação e inteferênciana fala. Revista Cefac, 2003; 5(4): 341-345

3. VARGAS BC, et al. Anquiloglossia: quando indicar a frenectomia lingual? Revista UNINGÁ, 2017; 18: 161-169 


\section{PC-101-2019 - FRENOTOMIA LINGUAL E SUA CORRELAÇÃO COM AMAMENTAÇÃO: RELATO DE CASO CLÍNICO}

Mirela Carolaine Cunha da Cruz ${ }^{1}$; Alfredo de Aquino Gaspar Junior ${ }^{1}$; Ana Cláudia da Silva Araújo $^{1}$; Mariana de Moraes Corrêa Perez ${ }^{1}$; Mariana Galindo Soares ${ }^{1}$; Kaio Aguiar Paixão Santos $^{1}$; Gutembergmann Batista Coutinho ${ }^{1}$; Camila Maria da Silva ${ }^{1}$

${ }^{1}$ Universidade Federal de Pernambuco - Recife - PE - Brasil

Autor Correspondente:

Mirela Carolaine Cunha da Cruz

mirela.carolaine@hotmail.com

Introdução: A anquiloglossia é uma anomalia congênita oral que pode trazer alguns prejuízos como a limitação da elasticidade e a mobilidade da língua, o que poderia causar alterações na amamentação, deglutição, mastigação e fala ${ }^{1,2,3,4,5}$. Objetivos: Descrever um caso clínico de anquiloglossia em um recém-nascido do sexo feminino. Relato de caso: A criança tinha seis dias de idade e os pais informaram relato de dificuldade na amamentação, no ganho de peso e com dor na mãe ao amamentar. A criança foi avaliada por um fonoaudiólogo, que realizou o teste da linguinha e obteve uma pontuação 8, que já sugere que o bebê necessita de intervenção cirúrgica devido à presença da anquiloglossia. Discussão: Foi então sugerida uma intervenção cirúrgica. Para isso, realizou-se a técnica de anestesia local tópica juntamente com anestesia infiltrativa com lidocaína, utilizando-se um sexto do tubete em cada lado do frênulo. Após o efeito do anestésico, realizou-se o corte da camada mucosa da estrutura e de suas fibras inseridas no músculo genioglosso. Durante o procedimento cirúrgico, realizou-se a hemostasia, utilizando-se a gaze estéril e imediatamente a criança foi colocada para fazer a amamentação. Ao final da cirurgia, a paciente recebeu orientações sobre o pós-operatório e retornou a clínica 10 dias após a cirurgia para a avaliação da cicatrização da paciente. Conclusões: Foi notória uma excelente melhora clínica da posição do frênulo lingual, dor da mãe ao amamentar e melhora da amamentação e do ganho de peso.

Descritores: Anquiloglossia; Amamentação; Cirurgia.

\section{Referências:}

1. BRAGA LA, et al. Prevalência de alteração no frênulo lingual e suas implicações na fala de escolares. Rev. CEFAC, 2009; 11(3): 378-390

2. BRITO SF, et al. Frênulo lingual: classificação e conduta segundo ótica fonaudiológica, odontológica e otorrinolaringológica. Rev. CEFAC, 2008; 10(3): 343-351

3. MARCHESAN IQ, et al. Frênulo lingual: modificações após frenectomia. Soc. Bras. Fonaudiol, 2012; 24(4): 409-412

4. MARTINELLI RL, et al. Protocolo de avaliação do frênulo lingual para bebês: relação entre aspectos anatômicos e funcionais. Rev. CEFAC, 2013; 15(3): 599-610

5. MARTINELLI RL, et al. Protocolo de avaliação do frênulo da língua em bebês. Rev. CEFAC, 2012; 14(1): 138-145 


\section{PC-102-2019 - GANCHO DE BARROS NO TRATAMENTO DA FRATURA DE ARCO ZIGOMÁTICO: RELATO DE CASO}

Cayara Boaventura de Carvalho후 João Artur Peixoto Granja ${ }^{1}$; Cláudia Nely Mendonça dos Santos $^{1}$; Vinicius Balan Santos Pereira ${ }^{2}$; Kalyne Kelly Negromonte Gonçalves ${ }^{3}$; Demóstenes Alves Diniz ${ }^{3}$; Rosa Rayanne Lins de Souza ${ }^{3}$; Caio César Gonçalves Silva ${ }^{2}$

${ }^{1}$ Centro Universitário Tiradentes - Recife - PE - Brasil

${ }^{2}$ Faculdade de Odontologia de Pernambuco - Recife - PE - Brasil

${ }^{3}$ Hospital da Restauração Governador Paulo Guerra - Recife - PE - Brasil

Autor correspondente:

Cayara Boaventura de Carvalho

cayara@hotmail.com

Introdução: $\mathrm{O}$ arco zigomático é frequentemente fraturado em virtude da sua localização e sua fragilidade, resultando, sobretudo, na perda do contorno facial ${ }^{1}$. Compondo o complexo zigomático - maxilar, tem função de dissipar foças provenientes da mastigação por meio dos pilares de reforço e sustentação, conferir contorno a face e servir de arcabouço para o globo ocular ${ }^{2}$. Objetivo: Relatar o caso de um paciente do sexo masculino, 27 anos, vítima de agressão física evoluindo com fratura de arco zigomático. Relato de caso: Ao exame físico, apresentava depressão em região de arco zigomático esquerdo com restrição da abertura bucal. O exame tomográfico evidenciou fratura de arco zigomático esquerdo. Foi proposto ao paciente redução incruenta da fratura de arco zigomático pela técnica com gancho de Barros. Nessa modalidade de tratamento a anestesia utilizada é local e realizada uma incisão de $1 \mathrm{~cm}$ para a instalação do gancho de Barros e redução da fratura. Após a realização do procedimento, o contorno facial e a abertura bucal foram reestabelecidos. Paciente segue em acompanhamento ambulatorial sem queixas visuais e/ou estéticas. Discussão: $\mathrm{Na}$ literatura constatou-se a indicação de gancho de barros, que consiste em reposicionar o osso através de tracionamento, para a terapêutica de fraturas clássicas do arco zigomático, por apresentar resultados favoráveis estéticos e funcionais. Esta técnica apresenta vantagens tais como não necessitar submeter o paciente a grandes recursos anestésicos, não o expõe a infecções, mínima cicatriz e não necessita de material de fixação óssea ${ }^{3}$. Para casos de fraturas de zigoma associada ao arco zigomático, a redução da fratura ocorre de forma obrigatoriamente aberta. Como descrito no relato de caso, foi lançado mão do gancho de barros. Conclusão: $O$ correto diagnóstico da fratura é fundamental para escolha do tratamento, assim como o acompanhamento clínico a fim de evitar futuras complicações.

Descritores: Arco zigomático; Cirurgia Maxilofacial; Tratamento.

\section{Referências:}

1. JARDIM EC, et al. Tratamento conservador de fratura de arco zigomático: uma visão conservadora. Salusvita, 2011; 30(1): 39-46

2. JARDIM EC, et al. Combinação de Técnicas para Tratamento Cirúrgico de Fratura do Complexo Zigomático-Maxilar: Relato de Caso. Arch Health Invest, 2013; 2(3): 33-36

3. ROCHA, et al. Avaliação de Tratamento da Fratura zigomático-orbitária, sem fixação. Journal of the Brazilian College of Oral and Maxillofacial Surgery, 2015; (1)3: 14-19 


\section{PC-103-2019 - GRANULOMA PIOGÊNICO ULCERADO EM PACIENTE COM PARALISIA CEREBRAL - RELATO DE CASO}

Fernanda Teles Pereira ${ }^{1}$; Pedro Henrique Barbosa de Melo ${ }^{1}$; Cleiton Rone dos Santos Lima ${ }^{1}$; Emerllyn Shayane Martins de Araújo'; Samuel Rodrigo de Andrade Veras ${ }^{2}$; Lidiane Jacinto do Nascimento $^{2}$; Ana Catarina Gaioso Lucas Leite ${ }^{2}$

${ }^{1}$ Faculdade de Odontologia de Pernambuco - Camaragibe - PE - Brasil

${ }^{2}$ Instituto de Medicina Integral Professor Fernando Figueira - Recife - PE - Brasil

Autor correspondente:

Fernanda Teles Pereira

fernandatelespereira@gmail.com

Introdução: O Granuloma piogênico é uma lesão que surge como uma resposta tecidual exuberante frente a uma irritaçãoo crônica local ${ }^{2}$. Apresenta-se como nódulo séssil ou pediculado, geralmente indolor, de superfície lisa, de coloração vermelha-arrocheada, sangrante ao mínimo toque, como resultado de uma vascularizaão intensa ${ }^{3,1}$. Objetivo: Relatar o caso clínico do paciente J.R.F. dos S., de 1 ano e dois meses de idade, com paralisia cerebral, encaminhado para o Ambulatório de Odontologia do IMIP para tratamento de lesão ulcerada em lábio inferior e face ventral da língua. Relato de caso: O paciente chegou ao Ambulatório de Odontologia do IMIP, encaminhado por um hospital do interior de Pernambuco. A genitora apresentava queixa de ferida na língua e no lábio que "não cicatrizava nunca". Ao exame clínico odontológico, a criança apresentava lesão ulcerada em lábio inferior e na face ventral da língua. Foi observado que os elementos dentários decíduos 71 e 81 apresentavam bordos cortantes. Na consulta inicial foram realizados desgastes dos bordos incisais dos referidos dentes, laserterapia com PDT e prescrição de antibiótico por um período de 7 dias, amoxicilina com clavulanato. A lesão do ventre da língua, Úlcera de Riga Fede, regrediu completamente na primeira semana de tratamento, entretanto, o paciente apresentou apenas melhora discreta da lesão labial. Optouse então, por fazer a biópsia excisional da lesão do lábio acusando compatibilidade com granuloma piogênico ulcerado. Discussão: Devido a fragilidade do epitélio do granuloma, rompe-se com facilidade e infecta-se com frequência. O local mais acometido é a gengiva (75\%), seguido por lábio, língua e mucosa jugal, podendo ocorrer na pele. O tratamento é a excisão cirúrgica e a remoção do fator irritante associado. Conclusão: Este relato de caso, mostra o sucesso de um tratamento cirúrgico de lesão labial em paciente pediátrico com paralisia cerebral.

Descritores: Granuloma; Odontopediatria; Dente Decíduo.

\section{Referências:}

1. CAVAZZOLA A, et al. Granuloma piogênico. Multidisciplinaridade na Saúde bucal, 2012; 2:52-57

2. GOMES SR, et al. Pyogenic granuloma of the gingiva: A case report and review literature. Journal of Indian Society Periodontology, 2013; 17:514-519

3. PINTO ACG. Odontopediatria. $8^{a}$ ed. São Paulo: Santos, 2012; 1064p 


\section{PC-104-2019 - GRANULOMA PIOGÊNICO: UMA REVISÃO DE LITERATURA}

Gabriella Rodrigues da Silva ${ }^{1}$; Katarina Haluli Janô da Veiga Pessôa ${ }^{1}$; Mariane Dias de Moura ${ }^{1}$; Taís Soares Ramos ${ }^{1}$; Laís Azevedo Lins de Holanda ${ }^{2}$

${ }^{1}$ Faculdade de Odontologia de Pernambuco - Camaragibe - PE - Brasil

${ }^{2}$ Hospital Universitário Oswaldo Cruz - Recife - PE - Brasil

Autor correspondente:

Gabriella Rodrigues da Silva

gabriella_rodrigues1@outlook.com

Introdução: $O$ granuloma piogênico é uma lesão proliferativa da cavidade bucal de natureza não neoplásica, que é resultado de respostas teciduais a estímulos nocivos de caráter crônico ${ }^{3}$. Objetivo: O objetivo deste trabalho é abordar a definição de granuloma piogênico, suas características principais e formas de tratamento. Metodologia: Para construir a presente revisão, foi realizada uma pesquisa através da coleta de trabalhos científicos nas bases de dados MEDLINE, PubMed, SciELO e LILACS. Revisão de literatura: Geralmente ocasionado por trauma, o granuloma piogênico é caracterizado por um aumento de volume com superfície lisa ou lobulada e pediculada ${ }^{2}$. Ele acomete principalmente a gengiva, possui uma predileção pelo sexo feminino e observa-se uma maior frequência entre crianças e adultos jovens ${ }^{2}$. Seu aspecto varia de acordo com a quantidade de vascularização, enquanto lesões jovens são altamente vascularizadas e com coloração azulada ou arroxeada, as lesões mais antigas apresentam pouca vascularização tendo uma cor mais rósea ${ }^{3}$. Os tratamentos podem ser excisão cirúrgica, criocirurgia, injeção de agentes esclerosantes e laserterapia, sendo importante salientar que a remoção do fator traumático é necessária ${ }^{1}$. Conclusão: É de suma importância o conhecimento acerca da lesão para que o cirurgião-dentista estabeleça um diagnóstico e tratamento adequados. O granuloma piogênico compromete a função e estética do paciente e, além disso, é o tipo mais comum de hiperplasia inflamatória que acomete a mucosa oral².

Descritores: Granuloma Piogênico; Granuloma; Lesão.

\section{Referências:}

1. ABREU CP, et al. Granuloma piogênico atípico extra-gengival: relato de caso. Políticas e Saúde Coletiva, 2017; 2(3): 61-66

2. AVELAR RL, et al. Granuloma piogênico oral: um estudo epidemiológico de 191 casos. RGO, 2008; 56(2): 131-135

3. NEVILLE BW, et al. Patologia Oral e Maxilofacial. $4^{\text {a }}$ ed. Rio de Janeiro: Guanabara Koogan, 2016; 928p 


\section{PC-105-2019 - HALITOSE: ASPECTOS DE IMPORTÂNCIA CLÍNICA PARA O CIRURGIÃO-DENTISTA}

Ademir Félix Arantes Júnior ${ }^{1}$; Aylanne Xavier de Lacerda Cavalcante Timoteo ${ }^{1}$; Carolaine Rayane Xavier da Silva ${ }^{1}$; Emerllyn Shayane Martins de Araújo ${ }^{1}$; Girlane Iris da Silva ${ }^{1}$; Kássia Regina de Santana ${ }^{1}$; Lucas Rafael Borges Santos ${ }^{1}$; Sally de Souza Brito ${ }^{2}$

${ }^{1}$ Faculdade de Odontologia de Pernambuco - Camaragibe - PE - Brasil

${ }^{2}$ Centro de Pós-graduação em Odontologia - Recife - PE - Brasil

Autor correspondente:

Ademir Félix Arantes Júnior

ademirarantesjr@gmail.com

Introdução: A halitose, também designado hálito fétido ou mau hálito, é uma condição caracterizada pela emanação de odores fétidos pela boca com prevalência estimada entre 10 a $30 \%$. A literatura descreve que $87 \%$ dos fatores etiológicos da halitose são originados na cavidade bucal ou em áreas relacionadas como o ouvido, nariz e garganta e 13\% são de origem extrabucal como desordens do trato respiratório ou gastrointestinal ${ }^{1}$. Objetivo: Apresentar uma revisão da literatura sobre a halitose, princípios básicos de sua etiologia e os possíveis tratamentos mecânicos e químicos disponíveis. Metodologia: Foram utilizadas as bases de dados da LILACS, PubMed e SciELO. Utilizaram-se os descritores: Halitose; Diagnóstico; Saúde Pública e selecionaram-se 11 artigos publicados entre 2014 e 2019. Revisão de Literatura: Má higiene bucal, gengivite e periodontite, saburra lingual, presença de compostos voláteis sulfurados (CVS), afecções no nariz e garganta (amigdalite, sinusite e rinite), diminuição da saliva, tabagismo e etilismo são os principais fatores associados à halitose. Outras causas orais: estomatites, neoplasias, polpa necrosadas expostas, alveolite, periimplantite, pericoronarite, ulcerações orais recorrentes ${ }^{1,2}$. O tratamento da halitose deve ser baseado no combate a causa que determina a produção dos gases voláteis causadores do mau odor. É essencial a remoção dos possíveis fatores etiológicos associados à condição como o tratamento periodontal básico, remoção de restos radiculares, selamento cavitário, instrução de higiene bucal e de próteses. Escovação dentária correta, limpeza da língua e uso de fio dental são estratégias relevantes no combate à halitose ${ }^{1,3}$. Quanto aos métodos químicos, o padrãoouro dos enxaguantes é a clorexidina $0.2 \%$ e aqueles que possūem em sua formulação triclosan, tendo destaque também, proporcionando leve melhora da condição a goma de mascar com probióticos $^{3}$. Conclusão: Com diagnóstico adequado e identificação da etiologia, podem ser tomadas medidas para criar uma abordagem terapêutica individualizada, bem-sucedida e interdisciplinar para cada paciente.

Descritores: Halitose; Diagnóstico; Saúde Pública.

\section{Referências:}

1. ARAUJO LMP, et al. Manejo de pacientes com halitose atendidos no serviço público de saúde. Revista Bahiana de Odontologia, 2016; 7(3): 191-198

2. BARBA L, VALERIO I. Halitosis: Principios básicos sobre su origen y tratamiento. Odovtos-International Journal of Dental Sciences, 2018; 3(4): 87-100

3. KAPOOR $\mathrm{U}$, et al. Halitosis: Current concepts on etiology, diagnosis and management. European journal of dentistry, 2016; 10(2): 292-300 


\section{PC-106-2019 - HEMATOMA SUBLINGUAL ESPONTÂNEO SECUNDÁRIO AO USO CONTÍNUO DE VARFARINA: RELATO DE CASO}

Carolina Pereira da Silva ${ }^{1}$; Heitor Tavares de Araújo ${ }^{1}$; Marcela Lins Braga ${ }^{1}$; Eugênia Leal de Figueiredo $^{1}$; Rosa Rayanne Lins de Souza ${ }^{2}$; Lucas Emmanuel de Morais Neves ${ }^{2}$; Ruan de Souza Viana $^{2}$; Suzana Célia de Aguiar Soares Carneiro ${ }^{2}$

${ }^{1}$ Faculdade de Odontologia de Pernambuco - Camaragibe - PE - Brasil

${ }^{2}$ Hospital da Restauração Governador Paulo Guerra - Recife - PE - Brasil

Autor correspondente:

Carolina Pereira da Silva

carolinapereeira@gmail.com

Introdução: A anticoagulação oral continuada está indicada em diversas situações clínicas, e a Varfarina é a droga mais amplamente utilizada para prevenção e tratamento de fenômenos tromboembólicos ${ }^{2}$. O uso indiscriminado da Varfarina, principalmente associado a outros fármacos, pode gerar consequências que variam de leves a graves, como equimoses, necrose de pele, dispnéia, hemorragias, até o óbito ${ }^{2}$. Objetivo: Relatar as consequências orais do uso de anticoagulantes orais sem supervisão médica através de caso clínico. Relato de Caso: Paciente, MGC, sexo feminino, 68 anos, deu entrada no serviço de urgência/emergência do Hospital da Restauração em Pernambuco, com história de aumento de volume espontâneo dentro de 12 horas, apresentando extenso hematoma de região sublingual e submentual, queixa fonética, respiratória e álgica; bem como equimoses nas extremidades, melena e intensa artralgia. Referiu usar Marevan 5mg, AAS 10mg e Digoxina 0,25mg após acidente vascular isquêmico, mas sem acompanhamento médico. Devido ao quadro clínico, necessitou-se a suspensão da medicação, coagulograma de rotina, endoscopia, e suporte ventilatório até a remissão dos sintomas; para posterior adequação da dosagem adequada Discussão: O efeito terapêutico dos anticoagulantes orais varia de indivíduo para indivíduo, dependendo de fatores genéticos e ambientais, que influenciam sua absorção, farmacocinética e farmacodinâmica ${ }^{3}$. Muitas medicações interagem com a Varfarina potencializando ou reduzindo seu efeito. Esses fatos obrigam a um controle terapêutico rigoroso, com correção da dose do anticoagulante de acordo com o tempo de protrombina, devendo ser realizado com a utilização de tromboplastinas com índice de sensibilidade próximo ao do padrão internacional e expresso pela razão normatizada internacional $(\mathrm{RNI})^{1}$. Conclusões: $\mathrm{O}$ conhecimento das reações adversas, que acometem a cavidade oral, das medicações utilizadas pelos pacientes com doenças de base favorece o diagnóstico e condução multidisciplinar do caso, aumentando a sua sobrevida e reduzindo os danos.

Descritores: Hematoma; Varfarina; Anticoagulante.

\section{Referências:}

1. ANSELL J, et al. The pharmacology and management of the vitamin K antagonists: the Seventh ACCP Conference on Antithrombotic and Thrombolytic Therapy. Chest Journal, 2004; 126(3): 204S-233S

2. SANTOS FC, et al. Complicações da terapia anticoagulante com warfarina em pacientes com doença vascular periférica: estudo coorte prospectivo. Jornal Vascular Brasileiro, 2006; 5(3): 194-202

3. SCHULMAN S. Care of patients receiving long-term anticoagulant therapy. New England Journal of Medicine, 2003; 349(7):675-683 


\section{PC-107-2019 - HIPERPLASIA ENDOTELIAL PAPILAR INTRAVASCULAR ORAL: REVISÃO DE LITERATURA}

Manuela França Andrade Passos ${ }^{1}$; Gustavo Afonso Duque Padilha²; Sinval Vinícius Barbosa do Nascimento ${ }^{1}$; Eduardo Vinícius de Souza Silva ${ }^{1}$; Fernanda Gomes Barros ${ }^{1}$; Francisco Henrique Lima Milhomens ${ }^{1}$; Kalyne Kelly Negromonte Gonçalves ${ }^{3}$

${ }^{1}$ Faculdade de Odontologia de Pernambuco - Camaragibe - PE - Brasil

${ }^{2}$ Faculdade de Ciências Médicas - Recife - PE - Brasil

${ }^{3}$ Hospital da Restauração - Recife - PE - Brasil

Autor correspondente:

Manuela França Andrade Passos

manuelaemj@gmail.com

Introdução: A hiperplasia endotelial papilar intravascular (HEPI) é uma lesão vascular reativa caracterizada pela proliferação endotelial excessiva localizada no interior de vasos sanguíneos comumente dilatados, associada a trombos em organização, ou secundária a outras lesões vasculares, como hemangiomas e granulomas piogênicos. Sua principal peculiaridade reside na semelhança histológica com o angiossarcoma e na possível interpretação errônea como neoplasia maligna ${ }^{3}$. Objetivo: Apresentar uma revisão de literatura a respeito das características histopatológicas e diagnóstico diferencial da HEPI. Metodologia: Foi realizada uma pesquisa na base de dados SciELO no período de 1976 a 2006 com os descritores: hiperplasia endotelial papilar, angiomatose intravascular e hemangioendotelioma. Foram encontrados onze artigos, dos quais usaram-se três. Revisão de literatura: A HEPI se caracteriza por ser uma lesão benigna que, sob um aspecto histopatológico, apresenta projeções papilares de tecido conjuntivo fibroso revestidas por uma ou duas camadas de células endoteliais no interior do lúmen vascular ${ }^{3}$. Tal lesão pode ocorrer em qualquer vaso sanguíneo no corpo, detendo maior prevalência na região de cabeça e pescoço. Entretanto, é excepcionalmente rara na cavidade oral, onde afeta indivíduos com média de 58 anos e exibe maior predileção pela mucosa do lábio inferior, seguida, em ordem decrescente, por língua, lábio superior e mucosa jugal ${ }^{1}$. Quanto à diagnose da hiperplasia endotelial, é possível haver dificuldade para o estabelecimento preciso devido à semelhança histológica entre a HEPI e angiossarcoma. Contudo, a HEPI é diferenciada do ângiossarcoma por não âpresentar atipia celular, como pleomorfismo celular, atividade mitótica significativa, tampouco áreas de necrose ou padrão de crescimento invasivo, já que é descrita classicamente como uma lesão bem circunscrita $^{2}$. Conclusão: Para determinar um diagnóstico diferencial se faz necessário o conhecimento anatomopatológico dessas duas lesões, por parte do cirurgião-dentista, ressaltando também a importância clínica do exame histopatológico, para que seja executado o tratamento compatível com a patologia.

Descritores: Angiomatose; Hemangioendotelioma; Hiperplasia.

\section{Referências:}

1. BUCHNER A, et al. Oral intravascular papillary endothelial hyperplasia. Journal of Oral Pathology \& Medicine, 1990; 19(9): 419-422

2. CLEARKIN KAP, ENZINGER FM. Intravascular papillary endothelial hyperplasia. Archives of Pathology \& Laboratory Medicine, 1976; 100(8): 441-444

3. FILHO JAVG, et al. Hiperplasia endotelial papilar intravascular oral: uma entidade rara. Jornal Brasileiro de Patologia e Medicina Laboratorial, 2006; 42(1): 31-35 


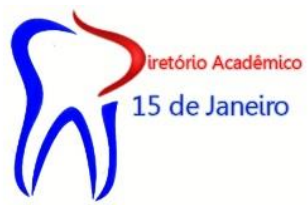

\section{PC-108-2019 - HIPERPLASIA FIBROSA INFLAMATÓRIA ASSOCIADA À SÍNDROME DA COMBINAÇÃO: RELATO DE CASO}

Lívian Nayane da Costa e Silva ${ }^{1}$; Ana Caroline Chalegre de Oliveira ${ }^{1}$; Emanuelly Soares de Melo Silva ${ }^{1}$; Hian Carvalho Souza ${ }^{1}$; Jeferson Batista Santiago ${ }^{1}$; Maíra Belo da Rocha Carvalho $^{1}$; Rafael Brito Lopes ${ }^{2}$; Rosa Natalia Rendall dos Santos Ratis ${ }^{3}$

${ }^{1}$ Faculdade de Odontologia de Pernambuco - Camaragibe - PE - Brasil

${ }^{2}$ Faculdade de Ciências Agrárias e da Saúde - Lauro de Freitas - BA - Brasil

${ }^{3}$ Universidade Tiradentes - Recife - PE - Brasil

Autor correspondente:

Lívian Nayane da Costa e Silva

nayanelivian@gmail.com

Introdução: A Hiperplasia Fibrosa Inflamatória (HFI) é definida como lesão benigna que acomete tecidos moles, decorrendo de traumas contínuos e crônicos, tendo predileção por usuários de próteses mal adaptadas, em alguns casos está associada à Síndrome da Combinação 1,3. Objetivo: O presente trabalho objetiva relatar um caso clínico de HFI associada à Síndrome da Combinação. Relato de Caso: Paciente leucoderma, 42 anos, gênero feminino, foi encaminhada ao curso de Aperfeiçoamento em Cirurgia Buco-Maxilo-Facial da ABO-PE para realização de uma cirurgia pré-protética. Ao exame clínico foi identificada uma lesão exofítica, eritematosa, pediculada na região de fundo de vestíbulo anterior de maxila, eventualmente sintomática. O exame radiográfico apresentou aumento da tuberosidade direita e perda óssea severa do rebordo superior em que a maxila desdentada se opunha aos dentes anteriores inferiores, caracterizando a Síndrome da Combinação. Posterior a uma biopsia excisional, realizou-se o exame histopatológico confirmando o diagnóstico de HFI. A paciente encontrase em preservação e foi orientada a não utilizar a prótese antiga, junto a recomendações para confecção de uma nova prótese e as possíveis formas de tratamento para a Síndrome da Combinação. Discussão: Constitui-se em uma resposta à irritação crônica de baixa intensidade, quase sempre associada ao uso de próteses incorretamente confeccionadas ${ }^{2}$. A HFI apresentase como numerosas projeções papilares vermelhas, edematosas, envolvendo frequentemente quase todo o palato duro ${ }^{2}$. Pode estar associada à Síndrome da Combinação que se caracteriza por reabsorção óssea do rebordo residual na região relācionáda com a prótese, extrusão dos dentes anteriores, reabsorção acelerada do rebordo, espessamento da mucosa na região das tuberosidades maxilares e hiperplasia dos tecidos na região palatina ${ }^{3}$. Conclusão: Com relação à HFI destaca-se a importância do exame histopatológico para o diagnóstico e quanto a Síndrome da Combinação é indicado o estabelecimento de um tratamento reabilitador e acompanhamento a fim de prevenir a recidiva da lesão.

Descritores: Hiperplasia; Patologia Bucal; Prótese total.

\section{Referências:}

1. FALCÃO AFP, et al. Hiperplasia fibrosa inflamatória: relato de caso e revisão de literatura. Revista de Ciências Médicas e Biológicas, 2009; 8(2):230-6

2. TOMASI LF. Diagnóstico em patologia bucal. São Paulo: Artes Médicas, 1982; 575p

3. VANZILLOTTA PS, et al. Síndrome da Combinação. Revista Brasileira de Odontologia, 2012; 69(2):199-202 


\section{PC-109-2019 - IMPACTO DA FRENOTOMIA LINGUAL NA MELHORIA DOS SINTOMAS DA AMAMENTAÇÃO EM NEONATOS: RELATO DE CASO}

Maria Fernanda Limeira Feitosa ${ }^{1}$; Douglas Felipe de Lima e Silva ${ }^{1}$; Niviane Marielly da Costa Oliveira $^{2}$; Caio César Gonçalves Silva²; Arthur Camillo de Souza Laranjeira²; Camila de Paula Rosendo ${ }^{2}$; Viviane Colares Soares de Andrade Amorim²

${ }^{1}$ Faculdade Maurício de Nassau - Recife - PE - Brasil

${ }^{2}$ Faculdade de Odontologia de Pernambuco - Camaragibe - PE - Brasil

Autor correspondente:

Maria Fernanda Limeira Feitosa

Mariafernandalimeira3@gmail.com

Introdução: A amamentação é uma prática fundamental para o recém-nascido devido aos benefícios imunomodulatórios e nutricionais, além da influência positiva na ligação emocional mãe-neonato ${ }^{3}$. Desta forma, o aparecimento da anquiloglossia é prejudicial ao ato, sendo caracterizada por um frênulo lingual curto que limita os movimentos da língua gerando sintomas na amamentação, sendo necessária a correção através de frenotomia ${ }^{1}$. Objetivo: Relatar um caso clínico de um neonato com anquiloglossia submetido à frenotomia lingual e suas implicações nos sintomas da amamentação. Relato de caso: Recém-nascido, a termo, parto normal, saudável, do sexo masculino, com 48 horas de vida e sua respectiva mãe. Segundo relato materno, o recém-nascido não conseguia mamar no seio materno, apresentava choro frequente, sinais de fome, insaciedade, engasgos e pausa entre as mamadas. A avaliação do frênulo lingual foi realizada por meio da aplicação do protocolo de Bristol (BTAT) resultado em escore dois, constatando a interferência do frênulo na movimentação da língua, sendo indicada a frenotomia. Foi realizada a cirurgia, em seguida o bebê foi colocado no seio materno para mamada em livre demanda. Após frenotomia houve melhora nos escores do protocolo, e posteriormente com um follow-up de quatro consultas até chegar ao primeiro mês de vida, constatou-se aleitamento materno exclusivo, cessação dos sintomas na amamentação e ganho de peso satisfatório para a idade. Discussão: Através da literatura consultada, foi possível verificar que a ocorrência de anquiloglossia em neonatos é considerável, sendo necessário realizar o diagnóstico nas primeiras semanas de vida, visto que bebês com anquiloglossia poderão desenvolver problemas na amamentação ${ }^{1,2}$. Conclusão: A frenotomia é um procedimento cirúrgico que melhora os sintomas da amamentação de neonatos com anquiloglossia e previne o desmame precoce.

Descritores: Aleitamento materno; Anquiloglossia; Freio lingual.

\section{Referências:}

1. MARTINELLI RLC, et al. Estudo longitudinal das características anatômicas do frênulo lingual comparado com as afirmações da literatura. Rev. CEFAC, 2014; 16(4): 1202-1207

2. PATEL J, et al. All Tied Up! Influences of Oral Frenulae on Breastfeeding and their Recommended Management Strategies. Journal of Clinical Pediatric Dentistry, 2018; 42(6): 407-413

3. PROCOPIO I, et al. Frenotomia lingual em lactentes. Revista Da Faculdade De Odontologia

- UPF, 2017; 22(1): 114-119 


\section{PC-110-2019 - IMPACTO DA SAÚDE BUCAL NA QUALIDADE DE VIDA DE CRIANÇAS E ADOLESCENTES COM CÂNCER}

Bruno Luiz Ferreira da Silva ${ }^{1}$; Elizabeth Louisy Marques Soares da Silva ${ }^{1}$; Maria Cecília Freire de Melo ${ }^{1}$; Thuanny Silva de Macêdo ${ }^{1}$; Márcia Maria Vendiciano Barbosa Vasconcelos ${ }^{1}$; Arnaldo de França Caldas Júnior ${ }^{1}$; Gustavo Pina Godoy ${ }^{1}$; Andressa Kelly Alves Ferreira ${ }^{1}$

${ }^{1}$ Universidade Federal de Pernambuco - Recife - PE - Brasil

Autor correspondente:

Bruno Luiz Ferreira da Silva

brunosilvall362@gmail.com

Introdução: Pacientes oncológicos infantojuvenis podem ter a qualidade de vida (QV) comprometida em seus domínios físico, emocional e psicológico em decorrência da doença e do tratamento ${ }^{1}$. Entre os efeitos adversos mais comuns do tratamento estão as alterações em cavidade oral, como quadros infecciosos e inflamatórios, que podem influenciar negativamente na QV desses pacientes ${ }^{5}$. Objetivo: Realizar uma revisão de literatura sobre o impacto da saúde bucal na QV de crianças e adolescentes com câncer. Metodologia: A busca eletrônica foi realizada nas bases de dados Biblioteca Virtual de Saúde, SciELO e PubMed, sendo selecionados artigos publicados nos últimos 10 anos. Revisão de Literatura: As complicações orais mais frequentes associadas ao tratamento oncológico em crianças e adolescentes são: mucosite, infecções, disfunções glandulares e alterações no paladar ${ }^{3}$. Estas repercussões orais podem atingir de forma negativa o psicossocial destes pacientes, uma vez que ocasionam dor, desconforto e dificuldades no aporte nutricional. Além disso, complicações orais podem levar ao aumento do tempo de hospitalização, elevando os riscos de complicações sistêmicas e afetando a motivação do paciente com seu tratamento ${ }^{4}$. O impacto negativo dos fatores relacionados à saúde bucal tem sido avaliado através de diferentes instrumentos reportados na literatura. Estes questionários, associados a dados clínicos, tem se mostrado bastante úteis no planejamento e melhorias de tratamento destes pacientes ${ }^{1,2}$. Conclusão: Alterações orais em pacientes infanto-juvenis oncológicos são bastante comuns e afetam negativamente sua qualidade de vida, sendo importante a presença de um cirurgião-dentista na equipe oncológica multidisciplinar para identificar e minimizar esses impactos durante o tratamento de crianças e adolescentes com câncer.

Descritores: Saúde bucal; Qualidade de vida; Oncologia.

\section{Referências:}

1. BARBOSA TS, et al. Qualidade de vida e saúde bucal em crianças e adolescentes: aspectos conceituais e metodológicos. Physis, 2010; 20(1): 283-300

2. BENNADI D, REDDY CVK. Oral health related quality of life. Journal of International Society of Preventive and Community Dentistry, 2013; 3(1): 1-6

3. FRAZÃO COB, et al. Pacientes oncológicos pediátricos: manifestações bucais da terapia antineoplásica. Revista Saúde e Pesquisa, 2012; 5(3): 587-592

4. LOPES IA, et al. Manifestações orais decorrentes da quimioterapia em crianças de um centro de tratamento oncológico. Pesquisa Brasileira em Odontopediatria e Clínica Integrada, 2012; 12(1): 113-119

5. MOTTA LJ, et al. Impacto da saúde buccal na qualidade de vida de crianças de 6 a 10 anos. ConScientiae Saúde, 2011; 10 (4): 715-722 


\section{PC-111-2019 - IMPACTOS DA CIRURGIA ORTOGNÁTICA NA QUALIDADE DE VIDA DOS PACIENTES: REVISÃO DE LITERATURA}

Emanuelly Soares de Melo Silva ${ }^{1}$; Ana Caroline Chalegre de Oliveira ${ }^{1}$; Jeferson Batista Santiago ${ }^{1}$; Olívia Augusta Araújo Dias ${ }^{1}$; Joana de Ângelis Alves Silva ${ }^{1}$; Mayara Monique Silva de Oliveira ${ }^{1}$; Ismael Sebastião da Silva Sousa ${ }^{1}$

${ }^{1}$ Faculdade de Odontologia de Pernambuco - Camaragibe - PE - Brasil

Autor correspondente:

Emanuelly Soares de Melo Silva

nelly-soares@outlook.com

Introdução: A cirurgia ortognática é um ramo da cirurgia bucomaxilofacial que oferece uma opção de tratamento ortocirúrgico indicado para pacientes que apresentam deformidades dentofaciais severas ${ }^{1,2}$. Assim, esse procedimento cirúrgico possibilita aos pacientes resultados funcionais e estéticos, proporcionando mudanças significativas na vida destes ${ }^{2}$. Objetivo: Apresentar uma revisão de literatura a respeito dos impactos da cirurgia ortognática na qualidade de vida dos pacientes. Metodologia: Foi realizada uma pesquisa na base de dados SciELO com os descritores: cirurgia ortognática, deformidades dentofaciais e qualidade de vida. Revisão de Literatura: A cirurgia ortognática consiste em um procedimento realizado em conjunto pelo ortodontista e pelo cirurgião bucomaxilofacial que trata da correção cirúrgica das deformidades dentofaciais tendo importância na correção da oclusão e da estética facial ${ }^{3}$. Isso significa que os aspectos psicossociais estão diretamente relacionados a esse tipo de tratamento, pois a aparência facial influencia a formação da imagem corporal, da identidade e da autoestima visto que, os benefícios que podem ser gerados por meio dela vão desde a melhora da oclusão, mastigação, fonação, respiração, sintomatologia dolorosa em articulação temporomandibular, estética facial até mesmo a inserção de indivíduos no convívio em sociedade, tornando esse procedimento um importante instrumento na melhora da qualidade de vida de muitos pacientes ${ }^{2}$. Compreendemos, através da leitura de alguns artigos, que a reparação da aparência facial interfere com a saúde em geral, mas a saúde mental tende a sofrer mais alterações positivas do que a saúde física ${ }^{1}$. Vale ressaltar que, atualmente os cirurgiões dispõemse de diversos softwares, métodos, técnicas e materiais que tornam a perspectiva do resultado final mais previsível e segura ${ }^{2}$. Conclusão: A cirurgia ortognática é um procedimento capaz de oferecer melhora da qualidade de vida para pacientes portadores de deformidades dentofaciais, por meio dos aspectos funcionais, estéticos e psicossociais.

Descritores: Cirurgia Ortognática; Deformidades Dentofaciais; Qualidade de Vida.

\section{Referências:}

1. CARVALHO SC, et al. Variáveis psicossociais associadas à cirurgia ortognática: uma revisão sistemática da literatura. Psicologia: Reflexão e Crítica, 2012; 25(3): 477-490

2. NÓIA CF, et al. Influência da cirurgia ortognática na harmonia facial: Série de casos. Rev. cir. traumatol. buco-maxilo-fac, 2015; 15(1): 21-2

3. RUBENS GF, et al. Qualidade de Vida em Pacientes Submetidos à Cirurgia Ortognática:

Saúde Bucal e Autoestima. Psicologia Ciência e Profissão, 2014; 34(1): 242-251 


\section{PC-112-2019 - IMPORTÂNCIA DA PROMOÇÃO À SAÚDE E EDUCAÇÃO ODONTOLÓGICA EM PACIENTES PORTADORES DE SÍNDROME DE DOWN}

Maria Luiza Feitosa Bandeira de Oliveira ${ }^{\mathbf{1}}$; Carolina Viana Vasco Lyra ${ }^{1}$; Déborah Abigail Morais Kirniew ${ }^{\mathbf{1}}$; Fernanda Gomes Barros ${ }^{1}$; Isabela Araújo de Lima ${ }^{1}$; Monique Maria de Souza Baltar ${ }^{1}$; Pedro Paulo Aguiar Santos Cavalcanti1 ${ }^{1}$ Sandra Conceição Maria Vieira ${ }^{1}$

${ }^{1}$ Faculdade de Odontologia de Pernambuco - Camaragibe - PE - Brasil

Autor correspondente:

Maria Luiza Feitosa Bandeira de Oliveira

m_luizafeitosa@hotmail.com

Introdução: A Síndrome de Down (SD) é uma das anomalias cromossômicas mais frequentes. Essa condição genética é caracterizada por atraso no desenvolvimento tanto nas funções motoras quanto na linguagem, com graus variáveis de retardo mental e onde há a prevalência de algumas anomalias dentárias ${ }^{1,2}$. Portanto, a prevenção e o tratamento odontológico adequado aos pacientes com Síndrome de Down são essenciais para o estabelecimento da saúde bucal como um todo. Objetivo: Fazer uma revisão de literatura acerca da Saúde Bucal de pacientes com Síndrome de Down, enfatizando a importância da promoção à saúde e educação de higiene oral. Metodologia: Foi realizada uma revisão de literatura. Foram utilizadas plataformas digitais como SciELO e PubMed, aplicando as publicações científicas sobre o tratamento odontológico e educação de higiene oral para indivíduos com SD. Revisão de Literatura: Sabe-se que pacientes com SD possuem maior tendência e prevalência de doença periodontal (DP), mesmo quando comparado com outros indivíduos com deficiência ${ }^{2}$. Por isso, a educação em saúde bucal, incluindo as técnicas de higiene bucal, devem ser aplicadas, precocemente, a pacientes com Síndrome de Down, tendo em vista suas deficiências motoras e neurológicas e a necessidade da prevenção das doenças dentais, sendo de extrema importância a formação de um vínculo entre profissional e paciente, estabelecendo assim uma relação de confiança ${ }^{3}$. Conclusão: Tendo em vista as dificuldades inerentes aos pacientes com SD, a educação em saúde bucal para eles e seus responsáveis é de suma importância para a prevenção de doenças bucais recorrentes a essa condição genética, assim como manter o vínculo entre profissional e paciente.

Descritores: Síndrome de Down; Assistência Odontológica para Pessoas com Deficiência; Educação em Odontologia.

\section{Referências:}

1. CAMERA GT, et al. O papel do cirurgião-dentista na manutenção da saúde bucal de portadores de síndrome de down. Odontologia Clínico-Científica, 2011; 10(3): 247-250

2. FERREIRA R, et al. Promoção de Saúde Bucal e Síndrome de Down: Inclusão e Qualidade de Vida por meio da Extensão Universitária. Odonto, 2016; 24(48): 45-53

3. FLEURY SBA. Saúde Bucal da criança com Síndrome de Down (Sentidos subjetivos gerados por seus cuidadores). Dissertação (Mestrado em Psicologia) - Pontifícia Universidade Católica de Goiás, Goiânia, 2014; 186p 


\section{PC-113-2019 - IMPORTÂNCIA ODONTO-LEGAL DAS ANOMALIAS DENTAIS}

Emilly Araújo Pereira ${ }^{1}$; Emília Alves do Nascimento ${ }^{1}$; Evelyne Pessoa Soriano ${ }^{1}$; Carolaine Rayane Xavier ${ }^{1}$; Gabriela Granja Porto Petraki ${ }^{1}$; Marcus Vitor Diniz de Carvalho ${ }^{1}$; Maria Carolina Tavares de Lyra Menezes ${ }^{1}$; Viviane Freire Lira ${ }^{1}$

${ }^{1}$ Faculdade de Odontologia de Pernambuco - Camaragibe - PE - Brasil

Autor correspondente:

Emilly Araújo Pereira

emillyaraujope@gmail.com

Introdução: A identificação humana faz-se necessária em diversas situações, como nos acidentes e desastres em massa ${ }^{1}$. Os métodos odonto-legais apresentam vantagens em face das características singulares e resistência que os dentes apresentam. A presença de anomalias dentais, quando bem documentadas pelo cirurgião-dentista, potencializa o processo de identificação ${ }^{3}$. Objetivo: Relatar dois casos de anomalias dentárias encontradas em esqueletos humanos e discutir a importância destas para a identificação odonto-legal. Para isso, foram estudados esqueletos provenientes da coleção do Centro de Estudos em Antropologia Forense da Universidade de Pernambuco (CEAF/UPE). Relato dos casos: Parecer $n^{\circ}$ 2.284.094; CAAE: 72907917.8.0000.5207. Primeiro caso - esqueleto do sexo masculino, 54 anos, apresentando, ao exame macroscópico, alvéolo dental com paredes ósseas preservadas, localizado entre os alvéolos correspondentes aos incisivos centrais superiores (não se confundindo com o forame incisivo), compatível com perda post-mortem de dente extranumerário. Segundo caso esqueleto do sexo masculino, 82 anos, apresentando dois caninos impactados e completamente invertidos, cada um em um seio maxilar. Discussão: Nos casos de desastres em massa, corpos putrefeitos, carbonizados e esqueletizados, a Odontologia Legal apresenta extrema relevância, pois muitas vezes o exame papiloscópico não é possível e o exame de DNA necessita de maior tempo e de material viável para que resultados sejam obtidos. A importância da identificação pelos dentes se dá pelas características e resistência que eles apresentam, permanecendo conservados em esqueletos, mesmo após anos de inumação ${ }^{4}$. Apesar das possíveis mudanças ocorridas por tratamentos realizados ao longo da vida, a combinação de anomalias, elementos hígidos, ausentes, cariados, restaurados é reproduzível e possibilita o cotejo de informações ante e post-mortem ${ }^{2}$. Conclusão: A presença de anomalias dentais é elemento valoroso para a Odontologia Legal. Contudo, é imprescindível que os cirurgiões-dentistas registrem adequadamente essas características no prontuário odontológico, a fim de que, quando necessário, esses documentos sejam utilizados numa perícia odonto-legal.

Descritores: Identificação Humana; Odontologia Legal; Anormalidades Dentárias.

\section{Referências:}

1. ALMEIDA CA, et al. A importância da odontologia na identificação post mortem. Odontologia e Sociedade, 2010; 12(2): 07-13

2. CARVALHO CM, et al. Identificação humana pelo exame da arcada dentária: relato de caso. Arquivo Brasileiro de Odontologia, 2008; 4(2): 67-69

3. JUNIOR EF, MOURA LCL. A importância dos arcos dentários na identificação humana. Revista Brasileira de Odontologia, 2014; 71(1): 22-27

4. MONTENEGRO JB, et al. A contribuição da odontologia legal em um caso de exumação judicial para identificação. Derecho y cambio social, 2012; 9(30): 17 


\section{PC-114-2019 - INATIVAÇÃO FOTODINÂMICA DE PATÓGENOS CARIOGÊNICOS UTILIZANDO A CURCUMINA COMO FOTOSSENSIBILIZADOR}

Pedro Henrique Barbosa de Melo ${ }^{1}$; Jéssica Meirinhos Miranda ${ }^{1}$; Lara Marques Magalhães Moreno $^{1}$; Eloíza Leonardo de Melo ${ }^{1}$; Vânia Ribeiro Cavalcanti ${ }^{1}$; Vanderlei Salvador Bagnato ${ }^{2}$; Marleny Elizabeth Márquez de Martínez Gerbi ${ }^{1}$

${ }^{1}$ Faculdade de Odontologia de Pernambuco - Camaragibe - PE - Brasil

${ }^{2}$ Universidade de São Paulo - São Carlos - SP - Brasil

Autor correspondente:

Pedro Henrique Barbosa de Melo

peduhmelo@gmail.com

Introdução: A Terapia Fotodinâmica (PDT) é uma técnica que utiliza luz para ativar fotossensibilizadores na presença de oxigênio para produzir radicais reativos ${ }^{1}$. Objetivo: Avaliar a suscetibilidade de Streptococcus mutans e Lactobacillus acidophilus quando cultivadas simultaneamente em lesões de cárie dentinária. Metodologia: Um meio de cultura de $1 \%$ de glicose, $2 \%$ de sacarose, $1 \%$ de cultura primária jovem de L. acidophilus $108 \mathrm{UFC} / \mathrm{mL}$ e S. mutans $108 \mathrm{UFC} / \mathrm{mL}$ foram utilizados para inocular a cárie induzida por bactérias nas placas de dentina humana. Diferentes concentrações do fotossensibilizador $(0,75,1,5,3,0,4,0$ e 5,0 g/L) foram ativados por exposição ao diodo emissor de luz com comprimento de onda central de 450nm e fluência de 5,7 J/cm2. Duas intensidades de luz $\left(19 \mathrm{e} 47,5 \mathrm{~mW} / \mathrm{cm}^{2}\right)$ foram testadas. Foram analisados quatro grupos diferentes: L-D- (grupo controle), L-D+ (grupo de medicamentos), $\mathrm{L}+\mathrm{D}+1$ (grupo PDT 1, intensidade luminosa de $19 \mathrm{~mW} / \mathrm{cm}^{2}$ ) e L+D+2 (Grupo PDT 2, intensidade de luz de 47,5 $\mathrm{mW} / \mathrm{cm}^{2}$ ). Os testes, ANOVA/Tukey, foram utilizados para comparar os grupos $(\alpha=5 \%)$. Resultados e Discussão: Ambas as intensidades de luz exigiram $5,0 \mathrm{~g} / \mathrm{L}$ de curcumina para redução bacteriana significativa $(\mathrm{p}<0,05)$. Nenhum efeito significativo foi encontrado para L-D+, provando a ausência de potencial toxicidade inerente. $\mathrm{O}$ uso da curcumina seguido da irradiação com luz LED azul reduziu a viabilidade dos microorganismos ${ }^{2,3}$. Conclusão: A curcumina tem um efeito tóxico nos microrganismos em concentrações apreciáveis após a fotoativação. No entanto, era necessário o uso da concentração máxima do medicamento para um procedimento sucedido.

Descritores: Dentina; Curcumina; Terapia Fotodinâmica.

\section{Referências:}

1. AL-WATBAN FA, ZHANG XY. Photodynamic therapy of human undifferentiated thyroid carcinoma-bearing nude mice using topical 5-aminolevulinic acid. Photomed Laser Surg, 2005; 23: 206-211

2. ARAÚJO NC, et al. Photodynamic effects of curcumin against cariogenic pathogens. Photomed Laser Surg, 2012; 30: 393-399

3. TONON CC, et al. Comparative effects of photodynamic therapy mediated by curcumin on standard and clinical isolate of Streptococcus mutans. J Contemp Dent Pract, 2015; 16: 1-6 


\section{PC-115-2019 - INDICAÇÕES DA FITOTERAPIA NA ODONTOLOGIA}

Normando Carlos da Silva Junior ${ }^{1}$; Carolina Pereira da Silva ${ }^{1}$; Heitor Tavares de Araújo ${ }^{1}$; Izabelle Glória dos Santos ${ }^{1}$; João Victor Neves Barbosa ${ }^{1}$; Lucas Rafael Borges Santos ${ }^{1}$; Mariana Renata Camilo da Silva ${ }^{1}$; Jéssica da Silva Cunha²

${ }^{1}$ Faculdade de Odontologia de Pernambuco - Camaragibe - PE - Brasil

${ }^{2}$ Hospital da Restauração Governador Paulo Guerra/SES - Recife - PE - Brasil

Autor correspondente:

Normando Carlos da Silva Junior

normando.carlos.jr16@gmail.com

Introdução: Fitoterapia é um ramo da ciência médica que utiliza plantas medicinais, drogas vegetais e preparadas, para tratamento de enfermidades, não sendo incluída substância de outra origem. O uso dos fitoterápicos tem como finalidade prevenir, curar ou minimizar os sintomas das doenças, com um custo mais acessível à população e aos serviços públicos de saúde, comparativamente àqueles obtidos por síntese química, que são em geral mais caros, devido às patentes tecnológicas envolvidas ${ }^{3}$. Objetivo: Apresentar uma revisão da literatura sobre a indicação e forma de utilização de plantas medicinais para alterações patológicas orais. Metodologia: Realizou-se cruzamento dos descritores selecionados sendo escolhidos 11 artigos publicados entre os anos de 2010 e 2019, encontrados nos periódicos das bases de dados LILACS, PubMed e SciELO. Revisão de Literatura: O crescimento mundial da fitoterapia entre os programas preventivos e curativos tem estimulado a avaliação dos extratos de plantas para o uso na odontologia com ação anti-bacteriana, antiinflamatória, anti-hemorrágica e anestésica. Dentre as espécies mais conhecidas encontram-se os óleos essenciais do cajueiro (Anacardium occidentale) e do cravo (Eugenia caryophyllata T.) que são indicados para as odontalgias. Estudos têm demonstrado que a romã (Punica granatum Linn), o óleo de copaíba (Copaífera multijuga), o Jucá (Caesalpinia férrea) e a Caapeba (P. Umbellata) possuem atividade antimicrobiana frente a microrganismos da cavidade oral, especialmente sobre Streptococcus mutans, importante na formação do biofilme dental. São procuradas também: Sara Tudo, andiroba (Caraba guianensis Aubl.), carapanaúba (Aspidosperma Discolor) e pedra ume cãa (Aulomyrcia sphareocarpa). Atualmente vem-se destacando também o chá ou extrato em gotas do Mulungu (erythrina velutina) para tratamento da gengivite ${ }^{1,2}$. Conclusão: Há indicações de chás, extratos, óleos para tratamento das afecções bucais, como odontalgias, gengivites, aftas etc. São plantas encontradas na própria natureza ou em mercados regionais. São de baixo custo, e de fácil aceitação popular.

Descritores: Fitoterapia; Práticas Integrativas e Complementares; Odontologia.

\section{Referências:}

1. EVANGELISTA SS, et al. Fitoterápicos na odontologia: estudo etnobotânico na cidade de Manaus. Revista Brasileira de Plantas Medicinais, 2013; 15(4): 513-519

2. JÚNIOR ET. Práticas integrativas e complementares em saúde, uma nova eficácia para o SUS. Estudos Avançados, 2016; 30(86): 99-112

3. MACHADO DC, et al. Percepções de coordenadores de unidades de saúde sobre a fitoterapia e outras práticas integrativas e complementares. Saúde em Debate, 2012; 36(95): 615-623 


\title{
PC-116-2019 - INFLUÊNCIA DO TIPO DE ÁGUA DE MANIPULAÇÃO NA ESTABILIDADE DIMENSIONAL LINEAR DO GESSO TIPO IV
}

\author{
Jonatas Silva de Oliveira ${ }^{1}$; Cleiton Rone dos Santos Lima ${ }^{2}$; Tamara Brunelle da Silva ${ }^{1}$; Roberta
} Gondim da Costa Gomes Corrêa de Arújo ${ }^{1}$; Cátia Maria Fonseca Guerra ${ }^{1}$

${ }^{1}$ Universidade Federal de Pernambuco - Recife - PE - Brasil

${ }^{2}$ Universidade de Pernambuco - Recife - PE - Brasil

Autor correspondente:

Jonatas Silva de Oliveira

jonatassilva517@gmail.com

Introdução: O gesso odontológico tem sido usado na obtenção de modelos na Odontologia e como auxiliar nos procedimentos laboratoriais relacionados a prótese dentária ${ }^{2}$. O uso correto desse material é essencial para o sucesso do tratamento, tem-se observado na literatura que o tipo de água usada na manipulação pode causar alteração no modelo ${ }^{1}$. Objetivo: Analisar a influência do uso da água de abastecimento público, mineral e destilada na alteração dimensional linear dos corpos de prova obtidos com gesso tipo IV (Durone - Dentsply). Metodologia: Na dependência do tipo de água para manipulação (água destilada, água mineral e água de abastecimento público), obteve-se 03 grupos de trabalho: G1- água destilada, G2água mineral e G3- água de abastecimento público. A partir de um modelo mestre com pontos de análise pré-definidos foram confeccionados 30 moldes que posteriormente foram divididos em três grupos com 10 modelos cada. A proporção água/pó seguiu as recomendações do fabricante $(19 \mathrm{ml} / 100 \mathrm{~g})$ para todos os grupos. A alteração dimensional linear foi avaliada com a máquina modelo Crysta574 fabricação Mitutoyo, medindo a distância entre os pontos: B1B2/B2-A/A-C1/C1-C2 e C2-B2 e comparado com o modelo mestre. Os dados foram analisados descritivamente através das medidas: média, desvio padrão (média \pm DP), mediana e desvio padrão e analisados inferencialmente através do teste estatístico t-Student para uma amostra. Resultados e Discussão: Apesar de ter sido observada uma discrepância numérica entre os grupos G2 (água mineral) e G3 (água de abastecimento público) em relação ao modelo mestre, essa diferença quando avaliada estatisticamente não foi significante. Isso pode ser relacionado pelas características químicas dos dois tipos de água que podem ser semelhantes ${ }^{3}$. Conclusão: Neste estudo, observou-se que os tipos de água empregados não mostraram diferença relevante entre si e que podem ser utilizadas para a manipulação do gesso tipo IV seguindo as normas dadas pelo fabricante.

Descritores: Água; Materiais Dentários; Sulfato de Cálcio

\section{Referências:}

1. FARINA AP, et al. Avaliação e comparação de propriedades físicas e mecânicas de gessos comerciais e experimentais. Rev. Clín. Pesq. Odontol, 2009; 5(3): 255-261

2.LOPES PAB, et al. Influência dos diferentes tempos de vazamento na variação dimensional de modelos de gesso. Prosthes. Lab. Sci., 2017; 6(24): 100-107

3. PROENÇA JSP. Avaliação das propriedades físicas e mecânicas de gessos odontológicos espatulados com diferentes tipos de água, PR. Trabalho de Conclusão de Curso (Graduação de Odontologia) - Universidade Estadual de Londrina, Londrina, 2013; 27 p 


\section{PC-117-2019 - INTERVENÇÃO CIRÚRGICA PARA TRANSMIGRAÇÃO DE CANINO: REVISÃO DE LITERATURA}

Jéssica Aparecida dos Santos Santana ${ }^{2}$; Fernando de Oliveira Martorelli' ${ }^{1}$; Isabele Gomes da Cruz $^{2}$; Lilian Renata Barbosa ${ }^{2}$; Maria Beatriz dos Santos Maia ${ }^{2}$

${ }^{1}$ Faculdade de Odontologia de Caruaru - Caruaru - PE - Brasil

${ }^{2}$ Faculdade Maurício de Nassau - Recife - PE - Brasil

Autor correspondente:

Jéssica Aparecida dos Santos Santana

j.a.parecida@hotmail.com

Introdução: $\mathrm{Na}$ dentição humana, os caninos maxilares e mandibulares, quando estão presentes em sua posição normal, são importantes tanto do ponto de vista estético como funcional ${ }^{4}$. Objetivo: Conduzir uma revisão de literatura em relação da intervenção cirúrgica para transmigração de canino. Metodologia: Foi realizado uma pesquisa na base de dados: SciELO e PubMed com os descritores: cirurgia, dente incluso e reabilitação. Revisão de literatura: A transmigração de caninos é um fenômeno raro, com evidência clínica e a literatura tem demostrado que a incidência de caninos transmigrados é maior nas mulheres ${ }^{1}$. Quando um canino inferior está fora de sua localização habitual, principalmente próximo à linha média, diz-se que se trata de uma transmigração que ocorrem devido a condições ambientais, sistêmicas ou locais, possuindo variadas combinações etiológicas ${ }^{2}$. Clinicamente, a maioria dos caninos inclusos encontra-se assintomática, não sendo relatador dor ou desconforto pelo paciente, nesses casos, o tratamento consiste em sua remoção cirúrgica, entretanto, são necessários exames por imagem, para auxiliar no diagnóstico correto e no planejamento cirúrgico ${ }^{3}$. Apesar do canino maxilar frequentemente estar mal posicionado ou incluso devido a múltiplos fatores, tais como o crescimento crâniofacial, a cronologia de erupção dentária e a morfologia humana, a falha do irrompimento de canino mandibular é pouco comum 4 . Conclusão: A intervenção cirúrgica para transmigração de caninos é mais comum em pacientes do sexo feminino no lado esquerdo, porém essa patologia rara. O tratamento mais utilizado foi remoção cirúrgica, devido a sua efićácia e seu baixo custo econômico.

\section{Descritores: Cirurgia; Dente Incluso; Reabilitação.}

\section{Referências:}

1. ASSIS NMSP, et al. Transmigracao de caninos mandibulares: relato de dois casos clínicos. Revista Brasileira de Odontologia, 2009; 66(1): 12-15

2. CANDEIRO GTM, TAVARES RN. Tratamento cirúrgico em transmigração de canino inferior impactado-relato de caso. Revista da Faculdade de Odontologia de Porto Alegre, 2009; 50(3): 39-41

3. GAETTI-JARDIM EC, et al. Condutas terapêuticas para caninos inclusos. Journal of Health Sciences, 2015; 14(1): 51-56

4. HYPPOLITO JOP, et al. Tratamento cirúrgico de canino incluso em mento: relato de caso. Revista de Odontologia da UNESP, 2011; 40(1): 42-46 


\title{
PC-118-2019 - ISOLAMENTO DE LEVEDURAS DO GÊNERO CANDIDA NO CONSULTÓRIO ODONTOLÓGICO
}

\begin{abstract}
Micaela Maria de Sousa ${ }^{1}$; Aylanne Xavier de Lacerda Cavalcante Timoteo ${ }^{1}$; Carolina Pereira da Silva ${ }^{1}$; Emerllyn Shayane Martins de Araújo ${ }^{1}$; Ingrid Patrícia de Moraes Lima ${ }^{1}$; Kássia Regina de Santana ${ }^{1}$; Laura do Nascimento Arruda ${ }^{1}$; Eliana Santos Lyra da Paz ${ }^{1}$
\end{abstract}

${ }^{1}$ Faculdade de Odontologia de Pernambuco - Camaragibe - PE - Brasil

Autor correspondente:

Micaela Maria de Sousa

micamds@hotmail.com

Introdução: A cavidade oral apresenta uma microbiota formada fundamentalmente por bactérias e fungos, que possuem uma relação harmônica com o seu hospedeiro ${ }^{1}$. A Candida albicans é o principal fungo patógeno humano, responsável por infecções como a candidose orofaríngea e a candidemia ${ }^{4}$. Objetivo: Esta revisão objetiva ressaltar a importância da prevenção da contaminação do ambiente odontológico por leveduras do gênero Candida. Metodologia: Foram efetuadas pesquisas nas bases de dados SciELO, BIREME e Google Acadêmico, com os descritores: Candidíase; Fungos; Contenção de Riscos Biológicos. Revisão de literatura: Foi observada uma prevalência na literatura de trabalhos a respeito dos riscos de contaminação cruzada no consultório odontológico através de sangue e secreções corpóreas, tidas como fontes de infecção que podem ser transmitidas para profissionais ou para outros pacientes por meio de equipamentos odontológicos que não foram submetidos a uma adequada desinfecção para a eliminação dos microrganismos existentes. A transmissão de infecções, no entanto, não se limita às secreções, saliva, gotículas e aerossóis presentes no ambiente de trabalho do cirurgião-dentista, pois essas doenças também podem ser transmitidas por superfícies e materiais não esterilizados ${ }^{3}$. A qualidade da água utilizada nos equipos de clínicas odontológicas tem preocupado os profissionais da área, uma vez que o uso de água contaminada por agentes microbianos representa riscos de infecção cruzada $^{2}$. Conclusão: Condutas e medidas técnicas de biossegurança são cruciais na prática odontológica ${ }^{5}$. Portanto, torna-se necessária a utilização de protocolos de biossegurança, assepsia, descontaminação e esterilização dos materiais, visto que o uso dessas medidas minimiza os riscos de contaminação.

Descritores: Fungos; Candidíase; Contenção de Riscos Biológicos.

\section{Referências:}

1. ANDRADE ETAS. Presença de candida em usuários de próteses removíveis atendidos em uma Unidade de Saúde da Família de um município do Recôncavo Baiano. Trabalho de Conclusão de Curso (Graduação em Odontologia) - Faculdade Maria Milza, Governador Mangabeira, 2018; 40p

2. JUNIOR FBP, et al. Prevalência de Candida em equipos das clínicas odontológicas da Faculdade de Odontologia de Pernambuco. Revista de Ciência, Tecnologia e Humanidades do IFPE, 2018; 10(1): 65-74

3. NUNES TSBS. Efeito da N-acetilcisteína em biofilme de Candida albicans. Dissertação (Mestrado em Reabilitação Oral) - Faculdade de Odontologia. Universidade Estadual Paulista, Araraquara, 2019; 95p

4. OLIVEIRA RC, et al. Conhecimento de graduandos em odontologia sobre o processo de esterilização e o monitoramento biológico. Revista de Odontologia da Universidade da Cidade São Paulo, 2016; 28(2): 96-100

5. PINELLI C, et al. Biossegurança e odontologia: crenças e atitudes de graduandos sobre o controle da infecção cruzada. Saude soc, 2011; 20(2): 448-461 


\section{PC-119-2019 - LESÃO CENTRAL DE CÉLULAS GIGANTES TRATADA POR MEIO DE RESSECÇÃO PARCIAL E RECONSTRUÇÃO MANDIBULAR COM CRISTA ILÍACA: UM RELATO DE CASO}

Larissa Constantino França1; Lucas Viana Silva Ramos ${ }^{1}$; Arthur José Barbosa de França ${ }^{2}$; Marina Gonçalves de Andrade ${ }^{2}$; Riedel Frota ${ }^{2}$; Fátima Eduardda Pires de Arruda ${ }^{1}$; Eveline de Lima Abreu $^{1}$; Miquéias Oliveira de Lima Júnior ${ }^{2}$

${ }^{1}$ Universidade Federal de Pernambuco - Recife - PE - Brasil

${ }^{2}$ Universidade de Pernambuco - Recife - PE - Brasil

Autor correspondente:

Larissa Constantino França

larissa.c.f.13@gmail.com

Introdução: A OMS classifica as Lesões Centrais de Células Gigantes (LCCG) como lesões intraósseas de tecido fibroso contendo focos hemorrágicos, agregados de células gigantes multinucleadas e ocasionalmente trabéculas de tecido ósseo imaturo ${ }^{1,2,4}$. Objetivo: O objetivo do presente trabalho consiste em relatar um caso clínico de LCCG agressiva, e sua reabilitação óssea. Relato de caso: Paciente do gênero feminino, 28 anos, admitida no serviço de Cirurgia e Traumatologia buco-maxilo-facial do Hospital Getúlio Vargas há cinco anos, com histórico de dor em mandíbula sem achados clínicos compatíveis; através do exame de imagem constatou-se lesão multilocular, envolvendo a região de corpo mandibular direito, se estendendo da região do dente 45 ao 47 , com cerca de $4 \mathrm{~cm}$ de diâmetro, e causando reabsorção dentária dos dentes 46 e 47, além de apresentarem mobilidade e perda de vitalidade. A paciente foi diagnosticada com Lesão Central de Células gigantes após o estudo de uma biopsia incisional realizada no serviço. Como conduta, foram realizadas terapias conservadoras com injeções intralesionais de corticosteroides (calcitonina) sem sucesso e com avanço progressivo da lesão. O tratamento proposto consistiu em ressecção mandibular parcial com margens de segurança que se excediam os $5 \mathrm{~mm}$, através de acesso intra-oral e instalação de placa de reconstrução do sistema 2.4, 3 meses após o procedimento programou-se enxerto de crista ilíaca por acesso de Risdon, minimizando as chances de contaminação intra-oral. Discussão: Os tratamentos das LCCG consistem na remoção cirúrgica, seguida ou não de curetagem e ressecção parcial, a terapia com calcitonina sistêmica e injeções intralesionais com corticosteroides. A conduta a ser seguida pelo cirurgião deverá levar em consideração critérios como a agressividade, localização, tamanho e aparências radiográficas. Em casos de recidiva, a combinação de terapias deverá ser considerada ${ }^{2,3}$. Conclusões: A técnica demonstrou êxito no tratamento de LCCG mais agressivas, com reabilitação óssea do paciente em menor tempo.

Descritores: Patologia Bucal; Enxerto Ósseo; Crista Ilíaca

\section{Referências:}

1. ABDELKARIM AZ, et al. Radiographic diagnosis of a central giant cell granuloma using advanced imaging: cone beam computed tomography. Cureus, 2018; 10(6): 01-05

2. DA ROSA MRP, et al. Central giant cells lesion: Report of a conservative management. European Journal of Dentistry, 2018; 12(2): 305-310

3. DIMITRIOU R, et al. Complications following autologous bone graft harvesting from the iliac crest and using the RIA: A systematic review. Injury, 2011; 42(1): S2-S15

4. GUPTA S, et al. Giant Cell Granulomas of Jaws: a Clinicopathologic Study. Journal of Oral \& MaxilloFacial Research, 2019; 10(2): 02-10 


\section{PC-120-2019 - LESÃO EM TECIDO MOLE NA REGIÃO BUCOMAXILOFACIAL DEVIDO A ACIDENTE DE TRABALHO: RELATO DE CASO}

Thayane Maria Botelho Florêncio'; Caio Pimenteira Uchôa ${ }^{2}$; Caroline Brígida Sá Rocha²; Isabela Araújo Lima ${ }^{1}$; Luiz Henrique Soares Torres²; Mateus Barros Cavalcante ${ }^{2}$; Pedro Paulo Aguiar Santos Cavalcanti ${ }^{1}$; Emanuel Dias de Oliveira e Silva ${ }^{1}$

${ }^{1}$ Faculdade de Odontologia de Pernambuco - Camaragibe - PE - Brasil

${ }^{2}$ Hospital Universitário Oswaldo Cruz - Recife - PE - Brasil

Autor correspondente:

Thayane Maria Botelho Florêncio

thayane.mbf@gmail.com

Introdução: O Traumatismo Facial está entre as principais causas de morbimortalidade ${ }^{3}$. Nas emergências, encontra-se diferentes causas, como violência interpessoal, acidentes de trânsito e de trabalho, sendo este último relacionado com a segurança no ambiente profissional associado ao déficit dos equipamentos de proteção individual ${ }^{1}$. Objetivo: Relatar caso clínico de Traumatismo Facial em tecidos moles devido à acidente de trabalho ocasionado por uso de maquita e discutir a conduta terapêutica empregada. Relato de caso: Paciente, sexo masculino, 30 anos, compareceu à emergência do Hospital da Restauração, relatando acidente de trabalho devido ao uso de maquita. Ao exame clínico, apresentava lesão extensa abrangendo região de lábio inferior e superior, ascendendo para região pré-auricular, atingindo apenas tecidos moles, confirmado pela radiografia facial. Foi adotada como conduta terapêutica a sutura por planos, respeitando as referências anatômicas, sob anestesia local. Para a sutura interna foram usados fios reabsorvíveis e externamente, fios de nylon 4-0. Após 14 dias de acompanhamento ambulatorial e retirada dos pontos, o paciente encontrava-se devidamente reabilitado. Discussão: Estudos apontam maior prevalência de traumatismos faciais no sexo masculino, faixa etária de 20-30 anos e região dos lábios superior e inferior ${ }^{3,4}$. O paciente do relato de caso, portanto, encontra-se nesse perfil. A conduta terapêutica adotada é a mais indicada segundo a literatura atual, pois o uso da sutura considerando fechamento primário proporciona mínima formação de tecido de granulação e menor risco de infecção já que a face é altamente vascularizada. A promoção de uma hemostasia eficaz, regularização das bordas, sutura por planos anatômicos, são pontos que contribuem também para o melhor resultado estéticofuncional ${ }^{2}$. Conclusões: O Traumatismo Facial é um problema de saúde pública e quando mal abordado deixa sequelas estéticas e funcionais. Sendo assim, é importante o conhecimento do Cirurgião buco-maxilo-facial sobre a abordagem e tratamento dessas lesões, visando obter o melhor resultado possível.

Descritores: Acidentes de Trabalho; Saúde do Trabalhador; Traumatismos Faciais.

\section{Referências:}

1. JARDIM ECG, et al. Ferimentos Faciais: relato de caso. Revista Odontológica de Araçatuba, 2010; 31(1): 73-77

2. ÖZKAN S, et al. Occupational injuries admitted to the Emergency Department. Turkish Journal Of Trauma \& Emergency Surgery, 2010; 16(3): 241-247

3. VIEIRA CL, et al. Lesão de tecido mole em pacientes vítimas de trauma buco-maxilo-facial. Revista de Cirurgia e Traumatologia Buco Maxilo Facial, 2013; 13(1): 89-96

4. WULKAN M, et al. Epidemiologia do Trauma Facial. Revista da Associação Médica Brasileira, 2005; 51(5): 290-295 


\section{PC-121-2019 - LESÃO EXTENSA EM FACE DECORRENTE DE TRAUMA: RELATO DE CASO}

Eduarda Lapenda Gomes da Fonseca ${ }^{1}$; Belmiro Cavalcanti do Egito Vasconcelos ${ }^{2}$; Caio César Gonçalves Silva ${ }^{2}$; Priscila Sarmento Pinto ${ }^{2}$; Demóstenes Alves Diniz ${ }^{2}$; Jéssica da Silva Cunha ${ }^{2}$; Livia Mirelle Barbosa ${ }^{2}$

${ }^{1}$ UNIFACOL - Centro Universitário FACOL - Vitória de Santo Antão - PE - Brasil ${ }^{2}$ Faculdade de Odontologia de Pernambuco (FOP/UPE) - Camaragibe - PE - Brasil

Autor correspondente:

Eduarda Lapenda Gomes da Fonseca

duda.-.lapenda@hotmail.com

Introdução: Lesões faciais em tecidos moles podem ocorrer frequentemente como resultado de acidentes de trânsito, quedas, agressões físicas, ou atividades esportivas ${ }^{4}$. A região maxilofacial está associada a diversas funções importantes: visão, olfato, alimentação, respiração e fala, essas, podem ser severamente afetadas com as lesões faciais em tecidos moles, comprometendo a qualidade de vida do paciente ${ }^{5}$. A face desempenha um papel importante na formação das relações sociais, e o trauma é a principal causa de sua desfiguração ${ }^{3}$. Objetivo: Relatar o caso de um paciente atendido no hospital da Restauração (Recife-PE), vítima de acidente de trânsito resultando em lesão extensa em face. Relato de Caso: Paciente masculino, 35 anos, vítima de acidente motociclístico, resultando em traumatismo craniano grave e ferimento extenso em face e couro cabeludo, sem fratura óssea no crânio e na face. O paciente foi submetido à síntese de tecidos moles, a sutura foi removida após uma semana. Em acompanhamento durante 2 semanas, os ferimentos apresentavam-se sem deiscência e débito. Discussão: Uma sequela comum de trauma para os pacientes com lesão facial é o sofrimento psicológico que ele causa ${ }^{3}$, além do problema clínico devido a sua importância anatômica com a presença de órgãos importantes, e início dos sistemas digestório e respiratório ${ }^{2}$. Algumas lesões faciais podem ser tratadas de forma eficaz com a aproximação tecidual, que é mais comumente conseguida via sutura, como foi realizada no presente caso. A sutura de tecidos moles da face, realizada de forma adequada, permite que as bordas da ferida sejam alinhadas com precisão, favorecendo resultados estéticos ${ }^{1}$. Conclusão: $O$ manuseio da lesão facial em tecido mole é desafiador para o cirurgião buco-maxilo-facial, e devōlver a forma e a função anterior ao trauma é o seu maior anseio, devido aos problemas físicos e mentais que o paciente fica sujeito após ser submetido a esse tipo de ferimento.

Descritores: Traumatismos faciais; Traumatismos Maxilofaciais; Acidentes de Trânsito.

\section{Referências:}

1. BRAUN TL, MARICEVICH RS. Soft Tissue Management in Facial Trauma. Seminars in Plastic Surgery, 2017; 31(2): 73-79

2. GADDIPATI R, et al. Analysis of 1,545 Fractures Of Facial Region - A Retrospective Study. Craniomaxillofacial Trauma \& Reconstruction, 2015; 8(4): 307-314.

3. PRASHANTH NT, et al. Anxiety and Depression in Facial Injuries: A Comparative study. Journal of International Oral Health, 2015; 7(9): 94-100

4. SCHEYERER MJ, et al. Maxillofacial injuries in severely injured patients. Journal of Trauma Management \& Outcomes, 2015; 9:4

5. SINGH V, et al. The maxillofacial injuries: A study. National Journal of Maxillofacial Surgery, 2012; 3: 166-171 


\section{PC-122-2019 - LESÕES BUCAIS DA PARACOCCIDIOIDOMICOSE: REVISÃO DE} LITERATURA

Kássia Regina de Santana ${ }^{1}$; Cleiton Rone dos Santos Lima'; Emerllyn Shayane Martins de Araújo $^{1}$; Aylanne Xavier de Lacerda Cavalcante Timoteo ${ }^{1}$; Micaela Maria de Sousa ${ }^{1}$; Cláudia Geisa Souza e Silva ${ }^{1}$; Ingrid Patrícia de Moraes Lima ${ }^{1}$; Eliana Santos Lyra da Paz ${ }^{1}$

${ }^{1}$ Faculdade de Odontologia de Pernambuco - Camaragibe - PE - Brasil

Autor correspondente:

Kássia Regina de Santana

kassiaupe2016.1@gmail.com

Introdução: Paracoccidioidomicose (PCM) é uma micose sistêmica causada pelo fungo termo dimórfico Paracoccidioides brasiliensis. Este fungo apresenta-se na forma micelial na temperatura de $25^{\circ} \mathrm{C}$, sendo está a produtora dos esporos ou conídios infectantes que, inalados pelos hospedeiros suscetíveis transformam-se em células leveduriformes nos tecidos, esta forma pode ser observada na temperatura de $37^{\circ} \mathrm{C}^{2}$. As lesões bucais apresentam-se como ulcerações de aspecto moriforme, que geralmente afetam a mucosa alveolar, gengiva e palato.

Objetivo: Esta revisão objetiva ressaltar o papel fundamental do cirurgião-dentista na equipe de saúde multidisciplinar. Metodologia: Foram efetuadas pesquisas nas bases de dados SciELO, BIREME e Google Acadêmico, com os descritores: Paracoccidioidomicose; Manifestações Bucais; Diagnóstico. Revisão de Literatura: O fungo causador da doença é muito comum na zona rural, atingindo assim em sua maioria trabalhadores rurais do sexo masculino com idade entre 30 a 50 anos $^{3}$. Foi observada uma prevalência na literatura de trabalhos de revisão e relatos de caso a respeito dos locais mais acometidos por lesões por PCM, pele, membranas mucosas, linfonodos, pulmões, ossos, meninges e baço. Embora pouco relatados, podemos observar trabalhos acerca da importância da manutenção da integralidade do paciente, uma vez que os pacientes muitas vezes buscam o atendimento apresentando manifestações bucais. Por não se tratar de uma doença de notificação compulsória, não se dispõe de dados precisos sobre sua ocorrência em nível nacional, portanto, sua real prevalência não pode ser calculada ${ }^{3}$, fato agravante, visto que a PCM pode ter como consequência sequelas graves se o diagnóstico e o tratamento não forem iniciados de forma precoce e correta. $\mathrm{O}$ diagnóstico definitivo destá patologia é obtido com a detecção do agente etiológico em fluidos biológicos ou tecido, principalmente por exame micológico direto e/ou histopatológico ${ }^{1}$. Conclusão: Dessa forma, vale enfatizarmos a importância do cirurgião-dentista no diagnóstico de lesões bucais oriundas de infecções sistêmicas.

Descritores: Paracoccidioidomicose; Manifestações Bucais; Diagnóstico.

\section{Referências:}

1. MACEDO MP, et al. Paracoccidioidomicose na cavidade bucal - relato de caso. Odontol. Clín.-Cient, 2016; 15(1): 1-4

2. SANTOS LA, et al. Paracoccidioidomicose: os desafios do diagnóstico e tratamento. Revista da Universidade Vale do Rio Verde, 2019; 17(1): 1-12

3. SILVA DF, et al. Paracoccidioidomicose e suas manifestações orais: perspectivas epidemiológicas no Brasil. Faculdade Evangélica de Goianésia, 2018; 1(1): 1-5 


\title{
PC-123-2019 - MANEJO CIRÚRGICO PARA REMOÇÃO DE ODONTOMA COMPOSTO EM REGIÃO ANTERIOR DE MANDÍBULA: RELATO DE CASO
}

\begin{abstract}
Kataryne Maria dos Santos ${ }^{1}$; Jeferson Batista Santiago ${ }^{1}$; Olívia Augusta Araújo Dias ${ }^{1}$; Mayara Monique Silva de Oliveira ${ }^{1}$; Joana de Ângelis Alves Silva ${ }^{1}$; Ismael Sebastião da Silva Sousa ${ }^{1}$; Igor Figueiredo Pereira ${ }^{1}$; Diego Dias Neves ${ }^{1}$
\end{abstract}

${ }^{1}$ Faculdade de Odontologia de Pernambuco - Camaragibe - PE - Brasil

Autor correspondente

Kataryne Maria dos Santos

kataryne.07@hotmail.com

Introdução: Os odontomas são os tumores odontogênicos mais comuns, considerados hamartomas ao invés de neoplasias verdadeiras, classificados em composto ou complexo ${ }^{1-3}$. Possui origem ectomesenquimal, idiopática, podendo estar associado a dentes impactados, infecções e/ou trauma ${ }^{3}$. Mais comumente observados em pacientes até a segunda década de $v_{\text {vida }}{ }^{1-2}$. Objetivo: Relatar um caso de remoção cirúrgica de odontoma composto localizado na região anterior da mandíbula. Relato de caso: Paciente de 18 anos, do sexo masculino, compareceu ao serviço de cirurgia e traumatologia buco-maxilo-facial encaminhado pelo ortodontista. Ao exame clínico, foi observado a ausência do elemento 42 e 43, com abaulamento em região anterior de mandíbula, sem sintomatologia dolorosa ou alteração sistêmica. Aos exames imaginológicos, observou-se que os elementos 42 e 43 , encontravam-se inclusos associados a lesões hiperdensas semelhantes a dentes. Sob anestesia geral, intubação nasotraqueal, foi realizada incisão em envelope, com descolamento mucoperiosteal total para exposição de toda a região cirúrgica. Foi realizada a osteotomia para remoção das lesões, odontossecção para remoção dos elementos inclusos e curetagem complementar. Ao final do procedimento, utilizou-se uma membrana hemostática absorvível, o paciente foi medicado com antibiótico, anti-inflamatório e analgésico e no dia seguinte recebeu alta hospitalar. Discussão: O tratamento foi considerado um sucesso e com um prognóstico excelente, já que apenas em casos raros podem ocorrer recidiva, desde que se faça a completa remoção dos tumores e correta curetagem do sítio cirúrgico ${ }^{3}$. Conclusão: O odontoma composto é uma malformação benigna, com evolução lenta. Seu tratamento consiste na excisão cirúrgica, na qual deve ser realizada a completa remoção e curetagem da lesão, a fim de promovêr à reabilitação precoce e/ou evitar futuras sequelas.

\section{Descritores: Odontoma; Dente não erupcionado; Hamartoma.}

\section{Referências:}

1. BEREKET C, et al. Complex and compound odontomas: Analysis of 69 cases and a rare case of erupted compound odontoma. Nigerian journal of clinical practice, 2015; 18(6): 726730

2. BOFFANO P, et al. Complex and compound odontomas. Journal of Craniofacial Surgery, 2012; 23(3): 685-688

3. MATOS A, et al. Odontoma composto em região posterior de mandíbula: relato de caso.

Oral Sciences, 2012; 4(2): 54-58 


\section{PC-124-2019 - MANEJO DE HEMATOMA APÓS PROCEDIMENTO DE BICHECTOMIA: RELATO DE CASO}

Thayane Cavalcante Mendes da Silva ${ }^{1}$; Beatriz Borba Barros Bernardo ${ }^{1}$; Kalyne Kelly Negromonte Gonçalves²; Demóstenes Alves Diniz ${ }^{2}$; Arthur Camillo de Souza ${ }^{1}$; Niviane Marielly da Costa Oliveira ${ }^{1}$; Livia Mirelle Barbosa ${ }^{1}$; Caio César Gonçalves Silva ${ }^{1}$

${ }^{1}$ Faculdade de Odontologia de Pernambuco - Camaragibe - PE - Brasil

${ }^{2}$ Hospital da Restauração - Recife - PE - Brasil

Autor correspondente:

Thayane Cavalcante Mendes da Silva

thayanecmss@gmail.com

Introdução: Bichectomia é um procedimento cirúrgico, intraoral, que consiste na ressecção parcial do corpo adiposo de Bichat (Bola de Bichat). A técnica cirúrgica é relativamente simples e rápida, mas pode apresentar algumas complicações pós-operatórias complexas. A cirurgia pode ser realizada por cirurgiões-dentistas ou cirurgiões plásticos para fins funcionais e estéticos ${ }^{1,2,3}$. Objetivo: Relatar o caso de uma paciente que apresentou hematoma após a realização de Bichectomia. Relato de Caso: Paciente A.L.R., 35 anos, sexo feminino compareceu ao ambulatório de Cirurgia Buco-Maxilo-Facial de um hospital localizado na cidade de Recife, com queixa de "trauma nas bochechas". Ao exame intraoral, observou-se nítida linha de mordiscamento traumático na região de mucosa jugal bilateral. Foi solicitado então, exames laboratoriais e após confirmação de normalidade nos valores optou-se por realização de Bichectomia sob anestesia local. Paciente retornou ao serviço 2 horas após a finalização do procedimento com aumento de volume bem localizado em hemiface direita, sugestivo de hematoma. Ao exame físico, apresentava trismo moderado, dor durante a palpação e discreto sangramento intraoral. Discussão: Nas intervenções por acesso intraoral no corpo adiposo bucal, hematomas podem estar relacionados a traumas na artéria inferior do $\mathrm{m}$. bucinador, ramo da artéria facial. No caso relatado neste trabalho o hematoma apresentado esteve, possivelmente, relacionado a algum trauma no referido ramo da artéria facial. Onde no caso foi optado pela drenagem cirúrgica do hematoma seguida de compressão da ferida cirúrgica com gaze. Conclusões: A Bichectomia é uma técnica segura e com resultados significativos quando bem indicada e realizada por profissional capacitádo. Entretanto, complicações como hematomas podem ocorrer e devem ser tratadas da forma correta para evitar danos estéticos, infecções e maiores sequelas aos pacientes.

Descritores: Gordura Subcutânea; Hematoma; Odontologia.

\section{Referências:}

1. ALMEIDA A, ALVARY P. A Bichectomia como procedimento Cirúrgico EstéticoFuncional: Um estudo crítico: Case report. J Business Techn., 2018;7(1):3-14

2. CEPEDA LRS, et al. Hematoma pós-operatório de bichectomia: Relato de caso, revisão da literatura. Rev. Bras. Cir. Plást., 2019;34(1): 93-95

3. MOREIRA JUNIOR R, et al. Bichectomia: aspectos relevantes e relato de caso clínico. ClipeOdonto, 2018; 9(1):37-43 


\section{PC-125-2019 - MANIFESTAÇÕES BUCAIS EM PACIENTES INTERNADOS EM UTI E A ATUAÇÃO DO CIRURGIÃO-DENTISTA: REVISÃO DE LITERATURA}

Bruno Luiz Ferreira da Silva ${ }^{1}$; Bruna Dantas Siqueira Nery ${ }^{1}$; Andressa Kelly Alves Ferreira ${ }^{1}$; Maria Cecília Freire de Melo ${ }^{1}$; Thuanny Silva de Macêdo ${ }^{\mathbf{1}}$; Gustavo Pina Godoy ${ }^{1}$; Arnaldo de França Caldas Júnior ${ }^{1,2}$; Elizabeth Louisy Marques Soares da Silva ${ }^{1}$

${ }^{1}$ Universidade Federal de Pernambuco - Recife - PE - Brasil

${ }^{2}$ Faculdade de Odontologia de Pernambuco - Camaragibe - PE - Brasil

Autor correspondente:

Bruno Luiz Ferreira da Silva

brunosilvall362@gmail.com

Introdução: Pacientes internados em UTI (Unidade de Terapia Intensiva) podem ter alterações bucais, dentre elas a xerostomia, disfagia, doença periodontal, cárie dentária e candidíase ${ }^{1}$. Procedimentos odontológicos realizados nestes pacientes proporcionam conforto e alívio, além de prevenir infecções devido às complicações na mucosa oral relacionadas a doenças sistêmicas ou decorrentes do uso de medicamentos ${ }^{4}$. Objetivo: Realizar uma revisão de literatura sobre as principais manifestações bucais encontradas em pacientes internados em UTI, além de mostrar a importância do Cirurgião-Dentista no ambiente hospitalar. Metodologia: Foi realizada uma pesquisa na Biblioteca Virtual de Saúde, SciELO e PubMed, para escolha de artigos publicados nos últimos 05 anos. Revisão de Literatura: Cárie dentária, doença periodontal, mucosite oral e xerostomia comprometem a saúde bucal de pacientes em UTI, podendo interferir nas condições sistêmicas e levando ao aumento do tempo e custo do tratamento hospitalar, além de afetarem a qualidade de vida dos pacientes ${ }^{3,4}$. A higienização bucal nesses pacientes é considerada um procedimento básico e essencial, cujo intuito principal é manter a saúde dos tecidos orais, sendo necessário para prevenção de infecções, para conservar a umidade da mucosa, além de propiciar melhor qualidade de saúde bucal ao paciente ${ }^{2}$. Conclusão: Pacientes acamados em UTI necessitam de medidas preventivas para a manutenção da saúde bucal, bem como um tratamento individualizado e específico através da importante atuação do CirurgiãoDentista como facilitador dessas práticas.

\section{Descritores: Odontologia; Saúde Bucal; Unidade de Terapia Intensiva.}

\section{Referências:}

1. BATISTA SA, et al. Alterações orais em pacientes internados em unidades de terapia intensiva. Revista Brasileira de Odontologia, 2015; 71(2): 156-159

2. GOMES SF, ESTEVES MCL. Atuação do cirurgião-dentista na UTI: um nono paradigma. Revista brasileira de odontologia, 2012; 69(1): 67-70

3. PINHEIRO TS, ALMEIDA TF. A saúde bucal em pacientes de UTI. Revista Bahiana de Odontologia, 2014; 5(2): 94-103

4. ROCHA AL, FERREIRA EF. Odontologia hospitalar: a atuação do cirurgião dentista em equipe multiprofissional na atenção terciária. Arquivos em Odontologia, 2014; 50(4): 154-160 


\section{PC-126-2019 - MANIFESTAÇÕES BUCAIS EM PACIENTES ONCOLÓGICOS PEDIÁTRICOS}

Leandro Pimentel Cabral ${ }^{3}$; Ana Paula Veras Sobral ${ }^{1}$; Fabiana Moura da Motta Silveira ${ }^{2}$; Híttalo Carlos Rodrigues de Almeida ${ }^{1}$; Rebeca Luiz de Freitas ${ }^{2}$; Ronaldo Gabriel Martiniano da Silva ${ }^{4}$

${ }^{1}$ Faculdade de Odontologia de Pernambuco - Camaragibe - PE - Brasil

${ }^{2}$ Instituto de Medicina Integral Prof. Fernando Figueira - Recife - PE - Brasil

${ }^{3}$ Universidade Federal de Pernambuco - Recife - PE - Brasil

${ }^{4}$ Centro Universitário Tiradentes de Pernambuco - Recife - PE - Brasil

Autor Correspondente:

Leandro Pimentel Cabral

leocabral.17@outlook.com

Introdução: No Brasil, o câncer é a principal causa de morte por doença em crianças e adolescentes $^{2}$. Cerca de $40 \%$ dos pacientes oncológicos submetidos ao tratamento quimioterápico apresentam complicações orais decorrentes de estomatotoxicidade direta ou indireta, como mucosite, xerostomia e etc ${ }^{1}$. Objetivo: Identificar as manifestações bucais mais frequentes nos pacientes pediátricos em tratamento antineoplásico no Setor de Oncologia Pediátrica de um Instituto de Medicina Integral de Pernambuco. Metodologia: A amostra desta pesquisa consistiu em 137 crianças e adolescentes entre zero e 19 anos de idade. Foi aplicado um questionário com perguntas objetivas e subjetivas, direcionado ao paciente e seu responsável, para a coleta dos seguintes dados: idade, gênero, tipo de câncer, sinais e sintomas das manifestações bucais apresentadas após a quimioterapia e hábitos de higiene bucal. Realizou-se um exame clínico intrabucal para visualização das alterações na mucosa oral e classificar a sua saúde bucal em favorável ou desfavorável. Foram utilizados os testes estatísticos de correlação e o Qui Quadrado de Pearson. Resultados e Discussão: Os resultados apontaram que a idade média foi de 6,8 anos; o gênero masculino $(57,7 \%)$ foi predominante na amostra; a neoplasia maligna mais frequente foi à leucemia $(67,9 \%) ; 70,1 \%$ dos pacientes apresentaram pelo menos uma manifestação oral, sendo a de maior incidência a mucosite $(56,2 \%)$, seguida da xerostomia $(46,7 \%)$ e gengivite $(41,6 \%)$. A saúde bucal desfavorável estava presente em $54,7 \%$. A mucosite possui etiologia multifatorial e é pouco compreendida, e sua prevalência está entre $40 \%$ a $76 \%$ dos pacientes sob quimioterapia. É uma resposta inflamatória da mucosa bucal às altas doses de quimioterapia e/ou radioterapia ${ }^{3}$. Conclusão: $\mathrm{O}$ paciente infantil deve ser avaliado por odontopediatra previamente ao início da terapia antineoplásica, para mitigar complicações bucais durante o tratamento oncológico.

Descritores: Oncologia; Saúde Bucal; Manifestações Bucais.

\section{Referências:}

1. ALBUQUERQUE RA, et al. Protocolo de atendimento odontológico a pacientes oncológicos pediátricos - revisão da literatura. Revista de Odontologia da UNESP, 2007; 36(3): 275-280

2. HESPANHOL FL, et al. Manifestações bucais em pacientes submetidos à quimioterapia. Ciência \& Saúde Coletiva, 2010; 15(1):1085-1094

3. LIMA SSC, et al. Câncer infantil: aspectos emocionais e o sistema imunológico como possibilidade de um dos fatores da constituição do câncer infantil. Revista Sociedade Brasileira de Psicologia Hospitalar, 2011; 14(2): 142-158 


\section{PC-127-2019 - MANIFESTAÇÕES OROFACIAIS DA SÍNDROME DE NOONAN}

Carolina Pereira da Silva ${ }^{1}$; Heitor Tavares de Araújo ${ }^{1}$; Francisco Henrique Lima Milhomens ${ }^{1}$; Cleiton Rone dos Santos ${ }^{1}$; Eugênia Leal de Figueiredo ${ }^{1}$; Rosa Rayanne Lins de Souza ${ }^{2}$; Jéssica da Silva Cunha ${ }^{2}$; Abdiel Ortega Gôndola ${ }^{2}$

${ }^{1}$ Faculdade de Odontologia de Pernambuco - Camaragibe - PE - Brasil

${ }^{2}$ Hospital da Restauração Governador Paulo Guerra - Recife - PE - Brasil

Autor correspondente:

Carolina Pereira da Silva

Carolinapereeira@gmail.com

Introdução: A síndrome de Noonan é uma das mais freqüentes síndromes de herança mendeliana, com incidência estimada entre 1:1.000 a 1:2.500 nascidos vivos. Esta síndrome comumente apresenta estenose valvar pulmonar associada à baixa estatura, dismorfismo facial, má oclusão e retardo mental moderado ${ }^{1,3}$. Objetivo: Relatar a importância do diagnóstico prévio e abordagem multidisciplinar de pacientes sindrômicos através de caso clínico. Relato de caso: Paciente, PG, sexo masculino, 15 anos, deu entrada no serviço de Cirurgia bucomaxilo-facial do Hospital da Restauração em Pernambuco, por demanda espontânea, com queixa de "mordida ruim e rosto torto". Na anamnese, o histórico do paciente revelava: estenose valvar pulmonar, pectus excavatum, déficit neuropsicomotor, pescoço alado e baixa estatura. Clinicamente, notou-se hipertelorismo, face longa, assimetria facial, atresia dos maxilares, implantação baixa das orelhas, maloclusão dentária e hipoplasia do esmalte dentário. Apresentava condução médica desde o nascimento, no entanto, nenhuma avaliação odontológica. Para adequada condução do caso, optou-se pelo tratamento orto-cirúrgico a fim de corrigir as deformidades dento-esqueléticas. Paciente encontra-se em preparo ortodôntico para ortopedia prévia dos maxilares e alinhamento dos dentes em relação às bases ósseas para posterior abordagem cirúrgica. Discussão: $O$ diagnóstico desta síndrome deve ser fundamentado nos achados clínicos, basicamente cardiopatia congênita e associações fenotípicas. As manifestações faciais fazem parte de seu fenótipo, no entanto, tais achados são sujeitos a grande variabilidade além de atenuação na fase adulta, o que dificulta sua percepção inicial, bem como a intervenção orto-cirúrgica nas fases adequadas ${ }^{2}$. Conclusões: $O$ diagnóstico precoce favorece a abordagem multidisciplinar eficaz, favorecendo a desenvolvimento neuropsicomotor e social do paciente, melhorando a qualidade de vida e diminuindo os danos associados.

Descritores: Síndrome de Noonan; Anormalidades Maxilofaciais; Má oclusão.

\section{Referências:}

1. BERTOLA DR, et al. PTPN11 gene analysis in 74 Brazilian patients with Noonan syndrome or Noonan-like phenotype. Genetic Testing, 2006; 10(3):186-191

2. MALAQUIAS AC, et al. Síndrome de Noonan: do Fenótipo à Terapêutica com Hormônio de Crescimento. Arquivos Brasileiros de Endocrinologia \& Metabologia, 2008; 52(5): 800-808 3. RODRIGUES ER, et al. Síndrome de Noonan. Residência Pediátrica, 2017; 7(1):25-28 


\section{PC-128-2019 - MECANISMOS BIOLÓGICOS ENVOLVIDOS NO ESTADO INFLAMATÓRIO DE PACIENTES OBESOS E SUAS POSSÍVEIS IMPLICAÇÕES CLÍNICAS NA ODONTOLOGIA}

Pedro Paulo Aguiar Santos Cavalcanti' ${ }^{1}$; Maria Eduarda Arruda de Lucena'; Gerciane Ramos Bezerra$^{1}$; Vanessa Bastos de Souza Rolim Lima ${ }^{1}$; Vinicius Balan Santos Pereira ${ }^{1}$; Belmiro Cavalcanti do Egito Vasconcelos ${ }^{1}$; Davi da Silva Barbirato ${ }^{1}$

${ }^{1}$ Faculdade de Odontologia de Pernambuco - Camaragibe - PE - Brasil

Autor correspondente:

Pedro Paulo Aguiar Santos Cavalcanti

pedropauloaguiar@icloud.com

Introdução: A obesidade é descrita como uma condição associada ao acúmulo e expansão excessiva dos adipócitos, e, aumento da infiltração de células macrofágicas nos tecidos

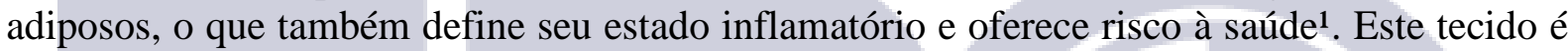
ativamente envolvido na regulação da inflamação e da imunidade, associada à liberação desregulada ou alterada de uma variedade de fatores pró-inflamatórios e anti-inflamatórios (leptina, adiponectina, citocinas e quimiocinas) ${ }^{2}$. Objetivo: Discutir sobre a importância de estudos clínicos sobre a relação entre a obesidade e eventos fisiopatológicos da cavidade bucal. Metodologia: Revisão integrativa de artigos científicos consultados nas bases de dados PubMed/MEDLINE, bvs (LILACS, BIREME, PAHO (OPAS), WHOLIS (OMS), Embase Excerpta Médica (Elsevier)), Web of Science, SciELO, SCOPUS, Cochrane Library e OpenGrey. As palavras-chave foram definidas utilizando as ferramentas do Mesh (PubMed) e DeCS (BVS). Revisão de literatura: $\mathrm{O}$ aumento dos adipócitos repercute em atividade alterada com liberação de mediadores pró-inflamatórios e redução da liberação de citocinas antinflamatórias. Durante o ganho de peso, a expansão das células adiposas induz uma regulação positiva de ligante de quimiocina 2 (CCL2) e, consequentemente, um maior recrutamento de macrófagos via sinalização de quimiocinas ${ }^{4}$. Citocinas pró-inflamatórias como a IL-6 e o TNF $\square$ também participam desse processo, sendo denominadas adipocitocinas, essas regulam a inflamação sistêmica e influenciam a sensibilidade à insulina e o metabolismo da glicose ${ }^{3}$. A IL-6 induz uma regulação negativa da sinalização de insulina e uma regulação positiva da oxidação de ácidos graxos e de secreção de proteína C-reâtiva pelo fígado ${ }^{3}$. Conclusão: $O$ paciente obeso apresenta um estado inflamatório importante e potencialmente relacionado com doenças inflamatórias crônicas, as quais grande parte das patologias bucais se enquadram. Assim, é possível que a obesidade potencialize o estabelecimento e a evolução de condições inflamatórias crônicas bucais e maxilofaciais, e, influencie o reparo tecidual e as respostas a tratamento.

Descritores: Obesidade; Inflamação; Citocinas.

\section{Referências:}

1. BOULOUMIÉ A, et al. Role of macrophage tissue infiltration in metabolic diseases. Current Opinion in Clinical Nutrition \& Metabolic Care, 2005; 8(4):347-354

2. FALAGAS ME, KOMPOTI M. Obesity and infection. Lancet Infect Dis, 2006; 6(7):438446

3. MAURY E, BRICHARD SM. Adipokine dysregulation, adipose tissue inflammation and metabolic syndrome. Mol Cell Endocrinol, 2010; 314(1):1-16

4. TILG H, MOSCHEN AR. Adipocytokines: mediators linking adipose tissue, inflammation and immunity. Nat Rev Immunol, 2006; 6(10):772-783 


\section{PC-129-2019 - MELANOMA MUCOSO DE CABEÇA E PESCOÇO: UMA REVISÃO DE LITERATURA}

Liana Carla Souza de Andrade Batista ${ }^{1}$; Bruna Lucena Borges ${ }^{1}$; Carolina Pereira da Silva ${ }^{1}$; Fernanda Gomes Barros ${ }^{1}$; Heitor Tavares de Araújo ${ }^{1}$; Letícia de Oliveira Santos ${ }^{1}$; Mariana Cecília de Oliveira Terêncio ${ }^{1}$; Rosa Rayanne Lins de Souza ${ }^{2}$

${ }^{1}$ Faculdade de Odontologia de Pernambuco - Camaragibe - PE - Brasil

${ }^{2}$ Hospital da Restauração Governador Paulo Guerra/SES - Recife - PE - Brasil

Autor correspondente:

Liana Carla Souza de Andrade Batista

Lianabatist20@gmail.com

Introdução: O melanoma mucoso de cabeça e pescoço (MMCP) é raro, porém, mais agressivo que o melanoma cutâneo, e pode acometer áreas como os seios paranasais, fossa nasal e a cavidade bucal. Objetivo: O estudo visa descrever os sinais, sintomas, forma de diagnóstico e tratamento, a fim de se obter uma melhor explanação sobre tal patologia. Metodologia: Foi realizada uma busca bibliográfica com artigos disponíveis no LILACS, PubMed e Bireme, publicados entre 2005 e 2019, com os termos "Melanoma", "Melanoma Maligno" e "Neoplasia". Revisão de Literatura: O melanoma é uma neoplasia rara, caracterizado pela proliferação atípica de melanócitos, com crescimento vertical agressivo e um possível surgimento de lesões-satélites ${ }^{2}$. Histologicamente os melanomas orais são compostos de células fusiformes, plasmocitóides e epitelióides dispostas em lençóis, arranjos organóides, alveolar, neurotrópico e desmoplásico. O diagnóstico é obtido através da biópsia da lesão. Pode ocorrer em qualquer faixa etária e mais comumente no palato e na gengiva superior; podendo apresentar sangramento, dor local e amolecimento dentário ou ser assintomático. Atualmente, a melhor opção para o tratamento é a cirurgia; porém, há controvérsias quanto à extensão da ressecção e à utilização de radioterapia e/ou quimioterapia adjuvante ${ }^{3}$. Conclusão: $\mathrm{O}$ prognóstico depende do avanço da lesão. Por isso, a observação das mucosas deve fazer parte do autoexame, pois o diagnóstico precoce é fundamental para o prognóstico dos pacientes com lesões melanocíticas malignas ${ }^{1}$.

\section{Descritores: Melanoma; Melanoma Maligno; Neoplasia.}

\section{Referências:}

1. BET DL, et al. Dermatoscopia das lesões pigmentadas das mucosas e considerações sobre um caso de melanoma do lábio. Surgical and Cosmetic Dermatology, 2014; 6(1): 73-75

2. MARTA GN, et al. Melanoma de mucosa oral. Revista Brasileira de Cancerologia, 2007; 53(1): 35-39

3. NETO JA, et al. Melanoma de assoalho de boca: relato de caso e diagnóstico diferencial. HU Revista, 2005; 31(3): 28-29 


\section{PC-130-2019 - NÍVEL DE SATISFAÇÃO E QUALIDADE DE VIDA EM IDOSOS USUÁRIOS DE PRÓTESES TOTAIS}

Amanda Thays Feitoza Viturino ${ }^{1}$; Carolina Pereira da Silva ${ }^{1}$; Heitor Tavares de Araújo ${ }^{1}$; Lucas Rafael Borges Santos ${ }^{1}$; Ademir Félix Arantes Júnior ${ }^{1}$; João Victor Neves Barbosa ${ }^{1}$; Izabelle Glória dos Santos ${ }^{1}$; Jéssica da Silva Cunha ${ }^{2}$

${ }^{1}$ Faculdade de Odontologia de Pernambuco - Camaragibe - PE - Brasil

${ }^{2}$ Hospital da Restauração Governador Paulo Guerra - Recife - PE - Brasil

Autor correspondente:

Amanda Thays Feitoza Viturino

amanda.thaysfv@hotmail.com

Introdução: A perda dos elementos dentários é resultante de diferentes fatores biológicos, comportamentais e psicossociais, o edentulismo é aceito pela sociedade como consequência natural do envelhecimento. Com relação à idade, observa-se que pessoas senis se sentem menos valorizadas e mais dependentes, o que pode causar danos a sua autoestima. Esse quadro também pode ser agravado por fatores sociais, como rejeição de familiares e falta de expectativa de vida. Sob tais circunstâncias, a perda dos dentes, que resulta no desequilíbrio da função mastigatória, deglutição, fala e estética, contribui sobremaneira para o declínio da auto-estima ${ }^{2}$. Objetivo: Apresentar uma revisão da literatura sobre a mudança no nível de satisfação e qualidade de vida de idosos após o uso de próteses totais. Metodologia: Através dos descritores escolhidos, foram selecionados 8 artigos publicados entre os anos de 2011 e 2019, identificados nas bases de dados PubMed, SciELO e LILACS. Revisão de Literatura: Pacientes reabilitados com próteses superiores as consideram satisfatórias quanto à retenção e à estabilidade, ao passo que classificam as próteses totais inferiores como insatisfatórias quanto à retenção e ao conforto. Em sua maioria, estão satisfeitos com suas próteses superiores e insatisfeitas com suas próteses inferiores. Por sua vez, as próteses dentais inferiores apresentam uma área basal menor em comparação às superiores. A região de suporte da mandíbula é menor que a da maxila e apresenta estruturas anatômicas que podem dificultar no prognóstico da reabilitação. Adicionalmente, as próteses inferiores estão sujeitas à movimentação da língua, que pode contribuir para o seu deslocamento e a sua desestabilização, inviabilizando o seu uso sem o devido ajuste ${ }^{1,3}$. Conclusão: As evidências sugerem que a qualidade de vida é multidimensional, incluindo dimensões físicas, psicológicas e sociais. Pacientes reabilitados com próteses totais relatam maior percepção de melhora na qualidade de vida após a reabilitação.

Descritores: Prótese Dentária; Satisfação do Paciente; Qualidade de vida.

\section{Referências:}

1. BELONI WB, et al. Avaliação do grau de satisfação e qualidade de vida dos portadores de prótese dental. Revista da Faculdade de Odontologia-UPF, 2013; 18(2): 160-164

2. ROCHA FR, et al. Impacto do uso de próteses totais na qualidade de vida de idosos. Revista Contexto \& Saúde, 2011; 11(20): 1015-1020

3. SOARES SLB, et al. Avaliação dos usuários de prótese total, abordando aspectos funcionais, sociais e psicológicos. Revista Saúde \& Ciência Online, 2015; 4(2):19-27 


\section{PC-131-2019 - O ACOLHIMENTO NA ATENÇÃO PRIMÁRIA A SAÚDE}

Normando Carlos da Silva Junior ${ }^{1}$; Carolina Pereira da Silva ${ }^{1}$; Heitor Tavares de Araújo; Izabelle Glória dos Santos ${ }^{1}$; João Victor Neves Barbosa ${ }^{1}$; Lucas Rafael Borges Santos ${ }^{1}$; Mariana Renata Camilo da Silva ${ }^{1}$; Regina Maria Lopes da Silva ${ }^{1}$

${ }^{1}$ Faculdade de Odontologia de Pernambuco - Camaragibe - PE - Brasil

Autor correspondente:

Normando Carlos da Silva Junior

normando.carlos.jr16@gmail.com

Introdução: Em 2000, com a XI Conferência Nacional de Saúde, o debate acerca do acolhimento ficou mais acirrado. Apontaram-se algumas dificuldades enfrentadas pelo SUS. Em 2003, na XII Conferência Nacional de Saúde, retornou-se ao debate sobre o acesso ao sistema, desde a valorização dos usuários e dos trabalhadores, até a participação e na gestão do SUS. Neste mesmo ano surge a Política Nacional de Humanização da Atenção e Gestão do SUS - Humaniza SUS (PNH) ${ }^{1}$. Objetivo: Apresentar uma revisão da literatura sobre o acolhimento como ferramenta na atenção primária a saúde. Metodologia: Foi realizado cruzamento dos descritores selecionados e selecionados 10 artigos publicados entre 2014 e 2019, encontrados nos periódicos das bases de dados LILACS, PubMed e SciELO. Revisão de Literatura: O acolhimento se configura com uma das diretrizes da Política Nacional de Humanização, que propõe o protagonismo de todos os sujeitos envolvidos no processo de produção de saúde, ou seja, os profissionais atuantes na área da saúde, bem como, a reorganização dos serviços a partir da problematização dos processos de trabalho ${ }^{3}$. Envolve uma postura ética e de cuidado, uma abertura humana e empática e respeitosa ao usuário e implica na avaliação de riscos e vulnerabilidades, eleição de prioridades, percepção de necessidades clínico-biológicas, epidemiológicas e psicossociais. Deve permitir hierarquizar necessidades quanto ao tempo do cuidado, e ainda distinguir entre necessidades desiguais e tratá-las conforme suas características. É uma proposta voltada para a melhoria das relações dos serviços de saúde com os usuários ${ }^{2,1}$. Conclusão: $\mathrm{O}$ acolhimento baseia-se no encontro do usuário que procura o serviço espontaneamente com os profissionais de saúde, em que há uma escuta, um processamento de sua demanda e a busca da resolução, se possível. Implica compartilhamento de saberes, angústias e invenções, buscando "abrigar" aqueles que procuram o serviço, com responsabilidade.

Descritores: Humanização da assistência; Acolhimento; Saúde Pública.

\section{Referências:}

1. FERMINOJM, et al. Potencialidades e dificuldades nas práticas de acolhimento na rede de atenção básica conforme a política nacional de humanização. Saúde \& Transformação Social, 2015; 6(2): 54-69

2. MARTINS CP, LUZIO FA. Política HumanizaSUS: ancorar um navio no espaço. InterfaceComunicação, Saúde, Educação, 2016; 21(60): 13-22

3. MOREIRAMADM, et al. Public humanization policies: integrative literature review. Ciência \& saúde coletiva, 2015; 20(10): 3231-3242 


\section{PC-132-2019 - O BRUXISMO NA INFÂNCIA: UMA REVISÃO DE LITERATURA}

Ada Caroline Soares Ferreira ${ }^{1}$; Aylanne Xavier de Lacerda Cavalcante Timoteo ${ }^{1}$; Carolina Pereira da Silva ${ }^{1}$; Heitor Tavares de Araújo ${ }^{1}$; Luanna Gabriela Ferreira Leão Brasil ${ }^{1}$; Pedro Xavier Moura da Silva ${ }^{1}$; Taiana Jéssica Oliveira Araújo ${ }^{1}$; Jéssica da Silva Cunha ${ }^{2}$

${ }^{1}$ Faculdade de Odontologia de Pernambuco - Camaragibe - PE - Brasil

${ }^{2}$ Hospital da Restauração Governador Paulo Guerra/SES - Recife - PE - Brasil

Autor correspondente:

Ada Caroline Soares Ferreira

adacaroline2@gmail.com

Introdução: O Bruxismo é definido como uma atividade repetitiva da musculatura mastigatória caracterizada por apertar e/ou ranger os dentes, seja durante o dia ou à noite, e que pode trazer consequências ao portador de tal hábito ${ }^{4}$. Objetivo: $O$ estudo visa descrever as características do bruxismo na infância e obter uma melhor explanação sobre tal hábito. Metodologia: Foi realizada uma busca bibliográfica com artigos disponíveis no LILACS, PubMed e Bireme, publicados entre 2006 e 2019, com os termos "Bruxismo", "Odontopediatria" e "Odontologia". Revisão de Literatura: Não existe uma etiologia única para o bruxismo, podendo estar relacionada a fatores locais, sistêmicos, ocupacionais, hereditários e psicológicos; Pesquisadores têm sugerido que fatores comportamentais, como estresse, ansiedade e características de personalidade se sobressaem a fatores locais ${ }^{4}$. Verificou-se que crianças com sono agitado apresentam mais chances de terem bruxismo; tal hábito causa o aumento das forças oclusais e isso resulta em cargas extras não só na dentição (como o desgaste excessivo e sensibilidade), como também em todo o sistema estomatognático, podendo causar efeitos variados como danos à $\mathrm{ATM}$, aos músculos mastigatórios, ao periodonto e à oclusão ${ }^{2,3}$. Conclusão: Há uma potencial associação entre o bruxismo e fatores psicológicos em crianças. As consequências do bruxismo devem ser prevenidas, sendo importante o seu diagnóstico precoce, assim como um acompanhamento psicológico na criança. As diferentes formas de tratamento devem ser individualizadas para cada paciente ${ }^{1}$.

Descritores: Bruxismo; Odontopediatria; Pediatria.

\section{Referências:}

1. DUQUE C, HEBLING J. Bruxismo na infância. Revista ABO Nacional, 2006; 14(4): 220224

2.NAHÁS-SCOCATE ACR, et al. Associação entre bruxismo infantil e as características oclusais, sono e dor de cabeça. Revista da Associação Paulista de Cirurgiões Dentistas, 2012; 66(1): 18-22

3. PIZZOL KEDC, et al. Bruxismo na infância: fatores etiológicos e possíveis tratamentos. Revista de Odontologia da UNESP, 2006; 35(2): 157-163

4. RIOS LT, et al. Bruxismo infantil e sua associação com fatores psicológicos - revisão sistemática da literatura. Revista de Odontologia da Universidade Cidade de São Paulo, 2018; 30(1): 64-76 


\section{PC-133-2019 - O DESAFIO DAS FACETAS UNITÁRIAS EM DENTES COM SUBSTRATO ESCURECIDO}

Giovanna Siqueira Faustino da Silva ${ }^{1}$; Túlio Marcos dos Santos Silva ${ }^{1}$; Claudio Heliomar Vicente da Silva ${ }^{1}$; Juliana Raposo Souto Maior ${ }^{2}$; Renata Pedrosa Guimarães ${ }^{1}$

${ }^{1}$ Universidade Federal de Pernambuco - Recife - PE - Brasil

${ }^{2}$ Centro de Pós-Graduação em Odontologia - Recife - PE - Brasil

Autor correspondente:

Giovanna Siqueira Faustino da Silva

giovsfs@gmail.com

Introdução: O trauma dentário acomete os elementos anteriores com maior frequência. Dentre as consequências dessa situação de urgência, pode-se observar a variação de cor do dente, que se torna mais escurecido ${ }^{3}$. Objetivo: Apresentar um relato de caso sobre reabilitação estética do elemento 11, o qual, após sofrer traumatismo e tratamento endodôntico, teve sua coloração alterada. Relato de caso: Após diversas tentativas pregressas de tratamento restaurador, a paciente ainda estava insatisfeita, tendo em vista o contraste de cor entre este elemento e os demais dentes anterossuperiores. Foi realizada então cimentação de pino de fibra de vidro intrarradicular, seguida de substituição da faceta existente por outra em resina composta, com o cuidado de melhor proporcionamento de agentes opacificadores e observação criteriosa das espessuras entre as diversas camadas de material restaurador em função de suas propriedades ópticas: resina de corpo, resina de efeito translúcido e resina de esmalte. Após finalização, cuidados foram tomados durante o acabamento e polimento da restauração, pela reprodução da textura de superfície vestibular, em relação ao elemento 21 , utilizando dispositivo multiplicador e associação com borrachas abrasivas. Discussão: Diante de uma sociedade que exige um padrão de beleza, esse comprometimento estético dentário é prejudicial ao indivíduo em virtude do impacto causado a sua autoestima ${ }^{1}$. As facetas em resina composta são uma excelente escolha para esses casos. O uso de pinos intracanais também favorece a reabilitação estética devido à coloração próxima a estrutura dental ${ }^{2}$. Dessa forma, é possível reestabelecer a harmonia e a estética, trazendo bons resultados para o paciente. Conclusão: No tratamento restaurador de elementos desvitalizados e escurecidos é fundamental um correto planejamento da espessura do preparo, uso correto de resinas opacificadoras, boa utilização de efeitos ópticos de múltiplas camadas e ainda um minucioso acabamento e polimento para a excelência dos resultados.

Descritores: Estética Dentária; Facetas Dentárias; Traumatismos Dentários.

\section{Referências:}

1. MACHADO AC, et al. Reabilitação estética e funcional com facetas diretas após histórico de traumatismo dento-alveolar. Rev Odontol Bras Central, 2016; 25(74): 154-161

2. PEREIRA N, et al. Pino de fibra de vidro associado à restauração classe IV e faceta direta em resina composta em dente anterior: relato de caso. Revista Gestão \& Saúde, 2017; 16(1): 21-29

3. SOUZA CR, et al. Reabilitação estética de dente anterior escurecido: relato de caso. Arch Health Invest, 2017; 6(8): 377-381 


\section{PC-134-2019 - O EMPREGO DA FOTOBIOMODULAÇÃO NO CONTROLE DA MUCOSITE ORAL DE PACIENTE SUBMETIDO Å QUIMIOTERAPIA E RADIOTERAPIA DA REGIÃO DE CABEÇA E PESCOÇO: RELATO DE CASO}

Amanda Pereira Melo; Thuanny Silva de Macêdo ${ }^{1}$; Elizabeth Louisy Marques Soares da Silva $^{1}$; Andressa Kelly Alves Ferreira ${ }^{1}$; Maria Cecília Scheidegger Neves Gueiros ${ }^{1}$; Gustavo Pina Godoy ${ }^{1}$; Maria Cecília Freire de Melo ${ }^{1}$

${ }^{1}$ Universidade Federal de Pernambuco - Recife - PE - Brasil.

Autor correspondente:

Amanda Pereira Melo

amandamlo@outlook.com

Introdução: O câncer de boca representa um problema de saúde pública, devido sua alta incidência, prevalência e mortalidade ${ }^{1,3}$. Apesar dos avanços na terapia antineoplásica, as modalidades terapêuticas consistem em cirurgia, quimioterapia (QT) e radioterapia (RTX) e embora, eficazes no tratamento podem gerar efeitos colaterais bucais incapacitantes como a mucosite oral $(\mathrm{MO})^{2,3}$. Objetivo: Relatar um caso clínico onde foi empregado a fotobiomodulação para controle da MO de paciente com câncer de língua submetido à QT + RTX. Relato de caso: A.S., 69 anos, masculino, leucoderma, não tabagista, não etilista, histórico de câncer de língua na família (irmã), apresentou lesão volumosa $(+-3 \mathrm{~cm})$, ulcerada, indolor na borda lateral de língua esquerda. Foi realizada a biópsia sendo compatível com neoplasia maligna em língua. Pela equipe médica foi realizada cirurgia oncológica com margem de segurança e indicada RTX (30 sessões), em conjunto com QT (Cisplatina + Cetuximabe). A.S foi encaminhado para realização da fotobiomodulação apenas na $10^{\circ}$ sessão da RTX o qual, já estava com MO Grau I (OMS). A partir de então, foi realizado diariamente laserterapia no espectro do vermelho visível $(\Lambda=660 \mathrm{~nm})$, aplicação de modo pontual, em contato e perpendicularmente. Os parâmetros utilizados foram potência fixa $=100 \mathrm{~mW}$, área do spot= $0,028 \mathrm{~cm}^{2}, \mathrm{E}=2 \mathrm{~J}, \mathrm{DE}=70 \mathrm{~J} / \mathrm{cm}^{2}$ e T por ponto $=20 \mathrm{seg}$. No final da RTX, A.S não desenvolveu $\mathrm{MO} \geq$ grau I e relatou o controle analgésico importante durante as sessões. Discussão: A MO é definida como um processo inflamatório que ocorre na mucosa oral podendo gerar importantes complicações, incluindo aumento de infecções e a interrupção do tratamento ${ }^{2}$. A laserterapia tem sido eficaz na tentativa de reduzir a incidência de MO e fatores associados à dor em pacientes que receberam altas doses de $\mathrm{RTX}$ e/ou $\mathrm{QT}^{2,4}$. Conclusão: $\mathrm{O}$ laser empregado no controle da MO demonstra-se benéfico principalmente por suas propriedades analgésicas, antiinflamatórias e de bioestimulação tecidual.

Descritores: Oncologia; Mucosite oral; Lasers.

\section{Referências:}

1. MORO JS, et al. Oral and oropharyngeal cancer: epidemiology and survival analysis. Instituto Israelita de Ensino e Pesquisa Albert Einstein, 2018; 16(2): 1-5

2. RAMPINI MP, et al. Utilização da terapia com laser de baixa potência para prevenção de mucosite: revisão de literatura. Revista brasileira de Cancerologia, 2009; 55(1): 59-68.

VIDAL AKL, et al. Mouth Cancer Control Program in the State of Pernambuco, Brazil. Oral Cancer, 2018; 2: 97-104

3. ZADIK Y, et al. Systematic review of photobiomodulation for the management of oral mucositis in cancer patients and clinical practice guidelines Support Care Cancer. Supportive Care in Cancer, 2019; 27: 1-15 


\section{PC-135-2019 - O USO DO ENXERTO ÓSSEO DE MENTO NA REABILITAÇÃO ORAL COM IMPLANTES: UM RELATO DE CASO}

Kamila Maria de Jesus da Silva Alves ${ }^{1}$; Larissa Sousa Rangel ${ }^{\mathbf{1}}$; Alyne Francisca Assis de Souza1; Marcelle Freitas Braz ${ }^{1}$; Raquel Sâmela Costa Feitosa ${ }^{2}$; Viviane Falcão Machado Martins $^{3}$; Isabella Macário Ferro Cavalcanti³; João Geraldo Carvalho Fernandes ${ }^{3}$

${ }^{1}$ Centro Universitário Maurício de Nassau - Recife-PE-Brasil

${ }^{2}$ Universidade de Pernambuco - Recife - PE - Brasil

${ }^{3}$ Universidade Federal de Pernambuco - Recife - PE - Brasil

Autor correspondente:

Kamila Maria de Jesus da Silva Alves

millamary16@gmail.com

Introdução: Na implantodontia, a fixação e a imobilização são etapas de suma importância para o sucesso dos procedimentos cirúrgicos que envolvam a manipulação óssea. Quando ocorre a perda óssea dos dentes, o tratamento ideal é o enxerto ósseo dentário, que é um procedimento que visa o aumento da altura e da espessura do osso no local em que será feita a cirurgia de enxerto ósseo autógeno, permitindo, assim, a instalação de implantes dentários ${ }^{1,4}$. Objetivo: O objetivo do trabalho é apresentar um relato de caso, descrevendo o processo de diagnóstico, planejamento, procedimento cirúrgico, realizando enxerto ósseo e, posteriormente, a colocação de implantes dentários. Relato de caso: $\mathrm{O}$ paciente $\mathrm{AMB}, 35$ anos, sexo masculino, compareceu a clínica particular, queixando-se de dificuldades na estética, mastigação e fonação, associada a ausência de alguns elementos dentários anteriores superiores 11, 12, 21, 22. Foi realizada anamnese e exame radiográfico. A partir da análise do material coletado, obteve-se o diagnóstico da necessidade de um enxerto ósseo dentário. Foi solicitado para o paciente os exames laboratoriais e posteriormente executou-se o procedimento cirúrgico com enxerto autógeno do mento, visando posteriormente a colocação de implantes dentários. Dessa forma, teve como finalidade devolver a altura e espessura óssea para colocação de implantes. $\mathrm{O}$ paciente está sendo acompanhado desde a cirurgia e, com 30 dias, apresentou uma recuperação considerável para continuidade do tratamento. Discussão: De acordo com primeiro processo cirúrgico a continuação da terapêutica segue, pois, segundo pesquisas científicas, o indicado é o enxerto autógeno, visto que o paciente é novo, saudável el possui indicações para o tratamento ${ }^{2,3}$. Conclusão: A perda de um ou mais elementos dentários causa o processo fisiológico de reabsorção óssea, dificultando a reabilitação oral do paciente. Desse modo, é de fundamental importância o conhecimento de tratamentos com enxertos ósseos, a fim de oferecer um correto tratamento.

Descritores: Enxerto Ósseo; Reabilitação Bucal; Implante Dentário.

\section{Referências:}

1. ALVAREZ G, et al. Protocolo de treinamento em reconstrução de cabeça e pescoço do serviço de residência em cirurgia plástica pucrs. Arquivos Catarinenses de Medicina, 2009; 38(1): 270-271

2. FARDIN A, et al. Enxerto ósseo em odontologia: revisão de literatura. Innovations Implant Journal, Biomaterials Esthetics, 2010; 5(3): 48-52

3. PEREIRA C, et al. Enxertos ósseos autógenos mandibulares para reconstrução de processos alveolares atróficos: revisão e técnica cirúrgica. Innovations Implant Journal, Biomaterials Esthetics, 2009; 4(3): 96-102

4. PORTINHO C, et al. Reconstrução microcirúrgica em cabeça e pescoço: análise retrospectiva de 60 retalhos livres. Revista Brasileira de Cirúrgia Plástica, 2013; 28(3): 434-43 


\section{PC-136-2019 - ODONTOMA COMPOSTO: UM RELATO DE CASO}

Diego Fillipe Tavares Silva ${ }^{3}$; Pedro Vinícius de Melo Alves ${ }^{1}$; Allan Vinícius Martins de Barros $^{2}$; Kleber Rós Santos²; Rômulo Augusto de Paiva Macedo²; Caio César Gonçalves Silva²; Fábio Andrey da Costa Araújo ${ }^{1}$; Emanuel Dias de Oliveira e Silva²

${ }^{1}$ Universidade de Pernambuco - Arcoverde - PE - Brasil

${ }^{2}$ Universidade de Pernambuco - Recife - PE - Brasil

${ }^{3}$ Faculdade Maurício de Nassau - Caruaru- PE - Brasil

Autor correspondente:

Diego Fillipe Tavares Silva

diegof.tavares2@gmail.com

Introdução: Os tipos mais comuns de tumores odontogênicos são os odontomas ${ }^{1}$. Sua prevalência ultrapassa a de todos outros tumores odontogênicos combinados. São considerados como distúrbios de desenvolvimento (hamartomas). Quando totalmente desenvolvidos, consistem basicamente em esmalte e dentina, e porções variáveis de polpa e cemento. Os odontomas ainda são subdivididos em tipo composto e tipo complexo ${ }^{2}$. Objetivo: $\mathrm{O}$ presente trabalho tem por objetivo relatar um caso clínico de odontoma composto, em que a lesão estava relacionada a retenção prolongada dos dentes decíduos e impacção dos permanentes. Relato de caso: Paciente M.V.F.S, 11 anos de idade, gênero masculino, ASA 1, foi encaminhado por uma ortodontista para o serviço de cirurgia e traumatologia bucomaxilofacial de um hospital universitário com hipótese diagnóstica de odontoma composto, após achado radiográfico de uma massa radiopaca localizada na extensão do canino superior direito ao segundo molar superior direito. Diante do diagnóstico, o tratamento proposto foi a remoção cirúrgica (enucleação da lesão), sob anestesia geral. Discussão: Os odontomas acomentem com maior frequência a maxila do que a mandíbula. $O$ tipo composto é usualmente encontrado na região anterior da maxila. Os achados radiográficos costumam ser diagnósticos, sendo pouco confundido com outras lesões ${ }^{2}$. Radiograficamente, aparece como uma coleção de estruturas semelhantes a dentes de variados tamanhos e formas, cercados por uma delgada zona radiolúcida ${ }^{2,3}$. Conclusões: $O$ tratamento cirúrgico possibilitou a remoção da lesão que não mostrou recidiva no pós-operatório até então de 3 meses.

Descritores: Odontoma; Tumores odontogênicos; Anormalidades dentárias.

\section{Referências:}

1. LUKES SM, WACHTER KM. Compound odontoma: a case study. The Journal of a Dental Hygiene, 2003;77(1): 47-9

2. NEVILLE BW, et al. Patologia oral e maxilofacial. $4^{\mathrm{a}}$ ed. Rio de Janeiro: Elsevier, 2016; $1682 \mathrm{p}$

3. SILVA LF, et al. Odontomas: a clinicopathologic study in a Portuguese population. Quintessence Int, 2009;40(1): 61-72 


\section{PC-137-2019 - ORIENTAÇÃO DE HIGIENE BUCAL PARA ADOLESCENTES: REVISÃO DE LITERATURA}

Fabiola Feitosa Freitas ${ }^{1}$; Évila Castro Lima ${ }^{1}$; Hian Carvalho Souza ${ }^{1}$; Maíra Belo da Rocha Carvalho $^{1}$; Renata Laís Pontes de Carvalho ${ }^{1}$; Fernanda Ariel da Silva Vasconcelos ${ }^{1}$; Ana Carolina de Souza Leitão ${ }^{1}$; Viviane Colares ${ }^{1}$

${ }^{1}$ Faculdade de Odontologia de Pernambuco - Camaragibe - PE - Brasil

Autor correspondente:

Fabíola Feitosa Freitas

fabiolafeitosaf@hotmail.com

Introdução: No processo de educação em saúde devem ser disponibilizados instrumentos e informações sobre saúde bucal que possibilitem a aquisição de hábitos favoráveis relacionados ao autocuidado. A adolescência é uma fase crítica com importantes mudanças físicas, cognitivas, sociais e emocionais, e este grupo apresenta alto risco para instalação de cárie dentária e doenças periodontais ${ }^{1,3}$. Objetivo: Apresentar uma revisão da literatura sobre a orientação de higiene bucal para adolescentes. Metodologia: Trata-se de uma pesquisa bibliográfica realizada na base de dados LILACS, através da Biblioteca Virtual em Saúde, Bireme. Revisão de literatura: Considerando a autonomia que se desenvolve nessa faixa etária é indispensável que cirurgião-dentista direcione estratégias educativas para esse grupo específico $^{2}$. Uma proposta de educação visando o controle da placa bacteriana com implementação de medidas de higiene bucal, deve envolver motivação, estimulação e reforço. O método adotado deve incluir técnicas de escovação e uso do fio dental ${ }^{3,2}$. Destaca-se que a motivação constante é um fator importante, como orientação direta, filmes e folhetos educativos. Recomenda-se a educação participativa na motivação ao autocuidado em saúde bucal com adolescentes. As instruções teóricas sobre higiene bucal devem estar associadas a demonstrações práticas. A evidenciação da placa bacteriana com corantes pode auxiliar no esclarecimento dos adolescentes, facilitando a percepção das necessidades de melhoria na prática de higiene. A obtenção do índice de placa pode ser útil como medida de mensuração da melhora da escovação. Os argumentos utilizados pelo profissional devem incluir motivos cosméticos, para estética mais satisfatória e hálito agradável, além da prevenção das doenças bucais. Conclusão: A orientação de higiene bucal voltâda ao adolescente deve ocasionar mudanças de comportamento com relação ao autocuidado em saúde bucal.

Descritores: Higiene Bucal; Medicina do Adolescente; Autocuidado.

\section{Referências:}

1. GOMES SSM, et al. Cárie dentária em adolescentes da cidade de Recife-PE. RFO, 2017; 22(1): 62-68

2. MENCHACA HRM, et al. Directriz sobre el cuidado de la salud oral en adolescentes. Revista ADM, 2019; 76(1): 26-29

3. SPIEZZA S. Alterações periodontais na adolescência. Revista Periodontia, 2018; 28(1): 4347 


\section{PC-138-2019 - OSTEOMA OSTEÓIDE EM CORPO MANDIBULAR- RELATO DE CASO}

Jessyca Maria Alencar e Sá1; Alleson Jamesson da Silva ${ }^{1}$; Maria Heloisa Martins ${ }^{1}$; Lucas Viana Silva Ramos ${ }^{1}$; Amanda Pereira Melo ${ }^{1}$; Yali Regina Santiago Correia ${ }^{1}$; Eugênia Leal Figueiredo Carolina $^{2}$; Carolina Chaves Gama Aires ${ }^{2}$

${ }^{1}$ Universidade Federal de Pernambuco - Recife - PE - Brasil

${ }^{2}$ Faculdade de Odontologia de Pernambuco - Camaragibe - PE - Brasil

Autor correspondente:

Jessyca Maria Alencar e Sá

jessyk_a.s@hotmail.com

Introdução: Os osteomas são proliferações de tecido ósseo, neoplasia benigna clinicamente consiste em massa bem delimitada que pode ser séssil ou pediculada, sendo assintomática e que dependendo da sua localização e tamanho, pode acarretar danos estéticos devido a assimetria e danos funcionais à oclusão, deglutição e fala ${ }^{2}$. Objetivo: Discutir um relato de caso de osteoma osteóide em região mandibular. Relato de Caso: Paciente N.B, do sexo feminino, 33 anos, foi atendida no Hospital da face queixando-se de aumento de volume endurecido à palpação em região submandibular esquerda. Ao exame físico, apresentava uma lesão endurecida, séssil e indolor, com tempo de evolução de aproximadamente 2 anos. Após exame clínico, foi solicitada a tomografia de face para avaliação complementar. A imagem tomográfica evidenciou a presença de uma lesão hiperdensa em região de corpo mandibular esquerda. Mediante o aspecto da lesão, optou-se pela excisão cirúrgica através de acesso extra-oral submandibular. Após excisão, a peça foi encaminhada para estudo anátomo-patológico que identificou a lesão como um osteoma osteóide. Discussão: O presente caso apresentado envolveu um paciente do sexo feminino, entretanto a literatura refere um acometimento maior no sexo masculino. A anamnese e exame físico são de suma importância para o diagnóstico do osteoma osteóide, por se tratar de uma patologia assintomática ${ }^{3}$. A conduta inicial do tratamento é o acompanhamento, caso o osteoma acarrete transtornos funcionais ou estéticos, o tratamento eleito é a exérese cirúrgica ${ }^{1}$. Conclusão: $O$ osteoma osteóide é uma neoplasia rara e benigna. Em alguns casos, a intervenção cirúrgica é necessária devido ao comprometimento estético e funcional, como relatado no presente caso.

Descritores: Osteoma; Osteoma osteóide; Neoplasias.

\section{Referências:}

1. BOROS LF, et al. Osteoma Compacto Central de Mandíbula: relato de caso clinico. Revista odontologia Clínico-cientifíca, 2011; 10(1): 89-93

2. MOURA LB, et al. Osteoma periférico mandibular - relato de caso. Dental Science, 2016; 7(26):47-52

3. TAKENAKA PMS, et al. Osteoma de mastóide: relato de caso e revisão de literatura. Revista brasileira de otorrinolaringologia, 2004; 70(6): 846-849 


\section{PC-139-2019 - OSTEONECROSE ASSOCIADA AO USO DE BISFOSFONATOS EM TÓRUS PALATINO}

Maria Heloisa Martins ${ }^{1}$; Paloma Rodrigues Genú ${ }^{1}$; Adriana Paula de Andrade da Costa e Silva Santiago $^{1}$; Alesson Jamesson da Silva ${ }^{1}$; Cibele Virgínia Morais de Melo ${ }^{1}$; Cibele Leandro da Costa $^{1}$; Jessyca Maria Alencar e Sá1; Taís Soares Ramos ${ }^{2}$

${ }^{1}$ Universidade Federal de Pernambuco - Recife - PE - Brasil

${ }^{2}$ Faculdade de Odontologia de Pernambuco - Camaragibe - PE - Brasil

Autor correspondente:

Maria Heloisa Martins

Heloisa711@gmail.com

Introdução: A osteonecrose pode ser induzida por radioterapia, infecções e determinadas drogas, da classe dos bisfosfonatos, caracterizados por reduzirem a reabsorção óssea e estimularem a atividade osteoblástica e a apoptose de osteoclastos. Por essas razões, são frequentemente administrados em pacientes com osteoporose e comumente empregados no tratamento do câncer de mama, próstata, pulmão e mieloma múltiplo². Objetivo: $O$ presente estudo teve como objetivo realizar uma análise da ocorrência de osteonecrose em tórus palatino associada ao uso de bisfofonatos. Metodologia: Foi realizada uma revisão de literatura a partir de artigos obtidos nas bases de dados SciELO e PubMed, utilizando os seguintes descritores: Osteonecrose, exostose e bisfosfonatos. Revisão de literatura: A osteonecrose é caracterizada pela exposição óssea na mandíbula ou maxila que não se repara em oito semanas ${ }^{3}$. A quantidade de osso exposta é muito variável em suas dimensões. Apresenta maior incidência na mandíbula em comparação com a maxila, em uma proporção de 2:1, em áreas com mucosa menos espessa, como as de tórus e linha milo-hioidea ${ }^{1}$. O tórus palatino é uma exostose comum que ocorre na linha média do palato duro. A sua patogênese tem sido questionada, discutindo-se uma origem genética ou fatores ambientais, como o estresse mastigatório ${ }^{5}$. A mucosa que recobre proeminências ósseas, como o tórus palatino, pode ser lesionada durante a mastigação. Em casos de osteonecrose, é mais comum a exposição óssea em tórus mandibular, quando comparada em tórus palatino, que se dá de forma mais rara ${ }^{4}$. Assim, a fragilidade da mucosa que cobre o tórus palatino pode permitir que traumas menores exponham o osso que se encontra mais suscetível ${ }^{3}$. Conclusão: Embora a osteonecrose em tórus palatino associada à terapia com bisfosfonatos seja considerada rara, é importante ressaltar a presença do tórus palatino, como um dos fatores de risco para osteonecrose dos maxilares.

Descritores: Osteonecrose; Exostose; Bisfosfonatos.

\section{Referências:}

1. BROZOSKI MA, et al. Osteonecrose maxilar associada ao uso de bisfosfonatos. Revista Brasileira de Reumatologia, 2012; 52(2): 260-270

2. DOTTO ML, DOTTO AC. Osteonecrose dos maxilares induzida por bisfosfonatos - revisão de literatura e relato de caso. Revista da Faculdade de Odontologia, 2011; 16(2): 229-233.

2. GODINHO M, et al. Torus Palatinus Osteonecrosis Related to Bisphosphonate: A Case Report. Case Reports in Dermatology, 2013; 5(1): 120-125

3. KANEKO K, TAKAHASHI H. Bisphosphonate-Related Osteonecrosis of the Palatal Torus. Brazilian Journal of Otorhinolaryngology, 2014; 76(6): 353-356

4. NEVILLE BW, et al. Patologia Oral e Maxilofacial. Rio de Janeiro: Elsevier, 2009; 989p 


\section{PC-140-2019 - OSTEONECROSE DOS MAXILARES POR USO DE BIFOSFONATOS: REVISÃO DE LITERATURA}

Hian Carvalho Souza ${ }^{1}$; Maíra Belo da Rocha Carvalho ${ }^{1}$; Olívia Augusta Araújo Dias ${ }^{1}$; Joana de Ângelis Alves Silva ${ }^{1}$; Mayara Monique Silva de Oliveira ${ }^{1}$; Ismael Sebastião da Silva Sousa ${ }^{1}$; Jeferson Batista Santiago ${ }^{1}$; Rafael Brito Lopes ${ }^{2}$

${ }^{1}$ Faculdade de Odontologia de Pernambuco - Camaragibe - PE - Brasil

${ }^{2}$ Faculdade de Ciências Agrárias e da Saúde - Lauro de Freitas - BA - Brasil

Autor correspondente:

Hian Carvalho Souza

hianvalho@gmail.com

Introdução: Os bifosfonatos (BF) são medicamentos que afetam o mecanismo do metabolismo ósseo, reduzindo a reabsorção óssea e estimulando a atividade osteoblástica, assim como são capazes de promover a apoptose dos osteoclastos ${ }^{1,2}$. Embora essa droga seja amplamente utilizada no tratamento da osteoporose, Doença de Paget, tumores ósseos com metastização óssea e hipercalcemia associada ao Mieloma Múltiplo, efeitos adversos têm sido observados, sendo uma das complicações a indução da osteonecrose dos maxilares ${ }^{1,2,3}$. Objetivo: Relatar através de uma revisão de literatura a etiopatogenia e o manejo odontológico da osteonecrose dos maxilares induzida por bisfosfonatos (ONMB). Metodologia: Foi efetuada uma revisão de literatura nas bases de dados BBO, Scielo, Medline e PubMed, entre os anos de 2006 e 2013. Revisão de literatura: Os maxilares são afetados pelo uso dos BFs, sendo resultante atividade antiosteoclástica e antiangiogênica. Os BFs podem alterar o mecanismo do tecido ósseo em vários níveis, tendo efeitos biológicos fundamentais no metabolismo do cálcio, inibindo a calcificação e a reabsorção óssea ${ }^{1}$. O mecanismo pelo qual os bifosfonatos promovem tal evento ainda é desconhecido ${ }^{1,3}$. Alguns fatores predispõem o desenvolvimento de ONMB, podendo incluir tipo, via de administração e tempo de uso do BF, assim como pacientes submetidos a exodontias $^{1,2,3}$. Clinicamente as lesões caracterizam-se por exposição óssea por mais de oito semanas, associada ao uso de bifosfonatos e sem exposição à radioterapia que podem ser sintomáticas ou não ${ }^{3}$. Conclusão: $O$ paciente com osteonecrose dos maxilares deve receber instruções de higiene oral e ser acompanhado regularmente pelo cirurgião-dentista através de exames clínicos e imaginológicos, além da observação de sintomas iniciais como mobilidade dental, dor, eritema, entre outros. Atualmente o tratamento mais indicado para esses casos é o controle microbiológico e eliminação dos sintomas.

Descritores: Osteonecrose; Doenças Maxilares; Difosfonatos.

\section{Referências:}

1. BROZOSKI MA, et al. Osteonecrose maxilar associada ao uso de bisfosfonatos. Rev Bras Reumatol, 2012; 52(2): 260-270

2. GEGLER A, et al. Bisfosfonatos e osteonecrose maxilar: revisão da literatura e relato de dois casos. Revista Brasileira de Cancerologia, 2006; 52(1): 25-31

3. JUNIOR CDF, et al. Osteonecrose associada aos bifosfonatos na odontologia. Rev Periodontia, 2007; 17(3): 24-30 


\section{PC-141-2019 - OSTEONECROSE POR MEDICAMENTO EM MAXILA - RELATO DE CASO}

Maíra Letícia Ferreira de Santana ${ }^{1}$; Carolaine Rayane Xavier da Silva ${ }^{1}$; Émilly Araújo Pereira ${ }^{1}$; Éwerton Daniel Rocha Rodrigues ${ }^{1}$; Ingrid Patrícia de Moraes Lima ${ }^{1}$; Joyce Feitosa Pinho Gomes$^{1}$; Lívia Xavier Teles²; Thais Cristina de Araújo Moreira ${ }^{3}$

${ }^{1}$ Faculdade de Odontologia de Pernambuco - Camaragibe - PE - Brasil

${ }^{2}$ Universidade Federal de Pernambuco - Recife - PE - Brasil

${ }^{3}$ Hospital Universitário da Universidade Federal do Piauí - Teresina - PI - Brasil

Autor correspondente:

Maíra Letícia Ferreira de Santana

maira_leticia12@hotmail.com

Introdução: A osteonecrose é definida como uma área de exposição óssea e necrose tecidual incapaz de cicatrizar em um período de oito semanas ${ }^{1}$. Objetivo: Apresentar um relato de caso clínico sobre a osteonecrose induzida por bisfosfonato de uso oral. Relato de caso: Paciente do gênero feminino, 60 anos de idade, diagnosticada com osteoporose, fazendo uso contínuo de alendronato de sódio $70 \mathrm{mg} 1 \mathrm{vez}$ por semana para tratamento desta, por 2 anos e 11 meses, chegou ao serviço de CTBMF de um hospital público com a queixa de "ferida na boca", relatando sintomatologia dolorosa e gosto ruim, após realização de exodontia em região posterior da maxila no lado esquerdo. A paciente não relatou outra doença de base, além da osteoporose e afirmou não fazer uso de outras medicações. Com base nos achados clínicos e radiográficos, foi sugerida a osteonecrose induzida por bisfosfonato de uso oral como a principal hipótese diagnóstica. Discussão: A mandíbula é frequentemente mais envolvida em $65 \%$ dos casos, a maxila em $27 \%$ e ambos os ossos gnáticos em $8 \%$. As modificações da vascularização inerentes à osteonecrose induzida por bisfosfonatos explicam, em parte, por que a mandíbula é mais afetada do que a maxila, uma vez que a primeira possui anatomicamente menos vascularização que a segunda. Os ossos gnáticos, assim, em especial a mandíbula, seriam locais de eleição porque são os únicos ossos suscetíveis à microtraumatismos constantes em função da presença dos dentes ${ }^{3}$. Conclusões: A osteonecrose dos maxilares induzida por bisfosfonatos é um efeito adverso grave relacionado com doenças reabsortivas ósseas e vem tornando-se cada vez mais frequente. Atualmente, observa-se uma grande variedade de tratamentos propostos, assim, há a necessidade de promover estudos e relatos que procurem comprovar a eficácia de técnicas de tratamento, bem como tornar mais claro o mecanismo fisiopatológico desta alteração².

Descritores: Osteonecrose; Bifosfonatos; Osteonecrose Associada a Bifosfonatos.

\section{Referências:}

1. ALLEN MR, BURR DB. The pathogenesis of bisphosphonate-related osteonecrosis of the jaw: so many hypotheses, so few data. J Oral Maxillofac Surg, 2009; 67(5): 61-70

2. FICARRA G, BENINATI F. Bisphosphonate-related osteonecrosis of the jaws: an update on clinical, pathological and management aspects. Head and Neck Pathol, 2007; 1(2): 132-40

3. SAWATARI Y, MARX RE. Bisphosphonates and bisphosphonate induced osteonecrosis. Oral Maxillofac Surg Clin North Am, 2007; 19(4): 487-98 


\section{PC-142-2019 - OSTEOSSÍNTESE EM FRATURA DE PAREDE ANTERIOR DE SEIO FRONTAL: RELATO DE CASO}

Cláudia Nely Mendonça dos Santos ${ }^{1}$; João Artur Peixoto Granja ${ }^{1}$; Maria Victorya Ferreira de Arruda $^{1}$; Caio César Gonçalves Silva ${ }^{2}$; Demóstenes Alves Diniz ${ }^{3}$; Kalyne Kelly Negromonte Gonçalves $^{3}$; Vinícius Balan Santos Pereira ${ }^{2}$; Belmiro Cavalcanti do Egito Vasconcelos ${ }^{3}$

${ }^{1}$ Centro Universitário Tiradentes - Recife - PE - Brasil

${ }^{2}$ Faculdade de Odontologia de Pernambuco - Recife - PE - Brasil

${ }^{3}$ Hospital da Restauração Governador Paulo Guerra - Recife - PE - Brasil

Autor correspondente:

Cláudia Nely Mendonça dos Santos

claudia_johari@msn.com

Introdução: O seio frontal é uma cavidade óssea pneumática, com forma triangular, localizada atrás dos arcos superciliares, entre o esplenocrânio e o neurocrânio ${ }^{2}$. O trauma em osso frontal não é raro, representando de 5 a $12 \%$ de todas as fraturas de face e sua principal causa são os acidentes com veículos automotores ${ }^{3}$. As fraturas de seio frontal podem acometer anatomicamente as paredes anterior e/ou posterior, com ou sem envolvimento do ducto nasofrontal ${ }^{1}$. Objetivo: Apresentar o tratamento clínico e cirúrgico de um paciente com fratura do seio frontal, vítima de agressão física. Relato de caso: Paciente do sexo masculino, 24 anos, compareceu em nosso serviço e ao exame físico, apresentou depressão em região frontal com comprometimento de contorno supraorbital esquerdo. O exame tomográfico evidenciou fratura de parede anterior de seio frontal. Foi proposto para o paciente acesso bicoronal e instalação de tela de titânio $1.5 \mathrm{~mm}$ para mascarar defeito ósseo. Paciente segue em acompanhamento ambulatorial sem queixas visuais e/ou estéticas. Discussão: Fraturas do seio frontal normalmente estão associadas a acidentes automobilístico e como segunda etiologia importante estão as agressões físicas, como no caso apresentado ${ }^{2}$. O tratamento dessas fraturas com procedimento cirúrgico previne a infecção do conteúdo intracraniano e promove o contorno do osso frontal ${ }^{2}$. As fraturas da parede anterior do seio frontal sem envolvimento da parede posterior ou de injúria do ducto fronto-nasal podem ser reconstruídas e, fixadas rigidamente com miniplacas e parafusos, podendo-se ainda utilizar de enxertos ${ }^{4}$. Neste caso, optou-se pela instalação dã tela de titânio. Conclusão: Os ossos dỏ seio frontal podem ser acometidos por diversos tipos fraturas, e o tratamento depende da sua complexidade. É necessário que o CTBMF saiba realizar o procedimento correto e tratar adequadamente seus pacientes para que possa proporcionar um bom resultado estético-funcional.

Descritores: Traumatismo da Região Frontal; Fixação Interna de Fraturas; Tratamento.

\section{Referências:}

1. ALBUQUERQUE AFM, et al. Abordagem das fraturas do seio frontal: relato de caso. Revista Extensão \& Sociedade, 2012; 1(4): 13

2. JARDIM ECG, et al. Fratura do seio frontal: relato de caso. Revista Odontológica de Araçatuba, 2010; 31(2): 35-39

3. LESSA ES, et al. Fraturas do seio frontal: conduta em relação ao ducto nasofrontal. Revista Brasileira de Cirurgia Plástica, 2010; 25(3):19

4. SILVA JJ, et al. Fratura tardia de seio frontal: relato de caso clínico. Revista de Cirurgia e Traumatologia Buco-Maxilo-Facial, 2005; 5: 51- 56 


\section{PC-143-2019 - PALATO OGIVAL E SEUS POSSÍVEIS TRATAMENTOS: REVISÃO DE LITERATURA}

Paloma Wanessa Basílio dos Santos ${ }^{\text {; }}$ Pedro Jordão de Almeida Silva Paz ${ }^{1}$; Júlio César Gomes de Santana ${ }^{1}$; Fernando de Oliveira Martorelli²

${ }^{1}$ Centro Universitário Maurício de Nassau - Recife - PE - Brasil

${ }^{2}$ Associação Caruaruense de Ensino Superior - ASCES - Caruaru - PE - Brasil

Autor correspondente:

Paloma Wanessa Basílio dos Santos

Palomawanessa6@gmail.com

Introdução: A atrésia esquelética do palato caracteriza-se pelo formato ogival, sendo alto, atrésico e com profundidade demasiada. Em pacientes infantis, alguns hábitos parafuncionais, nutritivos de sucção, respiração bucal e fatores genéticos são determinantes para que ocorra a modificação do palato duro ${ }^{2}$. Objetivos: Ampliar o conhecimento sobre o palato ogival relacionado a oclusão, assim como o tratamento de tal distúrbio em pacientes adultos e pediátricos. Metodologia: Pesquisas na literatura selecionadas das bases de dados PubMed, Biblioteca Virtual em Saúde e SciELO. Revisão de literatura: Alterações no osso palatino podem acarretar ao paciente maior dificuldade a respiração, inclinação vertical excessiva da língua, mordida cruzada posterior, apinhamento dentário e hipofunção do músculo orbicular da boca $^{2}$. A partir do diagnóstico, o tratamento de escolha é a expansão ortopédica da maxila com disjuntores dentomucossuportados. O disjuntor é mantido na boca por no mínimo 3 meses, tempo médio para a neoformação do osso ${ }^{3}$. Essa conduta é preferencialmente realizada em crianças, pois, a sutura intermaxilar ainda está em processo de formação. Com o envelhecimento, a resistência óssea é aumentada e a sutura intermaxilar e seus ossos são estabelecidos, fazendo-se necessária uma intervenção cirúrgica de expansão rápida da maxila. Onde, é realizada uma osteotomia na linha média entre as maxilas e a colocação de um disjuntor visando o afastamento dos ossos. Em ambos os casos, após a expansão, é observado o aparecimento gradativo de diastema entre os incisivos centrais, característico do afastamento dos ossos maxilares. Em alguns casos, pacientes que apresentam palato ogival com maloclusões classe 2 ou 3 assim como a mordida cruzada anterior, podem ser solucionadas apenas com ortodontia ${ }^{2,4}$. Conclusão: A atrésia do palato acarreta problemas secundários âo paciente e sua resolução é fundamental para uma melhor qualidade de vida. Portanto, quanto mais precoce for o diagnóstico, melhor e menos traumático será o tratamento.

Descritores: palato; ortodontia interceptora; osteotomia maxilar.

\section{Referências:}

1. MELO K, et al. Risks and complications in surgically assisted rapid maxillary expansion. Revista Gaúcha Odontol, 2013; 61(4): 615-616

2. PACHECO A, et al. Relação da respiração oral e hábitos de sucção não-nutritiva com alterações do sistema aestomatognático. Revista CEFAC, 2012; 14(2): 281-289

3. TANAKA O, et al. Detalhes singulares nos procedimentos operacionais de disjunção palatina. Revista Dental Press Ortodon, 2004; 9(4): 98-107

4. VASCONCELOS B, et al. Expansão rápida da maxila cirurgicamente assistida: estudo preliminar. Revista Bras Otorrinolaringol, 2006; 72(4): 457-461 


\section{PC-144-2019 - PAPEL DO CIRURGIÃO-DENTISTA FRENTE A PACIENTES ONCOLÓGICOS: REVISÃO DE LITERATURA}

Ademir Félix Arantes Júnior ${ }^{1}$; Carolaine Rayane Xavier da Silva ${ }^{1}$; Carolina Pereira da Silva ${ }^{1}$; Cláudia Geisa Souza e Silva ${ }^{1}$; Emily Araújo Pereira ${ }^{1}$; Girlane Iris da Silva ${ }^{1}$; Joyce Feitosa Pinho Gomes ${ }^{1}$; Amanda Maciel do Prado ${ }^{1}$

${ }^{1}$ Faculdade de Odontologia de Pernambuco - Camaragibe - PE - Brasil

Autor correspondente:

Ademir Félix Arantes Júnior

ademirarantesjr@gmail.com

Introdução: O câncer configura-se como um grande problema de saúde pública. No Brasil, é uma das maiores causas de morte por doença. Em geral, pacientes oncológicos apresentam necessidades odontológicas significativas que demandam atenção ${ }^{3}$. Objetivo: Mostrar como o cirurgião dentista pode atuar antes, durante e após o tratamento desses pacientes visando a diminuição das repercussões da doença na cavidade oral. Metodologia: Foram realizadas buscas nas bases de dados da LILACS e SciELO, utilizando os seguintes descritores: Oncologia, odontologia, tratamento. Foram encontrados cinco artigos, destes apenas quatro foram selecionados. Revisão de literatura: O tratamento oncoterápico pode resultar em sequelas ou efeitos adversos que podem até mesmo dificultar a continuidade da oncoterapia ${ }^{4}$. O nível de higiene oral, antes e durante a terapia, são fatores determinantes para a severidade das complicações bucais, como mucosite, danos as glândulas salivares, cárie de radiação e osteorradionecrose $^{2,1}$. O cirurgião dentista deve adequar a cavidade bucal visando a eliminação de focos de contaminação e traumas antes do início do tratamento oncoterápico - Manutenção da saúde, higiene oral e minimização dos efeitos adversos durante e após o tratamento ${ }^{1}$. Conclusão: $O$ cirurgião dentista é o profissional com melhores condições de avaliar e tratar as alterações bucais, assim como, aplicar medidas preventivas de acompanhamento da saúde bucal do paciente oncológico na área da cabeça e pescoço, visando minimizar os efeitos estomatológicos e funcionais causados por essa terapia, sendo imprescindível no diagnóstico precoce, tratamento e reabilitação.

\section{Descritores: Oncologia; Odontologia; Tratamento.}

\section{Referências:}

1. EMMI DT, et al. Radioterapia em cabeça e pescoço: complicações bucais e a atuação do cirurgião dentista. Revista Paraense de Medicina, 2009; 23(2): 1-8

2.HESPANHOL LF, et al.Manifestações bucais em pacientes submetidos à quimioterapia. Revista Ciência \& Saúde Coletiva, 2007; 15(1): 1085-1094

3. OSTERNE RLV, et al. Saúde bucal em pacientes portadores de neoplasias malignas: Estudo clínico-epidemiológico e análises de necessidades odontológicas de 421 pacientes. Revista Brasileira de Cancerologia, 2008; 54(3): 221-226

4. VIEIRA DL, et al. Tratamento odontológico em pacientes oncológicos. Revista Oral Sciences, 2012; 4(2): 37-42 


\section{PC-145-2019 - PAPILOMA ESCAMOSO ORAL EM REBORDO ALVEOLAR INFERIOR: RELATO DE CASO CLÍNICO}

Robson de Lima Gomes ${ }^{1}$; Andressa Cristina da Silva Queiroz ${ }^{1}$; Luiz Alcino Monteiro Gueiros ${ }^{1}$; Jair Carneiro Leão ${ }^{1}$; Marvison Henrique Ferreira da Silva ${ }^{1}$; Renata da Rocha Arcoverde ${ }^{1}$; Alessandra de Albuquerque Tavares Carvalho ${ }^{1}$

${ }^{1}$ Universidade Federal de Pernambuco - Recife - PE - Brasil

Autor correspondente:

Robson de Lima Gomes

robsonlimalive@outlook.com

Introdução: O papiloma escamoso oral (PEO) é um tumor benigno cuja patogênese tem sido associada ao papiloma vírus humano (HPV) $)^{1,2,3,4,5}$. Sua transmissão ocorre via sexual, mas existe a possibilidade por via sanguínea e contato direto ${ }^{2,4}$. Apresenta-se exofítico de superfície rugosa ${ }^{2,3,4}$. O diagnóstico é clínico e histopatológico, e a remoção cirúrgica representa o tratamento de escolha ${ }^{4}$. Objetivo: Relatar caso clínico de papiloma escamoso oral em rebordo alveolar inferior. Relato de caso: Paciente do sexo masculino, 48 anos, procurou o serviço de Estomatologia da Universidade Federal de Pernambuco, com histórico de um crescimento no rebordo alveolar inferior do lado esquerdo. Relatou possuir crise esquizofrênica e ter sido internado durante meses e ter tido relação sexual desprotegida. Ao exame físico intraoral foi identificada lesão de coloração esbranquiçada, nodular, superfície papilar, indolor. Foi realizada a biopsia excisional e a amostra encaminhada para o laboratório de patologia da UFPE, sendo confirmado o diagnóstico de PEO. Discussão: A transmissibilidade do HPV tanto por inoculação direta ou relação sexual desprotegida é relatada na literatura ${ }^{2,4}$. Com isso Possibilidades de lesões concomitantes nas regiões oral é possível, como é o caso do PEO $^{1,2,3,4,5}$. O PEO deve ser identificada e tratado e, também, requer uma abordagem profunda na anamnese e no exame clínico ${ }^{2,3,4}$. O diagnóstico definitivo deve ser feito por exame histológico, e a remoção cirúrgica representa o tratamento de escolha ${ }^{2}$. Conclusão: O paciente foi orientado quanto a importância do uso de preservativos para evitar novas infecções pelo HPV e sua relação com o PEO. Ainda se enfatiza a importância de exame clínico criterioso, destaca-se a necessidade de exame histológico para confirmação da lesão e a remoção cirúrgica é o seu tratamento de escolha.

Descritores: Papiloma; HPV; Estomatologia.

\section{Referências:}

1. AKERZOUL N, CHBICHEB S. The Efficacy of Low-Level Laser Therapy in Treating Oral Papilloma: A Case Reporting A Lingual Location. Contemporary Clinical Dentistry, 2018; 9(2): 369-372

2. ANDRADE SR, et al. Papiloma escamoso oral: uma visão sob aspectos clínicos, de fluorescência e histopatológicos. Einstein, 2019; 17(2): 1-4

3. SERRABONA JT, et al. Recurrence rate of oral squamous cell papilloma after excision with surgical scalpel or laser therapy: A retrospective cohort study. Med Oral Patol Oral Cir Bucal, 2019; 24 (4): 433-7

4. SILVA EJ, et al. Considerações relacionadas ao diagnóstico e tratamento do papilomavírus humano (hpv) em cavidade oral. Rev Odontol Univ Cid São Paulo, 2016; 28(2): 117-25.

5. VAN HWFP, et al. Human papillomavirus infection of the oral cavity: what the dentist should know. SADJ, 2017; 72(2): $52-55$ 


\section{PC-146-2019 - PARESTESIA TRANSITÓRIA UNILATERAL PÓS EXODONTIA DE TERCEIRO MOLAR INFERIOR: RELATO DE CASO}

Carolaine Rayane Xavier da Silva ${ }^{1}$; Ademir Félix Arantes Júnior ${ }^{\mathbf{1}}$; Aylanne Xavier de Lacerda Cavalcante Timoteo ${ }^{1}$; Emilly Araújo Pereira ${ }^{1}$; Girlane Iris da Silva ${ }^{1}$; Jiordanne Araújo Diniz ${ }^{1}$; Maíra Letícia Ferreira de Santana ${ }^{1}$; Maria Carolina Tavares de Lyra Menezes ${ }^{1}$

${ }^{1}$ Faculdade de Odontologia de Pernambuco - Camaragibe - PE - Brasil

Autor correspondente:

Carolaine Rayane Xavier da Silva

carolaineexavier@gmail.com

Introdução: A parestesia é uma condição que ocorre quando um nervo sensitivo é lesionado total ou parcialmente, tendo como principal sintoma a ausência de sensibilidade na região afetada de forma transitória ou permanente ${ }^{1}$. Objetivo: Relatar um caso clínico, no qual a paciente obteve uma parestesia unilateral temporária do nervo alveolar inferior após exodontia do terceiro molar inferior. Relato de caso: Paciente C.R.X.S, 22 anos, sexo feminino, compareceu no bloco cirúrgico de uma faculdade de odontologia de Pernambuco com indicação de exodontia dos terceiros molares por motivos ortodônticos. Nos exames de imagem foram observados os seguintes aspectos nos elementos 38 e 48: inclusão mésio-angular, acentuada dilaceração radicular e contato com o canal mandibular. Todo o procedimento e seus riscos foram explicados a paciente e a exodontia foi realizada. No período pós-operatório imediato e passado o efeito anestésico, a paciente percebeu ausência de sensibilidade na região do lábio inferior, mento, gengiva e dentes inferiores do lado direito. A sensibilidade retornou dentro dos primeiros 30 dias pós-operatório, caracterizando uma parestesia unilateral temporária. Discussão: A indicação ortodôntica é uma das principais razões para exodontia dos terceiros molares, entretanto, tal procedimento pode acarretar complicações, como a parestesia ${ }^{2}$. A avaliação de exames de imagem torna-se importante para conferir a posição anatômica assumida pelo canal mandibular em relação aos terceiros molares e não deve ser descartada pelos profissionais ${ }^{3}$. A parestesia apresenta como principal sintoma a ausência de sensibilidade na região afetada, mas, o paciente pode relatar a existência de outros sintomas, como formigamento e queimação ${ }^{1}$. Conclusão: Em alguns casos o quadro pode regredir de forma espontânea, porém, os cirurgiões-dentistas precisam èstâr cada vez mais cientes dos cuidados que devem ter para evitar a ocorrência de parestesia após a remoção dos terceiros molares inferiores em seus pacientes ${ }^{1}$.

Descritores: Parestesia; Cirurgia; Nervo Alveolar Inferior.

\section{Referências:}

1. DA ROSA FM, et al. Parestesia dos nervos alveolar inferior e lingual pós cirurgia de terceiros molares. RGO, 2007; 55(3): 291-295

2. KATO RB, et al. Acidentes e complicações associadas à cirurgia dos terceiros molares realizada por alunos de odontologia. Revista de Cirurgia e Traumatologia Buco-maxilo-facial, 2010; 10(4): 45-54

3. LOPES GB, DE FREITAS JB. Parestesia do nervo alveolar inferior após exodontia de terceiros molares. Arquivo Brasileiro de Odontologia, 2013; 9(2): 35-40 


\title{
PC-147-2019 - PLANEJAMENTO VIRTUAL PARA CORREÇÃO CIRÚRGICA DE DEFORMIDADE DENTOFACIAL: RELATO DE CASO
}

\author{
Torres ${ }^{5}$; Emanuel Dias de Oliveira e Silva ${ }^{4}$ \\ ${ }^{1}$ Centro Universitário Tiradentes - Recife - PE - Brasil \\ ${ }^{2}$ Centro Universitário Maurício de Nassau - Recife - PE - Brasil \\ ${ }^{3}$ Universidade Estadual Paulista - São Paulo - SP - Brasil \\ ${ }^{4}$ Hospital Universitário Oswaldo Cruz - Recife - PE - Brasil \\ ${ }^{5}$ Faculdade de Odontologia de Araraquara - São Paulo - SP - Brasil
}

Ranielly de Souza Silva ${ }^{1}$; Luana Jessica Fagundes da Silva ${ }^{1}$; José Igor Ferreira da Silva ${ }^{2}$; Natalia Barbosa de Siqueira ${ }^{3}$; Tatiane Fonseca Faro ${ }^{4}$; Kléber Rós Santos ${ }^{4}$; Luiz Henrique Soares

Autor correspondente:

Ranielly de Souza Silva

raniellyssantana@hotmail.com

Introdução: A cirurgia ortognática trata da correção cirúrgica das deformidades dentofaciais e a sua importância encontra-se na correção da oclusão e da estética facial ${ }^{1}$. Objetivo: relatar um caso clínico de um paciente com deformidade dentofacial cujo planejamento cirúrgico foi realizado por planejamento virtual utilizando-se um software de computador. Relato de caso: L.S.P, sexo masculino, 23 anos, procurou o serviço de CTBMF encaminhado pelo ortodontista após preparo ortodôntico prévio para cirurgia ortognática, a um hospital universitário de Pernambuco, queixando-se de "dor na mandíbula e aparência ruim". A análise facial evidenciou boa projeção de terço médio facial, desvio de linha média maxilar e mandibular de $1,13 \mathrm{~mm}$ para esquerda, cant maxilar de $2 \mathrm{~mm}$, overjet negativo de $3 \mathrm{~mm}$. Através de planejamento virtual utilizando-se o software Dolphin, foi programado correção de $1,3 \mathrm{~mm}$ de desvio de linha média, 1,5 de yaw para esquerda, $2^{\circ}$ de cant para esquerda. Foi realizada osteotomia Le Fort I em maxila e sagital do ramo mandibular bilateral. Encontra-se em acompanhamento pós-operatório de 12 meses. Discussão: A qualidade de vida relacionada à saúde de pacientes com desarmonia dentofacial grave, mostra o número de pacientes que necessitam realizar este tipo de cirurgia aumentou e eles são jovens. A avaliação feita pelo paciente é o indicador importante no tratamento, considerando que pode ocorrer insatisfação com os resultados cirúrgicos, mesmo sucedidos ${ }^{2}$. GATENO ašsegura que o planejamento cirúrgico e a confecção de guias cirúrgicos são realizados através do computador. Pacientes com deformidades craniofaciais e maxilofaciais se submetem à tomografia computadorizada. Um modelo de crânio em 3D é gerado, e são realizadas as osteotomias virtuais planejadas para cada paciente ${ }^{3}$. Conclusão: deformidades dentofaciais acarretam transtornos funcionais, estéticos e psicológicos. A execução de cirurgias ortognáticas obedecem a um planejamento em que o cirurgião tenha conhecimento a respeito desse tipo de cirurgia, para que não obtenha resultados desagradáveis.

Descritores: Cirurgia Ortognática; Anormalidades Maxilofaciais; Má oclusão.

\section{Referências:}

1. NICODEMO D, et al. Cirurgia ortognática: abordagem psicossocial em pacientes Classe III de Angle submetidos à correção cirúrgica da deformidade dentofacial. Rev. Dental Press Ortodon Ortop Facial, 2007; 12(5): 46-54

2. CUNNINGHAM SJ, et al. Development of a condition-specific quality of life measure for patients with dentofacial deformity: II. Validity and responsiveness testing. Community Dent. Oral Epidemiol, 2002; 30: 81-90

3. GATENO J, et al. The precision of computer-generated surgical splints. J. Oral Maxillofac. Surg., 2003; 61(7): 814-7 


\section{PC-148-2019 - PROGRAMA DE EXTENSÃO UNIVERSITÁRIA RESGATANDO SORRISOS: ESTUDO CLÍNICO E SOCIODEMOGRÁFICO DE USUÁRIOS DE PRÓTESE DENTÁRIA DA REGIÃO NORDESTE BRASILEIRA}

Maria Eduarda Ferrer Siqueira Carneiro ${ }^{1}$; Rafaella de Souza Leão ${ }^{1}$; JoelFerreira Santiago Junior $^{2}$; Fabyano Palheta Costa ${ }^{1}$; Francisco Henrique Lima Milhomens ${ }^{1}$; Rafaela Pereira Deschamps Muniz ${ }^{1}$; Bruna da Rocha Neves ${ }^{1}$; Sandra Lúcia Dantas de Moraes ${ }^{1}$

${ }^{1}$ Faculdade de Odontologia de Pernambuco (FOP/UPE) - Camaragibe - PE - Brasil

${ }^{2}$ Universidade Sagrado Coração (USC) - Bauru - SP - Brasil

Autor correspondente:

Maria Eduarda Ferrer Siqueira Carneiro

dudaferrer97@gmail.com

Introdução: A odontologia brasileira apresentou grandes avanços nas últimas décadas, houve uma expressiva redução da quantidade de dentes perdidos, assim como aumento da fluoretação nas águas, entretanto ainda há muitos pacientes desdentados totais no Brasil ${ }^{1}$. Objetivo: Realizar uma análise transversal clínica e sociodemográfica de pacientes edêntulos bimaxilares, os quais foram reabilitados, em um período de 3 anos (2017-2019), por meio de um programa de extensão universitária. Metodologia: Estudo epidemiológico transversal executado em 58 pacientes. O projeto foi aprovado no comitê de ética em pesquisa em seres humanos: CAAE 31255714.5.0000.5207/aprovação: 672.981. Resultados e Discussão: Observou-se que $74,13 \%$ da amostra é do gênero feminino. Perfil de participantes idosos com média de $63,0 \pm 10,61$ anos. Em uma análise da profissão dos participantes, 26,3\% eram aposentados, nos demais destacou-se o trabalho na agricultura ou atividades do lar. Os participantes se apresentavam desdentados totais em média 24,3 $\pm 15,3$ anos (maxila) e 22,14 $\pm 14,22$ (mandíbula). O tempo de uso das próteses totais foi semelhante entre a arcada superior $(11,97 \pm 10,97)$ e inferior $(11,45 \pm 8,69)$. Em relação ao método de higienização das próteses totais, destacou-se em $57,14 \%$ da amostra houve predominância do método de escovação com creme dental. Em relação ao hábito de dormir com a prótese, observou-se que 25 pacientes $(52,08 \%)$ apresentavam esta prática. Em uma análise considerando fibromucosa patológica, foram identificados 11 pacientes com estomatite e 35 normais. Observa-se que há necessidade de uma ampliação das políticas de saúde bucal e aumento no acesso da população ao serviço de prótese dentária. Assim como a realização de capacitações aos profissionais da Atenção Básica com relação ao acompanhamento e controle clínico destes usuários ${ }^{2,3}$. Conclusão: Salienta-se a necessidade de ampliação e fortalecimento da rede de atenção à saúde bucal.

Descritores: Prótese total; Saúde pública; Política de Saúde.

\section{Referências:}

1. DA VEIGA PESSOA DM, et al. Economic and sociodemographic inequalities in complete denture need among older Brazilian adults: a cross-sectional population-based study. BMC Oral Health, 2016; 17(1): 5

2. LEÃO RS, et al. Conhecimento sobre uso, conservação e higienização de próteses totais em população desfavorecida socioeconomicamente assistida por um projeto de extensão universitária. Salusvita, 2017; 36(2): 409-425

3. PUCCA GA JR, et al. Ten Years of a National Oral Health Policy in Brazil: Innovation, Boldness, and Numerous Challenges. J Dent Res, 2015; 94(10): 1333-7 


\section{PC-149-2019 - PROJETO SAÚDE COLORIDA: RELATO DE EXPERIÊNCIA}

Letícia Fernanda Serafim Cabral ${ }^{1}$; Fabiana de Godoy Bené Bezerra Laureano ${ }^{1}$; Raíssa Soares dos Anjos ${ }^{1}$; Laís Lavínia Cruz Soares ${ }^{1}$; Maria Beatriz Arruda Albuquerque ${ }^{1}$; Fernanda Ariel da Silva Vasconcelos ${ }^{1}$; Maria Clara Ribeiro de Amorim Tabosa ${ }^{1}$; Pedro Paulo Aguiar Santos Cavalcanti ${ }^{1}$

${ }^{1}$ Faculdade de Odontologia de Pernambuco - Camaragibe - PE - Brasil

Autor correspondente:

Letícia Fernanda Serafim Cabral

leticiafscabral@hotmail.com

Introdução: A adolescência é uma fase de grandes transformações biopsicossociais e desafios. Concomitantemente, a mídia impõe seu padrão de beleza que conduz os adolescentes a problemas como: baixa autoestima, isolamento social, comportamento alimentar inadequado e transtorno alimentar ${ }^{1,2}$. É nessa fase que o indivíduo fica mais vulnerável a comportamentos de risco à saúde, como anorexia e bulimia. Nesses casos, o Cirurgião-dentista pode ser um dos primeiros profissionais a suspeitar dessas patologias devido aos sinais e sintomas de erosão dental resultantes de um ambiente bucal cronicamente ácido ${ }^{3}$. Tais achados, apontam a importância de alertar os adolescentes sobre práticas de dieta pouco saudáveis ${ }^{4}$. Objetivo: Promover a prevenção dos comportamentos de risco à saúde do adolescente com relação aos seus hábitos alimentares através de ações coletivas de educação em saúde em sala de aula. $\mathrm{O}$ projeto tem como alvo os adolescentes entre 13 e 19 anos, de ambos os sexos, matriculados nas séries do Ensino Médio da escola Santa Apolônia (Camaragibe - Pernambuco). Relato de experiência: Os temas abordados pelo projeto são apresentados de forma educativa/lúdica, promovendo troca de experiências e construção de novos mecanismos de promoção à saúde. Além disso, as ações multidisciplinares envolvem os alunos de graduação e pós-graduação. Já os escolares se interessam pelos temas abordados e interagem nas dinâmicas propostas, esclarecendo dúvidas e sugerindo novos temas a serem debatidos nas próximas ações. Discussão: Percebeu-se que a maioria dos estudantes tem interesse e conhecimento sobre o tema. Portanto, ocorreu interação, discussão e esclarecimento de dúvidas durante os debates. Somado a isso, os participantes sugerem novos tópicos a serem abordados nas próximas ações do projeto. Conclusões: $O$ projeto contribui na conscientização dos adolescentes sobre distúrbios alimentares e medidas de controle de peso, mas a questão ainda é pouco abordada, sendo necessária a elaboração de outros mecanismos de promoção à saúde do adolescente.

Descritores: Adolescência; Hábitos Alimentares; Nutrição do Adolescente.

\section{Referências:}

1. CORSEUIL MW, et al. Prevalência de insatisfação com a imagem corporal e sua associação com a inadequação nutricional em adolescentes. Rev Educ Fís/UEM, 2009; 20: 25-31

2. GLANER MF, et al. Associação entre insatisfação com a imagem corporal e indicadores antropométricos em adolescentes. Revista Brasileira de Educação Física e Esporte, 2013; 27(1): $129-136$

3. TRAEBERT J, MOREIRA EAM. Transtornos alimentares de ordem comportamental e seus efeitos sobre a saúde bucal na adolescência. Pesqui Odontol Bras, 2001; 15(4): 359-363

4. WESTERBERG-JACOBSON J, et al. A 5-year longitudinal study of the relationship between the wish to be thinner, lifestyle behaviours and disturbed eating in 9-20-year old girls. European Eating Disorders Review, 2010; 18(3): 207-219 


\section{PC-150-2019 - PROMOÇÃO DE SAÚDE BUCAL NA PRAIA: RELATO DE EXPERIÊNCIA}

Lukas Mendes de Abreu ${ }^{1}$; Jacianny Laurindo Pereira ${ }^{1}$; Thalia Franciele Barreto Cordeiro ${ }^{1}$; Bergson Carvalho de Moraes²; Renata Patrícia Freitas Soares de Jesus ${ }^{2}$

${ }^{1}$ Centro Universitário Tiradentes - Recife - PE - Brasil

${ }^{2}$ Universidade Federal de Pernambuco - Recife - PE - Brasil

Autor correspondente:

Lukas Mendes de Abreu

lukasmendes.abr@gmail.com

Introdução: A exposição solar pode causar muitas vezes, danos irreparáveis, principalmente se ocorrer de forma constante e sem proteção adequada ${ }^{2}$. Na área odontológica, entre as patologias que podem ser desenvolvidas pela radiação, destaca-se a queilite actínica e o carcinoma epidermóide de lábio ${ }^{3}$. Objetivo: Apresentar um relato de experiência de um projeto de extensão de promoção à saúde. Relato de experiência: $O$ projeto realizou ações nas praias dos municípios de Recife, Olinda e Jaboatão dos Guararapes, no ano de 2018 e 2019 a atividades realizadas tiveram uma repercussão positiva tendo em vista que o público abordado era muito carente de informação e grande parte dele sempre demonstrava muito interesse pelas informações que eram passadas. O público relatou o desconhecimento acerca da existência de serviços voltados a saúde bucal e questionou bastante a falta de acessibilidade a tais serviços. Destaca-se que declararam se sentir esquecido pelo poder público e que apoiam iniciativas como a desse projeto o qual tem o potencial de modificar o status destes indivíduos em relação a sua saúde oral. Discussão: Diante disso, é preocupante a exposição de barraqueiros, ambulantes e pescadores de praias a radiação solar sem a devida proteção. Conclusão: Sabendo que tais trabalhadores estão expostos a fatores de riscos, como a exposição solar, sujeitos a condições de trabalho precárias, sem apoio e assistência necessária ${ }^{1}$, foi sugerido uma proposta de intervenção através de ações sociais com a extensão dos conhecimentos adquiridos na faculdade para a população, promovendo assim uma melhoria na qualidade de vida desses trabalhadores para que continuem a desenvolver suas atividades laborais de forma segura e preventiva.

Descritores: Carcinoma de Células Escamosas; Queilite; Saúde Bucal.

\section{Referências:}

1. ARAÚJO MCB, et al. Análise do comércio formal e informal na Praia de Boa Viagem, Recife, Pernambuco, Brasil. Revista de Gestão Costeira Integrada, 2012; 12( 3): 373-388

2. CINTRA JS, et al. Queilite actínica: estudo epidemiológico entre trabalhadores rurais do município de Piracaia-SP. Revista da Associacao Paulista de Cirurgioes Dentistas, 2013; 67(2):118-121

3. VÉO PCR, et al. Tratamento cirúrgico da queilose actínica. RGO. Revista Gaúcha de Odontologia (Online), 2010; 58(3): 393-397 


\section{PC-151-2019 - PRÓTESE ADESIVA DIRETA: ALTERNATIVA REABILITADORA PARA O SERVIÇO PÚBLICO DE SAÚDE}

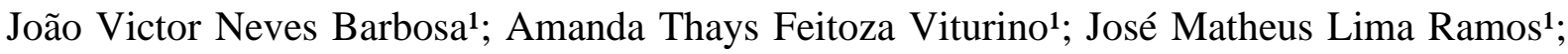
Carolina Pereira da Silva ${ }^{1}$; Normando Carlos da Silva Junior ${ }^{1}$; Mônica Maria de Albuquerque Pontes $^{1}$; Maria Regina Almeida de Menezes ${ }^{1}$; Juliana Raposo Souto Maior ${ }^{1}$

${ }^{1}$ Faculdade de Odontologia de Pernambuco - Camaragibe - PE - Brasil

Autor correspondente:

João Victor Neves Barbosa

barbosaj08@gmail.com

Introdução: Os elementos dentais anterossuperiores são mais comumente e gravemente afetados em caso de acidentes, tanto por sua anatomia como por sua posição na arcada dentária ${ }^{1}$. Tais acidentes podem provocar fraturas coronárias extensas, as quais são situações em que o plano de tratamento deve ser realizado de modo que se permita formular um bom prognóstico a médio e longo prazo, não apenas em termos de estética, mas também considerando os aspectos biológicos e funcionais ${ }^{4}$. Uma das técnicas de tratamento disponíveis para a substituição protética de um único dente é a prótese adesiva². Objetivo: Relatar um caso de paciente com fratura coronal extensa no terço cervical tratado com prótese fixa adesiva. Relato de caso: Paciente H.D.M.R., sexo masculino, 29 anos, apresentou-se em uma faculdade de odontologia de Pernambuco queixando-se de desconforto estético devido a uma fratura extensa no terço cervical da coroa do elemento dentário 21 , a qual estava sendo mantida em posição por um aparelho ortodôntico com tratamento finalizado. Foi realizada a remoção do aparelho ortodôntico e a exodontia do resto radicular do elemento dentário, e após uma semana, foi realizada a confecção da prótese fixa adesiva direta. Discussão: As próteses adesivas têm sido amplamente indicadas, principalmente devido à preservação da estrutura dentária, e, quando corretamente confeccionadas, demonstram um alto índice de sucesso ${ }^{3}$. Conclusões: As próteses adesivas diretas se apresentam como uma alternativa de tratamento reabilitador, devido à preservação da estrutura dentária, facilidade de confecção, estética e função adequadas.

Descritores: Prótese Adesiva; Tratamento; Estética.

\section{Referências:}

1. ANDREASEN JO. Etiology and pathogenesis of traumatic dental injuries. A clinical study of 1,298 cases. Scandinavian Journal of Dental Research, 1970; 78(4): 329-342

2. CASTRO JCM, et al. Prótese adesiva: uma opção estética, conservadora e funcional. Revista Gaúcha de Odontologia, 2006; 54(3): 225-229

3. JORGE JH, et al. Considerações gerais sobre prótese fixa adesiva. Arquivos em Odontologia, 2011; 47(3): 170-177

4. KEGLER E, et al. Tratamento estético em dentes anteriores: rapidez e simplicidade com procedimentos diretos. Revista Dental Press de Estética, 2009; 6(2): 64-76 


\title{
PC-152-2019 - PROTOCOLO CIRÚRGICO DE FERIMENTO EXTENSO EM FACE POR ARMA BRANCA: RELATO DE CASO
}

Ronaldo Gabriel Martiniano da Silva ${ }^{4}$; Amanda Regina Silva de Melo ${ }^{1}$; Carlos Augusto Pereira do Lago ${ }^{1}$; Felipe Ricardo Cisneiros Brito ${ }^{2}$; Greiciane Miguel de Azevedo Santos ${ }^{2}$; Kássia Regina de Santana ${ }^{2}$; Leandro Pimentel Cabral ${ }^{3}$; Rosa Rayanne Lins de Souza ${ }^{1}$

\author{
${ }^{1}$ Hospital da Restauração Governador Paulo Guerra - Recife - PE - Brasil \\ ${ }^{2}$ Faculdade de Odontologia de Pernambuco - Camaragibe - PE - Brasil \\ ${ }^{3}$ Universidade Federal de Pernambuco - Recife - PE - Brasil \\ ${ }^{4}$ Centro Universitário Tiradentes de Pernambuco - Recife - PE - Brasil
}

Autor correspondente:

Ronaldo Gabriel Martiniano da Silva

Ronaldo.rgms77@gmail.com

Introdução: As lesões traumáticas que acometem o complexo maxilofacial podem ser originadas, como exemplo, por acidentes de trânsito, agressões físicas, desportivos e de trabalho ${ }^{3}$. As injúrias em tecido mole causadas por arma branca ocorrem, em sua maioria, na faixa etária dos 15 aos 35 anos de idade associadas, frequentemente, ao consumo de bebida alcoólica, acarretando complicações graves ao paciente ${ }^{2}$. Objetivo: Relatar um caso clínico a respeito do tratamento cirúrgico de ferimento complexo por arma branca. Relato de Caso: Paciente, MS, sexo masculino, 24 anos, deu entrada no serviço de urgência/emergência do Hospital da Restauração em Pernambuco, vítima de agressão por arma branca, apresentando lesão corto-contusa associada à fratura cominutiva de região supra orbital esquerda e dilaceração do músculo temporal. Devido ao sangramento intenso, necessitou-se a abordagem da equipe da cirurgia buco-maxilo em bloco cirúrgico para realização de hemostasia, sutura extensa e fixação de fratura com placa e parafuso de titânio do sistema $1.5 \mathrm{~mm}$ em região. Discussão: $O$ tratamento deve priorizar inicialmente a estabilização do paciente com avaliação e manutenção das vias aéreas superiores, seguido de controle hemodinâmico e avaliação neurológica ${ }^{1}$. A fim de conter o sangramento, observou- se a importância da realização do procedimento adequado sob anestesia geral e, dessa forma, a fim de evitar segundo tempo cirúrgico, definiu-se a abordagem definitiva para reconstituição e fixação de fraturas. Conclusão: $\mathrm{O}$ tratamento feito com fixação da região supra orbital e a realização de sutura extensa, em área periocular, frontal e temporal, demonstrou excelente resultado. Porém, no póscirúrgico, o paciente apresentou sequela traumática de ptose ocular esquerda, em decorrência do dano causado ao ramo temporal do nervo facial.

Descritores: Traumatismos faciais; Lesões contundentes; Ferimentos penetrantes.

\section{Referências:}

1. JÚNIOR PA, et al. Ferimento a faca impactada na face (Síndrome de Jael): relato de caso. Revista de Cirurgia e Traumatologia Buco-Maxilo-Facial, 2010; 10(1): 09-14

2. PAIVA LGJ, et al. Fratura mandibular após ferimento por arma branca - diagnóstico e conduta clínica. Revista Odontológica do Brasil Central, 2013; 21(61): 100-102

3. PROVASI S, et al. Trauma facial: ferimento por arma branca. relato de caso. Revista de Odontologia da Universidade Cidade de São Paulo, 2017; 29(3): 305-311 


\section{PC-153-2019 - QUERATOCISTO MIMETIZANDO UMA LESÃO PERIAPICAL INFLAMATÓRIA}

Victor Alexandre Felício Trancoso ${ }^{1}$; Hélen Kaline Farias Bezerra ${ }^{1}$; Flávia Maria de Moraes Ramos-Perez ${ }^{1}$; Danyel Elias da Cruz Perez ${ }^{1}$; Maria Luiza dos Anjos Pontual ${ }^{1}$; Andrea dos Anjos Pontual $^{1}$; Eduarda Helena Leandro Nascimento ${ }^{1}$

${ }^{1}$ Universidade Federal de Pernambuco - Recife - PE - Brasil

Autor correspondente:

Victor Alexandre Felício Trancoso

victortrancoso11@gmail.com

Introdução: O queratocisto é classificado como um cisto odontogênico do desenvolvimento, que acomete preferencialmente pacientes do sexo masculino, entre a $2^{\mathrm{a}}$ e a $3^{\mathrm{a}}$ décadas de vida, e ocorre com maior frequência na região posterior do corpo e ramo da mandíbula ${ }^{3}$. Objetivo: Apresentar um caso de queratocisto odontogênico que, inicialmente, foi erroneamente diagnosticado e tratado como um cisto radicular. Relato de caso: Paciente do sexo feminino, 74 anos, compareceu a um serviço de Radiologia Odontológica para realizar um exame periapical completo. Nas imagens, observou-se uma imagem radiolúcida, bem delimitada, localizada na região apical dos dentes 43,44 e 45 , os quais apresentavam tratamento endodôntico há cerca de 1 ano. Como não foi possível visualizar totalmente os limites da lesão, uma radiografia panorâmica foi realizada, mostrando seu formato arredondado e parcialmente corticalizado. Para avaliar o aspecto vestíbulo-lingual da lesão, foi solicitada uma tomografia de feixe cônico, que revelou mínima expansão e afinamento da cortical vestibular, além de discreta reabsorção radicular dos dentes envolvidos. A principal hipótese de diagnóstico foi de um queratocisto que tinha sido erroneamente diagnosticado como um cisto radicular. Por fim, foi realizada a biópsia excisional da lesão e o exame histopatológico confirmou a presença de um queratocisto odontogênico. Discussão: $O$ presente relato aborda um caso de um queratocisto odontogênico que radiograficamente se observa fora das características mais comuns, como o crescimento ântero-posterior dentro dos espaços medulares na região posterior da mandíbula ${ }^{2}$. Assim como alguns cistos odontogênicos do desenvolvimento podem mimetizar lesões endodônticas, os tumores odontogênicos também podem mimetizar essas lesões periapicais ${ }^{1}$. Conclusão: Esse relato de caso destaca a importância do exame clínico e do teste de sensibilidade pulpar para excluir hipóteses de diagnóstico como as lesões periapicais inflamatórias. Também, os exames por imagem contribuíram de forma significativa para o diagnóstico da lesão.

Descritores: Cistos Ósseos; Diagnóstico; Diagnóstico por Imagem.

\section{Referências:}

1. AMORIM RFB, FREITAS RA. Ameloblastoma periapical mimetizando lesão de natureza endodontica. Revista brasileira de patologia oral, 2003; 2(3):36-39

2. CRUZ MK, THOMAZ LA. Avaliação da prevalência, características demográficas e aspectos radiográficos do tumor odontogênico queratocisto. Revista brasileira de cirurgia da cabeça e pescoço, 2015; 44(3):119-123

3. WRIGHT JM, VERED A. Update from $4^{\text {th }}$ Edition of the World Health Organization Classification of Head and Neck Tumors: Odontogenic and Maxillofacial Bone Tumors. Head and neck pathology, 2017; 11(1):68-77 


\section{PC-154-2019 - QUERUBISMO: REVISÃO DE LITERATURA}

Arthur Alves Thomaz de Aquino ${ }^{1}$; Carolina Pereira da Silva ${ }^{1}$; Francisco Henrique Lima Milhomens $^{\mathbf{1}}$; Heitor Tavares de Araújo ${ }^{\mathbf{1}}$; Hugo Igor Rodrigues de Barros ${ }^{\mathbf{1}}$; Marcela Lins Braga ${ }^{\mathbf{1}}$; Pedro Paulo Ribeiro de Farias ${ }^{1}$; Rosa Rayanne Lins de Souza ${ }^{2}$

${ }^{1}$ Faculdade de Odontologia de Pernambuco - Camaragibe - PE - Brasil

${ }^{2}$ Hospital da Restauração Governador Paulo Guerra/SES - Recife - PE - Brasil

Autor correspondente:

Arthur Alves Thomaz de Aquino

arthur.aquino29@gmail.com

Introdução: O Querubismo é uma lesão fibroóssea rara, benigna e não neoplásica, de caráter hereditário autossômico dominante, que acomete crianças com predileção pelo gênero masculino ${ }^{1}$. Objetivo: O estudo visa descrever as características do Querubismo, a fim de se obter uma melhor explanação sobre tal patologia. Metodologia: Foi realizada uma busca bibliográfica com artigos disponíveis no LILACS, PubMed e Bireme, publicados entre 2005 e 2019, com os termos "Querubismo", "Óssea" e "Patologia". Revisão de literatura: Tal lesão inicia na infância, na qual lesões proliferativas no interior da mandíbula e da maxila causam expansão progressiva e indolor, geralmente bilateral e simétrica, dando um aspecto de face alargada e arredondada, assim como um olhar fixo e para cima, características essas que os tornam semelhantes aos anjos representados nas artes do período renascentista, chamados de querubins; Essas lesões tendem a progredir até a puberdade, que é quando paralisa seu curso e evolui na idade adulta ${ }^{2,1}$. O diagnóstico geralmente é realizado por meio de exames radiográficos, histológicos, evolução clínica da doença e hereditariedade ${ }^{3,2}$. Conclusão: $\mathrm{O}$ tratamento para a doença depende do curso clínico, sendo necessário o seu acompanhamento clínico e radiográfico; porém não existe nenhum protocolo definindo qual é o melhor tipo de tratamento para cada caso. Sendo assim, fica a critério do cirurgião-dentista avaliar o melhor procedimento para seu paciente ${ }^{1}$.

Descritores: Querubismo; Osso; Patologia.

\section{Referências:}

1. OLIVEIRA FMP, et al. Querubismo: aspectos clínicos, radiográficos e terapêuticos. Journal of the Health Sciences Institute, 2008; 26(2): 254-257

2. PIVA F, et al. Querubismo: relato de caso. Revista Gaúcha de Odontologia, 2006; 54(3): 265-268

3. QUEIROZ AM, et al. Querubismo: revisão de literatura, relato de caso e tratamento odontológico-cirúrgico em paciente portador da síndrome de Ramon.Revista da Faculdade de Odontologia da UPF, 2005; 10(1): 13-16 


\section{PC-155-2019 - REABILITAÇÃO ESTÉTICA E FUNCIONAL EM PACIENTE COM CÁRIE SEVERA DA INFÂNCIA: RELATO DE CASO}

Thalia Franciele Barreto Cordeiro ${ }^{\mathbf{1}}$; Lukas Mendes de Abreu ${ }^{\mathbf{1}}$ Jacianny Laurindo Pereira ${ }^{\mathbf{1}}$; Bergson Carvalho de Moraes²; Valeria Fernandes Maranhão ${ }^{1}$

${ }^{1}$ Centro Universitário Tiradentes - Recife - PE - Brasil

${ }^{2}$ Universidade Federal de Pernambuco - Recife - PE - Brasil

Autor correspondente:

Thalia Franciele Barreto Cordeiro

thaliabarretoo789@hotmail.com

Introdução: A cárie precoce da infância (CPI), é uma doença crônica e infecciosa, de etiologia multifatorial e que é caracterizada pela presença de um ou mais dentes decíduos cariados, perdidos ou restaurados em crianças abaixo dos 6 anos de idade 3 . A existência de qualquer sinal de lesão de cárie em superfície lisa em crianças com menos de 3 anos de idade é indicativa de cárie severa da infância (CSI) ${ }^{1}$. Objetivo: Apresentar um caso clínico a respeito da reabilitação estética e funcional em paciente com carie severa da infância. Relato de caso: Paciente do gênero feminino, 2 anos e 7 meses de idade, não colaborativa, compareceu a clínica infantil do Centro Universitário de Pernambuco, conduzida pela mãe com a queixa principal que os dentes estavam quebrando e ficando escuros. Ao exame clínico, notou-se a existência de amplas destruições coronárias nos incisivos superiores, havendo a presença de fístula na região correspondente do dente 62. Optou-se por dividir o tratamento em duas sessões, na $1^{\text {a }}$ sessão foi realizada a remoção do tecido cariado com uso de instrumentos rotatórios nos dentes 51,52 , 61 e 62, tratamento endodôntico dos dentes 52, 61 e 62 . Na $2^{\mathrm{a}}$ sessão que foi feita a reconstrução coronária com o auxílio de matrizes anatômicas de celuloide nessa mesma sessão foi feito acabamento e polimento da reconstrução coronária que foi realizada com resina composta. Discussão: A CPI e a CSI são capazes de influenciar negativamente a qualidade de vida das crianças afetadas, causando dores, dificuldades na alimentação, no sono e no aprendizado ${ }^{2}$. As orientações e esclarecimentos prestados ao núcleo familiar da criança acometida pela CPI são de extrema importância para o sucesso do tratamento. Conclusão: De acordo com o caso clínico apresentado, o tratamento reabilitador estético e funcional na criança mostrou-se bem sucedido, sendo possível conduzi-lo em ambiente ambulatorial.

Descritores: Reabilitação Bucal; Odontopediatria; Estética Dentária.

\section{Referências:}

1. DAINEZI VB, et al. Reabilitação estética e funcional na primeira infância: relato de caso. Revista da Associacao Paulista de Cirurgioes Dentistas, 2015; 69(4): 387-393

2. LARANJO E, et al. A cárie precoce da infância: uma atualização. Revista da Portuguesa de Medicina Geral e Familiar, 2017; 33(6): 426-429

3. MIYATA LB, et al. Reabilitação estética e funcional em paciente com cárie severa da infância: relato de caso. Revista da Associacao Paulista de Cirurgioes Dentistas, 2014; 68(1): $22-29$ 


\section{PC-156-2019 - REABILITAÇÃO ORAL ESTÉTICA EM DENTES ANTERIORES COM LAMINADOS CERÂMICOS DE DISSILICATO DE LÍTIO: UM RELATO DE CASO}

Ana Paula Bezerra ${ }^{1}$; Cláudia Geisa Souza e Silva ${ }^{1}$; Cláudio Paulo Pereira de Assis ${ }^{1}$; Maria Hermínia Annibal ${ }^{1}$; Rodivan Braz da Silva Junior ${ }^{1}$; Rodivan Braz da Silva ${ }^{1}$

${ }^{1}$ Faculdade de Odontologia de Pernambuco - Camaragibe - PE - Brasil

Autor correspondente:

Ana Paula Bezerra

anapaula_a10@hotmail.com

Introdução: Na busca pela união da estética e função, os laminados cerâmicos de Dissilicato de Lítio possibilitam aumento da resistência, oferecendo longevidade na aplicabilidade clínica ${ }^{1}$. Objetivo: Relatar um caso clínico de reabilitação oral estética em dentes anteriores, utilizando um sistema cerâmico à base de Dissilicato de Lítio (IPS e.max Ivoclar Vivadent). Relato de caso: Paciente S. N. M, 23 anos, sexo feminino, apresentou-se à clínica da especialização em Dentística Estética da Faculdade de Odontologia de Pernambuco, insatisfeita com o escurecimento dos dentes 12 e 22 que eram tratados endodonticamente. Após o planejamento do sorriso realizou-se uma gengivectomia para o alinhamento dos zênites gengivais nos dentes anteriores superiores. Foram colocados pinos de fibra de vidro nos dentes 12 e 22 e confeccionados munhões em resina composta para coroas totais. Os dentes 13, 11, 21 e 23 foram preparados para receber laminados cerâmicos. Na cimentação utilizou-se os cimentos resinosos Allcem Veneer (FGM) para os laminados cerâmicos e Allcem Core (FGM) para as coroas cerâmicas. Os dentes foram previamente condicionados com ácido fosfórico 37\% (Condac 37 - FGM), seguidos da aplicação do sistema adesivo (Ambar-FGM). O preparo das superfícies internas das peças cerâmicas foi realizado com ácido fluorídrico a $10 \%$ (Condac Porcelana - FGM), seguido da aplicação do agente de união silano (Prosil - FGM) e do sistema adesivo. Posteriormente, o acabamento das margens com bisturi $\mathrm{n}^{\mathbf{0}} 12$ e o ajuste oclusal foi realizado. Discussão: Os laminados cerâmicos proporcionam pouco ou em alguns casos nenhum desgaste de tecido dentário sadio ${ }^{4}$. Entretanto, várias modalidades de tratamentos reabilitadores estão à disposição e desde que sejam bem indicados e executados, fica à critério do profissional a escolha para cada caso ${ }^{5}$. Conclusões: O Dissilicato de Lítio é um sistema cerâmico que une alta resistência à excelente estética, conferindo longevidade, desempenho clínico e boas propriedades mecânicas ${ }^{1}$.

Descritores: Cerâmica; Estética; Reabilitação.

\section{Referências:}

1. BISPO LB. Laminados cerâmicos na clínica integrada. Revista de Odontologia da Universidade Cidade de São Paulo, 2018; 30(1): 83-94

2. MENEZES MS, et al. Reabilitação estética do sorriso com laminados cerâmicos: Relato de caso clínico. Revista Odontológica do Brasil-Central, 2015; 24(68): 37-43

3. PERRONI AP, et al. Laminado cerâmico e coroa de dissilicato de lítio para restauração de incisivos centrais superiores. Revista PróteseNews, 2015; 2(2): 156-165

4. RIBEIRO RA, et al. Restabelecimento estético e funcional com laminados cerâmicos: Relato de caso. Revista Prosthesis and Esthetics in Science, 2016; 5(19): 67-77

5. VIEIRA AC, et al. Abordagem interdisciplinar na reabilitação estética do sorriso. Revista Odontológica de Araçatuba, 2018; 39(2): 54-59 


\section{PC-157-2019 - REAÇÃO DE CORPO ESTRANHO EM LÁBIO INFERIOR}

Heitor Tavares de Araújo ${ }^{1}$; Carolina Pereira da Silva ${ }^{1}$; André Filipe Moura Alves ${ }^{1}$; Cleiton Rone dos Santos Lima'; Demóstenes Alves Diniz²; Jéssica da Silva Cunha²; Kalyne Kelly Negromonte Gonçalves ${ }^{2}$

${ }^{1}$ Faculdade de Odontologia de Pernambuco - Camaragibe - PE - Brasil

${ }^{2}$ Hospital da Restauração Governador Paulo Guerra - Recife - PE - Brasil

Autor correspondente:

Heitor Tavares de Araújo

Heitortav@gmail.com

Introdução: $O$ piercing consiste na perfuração da pele ou de tecidos adjacentes, com o intuito de inserir um objeto metálico. Por ser um procedimento invasivo, a sua instalação pode trazer diversos transtornos. As complicações mais recorrentes são o sangramento, trauma tecidual e infecções, principalmente na cavidade bucal ${ }^{1}$. Objetivo: Relatar um caso clínico de uma paciente que após trauma local apresentou intrusão de piercing em lábio inferior. Relato do caso: Paciente do gênero feminino, 21 anos de idade, que procurou o serviço de Cirurgia e Traumatologia Buco-Maxilo-Facial de um hospital em Recife-PE, com história de presença de corpo estranho em lábio inferior há mais ou menos 15 dias, evoluindo com infecção local e febre. Ao exame físico apresentava aumento de volume em região de lábio inferior. O exame de imagem sugeria material radiopaco compatível com corpo estranho em lábio inferior. A paciente foi submetida à cirurgia sob anestesia local para remoção do objeto metálico no interior do tecido mole, bem como instalação de antibioticoterapia por via oral. Discussão: $O$ uso do piercing pode causar danos aos dentes, ao periodonto e aos tecidos de revestimento, devido as complicações, o cirurgião-dentista deve orientá-lo quanto à higienização, pois o piercing pode acumular placa e cálculo dental, dificultando a higienização do paciente ${ }^{2}$. Conclusões: Tendo em vista o aumento crescente do uso de piercing oral entre pacientes jovens, cabe aos Cirurgiões-Dentistas orientar os pacientes quanto às desvantagens do uso e aos cuidados com a higienização para que minimize os riscos na cavidade oral ${ }^{3}$.

Descritores: Piercing Corporal; Lábio; Inflamação.

\section{Referências:}

1. FERREIRA ICSR, et al. Reação de corpo estranho causada por piercing oral. Revista Brasileira de Patologia Oral, 2004; 3(2):88-91

2. MARQUEZAN M, et al. Piercing oral: beleza, riscos e o papel da odontologia. Revista da Faculdade de Odontologia de Porto Alegre, 2008; 49(1): 12-15

3. PÉCORA GA, et al. Complicações Decorrentes da Utilização do Piercing Bucal - Avaliação e Conduta Clínica. Revista Instituto Metodista de Ensino Superior, 2010; 18(36): 51-57 


\section{PC-158-2019 - REARMONIZAÇÃO ESTÉTICA DO SORRISO UTILIZANDO TÉCNICA SEMI-DIRETA: RELATO DE CASO}

Fernanda Gomes Barros ${ }^{1}$; Francisco Henrique Lima Milhomens ${ }^{1}$; Carolina Pereira da Silva ${ }^{1}$; Maria Eduarda Arruda de Lucena ${ }^{1}$; Manuela França Andrade Passos ${ }^{1}$; Maria Luiza Feitosa Bandeira de Oliveira ${ }^{1}$; Cláudio Paulo Pereira de Assis ${ }^{1}$; Rodivan Braz da Silva ${ }^{1}$

${ }^{1}$ Faculdade de Odontologia de Pernambuco - Camaragibe - PE - Brasil

Autor correspondente:

Fernanda Gomes Barros

fernandagomesbarros@ hotmail.com

Introdução: Um sorriso saudável fica sem harmonia frente a alterações dentárias. Uma abordagem através da versatilidade da resina composta garante resultados satisfatórios para o paciente, que recuperam a autoestima e a função do sistema estomatognático ${ }^{1-4}$. Objetivo: Apresentar um caso clínico de reanatomização dentária de dentes conóides e decíduo e a correção dessas contrariedades através de recontorno sem desgaste dental, através da resina composta semidireta. Relato de caso: Paciente, A.G.L., 22 anos, gênero masculino, compareceu a Especialização em Dentística da Faculdade de Odontologia de Pernambuco se queixando do seu sorriso (ausência do lateral e posição atípica de canino e 64). Foi optado pela realização de técnica semidireta para rearmonização e reanatomização dos elementos em questão. Discussão: Devido à necessidade de celeridade pelo paciente foi optado pela utilização de resina composta na técnica semidireta. Paciente foi moldado com alginato Hydrogum (Zhermack) e vazado com silicone Die (VOCO), obtendo-se o modelo do paciente de forma rápida. Após escultura as resinas foram levadas a autoclave para polimerização adicional, seguido de acabamento, polimento e posterior prova em boca (prova seca,e Pasta Try-In). Imediatamente foi feita a seleção de cor (neutra) para o cimento e preparou-se a peça com aplicação de ácido fosfórico 37\% (Condac - FGM), silano (FGM) e sistema adesivo universal (Ambar Universal - FGM). No dente foi aplicado ácido fosfórico 37\%, lavagem e secagem, e sistema adesivo. A cimentação foi realizada com cimento fotopolimerizável All Cem Venner, sendo o excesso de cimento removido com pincel fino e fio dental, seguido depolimerização. Conclusões: Foi possível rearmonizar o sorriso do paciente de forma conservadora e satisfatória, uma vez que não foi necessário desgaste na estrutüra dental. O resultado da plástica dental foi satisfatório, recuperando a proporção e harmonia do sorriso. Dessa forma, devolveuse ao paciente sua autoestima enquanto aguarda tratamento definitivo ortodôntico e protético ${ }^{3}$.

Descritores: Estética Dentária; Reabilitação Bucal; Restauração Dentária Permanente.

\section{Referências:}

1. BOSELLI G, PASCOTTO RC. Incisivos laterais conóides: diagnóstico, planejamento e tratamento restaurador direto. Revista Dental Press de Estética, 2007; 4: 111-117

2. COELHO LGC, et al. Reanatomização estética em paciente com hipodontia, dente conoide e permanência de elemento decíduo. Revista de Pós-Graduação, 2010; 17: 39-45

3. MONDELLI RFL, LOPES LG. Estabelecimento da harmonia estética do sorriso associado às técnicas de clareamento e reanatomização dental para finalização de tratamento ortodôntico - relato de caso. Jornal Brasileiro de Clínica e Estética em Odontologia, 2000; 4: 84-90

4. OMAIS S, YASSUMOTO M. Reanatomização e recontorno cosmético de dentes anteriores - relato de caso clínico. Jornal Brasileiro de Clínica Odontológica Integrada, 2001; 5: 499-502 


\section{PC-159-2019 - RECONSTRUÇÃO ANTERIOR DE MAXILA COM ENXERTO EM BLOCO AUTÓGENO: RELATO DE CASO CLÍNICO}

Paulo Roberto Kohno de Oliveira ${ }^{1}$; Caio César Gonçalves Silva ${ }^{1}$; Davi da Silva Barbirato²; João Vítor Queiroz Mendes dos Santos'; Rômulo Oliveira de Hollanda Valente; Vinícius Balan Santos Pereira ${ }^{1}$

${ }^{1}$ Faculdade de Odontologia de Pernambuco - Camaragibe - PE - Brasil

${ }^{2}$ Universidade Federal do Rio de Janeiro - Rio de Janeiro - RJ - Brasil

${ }^{3}$ Universidade Federal de Pernambuco - Recife - PE - Brasil

Autor Correspondente:

Paulo Roberto Kohno de Oliveira

paulo_kohno@hotmail.com

Introdução: A instalação de implantes em áreas com perda óssea pode estar associada a uma relação coroa-implante desfavorável, resultado estético insatisfatório e dificuldades de higienização, prejudicando o prognóstico do tratamento ${ }^{2}$. O enxerto ósseo possibilita a instalação de implantes em uma posição tridimensional favorável ${ }^{2}$. Objetivo: Apresentar um caso clínico de enxertia óssea em bloco autógeno para a reconstrução de maxila, visando o aumento do volume ósseo disponível para a instalação de implantes dentais. Relato de caso: Paciente 17 anos, sexo feminino, apresentava canino incluso em maxila em posição que impossibilitava o tracionamento ortodôntico, e queixa estética pela ausência do dente na região de inclusão. Foi proposto reabilitação com implantes dentários ósseo-integrados associado a reconstrução óssea com enxerto em bloco da região de ramo mandibular e preenchimento com biomaterial. A paciente foi submetida a anestesia geral com intubação nasotraqueal para exodontia do elemento dentário e preparo da área receptora. Foi então realizada incisão e descolamento da área doadora do ramo mandibular, osteotomia para remoção do bloco, que foi posicionado e fixado com parafuso, o alvéolo preenchido com biomaterial osteocondutor, e toda região enxertada recoberta com membrana de colágeno. $\mathrm{O}$ tratamento com implante dentário será realizado após seis meses. Discussão: O osso autógeno é o material padrão-ouro para reconstruções maxilomandibulares. Suas vantagens incluem relativa resistência a infecções, incorporação pelo hospedeiro, não ocorrendo reação de corpo estranho ${ }^{3}$. A técnica para obtenção dos enxertos intrabucais está muito mais relâcionadā com a habilidade do cirurgião e principalmente com as características do enxerto que o caso clínico necessita. Desta forma, as complicações e os riscos cirúrgicos são minimizados ${ }^{1}$. Conclusão: Os enxertos de osso autógeno mandibular constituem excelente opção para reconstrução de defeitos ósseos de médio e pequeno porte. Sua microarquitetura, a capacidade osteogênica, osteoindutora e osteocondutora possibilitam período curto de incorporação e com reabsorção mínima.

Descritores: Reabilitação bucal; Transplante autólogo; Transplante ósseo.

\section{Referências:}

1. FAVERANI LP, et al. Técnicas cirúrgicas para a enxertia óssea dos maxilares-revisão da literatura. Rev. Col. Bras. Cir, 2014; 41(1):061-067

2. JUNIOR HM, et al. Enxerto ósseo em bloco autógeno na maxila: relato de caso clínico. Revista da Associacao Paulista de Cirurgioes Dentistas, 2016; 70(2): 198-203

3. PERREIRA CCS, et al. Técnica cirúrgica para obtenção de enxertos ósseos autógenos intrabucais em reconstruções maxilomandibulares. Rev bras cir traumatol buco-maxilo-fac, 2012; 15(2): 83-9 


\section{PC-160-2019 - RECONSTRUÇÃO DE DENTES TRATADOS ENDODONTICAMENTE: RELATO DE CASO}

Guilherme de Melo Ribeiro Aragão Barbosa ${ }^{1}$; Francisco Henrique Lima Milhomens ${ }^{1}$; Héberte de Santana Arruda ${ }^{1}$; Eduardo Borges da Costa Leite ${ }^{2}$; Amanda Maciel do Prado ${ }^{1}$; Fernanda Gomes Barros ${ }^{1}$; Carolina Pereira da Silva ${ }^{1}$; Marcos Antônio Japiassú Resende Montes ${ }^{1}$

${ }^{1}$ Faculdade de Odontologia de Pernambuco - Camaragibe - PE - Brasil

${ }^{2}$ Universidade Federal de Pernambuco- Recife - PE - Brasil

Autor correspondente:

Guilherme de Melo Ribeiro Aragão Barbosa

guilhermemrab@yahoo.com

Introdução: A restauração de dentes tratados endodonticamente é um dos principais desafios da Odontologia Restauradora, uma vez que a estrutura dentária enfraquecida é mais propensa a falhas biomecânicas, como resultado da perda significativa de estrutura dentária ${ }^{1,2}$. Objetivo: O objetivo desse trabalho foi relatar, através de um caso clínico, a sequência detalhada da confecção de um pino de fibra de vidro. Relato de caso: Paciente procurou a Clínica do Curso de Especialização em Dentística relatando fratura de pequena porção da restauração em seus incisivos centrais inferiores. Após realização de exame clínico, radiográfico, fotográfico e remoção do material restaurador, observou-se adequado vedamento endodôntico e optou-se pela utilização de pino intrarradicular associado a uma restauração direta em resina composta, com o intuito de proporcionar adequado vedamento radicular e aumento da retenção do material restaurador. Discussão: Os dentes tratados endodonticamente apresentam maior risco de falha biomecânica em comparação aos dentes sadios, como consequência da perda excessiva de estrutura devido à cárie radicular e/ou coronária, extensa restauração, desequilíbrio oclusal e preparo para retentores intracanais ${ }^{1-3}$. Estudos in vivo e in vitro demonstraram que pinos de fibra de vidro associados a núcleos de resina composta são uma excelente estratégia para restauração de dentes tratados endodonticamente, apresentando excelente desempenho clínico. Os pinos pré-fabricados são indicados para proporcionar retenção ao material de preenchimento coronário sendo que a inserção do mesmo dependerá da quantidade de remanescente dental e da qualidade da estrutura radicular ${ }^{4}$. Conclusão: Constantemente observamos que em dentes restaurados após grande perda estrutural, as restaurações podem se deslocar ém médio prazo, mesmo utilizando procedimentos adesivos ${ }^{3,4}$. Os pinos de fibra de vidro apresentam propriedades mecânicas, como o módulo de elasticidade, semelhante à dentina, que reduz o risco de fratura radicular. Além disso, esses retentores são mais estéticos, práticos, eficientes e menos invasivos ${ }^{1}$.

Descritores: Técnica para Retentor Intrarradicular; Estética Dentária; Adesividade.

\section{Referências:}

1. BORZANGY SS, et al. Effect of restoration technique on resistance to fracture of endodontically treated anterior teeth with flared root canals. The Journal of Biomedical Research, 2019; 33(2): 131-138

2. FRÁTER M, et al. Fracture resistance and marginal gap formation of post-core restorations: influence of different fiber-reinforced composites. Clinical Oral Investigations, 2019; 23(5): 1143-1150

3. MORIS ICM, et al. Evaluation of Stress Distribution in Endodontically Weakened Teeth Restored with Different Crown Materials: 3D-FEA Analysis. Brazilian Dental Journal, 2017; 28(6):715-719 
4. OZ FD, et al. The Influence of Restorative Material and Glass Fiber Posts on Fracture Strength of Endodontically Treated Premolars after Extensive Structure Loss. Nigerian Journal of Clinical Practice, 2019; 22(6): 782-789
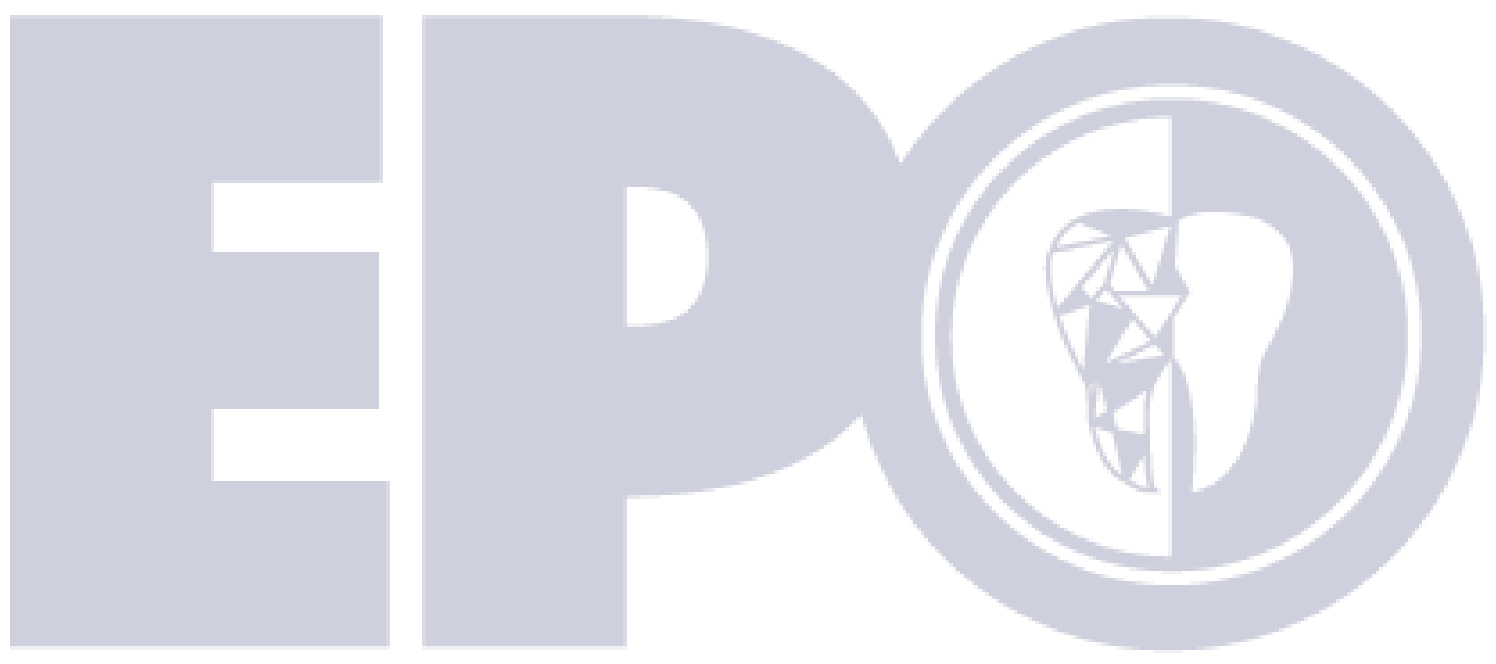

\section{ENCONTRO PERNAMBUCANO}




\section{PC-161-2019 - RECONSTRUÇÃO MANDIBULAR POR MEIO DA TÉCNICA “TENT POLE": RELATO DE CASO}

Francisco Henrique Lima Milhomens ${ }^{1}$; Fernanda Gomes Barros ${ }^{1}$; Carolina Pereira da Silva ${ }^{1}$; Maria Eduarda Arruda de Lucena ${ }^{1}$; Manuela França Andrade Passos ${ }^{1}$; Pedro Paulo de Aguiar Santos ${ }^{1}$; Darkililson Pereira Santos ${ }^{2}$; Éwerton Daniel Rocha Rodrigues ${ }^{1}$

${ }^{1}$ Faculdade de Odontologia de Pernambuco - Camaragibe - PE - Brasil

${ }^{2}$ Universidade Federal do Piauí - Teresina - PI - Brasil

Autor correspondente:

Francisco Henrique Lima Milhomens

franciscohenrique01@gmail.com

Introdução: A mandíbula atrófica representa um grande problema para o paciente idoso, bem como para o cirurgião e para o técnico em prótese dentária. Geralmente, quando não há possibilidade de reabilitação por meio de tratamentos convencionais, uma intervenção óssea é necessária. Além disso, a perda de tecido de suporte pode predispor a mandíbula a fraturas espontâneas. Várias técnicas de reconstrução para mandíbulas edêntulas severamente reabsorvidas são relatadas na literatura, todas com suas vantagens e desvantagens ${ }^{2-3}$. Objetivo: Este trabalho tem como objetivo ilustrar um caso clínico de reconstrução de uma mandíbula severamente atrófica, visando a reabilitação com prótese do tipo protocolo. Relato de caso: Paciente V.L.R.A., 58 anos, gênero feminino, compareceu ao serviço do Hospital Universitário de uma universidade do Piaú relatando uso de prótese superior e inferior a quase 20 anos e ausência de adaptação dessa última. Na tomografia, foi observado que a paciente apresentava a mandíbula extremamente atrófica. Foi optado pela realização da técnica de Tent Pole. Discussão: Foi realizada uma incisão extraoral submentoniana sucedida de um descolamento até a exposição da região alveolar da mandíbula. Em seguida, foram realizados 5 furos paralelos entre si na região anterior ao forame mentoniano bilateral. Após a realização das perfurações, os implantes foram instalados. Foi utilizado enxerto autógeno da crista ilíaca, que foi triturado e misturado com Bio-Oss para ser colocado na região encobrindo os implantes. Paciente aguarda a osseointegração dos implantes para que seja colocada a futura prótese. Conclusões: Esse tratamento apresenta resultado favorável com a reabilitação por meio de implantes e prótese implanto-suportada ${ }^{1,3}$. A utilização desta técnica proposta com enxerto ósseo possibilita obter maior controle e manutenção tecidual, diminuindo a possibilidade de recidiva da reabsorção óssea ${ }^{3}$.

Descritores: Mandíbula; Reconstrução Mandibular; Cirurgia Bucal.

\section{Referências:}

1. LOURO RS, et al. Reconstrução e reabilitação de mandíbula severamente atrófica com enxerto da crista do osso ilíaco e implantes osseointegrados: acompanhamento clínico e radiográfico de 36 meses. ImplantNews, 2013; 10: 779-784

2. MANFRO R, et al. Mandíbulas Edêntulas Severamente Reabsorvidas Tratadas com Implantes Curtos - Apresentação de 4 Casos Clínicos e Controle de 30 a 36 Meses. Journal of Oral Investigations, 2013; 2: 10-16

3. MOCHIZUKI CJ, et al. Reconstrução de mandíbula atrófica utilizando a técnica "tent pole" e enxerto ósseo de crista ilíaca - relato de caso. Revista de odontologia da UNESP, 2018; 47 : $2-12$ 


\section{PC-162-2019 - REDUÇÃO E FIXAÇÃO DE FRATURA DENTOALVEOLAR EM MAXILA: RELATO DE CASO}

Pedro Henrique Lopes Cavalcanti ${ }^{1}$; Emerllyn Shayane Martins de Araújo ${ }^{2}$; Cláudia Geisa Souza e Silva ${ }^{2}$; Mariana Souza de Barros ${ }^{1}$; Caio César Gonçalves Silva ${ }^{3}$; Demóstenes Alves Diniz $^{3}$; Ruan de Sousa Viana ${ }^{3}$; Kalyne Kelly Negromonte Gonçalves ${ }^{3}$

${ }^{1}$ Universidade Federal de Pernambuco - Recife - PE - Brasil

${ }^{2}$ Faculdade de Odontologia de Pernambuco - Camaragibe - PE - Brasil

${ }^{3}$ Hospital da Restauração - Recife - PE - Brasil

Autor correspondente:

Pedro Henrique Lopes Cavalcanti

pedrohlcavalcanti@gmail.com

Introdução: É comum, nos serviços de urgência, a presença de pacientes vítimas de traumatismos dentoalveolares ${ }^{2}$. Eles envolvem três estruturas básicas: dentes, porção alveolar e tecidos moles adjacentes ${ }^{3}$. O tratamento consiste em restabelecer a forma e a função do aparelho mastigatório ${ }^{1}$. Objetivo: Relatar um caso clínico de um paciente cursando com fratura de bloco dentoalveolar em maxila. Relato de caso: Paciente do gênero masculino, 48 anos de idade, compareceu ao serviço de Cirurgia e Traumatologia Buco-Maxilo-Facial do Hospital da Restauração, Recife-PE, com história de acidente motociclístico. Ao exame físico extraoral apresentava ectrópio em olho esquerdo, baixa da acuidade visual em olho esquerdo e presença de cicatrizes hipertróficas em face. Ao exame intraoral apresentava mobilidade em bloco dentoalveolar maxilar anterior e maloclusão. $\mathrm{O}$ exame de imagem sugeria fraturas de bloco dentoalveolar maxilar anterior, complexo zigomático orbitário esquerdo e ossos próprios do nariz. O paciente foi submetido à redução fechada com instalação de barra de erich para contenção do bloco dentoalveolar, entretanto, não se apresentava estável, sendo assim realizada redução aberta através de acesso vestibular maxilar e instalação de 01 placa do sistema $1.5 \mathrm{~mm}$ em pilar canino esquerdo. Demais fraturas não foram abordadas pela ausência de queixa estética ou funcional. Paciente segue em acompanhamento ambulatorial, com boa oclusão, sem mobilidade em maxila. Discussão: $O$ impacto traumático à estrutura dentoalveolar pode resultar em dano dental, mas também em fraturas dos ossos da face e é preciso tratá-las de forma imediata, respeitando-se as estruturas anatômicas e suas rêlações, a fim de obter restabelecimento funcional e estético ${ }^{2,3}$. Conclusão: Dessa forma, fica clara a importância do conhecimento e manejo de fraturas de bloco dentoalveolar e o conhecimento sobre a correta indicação do tratamento aberto.

Descritores: Traumatismos dentários; Fixação de fratura; Maxila.

\section{Referências:}

1. MELO REVA, et al. Traumatismo dentoalveolar. International Journal of Dentistry, 2003; 2(2): 266-272

2. OLIVEIRA FAM, et al. Traumatismo dentoalveolar: revisão de literatura. Revista de Cirurgia e Traumatologia Buco-Maxilo-Facial, 2004; 4(1): 15-21

3. SANTOS KSA, et al. Tratamento de traumatismos dentoalveolares e reabilitação protética em paciente jovem: relato de caso. Odontologia Clínico-Científica, 2010; 9(2): 181-184 


\section{PC-163-2019 - REDUÇÃO INCRUENTA DE FRATURA DOS OSSOS PRÓPRIOS DO NARIZ - RELATO DE CASO}

Alleson Jamesson da Silva ${ }^{1}$; Jessyca Maria Alencar e Sá ${ }^{1}$; Maria Heloisa Martins ${ }^{\mathbf{1}}$; Lucas Viana Silva Ramos ${ }^{1}$; Sinval Vinícius Barbosa do Nascimento ${ }^{2}$; Eugênia Leal de Figueiredo ${ }^{2}$; Carolina Chaves Gama Aires ${ }^{2}$

${ }^{1}$ Universidade Federal de Pernambuco - Recife - PE - Brasil

${ }^{2}$ Faculdade de Odontologia de Pernambuco - Camaragibe - PE - Brasil

Autor correspondente:

Alleson Jamesson da Silva

allesonjamesson@gmail.com

Introdução: Os ossos faciais fraturados mais comumente em pacientes adultos são os nasais.2 Haja vista a posição do complexo nasal e a reduzida espessura dos seus ossos, menos força é necessária para fraturar essa área do que para qualquer outro osso facial ${ }^{2,3}$. Objetivo: Discutir um relato de caso de fratura nasal tratada de forma incruenta. Relato de Caso: Paciente P.T.S, 32 anos, vítima de acidente ciclístico cursando com trauma facial. Após atendimento inicial, foram descartadas lesões abdominais, neurológicas ou outras, a paciente foi avaliada pela equipe de CTBMF. Ao exame físico, apresentava equimose periorbitária bilateral, escoriações em dorso nasal, crepitação e discreta mobilidade em ossos próprios do nariz (OPN), além de um desvio do dorso nasal para o lado direito. A tomografia evidenciou a fratura dos ossos próprios do nariz, sugerida pelo exame físico. Optou-se pela realização de redução incruenta dos OPN sob anestesia geral e intubação orotraqueal, tornando o procedimento mais confortável e menos doloroso para a paciente. Destaca-se a importância da anestesia local com anestésico com vasoconstrictor, diminuindo o risco de hemorragia no transoperatório. Após a redução foi colocado um splint nasal em ambas as narinas juntamente com gaze hemostática para diminuir o risco de epistaxe pós-operatória e modelagem de tala nasal termoplástica em dorso nasal. Discussão: Paciente foi operada após 3 dias do trauma e diminuição do edema. A redução incruenta sob anestesia geral torna o procedimento mais confortável e menos doloroso para o paciente. Resultados satisfatórios no reposicionamento são obtidos mediante rápida intervenção com mínimo de edema instalado, permitindo uma melhor análise do correto posicionamento nasal. Conclusão: $O$ tratamento cirúrgico através de redução fechada promove resultados aceitáveis, respeitando os princípios de avaliação da lesão e momento de indicação do tratamento $^{1}$. Desta forma, este método de redução é uma alternativa viável e eficaz no tratamento dessas fraturas.

Descritores: Fraturas Ósseas; Osso Nasal; Redução Fechada.

\section{Referências:}

1. BORGHESE B, et al. Estudo retrospectivo da abordagem das fraturas nasais no Hospital de Clínicas da Unicamp. Rev. Bras. Cir. Plást., 2011; 4:608-612

2.MILORO M, et al. Princípios de cirurgia bucomaxilofacial de Peterson. $3^{\mathrm{a}}$ ed. São Paulo: Santos, 2016; 1344p

3. MONNAZI MS, et al. Manejo das fraturas nasais com manutenção das vias aéreas superiores.

Rev. Cir. Traumatol. Buco-maxilo-fac., 2010; 2:55-60 


\title{
PC-164-2019 - REFLEXO TRIGÊMINO-CARDÍACO DURANTE EXTRAÇÃO DENTÁRIA: REVISÃO DE LITERATURA
}

\begin{abstract}
Nycole Valois Rocha Vieira da Silva ${ }^{1}$; Évila Castro Lima ${ }^{1}$; Hian Carvalho Souza ${ }^{1}$; Mariana Cecília de Oliveira Terêncio ${ }^{1}$; Maíra Belo da Rocha Carvalho ${ }^{1}$; Fabíola Feitosa Freitas ${ }^{1}$; Rafael Brito Lopes ${ }^{2}$; Rosa Natália Rendall dos Santos Ratis ${ }^{3}$
\end{abstract}

${ }^{1}$ Faculdade de Odontologia de Pernambuco - Camaragibe - PE - Brasil

${ }^{2}$ Faculdade de Ciências Agrárias e da Saúde - Lauro de Freitas - BA - Brasil

${ }^{3}$ Universidade Tiradentes - Recife - PE - Brasil

Autor correspondente:

Nycole Valois Rocha Vieira da Silva

valoisnycole@gmail.com

Introdução: O Reflexo Trigêmino-Cardíaco (TCR) caracteriza-se por uma resposta fisiológica repentina decorrente de estímulos a qualquer um dos ramos do nervo trigêmeo ${ }^{3,4}$ Oferece baixa morbidade, contudo podendo ser exacerbada, oferecendo riscos graves ao paciente. ${ }^{2} \mathrm{O}$ TCR tem sido relatado durante procedimentos cirúrgicos orais e do complexo craniomaxilofacial. Em decorrência da pressão ou do alongamento do nervo trigêmeo, esse arco reflexo apresentase com ocorrência de súbita bradicardia, hipotensão, apneia e hipermotilidade gastrointestinal $^{3,4}$. Objetivo: Realizar uma revisão da literatura acerca desse fenômeno e explorar possíveis etiologias correlacionadas aos procedimentos de extração dentária. Metodologia: Foi efetuada uma revisão de literatura nas bases de dados BBO, SciELO MEDLINE e PubMed, entre os anos de 2010 e 2018. Revisão de literatura: O TCR foi descrito como um subtipo do "reflexo oculocardíaco" (OCR) em 1908, sendo a primeira descrição como TCR em 1999, e há uma discussão em andamento sobre a sua definição clínica ${ }^{1}$. Trata-se de uma resposta a um arco reflexo que pode causar depressão da frequência cardíaca, variação na pressão arterial, apneia e alterações gástricas, através de estímulos do nervo trigêmeo como tração, pressão ou manipulação química. Diversos fatores são predisponentes para a ocorrência do TCR, tais como hipercapnia, hipoxemia, anestesia superficial e betabloqueadores insuficientes ${ }^{1,4}$. E qualquer intervenção cirúrgica que envolva a extensão do nervo trigêmeo apresenta um risco a precipitação deste fenômeno ${ }^{2}$. Conclusão: para que haja um gerenciamento eficiente durante ocorrência do TCR, é importante o conhecimento do cirurgiãodentista sobre a possibilidade desta complicação, os possíveis fatores etiológicos, os cuidados prévios como a manipulação cuidadosa na área de inervação do nervo trigêmeo e o correto diagnóstico e manejo do paciente.

Descritores: Bradicardia; Cirurgia Bucal; Reflexo Trigêmino-Cardíaco.

\section{Referências:}

1. ARAKERI G, ARALI V. A new hypothesis of cause of syncope: Trigeminocardiac reflex during extraction of teeth. Medical Hypotheses, 2010; 74(2): 248-251

2. BHARGAVA D, et al. Trigeminocardiac Reflex: A Reappraisal with Relevance to Maxillofacial Surgery. J Maxillofac Oral Surg, 2014; 13(4): 373-377

3. GUEDES AA, et al. Reflexo trigêmino-cardíaco tardio após cirurgia buco-maxilo-facial: relato de caso. Revista Brasileira de Anestesiologia, 2018; 69(3): 315-318

4. JOSHI UM, et al. Trigemino-cardiac reflex: a phenomenon neglected in maxillofacial surgery. Journal of Maxillofacial and Oral Surgery, 2017; 16(2): 181-185 


\title{
PC-165-2019 - RELATO DE VIVÊNCIA DISCENTE EM UM TERRITÓRIO DA ATENÇÃO PRIMÁRIA À SAÚDE DO RECIFE
}

\author{
Marvison Henrique Ferreira da Silva ${ }^{1}$; Márcia Maria Dantas Cabral de Melo ${ }^{1}$; Nylke Mirelle \\ Ferraz de Menezes ${ }^{1}$; Palloma Bernardino Albuquerque ${ }^{1}$
}

${ }^{1}$ Universidade Federal de Pernambuco - Recife - PE - Brasil

Autor correspondente:

Marvison Henrique Ferreira da Silva

mavinho_mm@hotmail.com

Introdução: As Diretrizes Curriculares para a Odontologia compreende o papel do estágio como eficaz instrumento viabilizador do percurso formativo do educando o mundo do trabalho no SUS ${ }^{2}$. Objetivo: Apresentar a vivência dos alunos do curso de odontologia/UFPE no Estágio Curricular I desenvolvido na Upinha Jardim São Paulo, Distrito Sanitário IV/Recife, semestre 2019.1. Relato de experiência: Os alunos do $4^{\circ}$ período, divididos em grupos, sob preceptoria do dentista e tutoria docente desenvolveram as atividades programadas por eixos pedagógicos. Eixos e atividades: Eixo 1- A unidade de atenção básica e a abordagem familiar: caracterização de aspectos estruturais e do processo de trabalho da equipe de saúde na USF e investigação com usuários; Eixo 2 - O território socioambiental: desenvolvimento de ações sobre o processo de territorialização/cadastramento das famílias ${ }^{1}$; Eixo 3 - A rede de atenção à saúde: caracterizar a rede de atenção à saúde do distrito onde a unidade desempenha o papel de ordenação das linhas de cuidado integral em saúde e a organização da referência/contrareferência ${ }^{3}$. Discussão: As vivências e as observações/investigações realizadas segundo os Eixos demonstraram efetivo norteamento didático para o entendimento do processo de trabalho em saúde/saúde bucal na rede básica de saúde. Durante o estágio observou-se a existência de uma equipe multiprofissional comprometida com o funcionamento da unidade, com $\mathrm{o}$ atendimento humanizado aos pacientes e com a melhora sanitária do território. Além disso, observou-se demanda elevada e falta de infraestrutura da unidade gerando insatisfação. Conclusão: As atividades vivenciadas no Estágio favoreceram aos discentes compreender a dinâmica do processo de trabalho em saúde e saúde bucal requerido à atenção primária, na perspectiva de oferecer respostas as necessidades socioepidemiológicas das famílias do território, despertando interesse pelo trabalho solicitado para a rede pública de atenção à saúde do Sistema Único de Saúde brasileiro.

Descritores: Atenção Primária à Saúde; Sistema Único de Saúde; Odontologia.

\section{Referências:}

1. MOYSES ST, et al. Saúde bucal das famílias: trabalhando com evidências. Cad. Saúde Pública, 2008; 24(11): 2725-2726

2. SILVA BS, CALDARELLI PG. O PET-Saúde em consonância com as Diretrizes Curriculares Nacionais de Odontologia no desenvolvimento de competências profissionais: relato de experiência. Rev. ABENO, 2013; 13(2): 34-41

3. VIACAVA F, et al. SUS: oferta, acesso e utilização de serviços de saúde nos últimos 30 anos. Ciênc. Saúde Coletiva, 2018; 23(6): 1751-1762 


\section{PC-166-2019 - REMOÇÃO DE CEMENTOBLASTOMA EM MAXILA: RELATO DE CASO}

Ranielly de Souza Silva ${ }^{1}$; Kemeron Leal Meneses ${ }^{1}$; João Artur Peixoto Granja ${ }^{1}$; Natalia Barbosa de Siqueira ${ }^{2}$; Mariana Barros Rocha ${ }^{3}$; Kléber Rós Santos ${ }^{3}$; Mateus Barros Cavalcante ${ }^{3}$; Belmiro do Egito Cavalcante Vasconcelos ${ }^{4}$

${ }^{1}$ Centro Universitário Tiradentes - Recife - PE - Brasil

${ }^{2}$ Universidade Estadual Paulista - São Paulo - SP - Brasil

${ }^{3}$ Hospital Universitário Oswaldo Cruz - Recife - PE - Brasil

${ }^{4}$ Faculdade de Odontologia de Pernambuco - Recife - PE - Brasil

Autor correspondente:

Ranielly de Souza Silva

raniellyssantana@hotmail.com

Introdução: Os cementoblastomas são neoplasmas odontogênicos raros e representam cerca de $1 \%$ a $6,2 \%$ de todos os tumores de origem odontogênica ${ }^{1}$. Objetivo: Relatar um caso clínico de cementoblastoma em maxila, discutir suas características clínicas e tratamento cirúrgico. Relato de caso: A.K.S, gênero feminino, 36 anos, melanoderma, foi encaminhada ao serviço de CTBMF do Hospital Universitário Oswaldo Cruz (HUOC/UPE), após visualização de radiopacidade em raiz do primeiro pré-molar superior esquerdo em radiografia panorâmica. Ao exame físico extra bucal, não apresentava aumento de volume ou assimetria facial. Ao exame intraoral, apresentava abaulamento em região anterior de maxila esquerda, sem alterações de coloração em mucosa. Uma imagem de natureza radiopaca associada a focos de radiolucidez, envolvendo a raiz do primeiro pré-molar superior esquerdo foi evidenciada em tomografia de feixe cônico. Cementoblastoma e odontoma foram incluídos em um diagnóstico presuntivo. Foi realizada enucleação da lesão e do elemento dental associado, sob anestesia geral. Através do exame histopatológico, comprovou-se diagnóstico de cementoblastoma. Atualmente, a paciente encontra-se em acompanhamento pós-operatório de 18 meses, sem sinais de recidiva da lesão. Discussão: Pacientes com esta lesão, apresentam sintomatologia e tumefação na área afetada em principal a região das raízes de molares e pré-molares, onde há expansão das corticais ósseas, e o diagnóstico final desse tumor só é possível após realização de exame histopatológico. Em umá revisão realizada por Brannon et al., (2002), conclui-se que o melhor tratamento consiste na enucleação da lesão juntamente com o dente ${ }^{2}$. Ocorre recidiva após a enucleação em casos de remoção incompleta da lesão, recorrência é um achado comum ${ }^{3}$. Conclusão: $O$ tratamento deve ser realizado de acordo com as características de cada patologia. Lesões de caráter não agressivo, o tratamento é de forma menos invasiva. Portanto, a enucleação realizada de forma adequada, se terá um prognóstico excelente, e a recidiva é incomum.

Descritores: Cementoma; Neoplasias bucais; Tumores odontogênicos.

\section{Referências:}

1. BRANCO R, et al. Cementoblastoma: an innocuous neoplasm? A clinicopathologic study of 44 cases and review of the literature with special emphasis on recurrence. Oral Surg Oral Med Oral Pathol Oral Radiol Endod, 2002; 93(3): 311-320

2. BRANNON RB, et al. Cementoblastoma: An innocuous neoplasm? A clinicopathologic study of 44 cases and review of the literature with special emphasis on recurrence. Oral Surg Oral Med Oral Pathol, 2002; 93: 311-320

3. PYNN BR, et al. Benign cementoblastoma: a case report. J Can Dent Assoc., 2001; 67(5): 260-2 


\section{PC-167-2019 - REMOÇÃO DE CORPO ESTRANHO EM CAVIDADE ORBITÁRIA: RELATO DE CASO}

Marcelle Freitas Braz ${ }^{1}$; Caio César Gonçalves Silva ${ }^{2}$; Kalyne Kelly Negromonte Gonçalves ${ }^{3}$; Demóstenes Alves Diniz ${ }^{3}$; Jéssica da Silva Cunha ${ }^{3}$; Rosa Rayanne Lins de Souza ${ }^{3}$; Luan Carlos Barbosa Lourenço $^{1}$; Suzana Célia de Aguiar Soares Carneiro ${ }^{3}$

${ }^{1}$ Faculdade Maurício de Nassau - Recife - PE - Brasil

${ }^{2}$ Faculdade de Odontologia de Pernambuco - Recife- PE- Brasil

${ }^{3}$ Hospital da Restauração Governador Paulo Guerra- Recife- PE- Brasil

Autor correspondente:

Marcelle Freitas Braz

Marcellefreitas1107@gmail.com

Introdução: A penetração de corpos estranhos na cavidade orbitária normalmente ocorre pelo trauma direto e penetrante. Dependendo da localização e composição do corpo estranho, o diagnóstico pode ser feito por observação direta ou mediante exames de imagens ${ }^{3}$. Objetivo: Relatar caso clínico de paciente apresentando corpo estranho em orbita decorrente de agressão por projétil de arma de fogo em face. Relato do Caso: Paciente do gênero masculino, 40 anos de idade, leucoderma, compareceu ao serviço de urgência de cirurgia e traumatologia BucoMaxilo-Facial do Hospital da Restauração, Recife-PE, com história de agressão em face por "Culatra" de Arma de fogo. Ao exame físico era observado edema em região periorbitário esquerdo endurecido à palpação com ferimento de entrada do corpo estranho, ao exame de imagem (Tomografia computadorizada de face) observava-se imagem hiperdensa compatível com corpo estranho em margem supraorbitária do lado esquerdo. A USG sugeria presença de imagem com áreas de hemorragia, focos de inflamação e material de aproximadamente $3 \mathrm{~cm}$ hiperecoico em orbital. O paciente foi submetido a protocolo de profilaxia antitetânica, antibioticoterapia endovenosa, remoção do corpo estranho sob anestesia geral, lavagem copiosa com soro fisiológico, remoção de fragmentos ósseos, hemostasia adequada e sutura da ferida por camadas, evitando assim a formação de espaços mortos. Paciente segue em acompanhamento ambulatorial, sem sinais de complicações e com exame visual pérvio. Discussão: Radiografias convencionais, ultrassonografias (USG), tomografias computadorizadas e a ressonôncia magnética são exames auxiliares nó diagnóstico. A conduta e o prognóstico dependerão da composição do corpo estranho, localização e presença ou não de infecção, sendo a palpação e a inspeção do globo ocular e da cavidade orbitária imprescindível $^{1,2,3}$. Conclusão: Dessa forma, fica claro que a presença de corpos estranhos na cavidade orbitária pode resultar desde pequenas lesões cutâneas a celulites orbitárias, lesões oculares, amaurose, perda parcial da acuidade visual, entre outras complicações.

Descritores: Ferimentos por arma de fogo; Órbita; Traumatologia.

\section{Referências:}

1. ARAÚJO AAS, et al. Urgência oftalmológica: Corpo estranho ocular ainda como principal causa. Arquivos Brasileiro de Oftalmologia, 2002; 65: 223-227

2. CASANOVA FHC, et al. Corpo estranho orgânico intra-orbitário: Avaliação tomográfica e conduta. Arquivos Brasileiro de Oftalmologia, 2001; 64: 297-301

3. VARELLAR, et al. Remoçãodecorpoestranhoemcavidadeorbitária:Relatodecaso.Revista de Cirurgia e Traumatologia Buco-Maxilo-Facial, 2012; 12(3):25-30 


\section{PC-168-2019 - REMOÇÃO DE CORPO ESTRANHO EM FACE: RELATO DE CASO}

Greiciane Miguel de Azevedo Santos ${ }^{1}$; João Artur Peixoto Granja²; Amanda Regina Silva de Melo $^{3}$; Cláudia Nely Mendonça ${ }^{2}$; Maria Victorya Ferreira de Arruda ${ }^{2}$; Thaisa Reis de Carvalho Sampaio $^{3}$; Caio César Gonçalves Silva ${ }^{1}$; Aída Juliane Ferreira dos Santos ${ }^{3}$

${ }^{1}$ Faculdade de Odontologia de Pernambuco - Recife - PE - Brasil

${ }^{2}$ Centro Universitário Tiradentes - Recife - PE - Brasil

${ }^{3}$ Hospital da Restauração Governador Paulo Guerra - Recife - PE - Brasil

Autor correspondente:

Greiciane Miguel de Azevedo Santos

greiciane_azevedo@outlook.com

Introdução: Corpos estranhos em face decorrentes de acidentes adversos, podem ultrapassar barreiras cutâneas e, dessa forma, causar risco de morte ao paciente ${ }^{1}$. Alguns fatores do objeto são levados em consideração a fim de proporcionar definição cirúrgica, como tamanho e proximidade anatômica a estruturas vitais ${ }^{2}$. Um exame clínico detalhado e de imagem (tomografias, ressonâncias) são fundamentais para identificar as injúrias do trauma ${ }^{3}$. Objetivo: Relatar um caso clínico de trauma com objeto metálico em face, o qual gerou amaurose bilateral durante acidente de trabalho. Relato de Caso: Paciente, sexo masculino, 23 anos, compareceu ao serviço de Cirurgia e Traumatologia Buco-maxilo-facial do Hospital da Restauração/Recife, vítima de acidente de trabalho com cortador de grama. Ao exame clínico emergencial observouse penetração de hélice metálica em região de terço superior de face, com perda importante de substância ocular e amaurose bilateral. Tomografia computadorizada e angiografia cerebral identificaram a profundidade e os possíveis danos vasculares em região. Dessa forma, realizouse um planejamento cauteloso para realização cirúrgica com desgastes de ósseos específicos, desprendimento e retirada do objeto, livre de complicações e hemorragias. Discussão: Diversos autores chamam atenção para o fato da amaurose ser causada pela isquemia que é decorrente principalmente de hipotensão arterial ou dilaceração do nervo óptico ${ }^{3}$. No entanto, a estabilização do paciente e retirada do objeto definiram a prioridade cirúrgica do caso. Conclusão: $O$ planejamento e tratamento de escolha evidenciaram melhor conduta para o caso clínico, evitando uma abordagem imediata com riscos maiores de sangramento e morte. Dessa forma, fica claro a importância do uso de EPI's para prevenção ou minimização de traumas em face.

Descritores: Amaurose; Lesões da cabeça; Acidentes de trabalho.

\section{Referências:}

1. LIMA EPA, et al. Presença de corpo estranho orgânico em região frontal: relato de caso. Revista de Cirurgia e Traumatologia Buco-Maxilo-Facial, 2012; 12(2): 59-64

2. LIMA EPA, et al. Presença de corpo estranho no complexo buco-maxilofacial: relato de 2 casos. Revista de Cirurgia e Traumatologia Buco-Maxilo-Facial, 2014; 14(3): 45-52

3. SOUZA VC, et al. Amaurose bilateral irreversível pós-cirurgia cardíaca. Revista brasileira cirurgia cardiovascular, 2004; 19(3): 320-322 


\title{
PC-169-2019 - REMOÇÃO DE PROJÉTIL EM CÔNDILO MANDIBULAR ASSOCIADO À CORONOIDECTOMIA: RELATO DE CASO
}

\begin{abstract}
Emerllyn Shayane Martins de Araújo; ${ }^{1}$ Fernanda Teles Pereira ${ }^{1}$; Sinval Vinícius Barbosa do Nascimento $^{1}$; Caio César Gonçalves Silva ${ }^{1}$; Jéssica da Silva Cunha ${ }^{2}$; Priscilla Sarmento Pinto ${ }^{2}$; Demóstenes Alves Diniz ${ }^{2}$; Kalyne Kelly Negromonte Gonçalves ${ }^{2}$
\end{abstract}

${ }^{1}$ Faculdade de Odontologia de Pernambuco - Camaragibe - PE - Brasil

${ }^{2}$ Hospital da Restauração - Recife - PE - Brasil

Autor correspondente:

Emerllyn Shayane Martins de Araújo

emerllyn_shayane@outlook.com

Introdução: Com o aumento da violência nos grandes centros urbanos, houve, também, um aumento de fraturas decorrentes de armas de fogo em civis, tornando-se necessário o seu estudo para elaboração de protocolos de diagnóstico e tratamento desses pacientes ${ }^{1}$. Os ferimentos causados por projéteis de arma de fogo apresentam alta incidência na região da cabeça e/ou face e, muitas vezes a articulação temporomandibular (ATM) pode estar envolvida ${ }^{2}$. Objetivo: Relatar um caso clínico de uma paciente vítima de agressão por projétil de arma de fogo (PAF) em face. Relato de caso: Paciente do sexo feminino, 19 anos de idade, procurou o serviço de Cirurgia e Traumatologia Buco-Maxilo-Facial do Hospital da Restauração, Recife-PE, com história de agressão por PAF em face. Ao exame apresentava edema difuso em face, telecanto traumático, limitação de abertura bucal, oclusão estável e dor persistente em região de côndilo mandibular esquerdo. Ao exame de imagem apresentava presença de projétil alojado em polo medial de côndilo mandibular esquerdo. Como exame complementar, foi realizada angiografia e embolização da artéria maxilar interna esquerda que estava associada ao projétil. A paciente foi submetida à cirurgia sob anestesia geral para remoção de projétil, através de acesso préauricular esquerdo e utilização de intensificador de imagem. Também foi realizada coronoidectomia contralateral para melhora da abertura bucal. Ela segue em acompanhamento ambulatorial, sem sinais de complicações associadas. Discussão: Tal abordagem cirúrgica para remoção do projétil de arma de fogo, associada à coronoidectomia traz bons resultados pósoperatórios, principalmente quando se avalia a abertura bucal do paciente ${ }^{2,3}$. Conclusão: Os traumas de face produzidos por projéteis de arma de fogo geralmente acometem a articulação temporomandibular, sendo necessário conhecer bem sua anatomia a fim de empregar o tratamento correto que permite ao paciente no pós-operatório uma oclusão estável e movimentos mandibulares normais.

Descritores: Armas de Fogo; Articulação Temporomandibular; Ferimentos e Lesões.

\section{Referências:}

1. BAIRRAL JV, et al. Otite média e anquilose na região temporomandibular causada por fratura de arma de fogo: relato de caso. Revista de Cirurgia e Traumatologia Buco-MaxiloFacial, 2011; 11(2): 27-32

2. BIANCHINI EMG, et al. Terapêutica interdisciplinar para fratura cominutiva de côndilo por projétil de arma de fogo: enfoque miofuncional. Revista CEFAC, 2010; 12(5): 881-888

3. VASCONCELOS BCE, et al. Anquilose da articulação têmporo-mandibular. Revista Brasileira de Otorrinolaringologia, 2008; 74(1): 34-38 


\section{PC-170-2019 - REPARAÇÃO DE DEFORMIDADE FACIAL COM AUXÍLIO DE BIOMODELO: RELATO DE CASO}

João Vítor Queiroz Mendes dos Santos ${ }^{1}$; Belmiro Cavalcanti do Egito Vasconcelos ${ }^{1}$; Caio César Gonçalves Silva ${ }^{1}$; Carlos Augusto Pereira do Lago ${ }^{1}$; Paulo Roberto Kohno de Oliveira ${ }^{1}$; Suzana Célia de Aguiar Soares Carneiro ${ }^{1}$

${ }^{1}$ Faculdade de Odontologia de Pernambuco - Camaragibe - PE - Brasil

Autor correspondente:

João Vítor Queiroz Mendes dos Santos

jvitorqueiroz@hotmail.com

Introdução: $\mathrm{O}$ ameloblastoma é uma patologia de maior significado clínico dentre os tumores odontogênicos devido sua natureza agressiva e destrutiva, bem como sua elevada taxa de recidivas, sendo um desafio para o profissional $^{2,3}$. Objetivo: Relatar o caso de pacientes que foram operados para tratamento de ameloblastoma em que se utilizou prototipagem. Relato de caso: Paciente, sexo masculino, 36 anos, compareceu ao Hospital da Restauração, Recife-PE, com queixa de aumento de volume em região mandibular direita e com resultado de histopatológico de Ameloblastoma, com histórico de 3 anos de evolução. Foram solicitadas tomografias computadorizadas e através deste exame foi confeccionado um protótipo, preparando uma prótese de resina acrílica para substituir a perda óssea após a exérese do tumor. Realizou-se uma embolização prévia das artérias maxilar interna, lingual e alveolar inferior do lado acometido pela lesão, seguindo-se um acesso submandibular. Ao expor o ameloblastoma realizou-se a demarcação na mandíbula de acordo com ensaio cirúrgico realizado no biomodelo, a exérese do tumor com margens de segurança de $1 \mathrm{~cm}$, instalação da prótese de resina acrílica e colocação da placa de reconstrução previamente modelada no protótipo. O paciente segue estável e sem recidivas do ameloblastoma. Discussão: Os avanços tecnológicos da prototipagem permitem a reprodução de estruturas anatômicas complexas, fabricam próteses, implantes, e podem ser utilizados para substituir peças ressecadas precisamente. $\mathrm{O}$ padrão ouro atual dessas reabilitações maxilofaciais são as microcirurgias avançadas com retalhos livres de fíbula com enxertos costocondraís de costela e osso ilíaco, quando não possível, uma reabilitação prostodôntica ou uma reabilitação por sistemas tridimensionais é o tratamento proposto ${ }^{1}$. Conclusão: Conclui-se que os biomodelos de prototipagem ajudam no planejamento da ressecção do Ameloblastoma e na reconstrução da perda óssea, simulando uma situação quase real do caso do paciente, otimizando o tempo do ato transoperatório e melhorando o reestabelecimento da função mandibular.

Descritores: Ameloblastoma; Estudo de Prova de Conceito; Tratamento

\section{Referências:}

1. FERNANDES N, et al. Reconstruction of an extensive midfacial defect using additive manufacturing techniques. Journal of Prosthodontics, 2016; 25(7): 589-594

2. JAMAYET N, et al. New Approach to 3D Printing of Facial Prostheses Using Combination of Open Source Software and Conventional Techniques: A Case Report. The Bulletin of Tokyo Dental College, 2017; 58(2): 117-124

3. KREPPEL M, ZÖLLER J. Ameloblastoma-Clinical, radiological, and therapeutic findings. Oral diseases, 2018; 24(1-2):63-66 


\title{
PC-171-2019 - RESOLUÇÃO DE APINHAMENTO SEVERO SEM EXTRAÇÃO COM APARELHO ORTODÔNTICO AUTOLIGADO
}

\author{
Joyce Monteiro de Souza ${ }^{1}$; Beatriz Paes de Araújo ${ }^{1}$; Maria Érica Lucena da Silva ${ }^{1}$; Amanda \\ Galindo Florêncio Miranda ${ }^{1}$
}

${ }^{1}$ Faculdade Maurício de Nassau - Caruaru - PE - Brasil

Autor correspondente:

Joyce Monteiro de Souza

joyce.montteiro@hotmail.com

Introdução: As indicações de extrações dentárias para dissolução de apinhamentos severos vem diminuindo consideravelmente no decorrer dos anos, graças aos tratamentos ortodônticos com o sistema autoligado ${ }^{1}$. Com esse sistema, grandes expansões de arcadas são conseguidas². Objetivos: Enfatizar a eficácia do sistema auto ligado para solução de apinhamento severo sem extração, através de um relato de caso. Relato de Caso: Paciente C. C. O. M., sexo masculino, 12 anos, compareceu ao consultório odontológico queixando-se da ausência do canino superior direito no sorriso, além do apinhamento anteroinferior. A documentação ortodôntica foi solicitada, onde constatou-se a presença do elemento 13 , porém a sua não erupção foi devido à ausência de espaço no arco, com apinhamento de $-12,5 \mathrm{~mm}$ superior e - $-6,5 \mathrm{~mm}$ inferior, além de mordida cruzada anterior e posterior esquerda. Ademais, o paciente apresentava medidas cefalométricas compatíveis com birretrusão, contraindicando, portanto, extrações dentárias. Para obtenção do espaço para o elemento 13 e descruzamento de mordida foi instalado disjuntor maxilar Hyrax, e posteriormente instalada uma barra transpalatina para manutenção da expansão. Após disjunção maxilar, o aparelho ortodôntico fixo auto ligado superior e inferior foi instalado, seguindo-se a mecânica de alinhamento e nivelamento dentário com fios de NiTi termo ativados e de aço, além da utilização de mola aberta. Ao final foram utilizados elásticos de intercuspidação para refinar os contatos oclusais, sendo o tratamento concluído com 21 meses. Discussão: O sistema auto ligado tem se mostrado como uma ferramenta fundamental para resolução de apinhamentos dentários severos onde as extrações dentárias não estão bem indicadas, como no caso de birretrusões esqueléticas ${ }^{3}$, além de promover um tratamento de excelência com menor tempo e menor quantidade de consultas ${ }^{1}$. Conclusão: Os aparelhos auto ligados possuem um grande impacto na Ortodontia, devêndo o ortodontista estar ciente quanto às suas indicações e vantagens, considerando todos os fatores inerentes à sua mecânica de atuação.

Descritores: Ortodontia Corretiva; Má Oclusão; Extração Dentária.

\section{Referências:}

1. PRIETO LA, et al. O uso do aparelho autoligado no dia a dia do consultório - revisão de literatura. Rev. Odontol. Univ. Cid. São Paulo, 2016; 28(3): 230

2. TAVARES S, et al. Sistema autoligável - tratamento de apinhamentos modernos e severos sem extrações. Orthod. Sci. Pract, 2015; 8(31): 294-304

3. TRESSE DF, et al. Aparelho ortodôntico autoligado. Brazilian Journal os Surgery and

Clinical Research, 2017; 19(3): 71-5 


\section{PC-172-2019 - RESSECÇÃO DE AMELOBLASTOMA EM MANDÍBULA: RELATO DE CASO}

Francisco Henrique Lima Milhomens ${ }^{1}$; Fernanda Gomes Barros ${ }^{1}$; Carolina Pereira da Silva ${ }^{1}$; Maria Eduarda Arruda de Lucena ${ }^{1}$; Manuela França Andrade Passos ${ }^{1}$; Bruna Lucena Borges ${ }^{1}$; Carlos Eduardo Mendonça Batista ${ }^{2}$; Éwerton Daniel Rocha Rodrigues ${ }^{1}$

${ }^{1}$ Faculdade de Odontologia de Pernambuco - Camaragibe - PE - Brasil

${ }^{2}$ Universidade Federal do Piauí - Teresina - PI - Brasil

Autor correspondente:

Francisco Henrique Lima Milhomens

franciscohenrique01@gmail.com

Introdução: O ameloblastoma é um turmor benigno comumente encontrado nos ossos gnáticos ${ }^{1}$. Trata-se de um tumor de crescimento lento, normalmente assintomático, que provoca deslocamento, mobilidade e reabsorção dentária ${ }^{1,2}$. Por ser um tumor agressivo, possui grande percentual de recidiva e o prognóstico depende de vários fatores. Acometem tanto a mandíbula quanto a maxila, tendo maior prevalência na primeira. Não há predileção quanto ao gênero e raça, apresentando maior incidência em adultos jovens ${ }^{1-4}$. Objetivo: $\mathrm{O}$ objetivo desse trabalho é relatar o caso de uma paciente do gênero feminino, apresentando um ameloblastoma mandibular, tratado por meio ressecção parcial de mandíbula. Relato de caso: Paciente H.M.P., 20 anos, gênero feminino, compareceu ao serviço do Hospital Universitário da Universidade Federal do Piauí relatando a presença de uma "massa" em sua boca. Ao exame clínico foi constatada a presença de aumento de volume em região esquerda de corpo de mandíbula e anterior da mesma. Discussão: A paciente foi submetida a uma biópsia incisional compatível com ameloblastoma. Devido à agressividade da lesão foi optado por uma ressecção parcial da mandíbula, com margem de $1,5 \mathrm{~cm}$ e em seguida foi realizada aplicação de endo-ice nos cotos remanescentes justificando-se pela sua propriedade de provocar lise celular, diminuindo assim as chances de recidiva. Foi realizada a reconstrução com placa do sistema 2.4, que foi previamente modelada utilizando um biomodelo prototipado. A partir desse foi confeccionado uma placa de reconstrução do sistema 2.4. A paciente segue em acompanhamento ambulatorial de 6 meses, será realizado o planejamento para enxertia óssea no defeito mandibular. Conclusões: Independente da abordagem utilizada é indispensável o acompanhamento pósoperatório, devido às consideráveis taxas de recorrência ${ }^{1,3}$. A ressecção marginal é a forma mais comum de tratamento, com menor taxa de recidiva ${ }^{3}$.

Descritores: Ameloblastoma; Patologia; Cirurgia Bucal.

\section{Referências:}

1. MUNIZ VRVM, et al. V14N4 Características Clínicas, Radiográficas e Diagnóstico do Ameloblastoma: Relato de Caso. Revista de Ciurgia e Traumatologia Buco Maxilo Facial, 2014; 14: 27-32

2. NEVILLE BW, et al. Patologia Oral e Maxilofacial. $2^{\text {a }}$ ed. Rio de Janeiro: Guanabara Koogan, 2004; 798p

3. RALDI FV, et al. Tratamento de ameloblastoma. Revista Gaúcha de Odontologia, 2010; 58: 8-23

4. SANTOS ML, et al. Ameloblastoma: revisão da literatura e relato de caso. Revista Brasileira de Cirurgia e Implantodontia, 2000; 7: 18-21 


\section{PC-173-2019 - SEQUELA DE FRATURA DO COMPLEXO NASO-ÓRBITO- ETMOIDAL: RELATO DE CASO}

Maysa Swellen Valentim de Oliveira ${ }^{1}$; Cláudia Geisa Souza e Silva ${ }^{1}$; Emerllyn Shayane Martins de Araújo ${ }^{1}$; Caio César Gonçalves da Silva ${ }^{2}$; Demóstenes Alves Diniz ${ }^{2}$; Jéssica Cunha da Silva' ${ }^{2}$; Rosa Rayanne Lins de Souza ${ }^{2}$; Kalyne Kelly Negromonte Gonçalves ${ }^{2}$

${ }^{1}$ Faculdade de Odontologia de Pernambuco - Camaragibe - PE - Brasil

${ }^{2}$ Hospital da Restauração - Recife - PE - Brasil

Autor correspondente:

Maysa Swellen Valentim de Oliveira

maysavalentim@outlook.com

Introdução: Os traumas e lesões do complexo naso-órbito-etmoidal (NOE) são de difícil diagnóstico e tratamento, devido à sua complexidade anatômica e a presença de estruturas nobres associadas ${ }^{3}$. O diagnóstico é baseado em exames clínicos e de imagem por meio da tomografia computadorizada (TC) ${ }^{1}$. O planejamento cirúrgico consiste na correção das assimetrias faciais e reabilitação funcional ${ }^{2}$. Objetivo: Relatar um caso clínico de um paciente com sequela de fratura NOE. Relato de caso: Paciente do sexo masculino, 41 anos de idade, procurou o serviço de Cirurgia e Traumatologia Buco-Maxilo-Facial do Hospital da Restauração, Recife-PE, com história de acidente motociclístico há 10 anos. O paciente havia sido submetido à cirurgia para reconstrução de região NOE, entretanto evoluiu com fístula associado ao material de síntese, bem como queixa estética. Ao exame físico apresentava afundamento em região de dorso nasal, fístula e retração cicatricial do tecido mole. Não apresentava, entretanto, queixa visual ou respiratória. O exame de imagem sugeria presença de material de síntese mal adaptado em região frontal e NOE. O paciente foi submetido à cirurgia sob anestesia geral, para remoção de tela através de acesso coronal, bem como reconstrução de região NOE através de instalação novo material de síntese, fistulectomia e reparo do tecido mole cicatricial. O paciente se encontra em acompanhamento ambulatorial, com melhora do contorno da região nasal e sem queixa estética. Discussão: As relações entre as estruturas precisam ser muito bem observadas, a fim de promover o restabelecimento da anatomia e evitar complicações tardias, como o desenvolvimento de sinusites infecciosas, mucoceles, abscessos cerebrais e fístulas ${ }^{1,2}$. Conclusão: Dessa maneira, chama-se atenção para necessidade de um tratamento precoce para as fraturas NOE, visto que são de difícil correção.

Descritores: Complicações Pós-Operatórias; Fixação de fratura; Traumatismos Faciais.

\section{Referências:}

1. MELO MFS, et al. Correção de fratura fronto-naso-órbito-etmoidal: passos cirúrgicos para resultado estético. Revista de Cirurgia e Traumatologia Buco-Maxilo-Facial, 2015; 15(1): 3340

2. SILVA HCL, et al. Fraturas naso-órbito-etmoidal: diagnóstico e tratamento. Archives of Health Investigation, 2014; 3(6): 46-54

3. SOARES LP, et al. Indicações da tomografia computadorizada no diagnóstico das fraturas naso-órbito-etmoidais. Revista de Clínica e Pesquisa Odontológica, 2004; 1(1): 1-6 


\section{PC-174-2019 - SEQUÊNCIA CIRÚRGICA PARA REDUÇÃO E FIXAÇÃO DE FRATURA DE MANDÍBULA: RELATO DE CASO}

Greiciane Miguel de Azevedo Santos ${ }^{1}$; João Artur Peixoto Granja ${ }^{2}$; Amanda Regina Silva de Melo $^{3}$; Priscilla Sarmento Pinto ${ }^{3}$; Rosa Rayanne Lins de Souza ${ }^{3}$; Ruan de Souza Viana ${ }^{3}$; Aída Juliane Ferreira dos Santos ${ }^{3}$; Rodolfo José Rangel Costa ${ }^{3}$

${ }^{1}$ Faculdade de Odontologia de Pernambuco - Recife - PE - Brasil

${ }^{2}$ Centro Universitário Tiradentes - Recife - PE - Brasil

${ }^{3}$ Hospital da Restauração Governador Paulo Guerra - Recife - PE - Brasil

Autor correspondente:

Greiciane Miguel de Azevedo Santos

greiciane_azevedo@outlook.com

Introdução: A mandíbula é o único osso móvel da face e tem importante função na mastigação, deglutição, fonação e estética facial. Devido à sua anatomia torna-se um osso muito exposto, fazendo com que a fratura mandibular ocupe o segundo lugar entre as fraturas dos ossos da face $^{1}$. A escolha da terapêutica baseia-se na idade do paciente, na severidade do caso, e no tempo transcorrido após a injúria; considerando-se as condições dos tecidos moles, dependendo da fratura será indicado tratamento fechado ou cirúrgico ${ }^{3}$. Objetivo: Relatar um caso de tratamento de fratura mandibular atendido no Hospital da Restauração. Relato de caso: Paciente sexo masculino, 25 anos, chegou ao serviço após acidente motociclístico. Ao exame físico paciente apresentava mobilidade em mandíbula e má-oclusão. Foi submetido a tratamento para redução e fixação de fratura sob anestesia geral, na qual foi realizada abordagem extraoral através de acesso submandibular, reposicionamento dos cotos, bloqueio intermaxilar, e fixação de duas placas do sistema 2.0. Em seguida, foi realizado a lavagem copiosa com SF 0,9\% e sutura por planos. Discussão: A oclusão dentária é a chave do tratamento das fraturas maxilomandibulares, tanto como objetivo final quanto como forma de assegurar mais facilmente a melhor redução e osteossíntese das fraturas. Estabelecer um bloqueio maxilo-mandibular estável, de forma rápida e segura, é o maior objetivo das diversas técnicas descritas na literatura. O método cirúrgico consiste em exposição da fratura por meio de acessos faciais (pré-auricular, submandibular, retromandibular, transcervical). A utilização de miniplacás âplica-se à règiões como ramo, ângulo, corpo e sínfise, fraturâs com cominuição mínima e grandes fragmentos ósseos intactos ${ }^{2,4}$. Conclusão: Nesses casos o mais importante é o restabelecimento da oclusão funcional e as funções mastigatórias do paciente, com o mínimo de sequela possível deverá ser sempre o pré-requisito antes de todo e qualquer procedimento cirúrgico.

Descritores: Mandíbula; Fraturas mandibulares; Fixação interna de fraturas.

\section{Referências:}

1. ALENCAR MGM, et al. Tratamento de fratura complexa de mandíbula por abordagem transcervical: Relato de caso. Rev. cirurgia traumatologia buco-maxilo-facial, 2015; 15(4): $1808-5210$

2. DANTAS BPSS, et al. Fratura complexa de mandíbula: relato de caso. Revista Odontológica de Araçatuba, 2017; 38(3): 43-48

3. GOMES ACA, et al. Tratamento das fraturas mandibulares: relato de caso clínico. Rev. cirurgia traumatologia buco-maxilo-facial, 2001; 1(2): 31-38

4. SILVA FMS, et al. Bloqueio intermaxilar pela técnica de fio interdental calibroso: descrição da técnica. Rev. cirurgia traumatologia buco-maxilo-facial, 2015; 15(1): 51-54 


\title{
PC-175-2019 - SESSÃO ÚNICA EM CASOS COMPLEXOS: UMA REALIDADE CONTEMPORÂNEA - RELATO DE CASO
}

\author{
Maria Izabel Silva Bezerra ${ }^{1}$; Marcelle Freitas Braz ${ }^{1}$; João Carlos Hazin de Godoy ${ }^{2}$; Glauco dos \\ Santos Ferreira ${ }^{3}$; Tayse de Carvalho Cordeiro ${ }^{3}$; Nilton Gomes Vivacqua ${ }^{4}$; Nathalia Marília \\ Pereira Ferraz ${ }^{4}$ \\ ${ }^{1}$ Centro Universitário Maurício de Nassau - Recife - PE - Brasil \\ ${ }^{2}$ Centro Universitário Tiradentes - Recife - PE - Brasil \\ ${ }^{3}$ Universidade Federal de Pernambuco - Recife - PE - Brasil \\ ${ }^{4}$ Faculdade de medicina e odontologia São Leopoldo Mandic - Fortaleza - CE- Brasil \\ Autor correspondente: \\ Maria Izabel Silva Bezerra \\ belbezerra54@gmail.com
}

Introdução: A Endodontia passou por uma grande evolução tecnológica, permitindo tratamentos e retratamentos em sessão única de forma mais segura e eficaz ${ }^{3,4}$. O sucesso endodôntico não está diretamente relacionado à tecnica utilizada, seja em sessão uníca ou multiplas e sim à forma correta de conduzi-las, visando que ambas apresentam vantagens especificas $^{2,4}$. Objetivo: $\mathrm{O}$ escopo desse trabalho é relatar um caso de retratamento em única sessão. Relato de caso: Paciente C. F. M. S, 31 anos, compareceu à Clínica da UNINASSAU, queixando-se de fratura do elemento 25. Ao exame clínico verificou-se fratura da cúspide lingual; na avaliação radiográfica observou-se tratamento endodôntico prévio com obturação aquém do limite periapical e presença de lesão na região de periápice, dilaceração na região apical e íntima relação com o seio maxilar. Realizou-se a desobturação com Logic RT (Easy), patência com c-pilot (VDW), odontometria eletrônica, limpeza e ampliação foraminal com Logic 15/.05, 25/.01, 25/.05 e 30/.05 $1 \mathrm{~mm}$ além do CRD, com clorexidina gel $2 \%$ e soro fisiológico 0,9\%. Realizou-se protocolo final de agitação das soluções com Easy Clean (Easy). A obturação foi com Sealer Plus (Mklife) e cone FM EL calibrado. Durante a proservação observou-se sinais de regressão da lesão. Discussão: O auxílio de magnificação, localizadores eletrônicos, motor elétrico e limas mecanizadas reduziram o tempo de concretização desse tratamento, permitindo realização em única sessão. A escolha das Logic's foi por serem, limas de NiTi CM com maior flexibilidade e menor força de restauração, sendo mais seguras nos condutos curvos ${ }^{4,5}$. A clorexidina, foi selecionada devido à proximidade com o seio e sua maior biocompatibilidade em relação ao hipoclorito de sódio, minimizando as chances de reação inflamatória no local e dor severa ${ }^{1}$. Conclusão: Conclui-se que o retratamento em sessão única é uma realidade, tornando-se a alternativa ideal mesmo em casos de retratamento de dente com lesão.

Descritores: Endodontia; Retratamento; Clorexidina.

\section{Referências:}

1. CÂMARA A, et al. Soluções irrigadoras utilizadas para o preparo biomecânico de canais radiculares. Pesquisa Brasileira em Odontopediatria e Clinica Integrada, 2010; 10(1): 127-133. 2. ENDO MS, et al. Endodontia em sessão única ou múltipla: revisão da literatura. Revista da Faculdade de Odontologia UPF, 2015; 20 (3): 408-413

3. FAVA LRG. Tratamento endodôntico em sessão única: vantagens e desvantagens. Revista Brasileira de Odontologia, 1999; 56 (6): 273-278

4. GAVINI G, et al. Nickel-titanium instruments in endodontics: a concise review of the state of the art. Brazilian Oral Research, 2018; 32: 44-65

5. MARQUES ACR. Endodontia: sessão única versus múltiplas sessões. Dissertação (Mestrado em Medicina Dentária) - Universidade Fernando Pessoa. Faculdade de Ciências da Saúde. 


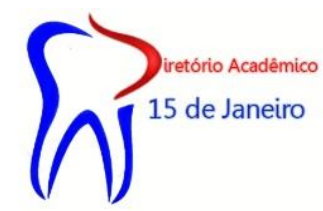

Porto, 2014; 58p
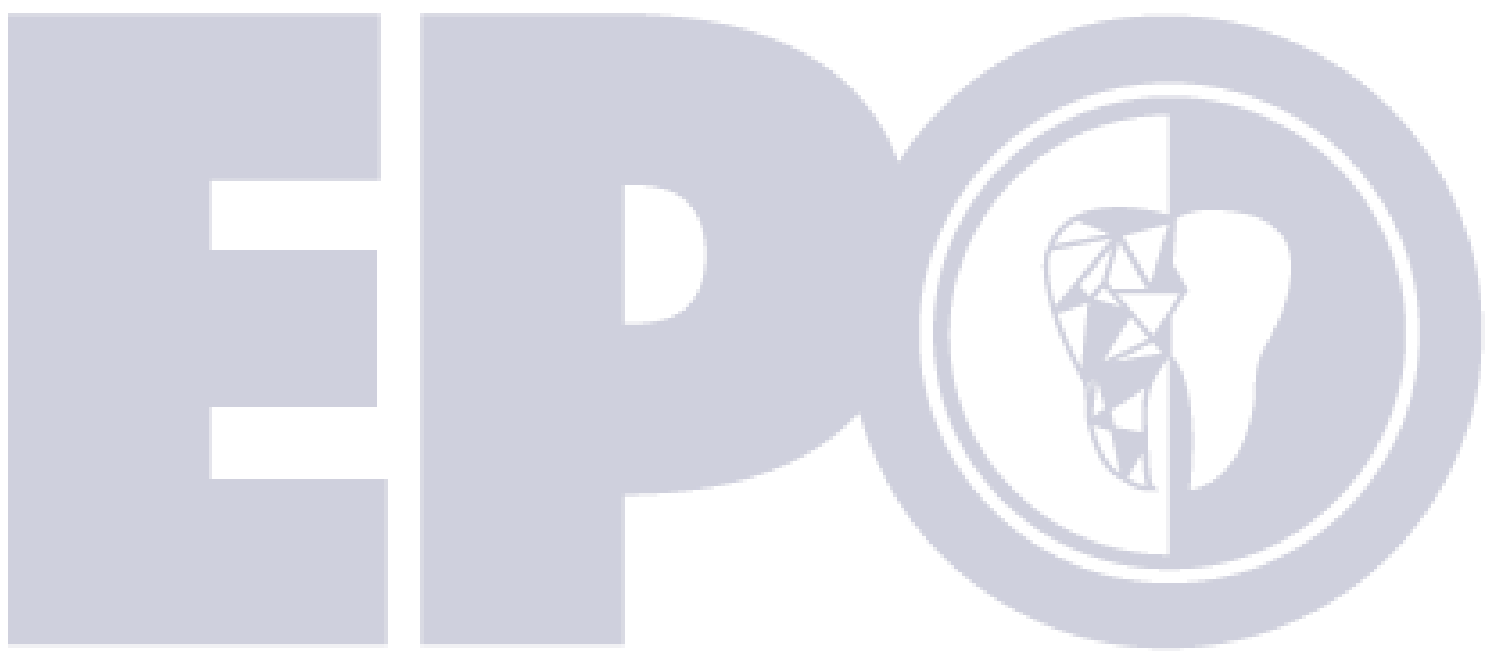

ENCONTRO PERNAMBUCANO DE ODONTOLOGIA 


\section{PC-176-2019 - SIALOMETAPLASIA NECROSANTE: ASPECTOS ETIOLÓGICOS, DIAGNÓSTICO E TRATAMENTO}

Laura do Nascimento Arruda ${ }^{1}$; Aylanne Xavier de Lacerda Cavalcante Timoteo ${ }^{1}$; Emerllyn Shayane Martins de Araújo ${ }^{1}$; Kássia Regina de Santana ${ }^{1}$; Lucas Rafael Borges Santos ${ }^{1}$; Ingrid Patrícia de Moraes Lima'; Maria Eduarda Lemos Avelino; ${ }^{1}$ Sally de Souza Brito ${ }^{2}$

${ }^{1}$ Faculdade de Odontologia de Pernambuco - Camaragibe - PE - Brasil

${ }^{2}$ Centro de Pós-graduação em Odontologia - Recife - PE - Brasil

Autor correspondente:

Laura do Nascimento Arruda

lauranarruda@gmail.com

Introdução: A sialometaplasia necrosante (SN) é uma inflamação rara das glândulas salivares menores que, na maioria dos casos, afeta as glândulas mucosas do palato duro. Primeiro descrito por Abrams et al. em 1973, SN constitui 1\% das biópsias orais. Embora a maioria dos casos afetem o palato duro, outros locais ao longo do trato respiratório superior, grandes glândulas salivares, mucosa e amígdalas foram documentadas ${ }^{1}$. Objetivo: Apresentar uma revisão da literatura sobre a sialometaplasia necrosante, aspectos etiológicos, diagnóstico e tratamento da patologia. Metodologia: Foi realizado cruzamento dos descritores selecionados e foram escolhidos 8 artigos publicados entre os anos de 2010 e 2019, encontrados nos periódicos das bases de dados LILACS, PubMed e SciELO. Revisão de Literatura: A etiologia da SN relaciona-se a um evento ísquico; no entanto, vários fatores adicionais foram mencionados na literatura como potenciais fatores predisponentes: trauma local induzido por tratamento ou aparelhos dentários, outras lesões traumáticas, uso de álcool e tabaco, infecções do trato respiratório superior e distúrbios alimentares. O diagnóstico pode ser sustentado por imunohistoquímica, mas o padrão-ouro é o histopatológico, já o diagnóstico diferencial clínico é feito com úlcera traumática, inflamatória, processos infecciosos e neoplasias malignas. Detalhes clínicos como a apresentação (uni ou bilateral), o curso (agudo ou crônico), sintomas (dor ou sem dor) e antecedentes do paciente com transtornos alimentares (DE) e depressão foram documentados. Embora na maioria dos casos SN seja autolimitante e cura espontaneamente com tratamento de suporte, casos raros podem atingir tamanhos grandes. Nestes casos, debridamento cirúrgico deve ser considerado como uma opção de tratamento viável, diminuindo o risco de sepse ${ }^{2,3}$. Conclusão: As evidências sugerem que a SN tem uma etiologia e patogenia ainda a ser estudada embora fortemente a isquemia seja considerada a principal causa, o histopatológico é indispensável, o diagnóstico diferencial requer acurácia, e a maioria dos casos é autolimitante.

Descritores: Sialometaplasia Necrosante; Glândulas Salivares; Diagnóstico.

\section{Referências:}

1. KAPLAN I, et al. The clinical, histologic, and treatment spectrum in necrotizing sialometaplasia. Oral surgery, oral medicine, oral pathology and oral radiology, 2012; 114(5): 577-585

2. KIM YH, et al. A case of necrotizing sialometaplasia involving bilateral parotid glands. American journal of otolaryngology, 2013; 34(2): 163-165

3. LEDESMA-MONTES C, et al. Review of the literature on necrotizing sialometaplasia and case presentation. Quintessence International, 2015; 46(1): 67-72 


\section{PC-177-2019 - SUBSTITUIÇÃO DE RESTAURAÇÕES EM AMÁLGAMA DE PRATA POR RESINA COMPOSTA PELAS TÉCNICAS DIRETA E INDIRETA: RELATO DE CASO}

Brenda Luhana Campos Silva ${ }^{1}$; Gabriela Queiroz de Melo Monteiro²; Jeferson Augusto Santos Carneiro da Cunha ${ }^{3}$; Amanda Azuirson Auto Guimarães ${ }^{3}$; Cláudia Geisa Souza e Silva²; Luís Felipe de Espíndola Castro²

${ }^{1}$ Universidade Federal de Pernambuco - Recife - PE - Brasil

${ }^{2}$ Faculdade de Odontologia de Pernambuco - Camaragibe - PE - Brasil

${ }^{3}$ Centro Universitário Brasileiro - Recife - PE - Brasil

Autor correspondente:

Brenda Luhana Campos Silva

brendaluhana2@gmail.com

Introdução: Resinas compostas são materiais de eleição para restaurações de dentes posteriores ${ }^{1}$. Entretanto, apresentam algumas desvantagens como o stress induzido por polimerização. Para compensar esse stress, a técnica incremental é indicada ${ }^{2}$. Em cavidades extensas, o uso das resinas compostas indiretamente também é uma opção, uma vez que a contração de polimerização do material é compensada durante a cimentação ${ }^{2,3}$. Objetivo: Relatar a substituição de duas restaurações em amálgama por restaurações em resina composta pela técnica direta e indireta. Relato de Caso: Paciente do gênero feminino buscou atendimento queixando-se de restaurações em amálgama nos dentes 46 e 47 . No elemento 46 foi realizada restauração em resina direta e no 47 , devido à extensão da cavidade, optou-se pela técnica indireta. Foi realizada a remoção das restaurações metálicas (\#1014), preparo cavitário para restauração indireta com ponta diamantada \#3131, moldagem do preparo com silicone de adição e obtenção do modelo de gesso. Em seguida, realizou-se alívio do modelo com cera, escultura da restauração com resina composta (Harmonize / Keer) e termopolimerização (um ciclo na autoclave). Posteriormente, fez-se o isolamento absoluto, condicionamento seletivo do esmalte com ácido fosfórico 37\% (30 segundos) nos dois dentes e na peça, aplicação do adesivo universal em ambos os dentes e na peça (polimerização por 20 segundos). Em seguida, foi realizada a cimentação da restauração indireta com cimento resinoso dual e escultura pela técnica incremental no dente 46 na mesma sessão. O ảcabamento e polimento foram efetuados na sessão seguinte. Discussão: A técnica direta apresenta como vantagem a necessidade de menores etapas clínicas, enquanto a indireta favorece uma maior conversão polimérica e facilita a escultura da restauração, uma vez que é realizada fora da boca ${ }^{1,2,3}$. Conclusões: As restaurações em resina composta propiciaram estética e funcionalidade, fornecendo máxima preservação da estrutura dentária.

Descritores: Amálgama Dentário; Dente Molar; Restauração Dentária Permanente.

\section{Referências:}

1. LAGO M, et al. Restaurações indiretas em resina composta - desmistificação da técnica. International Journal of Dentistry, 2011; 10(4): 282-286

2. PACHECO AF, et al. Técnica indireta-direta para resinas compostas - coroas leves. Clínica International Journal of Brazilian Dentistry, 2014; 10(1): 448-455

3.PINI NIP, et al. Versatilidade da resina composta para restaurações em dentes posteriores: técnica direta e indireta. Prosthesis Laboratory in Science, 2017; 4(16): 314-322 


\section{PC-178-2019 - TÉCNICA DE CHAMPY NA FRATURA DE ÂNGULO MANDIBULAR: RELATO DE CASO}

Maria Julia Falcone de Melo Trigueiroㅎ ; Beatriz Borba Barros Bernardo; Kalyne Kelly Negromonte Gonçalves ${ }^{2}$; Demóstenes Alves Diniz ${ }^{2}$; Carolina Chaves Gama Aires ${ }^{1}$; Niviane Marielly da Costa Oliveira ${ }^{1}$; Caio César Gonçalves Silva ${ }^{1}$; David Moraes de Oliveira ${ }^{1}$

${ }^{1}$ Faculdade de Odontologia de Pernambuco - Camaragibe - PE - Brasil

${ }^{2}$ Hospital da Restauração - Recife - PE - Brasil

Autor correspondente:

Maria Julia Falcone de Melo Trigueiro

majufalcone@gmail.com

Introdução: O ângulo mandibular é uma região anatômica localizada em uma zona de transição, entre o corpo e o ramo mandibular, sendo uma área de baixa resistência a fratura. Algumas condições como; alterações metabólicas, processos patológicos e tumores malignos, podem causar diminuição da resistência óssea e consequentemente aumentar o risco à fraturas ${ }^{1}$. As fraturas em região de ângulo mandibular geram as maiores frequências de complicações 0 - $32 \%$ em relação aos outros tipos de fraturas da mandíbula ${ }^{2}$. A técnica de Champy é uma possibilidade de tratamento, sendo utilizada para fraturas localizadas em região de ângulo, onde se lança mão da utilização de uma mini placa e parafuso monocortical na zona de tensão, por acesso intraoral. Objetivo: O presente trabalho tem como objetivo relatar a utilização da técnica de Champy no tratamento de fratura do ângulo mandibular. Relato de Caso: Paciente do sexo masculino, 28 anos, vítima de agressão física. Ao exame físico, observou-se hematoma em região de ângulo mandibular direito e mal oclusão. À palpação observou-se crepitação óssea na região. O exame radiográfico revelou uma fratura de ângulo mandibular esquerdo. Realizou-se, então, a redução e fixação da fratura pela técnica de Champy. Após um mês de acompanhamento, o paciente retornou com oclusão estável e a fratura bem posicionada e em fase de reparação. Discussão: Atualmente, no tratamento de traumas mandibulares, é uma realidade a utilização de fixação interna rígida com mini placas de titânio, o que nos permite abandonar o uso de fios de aço para fraturas de tal complexidade ${ }^{3}$. Conclusões: Dessa forma, pode-se observar que o tratamento de fraturas mandibulares utilizando a técnica de Champy pode possibilitar o restabelecimento da oclusão funcional e a continuidade mandibular, além de sua forma anátomo-funcional, reintegrando o paciente à sociedade e reduzindo o impacto socioeconômico.

Descritores: Cirurgia Bucal; Fixação Interna de Fraturas; Fixação de Fratura.

\section{Referências:}

1. CARVALHO NETO MF. Tratamento das fraturas mandibulares com fixação interna rígida: estudo comparativo entre via de acesso extra-oral e intra-oral com uso de trocarte percutâneo. Rev. Bras. Cir. Craniomaxilofac, 2008; 11(4): 132-141

2. RODRIGUES AR, et al. Fratura mandibular durante remoção do terceiro molar: fatores de risco, medidas preventivas e métodos de tratamento. Rev Odontol Bras Central, 2013;22(63): 124-127

3. SANTOS SE, et al. Fratura de ângulo mandibular após tentativa de exodontia de $3^{\circ}$ molar incluso: relato de um caso. Rev. Cir. Traumatol. Buco-Maxilo-fac., 2009; 9(3): 15-20 


\title{
PC-179-2019 - TÉCNICA DE ENXERTO GENGIVAL LIVRE PARA AUMENTO DE GENGIVA QUERATINIZADA: RELATO DE CASO CLÍNICO
}

\author{
Marilya Roberta Ferreira de Melo ${ }^{1}$; Letícia de Oliveira Santos ${ }^{1}$; Iasmin Cirino da Silva ${ }^{1}$; Ismael \\ Sebastião da Silva Sousa ${ }^{1}$; Eduardo de Farias Barbosa ${ }^{1}$; Gabriela Brito Vasconcelos ${ }^{2}$ \\ ${ }^{1}$ Faculdade de Odontologia de Pernambuco - Camaragibe - PE - Brasil \\ ${ }^{2}$ Universidade Federal de Pernambuco - Recife - PE - Brasil
}

Autor correspondente:

Marilya Roberta Ferreira de Melo

marilyaroberta@hotmail.com

Introdução: Enxerto gengival epitélio-conjuntivo, também denominado enxerto gengival livre (EGL) é uma técnica, descrita por Björn ${ }^{3}$, com objetivo de aumentar a faixa de mucosa queratinizada. Se tornou uma das primeiras técnicas de cirurgia plástica periodontal ${ }^{3}$, que consegue obter reconstruções de gengivas retraídas ou atrofiadas, mantendo a integridade da superfície da mucosa mastigatória da cavidade oral. Objetivo: Relatar um caso clínico com o intuito de demonstrar a indicação da técnica do EGL para ganho de gengiva queratinizada. Relato de caso: Paciente leucoderma, sexo feminino, 25 anos, procurou o serviço odontológico pela percepção da recessão gengival no elemento dentário 31. Foi observada a presença de recessão classe II de Miller no referido dente, com estreita faixa de gengiva queratinizada, e a presença de interferência oclusal na recessão gengival. $O$ tratamento instituído foi o plano periodontal básico, ajuste oclusal, e cirurgia de recobrimento radicular. A técnica cirúrgica utilizada foi a de enxerto gengival livre que consiste inicialmente no preparo do leito receptor com retalho de espessura parcial com incisões horizontais e verticais. Após hemostasia do leito receptor, um enxerto epitélio-conjuntivo é obtido da região doadora, região palatina, que posteriormente é posicionado e suturado na região receptora ${ }^{1}$. Discussão: A técnica do EGL pode ser realizada para recobrir recessões gengivais múltiplas e isoladas, bem como aumentar a largura de gengiva queratinizada ${ }^{1}$. O aumento de tecido queratinizado é uma das principais indicações do enxerto gengival epitélio-conjuntivo em altura e espessura, além disso, um certo grau de recobrimento é esperado dependendo do tipo de recessão apresentada ${ }^{2}$. A partir disto é percebido a importância da utilização da técnica de enxerto gengival livre com relação a recessão gengival afim de se garantir uma adequada morfologia do periodonto. Conclusão: EGL é uma técnica eficaz e aplicável para recobrimento de raízes expostas bem como para o aumento de tecido queratinizado.

Descritores: Retração Gengival; Gengiva; Cirurgia Bucal.

\section{Referências:}

1. FEITOSA DS, et al. Indicações atuais de enxertos gengivais livres. RGO, 2008; 56(2): 1-6.

2. KATO T, ALVES R. Emprego do Enxerto Gengival Epitélio-Conjuntivo no Recobrimento Radicular. RGO, 2005; 54(1): 81-83

3. RIBAS A, et al. Enxerto gengival livre versus enxerto de tecido conjuntivo livre - Relato de caso clínico. Braz J Periodontol, 2016; 26(4): 64-70 


\section{PC-180-2019 - TÉCNICA MINIMAMENTE INVASIVA DE ARTROCENTESE PARA PACIENTES COM DTM - RELATO DE CASO}

Vitória Lopes Ribeiro Pessoa ${ }^{1}$; Amanda Azuirson Auto Guimarães ${ }^{1}$; Carolina Chaves Gama Aires²; Carolina Pereira Da Silva²; Emelly Nayane Da Silva Ribeiro'; Eugênia Leal De Figueiredo²; Ricardo José De Holanda Vasconcellos ${ }^{2}$

${ }^{1}$ Universidade Brasileira - UNIBRA- Recife - PE - Brasil

${ }^{2}$ Faculdade de Odontologia de Pernambuco - Camaragibe - PE - Brasil

Autor correspondente:

Vitoria Lopes Ribeiro Pessoa

vitorialopes0906@hotmail.com

Introdução: Disfunções têmporo-mandibulares (DTM) têm se tornado um problema de saúde pública, sendo cada vez mais frequentes na população. Existem várias formas de tratamento, porém como primeira opção, estão tratamentos conservadores, fisioterapia, placa oclusal, medicação e mudanças de comportamento. Quando não é possível solucionar através destes tratamentos, partimos para procedimentos cirúrgicos. Artrocentese é uma das primeiras opções de tratamento cirúrgico para pacientes não responsivos. Sendo minimamente invasivo, realizado na articulação têmporo-mandibular com baixo risco de complicações, alta taxa de sucesso e baixo custo. Indicações incluem: deslocamento do disco articular, limitação da abertura bucal, dor articular e outros desarranjos internos ${ }^{2,3}$. Objetivo: Relatar o caso de paciente submetida a tratamento conservador sem melhora clínica, optando por uma técnica minimamente invasiva de artrocentese para lavagem intra-articular ${ }^{3}$. Relato de caso: Paciente C.R.L., compareceu ao ambulatório da Unimed Recife III apresentando algia intensa em ATM. Clinicamente, a paciente apresentava deslocamento de disco com redução, estalidos na ATM em abertura bucal, dor nos músculos da face, levando a suspeita de disfunção muscular. Apresentava cefaléia e cervicalgia. Discussão: Inicialmente, optamos por tratamento com termoterapia, dieta pastosa, placa miorrelaxante, relaxantes musculares e fisioterapia, sem melhora. Optamos então por procedimento cirúrgico sob anestesia geral, realizando técnica minimamente invasiva para artrocentese da ATM bilateral. Ao final, foi notado que não havia mais estalidos e foi conversado com a paciente que ela precisava mudar hábitos de vida. Nestes casos é muito importante à equipe multidisciplinar para o sücesso do tratamento. A paciente vem sendo acompanhada desde então, fazendo fisioterapia, acompanhamento com a nutricionista, usando a placa miorelaxante, evolui sem dores ${ }^{2,3}$. Conclusão: Conclui-se uma melhora efetiva de pacientes com desarranjos internos da articulação, submetidos a artrocentese.

Descritores: Síndrome da disfunção da articulação temporomandibular; Artrocentese; Irrigação Terapêutica.

\section{Referências:}

1. AKABANE STF, et al. Relato de caso clínico cirúrgico de artrocentese em paciente vítima de acidente motociclístico. Revista Arch Health Invest, 2017; 6(5):24

2. GROSSMANN E. Técnicas de artrocentese aplicadas às disfunções artrogênicas da articulação temporomandibular. Revista Dor, 2012;13(4):374-81

3. MANGANELLO LCZ, et al. Cirurgia da articulação temporomandibular. São Paulo:Santos, 2014; 252 


\section{PC-181-2019 - TERAPIAS REGENERATIVAS EM IMPLATODONTIA: O USO DO L-PRF}

Ingrid Melo Schüler Arreguy ${ }^{1}$; Carolina Chaves Gama Aires ${ }^{1}$; Eugênia Leal de Figueiredo²; Ricardo José de Holanda Vasconcellos²; Jessyca Maria Alencar e Sá1

${ }^{1}$ Universidade Federal de Pernambuco - Recife - PE - Brasil

${ }^{2}$ Faculdade de Odontologia de Pernambuco - Recife - PE - Brasil

Autor correspondente:

Ingrid Melo Schüler Arreguy

ingridarreguy@gmail.com

Introdução: As limitações de espessura e alturas ósseas, bem como a qualidade dos tecidos gengivais, ainda constituem grandes desafios ao implantodontista ${ }^{1}$. O L-PRF faz parte dos concentrados plaquetários de segunda geração obtidos a partir do sangue autógeno sem a manipulação bioquímica. A presença de plaquetas e seus fatores de crescimento, o estímulo a angiogênese, juntamente com a presença dos leucócitos e suas citocinas contribuem para a regulação imunológica no processo de cicatrização ${ }^{1}$. O potencial de estimular a regeneração tecidual do L-PRF o torna, atualmente, um grande aliado nas reconstruções de maxilas e mandíbulas atróficas, associados ou não a outros biomateriais ${ }^{3}$. Objetivo: $\mathrm{O}$ objetivo deste trabalho é discutir o uso do L-PRF na implantodontia, suas vantagens, limitações e a relevância teórica do tema. Metodologia: Foi realizada uma revisão de literatura na base de dados MEDLINE através do PubMed, utilizando os seguintes descritores: L-PRF, regeneração óssea, osseointegração e implantes dentários. Revisão de literatura: Existe moderada evidência científica dos benefícios clínicos do PRF na preservação do rebordo alveolar e na fase inicial da osseointegração, apesar de ainda permanecer incerta a sua efetividade na regeneração de tecidos moles ${ }^{4}$. Nas cirurgias para o levantamento de seio maxilar, a sua principal vantagem consiste em acelerar o processo de osseointegração, além de permitir um manejo adequado das perfurações da membrana sinusal, o que representa menor risco de reabsorção dos enxertos². Desde os primeiros manejos do L-PRF em 2001, houve uma evolução dos produtos e técnicas associadas. Conclusão: Os resultados encontrados são promissores, porém ainda há a necessidade de novos estudos para incrementar a sua aplicabilidade na prática clínica diária baseada em evidências.

Descritores: L-PRF; Regeneração Óssea; Osseointegração.

\section{Referências:}

1. CHENCHEV IL, et al. Application of Platelet-Rich Fibrin and Injectable Platelet-Rich Fibrin in Combination of Bone Substitute Material for Alveolar Ridge Augmentation - a Case Report. Folia Med (Plovdiv), 2017; 59(3): 362-366

2. MARELLI M, TATULLO M. Influence of PRF in the healing of bone and gingival tissues. Clinical and histological evaluations. Eur Rev Med Pharmacol Sci, 2013; 17(14): 1958-1962

3. PINTO GDDS, et al. Successful Use of Leukocyte Platelet-Rich Fibrin in the Healing of Sinus Membrane Perforation: A Case Report. Implant Dent, 2018; 27(3): 375-380

4. STRAUSS FJ, et al. The use of platelet-rich fibrin to enhance the outcomes of implant therapy: A systematic review. Clinical oral implants research, 2018; 29(18): 6-19 


\section{PC-182-2019 - TRATAMENTO CIRÚRGICO DE CISTO INFLAMATÓRIO ASSOCIADO A PROJÉTIL DE ARMA DE FOGO: RELATO DE CASO}

Carla Regina Lima de Barros ${ }^{\mathbf{1}}$; Caio César Gonçalves Silva ${ }^{2}$; Kalyne Kelly Negromonte Gonçalves; ; Demóstenes Alves Diniz; ; Allan Vinícius Martins de Barros²; Vinicius Balan Santos Pereira²; Luan Carlos Barbosa Lourenço ${ }^{1}$; Carlos Augusto Pereira do Lago ${ }^{3}$

${ }^{1}$ Centro Universitário Mauricio de Nassau- Recife-PE- Brasil

${ }^{2}$ Faculdade de Odontologia de Pernambuco- Camaragibe-PE- Brasil

${ }^{3}$ Hospital da Restauração Governador Paulo Guerra- Recife-PE- Brasil

Autor correspondente:

Carla Regina Lima de Barros

regina_lb@hotmail.com

Introdução: Os cistos de origem inflamatória são lesões que podem se fazer presentes tanto na maxila, quanto na mandíbula ${ }^{2}$. Corpos estranhos podem estar associados a essa patologia. A variação no tamanho do objeto, dificuldade de acesso e proximidade a estruturas vitais podem dificultar o diagnóstico. Dependendo da dimensão, cistos podem ser confundidos com outras patologias ${ }^{1}$. Objetivo: Relatar caso clínico de um paciente vítima de agressão por projétil de arma de fogo, com cisto inflamatório associado. Relato de caso: Paciente sexo masculino, 22 anos, compareceu ao serviço do Hospital da Restauração, com queixa de aumento de volume submandibular e cervical esquerdo. Á anamnese, o paciente relatava ter sido vítima de agressão por arma de fogo há aproximadamente seis meses. Ao exame extraoral apresentava aumento de volume endurecido a palpação com sintomatologia dolorosa. Ao exame intraoral apresentava oclusão estável sem expansão de corticais ósseas. A radiografia e ultrassonografia sugeriam lesão de aspecto misto associada a projétil de arma de fogo. Uma punção aspirativa foi realizada, apresentando conteúdo de coloração semelhante a palha. Foi realizada a cirurgia sob anestesia geral e selecionado um acesso submandibular esquerdo para a marsupialização como tratamento definitivo do cisto e remoção do projétil. O material foi enviado ao serviço anatomopatológico do hospital e obteve-se o laudo de cisto inflamatório associado a corpo estranho. O paciente segue em acompanhamento ambulatorial, com um ano de controle e sem sinais de recidiva da lesão. Discussão: Em caso de não tratamento, o crescimento continuado do cisto poderia ocasionar destruição significativa e enfrâquecimento da mandíbula. Lesões extensas quando tratadas adequadamente, através da marsupialização ou descompressão, obtém uma boa neoformação óssea ${ }^{3}$. Conclusão: Diante do exposto, fica claro a importância do correto diagnóstico possibilitando o tratamento adequado para evitar a permanência e evolução da lesão.

Descritores: Ferimentos por Arma de Fogo; Patologia Clínica; Corpos Estranhos.

\section{Referências:}

1. CAVALCANTE MB, et al. Cisto residual ectópico em associação a corpo estranho: relato de caso. Rev. Cir. Traumatol. Buco-Maxilo-Fac, 2019; 19(2):28-32

2. MORAES AP, RODRIGUES BS. Cistos odontogênicos inflamatórios: revisão de literatura. Revista da Graduação, 2011; 4(1): 28

3. OLIVEIRA DHIP, et al. Cisto Residual com Grande Dimensão: Relato de Caso e Revisão da Literatura. Rev. cir. traumatol. buco-maxilo-fac, 2011; 11(2):21-26 


\section{PC-183-2019 - TRATAMENTO CIRÚRGICO DE DISPLASIA FIBROSA: RELATO DE CASO}

Mariana Souza de Barros ${ }^{1}$; Emerllyn Shayane Martins de Araújo ${ }^{2}$; Maysa Swellen Valentim de Oliveira $^{2}$; Pedro Henrique Lopes Cavalcanti ${ }^{1}$; Caio César Gonçalves Silva ${ }^{3}$; Demóstenes Alves Diniz $^{3}$; Ruan de Sousa Viana ${ }^{3}$; Kalyne Kelly Negromonte Gonçalves ${ }^{3}$

${ }^{1}$ Universidade Federal de Pernambuco - Recife - PE - Brasil

${ }^{2}$ Faculdade de Odontologia de Pernambuco - Camaragibe - PE - Brasil

${ }^{3}$ Hospital da Restauração - Recife - PE - Brasil

Autor correspondente:

Mariana Souza de Barros

marianaszbarros@gmail.com

Introdução: A displasia fibrosa (DF) é uma desordem congênita do esqueleto, de caráter benigno $^{1}$. É provocada pela falha de produção de osso lamelar, que é substituído por tecido fibroso com trabeculação irregular ${ }^{3}$. Pode ocorrer como uma lesão isolada (forma monostótica), afetar múltiplos ossos (forma poliostótica) ou estar envolvida na síndrome de McCune Albright ${ }^{1}$. Objetivo: Relatar um caso clínico de uma paciente com diagnóstico de displasia fibrosa. Relato de caso: Paciente do sexo feminino, 46 anos de idade, procurou o serviço de Cirurgia e Traumatologia Buco-Maxilo-Facial do Hospital da Restauração, Recife-PE, com queixa de aumento de volume em face há 01 ano. Ao exame físico apresentava aumento de volume em região de corpo mandibular direito e malar esquerdo, causando assimetria facial e sem sintomatologia dolorosa associada. Ela relatou que o aumento de volume era presente desde a infância, contudo, negava história de fraturas prévias em ossos longos ou alterações endócrinas. $\mathrm{O}$ exame de imagem sugeria presença de lesão de aspecto misto, assemelhando-se a vidro fosco em região craniofacial. Foi realizada biópsia incisional da lesão, compatível com displasia fibrosa. A paciente foi submetida à cirurgia sob anestesia geral para osteoplastia de ossos faciais envolvidos com o tumor, para melhora da estética facial, através de acesso vestibular mandibular e maxilar. Ela segue em acompanhamento ambulatorial, sem sinais de complicações e apresentando melhora da estética facial. Discussão: Geralmente, o primeiro sinal clínico da displasia fibrosa é o aumento de volume, que pode causar assimetria facial ${ }^{2}$. Seu aspecto radiográfico é de aparência de "vidro fosco", com bordas irregulares devido à erosão endosteal e ao afinamento cortical ${ }^{1}$. A cirurgia deve ser considerada em pacientes com lesões sintomáticas, grandes dimensões ou com crescimento progressivo ${ }^{3}$. Conclusão: Dessa maneira, chama-se atenção para esta lesão, visto que, pode trazer comprometimento da estética e autoestima do paciente.

Descritores: Anormalidades Craniofaciais; Displasia Fibrosa Óssea; Ossos Faciais.

\section{Referências:}

1. ATALlA A, et al. Displasia fibrosa: relato de caso e revisão de literatura. Revista Médica de Minas Gerais, 2010; 20(N. Esp.): 399-403

2. MARTINS CAM, et al. Displasia fibrosa monostótica: um desafio terapêutico. Odontologia Clínico-Científica, 2010; 9(4): 385-388

3. RAMALHO D, et al. Displasia fibrosa: do diagnóstico à cirurgia. Revista Portuguesa de Ortopedia e Traumatologia, 2018; 26(3): 284-292 


\section{PC-184-2019 - TRATAMENTO CIRÚRGICO DE FRATURAS DO TERÇO MÉDIO E SUPERIOR DA FACE: RELATO DE CASO}

Joyce Stephany Martins Gomes ${ }^{1}$; Caio César Gonçalves Silva ${ }^{2}$; Kallyne Kelly Negromonte Gonçalves $^{3}$; Demóstenes Alves Diniz ${ }^{3}$; Jéssica da Silva Cunha ${ }^{3}$; Carolina Chaves Gama Aires²; Luan Carlos Barbosa Lourenço ${ }^{1}$; Carlos Augusto Pereira do Lago ${ }^{3}$

${ }^{1}$ Centro Universitário Mauricio de Nassau - Recife -PE - Brasil

${ }^{2}$ Faculdade de Odontologia de Pernambuco - Camaragibe -PE-Brasil

${ }^{3}$ Hospital da Restauração Governador Paulo Guerra - Recife- PE-Brasil

Autor correspondente:

Joyce Stephany Martins Gomes

joycestaphany@gmail.com

Introdução: Os traumas e lesões do complexo naso-órbito-etmoidal (NOE) são de difícil diagnóstico e tratamento, devido à sua complexidade anatômica e a presença de estruturas nobres associadas ${ }^{3}$. Objetivo: Relatar um caso clínico de paciente com fratura cominutiva de ossos da face evoluindo com sequela estética. Relato de Caso: Paciente do sexo masculino, 24 anos de idade, procurou o serviço de Cirurgia e Traumatologia Buco-Maxilo-Facial do Hospital da Restauração, Recife-PE, com história de acidente motociclístico. Ao exame físico apresentava afundamento em região de glabela, ferimento extenso em região frontal, telecanto traumático, desvio nasal, epífora em olho esquerdo, sem queixa respiratória e oclusão estável. $\mathrm{O}$ exame de imagem sugeria presença de fratura cominutiva de ossos frontal, NOE, complexo zigomático orbitário bilateral e maxila. $\mathrm{O}$ paciente foi submetido à cirurgia sob anestesia geral e selecionado os acessos através de ferimento pré-existente em frontal, combinado com acesso supra e infraorbitário esquerdo. Foi realizada redução dos fragmentos ósseos, com instalação de 01 tela de titânio em frontal, 01 tela de titânio $1.5 \mathrm{~mm}$ em blow out esquerda, bem como instalação com placas e parafusos de região NOE e CZO esquerdo. O paciente evoluiu no pósoperatório com melhora do telecanto traumático, do desvio nasal, do afundamento glabelar e da epífora. Segue em acompanhamento ambulatorial, sem sinais de complicações. Discussão: Traumas nessa região decorrem principalmente de agentes agressores de alta intensidade que resultam em diversos danos às estruturas ${ }^{3}$. O diagnóstico é baseado nos exames clinico e de imagem, a tomografia computadorizada é de escolha nesses câsos, âmbos devem ser realizados de forma minuciosa para que o diagnostico seja preciso e assim o tratamento, que depende da complexidade da fratura, seja instaurado de forma imediata e adequada a evitar sequelas ${ }^{1,2}$. Conclusão: Chama-se atenção para necessidade de um tratamento precoce para as fraturas NOE, visto que são de difícil correção.

Descritores: Ossos faciais; Fraturas orbitárias; Traumatismos Faciais.

\section{Referências:}

1. JESUS GP, et al. Tratamento das sequelas de Fraturas naso-órbito-etmoidal: relato de caso. Revista Brasileira de Cirurgia Buco-maxilo-facial, 2012; 10(2): 81-88

2. MELO MSF, et al. Correção de Fraturas fronto-naso-orbito-etmoidal: passos cirúrgicos para resultados estéticos. Revista de Cirurgia e Traumatologia Buco-maxilo-facial, 2015; 15(1): 3340

3. SILVA HCL, et al. Fraturas naso-orbito-etmoidais: diagnóstico e tratamento. Archives of Health Investigation, 2014; 3(6): 46-49 


\section{PC-185-2019 - TRATAMENTO CIRÚRGICO DE GRANULOMA PIOGÊNICO: RELATO DE CASO}

Cleiton Rone dos Santos Lima ${ }^{1}$; Hugo Igor Rodrigues de Barros ${ }^{1}$; Kássia Regina de Santana ${ }^{1}$; Heitor Tavares de Araújo ${ }^{1}$; Fernanda Teles Pereira ${ }^{1}$; Carolina Pereira da Silva ${ }^{1}$; Jonatas Silva de Oliveira ${ }^{2}$; Thyago Morais Vicente da Silva ${ }^{2}$

${ }^{1}$ Faculdade de Odontologia de Pernambuco - Camaragibe - PE - Brasil

${ }^{2}$ Universidade Federal de Pernambuco - Recife - PE - Brasil

Autor correspondente:

Cleiton Rone dos Santos Lima

cleitonrone@live.com

Introdução: Os processos proliferativos não neoplásicos (PPNN) são lesões caracterizadas pela proliferação tecidual, geralmente de natureza inflamatória, cujas mais prevalentes são: lesão periférica de células gigantes, granuloma piogênico, fibroma ossificante periférico e hiperplasia fibrosa. Dentre essas lesões, uma que merece considerável destaque é o granuloma piogênico, que se caracteriza como um processo mucocutâneo proliferativo, relativamente incomum na cavidade oral, composto por tecido de granulação, além de apresentar grande área de vascularização ${ }^{1,2}$. Objetivo: Relatar um caso clínico de granuloma piogênico tratado cirurgicamente. Relato de caso: Paciente do sexo masculino, 33 anos de idade, foi encaminhado para um Centro de Especialidades Odontológicas (CEO) de Pernambuco, para avaliação buco-maxilo-facial, com queixa de lesão em tecido mole de evolução de aproximadamente 4 anos. Foi observada lesão nodular, consistência firme, séssil, de superfície irregular, avermelhada, levemente ulcerada, sangrante ao toque e assintomática na região dos dentes 13, 14 e 15. Foi estabelecida biópsia excisional como forma de tratamento e diagnóstico da lesão. Realizou-se exérese da lesão, seguido de avanço de retalho vestibular para correção de defeito em mucosa. O material foi enviado ao Laboratório de Patologia Oral da Universidade Federal de Pernambuco, cujos achados foram compatíveis com granuloma piogênico. Discussão: $O$ tratamento dos pacientes com granuloma piogênico consiste na excisão cirúrgica conservadora associada à remoção dos fatores irritantes locais. Pode também ser realizado por meio de curetagem, cauterização química e elétrica, escleroterapia, e uso de laser ${ }^{3}$. O paciente do caso relatado foi trafado com sucesso por meio da excisão cirúrgica, técnica preconizada pela literatura e que apresenta bons resultados. Conclusão: $O$ granuloma piogenico em cavidade oral pode estar associado a um fator irritativo, acometendo principalmente gengiva, comumente em pacientes jovens. Ademais, pode ser tratado com êxito por meio da exérese.

Descritores: Granuloma Piogênico; Cirurgia Bucal; Patologia Bucal.

\section{Referências:}

1. AMADEI SU, et al. Prevalência de processos proliferativos não neoplásicos na cavidade bucal: estudo retrospectivo de quarenta anos. Rev Clin Pesq Odontol, 2009; 1(1): 38-42

2. AVELAR RL, et al. Granuloma piogênico oral: um estudo epidemiológico de 191 casos. Rev Gaúcha Odontol, 2008; 56 (2): 131-135

3. FREITAS DA, et al. Granuloma piogênico intraoral em gestante - relato de caso. Rev Bras Cir Cabeça Pescoço, 2011; 40(1): 43-45 


\title{
PC-186-2019 - TRATAMENTO CIRÚRGICO DE MÚLTIPLOS CERATOCISTOS ODONTOGÊNICOS: RELATO DE CASO
}

\author{
Rocha $^{3}$; Ana Claúdia Amorim Gomes ${ }^{3}$; Emanuel Dias de Oliveira e Silva ${ }^{1}$ \\ ${ }^{1}$ Faculdade de Odontologia de Pernambuco - Camaragibe - PE - Brasil \\ ${ }^{2}$ Hospital da Restauração - Recife - PE - Brasil \\ ${ }^{3}$ Hospital Universitário Oswaldo Cruz - Recife - PE - Brasil
}

Matheus Rodrigues Lacerda ${ }^{1}$; Maria Cecília Souza Pires Gurgel ${ }^{1}$; André Marquim Nogueira da Fonte Cornélio ${ }^{1}$; Kalyne Kelly Negromonte ${ }^{2}$; Marcelo Soares dos Santos ${ }^{3}$; Mariana Barros

Autor correspondente:

Matheus Rodrigues Lacerda

mrlacerda98@gmail.com

Introdução: O termo Ceratocisto Odontogênico é dado aos cistos dos maxilares que apresentam formação de queratina ${ }^{1}$. Estudos mostram que estas lesões se originam do epitélio odontogênico, particularmente de remanescentes da lâmina dentária ${ }^{2}$. Hoje, o ceratocisto é uma forma distinta de cisto odontogênico, com desenvolvimento peculiar devido seu comportamento clínico e a sua alta taxa de recidiva, apresentando grande potencial de infiltração nos ossos maxilares ${ }^{3}$. Objetivo: $\mathrm{O}$ objetivo deste trabalho é de relatar um caso de múltiplos ceratocistos odontogênicos em um paciente não sindrômico, com abordagem conservadora do quadro. Relato de Caso: Paciente do sexo masculino, 22 anos, leucoderma, foi encaminhado ao ambulatório de Cirurgia e Traumatologia Buco-Maxilo-Facial de um hospital universitário de Pernambuco para avaliação e tratamento de lesões múltiplas em maxila e mandíbula. Durante anamnese, o paciente não relatou incomodo ou sintomatologia dolorosa, apenas realização de biópsia há 1 ano, com laudo histopatológico de ceratocisto odontogênico. Para melhor avaliação e planejamento, foi solicitada tomografia computadorizada pela qual se observou a presença de quatro lesões císticas isoladas. O tratamento de escolha foi a enucleação das lesões em cirurgia e após exame histopaológico das mesmas, se confirmou o diagnóstico de múltiplos ceratocistos odontogênicos. O paciente evolui com pós-operatório satisfatório. Atualmente, encontra- se em acompanhamento ambulatorial sem sinais de recidiva. Discussão: Vários métodos de tratamento vêm sendo sugeridos no intuito de encontrar uma terapia que seja a mais conservadora possível e garanta baixos índices de recidiva. Para issô, no presente estudo, as lesões foram tratadas através da enucleação com osteotomia periférica promovendo a preservação óssea sem comprometer o controle da doença. Conclusão: O conhecimento por parte dos cirurgiões dentistas das lesões odontogênicas é de fundamental importância para proporcionar um diagnóstico e tratamento de tais lesões, evitando que assumam grandes dimensões e levem o paciente a uma mutilação significativa.

Descritores: Cirurgia Bucal; Diagnóstico; Tratamento.

\section{Referências:}

1. AMORIM B, et al. Ceratocisto Odontogênico: estudo epidemiológico de 26 casos. Revista Odonto Ciência - Fac. Odonto/PUCRS, 2003; 18(39): 23-30

2. MOURA S, et al. Keratocystic odontogenic tumor. Rev Col Bras Cir, 2016; 43(6): 466-471

3. VAROLI P, et al. Tumor odontogênico queratocistico: característica intrínseca e elucidação da nova nomenclatura do queratocisto Odontogênico. Journal Heath Sci inst, 2010; 28 (1): 8083 


\section{PC-187-2019 - TRATAMENTO DE DENTES ESCURECIDOS ATRAVÉS DE FACETAS DIRETAS EM RESINA COMPOSTA}

Pedro Paulo Aguiar Santos Cavalcanti ${ }^{1}$; Ana Paula Mendes Candido ${ }^{1}$; Francisco Henrique Lima Milhomens'; Bruna Lucena Borges ${ }^{1}$; Maria Luiza Feitosa Bandeira de Oliveira ${ }^{1}$; Leticia

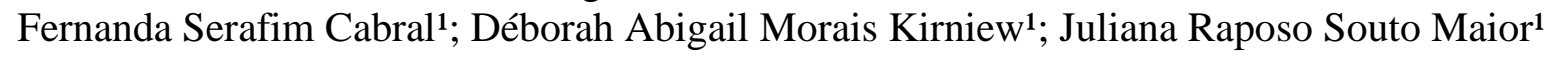

${ }^{1}$ Faculdade de Odontologia de Pernambuco - Camaragibe - PE - Brasil

Autor correspondente:

Pedro Paulo Aguiar Santos Cavalcanti

pedropauloaguiar@icloud.com

Introdução: Um dos maiores desafios na odontologia estética é a recuperação de cor e forma ao restaurar dentes anteriores que tiveram suas características naturais alteradas devido a trauma, fratura ou tratamento endodôntico ${ }^{1}$. Pensando-se em odontologia minimamente invasiva, o uso de técnicas restauradoras diretas com resina composta é uma das melhores maneiras de solucionar estes casos ${ }^{1}$. Isso requer do profissional um profundo conhecimento de anatomia dental, domínio das características do material restaurador e um delicado senso de como enxergar, entender e simular matiz, croma e valor ideais ${ }^{2}$. Objetivo: Discutir, através de um relato de caso, a importância das técnicas diretas com resina composta em dentes escurecidos. Relato de caso: Paciente do sexo feminino, 43 anos, procurou o atendimento com a necessidade de resolução estética do escurecimento dentário dos elementos 11,21 e 22. Apresentava tratamento endodôntico nos três dentes e alegou que ficaram escurecidos pós tratamento. Foi feito um desgaste para que se conseguisse mascarar o substrato escurecido e a confecção de facetas com resina composta, com as resinas Estelite Omega e a resina Harmonizer da Kerr. Discussão: Na realização de restaurações, os profissionais podem lançar mão de vários tipos de resina composta para replicar a complexidade de cores e formas dos dentes naturais ${ }^{2}$. Para minimizar as dificuldades no momento da seleção da cor, realiza-se o mapa cromático e prova da cor $^{2}$. Tal procedimento é denominado ensaio restaurador ou mockup direto ${ }^{2}$. A simulação, pode ser realizada em modelos, in vivo, ou digitalmente, que possibilita uma avaliação prévia do resultado e ajustes de cor e forma previamente ao trabalho definitivo ${ }^{1}$. Conclusão: A obediência a protocolos reabilitadores consagrados, conhecimento e domínio das propriedades físicas e ópticas dos materiais restauradores e respeito aos princípios éticos do conservadorismo promove um resultado estético altamente satisfatório, devolvendo harmonia ao sorriso e plena satisfação do paciente.

Descritores: Facetas Dentárias; Resinas Compostas; Dentística.

\section{Referências:}

1. BARATIERI LN, et al. Odontologia Restauradora (Fundamentos e Possibilidades). São Paulo: Santos, 2001; 739p

2. CARDOSO PC, et al. Facetas Diretas de Resina Composta e Clareamento Dental: Estratégias para Dentes Escurecidos. Rev Odontol Bras Central, 2011; 20(55): 341-347

3. MAIA EV. Clareamento dental: O estado da arte. Clínica - Int J Br Dent, 2005; 1:8-19 


\section{PC-188-2019 - TRATAMENTO DE REABSORÇÃO RADICULAR EXTERNA COM O USO DO MTA REPAIR HP: RELATO DE CASO}

Kamila Maria de Jesus da Silva Alves ${ }^{1}$; Raquel Sâmela Costa Feitosa ${ }^{2}$; Viviane Falcão Machado Martins; ${ }^{3}$ Marina da Cunha Isaltino ${ }^{4}$

${ }^{1}$ Centro Universitário Maurício de Nassau - Recife - PE - Brasil

${ }^{2}$ Universidade de Pernambuco - Recife - PE - Brasil

${ }^{3}$ Universidade Federal de Pernambuco - Recife - PE - Brasil

${ }^{4}$ Faculdade de Odontologia do Recife - Recife - PE - Brasil

Autor correspondente:

Kamila Maria de Jesus da Silva Alves

millamary16@gmail.com

Introdução: A reabsorção dentária pode ser definida como um evento fisiológico ou patológico, decorrente da ação de clastos ativados, caracterizada pela perda progressiva ou transitória de cemento e dentina ${ }^{2,4}$. Objetivo: O objetivo deste presente caso clínico é relatar uma alternativa no tratamento da reabsorção radicular externa inflamatória com o uso do MTA HP Repair (Angelus, Londrina, PR, Brasil). Relato de Caso: Paciente, 49 anos, compareceu a clínica de Pós-graduação da Faculdade de odontologia do Recife para realização do diagnóstico da origem de uma fístula na proximidade do elemento 24. O exame radiográfico detectou extensa reabsorção radicular externa no referido elemento, e por esse motivo, o tratamento endodôntico foi escolhido. Discussão: O trioxido mineral agregado -MTA- é um mineral altamente compatível com o corpo humano e sua habilidade de formar tecido mineralizado pode ser atribuída à sua capacidade de vedação, alcalinidade, efeito bactericida, biocompatibilidade, radiopacidade e capacidade de se instalar na presença de sangue ${ }^{3,5}$. Estudos avaliaram a citotoxicidade, biocompatibilidade e capacidade de mineralização do MTA HP. O ensaio de citotoxicidade mostrou maior viabilidade celular e biocompatibilidade e biomineralização semelhante ao branco MTA Angelus. O MTA HP tem alta plasticidade comparado com MTA Angelus branco ${ }^{1}$. Conclusão: $\mathrm{O}$ presente caso clínico, mesmo em processo de proservação, demonstra um exemplo de sucesso do MTA HP Repair utilizado como material alternativo para obturação dos canais radiculares em casos de reabsorção dentária. Por ser um material bioativo que permite a formação de tecido mineralizado, oferecendo condições para a organização dos tecidos de suporte dentário.

Descritores: Material Biocompatível; Endodontia; Reabsorção da raiz.

\section{Referências:}

1. CINTRA LTA, et al. Cytotoxicity, Biocompatibility and biomineralization of the new High Plasticity MTA material. Journal of Endodontics, 2016; 43(5): 774-778

2. CONSOLARO A. Reabsorções dentárias nas especialidades clínicas. $3^{a}$ ed. Maringá: Dental Press, 2012; 49p

3. JACOBOVITZ M, et al. Obturação com MTA associada à cirurgia parendodôntica no retratamento de reabsorção radicular apical externa - relato de caso. Revista Sul-Brasileira de Odontologia, 2009; 6(2): 209-2013

4. LOPES HP, SIQUEIRA JF. Endodontia: biológica e técnica. $4^{\mathrm{a}}$ ed. Rio de Janeiro: Elsevier, 2012; 736p

5. YILMAZ G, et al. Use of mineral trioxide agregate in the treatment of invasive cervical resorption: case report. Journal of Endodontics, 2009; 36(1): 160-163 


\section{PC-189-2019 - TRATAMENTO ENDODÔNTICO DE PACIENTE EM USO DE BIFOSFONATOS: RELATO DE CASO}

Cláudia Geisa Souza e Silva ${ }^{1}$; Aylanne Xavier de Lacerda Cavalcante Timoteo ${ }^{1}$; Camila de Paula Rosendo $^{\mathbf{1}}$; Niviane Marielly da Costa Oliveira ${ }^{1}$; Arthur Camillo de Souza Laranjeira ${ }^{1}$; Mônica Soares de Albuquerque; Viviane Colares Soares de Andrade Amorim¹; Caio César Gonçalves Silva ${ }^{1}$

${ }^{1}$ Faculdade de Odontologia de Pernambuco - Camaragibe - PE - Brasil

Autor correspondente:

Cláudia Geisa Souza e Silva

claudiageisa@outlook.com

Introdução: A terapêutica com bifosfonatos está indicada em casos específicos de paciente portadores de patologias ósseas. Essas drogas alteram o metabolismo ósseo, aumentando a massa desse tecido, diminuindo assim o risco de fratura. Eles atuam sobre os osteoclastos e osteoblastos, resultando na diminuição da remodelação óssea e influenciando no processo de reparo ${ }^{1}, 3$. Pacientes tratados com bifosfonatos têm mais riscos de desenvolverem Osteonecrose dos Maxilares e o tratamento endodôntico poderá desencadear essa patologia através de danos nos tecidos moles, principalmente durante a colocação do lençol de borracha e extrusão apical de detritos durante preparo químico mecânico do sistema de canais radiculares ${ }^{2}$. Porém, a terapia endodôntica é uma opção viável de tratamento quando realizada com cautela. Objetivo: Apresentar um caso clínico de tratamentos endodônticos realizados em sessões múltiplas, num paciente com Mieloma Múltiplo, fazendo o uso de bifosfonato. Relato de caso: Paciente leucoderma, 60 anos, sexo feminino, fumante, foi encaminhada para a clínica de endodontia do Centro de Pós-Graduação em Odontologia Recife - PE, relatou que sentia dor espontânea nos dentes 11,21 e 25 . Após a realização das radiografias, constatou-se espessamento do ligamento periodontal nos dentes 11 e 21, os quais precisavam de tratamento endodôntico. Discussão: Procedimentos cruentos, como exodontias, oferecem um risco maior aos pacientes portadores de patologias ósseas que fizeram o uso dos bifosfonatos, sendo o tratamento endodôntico, quando realizado com cautela, uma adequada alternativa terapêutica. Conclusão: Pacientes tratados com bifosfonatos têm mais riscos de desenvolverem a Osteonecrose dos Maxilares, sendo a terapia endodôntica a opção mais viável de tratamento, devendo ser reálizada de forma atraumática e com profilaxia antibiótica.

Descritores: Osteonecrose Associada a Bifosfonatos; Endodontia; Mieloma Múltiplo.

\section{Referências:}

1. GALLEGO L, et al. Rubber dam clamp trauma during endodontic treatment: a risk factor of bisphosphonate-related osteonecrosis of the jaw. Journal of Oral and Maxillofacial Surgery, 2011; 69(6): 93-95

2. IZQUIERDO C, et al. Therapy with bisphosphonates: implications for dental patient literature review. Revista da Faculdade de Odontologia da UPF, 2011; 16(3): 347-352

3. TARDAST A, et al. Bisphosphonate associated osteomyelitis of the jaw in patients with bony exposure: prevention, a new way of thinking. Journal of Applied Oral Science, 2015; 23(3): 310-314 


\section{PC-190-2019 - TRATAMENTO FECHADO DE FIBROADERÊNCIAS EM ATICULAÇÃO TEMPOROMANDIBULAR: RELATO DE CASO}

Luíza Flôres da Costa Fagundes ${ }^{1}$; Ana Beatriz Albuquerque Meira ${ }^{1}$; Bruna Lucena Borges ${ }^{1}$; Caio César Gonçalves Silva ${ }^{1}$; Davi da Silva Barbirato ${ }^{1}$; Déborah Abigail Moraes Kirniew ${ }^{\mathbf{1}}$; Marcela Lins Braga ${ }^{1}$; Vinicius Balan Santos Pereira ${ }^{1}$

${ }^{1}$ Faculdade de Odontologia de Pernambuco - Camaragibe - PE - Brasil

Autor correspondente:

Luíza Flôres da Costa Fagundes

luizaflorescosta@gmail.com

Introdução: A articulação temporomandibular (ATM) pode ser acometida de alguns tipos de desordens para as quais existem uma diversidade de tratamentos. Dentre estes, temos a artrocentese como uma abordagem minimamente invasiva ${ }^{1}$. Objetivos: Discutir tratamento diante de fibroaderências na ATM, através de caso clínico. Relato de caso: Mulher, 40 anos, procurou o Ambulatório do Hospital da Face queixando-se de dor severa a mastigação e fala. Analisados os exames físico e radiográfico, observou-se a limitação da abertura bucal, sem estalido ou crepitação óssea e a ausência de alterações ósseas. Foi proposto tratamento com medicação anti-inflamatória e relaxante muscular, na qual houve melhora momentânea em seu uso. Optou-se por abordagem minimamente invasiva, através de artrocentese de ATM e irrigação com soro fisiológico em que, após o retorno em uma semana, foi notada melhora significativa da abertura bucal e, após trinta dias, sessado o quadro de dor após o término da medicação ${ }^{2}$. Discussão: A artrocentese como uma opção mais recente de tratamento nas DTM, ainda que considerada minimamente invasiva, permanece de forma intermediária entre os tratamentos conservadores e os cirúrgicos ${ }^{3}$.Esta passa a ser usada como última medida antes de um tratamento cirúrgico, devido a simplicidade de sua execução, seu custo mais barato e aos resultados positivos já publicados. ${ }^{1}$ Seu princípio de funcionalidade está baseado na interrupção das adesões intra-articulares por meio da pressão hidráulica a qual produz, retornando assim, a mobilidade do disco e a abertura bucal, além de cessar o quadro álgico. Conclusão: $\mathrm{O}$ tratamento de DTM com artrocentese, desde sua utilização em combinação com antiinflamatórios e opioídes, ou não; garante uma melhora efetiva nos pacientes com limitações de abertura mandibular, travamento mandibular, e dor; além de ser considerada uma alternativa menos invasiva e mais acessível para a população.

Descritores: Articulação Temporomandibular; Artrocentese; Transtornos da Articulação Temporomandibular.

\section{Referências:}

1. GROSSMANN E. Técnicas de artrocentese aplicadas às disfunções artrogênicas da articulação temporomandibular. Revista Dor, 2012; 13(4): 374-381

2. SANTOS GS, et al. Artrocentese da articulação temporomandibular: relato de caso clínico. Revista de Odontologia da UNESP, 2014; 43(N Especial):344

3. VASCONCELOS BCE, et al. Artrocentese da articulação temporomandibular: avaliação de resultados e revisão da literatura. Revista Brasileira de Otorrinolaringologia, 2006; 72(5):6348 


\section{PC-191-2019 - TRATAMENTO PRÉ OPERATÓRIO EM UM QUADRO DE PERICORONARITE AGUDA: RELATO DE CASO}

Carolaine Rayane Xavier da Silva ${ }^{1}$; Ademir Félix Arantes Júnior ${ }^{\mathbf{1}}$; Aylanne Xavier de Lacerda Cavalcante Timoteo ${ }^{1}$; Carlos Augusto Pereira Lago ${ }^{1}$; Girlane Iris da Silva ${ }^{1}$; Joyce Feitosa Pinho Gomes $^{1}$; Maíra Letícia Ferreira de Santana ${ }^{1}$; Maria Carolina Tavares de Lyra Menezes ${ }^{1}$

${ }^{1}$ Faculdade de Odontologia de Pernambuco - Camaragibe - PE - Brasil

Autor correspondente:

Carolaine Rayane Xavier da Silva

carolaineexavier@gmail.com

Introdução: A pericoronarite é uma condição inflamatória que acomete principalmente os terceiros molares inferiores, onde a superfície oclusal do dente afetado é revestida por um tecido gengival, o qual favorece o acúmulo de alimentos e consequentemente a proliferação bacteriana ${ }^{3}$. Objetivo: relatar um caso clínico, no qual foi feito um tratamento pré-operatório em um quadro de pericoronarite aguda. Relato de caso: paciente A.R.X.S, 26 anos, sexo feminino, compareceu ao Hospital da Restauração queixando-se de dor, trismo e inchaço na hemiface direita. Após examinar a paciente e observar seus exames de imagem o cirurgião chegou ao diagnóstico de pericoronarite aguda na região do elemento 48. Antes de realizar a remoção do dente em questão foi necessário fazer um tratamento pré-operatório para reduzir o quadro infeccioso. A paciente fez uso de Dolamin $125 \mathrm{mg}$ durante cinco dias em intervalos regulares de seis horas e efetuou limpeza na região com água oxigenada e soro $0.9 \%$ durante duas semanas, após esse período houve uma melhora significativa da inflamação e a exodontia foi realizada. Discussão: a pericoronarite aguda é uma infecção que provoca dor de moderada a severa e que frequentemente é encontrada em adultos jovens com os terceiros molares inferiores em erupção ${ }^{2}$. Apresenta sintomatologia dolorosa e sinais clínicos como sangramento, trismo e halitose ${ }^{3}$. Para tratá-la é preciso ter controle sobre a placa bacteriana do local e uma das formas de fazer esse controle é através de limpeza com água oxigenada ${ }^{1}$. Conclusão: a pericoronarite pode ser controlada com uma correta higienização do dente e área de erupção e é sempre indicado o término da fase aguda para que se possa realizar o tratamento operatório ${ }^{1}$.

\section{Descritores: Infecção; Pericoronarite; Terceiro Molar.}

\section{Referências:}

1. FACO EFS. Terapêutica medicamentosa em odontologia: antibióticos. Dissertação (Mestrado em Cirurgia e Traumatologia Buco Maxilo Facial) - Universidade Estadual Paulista "Júlio de Mesquita Filho", Araçatuba, 2006; 130 p

2. LEONE SA, et al. Correlation of acute pericoronitis and the position of the mandibular third molar. Oral Surgery, Oral medicine, Oral Pathology, 1986; 62(3): 245-250

3. PINTO JR, et al. Pericoronarite relacionada com tonsilite recorrente: revisão da literatura e relato de um caso. Revista Odonto Ciência, 2005; 20(47): 88-92 


\section{PC-192-2019 - TRATAMENTO RESTAURADOR ATRAUMÁTICO INSERIDO NO PROGRAMA DE SAÚDE BUCAL DA ESTRATÉGIA DE SAÚDE DA FAMÍLIA}

Andreza Cibelle Amaral da Silva ${ }^{1}$; Elizabeth Louisy Marques Soares da Silva ${ }^{1}$; Giovanna Siqueira Faustino da Silva ${ }^{1}$; Maria Cecília Freire de Melo ${ }^{1}$; Patrícia Tereza Lopes de Souza ${ }^{1}$; Thaíssa Marcela de Lima Melo ${ }^{1}$; Túlio Marcos dos Santos Silva ${ }^{1}$; Thuanny Silva de Macêdo ${ }^{1}$

${ }^{1}$ Universidade Federal de Pernambuco - Recife - PE - Brasil

Autor correspondente:

Andreza Cibelle Amaral da Silva

andreza.odonto@gmail.com

Introdução: O Tratamento Restaurador Atraumático (TRA) teve sua abordagem mais intensificada por volta da década de 1990, preconizando a intervenção mínima nos procedimentos odontológicos. Além de ser uma técnica não dependente de um complexo de materiais ou da infraestrutura local, é adequada para programas de saúde bucal em regiões que enfrentam dificuldades no atendimento da demanda populacional ${ }^{1}$. Objetivos: revisar a literatura e inteirar acadêmicos e cirurgiões-dentistas acerca de como o TRA é vantajoso para estagnar a progressão da lesão cariosa nas populações em vulnerabilidade socioeconômica. Metodologia: Revisão de literatura onde buscou-se artigos publicados, no período de 20082019, disponíveis na internet, nos sistemas de bases de dados: MEDLINE, LILACS BBO, presentes no site da Biblioteca Virtual de Saúde. Os critérios para a escolha dos artigos foram baseados em normas estabelecidas de leitura crítica, as quais avaliam, em síntese, a adequação do desenho do estudo, a forma de condução da pesquisa, sua análise e representação. Revisão da literatura: O TRA foi desenvolvido com o intuito de minimizar o número de extrações dentárias realizadas nos países subdesenvolvidos ${ }^{2}$. Essa técnica é simples, pois utiliza somente instrumentos manuais na remoção dos tecidos cariados e requer restauração imediata da cavidade com um material restaurador adesivo, o ionômero de vidro. É considerado um tratamento definitivo, o que o diferencia da adequação do meio bucal, que consiste numa etapa de transição utilizando materiais temporários ${ }^{1}$. Conclusão: A técnica mostra-se eficiente no controle da progressão de lesões cariosas. Aparece também como uma alternativa ideal para o controle da ansiedade, sendo uma técnica de baixo custo e de fácil realização na Estratégia de Saúde da Família ${ }^{3}$.

Descritores: Cárie Dental; Restauração Dentária Permanente; Estratégia da Saúde da Família.

\section{Referências:}

1. MOBARAK EH, et al. Survival of occlusal ART restorations using high-viscosity glassionomer with and without chlorhexidine: A 2-year split-mouth quadruple-blind randomized controlled clinical trial. Journal of Advanced Research, 2019; 17: 117-123

2. MOIMAZ SAS, et al. Tratamento restaurador atraumático e sua utilização em saúde pública. Revista Gaúcha de Odontologia, 2008; 56(1): 75-79

3. SABER AM, et al. Atraumatic restorative treatment and interim therapeutic restoration: a review of the literature. Dentistry journal, 2019; 7(1): 28 


\section{PC-193-2019 - TRATAMENTO/CONTROLE DA DOR DENTOALVEOLAR PERSISTENTE}

João Victor Neves Barbosa ${ }^{1}$; Carolina Pereira da Silva ${ }^{1}$; Heitor Tavares de Araújo ${ }^{1}$; Lucas Rafael Borges Santos ${ }^{1}$; Isabela Araújo de Lima ${ }^{1}$; Mariana Renata Camilo da Silva ${ }^{1}$; Amanda Thays Feitoza Viturino ${ }^{1}$; Jéssica da Silva Cunha ${ }^{2}$

${ }^{1}$ Faculdade de Odontologia de Pernambuco - Camaragibe - PE - Brasil

${ }^{2}$ Hospital da Restauração Governador Paulo Guerra - Recife - PE - Brasil

Autor correspondente:

João Victor Neves Barbosa

barbosaj08@gmail.com

Introdução: O distúrbio da dor dentoalveolar persistente (DDAP) é definida como dor de dente, ou dor em um local onde um dente residiu, na ausência de evidências clínicas e radiográficas de patologia dentária ou outras patologias do tecido duro ou mole. Esta entidade, com ambiguidade, já foi chamada de odontalgia atípica, dor do dente fantasma, e dor neuropática dentária, e já foi considerada um subgrupo dentro de dor idiopática persistente ou facial atípica. Durante um recente consenso envolvendo especialistas e metodologistas clínicos, a entidade foi denominada distúrbio de dor dento-alveolar persistente ${ }^{1}$. Objetivo: Apresentar uma revisão da literatura sobre abordagens terapêuticas para tratamento e/ou controle da dor dentoalveolar persistente. Metodologia: Realizou-se cruzamento dos descritores selecionados e escolheu-se 10 artigos publicados entre os anos de 2014 e 2019, encontrados nos periódicos das bases de dados LILACS, PubMed e SciELO. Revisão de Literatura: É insuficiente o número de ensaios clínicos randomizados controlados para determinar uma melhor terapêutica para o tratamento da DDAP. Não há consenso sobre melhor fármaco para controle da dor. A evidência disponível de medicamentos de ação central, para outros distúrbios neuropáticos, como antidepressivos tricíclicos (como amitriptilina) e anticonvulsivantes (por exemplo, gabapentina), parecem ser a primeira escolha no tratamento do DDAP3. Descrições de casos sugerem ainda que alguns pacientes respondem favoravelmente à administração local de analgésicos (por exemplo, substâncias como a capsaicina ou uma combinação de carbamazepina a $4 \%$, lidocaína $1 \%$ e cetoprofeno $4 \%$, ou cetamina $4 \%$ com gabapentina $4 \%$ ), em combinação ou não com a medicação central empregada para a dor ${ }^{2}$. Conclusão: A melhor terapêutica é aquela que ameniza a dor, este controle depende de vários fatores que variam de um paciente para o outro, sendo os medicamentos de ação central a escolha mais aceita pela literatura para controle da DDAP.

Descritores: Dor Orofacial; Odontalgia; Terapêutica.

\section{Referências:}

1. MALACARNE A, et al. Persistent dentoalveolar pain disorder: a comprehensive review. Journal of endodontics, 2018; 44(2): 206-211

2. MOANA-FILHO EJ, et al. Amplified brain processing of dentoalveolar pressure stimulus in persistent dentoalveolar pain disorder patients. Journal of oral \& facial pain and headache, 2015; 29(4): 349

3. NIXDORF DR, et al. Classifying orofacial pains: a new proposal of taxonomy based on ontology. Journal of oral rehabilitation, 2012; 39(3): 161-169 


\section{PC-194-2019 - TRAUMA E INTRUSÃO DENTÁRIA: EFEITOS NA RAIZ E NO OSSO ALVEOLAR - REVISÃO DE LITERATURA}

Ieli Lima da Silva ${ }^{1}$; Alice Kelly Barreira ${ }^{1}$; Daniella de Andrade Monteiro ${ }^{1}$; Geovana Lemos da Silva $^{1}$; Marianne Pereira de Moura ${ }^{1}$; Roberto Lucas Martins Gomes ${ }^{1}$

${ }^{1}$ Universidade Federal de Pernambuco - Recife - PE - Brasil

Autor correspondente:

Ieli Lima da Silva

iely_lima_@hotmail.com

Introdução: Os traumas dentários comprometem a função e a estética do indivíduo, afetando sua vida social e o seu comportamento. São situações de urgência odontológica, que exigem do profissional um atendimento rápido, porém detalhado ${ }^{3}$. Objetivo: Identificar as sequelas mais comuns de intrusão dentoalveolar na raiz e no osso alveolar, e as implicações no tratamento. Metodologia: Para a construção dessa revisão de literatura foram utilizados artigos extraídos do banco de dados do LILACS (BVS), nos últimos 5 anos, utilizando os termos Intrusão Alveolar; Traumatismo Alvéolo-dentário; e Intrusão Dentária. Revisão de literatura: A intrusão dentária se caracteriza pelo deslocamento do dente para o interior do osso alveolar ${ }^{1}$. É pouco frequente na dentição permanente e geralmente resulta em sérios danos ao periodonto ${ }^{2}$. O diagnóstico da intrusão requer um correto e detalhado exame clínico e radiográfico a fim de direcionar o plano de tratamento ${ }^{3}$. O prognóstico de dentes permanentes instruídos depende de fatores tais como: idade do paciente, estágio de desenvolvimento radicular, mobilidade do dente no momento do acidente, grau de deslocamento, reação positiva aos testes de sensibilidade pulpar e percussão, procedimentos de redução e fixação empregados e tempo decorrido até o primeiro atendimento ${ }^{2,3}$. As sequelas da intrusão dentária, geralmente comprometem a longevidade do dente e pode envolver necrose pulpar, obliteração pulpar, reabsorção radicular inflamatória, anquilose e perda do suporte ósseo marginal ${ }^{3}$. O tratamento pode ser realizado por meio do acompanhamento da erupção espontânea, reposicionamento cirúrgico imediato ou por movimentação ortodôntica ${ }^{1}$. Conclusão: A luxação intrusiva tem recebido pouca atenção na literatura odontológica quando comparada com outros tipos de trauma. Assim, para que o tratamento dos dentes traumatizados alcance o sucesso almejado, impreterivelmente uma cuidadosa coleta e interpretação dos dados clínicos devem ser obtidos, a fim de propor um tratamento que minimize as sequelas ao elemento dentário e tecidos adjacentes.

Descritores: Lesões Dentárias; Traumatismo Dentário; Intrusão Dentária.

\section{Referências:}

1. COSTA TG, et al. Traumatismo dentoalveolar em emergência hospitalar: relato de caso clínico. Arch Health Invest, 2017; 6(5): 1-2

2. GOES KKH, et al. Avaliando os traumatismos dento-alveolares: Revisão de Literatura. Ver. Cir. Traumatol. Buco-Maxilo-Fac, 2005; 5(1): 21-26

3. KISE G, et al. Sobre os traumatismos dentários: Abordagem terapêutica na dentição permanente. OMNIA, 2018; 8(3): 27-34 


\section{PC-195-2019 - TUMOR ODONTOGÊNICO ADENOMATÓIDE: UMA REVISÃO DE LITERATURA}

Dayanne Karla de Carvalho ${ }^{1}$; Maria Eduarda Arruda de Lucena ${ }^{1}$; Fernanda Gomes Barros ${ }^{1}$; Francisco Lima Milhomens ${ }^{1}$; Hian Carvalho Souza ${ }^{1}$; Thayane Maria Botelho Florêncio ${ }^{1}$; Luíza Flôres da Costa Fagundes ${ }^{1}$; Éwerton Daniel Rocha Rodrigues ${ }^{1}$

${ }^{1}$ Faculdade de Odontologia de Pernambuco - Camaragibe - PE - Brasil

Autor correspondente:

Dayanne Karla de Carvalho

dayanne.kcarvalho@gmail.com

Introdução: O Tumor Odontogênico Adenomatóide (TOA) normalmente é uma lesão assintomática de crescimento lento. Quando assume dimensões grandes é visto um aumento em volume de consistência firme à palpação. Deslocamento de dentes vizinhos devido à expansão do tumor é muito mais comum que reabsorções de raiz. Radiograficamente mostra uma imagem unilocular circunscrevendo um dente não-erupcionado, às vezes com radiopacidades no centro e esclerose na periferia. Considerando que o tumor é encapsulado, o tratamento de escolha é enucleação ${ }^{3}$. Objetivo: Compilar de forma sistemática as características dos TOA e o tratamento indicado para essa lesão. Métodos: Revisão integrativa de artigos científicos consultados nas bases de dados PubMed/MEDLINE e SciELO. As palavras-chave foram definidas utilizando as ferramentas do Mesh (PubMed) e por meio de operadores booleanos "AND" e "OR" (estratégia de busca). Revisão de literatura: O TOA apresenta três variantes (folicular, extra folicular e periférico) bastante diferentes que fazem isto difícil de diferenciar de outras entidades patológicas ${ }^{4}$. Apresenta uma frequência relativa de 2,2 e 7,1\% entre os tumores odontogênicos ${ }^{4}$. Este tipo de tumor acomete mais mulheres $(1,9: 1)$ na segunda década de $v^{4} a^{4,1}$. O TOA não apresenta tendência à recidiva, sendo tratado cirurgicamente por enucleação e curetagem, limitadas à remoção da lesão ${ }^{2}$. Conclusão: É indispensável a realização de exame histopatológico para se estabelecer o correto diagnóstico e, consequentemente, adotar a terapia adequada. Destaca-se a intervenção cirúrgica conservadora como forma de tratamento de eleição nos casos de TOA.

\section{Descritores: Neoplasias Bucais; Tumores Odontogênicos; Medicina Bucal.}

\section{Referências:}

1. MENDIS BRRN, MACDONALD DG. Adenomatoid odontogenic tumour: a survey of 21 cases from Sri Lanka. Int J Oral Maxillofac Surg, 1990; 19: 141-3

2. OGATA DC. Tumor odontogênico adenomatoide extrafolicular: uma apresentação infrequente de um tumor raro. R. Bras. Cir. Cabeça Pescoço, 2008; 37(4): 234- 235

3. PARKASH H, et al. Adenomatoid odontogenic tumour of the jaws. J Dentistry, 1984; 12: 297-301

4. PHILIPSEN HP, REICHART PA. Adenomatoid odontogenic tumor: facts and figures. Oral Oncol, 1998; 35: 125-31 


\section{PC-196-2019 - TUMOR ODONTOGÊNICO CÍSTICO CALCIFICANTE COM PROLIFERAÇÃO AMELOBLASTOMOSA: REVISÃO DE LITERATURA}

Manuela França Andrade Passos¹; Gustavo Afonso Duque Padilha²; Sinval Vinícius Barbosa do Nascimento ${ }^{1}$; Eduardo Vinícius de Souza Silva ${ }^{1}$; Fernanda Gomes Barros ${ }^{1}$; Francisco Henrique Lima Milhomens ${ }^{1}$; Kalyne Kelly Negromonte Gonçalves ${ }^{3}$

${ }^{1}$ Faculdade de Odontologia de Pernambuco - Camaragibe - PE - Brasil

${ }^{2}$ Faculdade de Ciências Médicas - Recife - PE - Brasil

${ }^{3}$ Hospital da Restauração - Recife - PE - Brasil

Autor correspondente:

Manuela França Andrade Passos

manuelaemj@gmail.com

Introdução: Os cistos e tumores odontogênicos (CTOs) representam um relevante grupo de lesões da patologia oral e maxilofacial, dentre os CTOs, a variante com proliferação ameloblasmosa do tumor odontogênico cístico calcificante (TOCC) é rara ${ }^{2}$. Objetivo: Apresentar uma revisão de literatura a respeito da epidemiologia, características histopatológicas e clínicas e o tratamento do TOCC com proliferação ameloblastomosa. Metodologia: Foi realizada uma pesquisa na base de dados SciELO com os descritores: cisto odontogênico calcificante, ameloblastoma e diagnóstico bucal. Houve a inclusão de trabalhos de 2003 a 2018, nesse período de quinze anos, foram encontrados cinquenta artigos, dos quais usaram-se vinte. Revisão de literatura: O TOCC é predominantemente uma lesão intraóssea derivada de tecidos que dão origem ao órgão dentário e suas estruturas, acometendo, preferencialmente, a segunda e a terceira décadas de vida, sem predileção por sexo ${ }^{2}$. A variante ameloblastomosa é rara constituindo apenas $1 \%$ dos casos de tumores odontogênicos ${ }^{1}$. Manifesta-se como um aumento de volume na face, firme à palpação, de características normocrômica e indolor ${ }^{2}$. Histopatologicamente essa variante se apresenta como um tumor com espaço cístico revestido por epitélio odontogênico, retículo estrelado, células fantasmas e proliferação epitelial. As técnicas de tomografia computadorizada juntamente com a análise histopatológica são ferramentas mandatórias para o adequado diagnóstico e planejamento cirúrgico das lesões ${ }^{5}$. A conduta cirúrgica consiste naquelas utilizadas para o tratamento do ameloblastoma, isto é, ressecção em bloco ou enucleação do tumor seguido por curetagem³. Marsupialização e posterior enucleação do tumor também podem ser preconizadas ${ }^{3}$. A preservação durante longo período é recomendada, especialmente quando as estruturas adjacentes também forem afetadas e devido ao comportamento agressivo dos ameloblastomas ${ }^{5}$. Conclusão: Sendo um tumor raro, porém com recidiva, é de extrema importância o perfeito diagnóstico, feito com a união dos achados clínicos, imaginológicos e histopatológicos, um planejamento e tratamento cirúrgico eficaz e o acompanhamento do paciente tratado.

Descritores: Ameloblastoma; Cisto odontogênico calcificante; Diagnóstico bucal.

\section{Referências:}

1. AITHAL D, et al. Ameloblastomatous calcifying odontogenic cyst: a rare histologic variant. Journal of Oral Pathology \& Medicine, 2003; 32(6): 376-378

2. CARNASCIALI MCG, et al. Tumor odontogênico cístico calcificante com proliferação ameloblastomosa em seio maxilar. Jornal Brasileiro de Patologia e Medicina Laboratorial, 2012; 48(4): 293-296

3. DELGADO WA, et al. Tumor odontogénico híbrido: tumor odontogénico quístico calcificante con odontoma complejo y focos de ameloblastoma. Revista Estomatológica Herediana, 2006; 16(2): 120-125 
4. PAIVA LCA, et al. Potencial de recidiva do ameloblastoma. Revista de Cirurgia e Traumatologia Buco-maxilo-facial, 2010; 10(1): 27-34

5. UTUMI ER, et al. Distintas manifestações do tumor odontogênico cístico calcificante. Revista Einstein, 2012; 10(3): 366-370
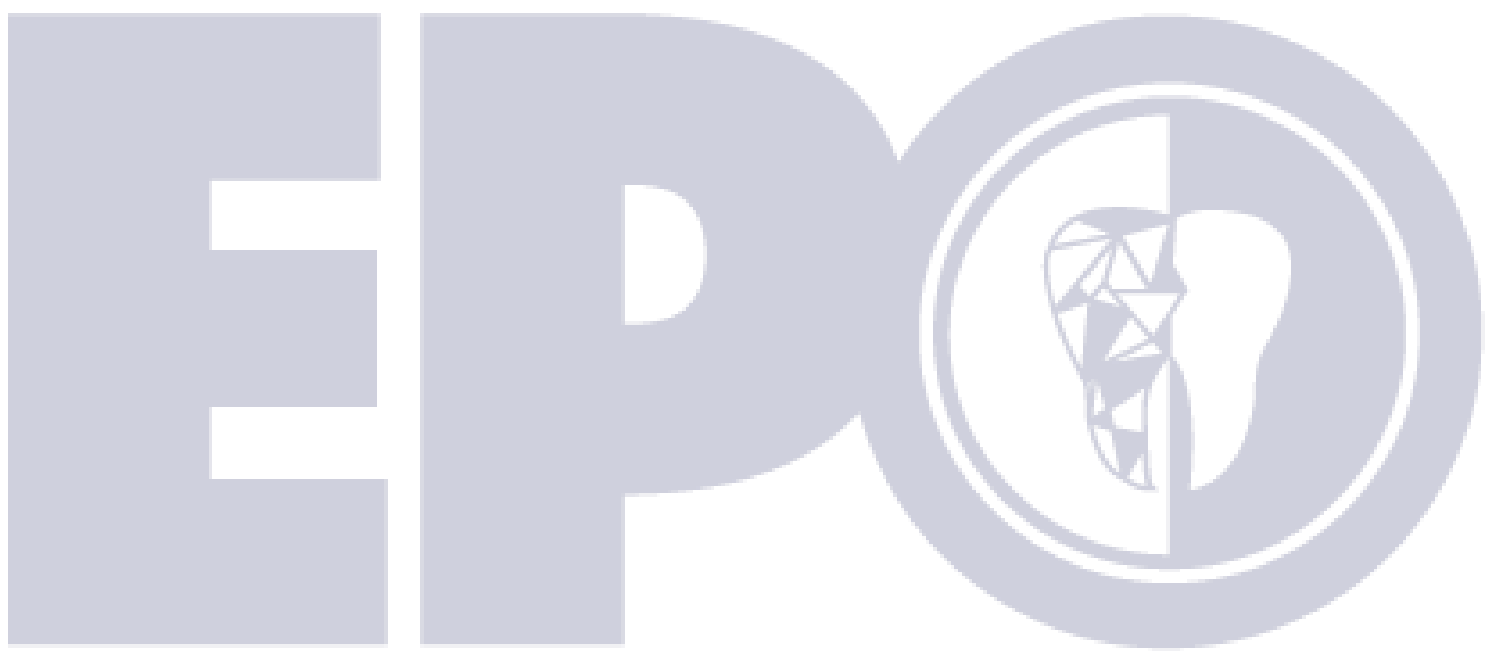


\section{PC-197/2019 - USO DA LUZ VIOLETA NO TRATAMENTO DE CLAREAMENTO DENTAL: REVISÃO DE LITERATURA}

Robson de Lima Gomes ${ }^{1}$; Alexandre Batista Lopes do Nascimento ${ }^{1}$; Andressa Cristina da Silva Queiroz ${ }^{1}$; Elvis Paulo Batista Travassos ${ }^{2}$; Maria Eduarda Ferreira Santiago ${ }^{1}$; Lucas Araújo Barbosa de Melo ${ }^{1}$; Renata Pedrosa Guimarães ${ }^{1}$; Hilcia Mezzalira Teixeira ${ }^{1}$

${ }^{1}$ Universidade Federal de Pernambuco - Recife - PE - Brasil

${ }^{2}$ Centro Universitário Tiradentes de Pernambuco - Recife - PE - Brasil

Autor correspondente:

Robson de Lima Gomes

robsonlimalive@outlook.com

Introdução: Devido importância social e interpessoal pela coloração dos dentes o clareamento dental se tornou altamente procurado na clínica odontológica ${ }^{4,5}$, sendo desenvolvida então técnicas mais eficazes ${ }^{1,2,3,4,5}$, como o surgimento do clareamento por luz LED violeta, no intuito de eliminar efeitos adversos ${ }^{1,3}$. Objetivo: O objetivo deste trabalho foi realizar uma revisão da literatura à cerca do clareamento dental, até o surgimento do clareamento usando a luz LED violeta, e debater sua efetividade. Metodologia: Busca por dados entre o período de 2016 a 2018, nas bases de dados: Periódicos Capes, Medline, PubMed, SciELO e Google Acadêmico. Revisão de literatura: $O$ clareamento dental se tornou altamente procurado pelos pacientes odontológicos, em razão da importância social e interpessoal atribuída à coloração dos dentes de um indivíduo ${ }^{4,5}$. Diversos métodos, materiais e técnicas foram desenvolvidos ao longo das décadas na intenção de proporcionar um clareamento cada vez mais eficaz, indolor e com custobenefício favorável ${ }^{2,4,5}$. Neste contexto, surgiram géis clareadores à base de peróxidos de carbamida e/ou hidrogênio, que apesar de serem bem sucedidos no clareamento, ainda apresentam a desvantagem de induzir a incômoda sensibilidade dentária, mesmo que temporária, no paciente ${ }^{1,2,5}$. No intuito de acabar com tal efeito adverso, surge a técnica de clareamento usando luz LED violeta isoladamente, a qual visa causar o clareamento por métodos físicos, e não mais químicos, assim, sem interferir na sensibilidade das estruturas e tecidos do dente ${ }^{1,3}$. Conclusão: O clareamento com uso exclusivo da luz LED violeta ainda não parece estar próximo de um consenso entre os profissionais; o clareamento com luz LED violeta demonstra efeitos positivos no clareamento dental e o uso dos géis clareadores à base de peróxidos ainda se mostram mais efetivos e com resultados mais rápidos.

Descritores: Luz; Sensibilidade dental; Clareamento dental.

\section{Referências:}

1. LAGO ADN, et al. Dental Bleaching with the use of Violet Light only: reality or future? Photodiagnosis and Photodynamic Therapy, 2017; 17:124-126

2. OMRANI LR, et al. Penetration of hydrogen peroxide into the pulp chamber after conventional and laser-assisted bleaching. SADJ, 2016; 71(2):58 - 61

3. RASTELLI ANS, et al. Violet LED associated to low concentration carbamide peroxide on the dental bleaching: A case report. Photodiagnosis and Photodynamic Therapy, 2018; 23:270272

4. SURECK J, et al. Clareamento dental com luz led violeta - relato de caso clínico. Revista Gestão \& Saúde, 2017; 17(2):30-36

5. VIEIRA APS, et al. Estudo comparativo da eficácia do led violeta em clareamentos dentais. Revista Campo do Saber, 2018; 4(5):100-123 


\section{PC-198-2019 - USO DA TERAPIA FOTODINÂMICA COMO COADJUVANTE NA DESCONTAMINAÇÃO EM CIRURGIA PARENDODÔNTICA: RELATO DE CASO}

Maria Fernanda Limeira Feitosa ${ }^{1}$; Douglas Felipe de Lima e Silva ${ }^{1}$; Niviane Marielly da Costa Oliveira $^{2}$; Silmara de Andrade Silva²; Caio César Gonçalves Silva²; Arthur Camillo de Souza Laranjeira $^{2}$; Camila de Paula Rosendo ${ }^{2}$; Diana Santana de Albuquerque ${ }^{2}$

${ }^{1}$ Faculdade Maurício de Nassau - Recife - PE - Brasil

${ }^{2}$ Faculdade de Odontologia de Pernambuco - Camaragibe - PE - Brasil

Autor correspondente:

Maria Fernanda Limeira Feitosa

Mariafernandalimeira3@gmail.com

Introdução: A cirurgia parendodôntica é indicada quando ocorre o insucesso da terapia endodôntica prévia decorrente da presença de patógenos intrarradiculares persistentes. A presença de bactérias resistentes faz necessária a utilização de alterativas que corroborem para uma descontaminação eficaz. Dessa forma, a terapia fotodinâmica é uma alternativa muito promissora na desinfecção bacteriana ${ }^{1}$. Objetivo: Relatar um caso clínico de cirurgia parendodôntica associada ao uso da terapia fotodinâmica como agente antibacteriano. Relato de caso: Paciente do sexo feminino, 48 anos, foi encaminhada a um curso de especialização em endodontia para realização de retratamento endodôntico no incisivo central superior, o qual já havia sido submetido ao mesmo tratamento duas vezes, porém, sem remissão dos sintomas. A paciente queixava-se de dor à palpação, mastigação e percussão vertical. Diante deste quadro, foi solicitado a paciente uma tomografia computadorizada de feixe cônico do elemento 11 para melhor avaliação. Diante das informações clínicas e achados da tomografia, a cirurgia parendodôntica foi indicada. Realizou-se retalho de Newman modificado, confecção de loja óssea e apicectomia removendo $3 \mathrm{~mm}$ da região apical. Para retropreparo utilizou-se inserto ultrassônico P1, logo após a retroinstrumentação, foi performada a terapia fotodinâmica utilizando o laser Duo da MMO com o corante azul de metileno 0,10\%, na qual houve uma préirradiação por cinco minutos e mais cinco ativações por trinta segundos, a retrobturação foi realizada com MTA e a loja óssea foi preenchida com Genox orgânico. Após sete dias a paciente estava assintomática e seis meses depois, pôde-se notar reparo da região. Discussão: A literatura evidencia a eficiência do laser no procedimento cirúrgico, sendó sua utilização eficiente para eliminação de bactérias ${ }^{2,3}$. Conclusão: $O$ uso da terapia fotodinâmica como coadjuvante no tratamento de infecções persistentes em cirurgias parendodônticas mostrou resultados positivos e promissores.

Descritores: Endodontia; Laser; Terapia Fotodinâmica.

\section{Referências:}

1. OLIVEIRA BP, et al. Photodynamic therapy: a novel ally for surgical endodontic treatment? Case report. J Lasers Med Sci, 2018; 9(4): 288-290

2. PIAZZA B, VIVIAN RR. O uso do laser e seus princípios em endodontia: revisão de literatura. SALUSVITA, 2017; 36(1): 205-221

3. SILVA EJ, et al. Evaluation of photo- dynamic therapy using a diode laser and diferent photosensitizers against Enterococcus faecalis. Acta Odontologica Latinoamericana, 2014; 27(2): 63-65 


\section{PC-199-2019 - USO DE ANTI-INFLAMATÓRIOS NÃO ESTERÓIRES (AINEs) EM PACIENTES HIPERTENSOS: UMA REVISÃO DE LITERATURA}

Maria Clara Ribeiro de Amorim Tabosa ${ }^{1}$; Letícia Fernanda Serafim Cabral ${ }^{1}$; Gleicy Fátima Medeiros de Souza ${ }^{1}$; Antonio Azoubel Antunes ${ }^{1}$

${ }^{1}$ Faculdade de Odontologia de Pernambuco - Camaragibe - PE - Brasil

Autor correspondente:

Maria Clara Ribeiro de Amorim Tabosa

tabosamariaclara@gmail.com

Introdução: Os anti-inflamatórios não esteróides (AINEs) constituem uma classe de fármacos utilizados para o controle da dor e inflamação e atuam inibindo o sistema enzimático de endoperóxido sintases, a via das cicloxigenases (COX), convertendo ácido araquidônico em prostaglandinas, tromboxanos e prostaciclina ${ }^{3}$. A sua potência varia de acordo com a dose empregada e a meia vida plasmática, podendo ser inibidores seletivos da COX-1, não-seletivos da COX, seletivos ou altamente seletivos da COX-21. Objetivo: Apresentar uma revisão de literatura sobre o uso de AINEs em pacientes hipertensos e sua interação com antihipertensivos. Metodologia: Foi realizada uma pesquisa em livros acadêmicos e artigos científicos acerca da interação dos AINEs com a hipertensão e anti-hipertensivos. Revisão de literatura: Os fármacos inibidores da COX-2 (coxibes) inibem seletivamente ou praticamente especificamente. Porém, a inibição seletiva pode trazer problemas, já que essa enzima regula funções renais como a excreção de sal através da renina, a homeostasia da pressão arterial e o controle da agregação plaquetária. Uma vez que inibem a síntese de prostaciclina, reduzem as defesas do endotélio vascular contra a hipertensão ${ }^{1}$, provocando aumento da pressão arterial sanguínea, particularmente em idosos, pois há uma potencialidade de decréscimo da função renal ou hepática e o retardo no metabolismo ${ }^{2}$. O uso concomitante de AINEs e alguns antihipertensivos pode causar uma elevação da pressão arterial, particularmente os fármacos dos seguintes grupos: Inibidores da enzima conversora de angiotensina (IECAs), Diuréticos e $\beta$ bloqueadores. Anti-hipertensivos que não dependem das prostracicilinas, como os inibidores de cálcio, não estão associados a esse tipo de interação ${ }^{1}$. Conclusão: Embora o uso de AINEs na odontologia, normalmente, seja por um curto tempo, é importante propor um protocolo que atenda ao paciente que faz uso de anti-hipertensivos, recomendando-se a troca de informações com o médico antes da prescrição. Na impossibilidade dessa conduta, deve-se ser empregado um corticosteróide ${ }^{1}$.

Descritores: Anti-inflamatórios não Esteróides; Hipertensão; Anti-hipertensivos.

\section{Referências:}

1. ANDRADE ED. Terapêutica Medicamentosa em Odontologia. $3^{a}$ ed. São Paulo: Artes Médicas, 2014; 238p

2. FORTES ZB, NIGRO D. Aspectos farmacológicos da inteiração de anti-hipertensivos e antiinflamatórios não-esteróides. Revista Brasileira de hipertensão, 2005; 12 (2): 108-111

3. FUCHS FD, WANNMACHER L. Farmacologia clínica e terapêutica. $5^{\mathrm{a}}$ ed. Rio de Janeiro: Guanabara Koogan, 2017; 852p 


\section{PC-200-2019 - USO DE BENZODIAZEPÍNICOS NO PRÉ-ATENDIMENTO ODONTOLÓGICO}

Isabella Maria da Silva Lemos ${ }^{1}$; Beatriz da Silva Lemos ${ }^{1}$; Aysmim Carla Camelo Alves ${ }^{1}$; Yuri Victor Dias de Oliveira ${ }^{1}$; Júlia Guedes Alcoforado Souza ${ }^{1}$; Palloma Bernardino Albuquerque ${ }^{1}$; Mariana Lopes Valença ${ }^{1}$; Manoela de Bortoli ${ }^{1}$

${ }^{1}$ Universidade Federal de Pernambuco - Recife - PE - Brasil

Autor correspondente:

Isabella Maria da Silva Lemos

isabellamlemos@gmail.com

Introdução: A ansiedade provoca aumento da pressão arterial, da sensação de dor, frequência respiratória e pulsação ${ }^{2}$. Nesse contexto, os benzodiazepínicos (BZD) representam uma ótima opção como pré-medicação no consultório odontológico, pois diminuem os sintomas da ansiedade e apresentam alta segurança ${ }^{1}$. Objetivo: Esse trabalho tem o objetivo de realizar uma revisão de literatura destacando a aplicabilidade dos benzodiazepínicos no pré-atendimento odontológico. Metodologia: Foram utilizadas as bases de dados: Google Acadêmico, LILACS, SciELO; de artigos publicados entre os anos de 2004 a 2014, utilizando-se os descritores: Benzodiazepinas; Ansiedade; Sedação consciente. Como critério de inclusão, foram considerados apenas artigos publicados nos idiomas português e inglês. Foram excluídos deste estudo trabalhos de relato de caso clínico. Revisão de literatura: O uso de BZD (via oral) mostrou-se uma alternativa para se obter a sedação consciente em odontologia ${ }^{1}$. Eles atuam na depressão do SNC causando sedação, relaxamento da musculatura, amnésia anterógrada. Na clínica odontológica destacam-se: Midazolam e Diazepam². O esquema posológico de preferência para esses benzodiazepínicos é o uso de um comprimido na noite anterior e outro uma hora antes do procedimento clínico ${ }^{3}$. Deve-se atentar as contraindicações nos casos de: portadores de insuficiência respiratória, gestantes, etilistas, bem como os efeitos adversos: diplopia, falta de coordenação motora, efeito paradoxal2 ${ }^{2}$. Conclusão: A ansiedade pode gerar insucesso no tratamento odontológico. Portanto, o profissional pode utilizar BZD de forma segura como pré-medicação desde que conheça as características das drogas, suas indicações e contraindicações.

Descritores: Benzodiazepinas; Ansiedade; Sedação Consciente.

\section{Referências:}

1. COGO K, et al. Sedação consciente com benzodiazepínicos em odontologia. Revista de Odontologia da Universidade Cidade de São Paulo, 2006; 18(2): 181-188

2. FERREIRA JLG, et al.O uso de ansiolítico no pré-atendimentoem odontologia- Revisão de literatura. Revista de Odontologia da Universidade Cidade de São Paulo, 2014; 26(3): 227-231 3. TEIXEIRA TF, QUESADA GA. Terapia ansiolítica para pacientes odontológicos. Revista do Centro de Ciências de Saúde, 2004; 30 (1-2): 100-103 


\section{PC-201-2019 - USO DE IMPLANTES IMEDIATOS: VANTAGENS E LIMITAÇÕES DA TÉCNICA - REVISÃO DE LITERATURA}

Giovanna Barbosa Brito de Sousa Bione' ${ }^{1}$ Carolina Chaves Gama Aires ${ }^{1}$; Eugênia Leal de Figueiredo ${ }^{2}$

${ }^{1}$ Universidade Federal de Pernambuco - Recife - PE - Brasil

2Universidade de Pernambuco - Recife - PE - Brasil

Autor correspondente:

Giovanna Barbosa Brito de Sousa Bione

giovannabione.gb@gmail.com

Introdução: A possibilidade do uso de implantes osseointegrados revolucionou o processo de reabilitação estética, fonética e funcional em Odontologia, sendo os imediatos os de melhor aceitação pelo paciente, devido ao menor período necessário para a reabilitação ${ }^{2}$. Objetivo: apresentar uma revisão de literatura acerca das vantagens e limitações da técnica em implantes imediatos. Metodologia: Foi realizada uma pesquisa nas bases de dados Google Acadêmico, PubMed e LILACS, com os descritores: implantes dentários, osseointegração e regeneração óssea. Revisão de literatura: A possibilidade de uso de implantes instalados imediatamente após a exodontia de um dente promove vantagens sobre a técnica cirúrgica de dois estágios, como a redução do tempo de tratamento e do custo, preservação da altura, espessura óssea alveolar e da dimensão do tecido mole, promovendo um contato osso-implante bem-sucedido ${ }^{1,3}$. Entretanto, para que isso ocorra com eficácia, existem limitantes: preservar margens ósseas alveolares pós-exodontia atraumática, estabilizar primariamente o implante na porção apical ou ao longo das paredes alveolares, ter cuidado controlado do retalho de tecido, estreito fechamento adaptado ao pescoço do implante e ótimo controle de placa durante a cicatrização ${ }^{2,3}$. Além disso, deve-se alinhar o implante relativamente ao dente a ser restaurado, para obter perfil de emergência correto. A cabeça do implante deve estar $3 \mathrm{~mm}$ apicalmente em relação à junção amelo-cementária do dente vizinho, permitindo manutenção das distâncias biológicas, evitando a reabsorção óssea e o comprometimento estético final ${ }^{3}$. Conclusão: $O$ sucesso das reabilitações aliadas à instalação de implantes imediatos depende das condições dos tecidos ósseo e gengivais após as exodontias, controle de placa do paciente e da destreza técnica do profissional para que cumpra os requisitos necessários e supere os limitantes, obtendo-se assim as vantagens advindas da técnica.

Descritores: Implantes Dentários; Osseointegração; Regeneração Óssea.

\section{Referências:}

1. MÜLLER A, et al. Implante unitário submetido à carga imediata. Revista Gaúcha de Odontologia, 2004; 52(1): 27-41

2. SOUZA JR, et al. Instalação de implantes osseointegrados com carga imediata. Revista Gaúcha de Odontologia, 2003; 51(4): 358-365

3. ZANI SR, et al. Colocação de implante imediato após exodontia: relato de caso clínico.

Odontologia clínico-científica, 2011; 10(3): 281-284 


\section{PC-202-2019 - USO DE MAGNETOS EM REABILITAÇÃO ORAL COM PRÓTESE TOTAL: RELATO DE CASO CLÍNICO}

Guilherme de Melo Ribeiro Aragão Barbosa ${ }^{1}$; Rayanna Thayse Florêncio Costa ${ }^{1}$; Rafaella de Souza Leão; Bruno Gustavo da Silva Casado²; Cátia Maria Fonseca Guerra ${ }^{3}$; Sandra Lúcia Dantas de Moraes ${ }^{1}$

${ }^{1}$ Faculdade de Odontologia de Pernambuco (FOP/UPE) - Camaragibe - PE - Brasil

${ }^{2}$ Centro Universitário Tiradentes (UNIT/PE) - Recife - PE - Brasil

${ }^{3}$ Universidade Federal de Pernambuco (UFPE) - Recife - PE - Brasil

Autor correspondente:

Guilherme de Melo Ribeiro Aragão Barbosa

guilhermemrab@yahoo.com

Introdução: Paciente desdentado parcial A.C.B.F., 64 anos, apresentou-se na clínica de Especialização em Prótese Dentária da Associação Brasileira de Odontologia (ABO/PE) em busca de tratamento reabilitador. Objetivo: Descrição da realização de uma prótese total (PT) superior imediata, seguido da realização de PT superior com dispositivo adicional de retenção magnético e prótese parcial removível (PPR) inferior convencional. Relato de caso: Na arcada superior foi indicada uma PT com sistema de retenção magnético nos dentes 13,15 e 25, uma vez que o paciente não optou pela reabilitação com implantes dentários. Para a arcada inferior foi planejada uma PPR convencional. A sequência clínica de planejamento se deu da seguinte forma: Moldagens de estudo superior e inferior, moldagem funcional superior, ajuste do plano de cera, montagem em articulador semiajustável (ASA), seleção e montagem dos dentes superiores e acrilização da PT (provisória) ${ }^{3}$. Com isso, primeiramente a PPR inferior classe I de Kennedy foi realizada: delineamento do modelo de estudo, preparo de boca, moldagem de trabalho, prova da estrutura metálica, moldagem funcional, ajuste do plano de cera, montagem em ASA, seleção e prova dos dentes e instalação ${ }^{1}$. Na sessão de instalação da PPR, foi programada a exodontia dos elementos 16,17, 21, 22, 26 e 27 e reembasamento da PT provisória. Assim, o processo de confecção dos núcleos imantados foi iniciado: desobturação de $5 \mathrm{~mm}$ do canal radicular dos elementos, modelagem dos condutos e cimentação dos núcleos. Após 3 meses da cirurgia foi iniciado a confecção da PT superior e na sessão de instalação, foi realizada a captura das bases metálicas. Discussão: $\mathrm{O}$ sistema adicional de retenção utilizado apresenta-se efetivo e de acordo com Telles ${ }^{2}$ apresenta potencial de maximizar a adaptação do paciente à nova prótese. Conclusões: Paciente reabilitado funcional e esteticamente ainda apresenta retenção satisfatória com 13 meses de acompanhamento após instalação.

Descritores: Prótese total; Retenção de dentadura; Prótese Parcial Removível.

\section{Referências:}

1. CARREIRO AFP, BATISTA AUD. Prótese Parcial Removível Contemporânea. São Paulo: Santos, 2013; 382p

2. TELLES DM. Prótese Total: convencional e sobre implantes. São Paulo: Santos, 2017; 162p

3. TURANO JC, et al. Fundamentos da Prótese Total. $9^{a}$ ed. São Paulo: Santos, 2010; 489p 


\section{PC-203-2019 - USO DA TOXINA BOTULÍNICA TIPO A NA CORREÇÃO DO SORRISO GENGIVAL: UMA REVISÃO DE LITERATURA}

Izabella Fernanda Alves da Silva ${ }^{1}$; Fabio Tavares da Silva ${ }^{1}$; Maria Fernanda Limeira Feitosa ${ }^{1}$; Douglas Felipe de Lima e Silva ${ }^{1}$; Renata Maria Queiroz Carlos ${ }^{1}$; Ítalo Martins da Silva ${ }^{1}$; Alice Mendes Siqueira ${ }^{1}$; Raphaella Karlla Machado Gonzaga ${ }^{2}$

${ }^{1}$ Centro Universitário Maurício de Nassau - UNINASSAU - Recife - PE - Brasil

${ }^{2}$ Universidade Federal de Pernambuco - UFPE - Recife - PE - Brasil

Autor correspondente:

Izabella Fernanda Alves da Silva

Izabella-fernanda@hotmail.com

Introdução: O sorriso gengival se caracteriza pela exposição de mais de $3 \mathrm{~mm}$ de gengiva, podendo ser causado por contração muscular excessiva, o comprimento do lábio, o comprimento clínico da coroa, a extrusão alveolar, a extrusão dentoalveolar e o excesso vertical da maxila ${ }^{1}$. Objetivo: Abordar o uso da toxina botulínica no tratamento do sorriso gengival. Metodologia: Trata-se de uma revisão de literatura com busca de artigos na base de dados: PubMed. A estratégia de busca utilizada foi o cruzamento dos descritores: gengiva AND botulinum toxins. Os critérios de inclusão foram: estudos que avaliaram a eficácia da toxina botulínica na correção do sorriso gengival, publicados nos idiomas português e inglês, nos últimos 5 anos. Foram excluídos os artigos não pertinentes ao objetivo deste estudo, duplicados e aqueles não disponíveis em texto completo. 3 artigos se enquadraram nos critérios de elegibilidade. Revisão de literatura: A toxina botulínica é uma proteína produzida pela bactéria Clostridium botulinum, que inibe a liberação de acetilcolina, bloqueando a contração muscular. Pode ser usada como tratamento independente do sorriso gengival, como adjuvante de outras técnicas invasivas ou como uma medida temporária enquanto se espera por uma solução permanente ${ }^{2}$. Os pontos de aplicação devem estar localizados nos músculos levantador do lábio superior e asa do nariz, levantador do lábio superior e zigomático menor ${ }^{1}$. A dose de toxina pode variar entre 2,0 e 2,5 $\mathrm{U}_{\text {por }}$ lado $^{3}$. Um efeito significativo do tratamento tende a ser estável até pelo menos 8 semanas de acompanhamento ${ }^{1}$. Conclusão: Dentre as opções terapêuticas disponíveis para correção do sorriso gengival, a toxina botulínica representa uma opção promissora por possuir ação rápida, baixo risco e ser menon invasiva quando comparada a outros métodos.

Descritores: Gengiva; Toxinas Botulínicas Tipo A; Estética.

\section{Referências}

1. CHAGAS TF, et al. Duration of effectiveness of botulinum toxin type a in excessive gingival display: a systematic review and meta-analysis. Braz. Res Oral, 2018; 32(1):1-11

2. NASR SFMW, et al. Botulinum toxin for the treatment of excessive gingival display: a systematic review. Aesthetic Surgery Journal, 2016; 36(1):82-88

3. POLO M. Commentary on: botulinum toxin for the treatment of excessive gingival display: a systematic review. Aesthetic Surgery Journal, 2016; 36(1):89-92 


\section{PC-204-2019 - USO DO INFILTRANTE RESINOSO NA ODONTOLOGIA: REVISÃO DE LITERATURA}

Wallacy Bruno Morais de Oliveira Silva ${ }^{1}$; Silas Cardoso Bezerra ${ }^{1}$; Héberte de Santana Arruda ${ }^{1}$; Felipe Tavares Arruda ${ }^{2}$; Rayanna Louise Silva de Melo²; Pedro Xavier Moura da Silva ${ }^{1}$; Carolina Pereira da Silva ${ }^{1}$; Amanda Maciel do Prado ${ }^{1}$

${ }^{1}$ Faculdade de Odontologia de Pernambuco - Camaragibe - PE - Brasil

${ }^{2}$ Faculdade Maurício de Nassau - Recife - PE - Brasil

Autor correspondente:

Wallacy Bruno Morais de Oliveira Silva

wallacybruno1@gmail.com

Introdução: As abordagens minimamente invasivas têm ganhado espaço, principalmente devido às mudanças nos conceitos de preparo cavitário. Diante da constante evolução das técnicas de preparo, novos materiais foram formulados visando reduzir o desgaste da estrutura mineralizada do elemento dentário no processo da restauração, almejando preservar ao máximo a estrutura dentária e suas funções. Dentre os materiais e métodos desenvolvidos, encontra-se o infiltrante resinoso. Objetivo: Apresentar uma revisão de literatura acerca do uso, características e dos resultados obtidos no uso do infiltrante resinoso. Metodologia: Foi realizada uma pesquisa na base de dados PubMed, na qual foi utilizado o termo "resin infiltration" e considerados apenas os trabalhos dos últimos cinco anos e que possuíam texto completo para a elaboração deste trabalho. Revisão de literatura: A técnica do uso do infiltrante resinoso consiste na inserção de uma resina de baixa viscosidade em lesões de cárie ainda não cavitadas através dos poros da lesão no esmalte, sendo possível sua utilização em outros quadros nos quais a porosidade do elemento dentário está aumentada, por exemplo a amelogênese imperfeita, a hipomineralização e a fluorose ${ }^{2}$. Os objetivos dessa técnica são estabilizar mecanicamente a estrutura porosa fragilizada e isolar os microrganismos responsáveis pela lesão dos nutrientes provenientes do meio, impossibilitando, assim, o metabolismo ${ }^{3}$. Tal técnica tem demonstrado ausência da progressão das lesões em avaliações de até 4 anos, podendo estender-se por maiores períodos ${ }^{1}$. Conclusão: Dessa forma, constatase que o uso da técnica do infiltrante resinoso é válida e se apresenta como uma das técnicas menos invasivâs, possibilitando a restauração do elemento dentário sem perda de estrutura mineral sadia.

\section{Descritores: Dentística Operatória; Resinas Compostas; Cárie Dentária.}

\section{Referências:}

1. CAGLAR E, et al. Four year Evaluation of Proximal Resin Infiltration in Adolescents. Acta Stomatologica Croatica, 2015; 49(4): 304-308

2. DOMÉJEAN S, et al. Resin Infiltration of Non-Cavitated Caries Lesions: A Systematic Review. Medical Principles and Practice, 2015; 24: 216-221

3. RAHIOTIS C, et al. Setting characteristics of a resin infiltration system for incipient caries treatment. Journal of Dentistry, 2015; 43(6): 715-719 


\section{PC-205-2019 - VANTAGENS DA UTILIZAÇÃO DE CIMENTOS DE IONÔMEROS DE VIDRO NA COLAGEM DE BRAQUETES ORTODÔNTICOS: REVISÃO DE LITERATURA}

Rebecca Siqueira da Cunha Machado ${ }^{1}$; Luiza de Carvalho Paranhos Agra ${ }^{1}$; Giovana Lordsleem de Mendonça ${ }^{1}$; Maria Eduarda Fidelis de Medeiros ${ }^{1}$; Maria Catarina Almeida Lago ${ }^{1}$

${ }^{1}$ Faculdade de Odontologia de Pernambuco — Camaragibe - PE - Brasil

Autor correspondente:

Rebecca Siqueira da Cunha Machado

rebecca_scm@hotmail.com

Introdução: Os cimentos de ionômeros de vidro (CIV) são materiais híbridos, constituídos por partículas inorgânicas de vidro dispersas em uma matriz de hidrogel ${ }^{5}$. A ortodontia faz uso do CIV modificado por resina (CIVMR) na colagem de braquetes, devido às suas propriedades retentivas e mineralizantes ${ }^{1,3}$. Objetivos: Analisar as propriedades dos cimentos de ionômeros de vidro, suas aplicações e resultados na prática odontológica. Metodologia: Foi realizada uma pesquisa nas bases de dados Scholar Google, SciELO e PubMed, com os descritores: Cimentos de Ionômeros de Vidro, Ortodontia e Braquetes Ortodônticos. Revisão de literatura: Os cimentos de ionômeros de vidro apresentam propriedades adicionais em comparação a outros materiais restauradores, como adesão do material à estrutura dentária por troca de íons, vedamento marginal e manutenção do selamento, aumentando a longevidade da restauração ${ }^{4}$. Além de sua baixa solubilidade e biocompatibilidade ${ }^{3,5}$, há contínua liberação de flúor, responsável pela remineralização de tecidos ${ }^{1}$, tornando-o excelente para utilização em pacientes com alto risco e/ou alta atividade de cárie ${ }^{4}$. $\mathrm{O}$ acúmulo de biofilme na superfície dental é potencializado com o uso de aparelhos ortodônticos, e as propriedades mineralizantes do CIVMR auxiliam na manutenção de uma superfície menos vulnerável à destruição da estrutura dentária, além de possuírem boa suportabilidade às tensões geradas nas forças mastigatórias e modificações ortodônticas ${ }^{1}$. Conclusão: A fim de realizar um tratamento seguro, anticariogênico e resistente para seus pacientes, é fundamental que o cirurgião-dentista possua o conhecimento da correta utilização do CIVMR e procure acompanhar as pesquisas recentes para ter um bom desempenho clínico ${ }^{4}$, pois esse composto apresenta-se como uma excelente opção na colagem dos braquetes pelos ortodontistas, uma vèz que suas propriedades físicoquímicas possuem vantagem em relação às das resinas compostas tradicionalmente utilizadas².

Descritores: Cimentos de Ionômeros de Vidro; Ortodontia; Braquetes Ortodônticos.

\section{Referências:}

1. BACCHI AC, et al. O Cimento de Ionômero de Vidro e sua utilização nas diferentes áreas odontológicas. Perspectiva Erechim, 2013; 37(137): 103-114

2. CORRER SOBRINHO L, et al. Influência do tempo pós-fixação na resistência ao cisalhamento de bráquetes colados com diferentes materiais. Pesquisa Odontológica Brasileira, 2002; 16(1): 43-49

3. FARRET MM, et al. Assessment of the mechanical properties of glass ionomer cements for orthodontic cementation. Dental Press Journal of Orthodontics, 2012; 17(6): 154-159

4. PARADELLA TC. Glass-ionomer cements in modern dentistry. Revista de Odontologia da UNESP, 2004; 33(4): 157-161

5. QUEIROZ VAO. Uso do cimento de ionômero de vidro na prática odontológica. Dissertação (Mestrado em Dentística) - Faculdade de Odontologia de Bauru. Universidade de São Paulo, Bauru, 2003; 94p 


\section{PC-206-2019 - VANTAGENS DO USO DO SISTEMA CAD/CAM EM RESTAURAÇÃO ONLAY: RELATO DE CASO}

Luiz Ricardo Gomes de Caldas Nogueira Filho ${ }^{1}$; Vinícius Antonio Correia Trindade ${ }^{1}$; Matheus Nascimento Marques Amorim ${ }^{1}$; Heitor Tavares Araújo ${ }^{1}$; Hugo Igor Rodrigues de Barros ${ }^{1}$; Cleiton Rone dos Santos Lima ${ }^{1}$; Maria Fernanda Limeira Feitosa ${ }^{2}$; Luiz Ricardo Gomes de Caldas Nogueira ${ }^{1}$

${ }^{1}$ Faculdade de Odontologia de Pernambuco - Camaragibe - PE - Brasil

${ }^{2}$ Faculdade Maurício de Nassau - Recife - PE - Brasil

Autor correspondente:

Luiz Ricardo Gomes de Caldas Nogueira Filho

Luiznog2001@gmail.com

Introdução: $\mathrm{O}$ sistema CAD/CAM é definido pelo processo de confecção da prótese através do desenho auxiliado por computador (CAD) obtido a partir do escaneamento intraoral e importação das imagens adquiridas em três dimensões. Já a manufatura auxiliada por computador (CAM), é responsável pela fresagem da restauração em bloco de cerâmica. Desse modo, essa tecnologia foi idealizada com intuito de simplificar e automatizar o processo de produção da restauração, a qual pode ser instalada em sessão única por não contar com etapas laboratoriais ${ }^{1,3}$. Objetivo: Demonstrar através do relato de caso que o sistema CAD/CAM é uma alternativa viável, pois diminui o tempo do tratamento por ser realizado em sessão única. Relato de caso: Paciente A.A.C.J., 18 anos, sexo masculino, relatou insatisfação estética no elemento 26. Ao exame clínico, pode-se constatar restauração insatisfatória neste elemento. Desta forma, foi indicada restauração onlay a partir do sistema CAD/CAM Cerec SW4 (Sirona), em que foi realizada a remoção da resina composta antiga, escaneamento intraoral, planejamento da peça através do software e usinagem de um bloco de cerâmica feldspática na cor A1. Ainda em mesma sessão, foi feita a instalação com cimento resinoso dual Relyx Ultimate (3M). Após dois anos, foi realizada sua preservação e constatada correta adaptação da peça. Discussão: Perante a literatura, a utilização do sistema CAD/CAM permite a produção de restaurações mais precisas e aumenta a produtividade por dispensar métodos convencionais de moldagem ${ }^{2}$. Conclusão: Com o sistema CAD/CAM foi possível realizar o planejamento adequado do processo de confecção da restauração protética com total controle do processo desde o escaneamento até à instalação em única sessão, conferindo, assim, boa adaptação marginal, o que garante uma adequada oclusão e uma maior satisfação do paciente e profissional.

Descritores: CAD-CAM; Estética dentária; Projeto auxiliado por computador.

\section{Referências:}

1. CAMARGO IF, et al. Sistemas cad/cam e suas aplicações na odontologia: revisão da literatura. Rev. UNINGÁ, 2018; 55(3): 211-228

2. HILGERT LA, et al. Odontologia restauradora com sistemas cad/cam: o estado atual da arte parte 1 - princípios de utilização. Clínica - International Journal of Brazilian Dentistry, 2009; 5(3): 294-303

3. MARQUES DS, et al. Reabilitação estética anterior de caso limítrofe com uso da tecnologia CAD-CAM: uma abordagem multidisciplinar. ARQ. BRAS. MED. NAVAL, 2017; 78(1): 1927 
PC-207-2019 - VISÃO DO PACIENTE EM RELAÇÃO AO GÊNERO E APARÊNCIA DO CIRURGIÃO DENTISTA

Fábio Victor Dias Silva ${ }^{1}$; Danielly Bruna Marques Neves ${ }^{1}$; Marcos Aurélio Vasconcelos Lima Júnior $^{1}$

${ }^{1}$ Centro Universitário de João Pessoa - UNIPÊ - João Pessoa - PB - Brasil

Autor correspondente:

Fábio Victor Dias Silva

fabio_vct@hotmail.com

Introdução: Atualmente, a indumentária branca convencional entre os dentistas, tem sido substituída por trajes coloridos, podendo gerar disparidades entre expectativas do paciente e do dentista e dissonância de satisfação ${ }^{2,3,4}$. Além disso, alguns aspectos da prática profissional podem influenciar preferências por determinado gênero e afetar o conforto e comportamento do paciente ${ }^{1}$. Objetivo: Analisar as expectativas de pacientes quanto aparência dos profissionais da odontologia, principalmente no tocante às vestimentas, e verificar se existe preferência pelo gênero do profissional. Metodologia: Foi realizada uma pesquisa exploratória com pacientes leigos de uma clínica escola, em João Pessoa - PB. A amostra proposta, do tipo não probabilística e intencional, foi de 150 participantes, com idades de 18 a 69 anos, com média de 35 anos, $63 \%$ destes do gênero feminino. Estes foram submetidos a uma entrevista com uso de instrumento para verificar suas preferências a respeito das vestimentas e gênero do dentista. Foram atendidos os requisitos da Resolução no 466/2012, tendo sido aprovado pelo Comitê de Ética em Pesquisa em Seres Humanos do UNIPÊ, sob Parecer Consubstanciado ${ }^{\circ}$ 3.051.193. Os dados foram tratados estatisticamente com uso do Micrososft Excel. Resultados e discussão: $58 \%$ alegaram preferência pela imagem com jaleco branco nas mulheres, e 56\% afirmaram ter a mesma preferência, quando se tratava de homens. $29 \%$ justificaram a escolha pelo branco, em função de achar que é um padrão para a profissão, e $12 \%$ o fizeram pela imagem de higiene. 66\% não tinham preferência pelo gênero do dentista, sendo esta característica indiferente. Conclusão: A indumentária branca foi a preferência da maioria dos entrevistados, para ambos os gêneros de profissionais, em virtude da relação do branco com imagem de limpeza e higiene, e a percepção de que esta cor é mais ligada à área de saúde. Não foi observada preferência significativa em relação ào gênero do dentista.

Descritores: Indumentária; Cirurgião-Dentista; Preferência do Paciente.

\section{Referências:}

1. BARBELA D, et al. Preferência da criança pelo gênero do odontopediatra. Revista Arquivos em Odontologia,2008; 44(2): 74-80

2. HASS MGM, et al. Influência da vestimenta do cirurgião-dentista e do ambiente do consultório odontológico na ansiedade de crianças pré-escolares durante consulta odontológica: resultados de um estudo piloto. Revista da Faculdade de Odontologia da Universidade de Passo Fundo, 2016; 21(2): 201-207

3. MOTA LQ, et al. Humanização no atendimento odontológico: acolhimento da subjetividade dos pacientes atendidos por alunos de graduação em Odontologia. Revista Arquivo em Odontologia, 2012; 48(3): 151-158

4. YONEKURA C, et al. Impressões de pacientes, médicos e estudantes de Medicina quanto a aparência dos médicos. Revista da Associação Médica Brasileira, 2013; 59(5): 452-459 